\title{
Lucien Febvre
}

(1878-1956)

Historien français

Membre de l'Institut, Professeur au Collège de France.

\section{Combats \\ pour l'Histoire}

(Première édition, 1952)

Librairie Armand Colin, Paris, 1992

Un document produit en version numérique conjointement par Réjeanne Brunet-Toussaint, et Jean-Marc Simonet, bénévoles.

Courriels: rtoussaint@aei.ca et jean-marc_simonet@uqac.ca

Dans le cadre de la collection: "Les classiques des sciences sociales"

Site web: http://www.uqac.ca/Classiques_des_sciences_sociales/

Une collection développée en collaboration avec la Bibliothèque

Paul-Émile-Boulet de l'Université du Québec à Chicoutimi

Site web: http://bibliotheque.uqac.ca/ 


\section{Politique d'utilisation de la bibliothèque des Classiques}

Toute reproduction et rediffusion de nos fichiers est interdite, même avec la mention de leur provenance, sans l'autorisation formelle, écrite, du fondateur des Classiques des sciences sociales, Jean-Marie Tremblay, sociologue.

Les fichiers des Classiques des sciences sociales ne peuvent sans autorisation formelle:

- être hébergés (en fichier ou page web, en totalité ou en partie) sur un serveur autre que celui des Classiques.

- servir de base de travail à un autre fichier modifié ensuite par tout autre moyen (couleur, police, mise en page, extraits, support, etc...),

Les fichiers (.html, .doc, .pdf., .rtf, .jpg, .gif) disponibles sur le site Les Classiques des sciences sociales sont la propriété des Classiques des sciences sociales, un organisme à but non lucratif composé exclusivement de bénévoles.

Ils sont disponibles pour une utilisation intellectuelle et personnelle et, en aucun cas, commerciale. Toute utilisation à des fins commerciales des fichiers sur ce site est strictement interdite et toute rediffusion est également strictement interdite.

L'accès à notre travail est libre et gratuit à tous les utilisateurs. C'est notre mission.

Jean-Marie Tremblay, sociologue

Fondateur et Président-directeur général, LES CLASSIQUES DES SCIENCES SOCIALES. 
Cette édition électronique a été réalisée conjointement par Réjeanne BrunetToussaint, bénévole, Chomedey, Ville Laval, Québec, et Jean-Marc Simonet, bénévole, professeur des universités à la retraite, Paris.

Correction : Réjeanne Brunet-Toussaint

Relecture et mise en page : Jean-Marc Simonet

Courriels: rtoussaint@aei.ca et jean-marc_simonet@uqac.ca

À partir du livre de :

Lucien Febvre (1878-1956)

historien français, fondateur, avec Marc Bloch de l'École des Annales.

\section{COMBATS POUR L'HISTOIRE}

Paris : Librairie Armand Colin, 1992, 456 pp. Collection: Agora. Première édition : 1952.

Polices de caractères utilisées :

Pour le texte: Times New Roman, 14 points.

Pour les citations : Times New Roman 12 points.

Pour les notes de bas de page : Times New Roman, 12 points.

Édition électronique réalisée avec le traitement de textes Microsoft Word 2004 pour Macintosh.

Mise en page sur papier format : LETTRE (US letter), 8.5" x 11')

Édition numérique réalisée le 13 mai 2008 à Chicoutimi, Ville de Saguenay, province de Québec, Canada. 


\section{Quatrième de couverture}

Les idées, les arts, les sociétés.

"Je définis volontiers l'Histoire comme un besoin de l'humanité, le besoin qu'éprouve chaque groupe humain, à chaque moment de son évolution, de chercher et de mettre en valeur dans le passé les faits, les événements, les tendances qui préparent le temps présent, qui permettent de le comprendre et qui aident à le vivre. Et j'ajoute : recomposer la mentalité des hommes d'autrefois; se mettre dans leur tête, dans leur peau, dans leur cervelle pour comprendre ce qu'ils furent, ce qu'ils voulurent, ce qu'ils accomplirent.

Et, d'autre part, je dis les hommes. Les hommes, seuls objets de l'Histoire, d'une histoire qui s'inscrit dans le groupe des disciplines humaines de tous les ordres et de tous les degrés, à côté de l'anthropologie, de la psychologie, de la linguistique, etc., d'une histoire qui ne s'intéresse pas à je ne sais quel homme abstrait, éternel, immuable en son fond et perpétuellement identique à lui-même, mais aux hommes toujours saisis dans le cadre des sociétés dont ils sont membres, aux hommes membres de ces sociétés, à une époque bien déterminée de leur développement, aux hommes dotés de fonctions multiples, d'activités diverses, de préoccupations et d'aptitudes variées, qui toutes se mêlent, se heurtent, se contrarient et finissent par conclure entre elles une paix de compromis, un modus vivendi qui s'appelle la Vie."

"Combats pour l'Histoire" est un recueil de trente-trois articles écrits entre 1906 et 1952 où Lucien Febvre développe sa vision d'ensemble du champs de l'Histoire, suivi de onze portraits des grands intellectuels des années 30. Un classique.

Lucien Febvre fut titulaire, dès 1912, de la chaire d'histoire de la Bourgogne à la faculté des lettres de Dijon, puis, en 1919, professeur d'histoire moderne à l'université de Strasbourg. Fondateur, en 1929, des "Annales d'histoire économique et sociale", avec Marc Bloch, il a été nommé, en 1933, professeur au Collège de France. Il a conçu et dirigé l' "Encyclopédie française”. Il fut, en 1949, le fondateur de l'EHESS, avec Charles Morazé, et en devint le premier Président. 


\section{Table des matières}

L'origine de chacun des chapitres de cet ouvrage est indiquée [entre crochets]

\section{Avant-propos}

\section{$\underline{\text { Avertissement au lecteur }}$}

\section{Professions de foi au départ}

De 1892 à 1933. Examen de conscience d'une histoire et d'un historien

[Leçon d'ouverture au Collège de France, 13 décembre 1933.]

Vivre l'histoire. Propos d'initiation

[Conférence aux élèves de l'École Normale Supérieure, 1941.]

Face au vent. Manifeste des «Annales» nouvelles

[Annales (E. S. C.), 1946.]

La vie, cette enquête continue

[Encyclopédie française, t. XVII, Conclusion (décembre 1935).]

\section{Les pour et les contre}

Pour une histoire dirigée. Les recherches collectives et l'avenir de l'histoire [Revue de Synthèse, XI, 1936.]

Contre l'histoire diplomatique en soi. Histoire ou politique? Deux méditations : 1930, 1945

[Revue de Synthèse, I, 1931. — Annales (E. S. C.), I, 1946.]

Pour la synthèse contre l'histoire-tableau. Une histoire de la Russie moderne. Politique d'abord?

[Revue de Synthèse, VII, 1934.]

Contre le vain tournois des idées. Une étude sur l'esprit politique de la Réforme

[Revue d'Histoire et de Philosophie Religieuses de Strasbourg, VII, 1927.]

Ni histoire à thèse ni histoire-manuel. Entre Benda et Seignobos

[Revue de Synthèse, V, 1933.] 
Et l'homme dans tout cela? Sur un manuel

[Annales d'Histoire Sociale, III, 1941.]

Contre l'esprit de spécialité. Une lettre de 1933.

Contre les juges suppléants de la vallée de Josaphat

[Annales d'Histoire Sociale, VIII, 1945. — Annales (E. S.C.), III, 1948.]

Sur une forme d'histoire qui n'est pas la nôtre. L'histoire historisante

[Annales (E. S. C.), II, 1947.]

Deux philosophies opportunistes de l'histoire ; De Spengler à Toynbee

[Revue de Métaphysique et de Morale, XLIII, 1936.]

\section{Alliances et appuis}

\section{La linguistique.}

Histoire et dialectologie. Aux temps où naissait la géographie linguistique

[Revue de Synthèse Historique, XII, 1906.]

Antoine Meillet et l'histoire. La Grèce ancienne à travers sa langue

[Revue de Synthèse Historique, XVII, 1913.]

Politique royale ou civilisation française? La conquête du Midi par la langue française

[Revue de Synthèse Historique, XXXVIII, 1924.]

Problèmes d'histoire greffés sur « le Brunot». La nationalité et la langue en France au XVIII ${ }^{\mathrm{e}}$ siècle

[Revue de Synthèse Historique, XLII, 1926.]

\section{La psychologie.}

Méthodes et solutions pratiques. Henri Wallon et la psychologie appliquée

[Annales d'Histoire Économique et Sociale, III, 1931.]

Une vue d'ensemble. Histoire et psychologie

[Encyclopédie française, t. VIII, 1938.]

Comment reconstituer la vie affective d'autrefois ? La sensibilité et l'histoire

[Annales d'Histoire Sociale, III, 1941.]

$\underline{\text { Psychologie et physiologie nationales. Les Français vus par André Siegfried }}$ ou par Sieburg?

[Annales d'Histoire Économique et Sociale, IV, 1932.]

\section{Regards chez le voisin ou frères qui s'ignorent}

\section{Les historiens de la littérature.}


L'homme, la légende et l'œuvre. Sur Rabelais : Ignorances fondamentales [Revue de Synthèse, I, 1931.]

Littérature et vie sociale. De Lanson à Daniel Mornet : Un renoncement? [Annales d'Histoire Sociale, III, 1941.]

Du goût classique au foisonnement romantique

[Annales d'Histoire Sociale, I, 1939.]

\section{Les historiens de la philosophie.}

Leur histoire et la nôtre

[Annales d'Histoire Économique et Sociale, VIII, 1938.]

$\underline{\text { Étienne Gilson et la philosophie du XIV }} \underline{\text { siècle }}$

[Annales (E. S. C.), I, 1946.]

Esprit européen et philosophie. Un cours de Léon Brunschvicg

[Annales (E. S. C.), III, 1948.]

\section{Les historiens de l'art.}

Histoire de l'art, histoire de la civilisation. De Sluter à Sambin

[Revue de Synthèse, IX, 1935.]

Résurrection d'un peintre : Georges de la Tour

[Annales (E. S. C.), V, 1950.]

Penser l'histoire de l'art

\section{Les historiens des sciences.}

Une science à travers sa bibliographie. Emmanuel de Margerie et la géologie du Jura

[Revue de Synthèse Historique, XXXVII, 1924.]

Un chapitre d'histoire de l'esprit humain. De Linné à Lamarck et à Georges

$\underline{\text { Cuvier }}$

[Revue de Synthèse Historique, XLIII, 1927.]

\section{Figures et souvenirs}

Hommage à Henri Berr. De la «Revue de Synthèse » aux « Annales »

[Annales (E. S. C.), VII, 1952.]

Albert Mathiez : un tempérament, une éducation

[Annales d'Histoire Économique et Sociale, IV, 1932.]

Albert Thomas historien

[Annales d'Histoire Économique et Sociale, IV, 1932.] 
Un tempérament d'historien : Camille Jullian

[Revue de Synthèse, I, 1931.]

Henri Pirenne à travers deux de ses œuvres

[Revue de Synthèse Historique, XLV, 1920.]

Un psychologue : Charles Blondel

[Ann. de l'Assoc. des Anciens Élèves de l'École Normale Supérieure, 1940.]

Deux amis géographes : Jules Sion, Albert Demangeon

[Annales d'Histoire Sociale, III, 1941.]

Les morts de l'histoire vivante: Gaston Roupnel

[Annales (E. S. C.), II, 1947.]

Souvenirs d'une grande histoire : Marc Bloch et Strasbourg

[Mémorial des années 1939-1945, Strasbourg, Faculté des Lettres.]

Georges Espinas : une conscience d'érudit

[Annales (E. S. C.), V, 1950.]

Une vie : Dom Bernard Berthet, historien-né

[Annales (E. S. C.), V, 1950.]

\section{Espoirs à l'arrivée}

Vers une autre histoire

[Revue de Métaphysique et de Morale, LVIII, 1949.]

\section{Bibliographie choisie et méthodique}

Index alphabétique 


\section{Avant-propos}

$\underline{\text { Retour à la table des matières }}$

$\mathrm{Si}$, en réunissant ces quelques articles choisis entre tant d'autres, j'avais été préoccupé de me dresser je ne sais quel monument, j'aurais donné au recueil un titre différent. Ayant fabriqué au cours de ma vie, et comptant bien fabriquer encore, quelques gros meubles meublants d'histoire - de quoi garnir, au moins provisoirement, certaines parois dénudées du palais de Clio - j'aurais appelé Mes copeaux ces épluchures de bois tombées sous le rabot et ramassées au pied de l'établi. Mais ce n'est point pour me mirer dans ces œuvres quotidiennes, c'est pour rendre quelques services à mes compagnons, surtout aux plus jeunes, que j'ai pratiqué ce rassemblement. Et donc, le titre que j'ai choisi rappellera ce qu'il y eut toujours de militant dans ma vie. Mes combats, certes non : je ne me suis jamais battu ni pour moi ni contre tel ou tel, pris en tant que personne. Combats pour l'histoire, oui. C'est bien pour elle que, toute ma vie, j'ai lutté.

$\mathrm{Si}$ haut que je remonte dans mes souvenirs, je me retrouve historien de plaisir ou de désir, pour ne point dire de cœur et de vocation. Fils d'un père que le prestige d'Henri Weil, l'helléniste à la Faculté des Lettres de Besançon puis à l'École Normale Supérieure, et celui, si grand alors, de Thurot, ce philosophe de la grammaire, détournèrent de l'histoire : mais il ne s'en désintéressa jamais ; neveu d'un oncle qui, toute sa vie, l'enseigna et dès ma prime enfance m'apprit à l'aimer; - trouvant à feuilleter dans la bibliothèque paternelle, au-dessous des fascicules du Daremberg et Saglio qui se succédaient régulièrement, ces deux albums que représentaient au vrai les grandes Histoires des Grecs et des Romains de Victor Duruy, chefs-d'œuvre de la maison Hachette première manière: toute l'Antiquité alors connue, temples, bustes, dieux et vases, figurés par 
les meilleurs graveurs; - dévorant surtout, avec une passion pIII jamais lassée, les tomes de cette grande édition Hetzel de l'Histoire de France de Michelet, remplis par Daniel Vierge, visionnaire hallucinant, d'illustrations si bien mariées à certains textes du grand voyant que je me sens gêné, aujourd'hui, s'il me faut les relire dans la morne édition que des gens se sont trouvés pour qualifier de " définitive »; - nourri de ces conseils, riche de ces lectures et des rêveries qu'elles faisaient naître en moi, comment ne serais-je pas devenu historien?

Mes maîtres sont là, mes véritables maîtres - à qui s'ajoutèrent plus tard, entre ma seizième et ma vingt-cinquième année : A Élisée Reclus et la profonde humanité de sa Géographie Universelle, Burckhardt et sa Renaissance en Italie, - Courajod et ses leçons de l'École du Louvre sur la Renaissance bourguignonne et française, à partir de 1900 1e Jaurès de l'Histoire socialiste, si riche d'intuitions économiques et sociales, - Stendhal, enfin et surtout, le Stendhal de Rome, Naples et Florence, de l'Histoire de l'art en Italie, des Mémoires d'un touriste, de la Correspondance : autant d' " invitations à l'histoire psychologique et sentimentale » qui, pendant des années, ne quittèrent point ma table de chevet: je les découvris presque par hasard, en ces temps lointains, massacrées par Colomb et imprimées par Calmann sur du papier à chandelle, avec de vieux clous...

Telle, mon «âme de papier». A côté, mon âme champêtre et rustique - cette autre maîtresse d'histoire que fut pour moi la Terre. Les vingt premières années de ma vie s'écoulèrent à Nancy : et j'y fis provision en parcourant les taillis et les futaies de la forêt de Haye, en découvrant les uns après les autres, si nettement profilés, les horizons des côtes et des plateaux lorrains, d'un lot de souvenirs et d'impressions qui ne m'abandonneront jamais. Mais avec quelles délices je retrouvais chaque année ma vraie patrie, la Franche-Comté ! Le doux Val de Saône d'abord, la petite majesté grayloise dominant cette prairie qui refit un bonheur à Proudhon; plus encore, ce vieux bourru de Jura, ses prés-bois et ses sapins, ses eaux vertes et ses gorges surplombées par de grands bancs calcaires, telles que d'un pinceau héroïque les peignait Gustave Courbet - la Franche-Comté, parcourue en tous sens dès mes premières années dans les vieilles diligences à caisse jaune des Messageries Bouvet : fortes senteurs de 
vieux cuir, âcre odeur des chevaux fumants, bruits joyeux des pIV grelots et du fouet claquant à l'entrée des villages; elle aussi, la Comté, dotée comme la Lorraine de ses hauts lieux solitaires et sacrés : la Haute-Pierre de Mouthier, le Poupet de Salins renvoyant, par delà les crêtes, son salut au Mont Blanc; plus loin la Dole, ce sommet littéraire, et tant d'autres moins notoires; lieux salubres où l'esprit souffle avec le vent et qui, pour toute une vie, vous donnent le besoin de découvrir, de respirer d'infinis horizons. Nous ne sommes point, Comtois, des conformistes. Courbet ne l'était guère, quand il brossait L'Enterrement à Ornans ou L'Atelier. Ni Pasteur, quand les Académies conjurées hurlaient à mort contre sa vérité. Ni Proudhon, le fils du tonnelier, quand, en hommage, il dédiait aux bourgeois bien nantis de Besançon sa Propriété, c'est le vol. Proudhon, qui de nous, Comtois, aurait donné sans doute la meilleure des définitions : «Des anarchistes... mais de gouvernement », si Michelet n'avait fourni la sienne : «Ils ont su de bonne heure deux choses : savoir faire, savoir s'arrêter. »

Alors, cumulant la double âpreté, «critique, polémique et guerrière ", de la Comté et de la Lorraine - que je n'aie pas accepté avec placidité l'histoire des vaincus de 1870, ses prudences tremblotantes, ses renoncements à toute synthèse, son culte laborieux, mais intellectuellement paresseux, du «fait», et ce goût presque exclusif de l'histoire diplomatique («Ah, si nous l'avions mieux apprise, nous n'en serions pas là !») qui, d'Albert Sorel, ce demidieu, à Émile Bourgeois, ce dixième de dieu, obsédait les hommes qui nous endoctrinèrent de 1895 à 1902 ; — que j'aie réagi instinctivement et à peu près sans appui dans le camp des historiens (mais j'en trouvais chez mes amis linguistes et orientalistes, psychologues et médecins, géographes et germanistes, de Jules Bloch à Henri Wallon, à Charles Blondel, à Jules Sion, à Marcel Ray, alors que les moins conformistes de mes frères historiens, à quelques rares exceptions près dont celle d'Augustin Renaudet, ralliaient sans plus, en se trouvant hardis, l'étendard ambigu de Charles Seignobos); que tout de suite, pour ma part, je me sois inscrit parmi les fidèles de la Revue de Synthèse Historique et de son créateur Henri Berr : rien d'étrange dans une telle aventure. Sinon ceci, qui qualifie une époque : ni mes hardiesses ni mes vivacités ne surent dresser contre moi tant de braves cœurs qui m'aimaient bien et, à $\mathrm{pv}$ chaque 
occasion, me le prouvaient; je pense à Gabriel Monod, à Christian Pfister, à Camille Jullian; à Gustave Bloch aussi - et à Vidal de la Blache (mais il avait fait pour lui, déjà, et pour ses successeurs, sa propre révolution). La haute Université de ce temps-là, une aristocratie du cour, à tout le moins. Et, chez les grands, une bienveillance agissante, une fraternité.

Donc, seul dans l'arène, je fis de mon mieux. Des choses que j'ai pu dire, depuis cinquante ans, d'aucunes sont tombées dans le domaine commun, qui semblaient hasardeuses quand je les formulai pour la première fois. D'autres demeurent toujours en question. Le sort du pionnier est décevant : ou bien sa génération lui donne presque aussitôt raison et absorbe dans un grand effort collectif son effort isolé de chercheur; ou bien elle résiste et laisse à la génération d'après le soin de faire germer la semence prématurément lancée sur les sillons. Voilà pourquoi, de certains livres, de certains articles, le succès prolongé étonne leur auteur : c'est qu'ils n'ont trouvé leur vrai public que dix ans, que quinze ans après leur publication, et quand des appuis leur sont venus du dehors.

Des appuis, et ce fut une grande sécurité pour moi que de découvrir, à partir de 1910, en me plongeant dans son petit volume de la Collection Flammarion, Les anciennes démocraties des Pays-Bas, puis dans les premiers tomes de l'Histoire de Belgique, en attendant que naissent les splendides mémoires qui furent son chant du cygne (Les Périodes de l'histoire sociale du capitalisme,1914; Mahomet et Charlemagne, 1922 ; Mérovingiens et Carolingiens, 1923 ; enfin, 1927, le petit livre sur Les villes du moyen âge, ce joyau); — ce fut une sécurité d'abord, et bientôt ensuite une joie personnelle, de savoir qu'un homme fort parcourait, d'un pas égal et dominateur, les champs d'histoire de la Belgique amie : Henri Pirenne. Et ce fut une autre joie quand, de huit ans moins âgé que moi et déjà, par lui-même, orienté d'une façon légèrement différente, un jeune historien vint m'épauler fraternellement, poursuivre et prolonger mon effort dans son domaine de médiéviste : Marc Bloch. Mais dans les Annales, qu'appuyés dès le premier numéro par la fidélité de Leuilliot nous fondâmes tous deux en 1929, avec bien plus que la bénédiction d'Henri Pirenne, sa magnifique collaboration - dans ces Annales rapidement conquérantes, ce qu'on voulut ${ }_{\mathrm{pVI}}$ bien d'emblée reconnaître de 
salubre et de vivant, comment omettre d'en reporter leur part de mérite à tous ceux qui formèrent autour de moi un cercle fraternel et fervent! Et qui le forment encore : n'est-ce pas, Fernand Braudel, puissant évocateur d'une Méditerranée si riche en résonances, hardi promoteur, demain, d'une histoire économique rénovée ; n'est-ce pas, Georges Friedmann, pénétrant analyste d'âmes individuelles et collectives, de Leibniz et de Spinoza aux servants anonymes de la machine - et vous, Charles Morazé, curieux et ardent découvreur de terres inconnues, intrépide dans la quête obstinée de méthodes nouvelles - vous enfin, vous tous, mes collaborateurs, mes lecteurs, mes élèves et mes confrères de France et de l'étranger dont l'exigeante affection maintient ma force et soutient mon élan ? - Je devais dire cela, je devais proclamer en tête de ce recueil mes dettes sentimentales envers tant d'hommes et de lieux, tant de maisons aussi qui m'accueillirent : de l'École Normale Supérieure (1899-1902) et de la Fondation Thiers aux Universités de Dijon et de Strasbourg; sans oublier, parmi tant d'autres dans le Vieux et le Nouveau Monde, 1'Université Libre de Bruxelles qui me prêta ses chaires pendant un an ; finalement, depuis 1933, ce noble Collège de France. C'est portée par ces hautes tribunes que ma voix réussit à se faire entendre si largement.

Puissent encore servir les causes qui me sont chères ces pages rapprochées les unes des autres et, je l'espère, d'autant plus parlantes ! En ces années où tant d'angoisses nous étreignent, je ne veux pas redire avec le Michelet du Peuple: "Jeunes et vieux, nous sommes fatigués. » Fatigués, les jeunes ? j'espère bien que non. Fatigués, les vieux? je ne le veux pas. Par delà tant de tragédies et de bouleversements, de grandes clartés luisent à l'horizon. Dans le sang et dans la douleur, une Humanité nouvelle s'enfante. Et donc, comme toujours, une Histoire, une Science historique à la mesure de temps imprévus s'apprête à naître. Je souhaite que, d'avance, mon effort ait su deviner et épouser ses directions. Et que mes ruisseaux puissent gonfler son torrent.

Le Souget, Noël 1952. pVII 
$\underline{\text { Retour à la table des matières }}$ 


\section{Avertissement au lecteur}

Retour à la table des matières

S'agissant de prolonger et d'étendre l'influence de quelques articles écrits, au cours d'un demi-siècle, pour propager et défendre des idées qu'on croyait et qu'on juge toujours utiles, on ne s'est interdit :

- ni d'apporter aux textes retenus quelques modifications de forme ;

— ni de les alléger de considérations par trop circonstancielles ;

— ni de modifier certains titres pour mieux souligner l'esprit d'un article ;

— ni même (mais très rarement) de renvoyer le lecteur à des travaux postérieurs et permettant une mise au point du texte premier.

On a, par contre, résisté à la tentation de procéder soi-même à cette mise au point. Aussi bien est-il salutaire que les jeunes historiens qui liront ce livre puissent prendre un sentiment exact de l'évolution des idées et du changement incessant des points de vue en histoire. Non pour qu'ils tirent vanité de ces transformations. Mais pour qu'ils se disent, en connaissance de cause, que leurs efforts ne seront point perdus. 


\title{
PROFESSIONS DE FOI AU DÉPART
}

$\underline{\text { Retour à la table des matières }}$

De 1892 à 1933

\author{
EXAMEN DE CONSCIENCE \\ D'UNE HISTOIRE ET D'UN HISTORIEN
}

Point de retour sur le passé, point de retour sur moi-même. Le Domine non sum dignus qui monte aux lèvres d'un homme quand, pour la première fois, dans ce Collège où tant de présences invisibles l'entourent et le guettent, il sent peser sur ses épaules le fardeau de sa faiblesse - j'aurai la pudeur de le garder secret. Aussi bien, ce qu'attendent de l'élu ses auditeurs et ses collègues, ce n'est point une effusion. C'est la promesse virile d'un effort, le don d'une énergie. A quelle entreprise ? Pour la définir, historien, j'irai droit aux dates.

1892 : à la mort d'Alfred Maury, le Collège de France supprime pour la transformer la chaire d'Histoire générale et de Méthode historique appliquée qu'il possédait depuis plus d'un siècle. Chaire d'Histoire et de Morale, pour l'appeler de son vieux nom : celle qui tour à tour, à Daunou le classique et à Michelet le romantique, permit de donner un enseignement novateur et brillant.

1933, quarante ans plus tard : le Collège obtient la création d'une chaire d'Histoire générale et de Méthode historique appliquée aux temps modernes: traduction personnelle et libre de la formule (Histoire de la Civilisation moderne) qu'on lira désormais sur l'affiche du Collège. 
1892, 1933, deux dates, un problème : celui que, de toute nécessité, je dois poser devant vous. Et si, pour le faire, je suis contraint de procéder à un examen sans complaisance des idées que reçurent les hommes de ma génération et des méthodes qui leur furent enseignées, vous n'y verrez point d'orgueilleuse présomption : un grand désir de clarté simplement, et le besoin, pour vous comme pour moi, d'éclairer une route désormais commune. p003

I.

En supprimant la chaire d'Histoire et de Morale, le Collège suivait en 1892 sa raison d'être. Il n'est pas fait pour voler au secours de la victoire, mais pour la précéder. Or, en 1892, l'histoire, telle qu'on la concevait alors, avait joué et gagné sa partie. Elle était dans les lycées, peuplés d'agrégés d'histoire, dans les Universités garnies de chaires d'histoire, dans les écoles spéciales réservées à son culte. Elle débordait, de là, sur les directions d'enseignement, les rectorats, tous les grande postes de l'Instruction publique. Fière et puissante dans le temporel, elle se montrait, dans le spirituel, sûre d'elle-même - mais un peu somnolente.

Sa philosophie ? Faite, tant bien que mal, de formules empruntées à l'Auguste Comte, au Taine, au Claude Bernard qu'on enseignait dans les lycées, si elle montrait des trous et des cassures, l'ample et mol oreiller de l'évolutionnisme était là, tout à point, pour les dissimuler. L'histoire se sentait à l'aise dans le courant de ces pensées faciles; je me le suis souvent laissé dire d'ailleurs, les historiens n'ont pas de très grands besoins philosophiques. Et me remémorant les narquois propos de Péguy dans un de ses plus brûlants Cahiers de la quinzaine $^{1}$ : «Les historiens font ordinairement de l'histoire sans méditer sur les limites et les conditions de l'histoire; sans doute, ils ont raison; il vaut mieux que chacun fasse son métier; d'une façon générale, il vaut mieux qu'un historien commence par faire de l'histoire sans en chercher aussi long : autrement, il n'y aurait jamais rien de fait!» - j'ai toujours eu peur que, lisant ces phrases

${ }^{1}$ De la situation faite à l'histoire et à la sociologie dans les temps modernes, $3^{\mathrm{e}}$ cahier $8^{\mathrm{e}}$ série, p. 28. 
faussement débonnaires, beaucoup d'historiens, naguère, n'aient hoché la tête d'approbation, sans percevoir l'arrière-goût vinaigré de cette malice d'Orléans...

Tout ceci, du dehors. Du dedans, les choses s'ordonnaient simplement.

Point de définition préalable: l'histoire, c'était l'histoire... Si pourtant on se mettait en peine de la définir, c'était, assez étrangement, non par son objet, mais par son matériel. Je veux dire : par une partie seulement de son riche matériel.

«L'histoire se fait avec des textes. » Formule célèbre : aujourd'hui encore elle n'a pas fini d'épuiser sa vertu. Qui certes fut grande. Aux bons travailleurs légitimement fiers de leur conscience p004 d'érudit, justement en bataille contre des œuvres faciles et lâches, elle servit de mot d'ordre et de ralliement. Formule dangereuse si l'on y prend garde, et qui semblait vouloir, contre le mouvement général des recherches humaines étroitement solidaires, s'inscrire en faux brutalement.

Par un lien étroit, elle liait l'histoire à l'écriture — et c'était le moment où la préhistoire, au nom bizarrement significatif, s'employait à rédiger, sans textes, le plus long des chapitres de l'histoire humaine. - Une histoire économique naissait, qui d'abord voulait être l'histoire du travail humain; et cette histoire du travail dont François Simiand déterminait ici, il y a un an, les conditions, comment la faire avec des papiers simplement ou des parchemins, dans l'ignorance des techniques? - Une géographie humaine naissait; elle attirait l'attention des jeunes hommes, vite gagnés à des études réelles et concrètes, à des études qui semblaient, dans la morne grisaille des salles de cours, faire pénétrer le ciel et les eaux, les villages et les bois, toute la nature vivante. "L'histoire se fait avec des textes »: et du coup semblait s'évanouir l'observation pénétrante des sites, l'intelligence aiguë des relations géographiques proches ou lointaines, l'examen des empreintes laissées sur la terre humanisée par le labeur acharné des générations, depuis les temps où les néolithiques, départ fait de ce qui resterait forêt ou deviendrait labour, 
établissaient pour la suite des temps les premiers types historiques connus des institutions primordiales de l'humanité.

Et certes, aux prises d'une telle formule de rétrécissement et de mutilation, les explorateurs des sociétés antiques échappaient heureusement. Vivifiées sans cesse et renouvelées par les fouilles, les trouvailles de monuments et de matériel humain, - leurs études, par là mises en contact avec ces réalités substantielles: une hache de métal, un vase de terre cuite ou crue, une balance et ses poids, toutes choses qu'on peut palper et tenir dans sa main, dont on peut éprouver la résistance et tirer par analyse de formes cent données concrètes sur la vie même des hommes et des sociétés, - leurs études, contraintes de s'appliquer avec exactitude au terrain et conduites par l'éveil du sens topographique à l'acquisition $d u$ sens géographique, ne s'asservissaient point aux prescriptions d'un code sévèrement défini.

Dans le domaine des études modernes par contre, les jeunes hommes, façonnés intellectuellement par une culture à base unique de textes, d'études de textes, d'explications de textes, passaient, sans rupture d'habitudes, des lycées où leurs aptitudes de textuaires les avaient seules classés, à l'École Normale, à la p005 Sorbonne, aux Facultés où le même travail d'étude de textes, d'explication de textes leur était proposé. Travail sédentaire, de bureau et de papier; travail de fenêtres closes et de rideaux tirés. De là, ces paysans qui, en fait de terre grasse, semblaient ne labourer que de vieux cartulaires. De là, ces possesseurs de seigneuries dont nul ne s'inquiétait de savoir ce qu'ils faisaient des produits de leur réserve, ou ce que représentaient leurs domaines pour eux aux diverses époques, en services ou en nature, en fidélités humaines ou en sommes d'argent. L'histoire était grande dame; l'humble réalité économique faisait, en face d'elle, figure de $\mathrm{M}$. Dimanche. On y vivait sans argent ni crédit. On y pratiquait une agriculture, une industrie, un commerce abstraits. Et par là, l'histoire affirmait mieux encore sa participation à la dignité, à la respectabilité, au parfait et aristocratique désintéressement des études textuelles et littéraires. Elle jouissait de la haute considération dont ces études bénéficient en France depuis la Renaissance. Si, aujourd'hui encore, pour former ses agrégés d'histoire, l'Université leur demande sans plus, en 1933, quatre devoirs français sur des sujets d'histoire, et quatre conférences, si possible «brillantes », sur des 
sujets d'histoire ; si, voulant les charger de restituer la vie des sociétés passées, - toute leur vie matérielle et spirituelle, politique économique et sociale, - elle ne leur demande ni s'ils savent lire et au besoin dresser, en tout cas critiquer une statistique; ni s'ils connaissent du droit et de son évolution les premiers rudiments; ni, je ne dirai certes pas s'ils ont écouté les théoriciens contradictoires de l'économie politique, mais s'ils sont capables d'expliquer avec précision ce qu'est une monnaie dans son maniement quotidien; ce que signifie le change; ce qui se passe réellement derrière la façade d'une Bourse des valeurs ou les guichets d'une Banque de dépôts ; si, pour comble de paradoxe, ne leur demandant même pas l'explication critique d'un texte, elle se paie à peu près uniquement de mots, de dates, de noms de lieux et d'hommes, - rappelons-nous la formule : «L'histoire se fait avec des textes.» Alors sans doute, nous comprendrons.

Mais par les textes on atteignait les faits? Or, chacun le disait: 1'histoire c'était : établir les faits, puis les mettre en œuvre. Et c'était vrai, et c'était clair, mais en gros, et surtout si l'histoire était tissée, uniquement ou presque, d'événements. Tel roi était-il né en tel lieu, telle année ? Avait-il, en tel endroit, remporté p006 sur ses voisins une victoire décisive ? Rechercher tous les textes qui de cette naissance ou de cette bataille font mention; trier parmi eux les seules dignes de créance ; avec les meilleurs composer un récit exact et précis : tout cela ne va-t-il pas sans difficulté?

Mais déjà, qu'à travers les siècles la livre tournois soit allée se dépréciant progressivement; qu'à travers telle suite d'années les salaires aient baissé, ou le prix de la vie haussé ? Des faits historiques, sans doute, et plus importants à nos yeux que la mort d'un souverain ou la conclusion d'un éphémère traité. Ces faits, les appréhende-t-on d'une prise directe ? Mais non : des travailleurs patients, se relayant, se succédant, les fabriquent lentement, péniblement, à l'aide de milliers d'observations judicieusement interrogées et de données numériques extraites, laborieusement, de documents multiples: fournies telles quelles par eux, jamais, en vérité. - Qu'on n'objecte pas : «Des collections de faits et non des faits... » Car le fait en soi, 
cet atome prétendu de l'histoire, où le prendrait-on? L'assassinat d'Henri IV par Ravaillac, un fait ? Qu'on veuille l'analyser, le décomposer en ses éléments, matériels les uns, spirituels les autres, résultat combiné de lois générales, de circonstances particulières de temps et de lieux, de circonstances propres enfin à chacun des individus, connus ou ignorés, qui ont joué un rôle dans la tragédie : comme bien vite en verra se diviser, se décomposer, se dissocier un complexe enchevêtré... Du donné ? Mais non, du créé par l'historien, combien de fois? De l'inventé et du fabriqué, à l'aide d'hypothèses et de conjectures, par un travail délicat et passionnant.

De là, entre parenthèses, l'attrait si fort qu'exercent sur les historiens les périodes d'origine : c'est que les mystères foisonnent qu'il y faut éclaircir, - et les résurrections qu'il faut tenter. Déserts infinis, au milieu desquels il est passionnant de faire, si l'on peut, jaillir des points d'eau - et, par la puissance d'investigations acharnées, naître, parties de rien, des oasis de connaissances neuves.

Et voilà de quoi ébranler sans doute une autre doctrine, si souvent enseignée naguère. "L'historien ne saurait choisir les faits. Choisir? de quel droit? au nom de quel principe? Choisir, la négation de l'œuvre scientifique... » - Mais toute histoire est choix.

Elle l'est, du fait même du hasard qui a détruit ici, et là sauvegardé les vestiges du passé. Elle l'est du fait de l'homme : p007 dès que les documents abondent, il abrège, simplifie, met l'accent sur ceci, passe l'éponge sur cela. Elle l'est du fait, surtout, que l'historien crée ses matériaux ou, si l'on veut, les recrée : l'historien, qui ne va pas rôdant au hasard à travers le passé, comme un chiffonnier en quête de trouvailles, mais part avec, en tête, un dessein précis, un problème à résoudre, une hypothèse de travail à vérifier. Dire : «ce n'est point attitude scientifique ", n'est-ce pas montrer, simplement, que de la science, de ses conditions et de ses méthodes, on ne sait pas grandchose ? L'histologiste mettant l'œil à l'oculaire de son microscope, saisirait-il donc d'une prise immédiate des faits bruts ? L'essentiel de son travail consiste à créer, pour ainsi dire, les objets de son observation, à l'aide de techniques souvent fort compliquées. Et puis, ces objets acquis, à "lire » ses coupes et ses préparations. Tâche 
singulièrement ardue; car décrire ce qu'on voit, passe encore ; voir ce qu'il faut décrire, voilà le difficile.

Établir les faits et puis les mettre en œuvre... Eh oui, mais prenez garde: n'instituez pas ainsi une division du travail néfaste, une hiérarchie dangereuse. N'encouragez pas ceux qui, modestes et défiants en apparence, passifs et moutonniers en réalité, amassent des faits pour rien et puis, bras croisés, attendent éternellement que vienne l'homme capable de les assembler. Tant de pierres dans les champs de l'histoire, taillées par des maçons bénévoles, et puis laissées inutiles sur le terrain. Si l'architecte surgissait, qu'elles attendent sans illusions — j'ai idée que, fuyant ces plaines jonchées de moellons disparates, il s'en irait construire sur une place libre et nue. Manipulations, inventions, ici les manœuvres, là les constructeurs : non. L'invention doit être partout pour que rien ne soit perdu du labeur humain. Élaborer un fait, c'est construire. Si l'on veut, c'est à une question fournir une réponse. Et s'il n'y a pas de question, il n'y a que du néant.

Vérités qui trop souvent échappaient à trop d'historiens. Ils élevaient leurs disciples dans l'horreur sacrée de l'hypothèse, considérée (par des hommes qui d'ailleurs ne cessaient d'avoir à la bouche les grands mots de méthode et de vérité scientifique) comme le pire des péchés contre ce qu'ils nommaient Science. Au fronton de leur histoire, ils affichaient en lettres flamboyantes un Hypotheses non Fingo péremptoire. Et pour le classement des faits, une seule maxime : suivre rigoureusement l'ordre chronologique... Rigoureusement? Michelet disait finement. Mais chacun savait bien que Michelet et l'histoire n'avaient rien de commun. Ordre chronologique : n'était-ce pas duperie? L'histoire p008 qu'on nous enseignait (et si je mets mes verbes à l'imparfait, n'y voyez point une excessive candeur), l'histoire qu'on nous montrait à faire n'était, en vérité, qu'une déification du présent à l'aide du passé. Mais elle se refusait à le voir - et à le dire.

Histoire de France : de la Gaule romaine, définie par César au seuil des Commentaires, jusqu'à la France de 1933 saisie dans ses frontières, elle descendait le fil du temps sans jamais se perdre ni 
s'égarer. Elle n'échouait pas sur des écueils cachés, ne sombrait jamais dans les rapides; parvenue au terme de son voyage, elle concluait : "Voyez; partie de la Gaule, j'arrive sans encombre à la France d'aujourd'hui: merveilleuse continuité d'une histoire nationale! » C'était vrai; mais partant de 1933, l'historien avait commencé par remonter le courant, reconnaître tous les affluents, éliminer les bras qui s'égaraient (je veux dire, ne conduisaient pas en droiture à César). Et ce majestueux déroulement qui l'enchantait, comme il introduisait dans une histoire vivante, faite de catastrophes, de tragédies, d'amputations et d'annexions sans lendemain, je ne sais quelle rigidité factice et, à tout prendre, cadavérique.

Donnons-nous à nous-mêmes, rien qu'en regardant avec des yeux neufs un Atlas historique, la prodigieuse représentation de toutes les figures étonnamment différentes les unes des autres qu'a présentées le pays que nous nommons France, du nom dont lui-même s'est appelé avec continuité depuis des siècles; évoquons devant nos yeux, si nous parvenons à nous libérer de la hantise du « ce qui est », cette suite de formations pour nous paradoxales : mais si l'une d'elles avait vécu, l'histoire, soyons-en certains, aurait en remontant retrouvé ses ancêtres : et cet alliage de France et d'Espagne, et cet autre de France et de Rhénanie, ou de France et d'Angleterre, ou de France et d'Italie, de France et de Pays-Bas... J'en passe : à ne pas faire leur place à tant de hasards, d'amorces et de novations, qui dira ce qu'une histoire perd en vie et en intérêt? Et si, dans cette chaire, je pouvais user d'autres mots que de mots scientifiques, qui dira le péril qu'elle peut présenter?

Histoire du Rhin, j'imagine ${ }^{2}$. Vous l'écrivez de bonne foi, partant de cette illusion que vous descendez le fil des événements p009 alors qu'en fait vous avez commencé par le remonter. Vous partez de ce qu'est le Rhin pour nous, - un Rhin chargé de haines nationales, un Rhin frontière, enjeu sanglant de politiques bellicistes. Et de proche en

2 Cf. Lucien FeBVRE, Le problème historique du Rhin, première partie du volume Le Rhin, publié en collaboration avec Albert DEMANGEON par la Société générale alsacienne de Banque, Strasbourg, Imprimerie Alsacienne, 1930, in- $4^{\circ}$. Repris dans Le Rhin, problème d'histoire et d'économie, Paris, A. Colin, 1935, in$8^{\circ}$. 
proche, vous parvenez jusqu'au texte fameux des Commentaires qui vaticine: "Le Rhin, séparation de la Gaule et de la Germanie... » Après quoi, vous redescendez. Innocemment, c'est entendu. Librement, d'accord. Mais dans votre main, tout au long du voyage, vous serrez fiévreusement les deux bouts de la chaîne. Le présent brûlant, vous l'avez projeté, malgré vous, dans les siècles refroidis. Vous l'y retrouvez, tel que vous l'avez mis. Méthode régressive, sans que vous vous en doutiez. Qu'un Guillaume II naguère l'ait préconisée, qu'à son exemple la prônent ceux qui, se prenant pour fin dernière du monde, entendent que le passé ne vaille tout entier que comme préparation et justification voulue de ce qu'ils sont et projettent — soit. Mais la science, là-dedans, où la mettre, où la prendre?

On allait ainsi et l'histoire triomphait. Du dehors, on l'enviait pour sa puissance. Cependant, peu à peu, elle se vidait de sa substance réelle. L'histoire, ce n'était pas, disait-on, une discipline particulière avec un contenu parfaitement défini. C'était une "méthode»: une méthode en passe de devenir, dans le domaine des sciences de l'Homme, la méthode quasi universelle. Comme si cette méthode, qu'un texte connu définissait : « la méthode employée pour constituer l'histoire » était autre chose, en réalité, qu'une des méthodes pratiquées par toutes les sciences : celle de la connaissance indirecte ? L'histoire n'avait pas perdu son ombre. Mais pour une ombre, elle renonçait à son vrai corps. Et ceux-là qui le lui disaient, ceux notamment que groupait autour de la Revue de Synthèse Historique l'homme, Henri Berr, qui en 1911, dans la préface de son essai critique et théorique aux La synthèse en histoire, avait le courage clairvoyant d'écrire (p. VI): "On affirme que c'est parce que l'histoire est trop scientifique qu'elle est sans contact avec la vie; je suis convaincu que c'est, au contraire, parce qu'elle ne l'est pas suffisamment $»$ - ceux-là préparaient l'avenir sans doute; ils ne maîtrisaient certes pas le présent.

II.

Et ce fut le réveil, brusque et désagréable. En pleine crise, au milieu des doutes. 
Doutes fils de la guerre. Doutes de ceux qui reprenaient leur métier pacifique mais hantés par l'idée qu'ils étaient là pour ${ }_{\mathrm{p} 010}$ faire chacun, non point telle qu'ils l'auraient faite si la tourmente n'avait roulé le monde dans ses tourbillons, leur tâche individuelle; — mais, par surcroît, la tâche de ceux qui n'étaient plus là, de ces deux générations atrocement décimées qui ne survivaient plus que par quelques débris, comme ces forêts de cauchemar qu' on traversait parfois, au front, sans s'en douter ${ }^{3} . .$. « Faire de l'histoire; enseigner de l'histoire; remuer des cendres, les unes froides déjà, les autres encore tièdes : cendres toutes, résidus inertes d'existences consumées... D'autres tâches, plus pressantes, plus utiles pour dire le grand mot, ne réclamaient-elles point que nous leur donnions le restant de nos forces ?»

Doutes de ceux qui raillaient « la faillite de l'histoire »; ils avaient moins de poids. Car, l'accuser de n'avoir rien prévu, ni prédit; ironiser sur l'écroulement de «lois» qu'on forgeait pour le plaisir d'en dénoncer l'inutilité ; à ce "spiritualisme économique » naguère signalé par un Frédéric Rauh ${ }^{4}$ comme déguisé sous le nom de «matérialisme historique », objecter les ressources d'une énergie morale dont personne ne niait les possibilités; à ceux qui parlaient du milieu et de sa contrainte, répondre en plaisantin, avec un Bernard Shaw: "L'homme raisonnable s'adapte au milieu; l'homme déraisonnable essaie d'adapter le milieu; c'est pourquoi tous les progrès sont l'œuvre d'imbéciles » — rien d'imprévu là-dedans, ni qui pût intéresser les historiens. Car ils le savaient bien: il y a, toujours distincts, l'ordre de la connaissance et celui de l'action; l'ordre du savoir et celui de l'inspiration; l'ordre des choses qui ont déjà commencé d'exister, et l'ordre de la création jaillissante. Des lois historiques parfaitement établies sauraient-elles jamais contraindre les hommes ? Et qui peut affirmer qu'un sentiment de création autonome ne soit pas nécessaire pour agir, dans un milieu donné, contre le poids des traditions, contre l'inertie des institutions - alors même qu'au regard de l'avenir l'effort autonome des novateurs s'inscrira sans doute parmi les conséquences du régime qu'ils combattent?

3 Lucien FEBVRE, L'histoire dans le monde en ruines, Leçon d'ouverture du cours d'histoire moderne à l'université de Strasbourg (Revue de Synthèse Historique, t. XXX, 1. n ${ }^{\circ} 88$, févr. 1920, p. 1 et suiv.).

4 Études de morale, Paris, Alcan, 1911, p. 64 et suiv. 
Plus grave, la crise de tout ce qui entourait, de tout ce qui encadrait l'histoire dans le domaine de l'esprit. Et ici, la guerre n'avait plus rien à voir. Ce monde moderne dont nous étions fiers et qui, à nos activités, offrait l'asile confortable de certitudes acquises; ce monde dominé par le mathématisme rigoureux d'une p011 physique traitée comme une géométrie du monde, vidant la matière de toute qualité, la ramenant à l'étendue toute nue; cette science des phénomènes naturels qui, de toute son ardeur, tendait vers l'objectif — un objectif soustrait aux influences du Moi, tirant valeur non de la qualité, mais de la quantité ; plus spécialement, cette science des faits de l'homme qui se constituait par application au domaine humain des méthodes éprouvées jusque-là dans le domaine d'une matière vouée au déterminisme le plus rigoureux — tout cela s'écroulait par larges pans, sous le choc répété d'idées neuves, de ces secousses profondes qui ébranlaient, disloquaient les assises séculaires de la physique.

Une faillite des vieilles idées, des vieilles doctrines rejetées au néant par de nouvelles venues? Allons donc ! Pas de mer géologique qui ne laisse d'étage attestant sa puissance. Une crise d'idéal, le retour nécessaire à un mysticisme primitif ou évolué ? Encore moins. Un enrichissement, certes, et un élargissement. Sur le point précis qui nous occupe, la possibilité, entrevue, de négociations neuves, de relations intelligibles entre ces deux domaines qu'un abîme jusqu'alors séparait: le domaine objectif de la Nature; le domaine subjectif de l'Esprit...

Ce n'est point le moment de rechercher comment, dans quelle mesure et sur quels point précis l'histoire - bien qu'à peine née à la vie générale des sciences - peut se trouver affectée par ces grandes transformations d'idées. Sinon tout un livre, il y faudrait un cours. Contentons-nous d'une simple constatation: Comment, au milieu de tels bouleversements, concevoir une histoire parfaitement immobile dans ses vieilles habitudes ? Comment ne pas sentir la nécessité, pour nous, de raccorder nos idées et nos méthodes à d'autres ? Comment, pour dire le mot, ne pas reconstruire, alors que partout apparaissent les lézardes? 
Reconstruire, mais sur quel fondement ? - Ne cherchons pas bien loin: sur le fondement solide de ce qu'il faut bien nommer l'Humanité.

Histoire science de l'Homme, science du passé humain. Et non point science des choses, ou des concepts. Les idées en dehors des hommes qui les professent? Les idées, simples éléments entre beaucoup d'autres de ce bagage mental fait d'influences, de ressouvenirs, de lectures et de conversations - que chacun de nous transporte avec lui ? Les institutions, séparées de ceux-là qui les font et qui, tout en les respectant, les modifient sans cesse ? p012 Non. Il n'est d'Histoire que de l'Homme, et d'histoire au sens le plus large. Quand James Darmesteter écrivait La vie des mots et prenait pour héros le Langage, on sait avec quelle vigueur, ici-même, au Collège, Michel Bréal dénonçait son illusion.

Histoire science de l'Homme, et alors les faits, oui : mais ce sont des faits humains; tâche de l'historien : retrouver les hommes qui les ont vécus, et ceux qui dans chacun d'eux, plus tard, se sont logés en eux avec toutes leurs idées, pour les interpréter.

Les textes, oui : mais ce sont des textes humains. Et les mots même qui les forment sont gorgés de substance humaine. Et tous ont leur histoire, sonnent différemment selon les temps, et même s'ils désignent des objets matériels, ne signifient que rarement des réalités identiques, des qualités égales ou équivalentes.

Les textes, sans doute: mais tous les textes. Et pas seulement ces documents d'archives en faveur de qui on crée un privilège - le privilège d'en tirer, comme disait cet autre ${ }^{5}$, un nom, un lieu, une date ; une date, un nom, un lieu - tout le savoir positif, concluait-il, d'un historien insoucieux du réel. Mais un poème, un tableau, un drame: documents pour nous, témoins d'une histoire vivante et humaine, saturés de pensée et d'action en puissance...

Les textes, évidemment: mais pas rien que les textes. Les documents aussi, quelle qu'en soit la nature; ceux qu'on utilise de

Le physicien Boisse. 
longue date ; ceux surtout que procure l'effort heureux de disciplines nouvelles: la statistique; la démographie se substituant à la généalogie, dans toute la mesure où Démos sur leur trône remplace les Rois et les Princes; la linguistique proclamant avec Meillet que tout fait de langue manifeste un fait de civilisation; la psychologie passant de l'étude des individus à celle des groupes et des masses : combien d'autres encore? dans les marais bourbeux du Nord, il y a des millénaires, le pollen des arbres forestiers est tombé. Un Gradmann aujourd'hui, l'examinant au microscope, en tire le fondement de ces études passionnantes de peuplement antique, que la science de l'habitat humain doit s'avouer impuissante à mener à bien - même en ajoutant aux données des textes l'étude des noms de lieux ou celle des vestiges archéologiques. Un document d'histoire, ce pollen millénaire. L'histoire fait son miel avec lui. L'histoire qui s'édifie, sans exclusion, avec tout ce que l'ingéniosité des hommes peut inventer et combiner pour suppléer au silence des textes, aux ravages de l'oubli... p013

Entre disciplines proches ou lointaines, négocier perpétuellement des alliances nouvelles; sur un même sujet concentrer en faisceau la lumière de plusieurs sciences hétérogènes : tâche primordiale, et de toutes celles qui s'imposent à une histoire impatiente des frontières et des cloisonnements, la plus pressante sans doute et la plus féconde.

Emprunt de notions? Quelquefois. Emprunt de méthodes et d'esprit avant tout. Fait de chercheurs isolés, quêtant pour eux l'appui des voisins ? c'est la règle aujourd'hui. Demain sans doute, fait de travailleurs d'éducation diverse s'unissant en équipes pour joindre leurs efforts: le physicien, j'imagine, posant le problème; le mathématicien apportant sa virtuosité à manier le langage scientifique ; un astronome enfin, choisissant dans l'immense champ du ciel les astres qu'il faut choisir, observant et contrôlant. Formule d'avenir sans doute. Au travail, elle enlèvera beaucoup de son intimité. Il ne sera plus, aussi profondément, la chose d'un homme et son émanation. Mais en efficacité, il retrouvera ce qu'il aura perdu en personnalité. Les temps de l'artisanat, qu'on le veuille ou non, descendent lentement au-dessous de notre horizon. Et comme tant d'autres, le petit artisan scientifique que nous sommes tous, que nous aimons jusque dans ses tares et ses manies; le petit artisan qui fait 
tout lui-même et par lui-même, crée son outillage, son champ d'expérience, ses programmes d'investigation - il s'en va rejoindre dans le passé tant de beautés mortes. Mais une autre beauté se dessine sur la terre.

Collaboration des hommes, concordance des méthodes, analogie des développements. D'une section de la philologie, la philologie comparée, elle-même issue de la découverte du sanscrit au XVIII siècle, une science nouvelle, la linguistique, s'est dégagée. Or, avant de s'orienter vers l'étude statique des faits du langage, abstraction faite de l'histoire des langues, elle se voua à peu près uniquement à celle-ci. Évolution qui, sans doute, préfigure de très loin et très grossièrement celle qu'un jour accomplira l'histoire, quand de l'étude globale des ensembles historiques - peuples et nations si l'on veut elle passera, sous une forme qu'on ne peut d'avance déterminer (parce qu'elle est fonction, largement, des progrès à venir d'autres sciences voisines) à l'étude statique des faits de l'histoire... Pour l'instant, modestement, ne lui assignons pas d'autre tâche que de poser des problèmes humains. Par souci d'humanisme, à la fois, et par pressentiment de ce qu'un jour pourra être l'histoire. La science des faits d'histoire. p014

Une science avec des lois ? Peut-être. Tout dépend de ce qu'on nomme Loi. Mot ambitieux, mot lourd de sens divers parfois contradictoires. Lois qui obligent pour l'action, non, nous l'avons dit. N'écrasons pas l'effort humain sous le poids stérilisant du pané. Répétons hautement, historiens - et parce qu'historien - qu'il n'oblige pas. Passé, du reste ? Soyons sans illusion. L'homme ne se souvient pas du passé ; il le reconstruit toujours. L'homme isolé, cette abstraction. L'homme en groupe, cette réalité. Il ne conserve pas le passé dans sa mémoire, comme les glaces du Nord conservent frigorifiés les mammouths millénaires. Il part du présent — et c'est à travers lui, toujours, qu'il connaît, qu'il interprète le passé.

En faut-il un exemple - et de tous sans doute le plus typique ? C'est celui de la coutume médiévale qu'hier alléguait justement Marc Bloch. Pendant plusieurs siècles, une règle de droit a été considérée comme valable, une redevance jugée légitime pour cette seule raison que règle ou redevance étaient immémoriales. Et le juge 
consciencieux, quand il recherchait la vérité juridique, se tournait vers le passé : «Qu'a-t-on fait avant moi ? Quelle est donc la coutume? » Le droit aurait donc dû demeurer stationnaire ? Il n'a cessé d'évoluer, et rapidement. Tout comme a évolué le christianisme, entre la paix de l’Église et la Réforme...

Nécessités vitales. Réactions de défense instinctives contre la masse formidable des faits, des idées, des coutumes d'autrefois. Pénétrer de présent la tradition elle-même : premier moyen de lui résister. Et certes, ce n'est point là la réaction de l'histoire objective. Se dégageant de ces interprétations, elle tente, elle, par un effort héroïque et direct, de reconstituer les systèmes successifs d'idées et d'institutions, dans leur état de fraîcheur originelle. Mais elle sait mesurer les difficultés d'une pareille tâche. Elle sait que, jamais, elle ne déclenchera l'appareil introuvable qui, après un sommeil de plusieurs siècles, lui ferait entendre, enregistrée telle quelle pour une éternité, la voix même du passé saisie sur le vivant. Elle interprète. Elle organise. Elle reconstitue et complète les réponses. Elle se fait le passé dont elle a besoin. Et point là de scandale, d'attentat à la majesté supposée de la Science. La Science ne se fait point dans une tour d'ivoire. Elle se fait à même la vie, et par des vivants qui baignent dans le siècle. Elle est liée par mille liens subtils et compliqués à toutes les activités divergentes des hommes. Elle subit même, parfois, l'influence des modes. Baignant dans le même milieu que toutes les autres disciplines humaines, comment échapperait-elle à leurs inquiétudes, cette Science dont Poincaré disait p015 qu'elle « devine le passé »? Disons, nous, qu'elle n'en touche jamais de sa baguette, pour les ressusciter, que certaines parties : celles-là seules qui ont du prix pour l'idéal qu'elle sert, au temps où elle le sert... Et je reviens à ma question de tout à l'heure.

Des lois ? Si vous parlez de ces formules communes qui, groupant des faits jusque-là séparés, en forment des séries - pourquoi pas ? C'est alors qu'une fois de plus l'histoire éprouvera l'Unité vivante de la Science; c'est alors qu'elle se sentira, mieux encore, la sœur des autres sciences, de toutes celles pour qui, aujourd'hui, le grand problème, c'est de négocier l'accord du Logique et du Réel — comme il est, pour l'histoire, de négocier l'accord de l'Institutionnel et du Contingent. 
Tâche difficile. Partout, dans toutes les sciences, aujourd'hui, ce ne sont qu'oppositions, conflits, antinomies. Ici, dans cette maison, laissons railler ceux qui vont ricanant et dénonçant nos impuissances. Ils n'oublient qu'une chose: à l'origine de toute acquisition scientifique, il y a le non-conformisme. les progrès de la Science sont fruits de la discorde. Comme c'est de l'hérésie que se nourrissent, s'étoffent les religions. Oportet haereses esse.

Combien ces idées, pour être vraiment explicitées, demanderaient de temps et d'efforts — je le savais en commençant cette leçon. Pardonnez-moi de ne m'être pas arrêté à des difficultés que je connaissais. Il s'agissait, pour moi, non d'édifier un système : de vous présenter un homme, ses intentions, ses partis pris peut-être et ses infirmités, sa bonne volonté à coup sûr.

Dans le beau livre jubilaire qu'a publié le Collège de France à l'occasion de son quatrième centenaire, on trouve, reproduit par les soins de Paul Hazard, un document émouvant. C'est une page de notes autographes de Michelet — notes de sa fine écriture jetées sur le papier avant l'une des dernières leçons qu'il professa ici. Voici ce qu'on lit sur cette feuille où déjà vibrent les cadences du grand poète de l'histoire romantique :

« Je n'ai point de parti... Pourquoi ? Parce que, dans l'histoire, j'ai vu l'histoire : rien de plus...

«Je n'ai point d'école... Pourquoi ? Parce que je n'ai pas exagéré l'importance des formules, parce que je n'ai voulu asservir aucun esprit : au contraire, les affranchir - leur donner la force vivante qui fait juger et trouver. »

$\mathrm{Au}$ terme de l'enseignement que j'inaugure aujourd'hui, pouvoir un jour, proche ou lointain, mériter que me soit rendu cet p016 hommage : « Dans l'histoire, il n'a vu que l'histoire, sans plus... Dans son enseignement, il n'a pas asservi les esprits, parce qu'il n'a pas eu de systèmes - de ces systèmes dont Claude Bernard disait, lui aussi, qu'ils tendent à asservir l'esprit humain : mais il a eu le souci des idées et des théories; des idées, parce que les Sciences n'avancent que 
par la puissance créatrice et originale de la pensée ; des théories, parce que nous savons bien sans doute qu'elles n'embrassent jamais l'infinie complexité des phénomènes naturels: elles n'en sont pas moins ces degrés successifs que, dans son désir insatiable d'élargir l'horizon de la pensée humaine, la Science gravit les uns après les autres - avec la magnifique certitude de n'atteindre jamais le faîte des faîtes, la cime, d'où l'on verrait l'aurore surgir du crépuscule. » p017 
VIVRE L'HISTOIRE

Propos d'Initiation

$\underline{\text { Retour à la table des matières }}$

J'aime l'histoire. Si je ne l'aimais pas, je ne serais pas historien. De sa vie faire deux parts; donner l'une au métier, expédié sans amour; réserver l'autre à la satisfaction de ses besoins profonds: voilà qui est abominable, quand le métier qu'on a choisi est un métier d'intelligence. J'aime l'histoire — et c'est pour cela que je suis heureux de vous parler, aujourd'hui, de ce que j'aime ${ }^{6}$.

J'en suis heureux, et c'est tout naturel. Je n'aime pas beaucoup mêler les genres, et substituer la confidence à la conférence. Mais enfin, je peux bien vous dire ceci. Quand en 1899 je suis entré, comme vous, dans cette maison après mon année de service militaire (la première des sept années que les hommes de ma génération ont en moyenne données à la vie militaire) - je me suis inscrit dans la Section des Lettres. C'était une trahison: j'avais depuis ma plus tendre enfance une vocation d'historien chevillée au corps. Mais elle n'avait pu résister à deux années de rhétorique supérieure à Louis-leGrand, à deux années de ressassage du Manuel de politique étrangère d'Émile Bourgeois (que j'allais retrouver comme maître de conférence à l'École). Anatole France raconte quelque part qu'enfant il rêvait d'écrire une histoire de France « avec tous les détails ». Nos maîtres, dans les lycées, semblaient nous proposer l'idéal puéril du

\footnotetext{
6 Ces propos s'adressaient aux élèves de l'École Normale Supérieure, à la rentrée de 1941. Prié de leur faire trois conférences d'orientation sur l'histoire économique et sociale, je crus pouvoir leur donner les conseils qu'on va lire.
} 
petit Anatole. On eût dit que faire de l'histoire, pour eux, ce fût apprendre sinon tous les détails, du moins le plus de détails possibles sur la mission de M. de Charnacé dans les Cours du Nord. Et qui savait un peu plus de ces détails que le voisin l'emportait naturellement sur lui : il était bon pour l'histoire !

J'ai un peu peur que les choses n'aient pas beaucoup changé depuis mon temps. Avec cet humour normalien qu'il conserva jusqu'à p018 ses derniers moments - un collègue que nous venons de perdre au Collège de France, le grand mathématicien Lebesgue, nous confiait un jour qu'il $y$ avait, à sa connaissance, deux espèces de mathématiques: l'une redoutable, celle des Inspecteurs Généraux, qu'il avouait ne pas bien comprendre - et l'autre accessible, celle qu'il faisait avancer chaque jour et dont aucune difficulté ne le rebutait. Y aurait-il pareillement deux histoires et tout le monde ne goûterait-il pas également la première des deux ? Question téméraire. En tout cas, ce n'est pas de celle-là que je veux vous parler. C'est de l'autre. De l'histoire tout court. Celle que j'essaie de faire progresser. Celle que j'aime.

I.

Histoire tout court? me direz-vous. Non, puisque vous annoncez des causeries sur l'histoire "économique et sociale». - Mais précisément, la première chose que je tiens à vous dire, c'est qu'il n'y a pas, à proprement parler, d'histoire économique et sociale. Non seulement parce que la liaison de l'Économique et du Social n'est pas un privilège - une exclusivité, comme dirait un Directeur de cinéma - en ce sens qu'il n'y a pas lieu de dire Économique et Social, plutôt que Politique et Social, plutôt que Littéraire et Social, plutôt que Religieux et Social, plutôt même que Philosophique et Social. Ce ne sont pas des raisons raisonnées qui nous ont donné l'habitude de lier l'une à l'autre, tout naturellement et sans plus y réfléchir, les deux épithètes d'Économique et de Social. Ce sont des raisons historiques, très faciles à déterminer - et la formule qui nous occupe n'est pas autre chose, en dernière analyse, qu'un résidu ou qu'un héritage : celui des longues discussions à quoi a donné lieu, depuis un siècle, ce qu'on nomme le problème du Matérialisme historique. - Ne croyez 
donc pas, quand je me sers de la formule courante, quand je parle d'histoire économique et sociale, que j'aie le moindre doute sur sa valeur réelle. Quand nous avons fait imprimer, Marc Bloch et moi, ces deux mots traditionnels sur la couverture de nos Annales, nous savions bien que « social », en particulier, est un de ces adjectifs à qui on a fait dire tant de choses, dans le cours des temps, qu'il ne veut finalement à peu près plus rien dire. Mais c'est bien pour cela que nous l'avons recueilli. Si bien recueilli que, pour des raisons purement contingentes, il se trouve figurer seul aujourd'hui sur la couverture des mêmes Annales devenues d'Économiques et Sociales, par une p019 nouvelle disgrâce, Sociales tout court. Une disgrâce que nous avons acceptée avec le sourire. Car nous étions d'accord pour penser que, précisément, un mot aussi vague que « social »semblait avoir été créé et mis au monde par un décret nominatif de la Providence historique, pour servir d'enseigne à une Revue qui prétendait ne pas s'entourer de murailles, mais faire rayonner largement, librement, indiscrètement même, sur tous les jardins du voisinage, un esprit, son esprit : je veux dire un esprit de libre critique et d'initiative en tous sens.

Donc, j'y reviens : il n'y a pas d'histoire économique et sociale. Il y a l'histoire tout court, dans son Unité. L'histoire qui est sociale tout entière, par définition. L'histoire que je tiens pour l'étude, scientifiquement conduite, des diverses activités et des diverses créations des hommes d'autrefois, saisis à leur date, dans le cadre des sociétés extrêmement variées et cependant comparables les unes aux autres (c'est le postulat de la sociologie), dont ils ont rempli la surface de la terre et la succession des âges. Définition un peu longue : mais je me défie des définitions trop brèves, trop miraculeusement brèves. Et celle-ci écarte, il me semble, par ses termes mêmes, beaucoup de faux problèmes.

C'est ainsi, tout d'abord, que je qualifie l'histoire d'étude scientifiquement menée, et non pas de science - pour la même raison que, traçant le plan de l'Encyclopédie française, je n'ai pas voulu lui donner pour base, comme les rites l'exigeaient, une classification générale des Sciences; pour cette raison surtout que, parler de Sciences, c'est avant tout évoquer l'idée d'une somme de résultats, 
d'un trésor si l'on veut, plus ou moins bien garni de monnaies, les unes précieuses, les autres non ; ce n'est pas mettre l'accent sur ce qui est le ressort moteur du savant, je veux dire l'Inquiétude, la remise en cause non pas perpétuelle et maniaque, mais raisonnée et méthodique des vérités traditionnelles - le besoin de reprendre, de remanier, de repenser quand il le faut, et dès qu'il le faut, les résultats acquis pour les réadapter aux conceptions, et, par delà, aux conditions d'existence nouvelles que le temps et les hommes, que les hommes dans le cadre du temps, ne cessent de se forger.

Et, d'autre part, je dis les hommes. Les hommes, seuls objets de l'histoire - d'une histoire qui s'inscrit dans le groupe des disciplines humaines de tous les ordres et de tous les degrés, à côté de l'anthropologie, de la psychologie, de la linguistique, etc. ; d'une ${ }_{\mathrm{p} 020}$ histoire qui ne s'intéresse pas à je ne sais quel homme abstrait, éternel, immuable en son fond et perpétuellement identique à lui-même mais aux hommes toujours saisis dans le cadre des sociétés dont ils sont membres - aux hommes membres de ces sociétés à une époque bien déterminée de leur développement — aux hommes dotés de fonctions multiples, d'activités diverses, de préoccupations et d'aptitudes variées, qui toutes se mêlent, se heurtent, se contrarient, et finissent par conclure entre elles une paix de compromis, un modus vivendi qui s'appelle la Vie.

L'homme ainsi défini, on peut bien le saisir, pour la commodité, par tel ou tel membre, par la jambe ou par le bras plutôt que par la tête : c'est toujours l'homme tout entier qu'on entraîne dès qu'on tire. Cet homme, il ne se laisse pas découper en morceaux ou alors on le tue : or l'historien n'a que faire de morceaux de cadavres ; l'historien étudie la vie passée - et Pirenne, le grand historien de notre époque, Pirenne le définissait un jour : " un homme qui aime la vie et qui sait la regarder ». Cet homme, d'un mot, il est le lieu commun de toutes les activités qu'il exerce - et on peut s'intéresser plus particulièrement à l'une de celles-ci, à son activité, à ses activités économiques, par exemple. A une condition, c'est de n'oublier jamais qu'elles le mettent en cause, toujours, tout entier — et dans le cadre des sociétés qu'il a forgées. Mais précisément, c'est là ce que signifie l'épithète de sociale, qu'on accole rituellement à celle d'économique ; elle nous rappelle que l'objet de nos études ce n'est pas un fragment 
du réel, un des aspects isolés de l'activité humaine - mais l'homme lui-même, appréhendé au sein des groupes dont il est membre.

Je m'excuse de ce qu'il y a d'un peu abstrait dans ces remarques. Et je ne perds de vue, en les formulant, ni mon dessein véritable - ni la raison profonde pourquoi je suis ici en ce moment. Je relisais hier, à votre intention, des texte curieux et beaux. Hauser a publié jadis, en 1914, des notes de Michelet, pleines d'éclairs comme toujours, d'éclairs de divination et de génie. Parmi elles, une leçon professée ici même, le 10 juillet 1834, aux élèves de troisième année qui allaient quitter l'École et partir en province. A ces jeunes hommes qu'attendait le dur métier de professeur dans un collège royal, dans une ville sans archives organisées, sans bibliothèques cataloguées, sans facilité de voyages ni possibilités d'évasion - Michelet donnait courage. p021 Il montrait comment, partout, un historien qui le veut peut travailler utilement. Le problème n'est plus le même aujourd'hui. Mais ce que tentait Michelet, avec son autorité et l'ardeur de sa parole et le rayonnement de son génie - c'est bien cependant, toutes proportions gardées, ce que je voudrais tenter avec vous. Si je pouvais rattraper, ou consolider quelque vocation chancelante d'historien ; si je pouvais désarmer des préjugés nés, contre l'histoire, d'un malheureux contact avec ce qu'on nous a offert sous ce nom, trop souvent - avec ce qu'on vous a dispensé et ce qu'on vous réclamera encore dans les examens jusqu'au Doctorat, le seul qui échappe, ou du moins qui puisse échapper au péril - si je pouvais vous donner le sentiment qu'on peut vivre sa vie en étant historien, j'aurais payé un peu de la dette que j'ai contractée envers notre maison.

Or, comment vous donner ce sentiment - le sentiment qu'on peut vivre sa vie en étant historien - sinon en examinant devant vous, avec vous, quelques-uns des problèmes vivants que pose l'Histoire, aujourd'hui, pour ceux qui se portent à l'extrême pointe de la recherche - pour ceux qui, à l'avant du bateau, interrogent sans cesse l'horizon de leurs yeux?

C'est que, poser un problème, c'est précisément le commencement et la fin de toute histoire. Pas de problèmes, pas d'histoire. Des narrations, des compilations. Or, rappelez-vous : si je n'ai point parlé 
de «science» de l'histoire, j'ai parlé «d'étude scientifiquement conduite ». Ces deux mots n'étaient point là pour faire riche. "Scientifiquement conduite », la formule implique deux opérations, celles-là mêmes qui se trouvent à la base de tout travail scientifique moderne : poser des problèmes et formuler des hypothèses. Deux opérations qu'aux hommes de mon âge on dénonçait déjà comme périlleuses entre toutes. Car poser des problèmes, ou formuler des hypothèses, c'était tout simplement trahir. Faire pénétrer dans la cité de l'objectivité le cheval de Troie de la subjectivité...

En ce temps-là, les historiens vivaient dans un respect puéril et dévotieux du « fait ». Ils avaient la conviction, naïve et touchante, que le savant était un homme qui, mettant l'œil à son microscope, appréhendait aussitôt une brassée de faits. De faits à lui donnés, de faits pour lui fabriqués par une Providence complaisante, de faits qu'il n'avait plus qu'à enregistrer. Il aurait suffi à l'un quelconque de ces docteurs en méthode de mettre, si peu que ce soit, son œil à l'oculaire d'un microscope et de regarder une préparation d'histologie, pour s'apercevoir aussitôt qu'il ne s'agissait pas pour l'histologiste d'observer, p022 mais d'interpréter ce qu'il faut bien nommer une abstraction. Cinq minutes, et il eût mesuré, dans la prise de possession par le savant de ce qu'il a d'abord longuement, difficilement préparé - en vertu d'une idée préconçue - toute la part personnelle de l'homme, du chercheur qui n'agit que parce qu'il s'est posé un problème et formulé une hypothèse.

Il en va tout de même de l'historien. De l'historien à qui aucune Providence ne fournit des faits bruts. Des faite doués par extraordinaire d'une existence de fait parfaitement définie, simple, irréductible. Les faits historiques, même les plus humbles, c'est l'historien qui les appelle à la vie. Les faits, ces faits devant lesquels on nous somme si souvent de nous incliner dévotieusement, nous savons que ce sont autant d'abstractions - et que, pour les déterminer, il faut recourir aux témoignages les plus divers, et quelquefois les plus contradictoires - entre qui nous choisissons nécessairement. De sorte que cette collection de faits qu'on nous présente si souvent comme des faite bruts qui composeraient 
automatiquement une histoire transcrite au moment même où les événements se produisent - nous savons qu'elle a elle-même une histoire - et que c'est celle des progrès de la connaissance et de la conscience des historiens. Si bien que pour accepter la leçon des faits, nous sommes en droit de réclamer qu'on nous associe d'abord au travail critique qui a préparé l'enchaînement de ces faits dans l'esprit de celui qui les invoque.

Et de même, si l'historien ne se pose pas de problèmes, ou si, s'étant posé des problèmes, il ne formule pas d'hypothèses pour les résoudre - en fait de métier, de technique, d'effort scientifique, je suis fondé à dire qu'il est un peu en retard sur le dernier de nos paysans : car ils savent, eux, qu'il ne convient pas de lancer leurs bêtes, pêle-mêle, dans le premier champ venu pour qu'elles y pâturent au petit bonheur : ils les parquent, ils les attachent au piquet, ils les font brouter ici plutôt que là. Et ils savent pourquoi.

Que voulez-vous? Quand, dans quelqu'un de ces gros livres dont la rédaction semble absorber depuis des années toutes les forces de nos meilleurs professeurs d'histoire - quand, dans quelqu'un de ces manuels honorables, consciencieusement préparés, soigneusement rédigés, tout bourrés de faits, de chiffres et de dates, d'énumérations de tableaux, de romans ou de machines - quand, dans l'un de ces livres, plus munis d'estampilles p023 flatteuses par l'Institut, la Sorbonne, les Universités régionales, que de panonceaux multicolores un de nos bons hôtels de tourisme - on découvre par fortune une idée, et que cette idée est la suivante : «La période que nous allons étudier (et c'est une des plus vivantes de notre histoire) continue celle qui précède et annonce celle qui suit; elle est remarquable parce qu'elle supprime, mais aussi par ce qu'elle établit», etc. continuerons-nous plus longtemps à nous demander pourquoi raillent l'histoire, se détournent de l'histoire, flétrissent et ridiculisent l'histoire maints bons esprits, déçus de voir tant d'efforts, tant d'argent, tant de bon papier imprimé n'aboutir qu'à propager cette philosophie-là - qu'à perpétuer cette histoire psittacique et sans vie où nul, jamais, ne sent (j'emprunte, et je tiens à emprunter ici son langage à Paul Valéry) "ce suspens devant l'incertain en quoi consiste la grande sensation des grandes vies - celle des nations devant la bataille où leur destin est en jeu; celle des ambitieux à 
l'heure où ils voient que l'heure suivante sera celle de la couronne ou de l'échafaud; celle de l'artiste qui va dévoiler son marbre ou donner l'ordre d'ôter les cintres et les étais qui soutiennent encore son édifice »? Étonnez-vous alors de ces campagnes violentes contre l'histoire, de cette désaffection des jeunes, de ce recul par suite et de cette crise véritable de l'histoire que les hommes de ma génération ont vu se développer, lentement, progressivement, sûrement. Songez que, lorsque j'entrais à l'École, la partie était gagnée. Trop gagnée pour l'histoire. Trop puisqu'elle n'apparaissait même plus comme une discipline particulière et limitée. Trop puisqu'elle prenait figure d'une méthode universelle s'appliquant indistinctement à l'analyse de toutes les formes d'activité humaine. Trop puisque, encore aujourd'hui, il est des attardés pour définir l'histoire non par son contenu, mais par cette méthode — qui n'est même pas la méthode historique, mais la méthode critique tout simplement.

L'histoire faisait, une à une, la conquête de toutes les disciplines humaines. La critique littéraire devenait avec Gustave Lanson histoire littéraire - et la critique esthétique, histoire de l'art, avec André Michel, successeur du tempétueux Courajod, ce Jupiter tonnant de l'École du Louvre. Et la vieille controverse se muait en histoire des religions. Satisfaite de ses progrès, fière de ses conquêtes, vaniteuse de ses succès matériels, l'histoire s'endormait dans ses certitudes. Elle s'arrêtait dans sa marche. Elle redisait, répétait, reprenait; elle ne recréait plus. Et chaque année qui passait donnait à sa voix, un peu plus, le son caverneux d'une voix d'outre-tombe. p024

Cependant, des disciplines nouvelles s'élaboraient. La psychologie renouvelait à la fois ses méthodes et son objet, sous l'impulsion de Ribot, de Janet, de Dumas ; la sociologie se constituait, à l'appel de Durkheim, de Simiand et de Mauss, en science tout à la fois et en école ; la géographie humaine instaurée à l'École Normale par Vidal, développée à la Sorbonne par Demangeon, au Collège de France par Jean Brunhes, satisfait un besoin de réalité qui ne trouvait rien pour sa satisfaction dans les études historiques, de plus en plus orientées vers l'histoire diplomatique la plus arbitraire, la plus coupée de toute réalité - et vers l'histoire politique la plus insouciante de tout ce qui n'était pas elle au sens étroit du mot. Aux jeunes disciplines, la faveur des jeunes hommes allait croissante. La guerre suivit, la crise éclata 
- ce fut chez les uns l'abandon, chez les autres le sarcasme. Or l'histoire tient trop de place dans la vie de nos esprits pour qu'on ne se soucie pas de ses vicissitudes. Et pour qu'on se contente de hausser les épaules en parlant d'attaques qui peuvent être injustes dans la forme, ou maladroites - qui le sont souvent - mais qui, toutes, traduisent ce à quoi il faut remédier, et vite : un désenchantement, une désillusion totale - l'amer sentiment que faire de l'histoire, que lire de l'histoire, c'est désormais perdre son temps.

\section{II.}

\section{Il faut y remédier — mais comment?}

En prenant une nette conscience des liens qui unissent, qu'elle le sache ou non, qu'elle le veuille ou non, l'histoire aux disciplines qui l'entourent. Et dont son destin ne la sépare jamais.

Michelet, dans sa leçon de 1834 : «En histoire, disait-il à ses élèves - c'est comme dans le roman de Sterne : ce qui se faisait dans le salon se faisait à la cuisine. Absolument comme deux montres sympathiques dont l'une, à 200 lieues, marque l'heure, tandis que l'autre la sonne. » Et il ajoutait cet exemple : «Ce n'est pas autre chose au moyen âge. La philosophie d'Abélard sonne la liberté tandis que les communes picardes marquent la liberté. » Formules bien intelligentes. Michelet, je le note en passant, n'établissait pas entre les activités diverses de l'homme une hiérarchie, un classement hiérarchique: il ne portait pas dans son esprit la métaphysique simpliste du maçon: première assise, deuxième assise, troisième assise - ou premier étage, deuxième, troisième. Il n'établissait pas non plus une généalogie : ceci dérive de cela, ceci engendre cela. Non. Il avait l'idée ${ }_{\mathrm{p} 025}$ d'un climat commun, - idée autrement fine, autrement intelligente. Et, entre parenthèses, il est bien curieux de constater qu'aujourd'hui, dans un monde saturé d'électricité, alors que l'électricité nous offrirait tant de métaphores appropriées à nos besoins mentaux - nous nous obstinons encore à discuter gravement des métaphores venues $\mathrm{du}$ fond des siècles, lourdes, pesantes, inadaptées; nous nous obstinons toujours à penser les choses de l'histoire par assises, par étages, par moellons - par soubassements et par superstructures, alors que le lancer des courants sur le fil, leurs 
interférences, leurs courts-circuits nous fourniraient aisément tout un lot d'images qui s'inséreraient avec beaucoup plus de souplesse dans le cadre de nos pensées. Mais il en va toujours ainsi. Quand un historien veut faire la théorie de l'histoire, pour s'inspirer de l'état des sciences il relit (s'il est très curieux d'esprit) l'Introduction à la médecine expérimentale de Claude Bernard. Grand livre, mais déjà d'intérêt tout historique. (Un petit siècle de retard, c'est la norme.) Le bon Plattard a écrit un article, jadis, pour s'étonner de ce que le système de Copernic n'ait pas eu plus de rayonnement immédiat en son temps et n'ait point opéré une brusque révolution dans l'esprit des hommes. Il y aurait un bien bel article à écrire, aujourd'hui, sur ce fait étonnant que, depuis trente ou quarante ans, sous la poussée de la physique moderne, tous les vieux systèmes scientifiques sur quoi nous reposions notre quiétude, se sont ébranlés et renversés; et pas seulement les systèmes, mais les notions de base qu'il faut considérer à nouveau, et remettre au point, toutes : à commencer par celle du déterminisme. Eh bien, dans cent ans je pense, quand une nouvelle révolution sera intervenue, quand les conceptions d'aujourd'hui seront périmées, les hommes intelligents, les hommes cultivés, ceux qui feront la théorie des sciences humaines et d'abord de l'histoire, s'aviseront, je pense, qu'il y a eu les Curie, Langevin, Perrin, les Broglie, Joliot et quelques autres (pour ne citer que des Français). Et s'empareront de quelques bribes de leurs écrits théoriques pour remettre leurs traités de méthode au point. Au point d'il y a cent ans.

Peu importe d'ailleurs. Car les historiens peuvent ne pas s'en apercevoir : la crise de l'histoire n'a pas été une maladie spécifique frappant l'histoire seule. Elle a été, elle est un des aspects - l'aspect proprement historique d'une grande crise de l'esprit humain. Ou plus précisément, elle n'est qu'un des signes, à la p026 fois, et qu'une des conséquences d'une transformation très nette, et toute récente, de l'attitude des hommes de science, des savants, vis-à-vis de la Science.

En fait, il est bien vrai qu'au point de départ de toutes les conceptions neuves que les savants (ou plutôt que les chercheurs, ceux qui créent, ceux qui font progresser la science et souvent se préoccupent plus d'agir que de faire la théorie de leurs actions) - il 
est bien vrai qu'à ce point d'origine, il y a ce grand drame de la relativité qui est venu secouer, ébranler tout l'édifice des sciences tel qu'un homme de ma génération se le figurait au temps de sa jeunesse.

Nous vivions, en ce temps-là, sans crainte et sans effort, sur des notions élaborées lentement et progressivement, au cours des temps, à partir de données sensorielles et qu'on peut qualifier d'anthropomorphiques. D'abord s'était constitué, sous le nom de Physique, un bloc de savoirs fragmentaires se tenant originellement pour autonomes et distincts, et groupant des faite comparables en ceci qu'ils étaient fournis aux hommes par tel ou tel de leurs organes sensoriels. Par la vue, et c'était l'optique. Par l'ouïe, et c'était l'acoustique. Par le sens tactile et musculaire, et c'était la chaleur. Plus compliquée déjà, la mécanique, science du mouvement des corps perçus à la fois par la vue et par le sens musculaire et combinant ainsi des données sensorielles d'origine différente; plus compliquée, mais plus rapide cependant dans son développement, peut-être en raison d'une plus grande richesse d'informations immédiates, d'une plus grande curiosité des hommes s'intéressant à la mécanique pour des raisons d'ordre pratique et technique: pour la construction de machines, de moulins, de scieries, par exemple, posant des problèmes de plus en plus compliqués d'hydraulique; pour la fabrication et le perfectionnement continuel d'armes à feu, en particulier de canons dont la construction posait des problèmes de balistique de plus en plus ardus. Les autres chapitres de la physique, ceux dans lesquels l'expérience humaine était moins immédiate, se développaient plus lentement, et plus lentement encore les domaines nouveaux de l'électricité et du magnétisme, où tout échappait, ou presque, à l'appréhension directe des organes sensoriels.

Je n'ai pas à dire et j'en serais fort empêché du reste, et ce serait d'ailleurs fort inutile à mon dessein — je n'ai pas à dire comment la mécanique se mit à conquérir peu à peu ces divers chapitres et à les pénétrer. D'abord elle s'annexa l'acoustique, en interprétant les sensations sonores à l'aide des vibrations. Ensuite, elle constitua une mécanique céleste, par application ${ }_{\mathrm{p} 027}$ aux astres de lois humaines du mouvement — de lois du mouvement dégagées par le cerveau de nos ancêtres de leur propre effort musculaire. - Ensuite elle étendit ses méthodes et ses lois sur tout le domaine de la chaleur, — sur tout le 
domaine des fluides. Et sans doute l'optique, le magnétisme, l'électricité résistaient - mais déjà on croyait pouvoir annoncer leur conquête; déjà et d'avance, on célébrait le triomphe universel et incontesté de la physique cartésienne, géométrie du monde; déjà d'immenses espoirs se faisaient jour, on annonçait, on voyait s'amorcer, on prédisait, toujours sur le même plan, la triomphale réduction du psychique au physique - et nous, historiens, nous étions à notre aise dans cet univers scientifique où tout, pour nous, semblait marqué en chiffres connus, quand brusquement ce fut la Révolution. Une Révolution en deux temps : d'abord la révélation imprévue que l'électricité, le magnétisme et même l'optique résistaient à l'annexion d'avance annoncée et célébrée. Et puis — issue de l'opposition formelle qui dressait contre la mécanique, édifiée par Newton sur les observations de Copernic, l'électro-dynamique fondée par Maxwell sur les expériences d'Ampère et de Faraday - ce fut cette prodigieuse synthèse qui, remaniant les notions primordiales de Temps, de Longueur et de Masse, embrassa la physique dans son entier, et lia, en gerbes de lois, les facteurs que l'ancienne conception laissait séparés.

Cependant, dans le domaine de la Vie, une révolution analogue s'opérait - une révolution engendrée par la microbiologie; la notion d'organismes composés d'un nombre immense de cellules de l'ordre du millième de millimètre se dégageait de l'observation. Et alors que les organismes vivants, observés à l'œil nu, apparaissaient de plus en plus comme des systèmes physico-chimiques, - les organismes que révélait la microbiologie, c'étaient des organismes sur lesquels l'action des lois mécaniques, de la pesanteur, etc., paraissait négligeable. Ils se dérobaient aux prises des théories explicatives, nées aux temps où les organismes aussi, tout au moins les organismes élémentaires, semblaient régis par des lois de la mécanique classique. Les organismes saisis par la microbiologie, c'étaient, au contraire, des organismes sans résistance propre, où il y a plus de vides que de pleins et qui, pour la plus grande part, n'étaient que des espaces parcourus par des champs de force. Ainsi, l'homme brusquement changeait de monde. Devant lui, d'une part, des organismes comme son 028 propre corps, visible à l'œil nu, palpable à la main; des 
organismes aux grands mécanismes desquels — pensons à la circulation sanguine, par exemple - les lois de la mécanique classique basée sur la géométrie euclidienne étaient et demeuraient applicables. Mais devant lui également, les milliards et les milliards de cellules dont cet organisme était formé. D'une grandeur ou d'une petitesse telle que nous ne pouvions nous la représenter. Et ce qui se passait au niveau cellulaire démentait perpétuellement ce qui se passait au niveau de nos perceptions sensorielles. Les organismes que nous saisissions ainsi, tout d'un coup, les organismes que nous révélaient les travaux récents, dépassaient pour ainsi dire et heurtaient « notre bon sens ». Et les vides dont ils étaient tissus nous habituaient, eux aussi, dans le domaine de la biologie, à cette notion du discontinu qui, d'autre part, s'introduisait dans la physique avec la théorie des quanta: décuplant les ravages déjà causés, dans nos conceptions scientifiques, par la théorie de la relativité, elle semblait remettre en question la notion traditionnelle, l'idée ancienne de causalité - et donc, d'un seul coup, la théorie du déterminisme, ce fondement incontesté de toute science positive - ce pilier inébranlable de la vieille histoire classique.

Ainsi, toute une conception du monde s'effondrait d'un seul coup, toute la construction, élaborée par des générations de savants au cours de siècles successifs, d'une représentation du monde abstraite, adéquate et synthétique. Nos connaissances débordaient brusquement notre raison. Le concret faisait éclater les cadres de l'abstrait. La tentative d'explication du monde par la mécanique newtonienne ou rationnelle se terminait par un échec brutal. Il fallait, aux anciennes théories, substituer des théories nouvelles. Il fallait réviser toutes les notions scientifiques sur lesquelles on avait vécu jusqu'alors.

Ce que fut cette révision, il serait trop long de l'indiquer ici en détail. Notons que rien n'y a échappé. Ni la conception du fait scientifique, ni la conception de la loi scientifique, ni celle du Hasard. $\mathrm{Ni}$, au total et d'ensemble, celle des sciences même, et de la Science. Des sciences, telles qu'Auguste Comte les présentait jadis, hiérarchisées dans une classification dont le double vice apparaissait brusquement : il était, et de méconnaître l'unité profonde du travail 
scientifique, et de transformer abusivement l'état de fait en état de droit ; il était, par exemple, de porter au ${ }_{\text {p029 }}$ sommet des sciences une géométrie et une mécanique orgueilleuses, qui se complaisaient dans l'image de leur perfection, et proposaient leurs lois aux autres sciences - leurs lois de vérité, leurs lois abstraites, absolues, universelles et nécessaires, comme autant de modèles et, pour ainsi dire, comme l'idéal. — Les sciences ? des champs de dislocation. Des magmas. Et toutes les découvertes se faisant non pas à l'intérieur de chacune d'elles, au cœur, mais sur les bords, sur les marges, aux frontières, là où elles se pénètrent. Les sciences. Mais la Science, de son côté, se rapprochait de l'Art, et on pouvait dire d'elle, d'ensemble, ce que Berthelot disait, en 1860, de la chimie organique fondée sur la synthèse quand, dans l'enivrement de ses premiers triomphes, il proclamait : «La chimie crée son objet. » Et quand il ajoutait : « Cette faculté créatrice, semblable à celle de l'art lui-même, la distingue essentiellement des sciences naturelles et historiques. »Car ces sciences, précisait-il, « ont un objet donné d'avance et indépendant de la volonté et de l'action du savant; elles ne disposent pas de leur objet », tandis que la chimie nouvelle « avait la puissance de former une multitude d'êtres artificiels, semblables aux êtres naturels et participant de toutes leurs propriétés ». Distinction qui devenait caduque, alors que, de plus en plus, ce qui apparait aux savants comme le terme même de l'effort scientifique, ce n'est pas la connaissance, c'est la compréhension. Distinction caduque, alors que, précisément, nos savants définissent de plus en plus la Science comme une création, nous la représentent «construisant son objet», et constatent en elle, à tous les moments, l'intervention constante du savant — de sa volonté et de son activité.

Tel est le climat de la Science d'aujourd'hui. Un climat qui n'a plus rien de commun avec celui de la Science d'autrefois - de la Science du temps où j'avais mes vingt ans. Cette Science, les postulats sur quoi elle reposait sont tous ébranlés, critiqués, dépassés. Les savants depuis des années y ont renoncé, les ont remplacés par d'autres. Et alors je pose une question, une simple, une seule question: Allons-nous continuer, nous historiens, à les reconnaître à nous tout seuls, comme valables ? Et d'ailleurs que vaudrait cette reconnaissance, s'il est vrai que tout le matériel de notions scientifiques que nous utilisons, nous l'avons emprunté précisément 
aux hommes qui, il y a plusieurs dizaines d'années, cultivaient les sciences au sens napoléonien du mot, les sciences du monde physique et de la nature ? N'y a-t-il pas lieu de substituer à ces vieilles notions périmées des notions nouvelles, plus exactes, plus approchées ? Tout au moins, n'y a-t-il pas lieu de ${ }_{\text {p030 }}$ renoncer, une bonne fois, à nous appuyer sur les «sciences" d'il y a cinquante ans pour étayer et justifier nos théories - puisque les sciences d'il y a cinquante ans ne sont plus que des souvenirs et des fantômes ? Voilà toute la question. Y répondre, ce serait résoudre la crise de l'histoire. Et s'il est vrai que les sciences sont toutes solidaires - la réponse est connue d'avance. Inutile de la professer solennellement.

Voilà le grand drame qui se déroule devant nous. Un des grands drames. Car il y en a bien d'autres qui se nouent et se dénouent sous nos yeux, sans que nous leur prêtions une minute d'attention. Ah si j'avais le temps ! Comme j'aurais aimé esquisser devant vous, à titre de référence et de comparaison, ce qu'on peut nommer la Tragédie du Progrès! Comme j'aurais aimé vous montrer les créateurs, les animateurs des fortes sociétés bourgeoises du $\mathrm{XIX}^{\mathrm{e}}$ siècle fondant les commencements de leur puissance sur la Raison, soutenant cette puissance à l'aide d'une philosophie nettement rationaliste - et puis, vers la fin du XIX ${ }^{\mathrm{e}}$ siècle, quand les difficultés dans le partage du monde s'annoncent, quand les masses s'organisent et réclament de plus en plus impérieusement un niveau de vie plus élevé - faisant volte-face, jetant la Raison par-dessus bord, et, au moment même où ils livrent leur vie aux techniques, à ces applications de la Science que jadis leurs pères exaltaient sous le nom même de Progrès - ces applications de la Science qui ne les servaient plus, mais les asservissaient - cessant de croire précisément à la Science et au Progrès dont ils proclamaient la faillite... Contradiction pathétique mais qui se résout, s'il est vrai que, ces hommes, c'est parce qu'ils ont cessé de croire à la valeur humaine de la Science qu'ils peuvent être asservis par ses techniques. Quand aucune fin majeure ne sollicite les hommes à la limite de leur horizon, c'est alors que les moyens deviennent des fins pour eux — et d'hommes libres, en font des esclaves. 
Grande leçon pour nous, historiens. Histoire, Science de l'Homme, ne l'oublions jamais. Science du changement perpétuel des sociétés humaines, de leur perpétuel et nécessaire réajustement à des conditions neuves d'existence matérielle, politique, morale, religieuse, intellectuelle. Science de cet accord qui se négocie, de cette harmonie qui s'établit perpétuellement et spontanément, à toutes les époques, entre les conditions diverses et synchroniques d'existence des hommes: conditions matérielles, p031 conditions techniques, conditions spirituelles. C'est par là que l'histoire retrouve la Vie. C'est par là qu'elle cesse d'être une maîtresse de servitude et de poursuivre ce rêve meurtrier, dans tous les sens du mot : imposer aux vivants la loi dictée, prétendument, par les morts d'hier. Et puisque j'ai le bonheur de savoir, dans cette salle, des jeunes hommes décidés à consacrer leur vie à la recherche historique, c'est avec certitude que je leur dis : pour faire de l'histoire tournez le dos résolument au passé et vivez d'abord. Mêlez-vous à la vie. A la vie intellectuelle, sans doute, dans toute sa variété. Historiens, soyez géographes. Soyez juristes aussi, et sociologues, et psychologues ; ne fermez pas les yeux au grand mouvement qui, devant vous, transforme, à une allure vertigineuse, les sciences de l'univers physique. Mais vivez aussi, d'une vie pratique. Ne vous contentez pas de regarder du rivage, paresseusement, ce qui se passe sur la mer en furie. Dans le bateau menacé, ne soyez point Panurge qui se salit de mâle peur, ni même le bon Pantagruel qui se contente, tenant le grand mât embrassé, de lever les yeux au Ciel et d'implorer. Retroussez vos manches, comme Frère Jean. Et aidez les matelots à la manœuvre.

Est-ce tout? Non. Ce n'est même rien, si vous devez continuer à séparer votre action de votre pensée, votre vie d'historien de votre vie d'homme. Entre l'action et la pensée, il n'est pas de cloison. Il n'est pas de barrière. Il faut que l'histoire cesse de vous apparaître comme une nécropole endormie, où passent seules des ombres dépouillées de substance. Il faut que, dans le vieux palais silencieux où elle sommeille, vous pénétriez, tout animés de la lutte, tout couverts de la poussière du combat, du sang coagulé du monstre vaincu — et qu'ouvrant les fenêtres toutes grandes, ranimant les lumières et rappelant le bruit, vous réveilliez de votre vie à vous, de votre vie chaude et jeune, la vie glacée de la Princesse endormie... 
L'unité du monde - du monde déchiré, rompu, sanglant et qui crie grâce: ce ne sont pas les interventions extérieures qui la rétabliront. A chacun de la refaire en lui, par le magnifique accord de sa pensée profonde avec son action désintéressée - par le don total qui, seul, libérera nos consciences de l'interrogation muette que je rappelais en commençant — qui, seule, à la grande question : Ai-je le droit? nous permettra, en toute sécurité retrouvée, de répondre oui. p032

Pardonnez-moi le tour qu'a pris cette causerie. Je le dis surtout pour les historiens. Mais s'ils étaient tentés de trouver que leur parler ainsi ce n'est pas leur parler on historien, je les conjure de réfléchir avant de formuler ce grief. Il est mortel.

L'histoire est comme toute discipline. Elle a besoin de bons ouvriers et de bons contremaîtres, capables d'exécuter correctement les travaux d'après les plans d'autrui. Elle a besoin aussi de quelques bons ingénieurs. Et ceux-là doivent voir les choses d'un peu plus haut que du pied du mur. Ceux-là doivent pouvoir tracer des plans, de vastes plans, de larges plans — à la réalisation desquels puissent travailler ensuite, utilement, les bons ouvriers et les bons contremaîtres. Pour tracer des plans, de vastes plans, de larges plans, il faut des esprits vastes et larges. Il faut une claire vision des choses. Il faut travailler en accord avec tout le mouvement de son temps. Il faut avoir horreur du petit, du mesquin, du pauvre, de l'arriéré. D'un mot, il faut savoir penser.

C'est ce qui manque terriblement aux historiens, sachons le reconnaître, depuis un demi-siècle. C'est ce qui ne doit plus leur manquer. Ou alors à la question : «Faut-il faire de l'histoire ?» je vous dirais tout net: répondez non. Ne perdez pas votre vie. Vous n'en avez pas le droit. Qu'au reste, une claire et large vision des rapports qui unissent l'histoire aux autres sciences ne soit pas pour empêcher de saisir les problèmes concrets, et de les poser de façon positive et pratique - au contraire ! - c'est ce que j'essaierai de vous montrer la prochaine fois. Et si à ces leçons les historiens prennent plus de goût peut-être et d'intérêt qu'à leur Introduction, je les prierai de réfléchir, simplement, que tout se tient. Et qu'une forte 
culture générale est peut-être plus utile à l'architecte, qu'une bonne pratique des tours de main de la maçonnerie.

Voilà ce que je voulais vous dire, aujourd'hui, sans apprêt. Et que je vous remercie d'avoir écouté sans lassitude. p033 


\section{FACE AU VENT}

Manifeste des Annales Nouvelles

$\underline{\text { Retour à la table des matières }}$

Les Annales, depuis 1929, n'ont pas cessé de paraître. Pas une année, quelles que fussent les calamités qui fondaient sur la France et sur le monde, elles n'ont déserté leur double tâche de science et d'éducation.

Les Annales continuent. Dans un climat nouveau, avec des formules neuves. Et un titre neuf.

«Quel amour du changement! Vous vous êtes appelés d'abord Annales d'Histoire Économique et Sociale. Puis Annales d'Histoire Sociale. Puis Mélanges d'Histoire Sociale. Vous voici maintenant ANNALES tout court, avec ce long sous-titre : Économies, Sociétés, Civilisations ?»

Nous pourrions répondre que ces changements furent en partie fortuits. Mais pourquoi cet air de nous excuser? Nous avons voulu, en 1929, Bloch et moi, des Annales vivantes - et j'espère bien que, longtemps encore, ceux qui prolongeront notre effort prolongeront aussi notre vouloir. Or, vivre c'est changer.

Nous admirons beaucoup, et il faut admirer, ces grandes revues qui s'installent sur un domaine du savoir avec la certitude tranquille, l'indifférente placidité d'une Pyramide d'Égypte. Elles y sont. Elles y restent. De loin, elles offrent une belle image de majesté. Mais après tout, les pyramides sont des tombeaux. Elles tiennent captif, au centre de leur masse, un mort illustre et momifié. Vive le ciment et le verre 
transparent! Quand leur assemblage ne répond plus à des besoins nouveaux, on le jette à bas sans peine ni remords. On reconstruit. On repart. C'est une autre force : la force en expansion de ces grandes cités d'Amérique qui, tous les dix ans, rebâtissent leurs avenues et font peau neuve. p034

Les Annales changent parce que tout change autour d'elles: les hommes, les choses ; d'un mot, le monde. Déjà, celui de 38 n'était plus du tout celui de 29. Que dire du monde de 42 ou de 46 - qu'en dire qui soit juste et donc efficace?

Car nous allons, communément, orchestrant le thème romantique des ruines. Nous allons décomptant les centrales électriques, les viaducs et les ponts, les quartiers de villes et les villages qui manquent à l'appel. Les yeux grands d'inquiétude nous ajoutons, tout bas : « Et la bombe atomique... Allons, le monde est ruiné !»-Ruiné ? Il y a bien autre chose que les ruines, et plus grave : cette prodigieuse accélération de la vitesse qui, télescopant les continents, abolissant les océans, supprimant les déserts, met en brusque contact des groupes humaine chargés d'électricités contraires - et les plus fondés, jusqu'à ce jour, à « conserver leurs distances », au moral comme au physique : contact brusque, court-circuit...

Voilà par quoi, essentiellement, notre monde est détruit. Il est vital de s'en rendre compte. Qui n'a d'yeux que pour les ruines se console bientôt : " Patience... Un an, deux ans, dix ans et tout sera rétabli. Les stations du métro toutes rouvertes. Les viaducs restitués. Et des bananes chez tous les fruitiers. »—- Fausse sécurité.

Pareillement, il y a une certaine façon de penser la vitesse qui nous égare aussi dangereusement: «Bah! problème d'échanges. On l'a résolu pour les Nations dans le cercle de leurs frontières. On travaille à le résoudre pour les Continents. Eh bien, on le résoudra pour la Planète entière ! Question de temps, d'études, de matériel. Surtout de matériel...» Illusion d'ingénieur. De politique aussi, entouré de fonctionnaires à qui, pour qu'ils sachent manier les hommes, on a bien appris l'algèbre.

Certes, il y a des problèmes techniques. Et des problèmes économiques. Mais pour l'avenir de l'humanité, le problème qui 
compte — c'est le problème humain. Celui qu'en 1932, rentrant d'une visite à l'Exposition Coloniale où j'avais vu se manifester, irrésistible, la hantise nouvelle, je posais en ces termes : "L'historien redescend vers la ville, méditant sur tout ce qu'ont produit, déjà, de dérèglements dans l'histoire, les variations alternées des distances entre races, entre peuples: les unes, les distances matérielles, chaque jour se raccourcissant ; les autres, les distances morales, énormes, peut-être infranchissables. » - Tout le drame est là. Le drame de civilisation. Il s'annonçait en 1932. Il se joue en 1946. p035

« Nous autres, civilisations, nous savons bien maintenant que nous sommes mortelles. » Cette phrase eut un grand retentissement, que Valéry écrivait à la fin des années 20 - et qui d'ailleurs, pour l'historien, ne rendait pas un son bien neuf; le vieux Ballanche, pour ne citer que lui, avait déjà dit textuellement la même chose, en 1817 : réflexion de sinistrés, ici et là. Mais Ballanche pouvait tenir un tel propos - Ballanche, citoyen d'une Europe prestigieuse, et qui se sentait, et se proclamait, en dépit des ricanements de Fourier, la terre civilisée par excellence. Valéry? Déjà, au temps des Regards sur le monde actuel, le problème n'est même pas de savoir si notre civilisation, que nous continuons d'appeler la civilisation, va mourir. Mourir, mot noble, empreint de majesté tranquille et de naturelle sérénité. Le problème n'est même pas de savoir si notre civilisation va périr, assassinée. Il est de savoir quelle civilisation s'établira demain sur ce monde nouveau qui déjà s'élabore au fond du creuset.

Car une civilisation peut mourir. La civilisation ne meurt pas. Cet instinct des hommes, ce propre des hommes : se dépasser, prendre sa volonté comme tremplin, pour toujours sauter plus haut. Seulement, jusqu'à présent, c'est dans le cadre étroit de groupes limités qu'ils donnaient leur plus grand effort. Ils produisaient ainsi des civilisations de groupes, de tribus, de nations, de continents même, ou de portions de continents. Des civilisations parquées. Demain, sans nul doute, pour la première fois et sauf catastrophe - ils présenteront sinon tout de suite une civilisation mondiale, la civilisation des terriens, épandue sur l'œkoumène - du moins une ou deux civilisations intercontinentales qui, grossies déjà de plusieurs civilisations locales, se prépareront, en s'affrontant, à s'absorber l'une l'autre. 
Quelles seront les étapes de cet immense procès ? Quelles, les premières réussites partielles? A quels niveaux successifs s'établiront-elles ? Que représenteront dans l'œuvre totale les apports des non-Européens ? Que passera-t-il de notre civilisation dans ces civilisations à l'échelle du monde qui, peu à peu, se substitueront à elle ? Secret d'avenir. Comme on voudrait prévoir, et sinon savoir, deviner...

«Folies, tout cela. Et sous la plume d'un historien ... ». - Eh, sous la plume de qui voudriez-vous qu'elles viennent, ces notations d'Histoire ? Car, enfin, que s'est-il passé, s'il vous plaît, en Europe, aux $\mathrm{VI}^{\mathrm{e}}, \mathrm{VII}^{\mathrm{e}}, \mathrm{VIII}^{\mathrm{e}}, \mathrm{IX}^{\mathrm{e}}$ et $\mathrm{X}^{\mathrm{e}}$ siècles ? Quoi, sinon déjà, au milieu de convulsions sans nom, d'éboulements, de massacres, d'incendies intermittents mais prolongés, avec des rémissions et des reprises une bataille de civilisations : barbares contre ${ }_{\mathrm{p} 036}$ romaines, nordiques contre méditerranéennes, asiatique contre européennes — une digestion de civilisations les unes par les autres. Au terme de quoi, toute fraîche, toute jeune, la civilisation chrétienne du moyen âge. Cette grande novation dont, hier encore, nous vivions uniquement. Dont nous sommes toujours saturés. Alors, mes «prédictions » d'historien ? Des retours en arrière.

Un fait est certain, dès maintenant: vivre, pour nous-mêmes et pour nos fils, ce sera demain, c'est aujourd'hui déjà, s'adapter à un monde perpétuellement glissant.

Un grand travail est commencé. Il ne s'arrêtera plus. Quelle que soit la durée des haltes et des répits. Liquidez vos "Branches-Vie », Compagnies d'assurance. Le temps est passé où les pères mettaient dans vos tirelires quelques centaines d'écus sur la tête de leurs fils pour les récupérer, vingt ans plus tard, avec les intérêts. Développez vos «Branches-Incendie », en les modernisant. Et vos «BranchesVol » aussi...

Oui. Nous allons être très menacés. Gémir ne sert à rien. Il faut s'accommoder. Et d'abord ne pas se perdre. Faire le point tous les jours. Se situer dans le temps, et dans l'espace. 
L'Espace - que nous nommons autrement l'Univers. Cette minuscule boulette de matière perdue, parmi des millions d'autres, dans un coin de la voie lactée - et qui déjà commence à ne plus suffire à nos rêves d'explorateur. Pour la première fois, nous prenons conscience de sa petitesse. Mesurée à la toise, elle était si grande ! Au kilomètre, déjà moins. A vitesse d'avion, ce n'est plus rien du tout. Qui monte dans son avion un matin à Karachi, prend le thé à Londres le lendemain, à 16 heures. Est-ce un hasard si, depuis dix ans, blasés sur une planète sans inconnu, nous rêvons de fusées, d'excursions dans l'infini, en direction de cette lune blafarde que nous finirons bien par atteindre un jour ?...

Oui, comme brusquement elle nous semble petite, mesquine, sans mystère, notre humble planète... Sur quoi tous cependant, blancs, noirs ou jaunes, nous devons, bon gré, mal gré, passer notre existence. La Maison des hommes - avec son «Règlement» au pied de l'escalier : à tout manquement, la mort...

Maison aux cent logements, maison aux mille chambrées. De toutes couleurs, de toutes dimensions, de tout ameublement. Mais il les faut connaître les unes comme les autres puisque maintenant quelques pas dans le couloir, ou deux paliers dans l'ascenseur - le jaune entre chez le blanc et le blanc chez le ${ }_{\text {p037 }}$ noir, mitraillette en main et sac tyrolien au dos, plein de bonnes choses à manger : les deux aspects du plus récent internationalisme.

Apprendre à connaître l'agencement de cet univers, le contenu de ces compartiments, pleins de marchandises et aussi de forces dont il nous faut dresser l'inventaire, mais, toujours, du seul point de vue de l'homme : première tâche de l'Européen 46. Seconde tâche ? Se situer par rapport non seulement aux sociétés qui, dans notre propre logement, ont vécu avant notre naissance - mais à toutes celles qui, dans les autres logements de la Maison des hommes, ont précédé les hôtes actuels, aménagé les lieux, laissé quelques meubles à leurs héritiers, noué quelques relations avec nos propres ancêtres. Première coordonnée, l'Espace. Seconde, le Temps. Empruntons sa formule à Gustave Monod, réformateur de notre enseignement secondaire: l'homme cultivé en 1946? "Celui qui est capable de saisir sa situation d'homme à la fois dans le temps et dans l'espace. De 
rapporter aux autres civilisations celle dont il est l'acteur et le témoin. L'homme qui, avec la connaissance d'un certain nombre d'événements essentiels, s'est acquis, dès l'école et par l'école rénovée, une sorte d'expérience de la vie et de la mort des civilisations... »

En clair, l'Espace : disons la géographie. Le Temps: disons l'histoire.

Certes, d'autres solutions ont leurs défenseurs.

«Regardez le voisin», disons-nous ici. De lui vient le danger. Même s'il ne vous veut pas de mal, un tel coude à coude s'est établi déjà entre les hommes - blancs, noirs, jaunes - que tout mouvement des uns se répercute immédiatement sur les autres. Un tel coudoiement. Ce qui ne veut pas dire une telle fraternité. Car autour de nous, quels étranges, quels inquiétants voisins ! Des hommes, c'est tout dire.

Je dis : oui, dit l'humaniste, des hommes. Et vous dites : regardezles; mais moi, je réponds, avec Socrate: "Regardez-vous vousmême. Prenez conscience de l'Homme qui est en vous. De l'Homme semblable à l'Homme, à travers les siècles et les civilisations. Toujours le même, dans ses vertus, ses qualités, ses excellences. Et dont seules changent les formes extérieures, les apparences. Négligez l'homme circonstanciel. Sans grandeur ni constance. Pittoresque, c'est tout dire. Allez droit à l'Homme éternel. Travaillez, enfant, à le dégager en vous. Achevez, adulte, de le sculpter en vous. Fort, fier, solide, capable de résister aux pressions du dehors, sans se faire écraser... " p038

L'Homme éternel ? Mais à cette belle académie, exécutée selon les règles (élire dix beaux modèles; prendre à l'un ses épaules, à l'autre ses jambes, etc ... ), tout notre effort à nous, jeunes « sciences de l'Homme »: et la psychologie, et l'écologie humaine, et l'ethnographie, et le folklore, et la sociologie, l'histoire naturellement - tout, jusqu'à la chirurgie de Leriche, qui chaque jour se veut plus humaine, plus soucieuse directement de l'être humain — tout notre 
effort n'est-il pas au contraire d'opposer, et de plus en plus, les hommes?

Il y a trente ans, les géographes ne parlaient-ils pas volontiers de «l'Homme», et de ses œuvres sur terre ? Ne les avons-nous pas conduits à ne plus parler que des groupes humains et de leurs prodigieux efforts d'adaptation par quoi s'explique la réussite terrestre d'êtres si faiblement armés par la nature, si fragiles, si vulnérables et qui pourtant se rencontrent aussi bien sous le cercle polaire que sous l'Équateur, au Groenland qu'au Congo - partout ou presque exactement partout sur la surface du globe ? Tout notre désir n'est-il pas de les saisir à l'œuvre, dans ce persévérant et magnifique effort qu'ils poursuivent, depuis qu'ils sont sur terre, pour s'insérer dans les milieux les plus hostiles, et en les disloquant, en les désagrégeant, en profitant des moindres fissures, s'y ménager une place toujours plus grande, s'y tailler un rôle — vivre, dans la plénitude humaine de ce beau mot?

« Regardez-vous vous-même ? » Mais quand nous descendons en nous, quand nous nous fouillons nous-mêmes en profondeur - non, ce ne sont pas les linéaments d'une académie aussi parfaite que possible dans son abstraite nudité - ce sont les vestiges de nos devanciers que nous nous étonnons de trouver si nombreux en nous : cette surprenante collection de témoins des anciens âges, des antiques croyances, des plus vieilles façons de penser et de sentir dont chacun de nous hérite au jour de sa naissance - sans qu'il le sache. Et que nos historiens découvrent jusque dans la conscience de Périclès, de Phidias, de Platon - au prix d'un sacrilège que réprouvent toujours nos humanistes de vieille observance. Car de telles trouvailles, au fond, ne nous plaisent pas beaucoup. Elles nous humilient. Elles nous rabaissent à nos propres yeux. Mais enfin, les faits sont là. Et parfois, sous le coup d'une violente émotion, individuelle ou plus souvent collective - ne ressort-il pas brusquement, le vieux fond hérité, le vieux fond sauvage, provoquant des paniques, animant toute une foule de fureur sacrée, s'emparant de nous au point de nous « aliéner »? p039

Regardons-nous nous-mêmes. Dans les couches successives de ces alluvions qui garnissent le fond de nos consciences - que de trouvailles pour l'archéologie des pensées humaines! Legs de nos 
ancêtres. Mais l'accepter sous bénéfice d'inventaire, impossible. Le mort nous tient, vifs que nous sommes.

Alors, vite à la besogne, historiens. Assez de discussions. Le temps passe, le temps presse. Vous voudriez peut-être qu'on vous laisse souffler? Le temps de balayer chacun devant sa porte ? Il s'agit bien de cela. Le monde vous pousse, le monde vous souffle au visage son haleine de fièvre. Non, on ne vous laissera pas tranquilles. Ni les Anglais, ni les Américains, ni les Russes, ni les Libanais, ni les Syriens, ni les Arabes, ni les Kabyles, ni les portefaix de Dakar, ni les boys de Saïgon. Tranquilles! Mais vous être pris dans la masse. Pressés, serrés, bousculés, par des gens qui n'ont pas appris les belles manières. Vos belles manières, dont vous êtes si glorieux. (Encore qu'à la moindre occasion on sache ce qu'elles deviennent, vos belles manières.) Ils vous marchent sur les pieds, les voisins : « Ôte-toi de là, je veux m'y mettre. » Que faire ? Prendre votre petit air pincé : « Mais monsieur... » Il ricanera un bon coup, Monsieur le Kabyle, Monsieur le Ouoloff, Monsieur le Tonkinois - et vlan, dans vos côtes, une bourrade vraiment fraternelle. - Alors tanks, canons, avions ? Mais ils en ont, eux aussi. C'est même vous qui les leur vendez. Et puis, ils sont trop, trop, trop... Saupoudrer l'univers de bombes atomiques, méthodiquement, kilomètre par kilomètre ? Carroyage de précision? Beau progrès ; mais on sait des moyens moins chers de se suicider...

Fini le monde d'hier. A tout jamais fini. Si nous avons une chance de nous en tirer, nous Français - c'est en comprenant, plus vite et mieux que d'autres, cette vérité d'évidence. En lâchant l'épave. A l'eau, vous dis-je, et nagez ferme. Cette solidarité de fait qui, dès maintenant, unit les naufragée - qui demain unira tous les hommes - travaillons à en faire une solidarité de labeur, d'échange, de libre coopération. Nous avons tout perdu, ou presque, de nos biens matériels. Nous n'avons rien perdu s'il nous reste l'esprit. Expliquons le monde au monde.

Par l'histoire. Mais quelle histoire ? Celle qui « romance » la vie de Marie Stuart? qui fait «toute la lumière » sur le Chevalier d'Eon et ses jupes? qui pendant cinquante ans, étudie les deux ${ }_{\text {p040 }}$ derniers segments de la quatrième paire de pattes ? Pardon, je confondais. 
Eh bien; non! Nous n'avons plus le temps. Trop d'historiens, et bien formés, et consciencieux, c'est là le pire - trop d'historiens encore se laissent égarer par les pauvres leçons des vaincus de 70. Oh, ils travaillent bien! Ils font de l'histoire comme leurs vieilles grandmères de la tapisserie. Au petit point. Ils s'appliquent. Mais si on leur demande pourquoi tout ce travail - le mieux qu'ils sachent répondre, avec un bon sourire d'enfant, c'est le mot candide du vieux Ranke : « Pour savoir exactement comment ça s'est passé. » Avec tous les détails, naturellement.

Nous n'avons plus le temps, nous n'avons plus le droit. En 1920, il $\mathrm{y}$ a vingt-six ans, montant pour la première fois dans ma chaire, à l'Université de Strasbourg libérée - moi rescapé, mais face aux cimetières où dormaient, mal apaisés, les morts de deux générations fauchées dans leur fleur - comme je m'interrogeais, anxieux, sur mon devoir!

Avais-je le droit, historien, de refaire de l'histoire ? de consacrer à l'histoire mon temps, mon activité, tout ce qui me restait de forces, alors que tant d'autres besognes requéraient impérieusement les citoyens? Avais-je le droit, professeur, de prêcher les autres d'exemple, d'engager de jeunes hommes, derrière moi, dans la voie qui était mienne? Avec quel redoublement d'angoisse aujourd'hui, dans une situation bien plus dramatique, devons-nous, tous, nous interroger?

Pour répondre net. Or, je réponds, ici, sans hésiter: «Faire de l'histoire, oui. Dans toute la mesure où l'histoire est capable, et seule capable, de nous permettre, dans un monde en état d'instabilité définitive, de vivre avec d'autres réflexes que ceux de la peur, des descentes éperdues dans les caves - et tout l'effort humain réduit à soutenir pour quelques heures, à étayer au-dessus des têtes branlantes, les toits crevés, les plafonds éventrés. »

L'histoire, qui ne lie pas les hommes. L'histoire, qui n'oblige personne. Mais sans quoi rien ne se fait de solide. Sur le haut de Montmartre qui veut bâtir le Sacré-Cœur pousse d'abord un sondage à travers la butte - jusqu'au niveau de la Seine. Sables, marnes, gypses, calcaires : quand on sait ce qui soutient, en dessous, le sol 
lépreux de la surface, alors on peut construire en connaissance de cause. La géologie, certes, ne contraint pas p041 l'architecte à faire du néo-byzantin plutôt que du néo-gothique. Quel que soit le style qu'il adopte finalement, elle lui permet de fonder sa bâtisse solidement, sans qu'elle s'affaisse dans l'année. Ainsi l'histoire. Celle qui comprend et fait comprendre. Celle qui n'est pas une leçon à apprendre chaque matin, dévotement - mais vraiment une condition permanente d'atmosphère. Ce qu'elle a toujours été, ici, pour Marc Bloch et pour moi. Ce qu'elle sera demain, pour tous les amis qui m'aideront dans ma tâche, L'histoire, réponse à des questions que l'homme d'aujourd'hui se pose nécessairement. Explication de situations compliquées, au milieu desquelles il se débattra moins aveuglément s'il en sait l'origine. Rappel de solutions qui furent celles du passé - et donc qui ne sauraient être, en aucun cas, celles du présent. Mais bien comprendre en quoi le passé diffère du présent, quelle école de souplesse pour l'homme nourri d'histoire?

«Ainsi, vous subordonnez la majesté d'une Science aux exigences de ce que nos journalistes nomment l'actualité... » Je ne subordonne rien du tout. Je ne confonds pas, faut-il l'assurer, les historiens avec ces dames obligeantes que les abonnés du téléphone, ayant formé les lettres S. V. P., sont en droit d'interroger sur l'âge de leurs notoires contemporains ou sur les galons de grade dans l'armée péruvienne. Mais je n'entends pas non plus subsumer sous le concept de l'Éternel le Fulgence Tapir du vieil Anatole France. Je demande aux historiens, quand ils vont au travail, de ne point s'y rendre à la Magendie: Magendie, ce maître de Claude Bernard, ce précurseur de la physiologie qui prenait tant de plaisir à flâner, les mains dans ses poches, à travers les faits rares et curieux - et comme le chiffonnier, disait-il, à travers les ordures. Je leur demande de s'y rendre à la Claude Bernard, une bonne hypothèse en tête. De ne jamais se faire collectionneur de faits, au petit bonheur, comme on se faisait jadis chercheur de livres sur les quais. De nous donner une Histoire non point automatique, mais problématique.

Ainsi agiront-ils sur leur époque. Ainsi permettront-ils à leurs contemporains, à leurs concitoyens, de mieux comprendre les drames 
dont ils vont être, dont ils sont déjà, tout à la fois, les acteurs et les spectateurs. Ainsi apporteront-ils les plus riches éléments de solution aux problèmes qui troublent les hommes de leur temps. p042

Méthode historique, méthode philologique, méthode critique: beaux outils de précision. Ils font honneur à leurs inventeurs et à ces générations d'usagers qui les ont reçus de leurs devanciers et perfectionnés en les utilisant. Mais savoir les manier, aimer les manier - voilà qui ne suffit pas à faire l'historien. Celui-là seul est digne de ce beau nom qui se lance dans la vie tout entier, avec le sentiment qu'en s'y plongeant, en s'y baignant, en s'y pénétrant d'humanité présente - il décuple ses forces d'investigation, ses puissances de résurrection du passé. D'un passé qui détient et qui, en échange, lui restitue le sens secret des destinées humaines. p043 


\section{LA VIE, CETTE ENQUÊTE CONTINUE}

Retour à la table des matières

Il ne sera point question, ici, de conclusion. Conclure, c'est arrêter. Tirer un trait. Sous quel paragraphe de quel chapitre? J'évoque tout ce que mes yeux ont lu et regardé, tout ce que mes oreilles ont entendu et écouté depuis que j'ai seize ans. J'évoque les transformations successives d'un esprit à deux ou trois reprises modifié, et jusqu'en son tréfonds, par des révolutions d'art et de littérature. Sous l'une, sous l'autre, pourquoi de préférence, comment tracer la barre : celle qui « arrête »?

Me voici à dix-sept ans - 1896 — à la veille de gagner Paris depuis ma province nancéienne. Je, moi, commodes pronoms; ils ne signifient, ici, que mes contemporains, les hommes nés entre 1875 et 1880. Notre bagage, à cette date ? Déjà, pour le reconstituer, il me faut un effort. Et tout ce que je vais dire, homme d'entre cinquante et soixante ans, paraîtra bien étrange aux lecteurs de trente.

Littérature ? En dehors du lycée, aux classiques reconnus, nous ajoutions les romantiques, Michelet, Flaubert (les romans et la correspondance), un peu de Renan parfois. Vigny avait ses fanatiques, Leconte de Lisle ses fidèles. Auteurs «modernes » mais avouables: signe certain d'adoption, dans la bibliothèque de nos parents ils avaient droit à la demi-reliure - en tout cas au bradel. Plus risquées, nos autres lectures : aussi les faisions-nous dans des volumes brochés - les «trois cinquante» blancs, rouges ou jaunes de Vanier, de Calmann ou de Charpentier. D'ailleurs, à l'heure même où nous tentions de nous dégager d'elle, c'était notre trop bonne formation lycéenne qui continuait à dicter nos jugements. Ainsi goûtions-nous surtout, chez France, les ironies pastichées de Jérôme Coignard ou 
l'érudition narquoise de La Reine Pédauque; ainsi, mieux que l'anarchisme subtil des trois romans idéologiques de Barrès, nous plaisaient Le Sang, la Volupté et la Mort teintant de couleurs romantiques une ${ }_{\mathrm{p} 044}$ Espagne plus qu'à demi-rhétoricienne. Pourtant, avec beaucoup d'émoi mais quelque résistance, nous commencions à goûter Verlaine. Quant à notre époque, Les nuits, les ennuis et les âmes de nos plus notoires contemporains (comment résister au plaisir de citer ce titre, si parfaitement daté, d'un livret d'Ernest La Jeunesse ? ) - ces Nuits, et quelques autres, nous révélaient le sens d'adjectifs à la mode : "décadent» et «fin de siècle». D'aucuns, parmi nous, s'aventuraient jusqu'aux Goncourt. D'autres, jusqu'à Huysmans. Mais tous, en cachette, nous lisions Maupassant. Un peu Daudet. Et Zola beaucoup.

Musique ? quelques concerts classiques. Du Beethoven, du Schumann. Du Berlioz rarement. Entre une reprise de Roméo et le triomphe de Werther ou d'Hérodiade, le Théâtre Municipal nous révélait, pêle-mêle, Samson et Dalila, Sigurd, ou L'attaque du moulin: toutes nouveautés fortement discutées. Derrière quoi, peureusement, se glissaient Lohengrin et Tannhäuser.

Peinture, sculpture, pas grand-chose. Par fortune, je pouvais aimer un Rodin - le Claude Lorrain juchant, dans le parc de la Pépinière, sa silhouette pataude, ses lourdes bottes et son visage ébloui sur le piédestal qu'entraînent, d'un si furieux élan, les chevaux d'Apollon. Mais, en dépit de curiosités fortement éveillées, à seize ans aucun de nous n'avait vu un Manet, un Monet, un Renoir. Connaissions-nous seulement les noms de ces réprouvés - même pas, de ces ignorés ? Ceux des grands hommes du Salon, oui. Avec la déférence requise, chaque année, dans le Figaro-Salon d'Albert Wolf, nous contemplions les Bonnat, les Benjamin Constant, les Jean-Paul Laurens - parfois, si audacieux, un Bernard ou, si révolutionnaire, un Henri Martin. Au reste, dans le pays du fer, nous usions nos ardeurs à maudire l'industrie. Nous avions bien des yeux pour admirer, la nuit, le flamboiement des coulées ou l'étrange paysage qu'au matin composent, surgissant de la brume, les usines aux silhouettes métalliques. Mais les dogmes étouffaient nos impressions. Comme ils nous empêchaient de rattacher à l'art tout ce qui n'était pas architecture, peinture, sculpture ou gravure. Il est vrai, en ce temps, 
les usines étaient lépreuses, les hauts fourneaux mesquins, les ponts métalliques sans ampleur. Il est vrai, la photographie (pour ne citer qu'elle) justifiait par trop les anathèmes de Flaubert: elle n'était qu'un moyen de fabriquer ces albums dont on ouvrait les fermoirs pour admirer la crinoline de tante Marie, ou le pouf de la cousine Jeanne.

Dans tout ceci, une nouveauté - une seule. Mais qui n'intéressait que l'«art décoratif». On nous lançait dans le monde p045 soigneusement munis de catégories étanches : il y avait l'Art, qui était Beauté, et l'Industrie, qui était Laideur; pareillement, aux arts « purs », inutiles et prestigieux, s'opposaient les arts " appliqués », souillés d'utilité et donc inférieurs. Or, c'était dans le domaine de ces derniers que naissait quelque chose : l'art sylvestre et floral d'Émile Gallé, qui déjà se transportait de ses vases pleins de mystère à ses meubles improvisés - à tous les plateaux de table en marqueterie qu'il jonchait des dépouilles d'un automne mordoré. Dûment stylisée, cette flore sinueuse commençait d'envahir le socle des monuments publics et la façade des hôtels bourgeois. Le "modern style» se constituait: iris, vigne-vierge, feuilles de platane et de marronnier. Aux devantures de Majorelle, nous assistions chaque soir à sa genèse. Tables à thé et bahuts, assiettes peintes et verreries, bois de fauteuil ou tentures, encadrements sculptés des portes et des fenêtres - le décor entier de notre vie s'abîmait dans une orgie de fleurs en bois sculpté et de rameaux en bronze.

Brusquement, Paris, 1896-1902. Luttes et crises - politiques, morales, esthétiques. Tout à la fois. En ces troubles années, petits provinciaux découvrant la Ville, nous nous battions pour nos vérités, pour nos raisons d'être - et aussi pour nous faire d'autres yeux, d'autres oreilles, une façon neuve de sentir le monde. Pour des joies inconnues.

Un dimanche après-midi, au Châtelet. Ce plastron blanc légèrement cabossé ; cette barbe nestorienne; cet homme replet qui s'incline : c'est, réprouvé par les fauteuils pour crime de wagnérisme, Édouard Colonne - frénétiquement acclamé par nous autres, les troisièmes galeries : debout, tous battoirs en action, toutes clameurs hors du gosier. Après quoi, pendant des heures, le long des quais et 
des rues, tandis que les savants discutaient thème et leitmotiv, les silencieux, encore émerveillés, écoutaient leur cœur sauter dans leur poitrine.

Autre dimanche: le Palais de l'Industrie. Par bataillons, par régiments, par corps d'armée, les portes grandes ouvertes «les» vomissent: dans la nef, tous se ruent, joyeux et repus, s'excitant d'avance au plaisir promis. Et parvenus au pied du socle sur quoi, tete en arrière, hautain et dédaigneux dans sa robe de bure, le Balzac de Rodin ne les brave point mais les rejette - ils crachent leurs plaisanteries et leurs rires obscènes.

Cependant la salle Caillebotte au Luxembourg - mais surtout, à l'Exposition de 1900, la Centennale de l'Art français — révèlent ${ }_{\mathrm{p} 046}$ à nos yeux, éblouis par tant de clarté, l'impressionnisme et ceux qui lui faisaient cortège. Eh quoi, la France était le lieu universel de la Peinture - mais on ne nous le disait pas? Révolte et, dans nos esprits, coup de pic formidable. Monet, Renoir, Pissarro, Sisley, Cézanne, Manet et Degas, et puis Rodin - tous entrent en nous. Fraternellement. Et nous occupent. C'est fini, le reste disparaît : nous n'irons jamais, plus aux Salons officiels révérer les virtuoses du faux dessin et du clair-obscur pédagogique. Nous connaissons nos dieux, les vrais. Ils nous refont une âme.

A nous, qui jamais n'avons tenu tire-ligne ni archet, ébauchoir ni pinceau. A nous philosophes, historiens, biologistes, médecins ou philologues. Sans doute, sur le moment nous n'analysons guère. Nous aimons, nous possédons ; nous ne faisons la théorie ni de nos amours, ni de nos brusques dégoûts. Entre la sérénité volontaire d'un Cézanne, absorbé dans ses soucis d'exactes mises en place; entre la santé et la joie d'un Renoir, aussi vierge qu'un Rabelais d'intentions littéraires - et, d'autre part, le romantisme germanique de Wagner, ou les cris, les sanglots, les appels désespérés qui montent d'un couple enlacé de Rodin; entre la dureté de Manet, la cruauté de Degas, les visions de Monet ou les fêtes sur l'eau vive de Sisley - qu'il y ait heurt, conflit, opposition certaine, nous ne voulons pas le voir. Brusquement dilaté, notre cœur est assez large pour les contenir tous.

Eux, et ceux qui déjà se pressent pour les remplacer - tant, en ces années fécondes, la sève est généreuse. Un jour, chez Druet, nous 
allons découvrir, après ses paysages, les nus de Marquet. Ou bien, chez Bernheim, place de la Madeleine, les portraits de Bonnard, les intérieurs de Vuillard, les églogues de Roussel. Chez Durand-Ruel, la robustesse plénière des Renoir. Un peu partout, les dessins de Rodin. Le tout, impunément? Je veux dire, bien enfermé dans un casier réservé, avec l'étiquette : «Plaisirs d'art et de littérature »? A pareille question si nous répondons : non, - ce n'est point pour avoir lu des traités d'esthétique. Mais nous avons senti s'opérer en nous, par la grâce de ces "ouvriers » et de leur art, la métamorphose qui nous a faits, vraiment, ce que nous sommes toujours, trente ans plus tard.

A quoi bon ces souvenirs? J'ai l'air de divaguer, de raconter pour rien, pour le plaisir, nos jeunes années... En fait: Encyclopédie française, tomes XVI et XVII, Arts et littératures, fin - il me semble que j'y suis en plein? 047

Quelque chose était entré en nous. De si fort, de si rayonnant que tout, brusquement, nous semblait par là désaccordé. Il fallait rétablir les liens rompus, recréer un ordre nécessaire. Raccorder. Et d'abord, le décor même de notre vie. Allez donc accrocher un Renoir, ou un Monet, dans un salon Félix-Faure, enlaidi de meubles aux profils ronds, aux courbes molles - encombré de bibelots hétéroclites et contournés, de lourdes tentures sombres, d'une profusion d'inutilités agressives ? Allez donc insérer les lignes d'un Cézanne dans un cadre « modern style »? Déjà Loos, depuis Vienne, nous prêchait la guerre à l'ornement. Mieux encore nous l'enseignaient, et agissaient, les tableaux des fils de Courbet et de Delacroix.

Raccorder, quoi encore ? Notre littérature ? Certes, si nous nous étions posé la question en termes abstraits, nous aurions été fort embarrassés pour la résoudre. De toutes ces toiles, de tous ces marbres et ces bronzes qui nous avaient conquis, je l'ai dit et nous le sentions confusément : une leçon unique ne se dégageait point. D'un Rodin, d'un Degas, d'un Renoir et d'un Monet contemplés dans une même matinée, avant une audition de Tristan — ou de Pelléas — nul n'aurait su déduire, ni que le romantisme avait disparu, ni que le naturalisme était enterré, ni qu'un lyrisme spontané achevait de vaincre, en combat singulier, un âpre réalisme. Mais pareillement, en 
littérature, nous n'avions pas renoncé d'un coup à tout ce que nous aimions «avant». Et dans ce que nous accueillions maintenant avec le plus d'élan, nous n'étions guère soucieux de discerner cette unité d'inspiration qui ne s'épanouit vraiment que dans les manuels. Pas plus que d'établir un lien de discours académique entre «nos» peintres, d'une part, et de l'autre (je cite pêle-mêle, à dessein, des œuvres fort disparates) — disons, les Histoires naturelles de Jules Renard (d'ailleurs illustrées par Bonnard) et son Poil de Carotte; et encore, les Charles-Louis Philippe, de Bubu aux Charles Blanchard; les Octave Mirbeau; les Pierre Hamp de La peine des hommes, ou Colette de La vagabonde. Il est certain toutefois qu'à l'origine de certaines répudiations, de certains dégoûts, de certaines impossibilités (par exemple, le théâtre des Boulevards et ses drames bourgeois) - il y eut pour nous, et pour combien d'autres, la prise de possession, aux environs de l'année 1900, et l'adoption passionnée de cette toute petite chose inconnue et négligeable dans l'histoire de la Civilisation d'Occident: la peinture française — celle des maîtres nés aux alentours de 1830 et de 1840 .

Faut-il aller plus loin ? parler de morale aussi à « raccorder », p048 ou de philosophie? Certes, entre l'impressionnisme et telles attitudes philosophiques qui alors séduisaient tant de jeunes esprits, nous nous défendrions de vouloir nouer des liens trop précis. Non moins qu'entre nos appétits fougueux de justice, nos besoins passionnés de clairvoyance et, par exemple, le propos de Monet à Renoir, à Sisley et à Bazille, ce jour de l'année 1862 où, devant un modèle vivant, Gleyre leur enjoignait de penser à l'antique : "Filons d'ici, l'endroit est malsain, on y manque de sincérité ... » Qu'il soit du moins entendu qu'au renversement des termes du problème nous opposerions, non pas seulement la question préalable, mais des dates positives et une question précise. Bergson et le bergsonisme? Mais pourquoi loger les peintres, qui œuvrèrent bien avant lui et sans lui, dans le décor fragile du philosophe - plutôt que la philosophie transitoire dans le palais éternel de la peinture ?

Il fallait raccorder. Nous raccordions. En éliminant. En accueillant. Mais aussi en regardant d'anciennes choses avec des yeux tout neufs. C'est le temps où quelques-uns d'entre nous s'avisaient d'acquérir l'édition Calmann — clous et papier à chandelle — des Promenades 
dans Rome et des Mémoires d'un touriste, tels que le bon Colomb les avait légués à une postérité qui d'ailleurs, à cette date, ne s'empressait pas beaucoup de les adopter... Déjà, dans ces années fiévreuses, nous étions prêts à accueillir Proust. Et Valéry. S'ils sont entrés en nous et dans la mesure où ils y sont entrés - c'est introduits par ceux qui nous ont transformés et contre qui eux-mêmes réagissaient. Comme c'est Wagner, en définitive, qui a donné audience, chez nous, à Debussy. Et Debussy à Ravel, à Strawinsky, à Florent Schmitt. Et ceux-ci... ne continuons pas. Qui donc disait: "Je vis peut-être en 1900 ; mais mon voisin, que vous voyez ici, vit en 1890 ; et cet autre, là-bas, en 1880. » - Au vrai, c'est chacun de nous qui vit, pour une part, en 1935, et aussi en 1920, et toujours en 1912.

Résumons tout d'un mot. Il n'y a pas que les conquêtes de la Science pour aboutir, parfois, à ce qu'on a nommé de véritables «mutations » de l'intellect humain : transformations soudaines et si profondes qu'en quelques années les notions mêmes dont la conquête a coûté le plus d'effort aux premiers génies scientifiques d'une époque, deviennent évidentes et faciles même pour les écoliers. Il y a ce qu'on peut, ce qu'on doit nommer les conquêtes p049 de l'art. Dont les résultats font «mutation » eux aussi, en s'incorporant, en quelques années, à la vision commune de l'Univers. Et pas à celle des artistes seulement; ou des amateurs d'art; ou même de cette "élite» dont parlait hier un excellent historien de l'art dénonçant, dans l'incompréhension totale, furieuse et obstinée des Français d'entre 1860 et 1900 pour Courbet, pour Manet, pour Monet, pour Rodin et combien d'autres, " un des multiples effets de la démocratie qui supprime les élites » : c'était bien cependant, sauf erreur, les " élites » qui remplissaient leurs salons des uniformes fort coûteux de ce Meissonnier dont on ne trouve pas trace dans la récente Histoire de la peinture en France de notre auteur - et des combats de ce Detaille et des portraits cotés de ce Chartran, et des imageries en couleurs de tant d'académiciens chamarrés, dont un homme cultivé rougirait de citer un seul nom aujourd'hui. Révolutions d'art. Quand elles ont la puissance, et l'ampleur, de celle qui s'accomplit sous nos yeux d'hommes dont les vingt ans sonnèrent aux horloges de 1900 reconnaissons en elles un des ferments les plus actifs de l'histoire humaine. 
Et l'on voit peut-être à quoi tend tout ceci ? D'abord (inutile maintenant d'y revenir) à achever de démontrer qu'aux volumes XVI et XVII de l'Encyclopédie aucune conclusion n'est désirable, ni possible. Parce que, même nous, les cinquantenaires d'aujourd'hui, nous n'avons pas tiré la barre sous nos conquêtes de 1900 à 1910 . Parce qu'au retour de la guerre (et la guerre, ici, n'est alléguée que comme un repère chronologique, non pas comme une cause ou, en tout cas, « la » cause) — nous avons connu, goûté d'autres peintres, d'autres sculpteurs, d'autres musiciens, une autre architecture encadrant d'autres décors. Bien plus, d'autres arts: l'homme collaborant, dans la photographie, au travail brut de la lumière; l'homme enregistrant le mouvement pour le recréer à sa guise. Tout ceci, dans un monde complètement bouleversé et rénové par un prodigieux ensemble de découvertes scientifiques aboutissant à la télégraphie sans fil, à l'aviation, au phonographe, à la radio - demain à la télévision, etc. Tout ceci, tellement fort et profond qu'hier Henri Wallon nous en avertissait : déjà, en si peu d'années, ces inventions d'une prodigieuse universalité ont commencé d'agir sur nos organismes, de modifier nos perceptions, de transformer une humanité depuis des siècles et des siècles à peu près immobile dans sa constitution. p050

Mais il y a autre chose. Dans le plan total de l'Encyclopédie, si j'ai fait aux Arts et aux Littératures, dès le début, une place ample et large; si, en face des deux volumes, nécessairement assignés à la physique moderne, cette révolution des révolutions de notre temps, j'ai voulu placer deux volumes, deux gros volumes destinés à « faire comprendre » ce qu'était l'art dans notre civilisation et dans nos vies ; si, ayant tenté un instant de ramener, pour des raisons de commodité, ces deux volumes à un seul, j'ai dû renoncer bientôt pour revenir à mon dessein primitif - ce ne fut point fantaisie gratuite. C'est que je trouvais, dans mon expérience même, dans mes souvenirs, dans ce que j'ai conscience d'avoir «été fait », la notion vivante que l'art ne s'inscrit pas, ou ne s'inscrit qu'accessoirement et au prix d'une déformation, parmi ces "Loisirs et Divertissements" dont il sera traité au tome XIV de l'Encyclopédie : sa vraie place, je l'ai marquée dès l'origine (Pierre Abraham a bien voulu le rappeler au seuil du 
tome XVI). Elle est parmi les plus efficaces moyens de Connaître et de Comprendre dont l'Humanité dispose. Dès maintenant - et sans préjuger de ce qu'elle sera demain.

De ce qu'elle pourra et devra être... Il faut le dire, à l'heure où les savants ouvrent devant nos yeux, à la fois ravis et troublés, les perspectives qu'on sait; à l'heure où ils nous montrent la recherche expérimentale et la recherche mathématique se relayant pour mieux capter l'univers dans les mailles du filet humain - pour mieux l'enclore dans de puissantes constructions, faites de ces formes et de ces notions abstraites que la raison tire des choses déjà connues. Explorateur des contrées sans limites dont parle Jean Perrin; prospecteur de ce cerveau humain «où dorment dans la nuit des possibles sans nombre que la conscience pourra ne jamais animer »le mathématicien tire d'objets connus ses chaînes indéfinies d'êtres rationnels. Jusqu'au jour où, le contenu des réalités se trouvant tout entier élaboré, il réclame aux travailleurs de l'expérimentation une moisson nouvelle de faits, éléments nécessaires des constructions futures.

Cycle sans fin, engrenage un peu terrifiant, entre les dents de quoi bien des choses sans doute, fragiles, tendrement vivantes et à quoi nous tenons, risqueraient de se voir broyer sans merci - si l'art précisément n'intervenait ici comme un contrepoids. Ou comme un perceur d'avenues ensoleillées. L'art, qui n'est pas l'antithèse de la Science. L'art qui ne doit point l'ignorer, ou la combattre - mais, de plus en plus, s'appuyant sur elle, prendre p051 ses données comme objet de son travail. Non seulement pour enrichir ses possibilités, se doter de moyens nouveaux, s'ouvrir des terres neuves, Mais encore, mais surtout, pour présenter à certains hommes qui ne sauraient l'accepter que de lui, cette interprétation générale des choses que la Science propose et que l'art suggère. L'art — ou les artistes.

Dans le cycle des deux recherches se suppléant l'une l'autre et conjuguant leurs efforts alternés, il est bon de prévoir un relais de l'art. Une troisième recherche. Plus en surface qu'en profondeur? Croyez-vous? Profondeur, qu'importe. Je me penche sur l'Océan, vous me dites : "Ici, trois mille mètres de fond. » Trois mille ou trois cents, c'est tout un. Ce qui compte, c'est de savoir jusqu'où la clarté 
descendra. C'est de faire descend la lumière plus loin, plus bas, toujours plus bas. De faire reculer l'obscurité. Et donc d'être profond : je veux dire, d'éclairer l'obscur. L'art peut l'illuminer. p052 


\title{
LES POUR ET LES CONTRE
}

$\underline{\text { Retour à la table des matières }}$

\author{
Pour une Histoire Dirigée \\ LES RECHERCHES COLLECTIVES \\ ET L'AVENIR DE L'HISTOIRE
}

Recherches collectives : la formule ou, si l'on veut, le programme n'a pas de quoi surprendre, ou choquer, le biologiste ou le physiologiste; pas même le psychologue; pas même, moins loin encore de nous, le géographe "humain », l'anthropogéographe, qui volontiers procède par "enquêtes". Qu'elle surprenne et choque, appliquée à l'histoire, la plupart de ceux qui se disent historiens, aujourd'hui, dans un pays comme la France : c'est un fait. Il faut comprendre ce fait pour l'expliquer.

On peut invoquer la tradition. Quand je suis né à l'histoire, au temps où naissait lui-même le $\mathrm{Xx}^{\mathrm{e}}$ siècle — la mode, dans la firme Clio, n'était certes pas au travail collectif. On se passait encore des histoires effarantes de vieux archivistes, cachant des dossiers par eux « découverts » et qu'ils faisaient disparaître pendant des années, pour s'en réserver l'usage éventuel. De temps à autre éclatait une histoire, parfaitement ridicule, de "priorité »; ou bien l'on assistait, un peu ému, à la lutte de vitesse de deux historiens travaillant sur le même fonds et qui, lancés à toute vapeur (métaphore d'un temps qui ignorait l'auto), cherchaient à se devancer l'un l'autre triomphalement. Individualisme puéril. Ce qui importait, ce n'était pas l'histoire, une 
science à promouvoir. C'était l'historien, un livre à signer. Des vanités d'auteur.

Que cet état d'esprit — un peu atténué sans doute — persiste encore, je ne suis pas assez naïf pour ne le point penser. Mais il est un effet, et non point une cause. Il procède de convictions fortes antagonistes en bonne logique, mais qui finissent cependant par se rejoindre. Pour les uns, conviction que l'histoire «n'est pas une science ». Pour les autres, conviction qu'étant une science l'histoire interdit à l'historien, "naturellement», tout p055 choix d'éléments, toute interposition d'idées (sous forme d'hypothèses, ou même de théories) entre la cueillette brute des documents et leur présentation au lecteur. N'entreprenons pas de discuter en détail ces conceptions contradictoires. La persistance de leur succès dans les milieux historiques ne s'explique que par une méconnaissance totale de la solidarité qui unit, bon gré mal gré, toutes les disciplines scientifiques les unes aux autres et, d'autre part, par une ignorance absolue et sereine de l'évolution, ou de la révolution, qui se produit de nos jours dans les idées de corporations entières de « savants » sur ce qu'on est convenu d'appeler l'objectivité scientifique.

D'un mot, notons-le simplement: non, la Science ne se fait pas dans une tour d'ivoire, par l'opération intime et secrète des savants désincarnés vivant, en dehors du temps et de l'espace, une vie de pure intellectualité.

La Science - et j'entends par là la Société des Sciences - la Science se fait par des hommes baignant dans le milieu de leur époque: le même pour les mathématiciens, les physiciens, les biologistes... et les historiens; le même, et qui agit sur tous de la même façon, et par qui s'opère la liaison de leurs activités scientifiques avec l'ensemble des autres activités de la même époque ${ }^{7}$.

Sur tout ceci, outre les comptes rendus des Semaines Internationales de Synthèse - notamment les exposés sur le thème Science et Loi $\left(5^{\mathrm{e}}\right.$ semaine ; Paris, Alcan, 1934, in-12) — voir l'intéressant volume collectif intitulé A la lumière du marxisme (Paris, E. S. I., 1935, in- $8^{\circ}$ ) et mes réflexions à ce sujet : 
En d'autres termes, la Science n'est pas un empire dans l'empire. Elle ne se sépare pas du milieu social dans lequel elle s'élabore. Elle y subit la pression, la contrainte de contingences multiples qui pèsent sur son développement. Et c'est pourquoi, entre parenthèses, l'histoire de la Science, bien loin de constituer un morne et poussiéreux conservatoire de théories mortes et d'explications périmées, représente au contraire un chapitre vivant de l'histoire générale de la pensée humaine : elle retrace, en définitive, l'adaptation de l'esprit aux choses et la prise de possession par l'homme de son milieu.

Il suit de là que, si les sciences de la Nature ont subi, dans les deux dernières décades, les effets d'une véritable révolution idéologique; si elles ont vu s'effondrer, par suite des progrès p056 soudains et étonnants de la physique, toute la construction théorique élaborée au cours des $\mathrm{XVII}^{\mathrm{e}}, \mathrm{XVIII}^{\mathrm{e}}, \mathrm{XIX}^{\mathrm{e}}$ siècles par des générations de savants ; si le concret faisant éclater les cadres de l'abstrait, la tentative d'expliquer le monde par la mécanique « rationnelle » s'est terminée par un échec brutal; s'il a fallu procéder à une révision d'ensemble de toutes les notions scientifiques sur lesquelles on avait vécu jusqu'alors ; si rien, finalement, de ce qui est essentiel n'a échappé à cette révision : ni la conception du fait scientifique, ni celle de la loi ; ni celle de la nécessité ; ni celle de la contingence; ni au total, celle des sciences même et de la Science...., de la Science construisant son objet avec l'intervention constante et grave des savants : l'histoire ne peut s'abstraire de tels bouleversements. Qu'elle le veuille ou non, elle $\mathrm{y}$ est impliquée. Se référer à tout un bagage d'idées " scientifiques » vieilles d'un siècle et totalement rejetées aujourd'hui par les «savants" à qui naguère elle les a empruntées : l'histoire se rend risible en s'obstinant à le faire. Et s'il est vrai que toutes les sciences sont solidaires, elle se rend risible pour rien — pour le plaisir. 
Or, que nous enseignent ces sciences solidaires, dont l'exemple doit peser sur l'histoire? Bien des choses, mais ceci notamment : que tout fait scientifique est "inventé » - et non pas donné brut au savant. Que la vieille distinction de l'observation, cette photographie du réel, et de l'expérimentation, cette intervention dans le réel, est tout entière à réviser. Qu'en aucun cas l'observation ne livre quelque chose de brut. Qu'elle est une construction. Comme sont des constructions les «prises de vue » elles-mêmes dont on entend se servir pour telle ou telle vérification ou démonstration de théorie. Que dès lors l'objection si souvent ressassée que "l'historien n'a pas le droit de choisir les faits » est inopérante ; parce qu'en fait le savant, quel qu'il soit, choisit toujours - et que d'ailleurs, toute l'histoire est déjà choix, du seul fait du hasard, qui a détruit tel témoignage, tel vestige du passé, tel ensemble de documents — et sauvegardé tel autre. Enfin, que s'attacher à tant de vieux préjugés, sur la véritable valeur du travail scientifique — c'est aller, à l'intérieur même de l'histoire, à la croyance absurde et naïve qu'assembler des faits " pour rien », pour le plaisir, en attendant la venue d'un esprit capable de les dominer, c'est œuvre pie ; et, s'agissant des rapports de l'histoire et des sciences voisines - à la théorie, si chère jadis aux sociologues (et

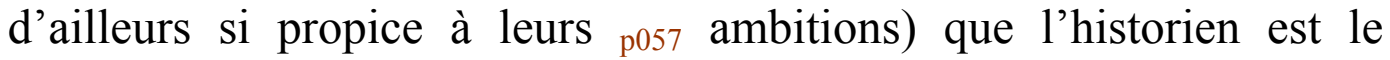
manœuvre voué à tirer de la carrière et à dégrossir les pierres de taille que le sociologue-architecte viendra seul assembler...

Bannissons une bonne fois ce naïf réalisme d'un Ranke s'imaginant pouvoir connaître les faits en eux-mêmes, "comme ils se sont passés ». C'est à travers les formes de notre esprit que nous apercevons aussi bien la "réalité historique » que la réalité physique. Et à la vieille distinction, au schéma traditionnel du travail historique : établir les faits, puis les mettre en œuvre - essayons d'en substituer un autre, qui tient compte à la fois, et de la technique d'aujourd'hui et de la pratique de demain telle que déjà elle s'annonce. Historien, ne raisonnons pas en logicien soucieux de s'élever progressivement, hiérarchiquement, du simple au composé et de reconstituer, degré par degré, l'escalier qui mène de la plus simple tâche à la plus élevée. L'ordre qui s'impose ici, c'est l'ordre génétique. Et de ce point de vue, ce qui tout d'abord importe, c'est l'existence, la confection et la 
mise à jour perpétuelle de programmes de recherches longuement médités et de vaste envergure ${ }^{8}$.

Alors, à la base de votre histoire, des «théories »? - Le mot n'a rien qui puisse me faire reculer. Sous la plume de qui lisais-je donc, il n'y a pas bien longtemps, ces propos subversifs : "Une théorie est une construction de l'esprit qui, répondant à notre besoin naturel et impérieux de comprendre, est destinée à nous fournir une explication des faits. Elle est en cela l'expression même de la Science... qui n'a pas pour ultime objet la découverte des lois... mais bien la compréhension des phénomènes. " Quel est ce métaphysicien suspect? Un biologiste, Anthony, cité par un autre biologiste, Fraipont ${ }^{9}$. Finis, révolus, les temps qu'évoquait dernièrement Louis Lapicque ${ }^{10}$ et cette excitation de chiffonnier en tournée que décrivait Magendie : " Je me promène là dedans comme un chiffonnier, et je trouve à chaque pas quelque chose d'intéressant à mettre dans ma hotte. » "Là dedans » c'était le dédale d'un corps vivant. "Là dedans », pour beaucoup d'historiens, aujourd'hui encore, c'est le dédale d'une Histoire vivante... Mais au propos de Magendie, Lapicque opposait celui de Dastre ; p058 sachons le retenir pour nous aussi, historiens ; la « Science » nous couvre : "Quand on ne sait pas ce qu'on cherche, on ne sait pas ce qu'on trouve. »

Ce qui vaut pour le biologiste, ce qui pour lui est sagesse et raison - comment pour l'historien serait-ce sottise, et déraison? Comment celui qui cherche à travailler sur la plus complexe de toutes les matières, sur l'activité historique des hommes, accepterait-il de se lancer plus longtemps à l'aventure, sans boussole, isolément, et de n'implorer comme dieu que le Hasard ? Actuellement encore, dans le champ de l'histoire, n'importe qui s'installe n'importe où, et avec n'importe quels matériaux, dans n'importe quelle direction, construit à sa fantaisie - un peu plus petit, un peu plus grand — son bout de

\footnotetext{
8 Voir plus haut, De 1892 à 1933 : Examen de conscience d'une histoire et d'un historien, page 3 .

9 Ch. Fraipont, Adaptations et mutations, Paris, Hermann, 1932, in- $8^{\circ}$.

10 L'orientation actuelle de la physiologie (R. Philosophique, 1930, $\mathrm{n}^{\circ}$ 9-10).
} 
mur. Après quoi, se frottant les mains : «Autant de fait pour le Palais futur! » Eh non! Rien de fait. Quand on voudra bâtir le palais, on fera venir un architecte, qui dressera son plan. Et d'abord fera jeter par terre tous les pans de murs disparates dont on aura encombré son terrain. Commençons, nous, par le commencement: par les plans d'architectes ${ }^{11}$.

Plan de coordination, essentiellement. Et de coopération. Par là, nous rejoignons les «recherches collectives», que nous n'avons jamais perdues de vue. Les temps sont passés de l'universalisme. Partout, dans tous les domaines. On nous dit: "Giard fut le dernier des naturalistes complets. » On nous dit : «Sylvain Lévi fut le dernier des indianistes complets. » Soit. Quelle leçon en tirer? Qu'Alexandre mort, son Empire se divise ? Je veux dire, qu'il viendra des hommes qui seront maîtres d'une des parties seulement de l'immense empire qu'un Sylvain Lévi pouvait encore posséder et régir tout entier? Mais est-ce bien la seule conclusion? Pour ma part, j'en vois une autre.

Restreindre le champ d'action du savant - c'est accroître la « spécialisation », ce fléau. C'est la rendre irrémédiable. Alors, si on laissait le successeur d'Alexandre régner sur tout l'empire, mais en lui imposant la collaboration de cinq ou six hommes - un général, un diplomate, un financier, un bâtisseur - dont il p059 n'aurait qu'à organiser la collaboration, régler la tâche et définir la besogne ?

Transposons: l'historien, si au lieu de faire lui-même toute la montre; et d'abord de se construire ses propres outils; et ensuite de fabriquer ses pièces; et finalement de les assembler et de les faire fonctionner - s'il se contentait du dernier rôle ? Si, ayant choisi, pour des raisons valables, un sujet d'études; l'ayant délimité avec soin; ayant marqué ce qu'avant tout il importait d'arriver à établir (car il

11 Qu'il me soit permis de rappeler, non sans fierté, que l'Encyclopédie française, telle que je l'ai conçue — Encyclopédie de problèmes, et non de références - représente la plus grande tentative qui ait été faite à ce jour, en aucun pays, pour rapprocher les uns des autres, et mettre en contact direct avec le public éclairé, non des vulgarisateurs de talent — mais les créateurs même, les " inventeurs » de la Science, dans tous les domaines: les hommes qui, placés à l'extrême pointe de la recherche mathématique, physique, biologique, etc. tirent leurs idées, non de traités ou de manuels, mais de leur lutte continuelle et journalière contre l'inconnu, sur quoi chaque jour ils mordent un peu plus. 
faut renoncer à l'idée puérile que tout est également intéressant pour tous) - il organisait les recherches d'une équipe composée, disons (en songeant à certaines enquêtes possibles et désirables d'histoire des techniques) d'un technicien proprement dit ; d'un chimiste au courant de l'histoire de sa science ; d'un économiste à l'esprit concret - si, se réservant le rôle entre tous difficile de dresser les questionnaires préalables; de rapprocher les réponses fournies; d'en dégager les éléments de solution; d'ordonner les suppléments d'enquête indispensables; surtout, de marquer les rapports du problème posé avec l'ensemble des problèmes historiques du temps qui le formula si, ayant pris cette voie longue, qui finalement se trouverait beaucoup plus courte que les vieux chemins sinueux d'autrefois, il parvenait à faire enfin de l'histoire une «science de problèmes à poser ", sinon toujours à résoudre avec certitude et du premier coup : je crois que son rôle serait singulièrement plus en vue que celui d'un vague fabricant de livres «personnels»; je crois que personne ne se demanderait plus si l'histoire est une science, ou un art; je crois qu'ou bien on ne qualifierait plus d'historien tel savant auteur de savants livres sur Louis $X V$ et les femmes, Le poison des Borgia, — ou qu'alors, l'historien, laissant à ces excellentes personnes, avec les prix académiques fondés pour eux, le nom même qu'ils décrient, se débaptiserait sans hésitation, pour ne pas être plus longtemps la victime d'une confusion désobligeante et à la fin trop absurde.

Si on veut hâter la venue de ces temps — et il le faut - la première chose à faire, c'est de prendre conseil d'autrui. De s'enquérir des réalisations déjà faites. De prendre appui sur ceux qui, dans leur domaine, ont organisé « la Recherche collective ». p060 


\section{Contre l'Histoire Diplomatique en Soi}

HISTOIRE OU POLITIQUE ?

DEUX MÉDITATIONS : 1930, 1945

$\underline{\text { Retour à la table des matières }}$

I.

L'histoire diplomatique de l'Europe (1871-1914) que, sous la direction de Henri Hauser, un groupe d'historiens français qualifiés a publiée il y a quelque temps aux Presses Universitaires (1929) ne tombe pas directement sous la juridiction d'une Revue comme la nôtre. Ne pas signaler cependant un aussi commode instrument de travail, ce serait commettre une façon d'injustice - et plus encore, renoncer à poser une question qui ne paraîtra point dépourvue d'intérêt.

On se doute bien, en ouvrant le livre, qu'auteur avisé de tant d'études d'histoire économique, Henri Hauser, personnellement, n'a eu garde d'oublier qu'une diplomatie nouvelle remplace progressivement « la politique des Cours et des Cabinets », et qu'elle est tenue de faire une part de plus en plus large aux mouvements de l'opinion publique comme aux intérêts des groupes. "Un conflit ouvrier entre nationaux qui défendent leur standard of life et manœuvres étrangers qui acceptent des salaires de famine, il n'en faut pas plus, écrit-il, dans une vigoureuse Introduction, pour dresser deux nations l'une contre l'autre. " Certes, et qu'on ouvre les journaux, qu'on feuillette les revues: traités de commerce, négociations douanières, entreprises de réorganisation financière ou d'équipement industriel, avances bancaires sollicitées et octroyées en contre-partie d'avantages économiques ou politiques : tel est, on s'en aperçoit sans peine, le pain quotidien d'une diplomatie qui, malgré elle, doit subir, 
avec l'action du milieu, le contrôle permanent et direct de parlements populaires. Évidemment, cette prise de l'économique sur la politique ne date pas d'hier; et que nombre de guerres anciennes aient été, si l'on va au fond des choses, des guerres pour le sel, pour les ${ }_{\text {p061 }}$ épices ou pour le hareng, si quelqu'un le sait, c'est bien l'auteur d'un excellent petit livre sur les Origines historiques des problèmes économiques actuels que nous avons eu le plaisir de signaler et de louer à son apparition. Mais il est bien vrai que, depuis un bon demisiècle, cette prise devient de plus en plus visible; pour prendre un ou deux exemples parmi les plus voyants, l'achat par Disraéli des actions du Khédive Ismaïl fut un facteur essentiel de la politique anglaise en Égypte dès 1875 ; le chemin de fer de Hérat faillit bien déclencher le conflit, souvent prédit, des Russes et des Anglais; la Triplice ne se conçoit bien que si l'on songe à la percée du Gothard; enfin, des problèmes de minerais, de combustibles, de débouchés commerciaux et de crédits industriels ont à coup sûr pesé sur les déterminations des hommes et des pays qui sont entrés en guerre en 1914.

Or, ces faits, très nettement circonstanciels ou, comme on dit parfois, "événementiels ", à peine qualifiés pour représenter, en raison même de leur éclat, cette obscure mais constante pression de l'économique sur la politique, qui est, entre plusieurs autres d'égale importance, un des facteurs déterminants de la conduite des États les uns vis-à-vis des autres - ces faits particuliers et dans une certaine mesure anecdotiques, les rédacteurs de l'Histoire diplomatique de l'Europe les relèvent bien à l'occasion : avec trop de réserve encore et de brièveté ; mais les forces cachées, les ressorts secrets qui font agir et se mouvoir les masses humaines, ils se soucient beaucoup moins de les tirer au grand jour. Il leur suffit qu'elles dorment dans de secrètes profondeurs. Ce sont «les couches sous-jacentes de l'histoire» comme l'écrit Hauser dans son Introduction. Eux, retranchés derrière un parti pris simple, celui de n'utiliser jamais que les documents diplomatiques proprement dits : ceux des recueils officiels, bleus, gris, jaunes ou rouges; ceux des grandes collections nationales, l'allemande et l'anglaise à défaut de la française, trop récente ; joignons-y les correspondances et les mémoires des acteurs et des témoins des événements; eux ne se soucient que de la croûte apparente de leur globe, de leur sphère politico-diplomatique... Faut-il 
leur en faire grief? A eux, non. A des hommes, non. A une tradition, peut-être.

Sur la couverture même des deux volumes de l'Histoire diplomatique, on lit cette formule : Manuel de politique européenne. Dirai-je que je ne l'aime pas? Mieux vaut noter qu'elle marque, dès l'abord, une certaine orientation, qu'elle traduit une certaine p062 conception, légitime si l'on veut, mais un peu spéciale. Celle-là même que des livres bien connus, publiés naguère sous la rubrique de Manuels historiques de politique étrangère, ont représentée en France, depuis 1892, et fait triompher petit à petit dans l'enseignement. Fait malheureusement triompher : je l'écris comme je le pense depuis bien longtemps, et non parce que je tiens pour de mauvais livres, techniquement parlant, ces manuels, mais parce qu'ils ont contribué plus que tous autres à substituer dans les cerveaux de plusieurs générations d'étudiants (dont beaucoup sont ensuite passés maîtres), la notion pragmatique ${ }^{12}$ d'une "politique historique » à la notion désintéressée d'une histoire «des relations » - je veux dire, d'une histoire se contentant de comprendre et de faire comprendre si possible (disons, dans toute la mesure où ce n'est pas impossible) les motifs réels, profonds et multiples de ces grands mouvements de masse qui, tantôt amènent les collectivités nationales à s'unir et à collaborer pacifiquement, tantôt les dressent les unes contre les autres, animées de passions violentes et meurtrières.

Or, ces motifs, il tombe sous le sens qu'il ne faut pas les chercher seulement dans l'humeur, la psychologie et les caprices individuels

12 Consciemment pragmatique, faut-il dire? Cf. Émile BourgeoIs, Manuel historique de politique étrangère, t. I, Avertissement, p. 7 (juillet 1892): «Autrefois, lorsque les peuples remettaient leurs destinées entre les mains des familles souveraines, les enfants de ces familles, fils et filles, étaient conduits dans les archives de l'Etat pour y être préparés, par l'étude du droit public et la connaissance des intérêts traditionnels de l'Etat, à la tâche qui les attendait. Partout aujourd'hui où la nation a repris sa souveraineté, c'est à elle qu'il appartient de donner à ses enfants ces leçons. » Les mêmes, inspirées du même esprit, fondées sur les mêmes considérations, dérivées des mêmes principes ? C'est toute la question; et l'ouvrage que nous citons l'a résolue sans l'avoir posée. 
des " grands », ni dans le jeu contradictoire de diplomaties rivales. Il en est de géographiques; il en est d'économiques ; de sociaux aussi et d'intellectuels, de religieux et de psychologiques. Et j'entends bien que, plus on s'enfonce dans le passé - je veux dire celui des États européens modernes - plus l'historien se trouve amené à donner d'influence aux facteurs personnels de politiques que les textes présentent toujours comme conduites par des souverains plus ou moins absolus, ou par des ministres encore plus absolus que leurs maîtres. J'entends bien aussi qu'il y a lieu de consacrer à ce qu'on peut nommer la technique diplomatique une place proportionnée à son rôle. J'entends enfin que, certes, le labeur n'est pas vain qui aboutit, au prix de difficultés parfois extrêmes et d'un effort critique toujours ardu, à dater, non pas à la semaine ni au jour, mais à l'heure parfois ou à la minute, des démarches diplomatiques dont l'influence a pu être décisive sur tel événement. J'entends tout ${ }_{\mathrm{p} 063}$ cela, et également ce qu'on pourrait y répondre en usant d'arguments non pas contraires, mais complémentaires; et je n'en dis pas moins qu'intituler un livre Manuel historique de politique étrangère ou, plus elliptiquement, Manuel de politique européenne, qu'on le veuille ou non, c'est audessus de l'histoire vivante d'États «en chair et en os », d'États « informant» des pays faits de terres et d'eaux, de forêts et de montagnes, mais aussi d'hommes pratiquant certains genres de vie, habitués à de certaines façons de penser, de sentir, de croire, le tout combiné dans des proportions si variables qu'il en résulte, pour chaque pays, une physionomie proprement individuelle; — c'est faire flotter au-dessus de ces réalités la perpétuelle abstraction d'une politique « étrangère », d'une politique « extérieure », d'une " grande politique » si l'on préfère (on a le choix des formules), voire d'une politique " européenne », se nourrissant dans le ciel diplomatique non pas d'intentions secondes comme la Chimère du bon Rabelais, mais de caprices royaux, de fumées impériales ou de "grands desseins » ministériels.

Et si l'on objecte : "Mais, entre les intérêts réels des nations et la grande politique des gouvernants, ce divorce que vous soulignez existe réellement bien souvent », je répondrai qu'alors des ouvrages qui, par définition, font le silence sur ce fait d'importance capitale, des ouvrages qui semblent présenter des systèmes abstraits de diplomaties (eux-mêmes considérés en tant qu'êtres abstraits) comme traduisant 
les sentiments unanimes, les idées, les volontés et les intérêts des groupements nationaux au nom de qui ces diplomates parlent, écrivent et agissent : ces ouvrages passent à côté du vrai problème, du seul problème qui vaille d'être posé. Ceci, pour n'envisager que l'aspect purement scientifique du débat. S'il nous appartenait de nous placer ici à un autre point de vue; s'il nous fallait, avec certains auteurs, parler de formation professionnelle ou d'éducation civique, on devine aisément ce que nous aurions à dire. Masquer de tels divorces, quelle lourde erreur alors, pour ne pas employer de mots plus sonores?

Concluons et résumons d'un mot ces quelques remarques, accrochées librement à un ouvrage dont nous estimons l'impartialité, la tenue et la conscience.

On a chassé à peu près complètement du champ des bonnes études, on a relégué dans les solitudes glacées où «bombinent »les rêveries scolastiques, cet homo œeconomicus à qui sourirent p064 complaisamment tant d'économistes bien intentionnés. Lorsque du même champ on aura achevé d'éliminer l'homo diplomaticus avec ses politesses protocolaires, ses formules de salutation savamment graduées et l'affreuse barbarie que fardent mal ses courtoisies grimaçantes, on n'aura pas seulement, d'un point de vue purement scientifique (le seul qui compte ici pour nous, le seul qui doive compter pour des historiens), assuré le triomphe de la raison éclairée sur une routine desséchante ; d'un point de vue tout pratique, on aura, par surcroit, réalisé une bonne action, qu'il s'agisse de préparer à leur rôle futur des apprentis diplomates, ou d'éclairer simplement des citoyens libres.

Nos arrière-grands-pères connurent une politique tirée de l'Écriture sainte. Y a-t-il lieu d'enseigner à nos contemporains une politique tirée de l'histoire diplomatique, au sens étroit du mot? J'y vois à redire, et à contredire. Ce que je sais, à n'en pas douter, c'est que cette politique et l'histoire font deux: l'histoire qui, des intérêts fondamentaux des dirigés n'isole pas arbitrairement les volontés, ou les velléités, des dirigeants ; l'histoire qui ne sait ce que sont ni une diplomatie en soi ; ni une politique sans lien avec l'économie ; ni une économie ne reflétant pas, avec l'action de facteurs physiques et 
naturels puissants, le jeu non moins ardent de ces forces spirituelles ou psychologiques qu'on voit (ou qu'on sent) courir au milieu de toutes les manifestations de l'activité humaine, comme le feu entre les brandes, « infatigable et strident ».

\section{II.}

Quinze ans plus tard. Un livre paraît dans la petite collection Armand Colin. Titre : La paix armée (1871-1914). Je suis un peu gêné pour en faire la critique. C'est que ce livre est un livre fait en conscience par un bon universitaire, habitué à un travail honnête, et qui s'est documenté aux meilleures sources.

Cependant, il pose un problème d'une telle gravité qu'il faut bien l'examiner sans parti pris.

Ne nous arrêtons pas au titre. "Paix armée », c'est un système, au sens strict et restreint des mots, qui pourrait mériter une étude. Ce n'est pas de cette étude qu'il s'agit ici, mais d'un résumé précis de toute l'histoire des relations diplomatiques qui couvrent la période de 1871 à 1914 : celle qu'on appelle généralement la " période de la paix armée ». Ce qui ne veut pas dire grand-chose, avouons-le. Car la paix d'après 1920 n'a pas été moins "armée » p065 que la paix d'avant 1920. Et je ne vois pas que la paix d'après 1946 soit fort " désarmée " ? L'important, c'est que ce livre clair, muni à la mode scolaire de ses titres, sous-titres, paragraphes et alinéas, ce livre se situe assez exactement aux antipodes de ce qui, pour nous Annales, fait le bon livre d'histoire contemporaine.

Géographie, néant. On ne voit pas que l'auteur ait été influencé, si peu que ce soit, ni par les travaux de l'école géographique française, ni par les travaux des géopoliticiens allemands. Et, tout de même, il est bien de préserver sa vertu, quand on se trouve en contact avec ces sirènes germaniques ; on n'y a, d'ailleurs, pas toujours grand mérite ; encore faut-il savoir qu'elles existent, quand on publie, en 1945, un livre terminé en 1940 sur ces problèmes de «relations internationales » qui ne se déroulent certes pas en dehors de l'espace. Le sens géographique dont Jacques Ancel témoignait dans son travail 
géographique dont Jacques Ancel témoignait dans son travail et par quoi il tentait de rénover l'histoire des relations diplomatiques - il faut constater qu'il reste totalement étranger à notre auteur.

Économie, néant. Oh, bien sûr, un mot de ci de là, un mot accessoire : l'économie à la traîne... — ne serait-ce donc pas pour des intérêts économiques que, de plus en plus, le monde prend parti, que les puissances jouent leur jeu?

«Quel est le sujet?» questionnent les grammairiens quand ils font expliquer aux débutants une phrase de César. A. Roubaud et avec lui tous les tenants de cette vieille et néfaste " histoire diplomatique » répondent : « la diplomatie ». Mais non! La diplomatie n'est pas le sujet. Et les diplomates ne sont pas les épithètes du sujet. Le sujet, c'est le Monde de 1871 à 1914.

Le Monde. Je ne dis pas l'Europe. Le Monde, ses découvertes, ses réussites, ses passions. Car le Monde s'est fait pendant les années dont on nous énumère les conflits diplomatiques. Je veux dire qu'un certain régime de vie, jusque-là localisé dans quelques pays, et, dans ces pays mêmes, confiné dans de certaines contrées, dans de certains milieux - un certain régime de vie, soudain, s'est universalisé, tous les hommes de tous les pays usant de tous les produits humains, soit intellectuels, soit matériels : le but s'est défini. Dégagé. On y tend. Et ceci implique échange, échange, encore échange...

Donc le Monde. Ses passions. Ses appétits. Ses astuces. - La diplomatie là-dedans? Un moyen entre d'autres, un des moyens qu'emploie ce Monde sauvage, déréglé, véhément, passionné, p066 traversé de forces si énormes qu'elles risquent d'échapper, à chaque instant, des mains de ceux qui les manient avec prudence; - un des moyens qu'emploie ce Monde dont les grands moteurs se nomment les capitaux, le crédit, l'industrie, les organismes de vente et d'échange, pour assouvir ses passions, satisfaire ses appétits, manifester ses astuces. Un des moyens. Il y en a d'autres : la force ouverte et brutale des armées, la force sournoise et rongeante de la corruption et de la propagande.

Fermer les yeux à tout cela; nous annoncer tranquillement que « les raisons complexes des événements et en particulier les mobiles 
qui ont dirigé les gouvernants demeurent enveloppés d'obscurités qui, parfois, ne seront jamais dissipées "; s'hypnotiser et vouloir hypnotiser le lecteur sur ces « mobiles des gouvernants », qui ne sont au plus que de l'anecdote; faire comme si les vraies causes, les profondes causes, les mondiales causes n'étaient pas là, aveuglantes et certaines, - je veux dire les grandes révolutions de la technique industrielle, filles elles-mêmes des grandes révolutions de la technique scientifique et génératrices des grandes révolutions de l'économie mondiale, — c'est tenir une gageure. Une mauvaise gageure.

Quand notre auteur, prenant la défense de la diplomatie secrète, évoque avec attendrissement ces techniciens, doués du sens des réalités, qui travaillent sous le contrôle de ministres responsables, «à l'abri des passions et des utopies", on croit rêver. "A l'abri des passions et des utopies »? A vous Laval, à vous $\mathrm{X}, \mathrm{Y}, \mathrm{Z}$ (ne citons pas de tristes noms), "sous le contrôle" impartial, le contrôle " objectif », le contrôle désintéressé de qui ces délicieux techniciens ont si bien travaillé... Nous, nous n'allons pas continuer. Ce petit jeu paisible d'avant 1940, ce petit jeu qui nous a menés, nous, nos diplomates et notre diplomatie, là où il nous amenés - ce petit jeu a vraiment assez duré. Avant 1940, on pouvait dire, en haussant les épaules : faute contre l'esprit. Après 1940, on doit dire : faute contre la France. Nous n'en voulons plus. Nous le crierons aussi haut, aussi fort qu'il faudra. Et nous la répéterons, nous la répéterons sans cesse la phrase de Marc Bloch : La défaite de la France a été, avant tout, une défaite de l'intelligence et du caractère.

Depuis 1850, la France qui dominait, dirigeait, orientait les révolutions dans le monde - la France a passé la main sans s'en apercevoir (ou lorsqu'elle s'en apercevait, en s'en glorifiant). p067

C'est que la révolution matérielle est née, et que les Français, se retranchant derrière leur vieille philosophie de la modération, de la sagesse, de la prudence, ont continué à faire de la politique, rien que de la politique, toujours de la politique. «A bas la Monarchie, vive la République ! A bas la République, vive l'Empire ! A bas l'Empire, vive la République ! A bas la République, vive le Roi ! — - ce roi fûtil un maréchal. Raccourci un peu sommaire, mais exact, de l'histoire 
des pensées et des préoccupations françaises depuis 1848. Des pensées et des préoccupations à peu près unanimes.

Cependant, par grandes vagues successives et de plus en plus furieuses, la civilisation mécanique déferlait sur le monde. Que faire ? Sauter dans sa barque, empoigner les rames d'une main virile, prendre la tête du mouvement. Tout au moins, la tête spirituelle. On a cherché la France. On a fini par la trouver, la brave petite France, si sage, si raisonnable, si modeste dans ses vieux habits d'autrefois, assise dans le jardin de sa charmante vieille maison de famille, et, les doigts dans les oreilles pour ne rien entendre, lisant et relisant ses vieux classiques. Les maîtres de la Modération française.

De la Modération ou de la Médiocrité ?

Oui, c'est touchant. Et mortel. La France a choisi. Elle a choisi la catastrophe. Et ce choix, personne ne le comprend. On cherche la France là où elle devrait être. On ne la trouve pas. Elle joue avec les vieilles poupées de sa grand-maman. Sagement. Saintement. Stupidement.

Eh bien! il faut que cela finisse. Il faut que les Français - et d'abord ceux qui endoctrinent les autres - regardent les choses en face. Qui donc mène le Monde ? Les diplomates ? les politiciens ? ou bien ces deux élites que nous montre à l'œuvre, dans son livre récent, M. Chappey : ici, les techniciens de l'esprit, littérateurs, artistes, moralistes ; là, les techniciens de la matière, fabricants et négociants ; alliés, malgré les brocards qu'ils peuvent se lancer parfois, pour s'amuser - alliés, unis pour gouverner le monde depuis des décades ?

«Les partisans du matérialisme historique cherchent toujours à accroître la part des facteurs économiques dans les conflits internationaux, au détriment des facteurs politiques et moraux », écrit bravement A. Roubaud, à la page 212 de son livre. Eh ! juste ciel, que vient faire ici le «matérialisme historique »? Et que p068 signifie ce balancement candide : "Sans doute... Mais enfin »? Le Monde est le Monde. Dites-nous : avant la guerre de 1914, il n'était pas tout à fait ce qu'il est devenu de 1920 à 1940. Mais il n'était déjà plus, de 1871 à 1914, ce qu'il avait été de 1848 à1870. Pourquoi ? Pour des raisons Politiques? ou morales? Eh non! pour des raisons économiques. Cela crève les yeux. 
Et je le répète : le dire en 1945, ce n'est pas servir l'intelligence et l'histoire. C'est, pour un Français, servir la France. p069 


\section{Pour la Synthèse contre l'Histoire-Tableau \\ UNE HISTOIRE DE LA RUSSIE MODERNE POLITIQUE D'ABORD?}

Dans une brève Préface, Ch. Seignobos présente au public français une Histoire de Russie en trois gros volumes ${ }^{13}$ — dont il a conçu l'idée et dirigé l'exécution avec Ch. Eisenmann, et, avant tout, avec Paul Milioukov, historien bien connu de la civilisation et de la pensée historique russe : œuvre collective d'hommes habitués à la pratique du travail historique et qui plus ou moins en délicatesse avec le régime actuel de leur patrie, ont voulu faire bénéficier leurs lecteurs français d'un savoir et d'une compétence incontestables.

Il faut applaudir à l'initiative prise par les directeurs. Nous n'avions en France, comme Histoire de Russie, que le manuel d'A. Rambaud, qui fut neuf en son temps: inutile de dire qu'il date aujourd'hui. C'est donc avec infiniment d'espérance qu'on se précipite sur les trois gros volumes que la Librairie Leroux a fait se succéder avec rapidité. Après quoi... Je ne veux pas dire que nous soyons déçus. C'est un gros mot. Mais il devient vite évident au lecteur que cette grosse tentative ne rendra pas, loin de là, tous les services qu'on en attendait. Si bien que, parfois, on se sent tenté de croire que les typographes se sont trompés en imprimant 1932 sur la couverture : d'instinct, on dirait 1902. Pourquoi ?

13 Paris, Ernest Leroux, 1932, 3 vol. in- $8^{\circ}$ de XX-438, 439-828, 829-1416 pages. Le titre annonce : Histoire de la Russie, des origines à 1918. En réalité, toute la période contemporaine, depuis la mort d'Alexandre II, est résumée en quelques pages. 
D'abord, l'Histoire de Russie proprement dite commence à la page 81 avec l'article de Miakotine qui introduit dans l'histoire de l'Europe orientale, aux environs du VII ${ }^{\mathrm{e}}$ siècle, les tribus slaves. Page $81, \mathrm{le} \mathrm{VII}^{\mathrm{e}}$ siècle ; p. 150, déjà, Ivan le Terrible (1533-1584); p. 267, Pierre le Grand! Récapitulons: une histoire p070 de 1416 pages, en trois volumes; 200 pages pour dix siècles $\left(\mathrm{VII}^{\mathrm{e}}-\mathrm{XVII}{ }^{\mathrm{e}}\right)$ contre 1140 pour deux siècles et demi (1682-1932)... Alors, quand on lit à la page XI la petite phrase de Ch. Seignobos assurant avec sérénité «qu'un équilibre judicieux a été maintenu entre les périodes successives aussi bien qu'entre les matières de différente nature », on a beau savoir que le préfacier cultive volontiers l'ironie, on ne s'en frotte pas moins les yeux...

Et le pis, c'est que Ch. Seignobos justifie ! Car on nous aurait dit : «Pardonnez-nous ! les temps sont durs ; les éditeurs sont terribles ; ils se sont mis en tête que l'histoire du monde (celle qui paie) commence en 1900 ; que voulez-vous faire là contre ?»- ou encore : « Nous sommes démunis de collaborateurs pour ces périodes qui requièrent de véritables spécialistes; excusez-nous...» — nous aurions gémi, parce qu'on nous privait ainsi de ce sur quoi nous comptions le plus. De ce dont nous avons un besoin évident ${ }^{14}$. Mais enfin, nous nous serions inclinés : force majeure! — Pas du tout ! Ch. Seignobos tient à plaider pour sa judiciaire. On ne vous dit rien, explique-t-il catégoriquement, parce qu'il n'y a rien à dire " faute de documents " en premier lieu et "faute d'événements » en second lieu... Ah! voilà qui ne fait plus l'affaire; et si c'est un système, souffrez que nous disions : il est détestable.

«Pas d'événements. » Alors, vous nous conviez à identifier, tout bonnement, " histoire » et « événement » ? Et, majestueusement assis sur cet immense fatras de papiers en sciure de bois, bleuis (et au bout de dix ans blanchis) à l'aniline que vous nommez vos « documents ", vous proclamez: "L'histoire de dix siècles est inconnaissable?» Pardon! Elle est tout ce qu'il y a de plus connaissable. Tous ceux qui

14 Qu'on rouvre le petit chef-d'œuvre de Henri Pirenne sur les villes au moyen âge, on y trouvera, rien qu'en relisant les pages, quelques exemples de ce à quoi peut servir l'histoire de Russie pour la compréhension d'un chapitre de l'histoire européenne médiévale... 
s'en occupent le savent, tous ceux qui s'ingénient non pas à transcrire du document mais à reconstituer du passé avec tout un jeu de disciplines convergentes s'appuyant, s'étayant, se suppléant l'une l'autre ; et votre devoir d'historien, c'est précisément de soutenir leur effort, de le décrire, de le promouvoir le plus possible ; ce n'est pas de justifier une paresse réelle et une courte vue regrettable en proclamant, du bout de lèvres dédaigneuses : «Rien à faire... »

Voilà pour l'équilibre entre les périodes. Mais le dosage des « matières », comme on dit en pharmacologie ? Il faut bien avouer qu'il n'est pas plus heureux. Politique d'abord ! il n'y a pas qu'un p071 Maurras pour le dire... Nos historiens font plus que de le dire; ils l'appliquent. Et c'est bien un système. C'est même, peut-être, un contre-système ? - Une fois de plus, Ch. Seignobos entonne le péan en l'honneur de l'histoire-tableau — qui est l'histoire-manuel. En voilà un homme que les années n'ont pas entamé ! Les auteurs, nous explique la Préface (p. X), « ont tenu à présenter un tableau historique de tous les aspects de la vie russe : régime politique intérieur et politique extérieure; mouvement de la population et organisation de la société ; agriculture, industrie et commerce ; lettres et arts, sciences et enseignement». Et plus loin, ce programme : "Présenter séparément et successivement les groupes de faits de natures différentes, politique, sociale, économique, intellectuelle. »-C'est ce que j'ai coutume d'appeler « le système de la commode », la bonne vieille commode en acajou, gloire des petits ménages bourgeois. Si bien rangée, et en si bel ordre! Tiroir du haut, la politique: «l'intérieure » à droite, "l'extérieure » à gauche, pas de confusion. - Deuxième tiroir: le coin à droite, «le mouvement de la population »; le coin à gauche, «l'organisation de la société ». (Par qui ? j'imagine par le pouvoir politique, qui du haut du tiroir $n^{0} 1$ domine, régit et gouverne tout, comme il sied.) - C'est une conception; et c'en est une aussi que de mettre "l'économie » après la « société »; mais elle n'est pas neuve. J'étais un petit jeune homme qui se cherchait tant bien que mal, quand parut, dans l'Histoire de France dite de Lavisse, le Seizième siècle de Henri Lemonnier. Je me souviens toujours de mon émoi candide (j'avais vingt ans !) quand je découvris avec horreur que l'auteur traitait, en bonne simplicité, des « classes » de la société avant de nous parler de la vie économique... Trente-cinq ans ont passé depuis; et nous mesurons le progrès en 
voyant qu'après avoir fourré, triomphalement, l'organisation de la société dans le second tiroir, l'Histoire de Russie loge dans le troisième... les phénomènes économiques ? non, mais en personne les trois vieilles elles-mêmes, les trois mamelles-sœurs, si vous préférez : l'Agriculture, l'Industrie et le Commerce que suivront les Lettres et les Arts. Oh ! comice agricole de Yonville ! Seulement, à Yonville, le Commerce venait en tête ; dans l'Histoire de Russie, on nous le met en queue. N'est-ce pas naturel, s'agissant d'un pays où, j'imagine, il a dû consister d'abord... à vendre, tant sur place qu'à l'étranger, les produits d'une agriculture travaillant de bonne heure pour l'exportation, et d'une industrie marchant sur ses traces ? - Histoiretableau, ce sont là de tes coups... p072

En fait, nous n'avons pas une Histoire de Russie. Nous avons un Manuel d'histoire politique de la Russie de 1682 à 1932, avec, en tête, une Introduction de quelque 200 pages, qui comporte un Rückblick sur la Russie avec Pierre le Grand. Dans ces limites tout va. Et il faut nous dire contents de ce qui nous est donné. Il est évident que, dans le cadre traditionnel des règnes, les collaborateurs de Paul Milioukov et Milioukov lui-même ont su composer un récit très précis et suffisamment nourri des «événements» de l'histoire russe événements politiques, avec des excursus plus ou moins brefs sur les événements économiques, sociaux, littéraires et artistiques dans la mesure où ils sont commandés par l'action politique des gouvernements. Mais...

Mais voilà : vous avez devant vous la Russie. Moi, je ne la connais pas de visu, comme disait cet autre, je ne l'ai jamais étudiée spécialement; tout de même, je me représente que la Russie, l'immense Russie terrienne et paysanne, féodale et orthodoxe, traditionnelle et révolutionnaire, c'est quelque chose d'assez puissant ? - Or, j'ouvre l'Histoire de Russie : tsars falots, échappés d'Ubu Roi ; tragédies de palais; ministres concussionnaires; bureaucrates-perroquets; oukazes et prikazes à discrétion. Mais la vie forte, originale et profonde de ce pays; la vie de la forêt et de la steppe, le flux et le reflux des populations mouvantes, la grande marée au rythme irrégulier qui par-dessus l'Oural déferle jusqu'à l'ExtrêmeOrient sibérien; et la vie puissante des fleuves, les pêcheurs, les bateliers, le transit; et la pratique agricole des paysans, leurs 
instruments, leur technique, la rotation des cultures, le pâturage ; l'exploitation forestière et le rôle de la forêt dans la vie russe; le fonctionnement du grand domaine; la fortune terrienne de la noblesse et son mode de vie; la naissance des villes, leur origine, leur développement, leurs institutions, leurs caractères ; les grandes foires russes ; la lente constitution de ce que nous nommons une bourgeoisie - mais y eut-il jamais une bourgeoisie en Russie ? - la prise de conscience par tout ce monde d'une Russie évoquant en eux quelles représentations précises et de quel ordre? ethnique? territorial? politique ? le rôle de la foi orthodoxe dans la vie collective russe et, s'il y a lieu toutefois (s'il n'a pas lieu, dites-le), dans la formation individuelle des consciences; les questions linguistiques; les oppositions régionales et leurs principes - que sais-je encore ? Sur tout cela, qui se pose devant moi sous forme de points d'interrogation, sur tout cela qui pour moi est l'histoire même de Russie : si peu que rien, dans ces 1400 pages. Suis-je un anormal, un phénomène de foire, un monstre? Mais $\mathrm{M}^{\text {me }}$ de Krudner p073 et ses rapports avec Alexandre, et cette tsarine qui était fille d'un cabaretier, et cette autre qui aimait les beaux hommes, et tout ce fatras anecdotique : non, ce n'est pas cela l'histoire.

L'histoire, c'est ce que je ne trouve pas dans cette Histoire de Russie qui de ce fait naît morte.

Et faut-il le dire encore, bien que ce soit délicat? Pas assez d'ouvertures, peut-être, sur le présent et l'avenir russes.

Un bref chapitre expose ce qui s'est passé en U. R. S. S. depuis octobre-novembre 1917. Effort vers l'objectivité certain. J'ajoute méritoire, puisque ces pages sont signées Milioukov. Mais précisément, à Milioukov, qui fut acteur dans la tragédie, était-il bien indiqué de demander ces pages? De quoi s'agissait-il ? De faire comprendre. Rien de plus, rien de moins. Or pas de compréhension véritable, en dépit de tous les efforts, là où il y a marque de sympathie nécessaire et fatale.

Si nous voulons savoir ce qui vraiment anime les hommes qui depuis seize ans ont la rude charge de piloter la barque de l'U.R.S.S. sur des flots terriblement agités - les hommes qui louvoient, tirent des bordées, hésitent, se heurtent et parfois s'entre-détruisent, mais 
tiennent le coup, et tout de même pétrissent avec une belle puissance la pâte humaine - nous le demanderons à dix observateurs français, anglais, américains ou autres, qui ont vu et font voir, d'ailleurs se contredisent (heureusement!) sur beaucoup de points, mais s'accordent sur d'autres - et tous laissent une impression de vie, de force, d'action tendue et de volonté créatrice qui, faut-il le dire, satisfait l'esprit : car enfin, expliquer l'histoire par du néant, c'est une gageure ? On ne demandera à l'Histoire de Russie sur tout cela — qui, encore une fois s'appelle pour moi l'histoire - en ne lui demandera, une fois de plus, qu'un précis d'événements politiques, vus par un de leurs acteurs. p074 
Contre le Vain Tournois des Idées

UNE ÉTUDE SUR L'ESPRIT POLITIQUE DE LA RÉFORME

$\underline{\text { Retour à la table des matières }}$

Un gros livre, récemment publié chez Picard, m'a été adressé avec prière $d$ 'en rendre compte dans cette Revue ${ }^{15}$. Me voici bien embarrassé. Car il est l'œuvre d'un esprit curieux, désireux de comprendre et que l'histoire des idées intéresse par elle-même. Il témoigne, par ailleurs, d'un labeur considérable, de lectures sérieuses et étendues, de réflexions et de méditations prolongées. Mais, en vérité, je suis aussi mal fait que possible pour en parler ici.

M. de Lagarde a fait imprimer un volume de 486 pages. C'est beaucoup, semble-t-il. Qu'on songe cependant à ce qu'il prétend embrasser ? Voici l'Introduction : elle traite de «la pensée politique au moyen âge »; ce n'est pas un petit sujet. Voici le chapitre I : «Le point de vue politique de la Réforme » et M. de Lagarde d'y passer en revue, tour à tour, la pensée politique de Luther, de Zwingli, de Calvin, celle des paysans d'Allemagne révoltés en 1525 (il les nomme, je ne sais pourquoi, les Rustauds, du nom qu'on leur a donné en Lorraine); il n'oublie ni la pensée politique des anabaptistes, ni celle des monarchomaques : de quoi, proprement, donner le frisson. - Après quoi, il s'attaque à la théorie du Droit chez les réformés ; à leur conception de l'État; à leur notion de la Souveraineté. — Puis il cherche à déterminer la place que tiennent les idées individualistes dans la philosophie et l'ecclésiologie des réformateurs. Et c'est, à 15 Georges DE LAGARDE, Recherches sur l'esprit politique de la Réforme, Paris,
Picard, 1926, in-8 $8^{\circ}$. 
nouveau, le défilé de quelques menus problèmes: libre examen; liberté chrétienne ; sacerdoce universel... Comprend-on le sentiment de malaise que j'éprouve en fermant ce livre ? Le sujet est de ceux que, selon ses goûts et ses talents, on traite en 200 pages, sans p075 notes, quand on y a réfléchi vingt années. Ou alors, en six volumes de 500 pages, quand on y a donné sa vie.

Ce n'est pas seulement parce que, sur tant de questions dont chacune a de quoi effrayer un historien par son ampleur, M. de Lagarde, malgré toute sa bonne volonté, ne peut nous apporter que des considérations de surface. Il s'agit là, pour moi, d'une question de méthode. Ce livre est bâti sur un certain nombre de livres. Choisis, naturellement, et avec beaucoup de conscience — tout de même arbitrairement - sur les kilomètres de rayon de ces bibliothèques formidables : la luthérienne, la zwinglienne, la calvinienne, pour ne point parler des autres. Ayant lu ces livres, M. de Lagarde leur a appliqué les ressources d'une intelligence claire, lucide et loyale. Comme il le dit dans une formule très nette : «Groupant les matériaux anciens, j'ai essayé de comprendre. »C'est là que gît la difficulté.

Comprendre ? On peut comprendre en saisissant d'une prise directe, dans des livres, les idées politiques des réformateurs, en les comparant, en notant leurs combinaisons possibles, leurs contradictions inaperçues, leurs conséquences probables. Mais ce n'est pas là ce qu'un historien appelle comprendre. Pour lui, comprendre, ce n'est pas clarifier, simplifier, réduire à un schéma logique parfaitement net: tracer une épure élégante et abstraite. Comprendre, c'est compliquer. C'est enrichir en profondeur. C'est élargir de proche en proche. C'est mêler à la vie.

Dans le cerveau de Luther (mais Luther n'est-il qu'un cerveau ?), dans le cerveau de Zwingli, dans celui de Calvin (et la même question préjudicielle se pose, ici aussi), circonscrire d'un coup de bistouri bien tranchant le compartiment des «idées politiques»; - l'enlever ensuite, en le séparant de tout ce qui l'entourait, de tout ce qui l'encadrait, en coupant les artères et les nerfs qui lui donnaient la vie - et puis, décrire cette chose morte comme si la vie ne s'en était point retirée : jamais un historien n'adhérera à semblable méthode. Bien que, depuis des années, elle soit appliquée avec le plus grand 
succès académique, par des hommes qu'on considère (et qui se considèrent) comme des maîtres. Mais à lire leurs écrits - ceux dont s'est inspiré M. de Lagarde — on sent précisément un malaise qui vous confirme dans l'idée qu'on est « historien »... - On voit dès lors d'où vient mon embarras à rendre compte du livre de $\mathrm{M}$. de Lagarde.

Qu'on l'ouvre à la première page. Elle contient le sommaire de l'Introduction. Et ce sommaire débute ainsi : «Les trois sources de la pensée politique du moyen âge : la philosophie scolastique ${ }_{\text {p076 }}$ et la théologie; le Droit romain et les légistes; les Canonistes. » — Eh quoi ! ce sont là les sources de la pensée politique du moyen âge, les seules, et il n'y en a pas d'autres ? Cette pensée ne se nourrissait que de livres, ou plutôt de manuscrite, de traditions livresques et de spéculations doctrinales? Les hommes de ce temps, murés dans des bibliothèques hermétiquement closes aux bruits du dehors, ne s'inspiraient que de ces «traditions», l'enseignement des jurisconsultes romains et la tradition patriotique ? J'entends que M. de Lagarde ajoute : "Collaboration des idées et des faits. 》 J'entends qu'il indique, page 13, que "plus encore que dans les Universités, c'était sur les champs de bataille et dans les chancelleries que la renaissance de l'État s'était produite ». Mais il y a bien autre chose que les champs de bataille, et que les chancelleries, dont il faut tenir compte - si l'on veut « comprendre ».

Et pareillement: Luther, Zwingli, Calvin, les anabaptistes, les paysans, les monarchomaques, tous à la fois, tous dans le même sac, si j'ose dire, tous représentants de cette abstraction personnifiée, la Réforme ? Quand je lis le petit raccourci d'histoire des pages 114115 : «le monde réformé » disloqué et dépourvu d'orientation en 1530, parce que Luther est absorbé par l'organisation de l'Église de Saxe, Zwingli défait à Cappel, Strasbourg occupé par des docteurs divergents; et puis brusquement, alors que « la Réforme s'émiettait», Calvin surgissant: "Avec Calvin s'ouvre une nouvelle phase de son histoire... La Réforme se reprend et s'organise autour d'une doctrine plus intellectuelle. Elle se dessèche, mais se fortifie d'autant. Elle rompt avec l'esprit du luthéranisme indécis et diffus », etc. — J'ai peur de ne plus comprendre. Quoi ? Calvin fut donc le fossoyeur du luthéranisme ; ce fut lui, " de sa main latine », qui ensevelit le buveur de bière de Wittemberg ? Quelle imagination! Mais visiblement, M. 
de Lagarde ne se soucie pas, dans son livre, de rechercher les origines profondes, singulièrement hétérogènes cependant, de la Réforme française, de la Réforme allemande, de la Réforme zurichoise - pour employer des dénominations ethniques qui ne sont pas plus satisfaisantes que les dénominations de personnes. Je ne crois pas que le nom de Lefèvre d'Étaples soit cité dans tout son livre. La Réforme, pour l'auteur, il semble que ce soit une invention de Luther, de l'Allemand Luther, qui frappa d'admiration le Suisse Zwingli ; quand il arriva à ces deux protagonistes des malheurs qui menaçaient de dislocation la Réforme, la seule, l'unique, — alors, parut Jean Calvin qui la sauva pour un temps, en la latinisant. p077 Que voilà donc vraiment, en 1926, une étrange conception ! Où est donc, dans tout ce livre, le souci des milieux si différents, dans lesquels ont baigné des hommes, eux-mêmes aussi différents par leur naissance, leur origine sociale, leur formation, leur nationalité, leurs expériences vécues, leur époque même, qu'un Luther, un Zwingli, un Calvin... ? Et comment les « comprendre », ces hommes, si on les abstrait ainsi de tout ce qui les explique — de tout ce qui nous rend compte, à la fois, de leurs ressemblances profondes et de leurs différences radicales?

Commentant dans une note (p. 114) un texte bien connu de Florimond de Raemond, M. de Lagarde nous dit que «Strasbourg était le refuge de tous les adeptes français du luthéranisme ». C'est nous qui soulignons cette curieuse formule. On ne s'étonne pas de la rencontrer sous la plume de Josse Clichtoue ou de notre maître Béda : c'était de bonne guerre. Mais ici, dans ce livre? Tous les adeptes... C'est beaucoup. Ou bien peu. Car, après tout, quels ont été les réfugiés français de Strasbourg, ceux qui comptent? Lefèvre d'Étaples ; Gérard Roussel ; Guillaume Farel ; Jean Calvin. Auquel de ces quatre hommes, si dissemblables du reste, s'appliquerait correctement la formule de M. de Lagarde: «adeptes français du luthéranisme »? - On comprend maintenant, j'imagine, la nature des réserves, préjudicielles en quelque sorte, que nous inspire le livre de M. de Lagarde. Réserves de méthode et, si l'on veut, de principe. Réserves d'instinct pour un historien appliqué à cultiver en lui le goût et le sens des différences spécifiques - si fécondes.

On me dira que je m'appesantis bien longuement sur un livre dont la conception plus que l'exécution soulève des critiques - mais des 
critiques qui n'ont rien de spécial à l'auteur. — Peut-être. Mais il y a tant d'ardeur et de bonne volonté dans ce gros volume qu'on s'irrite de voir gaspiller des forces qui, concentrées sur un objet bien délimité, choisi sans excès d'ambition ni de timidité, aurait pu produire d'excellents effets.

Quant à discuter les thèses de l'auteur, je viens de dire précisément pourquoi je ne m'y sens pas enclin. Je ne suis pas controversiste. Je m'efforce d'être historien. Et je n'incrimine point les intentions de M. de Lagarde, mais, encore une fois, sa méthode. Voilà trente ans pour ma part que j'étudie avec passion le XVI ${ }^{\mathrm{e}}$ siècle. Sur tous les sujets, si nombreux, si énormes, si prodigieusement variés qu'aborde tour à tour, avec une belle intrépidité, M. de Lagarde, empressé à courir de Gerson à Grotius sur les traces de Figgis — je ne suis pas à court

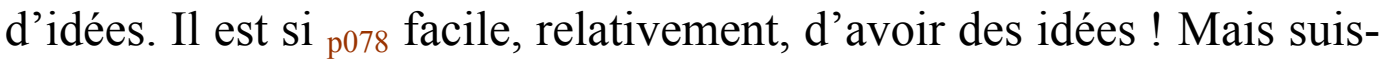
je certain de «comprendre »? Je ne nourris pas une illusion aussi grossière.

Des idées qui ne sont que des idées - il peut être agréable de les choquer contre celles d'un galant partenaire, quand on se sent en veine de discussion; en être la dupe soi-même, voilà le vrai péril - même lorsqu'on les étaie, selon des recettes connues et faciles à suivre en voyage, sur quelques-unes de ces citations qui ne disent rien parce qu'elles disent tout, et qu'arrachées hors de leur milieu elles demeurent sans racines, comme vidées de leur sève. L'individualisme n'est pas «l'axe de la révolte des réformateurs», affirme, assez bizarrement, M. de Lagarde. Cette proposition me paraît aussi vraie, et du même genre de vérité que la proposition diamétralement opposée. Flatus vocis. Il s'agit de comprendre. Je ne dis pas seulement de définir ce qu'on entend par individualisme, mais de comprendre les hommes de la Réforme. Et si on comprend vraiment en profondeur un Luther et un Calvin ; si on comprend ce qu'étaient la foi et l'intensité du sentiment religieux qui les brûlait; si on restitue, derrière les phrases qu'ils ont proférées, les sentiments qui les ont mus, les idées qui les ont déterminés - comme ces controverses, ces chocs d'idées, ces dilemmes triomphants, tout l'arsenal d'une dialectique juridicoscolastique périmée à l'heure même où elle se croit en pleine prospérité - comme tout cela, en vérité, paraît oiseux ! Écrire que « tout le message tapageur de liberté » des réformateurs « se réduisait, 
en définitive, au droit de secouer le joug romain pour trouver un autre maître » - c'est montrer simplement à quel point on se soucie peu de descendre dans l'intimité de la conscience luthérienne. C'est commettre exactement le genre de méprise dont $\mathrm{M}$. de Lagarde fait grief aux naïfs qui prennent Luther pour « le père du libre examen et de la raison moderne $»$.

En fait, pour m'intéresser à ce choc de formules qui retient l'attention de M. de Lagarde, il faudrait que je dépouille toutes mes habitudes d'esprit. Ou alors que, me sentant dans la main d'un de ces guides introuvables qu'on ne rencontre qu'une fois ou deux dans sa vie, et qu'on suit avec délices, mais non sans un secret effroi - je sois tenté de faire à mes joies de lettré le sacrifice temporaire de mes scrupules d'historien. p079 
Ni Histoire à Thèse ni Histoire-Manuel

ENTRE BENDA ET SEIGNOBOS

$\underline{\text { Retour à la table des matières }}$

C'est un fait assez curieux, si l'on y réfléchit, que l'espèce de timidité avec laquelle, pendant un demi-siècle, en France, des historiens de valeur ont fui, ne disons pas les " grands sujets» - la formule a de fâcheuses résonances académiques - les amples sujets si l'on préfère, ceux qui débordent le cadre étroit de la monographie.

$\mathrm{Ne}$ cherchons pas longuement les causes de cette carence. Il faudrait, pour les découvrir, entreprendre l'histoire de l'histoire en France, depuis plus d'un demi-siècle. Relevons simplement un des signes frappants de ce renoncement : l'absence d'Histoires de France au sens traditionnel du mot.

Rien d'individuel, rien de collectif non plus. La dernière tentative, celle de Lavisse, a pu réussir en librairie, elle a pu susciter un chefd'œuvre authentique, le Tableau géographique de Vidal de la Blache : elle n'en a pas moins produit un ouvrage sans unité de conception, partant sans vie - une collection de volumes bornant leur ambition à munir les candidats de notions utilitaires. De celles-là et non d'autres. De sorte que, si le public proprement dit a été induit à acheter ces volumes - ce fut abus. Ils ne répondent que mal aux vraies curiosités pragmatiques, ils étaient incapables d'en susciter de neuves, d'élargir l'horizon de lecteurs cultivée en les mettant au fait du labeur que, silencieusement, les meilleurs travailleurs poursuivent, loin des lieux où l'on parle trop. 
Sur quoi, il est plaisant d'entendre nos historiens crier : «On nous ignore ! on nous met à l'écart ! » et cependant les éditeurs gorgent de 《 vies romancées », d' " indiscrétions de l'histoire », de « dessous » et de "révélations » frelatées un public avide d'être trompé. Voire. Mais d'abord vos griefs contre tout ce fatras p 080 paraissent sans fondement. Erreurs, dites- vous : ce n'est pas la question. Petits et gros livres qui vous échauffent si fort, seraient-ils d'une admirable exactitude quant aux dates et aux faits : en quoi cette correction devrait-elle désarmer les critiques? Reprochez-leur d'entretenir dans le public l'illusion qu'ils sont «de l'histoire » et que l'histoire, précisément, c'est ce qu'ils contiennent : illusion que partagent même de bons esprits ${ }^{16}$. Et pour que vos reproches portent, faites vous-même de l'histoire, de la véritable histoire, non pas dans vos arrière-bibliothèques et pour vingt spécialistes : devant le public, en public. On vous demande du passé intelligible, de l'Humanité vive et vraie : cessez de nous tendre des mémentos scolaires.

Or, devant moi, deux petits volumes, du format des romans ${ }^{17}$. L'œuvre, et d'un essayiste qui volontiers tente des voies nouvelles; et d'un professionnel réputé de la pédagogie historique. Tous deux, à quelques semaines d'intervalles, nous offrent une Histoire de France. Oh! avec des scrupules que les mots traduisent : Esquisse ici, et là Essai ; mais enfin en grosses lettres noires ou rouges, on lit bien: Histoire des Français, et puis Histoire de la nation française. La prescription serait-elle interrompue ? Voyons, sans préjugé.

I.

L'essayiste, Julien Benda. Inutile de rappeler son goût pour les batailles d'idées. Cette fois c'est aux historiens qu'en a l'analyste, un peu chagrin, de la Fin de l'Éternel. Il leur reproche, lui aussi, leurs

\footnotetext{
16 Faut-il rappeler les retentissantes attaques de Paul Valéry (Regards sur le monde actuel, 1931) dirons-nous contre 1'histoire ? Contre ce que le grand public nomme histoire, oui bien ; mais l'histoire, est-ce cela ? Voilà la vraie question.

17 Julien BENDA, Esquisse d'une histoire des Français dans leur volonté d'être une nation, Paris, Gallimard, 1932, 271pages in-16. — Charles SEIGNOBOS, Histoire sincère de la nation française, essai d'une histoire de l'évolution du peuple français, Paris, Rieder, XII-520 pages.
} 
silences et, parmi tant de grands sujets sur quoi ils se taisent, leur en signale un, qui ne manque point d'envergure.

Une grande nation - et nommément, cette nation française dont l'histoire se développe sur plus de vingt siècles déjà — comment s'est-elle faite à travers les siècles ? Ce n'est pas seulement le problème du patriotisme, sur quoi nous continuons à ne rien posséder que des déclamations ou des indications mal reliées. C'est le problème fondamental de la nation, pris corps à corps et d'une poigne vigoureuse. Qui l'a forgée, sur l'enclume ${ }_{\mathrm{p} 081}$ des siècles ? Ses chefs, ses rois, comme on le dit souvent? Ou bien, formant corps et groupe, la totalité de ses membres animés d'une obscure mais puissante volonté collective ? « La formation actuelle des Français en nation, répond $\mathrm{M}$. Benda (p. 16), est le résultat d'une volonté qu'ils eurent, et qu'ils eurent de bonne heure - et non, comme l'enseigne une certaine école, d'une série de transformations effectuées par eux, en quelque sorte mécaniquement, sous la pression de forces extérieures et en dehors (du moins pendant de longs siècles) de toute tendance, même inconsciente, vers l'organisme qu'ils nous présentent. »

On voit l'ampleur de la proposition et tout ce qu'elle engage. Mais J. Benda ne prétend pas retracer les faits dans leur détail. Il n'est pas historien, il le dit sagement. Son dessein ? Émouvoir les historiens ; les amener à faire le travail qu'il esquisse ; surtout, leur en faire saisir la nécessité. Il y aurait une manière absurde et déloyale de critiquer son livre : ce serait de l'éplucher page par page, avec l'âpreté du petit boutiquier d'histoire qui craint la concurrence. - Il y en aurait une autre, parfaitement légitime celle-là : reprendre son esquisse trait par trait, approuver, critiquer, corriger, remanier... Mais ce serait vouloir, pour son compte, brosser une " Histoire des Français ». - Bornonsnous à un examen de méthode et d'idées, à quoi nous invite l'auteur même. Sa thèse, croit-il (p. 32), rencontrera «deux sortes d'opposants »: ceux pour qui l'histoire n'est œuvre que des individus ; et ceux qui déclareront : " Passe pour les temps modernes ; mais pour le moyen âge, et le haut moyen âge, et les origines : non, mille fois non ». - Pardon, mais je demande à m'inscrire dans une troisième catégorie. 
Je ne suis pas de ceux pour qui l'histoire " n'est œuvre que des individus ». Elle est, à mon sens, l'œuvre des individus et des groupes, pour prendre à dessein un mot très général. L'individu historique — je m'en suis expliqué ailleurs ${ }^{18}-1 \mathrm{e}$ personnage historique plus exactement, se développe dans et par le groupe. Il s'en dégage un temps, et du doigt lui montre des chemins nouveaux. Mais pour accomplir son œuvre - celle d'un ferment qui fait lever la pâte humaine - il faut bien qu'il se replonge en elle, le plus tôt possible, qu'il se réincorpore au groupe ; et alors, usant du langage courant, nous disons repli, voire recul. Repli que l'évadé temporaire effectue par lui-même; ou par ses p082 disciples; ou par sa doctrine que la masse, après un refus plus ou moins long, suivi parfois d'un semblant d'acceptation littérale, ne s'assimile finalement qu'après l'avoir remaniée, repensée à sa mode, rendue telle qu'elle puisse, précisément, se l'assimiler...

Et je suis encore moins de ceux qui vous disent, avec ingénuité : tout ce qui vit et compte dans l'histoire de l'Humanité date du " début des temps modernes ». Je crois comprendre un peu notre $\mathrm{XVI}^{\mathrm{e}}$ siècle. Je pense que si j'ai pu donner de lui, sur quelques points, une représentation plausible, c'est parce que, de toutes mes forces, toujours, j'ai réagi contre l'idée puérile qu'il était «un commencement ».

Mon attitude est simple. Je voudrais penser que c'est l'attitude même de l'historien. Devant moi, une thèse. Une thèse métaphysique, précise-t-on ${ }^{19}$. Peu m'importe. Je n'y vois, pour ma part, qu'une

18 L'individualité en histoire, le personnage historique (Troisième Semaine internationale de Synthèse), Paris, Alcan, 1933, in-16, p. 123-138). Je rappelle aussi tout ce qui, dans Un destin, Martin Luther (Paris, Rieder, 1928, in-16; $3^{\mathrm{e}}$ éd., Paris, Presses Universitaires, 1951, in- $8^{\circ}$ ), a trait au problème des rapports du personnage historique et de la collectivité en Histoire.

19 Cette volonté d'une collection d'hommes que j'assimile à une volonté individuelle, qui transcende les volontés de ses parties... est éminemment un produit du pouvoir abstracteur de mon esprit, une notion d'ordre métaphysique. Elle existe nécessairement chez tout homme qui parle de l'histoire de la France, de la « volonté séculaire de la France »... encore que ceux qui tiennent ce langage professent parfois le plus hautain mépris pour les notions abstraites, et prétendent « ne connaître que des faits ». Notre seule valeur en cet écrit est peut-être que, y étant métaphysicien, nous savons que nous le sommes » (Brenda, p. 39). Notons simplement, en passant, qu'entre les deux formules, «l'histoire de la France » et 
hypothèse de travail. Et je me mets à la besogne avec mes outils et la technique de mon métier. Quoi, pour ou contre ? Façons grosses de parler. Sous quelles conditions, historiquement parlant, et à quelles conditions l'hypothèse peut-elle être considérée comme répondant à une réalité ? Voilà le problème.

« Je crois, dites-vous, que la volonté de former une nation a existé en France non seulement dans les temps derniers, dans les siècles modernes, mais bien avant.» $\mathrm{Ni}$ "votre croyance», ni «l'incroyance» de vos contradicteurs n'importent. Montrez-nous comment la chose a pu, ou n'a pas pu se faire, et nous vous suivrons.

«Je n'en ai d'autre preuve, articulez-vous (p. 34), que le contentement qu'au dire des historiens les Français semblent avoir manifesté chaque fois que se réalisait une des conditions par lesquelles se formait peu à peu la nation: rassemblement de territoires, progrès de l'autorité centrale, soustraction à la mainmise de l'étranger. » Je m'arrête net à ce dernier mot : l'« étranger », serait-ce donc une notion constante à travers toute l'histoire d'un pays comme la France ? La « mainmise de l'étranger » - ${ }_{\mathrm{p} 083}$ ailleurs, J. Benda (p. 16) parle de « la résolution que forme l'étranger de prendre leur terre aux Français $»$ - cette mainmise, comment les Français, aux diverses époques, pouvaient-ils vraiment se la représenter? Telle quelle, avec le cortège d'idées juridiques et politiques précises qui l'accompagnent nécessairement dans nos esprits, cette formule peut-elle traduire les façons de voir et de sentir, tout aussi bien des contemporains de Clovis que des soldats de l'an II, des sujets de Charlemagne et des poilus de 1914? Et ces autres formules, si claires pour nous, rassemblement de territoires et progrès de l'autorité centrale: dans une « Histoire de France» des origines à nos jours, ne masquent-elles point l'absence d'autres formules, les seules intelligibles pour des générations entières de ces Français «qui ont fait la France»: soumission au naturel seigneur, respect religieux de la personne sacrée

« la volonté séculaire de la France»,il y a une faille. Elles ne soulèvent pas les mêmes questions, l'une et l'autre. 
du roi, parentés senties de coutumes, de parlers, de fréquentations, de dévotions, etc. ?

Analysez, encore une fois. Dressez exactement vos tables d'absence et de présence. Vous n'êtes pas devant le Sphinx. Vous ne serez pas mangé si vous ne trouvez pas le mot. Mais votre travail sera vain, votre coup d'épée ne tranchera que l'eau claire, si vous nous demandez, à nous, historiens, de résoudre des problèmes historiques à coup d'affirmations logiques, — ou encore, par l'appel au vieux fonds d'une "psychologie de nation » supposée immuable à travers vingt siècles, mais non par l'étude des réactions particulières aux hommes des diverses époques, étudiées en elles-mêmes et pour elles-mêmes. Réactions humaines, c'est entendu, et l'homme demeure l'homme. Réactions de groupes où, le plus souvent, nous comptons nos ancêtres et qui, par conséquent, nous sont proches parents dans le temps. Mais dans le temps, et mutatis mutandis : or, ce qu'il y a à «muter » est énorme, et cette vaste marge entre passé et présent, c'est là précisément notre domaine, notre champ de fouille et d'action.

« Nation », écrivez-vous. Mais quoi, nation? De quand date le mot? Quels synonymes lui ont fait cortège ? Et comment les distinguait-on de lui ? Surtout, derrière ces mots, quelles réalités les Français ont-ils entassées successivement? Tant que vous n'avez pas dit, ou essayé de dire cela, nous n'avez rien dit pour un historien. Vous avez seulement renforcé la tendance à prendre les mots les plus clairs, aujourd'hui, pour les hommes d'aujourd'hui, comme autant de véhicules confortables et sûrs pour remonter, bien assis, le cours des siècles, sans avoir besoin de changer jamais de place, ou de voiture. Constantes historiques, j'entends bien. Je n'oppose pas du tout l' " atomisme » de celui-ci ${ }_{\mathrm{p} 084}$ au « continuisme » de celui-là. Mais les constantes historiques, il y a deux façons de les mettre en lumière. L'une, la métaphysique ; celle de Bossuet si l'on veut, puisque Benda allègue Bossuet ${ }^{20}$. L'autre, l'historique. Quand nous recherchons ce que pouvait être, pour un homme du XIII ${ }^{\mathrm{e}}$ siècle ou du $\mathrm{XVI}^{\mathrm{e}}$, l'équivalent des idées, des sentiments, des réactions de toute espèce que signifie pour nous, hommes de 1933, la formule : « résistance à la

20 « Le continuisme systématique de Bossuet n'est peut-être pas une plus grande erreur que l'atomisme non moins systématique de Stendhal » (ouvr. cité, p. 45). 
mainmise de l'étranger », ou encore «à la résolution formée par l'étranger de prendre leur terre aux Français" - nous ne méconnaissons pas une constante. Nous refusons, simplement, de mettre un anachronisme à la base d'une continuité. Nous repoussons la solution de facilité donnée au vrai problème : comment au sein d'un même agrégat humain, sous quelles formes successives au cours des âges, à travers quels ensembles mouvants de sentiments et d'idées, se sont exprimées des volontés élémentaires - qu'il ne s'agit pas de promener, revêtues d'oripeaux modernes, à travers toute l'histoire changeante des âges disparus.

$\mathrm{Au}$ total, nous autres gens de métier, comment prendre ce livre plein de curiosités intelligentes, et rédigé par un évêque du dehors à l'intention, en partie, des clercs de l'histoire?

D'abord comme un document sur l'état d'esprit d'un certain public cultivé. Julien Benda «n'admet pas» (p. 8) l'objection qu'un grand historien, « en raison même du nombre immense de faits de toute nature qu'il sait, n'acceptera jamais de les réduire à une idée simple ». Et il ne conçoit pas qu'un « grand esprit scientifique » puisse, quand il en a les moyens, renoncer délibérément à exprimer sa philosophie de savant; il n'estime pas qu'un grand historien « trahisse », s'il exprime sa philosophie de l'histoire, avec «ce qu'elle comporte nécessairement d'arbitraire et de poétique ». N'épluchons pas ces formules. N'en retenons que le sens général. Elles justifient ce que nous écrivions au début de cet article.

Le livre de Benda, c'est autre chose encore: une invitation à réfléchir sur l'intervention, fréquente et grave dans l'histoire, d'un certain genre de facteurs historiques « dont les historiens ne font peutêtre pas assez d'état» (p. 42). Entendez, par exemple, ces volontés de groupes qui « transcendent la volonté des membres du groupe ». Il est vrai. Il y a là un gros problème. p085 
Et je l'ai dit bien des fois, pour ma part ${ }^{21}$ : ceux qui ne prétendent connaître que « les faits »; ceux qui ne se rendent pas compte qu'une grande partie des faits qu'ils utilisent ne leur est pas «donnée » à l'état brut, mais se trouve créée, inventée en quelque sorte par le labeur d'érudition, dégagée de centaines et de centaines de témoignages, directs ou indirects ; ceux qui, dès lors, paresseusement, ne se soucient que des faits enregistrés dans des documents tout établis, ces historiens qui se déclarent prudents et ne sont que bornés, se placent en réalité hors des conditions primordiales de leur métier.

«La question de savoir avec quels sentiments la population moyenne dans les diverses provinces a accueilli sa réunion à la France est le type de la question qui, ayant pour sujet une humanité obscure et anonyme, n'est pas traitée par l'historien. » Prêtons attention à ces paroles de J. Benda (p. 12, n. 1). Certes, je ne crois pas que, si nos histoires de réunion sont des histoires politiques, diplomatiques et militaires avant tout, c'est parce que les masses, les hommes « obscurs et anonymes " sont particulièrement difficiles à connaître dans l'intimité de leurs sentiments ${ }^{22}$. Pense-t-on que nous soyons mieux assurés lorsqu'il s'agit des grands, et qu'il faut démêler ce qui pouvait les mouvoir dans un sens ou dans l'autre: ambitions territoriales, rancunes familiales, liens de clientèle, hérédités de loyalisme ou de rébellion?

En fait, les historiens se taisent parce que les textes ne leur donnent pas de réponses toutes faites. Parce qu'ils ont trop l'habitude, non d'en extraire ce qu'ils ne livrent pas d'emblée, mais d'y puiser ce qu'ils offrent, comme ils l'offrent. S'il y avait dans les archives départementales des dossiers constitués administrativement par des préfets du temps de Philippe-Auguste ou des procureurs généraux du temps de Louis XI, et portant sur le plat, en belle ronde, l'inscription : "État de l'opinion publique», les historiens auraient depuis longtemps traité la question avec cette sorte d'empressement indifférent qu'ils mettent à accepter les sujets tels qu'ils leur sont

\footnotetext{
21 Notamment, dans l'article History de l'Encyclopcedia of the Social Sciences, article écrit en collaboration avec Henri BERR.

22 C'est cependant l'avis de Ch. Seignobos: voir plus loin l'amorce d'une discussion.
} 
offerts. Mais il est très vrai qu'ils sont passifs, trop souvent, devant les documents, et que l'axiome de Fustel (l'histoire se fait avec les textes) finit par revêtir pour eux un sens délétère. Par prêcher la paresse d'esprit et la passivité.

L'histoire se fait, d'abord, avec le sens et la passion de l'histoire : avec cet ensemble d'aptitudes spéciales qui, seul, qualifie pour le bon exercice d'un métier intellectuel. Et c'est chose p $086_{6}$ étrange qu'on en convienne s'il s'agit d'un mathématicien, voire d'un philosophe ; mais qui donc, dans nos Universités, a jamais réussi (s'il y a pensé) à décourager un «inapte à l'histoire »; et ne paraît-il pas naïvement scandaleux à beaucoup d'exiger, avant tout, d'un historien « le don »?

Esprit d'abord, culture ensuite. L'histoire ne se fait pas sans un minimum de connaissances positives parfaitement adaptées aux besoins de l'historien. Et, j'ajoute, sans un matériel dont nul n'a le droit de donner préventivement un inventaire limitatif, - parce que, précisément, l'une des formes de choix de l'activité historique consiste à multiplier ses éléments, à découvrir que, quand on n'a pas de textes, on peut tirer beaucoup de l'étude sagace des noms de lieux; ou de l'examen comparé de certains groupes de mots; ou encore, de la répartition des types de sépulture, de l'expansion d'un mode de construction, de la répartition des noms de saints portés par des églises, de rites religieux, de formules juridiques, de cérémonies ou d'usages, que sais-je encore? — S'ingénier. Etre actif devant l'inconnu. Suppléer et substituer et compléter: travail propre de l'historien.

De l'historien qui n'a qu'un but. Savoir ? ce n'est qu'un début. Juger, non. Prévoir, moins encore. Comprendre et faire comprendre en vérité, oui.

II.

Le livre de l'essayiste a précédé d'un an le livre du professeur. Et l'on put se dire, voyant celui-ci aux devantures : « Eh quoi, le mauvais sort serait-il conjuré ? Un historien en possession d'état répondrait-il enfin à l'interrogation de Julien Benda? » On ouvrit le volume. En toute simplicité, je voudrais dire pourquoi l'ayant lu d'aucuns durent 
avouer qu'ils s'étaient trompés; qu'au lieu d'une véritable "Histoire» ils ne possédaient, une fois de plus, qu'un manuel scolaire, très habilement fait d'ailleurs et congrûment traditionaliste ; finalement, que le livre dont ils rêvaient demeurait à écrire. En toute simplicité, et sans la moindre arrière-pensée personnelle : par-delà ce livre, ce n'est pas à un historien, c'est à une certaine conception de l'histoire que je m'attaque ; une conception que pendant des années, de par ses fonctions, son influence personnelle et ses écrits, M. Seignobos a été à même de servir avec des moyens puissants ${ }^{23}$; 087 une conception que je repousse de tout mon être et que, volontiers, je tiendrais pour responsable, en partie, de cette sorte de discrédit, à la fois injuste et justifié, dans lequel l'histoire est trop souvent tenue par les « laïcs ». Une certaine histoire. Celle dont Seignobos, précisément, a tenu à nous donner, dans le livre qui nous occupe, un nouvel et significatif échantillon.

Nous voilà donc à l'aise pour déblayer, et passer vite sur deux ou trois questions qu'on ne doit ni négliger, ni amplifier. - On le devine, il s'agit d'abord du titre. Titre désagréable, j'en demande pardon à la fois à l'auteur et à son complice, Ch.-V. Langlois, dont il invoque le témoignage posthume. Le savant maître de Sorbonne va-t-il lancer une mode? Rivalisant avec lui, verra-t-on demain Antoine Meillet annoncer un Exposé sincère des caractères généraux des langues germaniques, ou Georges Dumas, un Traité sincère des émotions? Nous possédons déjà une Géographie cordiale de l'Europe; mais ce n'est pas l'œuvre d'un géographe. Entre parenthèses, épithète pour épithète, $\mathrm{j}$ 'aurais mieux aimé que Seignobos tentât de nous donner une Histoire cordiale de la nation française. Il ne nous a pas laissé le choix. Et puisque, aussi bien, il s'attend au coup droit, pourquoi ne pas lui dire avec force : «Que nous veut votre sincérité ?»

« Sincérité, affaire entre votre conscience et vous. Vous qui parlez de science et d'esprit scientifique, ouvrez un de ces livres excellents

23 Ce qui, entre parenthèses, rend assez surprenantes ses récriminations contre « la version de l'histoire de France reçue dans l'enseignement» (p. 12). Car enfin, pendant des années, les Manuels Seignobos ont eu, dans l'enseignement, une fort belle audience et toute licence d'introduire dans les esprits des enfants une version satisfaisante - je veux dire, qui satisfasse Seignobos? 
où toute la finesse d'une société polie et courtoise semble condensée en formules exquises; ouvrez ces Synonymes françois du bon abbé Girard que je ne remets jamais sans reconnaissance sur leur rayon de bibliothèque ; vous lirez : "La sincérité empêche de parler autrement qu'on ne pense, c'est une vertu " ${ }^{24}$. Mais précisément, de «vertu » chez ceux qui la font, l'histoire n'a cure ; et vous déplacez la question. Ne point parler autrement qu'on ne pense, devoir? - D'homme privé peut-être, mais vis-à-vis de qui et de quoi ? de lui-même ; de ses «opinions »; au total, de son Moi le plus personnel et le plus nettement individualisé, de son Moi partisan, tout engagé dans les passions du siècle, dans les liens du métier, de la classe, du parti politique, de la religion ou de l'incrédulité. Vous serez « sincère "; mais par rapport à vous, à vos façons privées de penser et de sentir (Littré, v ${ }^{\circ}$ Sincère : « qui exprime avec vérité ce qu'il pense, ce qu'il sent »). Le pire des subjectivismes en réalité. Soyez véridique vis-àvis des documents que vous utilisez, des faits que vous amassez; mais p088 en ce sens où Littré définit, après l'abbé Girard, le mot malencontreux que vous employez: ne soyez pas sincère. C'est le plus grand service que vous puissiez rendre à une histoire d'esprit scientifique.

Histoire « sincère », donc "intrépide »: la pente des vertus est glissante. Écoutons Ch. Seignobos dans sa Préface : il parlera « sans réticence, sans aucun égard pour les opinions reçues, sans ménagement pour les convenances officielles, sans respect pour les personnages célèbres et les autorités établies ». Le grand serment. Résultat de tant d'audace ? En 520 pages, trois ou quatre boutades.

Voici Vercingétorix sur son Mont-Auxois. Toujours alerte, Charles Seignobos, grimpant sur le morne piédestal du vaincu d'Alésia, s'en va gentiment lui tirer les moustaches (p. 30). Un héros national! A d'autres! Et que nous veut cette invention de «patriotes rétrospectifs »? Il n’y avait pas de «nation » en Gaule au temps de

24 Je me sers de l'édition de Paris, 1780, augmentée par Beauzée ( 2 vol. in-12 ); l'article Sincérité (comparée à Franchise, Naïveté, Ingénuité) s'y trouve au tome $\mathrm{I}^{\mathrm{er}}$, p. 386 (art. 341). 
Vercingétorix : affirmation péremptoire qui suffit évidemment, en bonne méthode, à jeter par terre les conclusions contraires d'une Histoire insincère de la Gaule à quoi, comme chacun sait, Camille Jullian a consacré sa vie ? - Les Gaulois n'ayant « jamais formé une nation », Vercingétorix ne peut avoir été le héros «national» des Gaulois. C. Q. F. D.

Ne notons pas qu'ici Seignobos semble avoir une idée précise de ce qu'il faut entendre par "nation »; il aurait bien dû, nous l'allons voir, tirer parti de cette précision lorsqu'il formait le dessein de son livre. Ne demandons pas non plus ce que fut, «en vérité », Vercingétorix. "Un chef arverne ayant servi dans l'armée romaine », répondrait Seignobos (p. 30) et qui, « un soulèvement général » ayant éclaté en Gaule (général, non pas national, vous l'entendez assez), fut prié de prendre la tête d'une "ligue de guerre contre les envahisseurs étrangers ». - En somme, un commandant en chef de forces interalliées ? Alors, qualifions Vercingétorix de « héros polynational des Gaules » et n'en parlons plus. Les «patriotes rétrospectifs » y pourront voir une promotion, et la sincérité de Seignobos s'épanouira d'aise.

Il y a Jeanne d'Arc aussi... C'était prévu. Incarnation du patriotisme? Allons donc! fadaises à la Michelet, ce Michelet qui n'avait pas la Méthode. (Ce qui n'empêche pas que la seule Jeanne d'Arc intelligible que nous ayons, jusqu'à présent, ce ne soit toujours la Jeanne d'Arc de Michelet ... ) - Jeanne d'Arc ? p089 Une partisane, sans plus (p. 201). "Son loyalisme s'adressait au roi de son parti, plutôt qu'au roi de la nation française, » Ce n'est pas nouveau et c'est simple; si simple que je comprends mal. D'abord, si l'un des deux partis, le bourguignon, était apparu comme l'allié de l'étranger, et que ce ne fût pas, précisément, celui de Jeanne ? Surtout, roi d'un parti, roi de la nation, je ne comprends pas. Mais je voudrais savoir ce qu'était le roi de France, à cette date, dans l'opinion commune des hommes. Toute la question gît là.

Car, un historien, on ne lui demande pas de dire (sauf dans les journaux, quand on l'interviewe; mais alors, il ne s'agit plus d'histoire) - si, oui ou non, Vercingétorix et Jeanne d'Arc méritent le titre de « héros nationaux ». On lui demande d' « expliquer » l'un et 
l'autre de ces personnages historiques. "Résistance à l'étranger », j'y reviens et ce n'est pas ma faute si le professeur d'histoire m'y incite après le «métaphysicien ": je voudrais savoir ce que, dans l'esprit des Gaulois soulevés "généralement" contre Rome, cette formule pouvait représenter d'idées et de sentiments, sans doute radicalement différents de nos idées et de nos sentiments à nous? Donc, ce qu'incarnait réellement le chef commun de cette résistance, Vercingétorix ? Ou encore, ce que les «Armagnacs» du temps de Charles VII pouvaient mettre derrière leur lutte " contre les bandes au service du roi d'Angleterre » ? En d'autres termes, m'apprendre ce qui animait à la lutte Jeanne et ses compagnons, ce qu'étaient pour eux le roi qu'ils combattaient et le roi qu'ils soutenaient, voilà ce que je demande à l'historien. Et, s'il ne peut satisfaire mes curiosités, qu'il dise du moins : "J'ai cherché. Les questions que je me suis posées, les voici. Je n'ai rien trouvé. Demain, peut-être, un autre, plus heureux... »

La porte ouverte, toujours. Des mises en place, non des déboulonnements. Des programmes d'enquête et non des boutades pour ennuyer $X . .$. ou dire son fait à $Y$... De la sincérité ? affaire à vous. Mais du sens historique, oui. Je veux dire : un effort constant, tenace, désespéré pour entrer, et faire entrer le lecteur dans la peau même des hommes d'autrefois.

Cela dit, quel a été, exactement, le dessein de Ch. Seignobos? Qu'a-t-il voulu nous donner? Histoire de la nation française, répond le titre : c'est précisément ce que réclamait Benda, — Julien Benda dont la thèse s'oppose si catégoriquement à la p090 thèse de $\mathrm{Ch}$. Seignobos ${ }^{25}$, et qui, sur ce qu'il entend par Nation, ne laisse planer

\footnotetext{
25 Rappelons-nous son propos : la nation n'est pas le résultat de transformations «mécaniques » effectuées sous la pression de forces extérieures. Mais Seignobos, première phrase de la première page : «L'évolution d'une nation dépend des conditions matérielles dans lesquelles elle a vécu. » Il est vrai que la suite dément aussitôt cette affirmation à la gloire du « milieu » : car il y a, outre le milieu, « la race "; car le milieu «n'agit pas de la même façon sur toutes les populations »; car «la nature ne produit ses effets que là où les hommes savent les lui faire produire ». Sages réserves ; mais alors pourquoi le coup de trompette du début? et le résumé si morne, qui suit, à la gloire des avantages matériels du sol français?
} 
aucune sorte de doute. Mais Seignobos: «J'ai voulu faire une esquisse de l'histoire de l'évolution du peuple français». Donc, peuple français égale nation française ? Est-ce bien sûr ? - « Montrer en quel temps, continue Seignobos, en quel lieu et par quels motifs se sont créés les usages, les institutions, les conditions de vie qui me paraissent former le fondement de la nation française... » Nous voici loin de la Nation au sens de Benda, en pleine " histoire de la société », ou des sociétés qu'aux époques diverses les Français de toutes les conditions, de tous les états, de toutes les cultures ont constituées, le fort portant le faible, comme disaient les fiscaux ? - Est-ce bien sûr encore? En cent passages, Seignobos témoigne d'une conception toute majoritaire de sa «nation française ». La masse, voilà ce qui le préoccupe. En vertu d'un raisonnement singulier et qui révèle la plus étrange conception qui soit du rôle des idées et de la façon dont elles se propagent, il lui sacrifie les Arts, les Sciences, les Lettres ${ }^{26}$. Il lui dédie, par contre, les faits de la vie quotidienne : n'ont-ils pas toujours formé «l'intérêt principal de la vie de l'énorme majorité des individus ? » - Alors quoi ? On s'y perd. Histoire de la nation, ou du peuple français, ou du peuple de France, ou des masses populaires ? Une sarabande, et dans un livre d'éducation publique, faut-il dire, dès le début, un bon exemple?

En marge, il y aurait aussi quelques points d'exclamation. Et qui se multiplieraient dès lors qu'on en viendrait au moyen âge.

\footnotetext{
26 Ouvr. cité, p. x : « Je ne m'excuse pas d'avoir relégué à un rang secondaire les lettres, les arts et les sciences ; il est trop certain que leur action ne peut avoir été forte sur la masse de la nation qui en connaissait à peine l'existence. » - Il est certain ? Seignobos exagère, mais notre article est déjà trop long. — Et puis, soit : ne citez ni Buffon, ni Lavoisier, ni Lamarck, ni Cuvier, ni Claude Bernard, ni Pasteur, ni... (il me faudrait vingt lignes pour énumérer toutes ces exclusions) dans une histoire où vous ne retenez que «les faits les plus importants par leurs conséquences »; mais alors, laissez-nous tranquilles avec Baluze, Budé, Casaubon, etc... Laissez-nous tranquilles avec le salon de $\mathrm{M}^{\mathrm{me}}$ Geoffrin, dont je me demande, avec horreur, s'il a été « plus important par ses conséquences » que l'œuvre scientifique, les idées propagées, les " genres de vie » institués par des hommes de la trempe de ceux que j'énumérais à l'instant - Berthelot et sa chimie par exemple?
} 
Ch. Seignobos ne l'aime pas. C'est son droit d'homme privé, p091 sinon d'historien. Il le tient pour puéril, et volontiers s'apitoie sur sa « naïveté »; dans les vingt lignes qu'il consacre à la religion des hommes du moyen âge (p. 186), l'épithète revient jusqu'à l'obsession : foi naïve ; transposition naïve ; imagination naïve ; pour conclure : christianisme naïf. J'ai de la méfiance. Les naïfs, lorsque nous tranchons ainsi, d'un mot, ne seraient-ce point nous? Mais passons. Du moyen âge, M. Seignobos s'est occupé jadis, lorsque, sortant des leçons de Fustel, il soutenait une thèse sur le Régime féodal en Bourgogne. Je me demande si ce n'est pas tant pis. On n'oublie jamais ce qu'on a cru savoir aux environs de la trentaine ; et pour traiter aujourd'hui les questions qui occupaient Seignobos il y a cinquante ans, combien ne faut-il pas oublier de notions reçues dans les années 80 et 90 ?

Aussi, les quatre chapitres que l'auteur dédie, dans l'ordre des préséances, aux Vilains, aux Nobles, aux Bourgeois et aux Clercs, satisfaisants si on les date de 1895 ou de 1900, ne sont plus à jour en 1933. Sur les villes en particulier et la bourgeoisie, ils laissent trop voir que l'auteur n'a pas suivi le travail intense ( et si vivant dans ses approfondissements successifs, ses retours, ses contradictions et ses élargissements ) qui s'est fait sur ces questions un peu partout : mais surtout en Belgique avec H. Pirenne et ses disciples ; en France même avec Georges Espinas et quelques autres (malgré l'abstention, souvent dénoncée, de nos historiens universitaires). Surtout, les partis pris aussi nets que «sincères » de Seignobos l'amènent à colorer parfois d'étranges couleurs ses héros collectifs. Quand, pour prendre un exemple entre vingt, il affirme que «le noble ne s'intéressait à son domaine que comme source de revenus », cet accès de matérialisme économique larvé me laisse point que de nous déconcerter ${ }^{27}$. Et

27 Le «noble», dit-il (et j'espère bien que ce n'est point là une de ces abstractions personnifiées, comme «le Français » ou «l'Allemand» dont ses anciens élèves nous content que leur maître avait la phobie ) - le «noble » : il nous faut traduire, j'imagine, le « seigneur » ? Mais perpétuer ainsi une confusion regrettable, ce n'est pas le moyen d'éduquer son public. Et puis, surtout, sur quoi s'appuie cette formule si tranchante ? "Le noble ne s'intéressait à son domaine que comme position stratégique » : l'affirmation serait aussi plausible - et aussi gratuite - que celle de Ch. Seignobos. Le prudent professeur n'aurait-il pas, pour une fois, «comblé les lacunes de... ses connaissances... par des raisonnements fondés sur des généralisations imprudentes »? 
pareillement, quand il brosse (p. 177) ce tableau de «la vie dans les villes" au XVIII ${ }^{\mathrm{e}}$ siècle : " La vie urbaine de ce temps diffère profondément de la vie à la campagne. L'enceinte qui défend les habitants contre le dehors les force à vivre entassés dans un espace très étroit... Ils n'en sortent guère ; la campagne n'a rien qui les attire (?), elle a été dégarnie de maisons (?) et d'arbres pour pouvoir surveiller les environs; ils ne s'y sentiraient pas en sécurité ; p092 aucun indice ne montre qu'ils aillent s'y promener $»$, — devine-t-il à quel point cette esquisse laisse pantois, incrédules et déconcertés ceux de ses lecteurs qui savent combien, au $\mathrm{XVI}^{\mathrm{e}}$ siècle encore, ville et campagne se pénétraient intimement au lieu de se tourner le dos, et qui se représentent, dans ces villes déjà relativement " modernisées », le va-et-vient continuel des volailles, des chiens, de chevaux, les divagations des porcs se vautrant en pleine rue, le rassemblement chaque matin par le berger communal, du troupeau de la ville ou du quartier, et son retour chaque soir dans les rues étroites, aux abois des chiens, aux meuglements des bêtes ? Pour ne point parler de l'attente, dès le soleil levant, devant les portes encore closes, des vignerons hotte au dos, des bourgeois outils en main qui, sitôt le concierge réveillé et le pont-levis baissé, se ruent vers les vignes et les jardins, cependant que les paysans, par un mouvement inverse, arrivent à la ville avec leurs fagots, leurs fruits, leurs bottes de paille?

L'ai-je donc rêvé ? qu'en ces temps où le numéraire, si rare, s'égarait si peu dans les escarcelles du commun, l'idéal des petits bourgeois c'était nécessairement, non de s'approvisionner dans les grands magasins (plutôt rares !) et d'y dépenser l'argent qu'ils n'avaient pas ${ }^{28}$, mais de posséder, d'exploiter ou de faire exploiter les

28 Ch, Seignobos consacre bien aux faits monétaires quelques notations sporadiques. Mais elles restent en marge de son texte, et de son esprit. Il ne pense pas économiquement. Sur le terrain doctrinal, ses tentatives en ce domaine n'ont pas été heureuses; sur le terrain des faits, on ne peut même pas parler de tentatives. Nous montrer le paysan médiéval ( sans autre spécification ) « enfermé dans l'horizon de son village, dépourvu de tout moyen de changer sa condition, n'ayant ni argent, ni connaissances pour améliorer ses cultures »-c'est entasser en deux ou trois lignes une quantité stupéfiante d'anachronismes. Le paysan « enfermé »? Mais Ch. Seignobos n'a donc jamais rencontré dans les textes cette armée prodigieuse de vagabonds, de fugitifs, d'errants, de nomades qui couraient les campagnes, hantaient les forêts, répondaient à l'appel des entrepreneurs de défrichement, s'enfonçaient dans ces domaines forestiers qui constituaient au sein 
trois ou quatre journaux de terre, le moins loin possible de leur ville, qui leur donneraient leur blé et leur «boire» et, si possible, leur chanvre pour le linge? L'ai-je rêvé qu'en la ville subsistaient amplement les espaces vides, les jardins, les clos, les prés et les vignes? « La campagne n'a rien qui p093 les attire. » Esthétiquement peut-être; il faut vivre avant de contempler et, comme on dit, chez moi, « la beauté ne se mange pas à la cuiller ». Mais ce que produit la campagne attire, et fortement. "Ils n'y vont pas se promener?» Évidemment. Le camping ne date point du XIII ${ }^{\mathrm{e}}$ siècle. Mais ils y vont « labourer », au vieux sens du mot; et négocier; et tout de même, en avril, cueillir l'aubépine et la violette. Les hommes qui ont modelé, pour la délectation de leurs contemporains et la glorification d'un Dieu créateur de beautés naturelles, les silhouettes de faucheurs et de moissonneurs de nos calendriers de pierre, dans nos vieilles églises : qui donc les prétendrait fermés à ce que nous nommons le sens de la nature ? Et cependant, méditant devant leurs coffres cadenassés, les gros marchands rêvaient à la seigneurie qu'ils acquerraient, un jour...

Divorce de la ville et de la campagne ? le beau thème d'Histoire comparée $^{29}$, la belle occasion perdue ! Il fallait la faire toucher du doigt, cette différence profonde qui, à ce point de vue, sépare un pays comme l'Allemagne où les villes, s'isolant en effet, se murant jalousement, rayonnent peu sur un plat pays totalement étranger à elles par son statut politique, son droit, son inculture et qui se venge

d'un pays comme la France autant d'énormes colonies de peuplement? Entre mille autres, je dédie à $\mathrm{Ch}$. Seignobos ce mot que je relevais hier dans la thèse d'un géographe, M. DEFFONTAINES, sur Les hommes et leurs travaux dans les pays de la moyenne Garonne : il conclut une longue étude par cette formule : «Un pays sans cesse repeuplé. » Qui de nous, connaissant une région de la France intimement, ne la ferait sienne ? Ce n'est pas moi, Franc-Comtois et Jurassien (le Jura, cette colonie de peuplement à la charnière de plusieurs mondes ). Quand à ajouter par surcroît que le paysan, s'il eût eu « de l'argent» et... les conseils du professeur départemental d'agriculture, aurait pu, au XIII siècle, «améliorer ses cultures »- alors qu'on nous a exposé plus haut, tant bien que mal ( p.130 ), le système des servitudes agraires ( mais il apparaît bien qu'on ne l'a pas réalisé dans son esprit - est-ce contribuer à répandre des idées saines et justes ?

29 En dépit d'affirmations théoriques, Ch. Seignobos (et ce n'est pas notre moindre étonnement) n'a nulle part réussi à replonger l'histoire française dans le grand bain d'histoire occidentale où, dans un livre de vulgarisation et d'éducation populaire, il aurait fallu donner au public le sentiment qu'elle baigne. Relisons le discours de Pirenne sur l'Histoire comparée, et l'exposé de Marc Bloch sur les conditions de cette Histoire (Revue de Synthèse Historique, t. XLVI, 1928). 
en les rendant impuissantes - et un pays comme la France où de si bonne heure les campagnes, s'urbanisant, assimilent ce qu'elles peuvent de droit urbain et créent cette civilisation relativement homogène et cohérente qui fut de bonne heure un des traits distinctifs de notre pays.

En vérité non, le moyen âge ne réussit pas à Charles Seignobos.

Des points d'interrogation, des points d'exclamation: mais il y aurait aussi des Très bien dans la marge ? Assurément. Encore ne les mettrais-je pas toujours là où tant de critiques compétents journalistes, politiciens, moralistes et autres - nous ont appris gentiment qu'il convenait de les placer.

« Histoire sans protagonistes, ô merveille! Dans le chapitre sur la Révolution, cherchez Mirabeau ? il n'y est pas ; Danton ? il n'y est pas ; Carnot, Vergniaud, Desmoulins, Hébert..., néant! Quelle magnifique audace ! »C'est vrai (la magnificence à part). p094 Mais avant de crier Noël, souvenons-nous que Seignobos fit ses premières armes sous les enseignes de Fustel. Et que déjà l'auteur de La Cité antique, bien que la démocratie n'ait point accoutumé de saluer en lui un de ses pères, professait que le seul agent des phénomènes sociaux, c'est la foule. Et l'on peut fermer les Institutions de l'ancienne France sans avoir rien appris sur Dagobert, Charlemagne, Louis le Pieux ou Charles le Chauve ; rien, pas même leur nom.

Mais le souci des faits de la vie quotidienne - ces faits dont Seignobos donne d'ailleurs une énumération assez singulière: alimentation, vêture, habitat, et puis les " usages de famille » et... le droit privé en appendice ? Certes, il y aurait à dire sur la façon dont ils sont, non pas présentés mais énumérés par un auteur soucieux, diraiton, de laisser soigneusement ignorer à ses lecteurs tout ce qui préoccupe, autour de lui, géographes, historiens, économistes, folkloristes, juristes en plein travail. «Le paysan habitait d'ordinaire une chaumière petite, humide, sombre..., construite le plus souvent en lattes (?) de bois et en argile, etc. » Voilà à quoi aboutissent (p. 140) cinquante années d'études sur l'habitation en France, tout ce que nous savons sur la variété extrême des formes, du dispositif et du mode de 
construction des maisons rustiques dans les diverses parties du pays, tout le complexe de problèmes passionnants qui se posent à ce sujet... «Le » paysan et « la » chaumière : au temps du romantisme honni de Seignobos, les peignait-on sous d'autres couleurs?

Continuons : «Le paysan se nourrissait surtout de bouillie, de pain noir, de seigle, de légumes très peu variés, de lard et de fromage. » Bouillies, oui ; mais les soupes ? (décoctions, acides ou douces). Pain, oui ; mais les simples galettes ? Et puis, bouillies de quoi ? - Un mot m'inquiète : « légumes très peu variés ». Voilà donc masqué ce grand fait d'histoire de l'alimentation, je veux dire, la diminution constante du nombre des plantes alimentaires récoltées sur place. Un long effort de simplification et d'amélioration n'a-t-il pas peu à peu conduit l'homme à négliger un nombre sans cesse croissant de plantes de ramassage, ou de plantes cultivées de valeur moindre; à ramener à une seule, le froment, la très grande variété des céréales panifiables anciennement usitées ; finalement, à substituer, aux bouillies de millet et de sarrasin, aux galettes et soupes de toute espèce, encore en plein usage dans la France du XVIII ${ }^{\mathrm{e}}$ siècle — une alimentation dont les bases végétales sont le pain de froment et la pomme de terre ? Cependant que, par un mouvement inverse et de plus en plus rapide, la création d'un vaste réseau de circulation p095 mondiale amène sur la table non seulement des riches citadins, mais des ouvriers et des paysans, une provende toujours croissante de légumes et de fruits nouveaux venus des quatre vents du monde?

Rétrécissement, stabilisation, élargissement, progrès qualitatif au bout du compte : dites-nous tout cela, esquissez ce schéma. Et quand vous signalez l'avènement des chemins de fer, ayez un mot au moins pour marquer que, de plus en plus, ils vont amener les Français à ne point vivre exclusivement sur le fonds de leur pays. Quand vous parlez du moyen âge, ayez un mot, un seul, pour dire que l'alimentation française n'est pas uniformément et exclusivement française; que les faits capitaux débordent la France - mais que, souvent aussi, ils ne recouvrent pas la France entière; qu'il y a, alimentairement et culinairement parlant, bien autre chose que la France de 1'huile et celle du beurre (et que de choses à dire sur le beurre !) ; qu'il y a à tout le moins, en France, des régions culinaires comme des régions linguistiques... ou des régions végétales. 
Cela dit, j'ajoute : non, le souci des choses de la vie quotidienne chez un historien français ne saurait dater de 1933. Le vieux Monteil (Amans-Alexis), pour ne pas remonter plus haut, prospectait déjà ces terres inconnues lorsqu'il composait, à partir de 1827, son Histoire des Français de divers états. Et plus proche de nous et de nos méthodes, l'excellent Rambaud, quand il compilait son Histoire de la civilisation française où j'ai tant appris quand j'avais quatorze ans.

Ces réserves faites, il y a de bonnes choses dans le livre de Seignobos. De grandes choses, non. Je veux dire, de ces hypothèses larges qui, groupant des milliers de menus faits épars, les éclairent par leur rapprochement; et suscitent tout un labeur fécond de vérifications, de démolitions et de reconstructions : la vie même d'une science et de ses savants. De petites réflexions incisives par contre, frappées au coin d'un bon sens un peu court, vigoureux et caustique dans ses limites. La forme et le tour en sont plus souvent négatifs que positifs et désabusés qu'enthousiastes : c'est le lot de Seignobos. Les bonnes fées ses marraines ne lui ont point donné d'indiquer joyeusement les chemins nouveaux, d'exciter les voyageurs à la hardiesse et les aventuriers aux découvertes. Railler l'enthousiasme ; enseigner qu'à mettre un pied devant l'autre on risque gros (tomber dans un trou, se ${ }_{\mathrm{p} 096}$ donner une entorse, se casser le nez... ) ; enfin, tout le long de la route royale des études historiques (et spécialement aux carrefours et aux bifurcations), dresser des poteaux encourageants : «Attention, danger de mort!»— cela, oui, c'est son triomphe. Ce n'est que trop son triomphe.

Car nous pouvons maintenant aller droit au fait. Seignobos n'a point écrit son livre pour le vain plaisir de noircir du papier. Ou je me méprends totalement sur son compte, ou il s'est proposé de créer un livre d'éducation populaire, susceptible d'une large diffusion. Livre d'éducation et, en même temps, il faut le supposer, livre d'initiation à l'histoire, à ses méthodes, à son esprit, à son objet? Jugée de ce double point de vue, que dire de l'Histoire sincère? Qu'elle est, en 
vérité, déconcertante. Et d'abord par son conformisme. Car ce livre est, d'un bout à l'autre, traditionnel ${ }^{30}$.

La conception de son sujet? Seignobos l'a prise dans le domaine public. Tout au long de son livre, il fait de la France un «donné tout fait », un lit prédestiné qui, dès la première page de l'Histoire sincère, attend, toutes couvertures providentiellement faites, que l'Élu s'y couche? Et cependant l'ai-je rêvé, que Vidal de la Blache dans son Tableau, il y a trente ans, a magistralement posé le vrai problème : rechercher comment et pourquoi des contrées hétérogènes, qu'aucun décret nominatif de la Providence ne désignait pour s'unir dans un certain ensemble, ont cependant fini par former cet ensemble : celui, en l'espèce, que pour la première fois nous saisissons dans les textes de César dessinant par ses «limites naturelles» une Gaule, préfiguration approximative de notre France?

Mais former un tel ensemble, c'est beaucoup et ce n'est rien. Car il ne vaut que s'il s'est maintenu. Cent ensembles différents auraient pu se constituer, et se sont constitués temporairement, qui n'ont pas duré et que nous négligeons parce que l'histoire n'enregistre que les réussites. Comment, pourquoi, malgré tant « d'offres », comme aurait dit Lavisse, tant d'essais ratés de nations franco-anglaises, ou francoibériques, ou franco-lombardes, ou franco-rhénanes, entrevues comme possibles ou, parfois, temporairement réalisées dans les faits ${ }^{31}$ comment, pourquoi la formation Gallia, après maintes tourmentes, a-telle toujours réussi à reparaître et à rattrouper autour d'un germe (dont nulle part la notion féconde n'apparaît dans le livre de Ch. Seignobos) les membra disjecta que des événements, par p097 nous qualifiés de « hasards », avaient temporairement dissociés de l'ensemble? N'y eut-il là, en effet, que "contrainte mécanique d'événements extérieurs ", ou bien faut-il faire place à d'autres facteurs, ceux que J. Benda voudrait mettre en lumière ? - Et encore, quand nous parlons de Français dès le seuil d'une histoire dite «de France » et que nous continuons à en parler tout au long de cette histoire, avons-

\footnotetext{
30 Indiquons simplement qu'à la mise en vente une bande promettait sur chaque exemplaire : " La Vérité contre la Tradition. »

31 Indiquons simplement qu'à la mis en vente une bande promettait sur chaque exemplaire : La Vérité contre la Tradition. »
} 
nous raison? Ces Français, ne devrions-nous pas, à toutes les époques, nous soucier de dire qui ils étaient - de préciser ce que nous nommons Français à une certaine date, et ce que nous excluons de la France, et quels étaient, sur les points importants qui nous retiennent, les sentiments des exclus, des Français séparés?

Il est commode d'escamoter une question. Le problème demeure, qu'il faut énoncer si l'on veut donner au public une réelle leçon d'indépendance d'esprit. - Ce problème que Vidal posait en grand géographe, Benda, en métaphysicien pressant. Et que Seignobos a refusé de poser en historien. Parce que la notion même de problème lui demeure étrangère, comme "répugnante" celle d'hypothèse. Nouvelle fidélité à des idées de toujours.

Sens du mouvement, vertu cardinale de l'historien. Refus de prendre comme postulat une sorte de nécessité perpétuelle des nations et des formations politiques, supposées permanentes de droit à travers les siècles. Goût de la vie qui n'est que constructions et démolitions, assemblages et dislocations. Pour être ancien n'est-il pas riche de sens ce texte, qui rappelle si bien à l'historien la perpétuelle relativité de son labeur? "Les sociétés périssent; de leurs ruines naissent des sociétés nouvelles; lois, mœurs, usages, coutumes, opinions, principes même : tout est changé... La France doit recomposer ses annales pour les mettre en rapport avec les progrès de l'intelligence. » L'esprit même de l'histoire? Oui. Défini par Chateaubriand. p098 


\title{
ET L'HOMME DANS TOUT CELA?
}

\author{
SUR UN MANUEL
}

$\underline{\text { Retour à la table des matières }}$

Nous rabâchons. Nous ressassons. Nous avons l'air de nous acharner. Contre des hommes ? Certes non. Les hommes exécutent, en toute conscience, le programme qu'on leur a tracé, et qu'ils ont accepté. Ils font l'histoire qu'on leur a appris à considérer comme de l'histoire. Mais pour nous, cette histoire est inopérante. Questions de méthode ? De tempérament aussi ? En tout cas, conflit net, opposition nette de deux écoles.

Et donc, voici encore un de ces manuels qui, si souvent, provoquent nos réserves. Le titre est séduisant: Démocraties et capitalisme. Que de problèmes! Que de réflexions tragiques, en vérité, sur ces deux thèmes d'une ampleur déconcertante! Que de leçons critiques et positives à donner aux jeunes — et même aux vieux qui, d'aventure, attirés par les promesses d'une belle enseigne, ouvriraient avec une fervente curiosité ce gros livre d'aspect sympathique?

On l'ouvre donc. C'est l'avant-dernier, si je ne me trompe, des volumes qui manquent à la Collection Peuples et Civilisations pour qu'elle soit complète ${ }^{32}$. Il traite de l'Europe et du monde entre 1848 et 1860 . Il en traite comme un manuel. Avec (en ce qui concerne

32 Paris, Presses Universitaires, $1941 ; 640$ pages in- $8^{\circ}$ (Coll. Peuples et Civilisations, vol. XVI). 
l'objet propre de nos études à nous) des partis pris et des oublis également singuliers.

Non qu'il ne fasse point sa place à l'économie. Il décrit la « révolution des transports» et les progrès des techniques industrielles; il annonce l'avènement du crédit; mais de la structure sociale des peuples et des nations, rien. Les choses, oui bien. Les hommes ? qu'est-ce qu'ils viendraient faire dans les ateliers de Clio ?

Donc, rien sur l'évolution des bourgeoisies pendant cette période si riche en faits sociaux. Rien sur l'évolution des masses ${ }_{\mathrm{p} 099}$ artisanales et ouvrières à la même époque. Rien du conflit vivant et charnel des idées incarnées dans les hommes et dans leurs groupements pullulants et contradictoires. Le livre meut des machines, non des êtres humains. Il compte, il énumère, il recense, inlassablement. Voici, page 201, les "chaudières de Belleville», et les "réchauffeurs Farcot» perfectionnés eux-mêmes par la Société Industrielle de Mulhouse, et les turbines de Tournaire, « les moteurs à air chaud d'Ericson, 1862, et de Franchot, 1853, de faible puissance », et « les moteurs à gaz qui, trouvés en principe par Lebon, en 1801, connaissent l'application industrielle avec le moteur de Hugon, en 1858, et surtout avec la machine horizontale de Lenoir, en $1860 »$. Je me demande ce que ces litanies - un nom, une machine, une date ; une machine, un nom, une date - peuvent bien représenter d'intelligible pour un lecteur dont le cerveau ne se réduit pas tout entier à une mémoire mécanique? Énumérations : mais où donc se trouve mis en lumière le rôle nouveau qu'assument les machines dans la vie des hommes ? Et quel est ce rôle ? Et combien de ces machines, proportionnellement? Et quel rendement? - Bref, en dépit d'un beau titre que tout le contenu de l'ouvrage semble fait pour trahir — nous n'avons pas là un livre d'histoire, mais un manuel, encore un manuel, toujours un manuel. Au mauvais sens du mot.

- Mais enfin, des manuels, il en faut ? - Voire. Pour les enfants des écoles, il faut des livres classiques. Les savants auteurs que mobilise la collection Peuples et Civilisations ne travaillent point pour cette clientèle. J'admets, pour elle, des livres de lecture bien faits - et des mémentos précis, à condition que tout ce qu'ils enseignent aux enfants débouche sur la vie. Et que, s'ils réunissent des faits, ce soit 
très peu de faits, mais bien choisis, de réelle importance, expliqués vraiment à fond. A condition, surtout, qu'ils ne recherchent pas, mais proscrivent les formules, les affreuses formules qui s'apprennent « par cœur », et pour toute la vie dispensent les paresseux du travail de juger par eux-mêmes : lourd travail, devant qui la plupart des hommes reculent opiniâtrement... - Quant aux jeunes de 17, de 18, de 20 ans, qui débutent dans les Facultés; quant aux hommes faits, à plus forte raison, et aux maîtres préparant leurs cours - je dis résolument : non. Des états de question bien faits : il y en a quelques-uns de réussis, déjà, dans la Collection Clio (quelques-uns, pas tous; mais les modèles existent). Cela, oui, qui incite, ou peut inciter, à penser, à chercher, à lire. Des manuels «clos » et dont l'ambition se réduit à décrire toutes choses du dehors, avec le maximum de détails, vu la place : non, non, mille fois non. p100

Et notez bien que ce qui est vrai de l'économie est non moins vrai de l'art. L'auteur du livre rencontre devant lui Courbet. Ici, je cite : "Courbet, libéré de toute prudence par son enthousiasme révolutionnaire, donne, en 1849, les Casseurs de pierres; en 1850, l'Enterrement d'Ornans (restituons-lui, grincheux, son vrai nom: l'Enterrement à Ornans); en 1851, les Demoiselles de village; en 1853, les Lutteurs, puis, en 1854, les Cribleuses de blé et la Rencontre ; en 1855, l'Atelier. » Courbet, libéré de toute prudence... La formule est curieuse. Je ne crois pas, en vérité, qu'un Courbet se soit délivré du poids de ses œuvres par «imprudence», ou par « enthousiasme révolutionnaire ». Mais laissons cela. Ces titres et ces dates ? Voilà Courbet aussi bien traité que la machine à vapeur. Titres, toiles et dates, dates, toiles et titres. Demain, le jeune Durand, de Mende, qui oncques ne vit un Courbet (pas plus qu'un réchauffeur Farcot) - et le jeune Dupont, de Béziers, qui est bien doué pour l'histoire (doté d'une mémoire chevaline, il réussit mal en français, en philosophie, en latin, en grec, et ne mord pas aux mathématiques, ce qui le voue irrémédiablement à Clio, ce gagne-pain des laissés pour compte) - donc ces deux futurs "historiens» liront, reliront, répéteront à haute voix, cinquante fois s'il le faut, ces huit titres et ces huit dates, avec un zèle furieux; " et le sçauront si bien que, au coupelaud, le rendront par cueur, à revers ». Perfection gargantuesque. Mais, plus astucieux, le jeune Martin, de Castelnaudary, s'avisera peut-être d'apprendre dans un autre livre quelques dates et quelques 
titres supplémentaires. Car, après tout, pourquoi pas cette autre liste courbétique : « Le Portrait de Baudelaire de 1845 ; le puissant Berlioz de 1848 ; l'Homme à la ceinture de cuir de 1849 ; l'Homme à la pipe de 1850 ; l'Après-Dîner à Ornans, 1849 ; les Baigneuses, 1853 ; la Roche de dix heures, 1855, et l'Hallali, 1858 »? Autant de chefsd'œuvre : huit contre huit - et ce sournois de Martin, fort capable (tant il est doué !) de contaminer les deux listes, passera devant Dupont et Durand déconfits, et sera reçu premier en sa licence tel Nostre Maître Janotus ! Car la règle du jeu n'est-elle pas : dire tout ce qu'on sait de faits, de noms et de dates en dix lignes, ou en deux pages, ou en dix — selon le gabarit de l'examen?

Ainsi, se fabriquent, ainsi se perpétuent ces générations d'historiens sans idées, sans pensées, sans exigences intellectuelles et qu'on repaît de noms, de titres et de dates. Impavides, ils redisent et rediront à perpétuité, en commençant leurs leçons ou, hélas, leurs livres, ces formules magnifiques en quoi s'enclôt la Sagesse et la Philosophie de l'École : «La période que nous p101 allons étudier continue celle qui précède, et annonce celle qui suit. Elle est remarquable par ce qu'elle supprime, mais aussi par ce qu'elle établit », etc., etc. - J'exagère ? Hélas, je ne fais que citer (p. 1) : « La période qui s'étend de 1848 aux alentours de 1860 a imprimé sa marque dans l'histoire (?) et par ce qu'elle a détruit et par ce qu'elle a commencé de construire... En ce sens, le mouvement de 1848 appartient à la période antérieure et la conclut. Mais il est aussi un commencement, et il a orienté l'avenir. » Pourquoi ne pas donner de ces textes et de quelques autres, sous la rubrique flatteuse d'Idées générales (ou même, si l'on préfère, de Philosophie de l'histoire), une bonne édition muette - je veux dire dates et noms en blanc ? Chacun les remplirait à sa guise. Et je vois très bien l'historien de Ramsès II Sesostris débutant : «La période qui s'étend de... aux alentours de... a imprimé sa marque dans l'Histoire », etc.

Qu'on s'étonne, après cela, des colères et des ironies de tant de bons esprits qui, venant à l'histoire, croient trouver dans des livres de ce genre la satisfaction de leurs curiosités - et s'irritent, expérience faite, de voir tant d'efforts, d'argent, et de bon papier imprimé, n'aboutir qu'à propager cette philosophie - cette conception d'une histoire psittacique sans mystère et sans vie — d'une histoire où nul 
ne sent plus, pour emprunter son langage à Paul Valéry (que je tiens à citer, à dessein), «ce suspens devant l'incertain en quoi consiste la grande sensation des grandes vies, celle des nations devant la bataille où le destin est en jeu; celle des ambitieux à l'heure où ils voient que l'heure suivante sera celle de la couronne ou de l'échafaud; celle de l'artiste qui va dévoiler son marbre ou donner l'ordre d'ôter les cintres et les étais qui soutiennent encore son édifice ». Et s'il n'y avait que cela!

Je reprends le livre. Totale absence des hommes. Toute insouciance de ce qu'ils furent, de leur formation, de leur caractère, de leur psychologie. L'être humain sentant, pensant, souffrant, agissant, jouissant : nous n'en usons point céans. A trois ou quatre reprises, on mentionne bien l'intervention d'un nommé Marx. Ou, ailleurs, les livres d'un certain Comte. Les hommes qui portèrent ces noms: pourquoi s'intéresser à eux ? Titres, noms, dates, dates, titres, noms, voilà réponse à tout. De temps à autre, cependant, une formule. Voici, énumérés, les derniers écrits d'Auguste Comte: "Le sentiment y vient retrouver place à côté de l'intelligence — et l'amour guider l'action. » - L'Amour guidant l'Action et le Sentiment retrouvant sa place au foyer de l'Intelligence: deux beaux sujets de médailles, en vérité. Mais ${ }_{\mathrm{p} 102}$ je me dis que pour Dupont et pour Durand, séduits, il y a bien des chances que ces mots bien frappés tiennent lieu, toute leur vie, d'Auguste Comte - et retentissent dans le vide de leurs cervelles incultes - dans un néant de pensées et d'expériences. Et c'est là ce qui m'effraie. Car toute pédagogie va loin — et celle de l'histoire plus loin que d'autres, peut-être...

Résumons: Absence des individus en tant que tels. Impossible discrimination entre les quelconques et les très grands. Encombrement de médiocrités dont on se demande ce qu'elles ont à faire avec l'histoire. Murger, Laprade, qui encore ? - Allons, une fois encore, et ce ne sera pas la dernière ; une fois encore, et sans faire acception de personnes (est-il besoin de le dire), répétons ces grosses choses. Ces choses que les manuels ne disent jamais, et qu'il faut donc proclamer dix fois plutôt qu'une : "L'homme, mesure de l'histoire. Sa seule mesure. Bien plus, sa raison d'être. » Dans nos vieilles maisons de Franche-Comté, au temps de ma jeunesse, il y avait toujours, au fond de l'alcôve des vieux, un DIEU SEUL, encadré de noir. Les Annales 
sont toutes prêtes à faire fabriquer, à l'usage des historiens, autant d'HOMME SEUL qu'il faudra pour leur satisfaction personnelle. Allons, qui s'inscrit? $\mathrm{p} 103$

$\underline{\text { Retour à la table des matières }}$ 


\section{CONTRE L'ESPRIT DE SPÉCIALITÉ}

Une Lettre de 1933

$\underline{\text { Retour à la table des matières }}$

MON CHER AMI, je regrette votre décision, je la regrette même beaucoup. L'Encyclopédie VEUT grouper, DOIT grouper les têtes, dans tous les domaines de la recherche française. Elle les groupera, elle les groupe déjà. J'aurais bien voulu que la vôtre ne manquât point à l'appel.

Vous me répondez trois choses : Travaux déjà engagés - et là, je n'ai rien à dire. - Difficulté extrême et disproportion de l'effort : trop de peine matérielle pour trop peu d'initiative intellectuelle. Ici déjà, nous commençons à divorcer, car, bien au contraire, la part d'initiative et de novation dans l'œuvre que je voudrais voir entreprendre, m'apparaît comme énorme ; il ne s'agit pas de faire un album d'images avec le petit commentaire restreint qu'on lit en bas de page dans tous les albums dits "commentés »; il s'agit d'écrire de belles pages d'histoire et de géographie à l'aide de représentations rapprochées, et combinées, s'étayant et s'éclairant l'une l'autre : cartes, tableaux statistiques et vues proprement dites, réunies sur les mêmes pages, avec une recherche intelligente et ingénieuse de procédés nouveaux de présentation, et aussi de traduction (faire varier les chiffres d'un tableau statistique, en découpant autrement les « périodes », j'imagine, et montrer, en face de la carte immuable et de la «photographie-témoin », les conséquences, etc., etc.). C'est difficile, oui : non pas mécaniquement (bien que l'ingéniosité mécanique ne soit pas chose à dédaigner) mais intellectuellement. Si difficile que, du premier coup, on n'arrivera pas à la perfection. Mais 
l'Encyclopédie est un ouvrage en évolution perpétuelle et qui, d'année en année, se complétera, se retouchera, se refera.

Enfin, troisième argument - et là, le divorce est net. Vous me dites : "Où est la Géographie dans tout cela »? Mais, mon cher ami, elle est partout et nulle part. Exactement comme l'histoire de l'art. Exactement comme le droit. Exactement comme la morale. Exactement ${ }_{\text {p104 }}$ comme... je ne continue pas. Pourquoi ? Parce que je ne fais pas une Encyclopédie des sciences.

J'ai repoussé ce point de vue avec énergie, avec violence même. Je l'ai trouvé devant moi, représenté par un notable philosophe l'an dernier : il nous avait apporté une complète classification des sciences et demandait que, les unes après les autres, chacune de celles qu'il avait recensées (et la géographie en était, et la morale, et la logique, et la métaphysique, et le droit, et l'esthétique, etc., etc.) ait dans l'Encyclopédie son chapitre, petit ou grand, où les beautés de l'esprit spécialiste s'épanouiraient une fois de plus. Non, non et non.

Ceci, c'est le vif même du débat entre nous. D'accord avec tous ceux qui ne cessent de me répéter toute la journée : «Soyez dur! Pas une concession à l'esprit de spécialité, qui est l'esprit de mort dans l'état actuel du travail humain »; d'accord, j'ose le dire, avec moimême dont toute la vie, toute l'action a été, jusqu'à présent, dirigée contre l'esprit de spécialité - voyez en dernier lieu mes Annales d'Histoire Économique et Sociale - j'ai dit : Non, pas les sciences ces combinaisons circonstancielles et locales d'éléments associés souvent arbitrairement. Briser les cadres abstraits, aller droit aux problèmes que l'homme non spécialisé porte en lui, se pose pour luimême et pour les autres en dehors de tout souci d'école, de tout « esprit de bouton », comme on dit dans la Marine - tel est mon but dès l'origine, dès la première petite note rédigée à la diable, en octobre 1932, qui est le germe de l'Encyclopédie. Par là, l'unité de l'esprit humain, l'unité de l'inquiétude humaine devant l'inconnu sera rendue sensible à tous : cette unité que masque le pullulement des petites disciplines jalouses de leur autonomie et se raccrochant désespérément, elles aussi, à une autarcie aussi vaine dans le domaine intellectuel, et aussi funeste, que dans le domaine économique. Faisons, les uns et les autres, quand il y a lieu, des Traités et des 
Manuels de nos sciences respectives : c'est une nécessité pratique. Mais ils n'auront de valeur humaine qu'animés du large esprit d'unité scientifique que l'Encyclopédie précisément veut servir et servira.

Cela, c'est une pensée de toujours. Et je ne trahis pas un secret en vous disant que, si je me suis lancé dans l'Encyclopédie avec tout ce que je puis garder encore d'élan, c'est parce que j'y ai vu le moyen, qui brusquement m'était donné, et de la façon la plus imprévue, de servir des idées qui sont miennes depuis toujours et qui, de plus en plus, sont celles des savants qui pensent leurs sciences dans le cadre de la Science. Non, la géographie ${ }_{\mathrm{p} 105}$ humaine ne figure pas, en tant que telle, dans l'Encyclopédie. Et je reprends votre formule finale, et le vœu qu'elle exprime, pour mieux traduire ma pensée : non, mon cher ami, jamais la géographie humaine ne trouvera « sa petite maison indépendante dans l'édifice encyclopédique ». Pas plus que la chimie, la botanique, etc. Ce serait la négation même du programme, du dessein de l'Encyclopédie. Elle n'est pas une «cité-jardin» des sciences et des arts : cent petits pavillons isolés, chacun avec leur concierge, leur petit chauffage central, et le maître de céans avec ses petites habitudes; elle est la maison commune de tous les savants et de tous les artisans, s'entretenant les uns les autres de leurs idées, de leurs méthodes, de leurs recherches et de leurs soucis : reconnaissant qu'ils sont frères d'intention et d'effort, qu'ils ont les mêmes buts et que, de la réussite ou de l'échec de l'un, l'autre doit tirer profit et enseignement.

Parce que je ne demande pas à des professeurs éminents de composer des Manuels ou des traités d'anatomie, de minéralogie ou de chimie - je ne méprise pas tout ce qu'implique de puissance intellectuelle et d'ingéniosité technique l'art de fabriquer l'oxygène, ou l'acide sulfurique, ou le pyramidon. Je fais autre chose, voilà tout, et de propos délibéré — pour des fins que je crois très hautes, très utiles aujourd'hui, et qu'on s'accorde autour de moi à trouver telles : on, des hommes, et qui sont maîtres dans leur domaine, reconnus comme tels et consacrés comme tels par le monde entier; mais qui sont également soucieux de jeter bas les cloisons et de faire circuler au-dessus des petites boîtes closes où les spécialistes opèrent, toutes fenêtres fermées, le grand courant d'un esprit commun, d'une vie générale de la Science. 
Je m'arrête et il faut que je m'arrête parce que, cela, c'est le fond même de ma pensée, ce à quoi je tiens par-dessus tout - et alors, excusez le débordement... Donnez à vos étudiants le Traité qui résumera, qui prolongera votre expérience et votre effort fécond dans le cadre de votre discipline à vous : je ne serai pas le dernier, vous le savez, à me réjouir quand je tiendrai enfin, pensé et rédigé par vous, le livre qui nous manque : mais ceci est une chose, l'Encyclopédie en est une autre, très différente, tout aussi légitime. J'aurais aimé que vous passiez d'un plan à l'autre, comme ceux qui me suivent - et que vous serviez à la fois non pas deux dieux jalousement antagonistes et rivaux: le même dieu sous ses deux aspects, le «local» et « l'universel ».

Croyez, etc... p106 
CONTRE LES JUGES SUPPLÉANTS

DE LA VALLÉE DE JOSAPHAT

$\underline{\text { Retour à la table des matières }}$

\section{CAMILLE DESMOULINS :}

HISTOIRE OU RÉQUISITOIRE?

Historien, dénicheur de saints. Le saint, aujourd'hui, c'est Camille Desmoulins. La niche, son Vieux Cordelier ${ }^{33}$. Le dénicheur, Albert Mathiez $^{34}$.

«Le Vieux Cordelier fut, non pas un cri de douleur, mais la rouerie calculée d'un pamphlétaire aux abois.» - Sa verve de "satirique picard et parisien », elle est trop souvent celle d'un " obscur gazetier écossais » (entendez Gordon, auteur du Discours sur Tacite, 1728, et sur Salluste, souventes fois réimprimés en Angleterre et traduits en français à plusieurs reprises : A. Mathiez établit que Desmoulins s'en servit copieusement dans certains numéros du Vieux Cordelier). "Comme un élève paresseux, comme le journaliste pressé par la besogne, Desmoulins cueille et assemble hâtivement des fragments empruntés à un ouvrage de sa bibliothèque. » Et alors, " que penser de la sincérité du plus grand des dantonistes »?

Ces quelques citations, que j'emprunte à l'Introduction, nous renseignent sur le «climat» de la publication. Elle est certes des plus savantes, sérieuses et fouillées. Elle nous procure d'un texte souvent

\footnotetext{
33 Librairie Armand Colin (Les Classiques de la Révolution), 1936.

34 Qui ne put achever le travail : sa mort prématurée en laissa le soin à un de ses élèves, Henri Calvet, qui s'en est acquitté fort bien.
} 
allégué et toujours goûté une édition critique, solide, bien annotée, copieusement bourrée d'appendices que, pour ma part, j'aurais préféré voir grouper et fondre ensemble dans une étude liminaire - mais qui, tels quels, sont pleins d'utilité et de savoir ; ils projettent la lumière la plus aiguë sur les circonstances de la publication, sur son intérêt, sa portée, ses effets et, surtout, sur le sens politique véritable de la manœuvre qu'elle servait. p107

Cela dit, je répugne tout à fait à ce ton de procureur que prend perpétuellement un historien - Mathiez - drapé dans ses vertus civiques et s'arrogeant un droit de jugement rétrospectif un peu enfantin, fort déconcertant en tout cas, puisqu'il ne se fonde sur rien que sur son sens propre: "Accusé Desmoulins, levez-vous... Qu'avez-vous à dire pour votre défense? Vous prétendez que la liberté ( $\mathrm{n}^{\mathrm{o}}$ VI, p. 187) c'est « la fraternité, la sainte égalité, le rappel sur la terre ou du moins en France de toutes les vertus patriarcales » - mais êtes-vous «bien justifié pour faire l'éloge des vertus patriarcales ?» (sic; note 5, p. 187).

$\mathrm{Ne}$ continuons pas. Toute une génération d'historiens s'est complue dans ces allures. Se dressant en pied, tel le Procureur d'un film judiciaire, elle s'occupa à requérir ainsi les peines les plus sévères contre les acteurs ou les comparses de l'histoire, au nom d'une morale variable dans ses principes et d'une politique inspirée par l'idéologie tantôt de "gauche ", tantôt de «droite » : les procureurs de gauche s'indignant, de bonne foi du reste, contre ceux de droite, et réciproquement. Il est temps d'en finir avec ces interpellations rétrospectives, cette éloquence de Parquet et ces effets de manche noire.

L'historien n'est pas un juge. Terminant sa réédition du $n^{0} 1 \mathrm{du}$ Vieux Cordelier (p. 48), Albert Mathiez annote: «La fin de ce numéro est peu modeste. La prétention de Desmoulins d'être un penseur est risible, etc. » - Soit. Mais, après avoir lu ce passage du $n^{0}$ V du Vieux Cordelier (p. 164) : "Qu'est-ce, dans un moment de guerre où j'ai eu mes deux frères mutilés et hachés pour la liberté qu'est-ce que la guillotine, sinon un coup de sabre, et le plus glorieux de tous pour un député victime de son courage et de son républicanisme ?»-quand je trouve cette remarque en bas de page : 
«Il est pénible, en lisant ce morceau de bravoure, d'évoquer l'attitude de Camille Desmoulins au moment de son exécution », je me sens gêné moralement. Et, pesant mes mots, je dis moi aussi, au prêcheur de modestie de la page 48 : "Soyons modestes. Ne jugeons pas. » D'abord parce que, quand nous faisons de l'histoire, ce n'est pas notre métier. Ensuite...

Lâcheté, courage, courage, lâcheté : ces mots-là, ces pauvres mots vous paraissent si clairs, à vous et si simples ; vous croyez qu'on peut, humainement, les manier avec tant de certitude ? Je sais beaucoup d'hommes de ma génération qui, expérience faite (une expérience qui a manqué à Mathiez) ont perdu pour toujours le goût de les prononcer, en Fouquier-Tinvilles de mélodrame. p108

Non, l'historien n'est pas un juge. Pas même un juge d'instruction. L'histoire, ce n'est pas juger, c'est comprendre - et faire comprendre. Ne nous lassons pas de le répéter. Les progrès de notre science sont à ce prix.

\section{UN LIVRE PIAFFANT SUR LA RÉVOLUTION}

Vous m'apportez du nouveau. Du nouveau vraiment nouveau. Merci. Mais est-ce à vous de le crier sur les toits, avec de grands cocoricos de coq égosillé ? Si c'est vrai, nous le verrons bien. Et nous le dirons. Si vous nous laissiez le dire en paix ?

Est-ce à vous, vraiment, de vous proclamer, implicitement, seul intelligent et seul clairvoyant? seul digne d'être lu, entendu, approuvé ? Et aux malheureux qui vous ont précédé, et qui n'ont, les pauvres, ni vos dons évidemment exceptionnels, ni votre héroïsme certainement surhumain, croyez-vous légitime de présenter cette simple alternative : « Imbéciles ou vendus »?

Auteur d'un livre piaffant sur La lutte de classes sous la première République, M. Daniel Guérin commence par rappeler à ses devanciers (p. 368) que Trotzky les qualifiait de «falsificateurs ». Et d'un. Figure de rhétorique cicéroniane, disait Panurge. Pour son compte, M. Guérin les traite, lui, de gros malins qui, « astucieusement», tentent de "tirer de la Révolution française la 
justification de leur domination de classe ». Eh oui, tous. Tous ces historiens démocrates qui (p. 369) ne réussissent point à se dégager du « cocon de la démocratie bourgeoise » (bravo pour le cocon!). Jaurès d'abord. Ce faux socialiste. Qui n'a jamais rompu «le cordon ombilical qui le liait à la démocratie bourgeoise » (p. 371). Qui n'a jamais réussi, le pauvre homme, qu'à « digérer en partie » la méthode matérialiste, la vraie. Qui prétend à la fois être "matérialiste avec Marx et mystique avec Michelet ». Ce qui n'est pas tout à fait exact ; Jaurès a seulement écrit : "Notre interprétation de l'histoire sera, à la fois, matérialiste avec Marx, et mystique avec Michelet »; et vous me direz: «Ce n'est tout de même pas si mal, puisque Michelet, $M$. Daniel Guérin nous dit, p. 370, et il a raison de nous dire, "qu'il domine de cent coudées, par son génie, tous les historiens de la Révolution ». Mais vous n'y êtes pas. Cette collusion de Michelet et de Marx, un inceste. Elle ne peut engendrer que bâtardise. Soyons purs. p109

Encore doit-on à Jaurès quelques égards... relatifs. Mais voici Mathiez. Pauvre Mathiez! Un imbécile ou un vendu. Tout comme les autres. De la méthode matérialiste il a sans doute cherché à vulgariser (p. 376) "ce qu'il était parvenu à en comprendre» - mais en choisissant. Car, " ce qu'il en a compris », c'est ce qu'elle « offrait de moins dangereux pour la classe dominante ». Vous partez d'un franc éclat de rire, à l'idée de ce Mathiez se travaillant pour ne nuire que le moins possible à cette brave classe dominante: vous avez tort. N'essayez même pas de suggérer : "C'était inconscience chez lui ; mais il était de bonne foi... » Impitoyable, M. Daniel Guérin vous dira : Bonne foi, nous n'en usons point céans! Tous ces historiens démocrates sont à mettre, finalement, dans le même sac. «Emportés qu'ils sont par leurs passions », ils subissent, tous, " la pression de leurs intérêts de classe ». Bonne foi, mauvaise foi ? La psychanalyse - on l'attendait, et on souffre de ne la voir entrer en action qu'à cette tardive page 388 du tome II — la psychanalyse n'a-t-elle pas fait s'évanouir toutes ces distinctions périmées ? - Le vrai, c'est que tout historien de la Révolution qui n'est pas Daniel Guérin, « ment ». Peutêtre inconsciemment, en tant qu'homme privé; mais en tant qu'homme de classe, "il ment intentionnellement, et pour mieux asservir » (p. 388). Or, Mathiez (pour revenir à lui), vous n'allez pas prétendre que, « fonctionnaire de la III ${ }^{\mathrm{e}}$ République, loyal serviteur de 
la démocratie bourgeoise » (p. 378), il ne se soit pas vendu, corps et âme, à la classe possédante ? A d'autres! Et quant à Georges Lefebvre, lui non plus (p. 379), il « ne se dégage pas entièrement du cocon de la démocratie bourgeoise» (heureux cocon, qui peut resservir tant de fois sans s'user !) ; on doit, bien sûr, saluer son effort. Mais « regretter sa timidité $» . .$.

Sa timidité ? Joie pure pour un homme du XVI ${ }^{\mathrm{e}}$ siècle comme moi! Il y avait déjà un "timide Lefebvre» dans l'Histoire. En voici maintenant deux. A celui d'Étaples, que depuis quatre cents ans tous les doctrinaires protestants de stricte observance blâment d'avoir été Lefebvre, et non Farel - et cela, par peur, par pure crainte d'être rôti sur le bûcher comme hareng soret; car, pour ces doctrinaires, on ne peut renâcler devant leur doctrine que par peur; elle est logiquement irrésistible - à celui d'Étaples, voici que vient s'adjoindre celui de Lille ; celui qui se prénomme Georges et non point Jacques ; ce maître dans l'art des allusions qui, "dégagées des voiles de la prudence », seraient «susceptibles de se transformer en nettes et vigoureuses conclusions » (p. 379). Car, pas de doute: si Georges Lefebvre ne parle p110 point comme Daniel Guérin lui-même, c'est uniquement qu'il a peur. Psychologie simple. Cordiale. Subtile. Celle de tous les fanatiques dans tous les temps.

Là-dessus, une petite dissertation sur «l'histoire impartiale » (p. 379-382). Le souffle rafraîchissant du baccalauréat de philosophie. Et quand on se sent l'haleine un peu courte, une bonne citation de Raymond Aron - qui n'en peut mais. Bien vite, on revient au propos fondamental : les historiens bourgeois ? " ils ont tous quelque chose à cacher» (p. 386). Seul, M. Guérin «n'a rien à cacher» (p. 389). Eux ? ils ont les mains pleines de vérités, mais les ouvrir, jamais. Ils causent ainsi « à l'histoire »(mais qui est cette dame ?) un préjudice « dont il n'est pas possible de déterminer l'importance ». En bref, ces menteurs, « ils nous trompent ».

Oh ! M. Guérin est bon prince. Il consentira à dire, si on l'en prie bien fort: «Ils se trompent ou nous trompent» (p. 388). Formule qui lui semble « moins discourtoise à l'égard de maîtres qui... », etc. Mais, cher Monsieur, les traiter de faussaires, avec Trotzky, ces maîtres ; et puis de menteurs; et puis de fabricants d'allusions, obscures par 
«prudence»; écrire que vous les prenez «en flagrant délit de dissimulation » - serait-ce courtoisie ? La colère vous emporte. «Pourquoi n'aurions-nous pas le droit d'être en colère ? (p. 389)» Oh! vous en avez le droit. Pleinement le droit. Soyez " en colère ». Comme le Père Duchêne, f... Mais il était, ce b... là, il était, f..., infiniment plus drôle que vous avec ses colères à chaud, f... Nous redemandons le Père Duchêne. Il ne pissait pas du vinaigre à froid. Vive sa verve, et qu'on nous laisse tranquille avec ces échauffements laborieux d'écrivain. Qui n'a pas nécessairement « les bras nus ».

Ce genre de ton-là ? Il me rappelle quelque chose - ou quelqu'un. Ah oui! Georges Sorel. Brandissant avant la lettre son " couteau de cuisine » contre Jaurès. Le cher Sorel de Lagardelle et de Mussolini. — Vive le Père Duchêne, foutre !

Un dernier mot. Puisque nous sommes tous ou des idiots ou des vendus - c'est couru d'avance — pourquoi faire à nos revues « bourgeoises », à nos revues «qui ont quelque chose à cacher », à nos revues qui mentent et dissimulent, le service de votre livre ? Ce n'est pas vous, c'est l'éditeur? Eh, on a pendu, au nom de bonnes doctrines, beaucoup de braves gens qui n'avaient pas de ces collusions-là sur la conscience !

Cela dit, qu'il fallait dire (et je prie le lecteur de considérer que je ne suis pas historien de la Révolution, heureusement pour moi ; que j'ai à peine connu Mathiez et de fort loin; et ${ }_{\mathrm{p} 111}$ donc que j'interviens dans ce débat à titre purement gratuit : à titre de vieille bête, sans plus, qui date de l'autre siècle et ne comprend rien à rien) — cela dit, si nous abordons le livre même de M. Daniel Guérin, qu'y trouvonsnous?

Une étude, une enquête de seconde main, mais poussée et vivante, sur ce thème: "La Révolution française fut une révolution bourgeoise. Mais elle fut autre chose également : l'amorce, l'embryon d'une révolution prolétarienne. Essayons de le démontrer. Examinons, avec une particulière attention, l'histoire, même fragmentée, même embryonnaire, de cette révolution prolétarienne... »

Ici, j'ai bien envie de répondre : « Mais, cher Monsieur, examinez. Tout à votre aise. Quel inconvénient pensez-vous que nous y 
trouvions ? » Je dirai plus. J'ai bien envie de répondre : « Mais cela va de soi! Vous nous apportez une révélation subite. Vous nous confiez votre grand dessein comme s'il était miraculeux. Vais-je vous avouer que je n'y vois rien de miraculeux, pour ma part? Et que, d'avance, je suis assez disposé à vous croire ? J'ai lu, tout comme un autre, des textes comme ces lettres de Babeuf antérieures à 1789, qui m'ont toujours saisi. Et pourquoi refuserais-je de donner audience aux faits que vous nous apportez?»

— «Eh, parce que vous êtes pourri de sentiments de classe Vous n'êtes pas trotzkiste... - Cher Monsieur, je n'en sais rien : vous non plus. Ce sont mes petites affaires. Et que je sois trotzkiste, ou staliniste, ou papiste, ou bouddhiste, qu'est-ce que cela peut bien vous faire ? Quand je fais de l'histoire, je suis historien. — Imbécile ! Vous êtes au service d'intérêts qui vous tiennent... Et si sot que vous ne vous en rendez même pas compte. Ou alors, si canaille que vous faites comme si... Voyez, mon argumentation est simple; elle consiste en toute occasion à vous offrir le choix : idiot? ou vendu ? ou les deux à la fois ? Pas de cassement de tête... »

Parlons sérieusement. L'inconvénient, entre bien d'autres, des procédés de discussion qu'adopte $D$. Guérin, c'est qu'ils vous empêchent presque de dire : "Je suis de son avis » - si on a quelque sentiment de sa dignité (mais, après tout, depuis la psychanalyse, y at-il encore lieu de parler de sa dignité ? ). On se sent gêné. Si on le contredit, D. Guérin, c'est par intérêt, dira-t-il, ou par peur. Si on l'approuve, ne sera-ce point par peur, ou par intérêt?

On l'approuve? Il ne s'agit pas du fond. Aux historiens spécialisés dans l'étude de la Révolution d'en discuter. Il s'agit de l'effort et de la tentative. Pour ma part, je ne vois rien qui p112 m'empêche de l'approuver. Je définis volontiers l'histoire un besoin de l'humanité le besoin qu'éprouve chaque groupe humain, à chaque moment de son évolution, de chercher, et de mettre en valeur dans le passé les faits, les événements, les tendances qui préparent le temps présent, qui permettent de le comprendre et qui aident à le vivre. Et j'ajoute : recomposer la mentalité des hommes d'autrefois; se mettre dans leur tête, dans leur peau, dans leur cervelle pour comprendre ce qu'ils furent, ce qu'ils voulurent, ce qu'ils accomplirent; mais ne pas 
considérer, cependant, qu'il dépend d'un homme d'arrêter son œuvre à un certain point, à partir du moment où cette œuvre se répand sur le monde; être attentif, au contraire, à ce drame perpétuel du grand homme, du grand chercheur, du grand inventeur, de l'homme de génie à qui son œuvre échappe de son vivant même, — son œuvre qui se déforme, son œuvre qui s'altère, son œuvre qui, adoptée par la foule et déroulant ses effets au cours des temps, finit souvent par dire le contraire, très exactement, de ce qu'il voulait qu'elle dise (voyez Luther et le luthéranisme) - tel est le devoir même de l'historien. Alors, qu'est-ce qui peut bien me gêner, cher Monsieur, dans votre tentative ? Je le cherche en vain, je ne le vois pas. Je ne vois que des injures. Elles me gênent. Ne me prenez pas pour une femmelette. Je sais dire... non, tout comme un autre. Mais je ne crois pas aux grands gestes de manchette des procureurs de cinéma. Aux réquisitoires filmés. Aux mépris de ministère public. Pardonnez-moi. Je suis un vieil historien très ridicule. Bien de la chance à nos successeurs, si ce ton-là doit devenir la règle. p113 


\title{
Sur une Forme d'Histoire qui n'est pas la nôtre
}

\author{
L'HISTOIRE HISTORISANTE
}

$\underline{\text { Retour à la table des matières }}$

J'ai lu avec soin, et naturellement avec intérêt, le petit livre que mon vieil ami Louis Halphen, utilisant les loisirs forcés que lui faisait le gouvernement de Vichy, a composé dans la solitude, loin de ses livres volés et de ses papiers dispersés par les "occupants», avec le seul soutien de son expérience : celle d'un historien qui n'a cessé de travailler depuis 1900, tantôt pour son compte personnel, tantôt en provoquant et en dirigeant le travail des autres: je songe naturellement à cette Collection Peuples et Civilisations à quoi s'attache, en même temps que celui de Sagnac, son nom.

Ce petit livre, Halphen l'intitule Introduction à l'histoire ${ }^{35}$. Mais, plutôt qu'une Introduction, c'est une Défense de l'histoire qu'il entreprend. "On n'a jamais aussi vivement contesté, nous dit-il, l'utilité des études historiques... Mon dessein n'est pas de plaider une cause qui se défend d'elle-même... » Eh ! pas si bien que cela, faut-il croire; sans quoi les attaques auraient cessé depuis longtemps. Louis Halphen s'en doute, qui aussitôt entreprend de plaider, de justifier une prise de position depuis longtemps connue, et sans mystère.

«De toutes les fidélités, écrit le Gide des Prétextes (p. 97), celle à soi-même est la plus sotte, dès qu'elle n'est plus spontanée. » Rien de plus spontané, donc de plus légitime, que la fidélité de l'historien de Charlemagne à ses idées. Tel nous le retrouvons sous ses chevrons, tel 
il était au sortir de l'École des Chartes : le paladin convaincu de cette forme d'histoire que Henri Berr a baptisé heureusement l'histoire historisante. A elle, Louis Halphen a consacré sa vie. Et s'il nous dote aujourd'hui d'une ${ }_{\mathrm{p} 114}$ Introduction à l'histoire, entendez bien que ce n'est point à l'universelle Clio qu'il offre ce sacrifice - à Clio abritant sous les plis de son péplum toutes les formes, toutes les variétés, toutes les diversités des écoles historiques, de même que la Vierge de Miséricorde abritait sous son manteau tous les représentants valables de la chrétienté. Plus modeste, et plus orgueilleux, Halphen ne pense qu'à une certaine forme d'histoire : celle qu'il cultive ; et il nous fait l'honneur de penser que nous l'acceptons tous comme la seule qui vaille. Introduction à l'histoire ? Défense de l'histoire ? Non. Plaidoyer pour l'Histoire historisante, celle dont Berr écrivait, en 1911 : «Il y a là une forme d'histoire qui, se suffisant à elle-même, prétend suffire en outre à la connaissance historique. » Cette phrase me réjouit. Elle forme, à elle toute seule, le compte rendu critique du livre de Louis Halphen ${ }^{36}$.

Qu'est-ce en effet qu'un historien historisant? Utilisant les termes d'une lettre qu'Halphen lui-même lui écrivait en 1911, Henri Berr répondait en substance: un homme qui, travaillant sur des faits particuliers par lui-même établis, se propose de lier ces faits entre eux, de les coordonner, puis (je cite l'Halphen de 1911) «d'analyser les changements politiques, sociaux et moraux que les textes nous révèlent à un moment donné ». Les changements particuliers, entendez bien, puisque, pour notre auteur, l'histoire se définit une science du particulier ${ }^{37}$.

Or, ouvrons l'Introduction à l'histoire de 1946. Trois chapitres fondamentaux au cours du livre: I, L'établissement des faits ; II, La

\footnotetext{
36 L'histoire traditionnelle et la synthèse historique, Paris, Alcan, 1921, 146 pages. La « Discussion avec un historien historisant », qui fait le fond du chapitre II, date déjà de 1911.

37 Un particulier qui, saisi à l'intérieur d'un même cercle de civilisation, à une certaine époque, ressemblerait furieusement à un général. Si on donne audience à cette grande dame, chère à Pirenne, chère à Marc Bloch, chère à nous tous ici, qui s'appelle l'histoire comparée.
} 
coordination des faits; III, L'exposé des faits. La doctrine n'a pas changé, la vieille doctrine des deux opérations qui constituent l'Histoire ; établir les faits d'abord, les mettre en œuvre ensuite. Ainsi, nous dit-on, procédaient Hérodote et Thucydide. Ainsi Fustel et Mommsen. Ainsi nous tous aujourd'hui. Je veux bien. Mais, établir les faits, puis les mettre en œuvre : voilà une de ces formules claires qui laissent anxieux, et pantois, tous les esprits curieux...

Car enfin, les faits... Qu'appelez-vous les faits ? Que mettez-vous derrière ce petit mot, "fait»? Les faits, pensez-vous qu'ils p115 sont donnés à l'histoire comme des réalités substantielles, que le temps a enfoui plus ou moins profondément, et qu'il s'agit simplement de déterrer, de nettoyer, de présenter en belle lumière à vos contemporains? Ou bien reprenez-vous à votre compte le mot de Berthelot, exaltant la chimie au lendemain de ses premiers triomphes - la chimie, sa chimie, la seule science entre toutes, disait-il orgueilleusement, qui fabrique son objet. En quoi Berthelot se trompait. Car toutes les sciences fabriquent leur objet.

Bon pour nos devanciers, les contemporains des Aulard, des Seignobos, des Langlois, bon pour ces hommes à qui « la Science » en imposait si fort (mais ils ignoraient tout de la pratique des sciences et de leurs méthodes), bon pour eux de se figurer qu'un histologiste est un homme à qui il suffit de mettre sous son microscope une tranche de cervelle de rat : il saisit aussitôt des faits bruts, des faits indiscutables, des faits «tout cuits », si j'ose dire ; il n'a plus qu'à les ranger dans ses tiroirs. Don, non pas de Michelin, mais de la Nature elle-même... On les eût bien étonnés, les historiens, nos aînés, en leur disant qu'un histologiste, en réalité, fabrique d'abord, à grand renfort de techniques délicates et de colorants subtils, l'objet même de ses recherches et de ses hypothèses. Il le "révèle" en quelque sorte, au sens photographique du mot. Après quoi, il l'interprète. "Lire ses coupes », opération qui n'est pas simple. Car décrire ce qu'on voit, passe encore, mais voir ce qu'on doit décrire, voilà le redoutable ! On les eût bien étonnés, oui, nos aînés, en définissant les faits, comme un philosophe contemporain, «des clous à quoi s'accrochent les théories ». Des clous qu'il faut forger avant de les planter dans le mur. Et s'agissant d'histoire, c'est l'historien qui les forge. Ce n'est pas, 
comme il dit, «le Passé». Ou, par une étrange tautologie, « l'histoire ».

Êtes-vous d'accord? Dites-le. N'êtes-vous pas d'accord? Discutez. Mais, de grâce, ne passez pas sous silence ce problème. Ce mince problème. Ce capital problème.

Voilà un premier silence qui nous sépare. Et que de conséquences !

Avez-vous assez entendu nos aînés répéter : «L'historien n'a pas le droit de choisir les faits. De quel droit? Au nom de quels principes ? Choisir, en attentant contre la "réalité », donc contre la " vérité ». Toujours la même idée ; les faits, de petits cubes de p116 mosaïque, bien distincts, bien homogènes, bien polis. Un tremblement de terre a disloqué la mosaïque ; les cubes se sont enfouis dans le sol; retirons-les et, surtout, veillons à ne pas en oublier un seul. Ramassons-les tous. Ne choisissons pas... Ils disaient cela, nos maîtres, comme si, du seul fait du hasard qui a détruit tel vestige et protégé tel autre (ne parlons pas, en ce moment, du fait de l'homme), toute histoire n'étant pas un choix. Et s'il n'y avait que ces hasardslà ? - En fait, l'histoire est choix. Arbitraire, non. Préconçu, oui. Et ceci, encore, cher ami, nous sépare.

Hypothèses, programmes de recherches, théories même : autant de choses qu'on cherche dans votre introduction: mais elles ne s'y trouvent point.

Or sans théorie préalable, sans théorie préconçue, pas de travail scientifique possible. Construction de l'esprit qui répond à notre besoin de comprendre, la théorie est l'expérience même de la science. D'une science qui n'a pas pour ultime objet de découvrir des lois, mais de nous permettre de comprendre. Toute théorie est naturellement fondée sur ce postulat que la nature est explicable. Et l'homme, objet de l'histoire, fait partie de la nature. Il est pour l'histoire ce qu'est la roche pour le minéralogiste, l'animal pour le biologiste, l'étoile pour l'astro-physicien : quelque chose à expliquer. A faire comprendre. Donc à penser. Un historien qui refuse de penser le fait humain, un historien qui professe la soumission pure et simple à 
ces faits, comme si les faits n'étaient point de sa fabrication, comme s'ils n'avaient point été choisis par lui, au préalable, dans tous les sens du mot choisi (et ils ne peuvent pas ne pas être choisis par lui) - c'est un aide technique. Qui peut être excellent. Ce n'est pas un historien ${ }^{38}$.

Et je termine par mon grand grief. Introduction à l'Histoire, Méthode de l'histoire, Théorie de l'histoire, Défense de l'histoire... Mais qu'est-ce donc que l'histoire?

Je vais vous le dire... Vous recueillez les faits. Pour cela vous allez dans les Archives. Ces greniers à faits. Là, il n'y a qu'à se baisser pour en récolter. De pleines panerées. Vous les époussetez bien. Vous les posez sur votre table. Vous faites ce que font les p117 enfants, quand ils s'amusent avec des « cubes », et travaillent à reconstituer la belle image qu'on a brouillée pour eux... Le tour est joué. L'histoire est faite. Que voulez-vous de plus ? - Rien. Sinon : savoir pourquoi. Pourquoi faire de l'histoire ? Et donc, qu'est-ce que l'histoire ?

Vous ne me le dites pas? Alors je m'en vais. Vous me rappelez ces pauvres gens à qui l'Université, par une déplorable aberration, confiait la tâche — cependant difficile entre toutes — d'initier aux mathématiques les petits " littéraires » que nous étions, sur les bancs de la sixième, et de la cinquième, et de la quatrième classique. Comme ils ont bien réussi à m'empêcher de faire des mathématiques ! C'est qu'ils les réduisaient à je ne sais quelle révélation de petits procédés, de petits artifices, de petites recettes pour résoudre les problèmes. Des «trucs», comme nous disions dans notre argot d'écoliers, aujourd'hui désuet...

Mais voilà : les «trucs » ne m'intéressaient pas du tout. On me donnait de «bons tuyaux» pour faire quelque chose dont on ne me disait jamais pourquoi ce quelque chose méritait d'être fait. Comment

38 Il y a un Index des noms d'auteurs dans le livre de Louis Halphen. C'est un témoignage à sa façon. N'est-il point remarquable que n'y figurent ni Camille Jullian, ni Henri Pirenne, ni Marc Bloch, ni Georges Lefebvre, ni personne de ceux, au total, qui pour nous sont les historiens, les véritables historiens de ce temps ? Je ne parle pas Vidal : la géographie n'a pas droit de cité dans l'histoire historisante. 
et pourquoi on l'avait inventé. Et finalement, à quoi cela servait... A entrer un jour à l'École Polytechnique ? Mais Polytechnique n'est pas une fin en soi. Et dès ce temps-là (tant pis pour moi) j'avais quelques exigences fondamentales d'esprit... Alors, c'était bien simple. Je tournais le dos aux mathématiques. Et ceux-là de mes camarades qui n'en demandaient pas tant, triomphaient...

L'histoire historisante demande peu. Très peu. Trop peu pour moi, et pour beaucoup d'autres que moi. C'est tout notre grief : mais il est solide. Le grief de ceux à qui les idées sont un besoin. Les idées, ces braves petites femmes, dont parle Nietzsche, qui ne se laissent pas posséder par les hommes au sang de grenouille. p118 


\title{
Deux Philosophies Opportunistes de l'Histoire
}

\author{
DE SPENGLER A TOYNBEE
}

$\underline{\text { Retour à la table des matières }}$

Trois gros livres sur ma table. A la première page, un nom bien connu en Angleterre (et même hors d'Angleterre), pour des mérites pragmatiques autant que pour des auvres scientifiques: Arnold J. TOYNBEE. Titre : A Study of History ${ }^{39}$. Ne nous donnons pas l'air de découvrir une œuvre, qu'on assure devoir prendre rang, par son allure et ses dimensions, aux côtés de l'œuvre célèbre de sir James Frazer. De même que l'auteur du Rameau d'or a instauré l'étude comparative des institutions religieuses "primitives" - de même A. Toynbee prétend mener à bien, en une vingtaine de volumes, une étude comparative des civilisations que l'humanité a successivement créées : l'étude, si l'on veut, des expériences humaines en matière de civilisation.

Ample et généreux dessein. S'il nous inspire dès l'abord un effroi que nous ne songeons point à dissimuler; s'il doit, toutes choses bien pesées, nous inspirer finalement un éloignement méthodique et raisonné, nous n'opposerons du moins à son auteur aucune question préalable. Nous n'entrerons pas dans ces gros livres avec un âpre désir d'orchestrer la revanche facile du «spécialiste» sur l'essayiste séducteur. Le livre est complexe. Positif et négatif à la fois, il se rattache par un lien évident à toute une série de manifestations récentes - diverses dans leur forme, pareilles dans leur esprit.

39 Oxford University Press; London, Humphrey Milford ; $1^{\text {re }}$ éd., juin 1934. 
Les historiens ont le privilège, depuis quelques années, d'être mis sur la sellette par un lot varié d'hommes remarquables - poètes, romanciers, journalistes, essayistes - qui, distrayant en faveur de Clio quelques moments d'une vie dédiée à d'autres cultes, comprennent instantanément (ils l'assurent du moins) ce ${ }_{\text {p119 }}$ que des années d'études exclusives n'ont jamais laissé les historiens capables de saisir et d'exprimer. Après quoi, avec une charité nuancée, chez les uns d'ironie française, chez les autres de fureur germanique ou d'humour anglais, ces esprits brillants et rapides nous communiquent, en quelques traits de flamme, leurs découvertes ou leurs systèmes. Que faire? Les remercier sans fausse honte; examiner en toute sincérité leurs critiques; nous rendre ou résister? Oui, si nous voyons en eux des camarades de combat, et qui peuvent nous toucher soit par des arguments rationnels, soit par des appels au sentiment : car après tout, historiens, nous vivons dans la même atmosphère de crise que les autres hommes nos contemporains - et il nous faut, pour persévérer, de la confiance en nous et en nos œuvres. Non, si, derrière un paravent d'histoire, nous décelons chez ces hommes la séduction d'erreurs et d'illusions. Non, résolument non, si dans leurs écrits nous constatons l'action d'un poison de l'esprit. Et voilà qui nous oblige à un long examen.

Toutefois, avant d'aborder Toynbee et son œuvre, un rappel. Par manière d'introduction, mais non point de hors-d'œuvre.

\section{Oswald Spengler : Grandeur et décadence d'un prophète}

En 1922, un livre paraissait en Allemagne. Nom d'auteur inconnu, SPENGLER. Titre à effet : Der Untergang des Abendlandes ${ }^{40}$. Je vois encore aux devantures des librairies rhénanes s'enlever les piles impressionnantes de ces in-octavo: elles fondaient comme neige au soleil. En quelques semaines le nom d'O. Spengler était célèbre dans le monde germanique - et son livre connaissait le plus grand succès qu'un livre de philosophie historique ait connu en Allemagne depuis

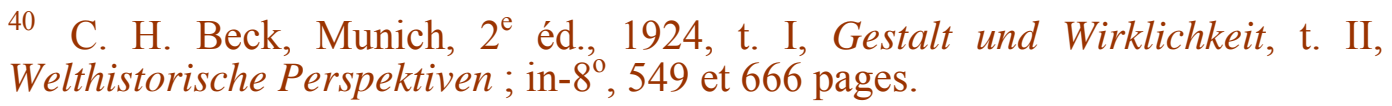


Gibbon. Encore succès n'est-il pas le vrai mot : il faudrait parler de révélation.

A l'étranger, accueil moins chaleureux. Curiosité réservée en Angleterre ; méfiance ironique chez nous : on attendit trois ans (1925) le petit livre de Fauconnet qui cataloguait les thèmes spenglériens, et deux ans une traduction à retardement. Cependant, une copieuse littérature (Der Streit um Spengler ; O. Spengler und das Christentum, etc.) retournait sous toutes les faces, avec une patiente monotonie, les idées du prophète, de celui qui n'hésitait point à se proclamer luimême le "Copernic de l'histoire ». Ne le jugeons point; juger n'est pas le fait d'un historien; ${ }_{\mathrm{p} 120}$ essayons de le comprendre, ce qui veut dire, en l'espèce, de mettre son livre, et son succès, en rapport avec les besoins d'une Allemagne dès lors en gestation de ce qui allait devenir le national-socialisme hitlérien.

L'homme - il est mort en 1936 dans un grand abandon l'homme était né en 1880 dans la Prusse orientale. Protestant, de famille modeste, il passa en 1904 son doctorat de «Sciences naturelles » avec une dissertation sur Héraclite. Or, tout le Déclin de l'Occident porte témoignage d'une haine violente contre le respect dont trop d'Allemands entouraient les sciences de la Nature et le libéralisme de leurs adeptes, leur conception du progrès notamment; progrès, libéralisme, les dieux dont le culte avait été imposé au jeune Spengler par son milieu familial, ses maîtres et ses compagnons d'étude. Là contre, réaction brutale - et aussi contre l'atomisme historique, le travail de monographie, le découpage de l'histoire en tranches qui s'ignorent : histoire diplomatique, économique, littéraire, histoire des arts, des sciences, des philosophies, etc. A la place de tous ces compartiments, un vaste et clair palais. Une histoire totalitaire. Peuples et langues, dieux et nations, guerres, sciences et philosophie, conceptions de la vie et formes de l'économie : autant de symboles à interpréter. Analogie, la méthode même de l'histoire. Entre le calcul intégral et la politique de Louis XIV, entre la géométrie euclidienne et la cité grecque, entre le téléphone et le mécanisme du crédit, les relations et les correspondances ne sont pas superficielles et fortuites. Elles sont intimes et essentielles. 
Tous les faits humains d'une même époque s'intègrent dans des « cultures ». Et ces cultures sont des êtres vivants. Disons, des plantes - qui naissent, s'épanouissent, se fanent et meurent. Leur destin commence quand la poussée, la prolifération de tout ce qu'elles englobent dans leur unité se fait anarchique et déréglée. Au reste, bien que toutes accomplissent dans le même ordre les mêmes étapes chacune diffère profondément de ses voisines par l'âme même qui l'anime. Notre culture occidentale possède l'âme de Faust - éternelle tension, désir de l'impossible, dynamisme du cœur et de l'esprit. De la culture antique l'âme était «apollinienne »: statisme et non point dynamisme; calme, lenteur, sérénité ; pas de chronomètre ni d'histoire scientifique, mais la colonne dorique et la géométrie d'Euclide. Et pareillement pourrait-on donner à la culture égyptienne son symbole : le chemin coupé, étroit et mystérieux qui guide le visiteur vers le tombeau secret du Pharaon. Mais toutes ces cultures, si distinctes soient-elles, connaissent successivement une période ${ }_{\mathrm{p} 121}$ ascendante (Kultur); une période descendante (Civilization) finalement, la mort.

Faut-il se pencher sur ces imageries vivement coloriées comme l'amateur se penche, avec sa loupe, sur une épreuve avant la lettre de la Foire de l'Impruneta? - Que nous veulent ces cultures unifiées et totalitaires, que partageraient indistinctement et pareillement tous les hommes vivant à la même époque, quelle que soit leur condition sociale - et qu'il s'agisse de Bergson ou de Babitt, du commis du Printemps derrière son comptoir, du savant dans son laboratoire ou du fermier dans son village ? Alors quoi, tous, l'âme faustienne et sa grandeur violente? - Mais ces beaux mots, ces métaphores vitalistes : naissance, épanouissement, mort des cultures ? Du vieux neuf. Et qui reporte le lecteur français aux beaux temps (1887) d'Arsène Darmesteter et de son petit livre, La vie des mots ${ }^{41}$, si vite remis au point par Michel Bréal : ce siècle n'était pas né.

\footnotetext{
41 Paris, Delagrave, 1887, in-12, XII-212 pages. Introduction, p. 3 : « Les langues sont des organismes vivants, dont la vie, pour être d'ordre purement intellectuel, n'en est pas moins réelle - et peut se comparer à celle des organismes du règne végétal ou du règne animal.» - Cf. également, à la fin, p. 175 : «Dans la vie organique des végétaux et des animaux, comme dans la vie linguistique, nous retrouvons l'action des mêmes lois », etc.
} 
Comment donc s'expliquer le succès prodigieux de Spengler, et pas seulement auprès du grand public, sans défense contre ses impressions: auprès de tous les hommes cultivés d'Allemagne et d'Autriche, les jeunes surtout?

C'est qu'à tous Spengler apparaissait comme un libérateur. Quand nous lisons ses apostrophes et ses objurgations: "Assez de monographies, des synthèses !» — nous sommes tentés de sourire. Certes, nous avons, nous aussi, nos myopes, nos taupes fouisseuses ${ }^{42}$ - mais les synthèses substantielles et vivantes ne nous font point défaut. En Allemagne, par contre, l'histoire restait soumise, au lendemain de la guerre encore, à un régime de spécialisation outrancière. Écrites en jargon par des techniciens pour des techniciens, les monographies ne sortaient pas des cercles universitaires; l'histoire dont elles édifiaient patiemment les fondations, c'était la chose de docteurs acharnés à se contredire : Vadius déchirant Trissotin. Un monde clos, ce domaine des techniciens et de leurs barbares dissertations inaugurales. p122 L'homme normal cultivé n'avait point à y pénétrer. Fach, et sacrilège, le laïc qui portait la main sur un Fach.

Or, Spengler prêchait ce sacrilège - et la mise en commun des richesses pillées. Spengler le prêchait, non en jargon de spécialiste, mais dans une langue claire, vivante, pleine de cadence et d'éclat. A l'inquiétude intellectuelle des bourgeois d'après guerre il jetait en pâture une histoire par lui dérobée aux historiens patentés - une histoire traduite en formules dont chacune recouvrait des siècles de passé humain. Entre faits jusqu'alors parqués strictement dans des compartiments étanches - il nouait des relations qui saisissaient par leur imprévu et divertissaient par leur variété : la géométrie d'Euclide tendant la main à la colonne dorique, quel spectacle piquant! Tout un public allemand dut à Spengler la joie naïve et pure de découvrir l'histoire — ou du moins une histoire mise à sa portée, avec des

42 Cf. les réflexions de Georges EspinAs, dans les Annales d'Histoire Économique et Sociale, t. VI, 1935, p. 365: De l'horreur du général : une déviation de la méthode érudite. 
perspectives dessinées pour lui. Et ce public prit l'offrande avec reconnaissance.

D'autant que l'auteur, se muant en prophète, annonçait le déclin de tout ce à quoi ses lecteurs tenaient vraiment: source nouvelle de joie et de libération. Car, enfin, participer à l'essor d'une civilisation qui monte, bien. Vivre les jours d'un déclin, mieux. Et, placé devant le trépas, l'accepter virilement: «Soit, qu'il vienne !» — belle attitude romantique; on se sait gré à soi-même de l'adopter. Certes, les historiens de profession haussaient les épaules ou criaient au scandale - quitte à ramasser quelques miettes du gâteau sous la table, en cachette. Certes, les marxistes s'indignaient, dénonçant une doctrine indifférente à tous les aspects sociaux de l'histoire et de la vie. Le lecteur moyen, lui, se sentait flatté dans son amour-propre individuel et dans son amour-propre actuel. Petit bourgeois prussien ou saxon, il n'avait pas sans doute l'âme faustienne : mais il désirait l'avoir, ou se figurer qu'il l'avait; Faust symbole de toute la civilisation d'Occident, l'incarnation était plaisante et douce à son cœur. Après cela, que telle théorie de Spengler lui parût fumeuse ou malaisée, qu'importait? Sentir confusément, c'est plus facile encore, et moins fatigant, que comprendre en toute lucidité.

Notons-le enfin (et quelques naïvetés de la critique française ne rendent point la note inutile) : la philosophie de l'histoire n'était qu'un des aspects de la pensée spenglerienne - et le moindre à son gré. L'histoire, un buste de Janus : une face vers le passé, mais l'autre vers l'avenir: et quel avenir? Le déclin de l'Europe, préfiguré déjà, suivant les règles de l'analogie, par le déclin de l'Empire romain. La constitution d'Empires gigantesques. p123 La guerre entre ces Empires, et d'abord, et surtout, entre l'Empire britannique, d'essence capitaliste, et l'Empire germanique, d'essence étatiste. L'avenir ? Une poignée de grands hommes, d'une part; la masse, d'autre part. D'où les prêches aux jeunes : «Ne perdez plus votre temps à la poésie, à la philosophie, à la peinture. Passé mort. Formez en vous la matière première d'où surgiront les grands hommes. »- Thèmes esquissés dans Le déclin, mais repris et orientés dans Neubau des deutschen Reiches ou dans Politische Pflichten der deutschen Jugend, programmes politiques d'un homme qui compta, dit-on, parmi les tout premiers adhérents du national-socialisme. 
C'est que, en ce temps-là, Spengler et ses lecteurs, les futurs Nazis de stricte obédience, avaient des ennemis communs : la démocratie, le libéralisme bourgeois et le marxisme. Spengler tenait boutique, en ces années 20, des denrées alors les plus convoitées : disons, un certain pathétique, un anti-intellectualisme résolu, la notion héroïque du destin, l'anti-esthéticisme, le frisson de la créature humaine devant la majesté, l'ample majesté de l'histoire. Et encore (voir son travail de 1920, Der Mensch : Die Technik) la prophétie de ruine, si chère au petit bourgeois nazi, si bien accordée à ses rêves d'autarcie : "Les excès du machinisme perdront l'Europe; les races de couleur apprendront de la race blanche à forger, dans ses propres ateliers, les armes dont elles se serviront contre elle... » Voilà ce qui mérita à Spengler ses succès : ceux, non pas d'un historien analyste et déductif, mais d'un prophète, d'un magicien, d'un visionnaire parfaitement Adapté aux besoins de l'Allemagne troublée d'entre 1922 et 1929. Et, contre-épreuve probante: s'il a perdu dans ses dernières années l'estime générale des milieux nazis - ce n'est point parce que ses théories d'historien ont été reconnues fausses. C'est parce que l'attitude sentimentale qui avait assuré son succès, c'est parce que ses prophéties tenaces ont cessé de s'accorder avec l'idéologie du parti triomphant, dès lors que celui-ci fut maître du pouvoir.

« Nous allons changer le monde. Ou tout au moins l'Allemagne » : mot d'ordre d'après la victoire. Umbruch; Neubeginnen; Der neue Mensch : expressions lourdes d'optimisme actif, et qui, du jour au lendemain, furent dans toutes les bouches et sous toutes les plumes. A ce besoin de confiance et de foi dans l'avenir, à ce besoin fanatique d'espérances propres à faire surgir ${ }_{\mathrm{p} 124}$ les énergies et les vaillances nécessaires au labeur quotidien, comment accorder les prédications pessimistes de l'homme qui, pendant des années, avait redit, inlassablement, la fatalité du destin, l'écrasement du présent par le passé, la vanité de vouloir secouer le joug de l'histoire en donnant, à une civilisation agonisante, un illusoire élan? 
Spengler ne le sentit pas, et son dernier livre - Jahre der Entscheidung ${ }^{43}$ - acheva de le brouiller avec les nationauxsocialistes. Il abondait en redites : la fin du monde viendrait des races de couleur ; l'idéologue ne peut rien dans le domaine de la politique extérieure et de l'économie internationale, etc. Il caractérisait durement les illuminés du national-socialisme, « ces petits jeunes gens éternellement excités » (schwärmende ewige Jünglinge), ces enfants sans maturité, dépourvus d'expérience et de la volonté, même de faire des expériences - d'un mot, ces adeptes, non plus du romantisme social des communistes, mais d'un romantisme politico-économique qui tenait pour des faits positifs et probants, le nombre de voix dans les élections, l'ivresse triomphale des grands discours, et les théories monétaires de quelques incompétents. - Des hommes, non : des têtes de moutons dans un troupeau. Et qui, se sentant innombrables, s'aveuglent volontairement sur leur impuissance (p. 8), en parlant de leur victoire sur l'individualisme.

Manque de contact caractérisé avec l'Allemagne nouvelle. De quoi faire douter des qualités de prophète et d'historien de Spengler. Et par là-dessus, ce ridicule : l'homme qui rompait ainsi avec le peuple de ceux qui l'avaient acclamé, continuait de s'offrir aux nazis comme leur vrai conseiller. C'est que, expliquait-il gravement (p. 7) : «Qui agit ne voit pas loin. Il va, poussé par les événements, sans bien voir le but. Peut-être, s'il l'apercevait, se mettrait-il en travers du mouvement - car la logique du Destin n'a jamais pris cure du désir des humains ; mais, le plus souvent, il se laisse égarer par le mirage trompeur des choses qui l'entourent...» Que faire, sinon se fier à l'histoire - et croire en Spengler, détenteur souverain de la Clef magique qui ouvre à la fois l'histoire du passé et celle de l'avenir ?

Pion, pion! répondaient les nazis : Oberlehrer, Oberlehrer! Et encore, songeant à la thèse spenglerienne de l'homme bête féroce et du monde croulant de guerre en guerre et de révolution en révolution dans l'abîme final: "Sadique de bureau! Faiseur de p125 mélodrames !» — Car il fallait croire en Allemagne, en 1936, que

43 Munich, C. H. Beck, 1933, in- $8^{\circ}, 165$ pages. - Critiques nazistes : voir notamment A. ZWEININGER, Spengler und 3. Reich, 1933, et G. GRAUDEL, Jahre der Ueberwendung, 1934. 
l'homme moyen était bon, et que la paix du monde serait l'œuvre dernière du national-socialisme triomphant...

L'histoire, dans tout cela ? Comme il a vite craqué, le mince vernis d'historien qui recouvrait, dans l'Allemagne troublée de 1922 à 1929, la mixture politique d'un homme adroit, séducteur et bien disant...

\section{L'ascension d'un nouveau prophète : Arnold J. Toynbee}

Or, voici qu'une dizaine d'années après l'apparition du livre de Spengler, voici qu'en langue anglaise, cette fois, et s'adressant à un public anglais, une œuvre commence à se réaliser - qui, elle aussi, se donne comme une révélation: celle d'une philosophie de l'histoire inédite et novatrice.

En fait, pas plus que celles d'Oswald Spengler, les idées d'Arnold Toynbee ne sont les idées désintéressées d'un homme de science. Si différentes que soient les deux œuvres, si autonome que s'avère, par rapport au doctrinaire allemand, le publiciste anglais - il reste qu'ici et là le mélange est le même (sinon le dosage) d'éléments critiques (attaques contre les historiens et leur inefficacité), d'éléments constructifs (philosophie de l'Histoire se donnant comme originale), d'arrière-pensées politiques enfin, à la fois conscientes et déterminantes. Dans des milieux qui ne s'étaient point ouverts à Spengler, A Study of History a provoqué de vives curiosités, des enthousiasmes certains - on pourrait dire des passions. En quelques mois, tout un vocabulaire qui peut aisément se tirer de son livre a été adopté par des milieux entiers d'historiens, d'ethnographes et de sociologues britanniques. Il a passé le canal avec les livres mêmes de Toynbee. On a crié, ici et là, à la nouveauté, à la révélation, au chefd'œuvre. Essayons de voir ce qu'au fond des trois livres, matériellement bien présentés, clairs à lire et à consulter, qui représentent le "premier train» de l'œuvre, un historien peut recueillir de leçons et d'enseignements. Et laissant l'accessoire, allons droit à ce qui constitue l'apport de Toynbee : sa théorie des Sociétés et des Civilisations.

Sociétés, civilisations : les objets véritables de l'histoire, nous ditil. Elles et non point les nations prises une à une. Or, on en compte 
cinq — qui de nos jours vivent simultanément : la nôtre en Occident ; l'orthodoxe dans les Balkans, le Proche-Orient et la Russie ; plus loin, l'Islamique; plus loin encore, l'Indienne p126 - et finalement, l'Extrême-Orientale. A quoi s'ajoutent quelques débris de sociétés agonisantes : la chrétienté monophysite; la nestorienne; la société juive et celle des Parsis; les deux sociétés bouddhistes des Mahaganiens et des Hinaganiens, — dans l'Inde, celle des Jains. Prédominance d'étiquettes religieuses comme on voit; notre civilisation, toutefois, s'en prive ; "chrétienne » ne signifierait pas grand-chose ; catholique ne s'appliquerait ni au pays d'Henri VIII, d'Elizabeth, de Cromwell, ni à ceux de Luther, de Calvin, de Zwingli - (et même de quelques autres; nommons au hasard: Voltaire, Diderot, Karl Marx et Lénine). Passons, et voyons ce que l'Histoire peut tirer de l'étude des sociétés substituée à celle des nations : un double élargissement, dans l'espace et dans le temps.

Une société dont on fait l'histoire, il faut, nous dit Toynbee, s'installer d'abord en son cœur, là où on la saisit le mieux dans sa plénitude originale. Et puis, partant de là, remonter de proche en proche jusqu'au point où on se heurte, sans doute possible, à une autre société bien nettement perceptible et saisissable. Par exemple, notre société occidentale : remontons le cours des temps, nous arriverons de proche en proche dans une sorte de noman's land historique - où tout ce qui sert à la caractériser, au moins rudimentairement, disparaîtra. Si nous dépassons les alentours de l'année 775, nous aurons la sensation de pénétrer à l'intérieur de quelque chose qui ira se caractérisant de plus en plus comme société distincte et originale, quelque chose qui, au début, n'est plus la société occidentale mais, si l'on veut, la frange d'une société romaine. L'idée n'est pas neuve et je ne saurais la critiquer: j'ai depuis longtemps proposé aux historiens de l'utiliser pour résoudre le problème des coupures chronologiques de l'histoire ${ }^{44}$.

Or, ces réflexions conduisent Toynbee à poser ce qu'il appelle le problème de l'application: celui des rapports, si l'on veut, qui peuvent unir entre elles deux sociétés qui se succèdent. Succession

\footnotetext{
44 Observations sur le problème des divisions en histoire, Bull. du Centre internat. de Synthèse, nº 2, 1926, p. 22-26 (R. S. H., t. XLII, Appendice).
} 
directe, immédiate, dans le temps ? Pas nécessairement. Voyez le Califat de Bagdad. Il n'est pas né lentement, comme l'Empire romain. Il est né d'un seul coup, d'une victoire remportée sur le Califat de Damas (I, 73). Or, cette victoire rétablissait entre la Syrie et l'Égypte, anciennes provinces romaines, et l'Arabie, province sassanide, le lien naguère noué par l'Empire des Achéménides - celui que détruisit Alexandre le Grand. La victoire des Abassides opérait donc, après un millénaire, la p127 résurrection d'une grande formation historique détruite par la brutalité d'un choc tout extérieur. Et voilà la filiation dégagée ; voilà Toynbee passant à coup de métaphores - paralysie, mise en sommeil, réveil, guérison (I, 17) — sur ces dix siècles, cependant pleine d'Histoire vivante - et reliant, par-dessus les formations intermédiaires, l'État des Abassides à celui des Achéménides...

Ne le suivons pas dans ces sauts périlleux en arrière, dignes d'un Colleano. Que veut-il prouver? Que, si l'on applique sa réflexion à l'étude d'une formation politique et sociale complexe (à qui l'on peut cependant attribuer une date de naissance valable), on peut s'apercevoir, le plus souvent, qu'à des époques parfois séparées par de très vastes intervalles, cette formation a été préfigurée par d'autres, en qui l'on peut sans trop d'effort retrouver quelques-unes de ses caractéristiques formelles? Mais nous sommes tous rompus, historiens, à la recherche de telles préfigurations! Seulement, ou bien elles ne sont qu'un jeu, ou bien elles aboutissent à une vue d'ensemble sur la genèse des formations humaines. Ou, pour reprendre (à contrecœur du reste) le vocabulaire si peu analysé et si approximatif de Toynbee - sur la genèse des « civilisations ».

Or, touchant ce gros problème, que nous apporte Toynbee d'original?

La race, il l'écarte délibérément. Ce n'est pas elle qui crée les civilisations. Il n'y a pas de race pure ; la notion savante et le concept populaire de race ne se rejoignent pas. Il n'y a pas non plus de race privilégiée : des vingt et une civilisations qu'il dénombre, les unes sont l'œuvre de Blancs, les autres de Noire, de Jaunes ou de Rouges (I, 223). - Le milieu géographique ? le climat ? la topographie des 
lieux ? Même attitude (I, 249). Des pays physiquement comparables - le Canada par exemple, et la Russie — ont vu naître des civilisations toutes différentes. Et les civilisations fluviales, celle du Nil ou celle du Yang-Tsé, sont aussi peu semblables les unes aux autres que ces civilisations «archipélagiques »: la minoenne, la japonaise et l'hellénique (I, 269).

Le vrai, c'est que les sciences de la Nature ne sauraient nous fournir le mot de l'énigme. Toynbee rejoint ici Spengler. Il s'agit d'un problème humain - et la loi qui régit tout ce vaste domaine, c'est une loi de vie, la loi de Challenge and Response ; traduisons, si l'on veut : Sommation et Adaptation. Loi éternelle : tous les livres fondamentaux de l'Humanité la connaissent et p128 l'enseignent: le Livre de la Genèse comme le Livre de Job, le Faust de Gœthe comme le Voluspà des Scandinaves ou l'Hippolyte d'Euripide ; et d'Hésiode à Volney, de saint Mathieu et d'Origène à Gœthe, de saint Paul et de Virgile à Turgot, c'est toute une revue (I, 271 à 302) de dieux, de demi-dieux et de héros, rangés autour du berceau de la grande idée. Cette revue, Toynbee la passe gravement, - non sans que naisse parfois, au cours de cette longue cérémonie, un aimable sourire sur les lèvres du lecteur français, "né malin ». Cependant tout le tome II d'A Study nous fournit l'exposé d'une sorte de "physiologie», assez mêlée, de la "Sommation ». Ou des sommations, car l'auteur les classe en cinq catégories.

Et d'abord, les brutales. La sommation doit avoir vigueur. Donc, n'en cherchons point dans les contrées faciles la patrie d'élection. Souvent, la genèse d'une civilisation représente un "tour de force » humain - et si exceptionnel que les effets n'ont pu s'en prolonger : c'est la leçon que nous donnent les ruines des Mayas, témoins d'une lutte tragique de l'homme contre la forêt vierge — ou les monuments étouffés sous les lianes de Ceylan et du Cambodge — ou, dans un autre milieu, les ruines de Palmyre nées d'un appel direct du désert.

Contre-épreuve : la sommation est trop douce, les conditions de vie trop favorables : nous voici à Capoue, perfida Capua, la traîtresse qui 
perdit les soldats d'Hannibal ${ }^{45}$. Mais la loi ne se vérifie-t-elle point partout ? Où naquit la civilisation chinoise ? Aux rives du gracieux Yang-Tsé, ou du démoniaque Hoang-Ho ? Où, la civilisation andine ? $\mathrm{Au}$ Chili tempéré ? Non, au Pérou - là où se posent de rudes problèmes d'irrigation et de culture (II, 34). L'Attique, Grèce des Grèces, n'est-elle pas aussi sèche ${ }^{46}$ que grasse et verdoyante la lourde Béotie? Mais partout, mais toujours il en va de même. L'Allemagne moderne n'est pas née dans le beau jardin rhénan; elle a été forgée sur la dure enclume ${ }_{\mathrm{p} 129}$ brandebourgeoise. Les Habsbourgs ne sont point sortis de la plus noble, mais de la plus maigre contrée de leur héritage. Sommations de la rudesse: en liaison avec elles, l'appel de la nouveauté - l'appel puissant de la terre neuve : la civilisation de Babylone est née en Assyrie, là où la terre était à défricher - et celle de l'Inde dans le Sud de la Péninsule, contrée de terres incultes.

Les sommations, du reste, ne viennent pas que de la nature. Il en est d'humaines, d'ordre et d'origine. Telles les réactions que provoquent des épreuves soudaines, une défaite, des catastrophes: Rome réagissant au lendemain de l'Allia, l'Empire ottoman plus fort, cinquante ans après, qu'à la veille de la défaite d'Angora et du triomphe de Timour Lenk (II, 702). Loi qui se vérifie à travers toute l'histoire, de Zama à Verdun... en passant par la Pentecôte qui vit, attesté dans les Actes, l'élan des Apôtres. provoqué par la seconde disparition du Maître...

45 Désire-t-on d'autres exemples ? La Circé d'Ulysse intervient à point nommé, suivie de Calypso, escortée des délices de Chanaan. Mélanger à tout propos les références historiques aux références poétiques, mythiques ou légendaires, parti pris de Toynbee.

46 Compte non tenu des modifications, très sensibles, que l'Attique a connues depuis l'Antiquité. A deux pas d'elle, Chalcis, territoire fécond, mais minuscule. Il fallait essaimer : d'où l'expansion de Chalcis jusqu'en Thrace et en Sicile (II, 42). - Passons en Syrie. Là a été inventé l'alphabet, découvert l'Atlantique, élaboré une notion de Dieu commune au Judaïsme, à la religion de Zoroastre, au Christianisme et à l'Islam - mais étrangère aux religions sumérienne, égyptienne, médique et hellénique (II, 50). — Or, quels peuples ont propagé de pareilles découvertes? Les gras Philistins, ou les maigres Phéniciens, habitants d'une terre pauvre, stimulés à la fois par la mer et par le désert — et qui s'en allèrent découvrir tout un monde inconnu, l'Atlantique, cependant que vivant, elle aussi, dans les pires conditions, sur les pierrailles d'Ephraïm et de Juda, une petite communauté de nomades découvrait le monothéisme? 
Stimulus of blows. A côté, la réponse aux pressions continues: stimulus of pressures. Histoire politique de l'Égypte? Celle d'une tension entre deux pôles extrêmes placés, respectivement, au Nord et au Sud - le cœur, Thèbes, se trouvant au centre. Vitalité, robustesse, fécondité politique des pays frontières? Voyez l'Inde : du Penjab, d'un pays qui a dû réagir sans cesse aux poussées extérieures — se tire, aujourd'hui encore, la meilleure part de l'armée des Indes. Et tant que le centre culturel fut Delhi, exposée aux coups, il fut vivant et agissant; transféré au Bengale parles Anglais, il s'étiole ${ }^{47}$. Mais où prit naissance le royaume des Mérovingiens? En Austrasie, sous la menace des Saxons et des Avares. Et la Saxe conquise, comme elle était aux avant-postes, ce fut elle qui devint, sous Otton, la province vitale entre toutes ${ }^{48}$.

Enfin, dernier stimulus: la riposte aux persécutions, Stimulus of penalizations, c'est le christianisme redevable de sa vie secrète, mille fois plus intense que sa vie officielle, aux persécutions des païens et des empereurs. Ce sont les Phanariotes devant à leur condition d'hôtes précaires d'un ghetto chrétien leur activité de marchands, leur prise de contact avec les Occidentaux et leurs talents d'administrateurs acquis dans la gérance des biens du Patriarchat; toutes qualités qui, à la fin $\mathrm{du} \mathrm{XVII}^{\mathrm{e}}$ siècle, leur ${ }_{\mathrm{p} 130}$ valurent dans l'Empire ottoman une revanche matérielle et morale éclatante.

Conclusion : les civilisations naissent de la difficulté, et non de et dans la facilité. Plus forte la sommation, plus vive la réponse, jusqu'à une certaine limite toutefois. Ce n'est pas en Norvège, dans la terre la moins rude; ce n'est pas au Groenland, dans la plus rude : c'est en Islande que la civilisation scandinave s'est le plus fortement développée. Parce que cette civilisation devait y répondre, d'abord, aux sollicitations d'une migration transmarine. Et par ce qu'elle y

\footnotetext{
Aujourd'hui, c'est sur la côte, aux frontières de mer, à Bombay que, répondant aux excitations de l'Occident vainqueur, s'éveille le grand mouvement national indien.

48 Vérités d'Europe, vérités d'Amérique : Toynbee, pour terminer son périple, nous mène aux Andes, à Cuzco, à Tenochtitlan, capitales actives (elles, et non Tlaxcela ou Cholula, cités abritées de l'intérieur) - parce que sur elles s'exerçait la pression des tribus de la Forêt ou des Chichimecs (III, 207).
} 
trouvait des conditions de vie plus dures qu'en Norvège. Plus dures, mais pas trop dures : le cas du Groenland.

Ainsi Toynbee prétend nous dire comment naissent les civilisations. Mais naître? Il faut vivre. Et durer. L'histoire est pleine de civilisations avortées, - ou de civilisations arrêtées, qui, sans être détruites par des forces externes, cessent de se développer à un certain moment, se pétrifient pour ainsi dire et se heurtent à des difficultés trop constantes et trop fortes, continuent à vivre dans une affreuse tension sans jamais parvenir au plein épanouissement. Exemple : la civilisation des Eskimos, arrêtée, nouée pour ainsi dire par l'excès même du "tour de force humaine " que suppose l'existence quotidienne dans un pareil milieu. Exemple encore : les civilisations des nomades, payant leur audace d'affronter la steppe. Exemples plus développés enfin : ceux que fournissent à Toynbee la civilisation des Osmanlis et celle des Spartiates.

Une réponse, la première, à des sommations d'ordre humain. Le problème était de dominer des communautés fortement implantées sur le sol que les Osmanlis convoitaient. Les Osmanlis, d'anciens conducteurs de troupeaux dans la steppe. Et qui gardaient leurs habitudes de pasteurs - et qui en tirèrent leurs moyens de réussir. Le pasteur et ses chiens, et ses chevaux, ses animaux qu'il sait domestiquer et qui lui permettent de mener le troupeau. Les Padishahs ottomans eurent des hommes, qu'ils domestiquèrent en place d'animaux. Soldats ou fonctionnaires, ils en firent des chiens de garde humains. Et par un paradoxe qui n'est qu'apparent, ils les prirent non point parmi eux, mais parmi les chrétiens. C'est que le dressage de ces gardiens d'hommes supposait un tel «tour de force», un tel rétablissement que, seuls, des êtres totalement déracinés de leur milieu humain étaient capables de l'exécuter. Et, d'ailleurs, sitôt qu'à la fin $\mathrm{du} \mathrm{XVI}^{\mathrm{e}}$ siècle ${ }_{\mathrm{p} 131}$ des musulmans libres furent admis dans les rangs des janissaires - ce fut la fin de l'institution, sa désagrégation et la défaite (III, 46).

Différent, et cependant analogue, le cas des Spartiates. Quand, vers le VIII siècle avant Jésus-Christ, le surpeuplement des cités posa devant le monde grec un problème tragique - Sparte ne le résolut 
point par l'expansion sur mer. Et pour cause. Elle se jeta sur ses voisins, les Messéniens. Mais ce n'étaient pas là, comme les Barbares colonisés par les autres Grecs, des porteurs de civilisation inférieure ${ }^{49}$. Et la victoire des Spartiates sur eux fut de celles « où le fer entre dans l'âme du vainqueur » (III, 53). Toute la vie de Sparte n'eut dès lors qu'un but : maintenir la conquête, et pour cela forger une machine de police et d'exploitation sans cesse plus rigide et plus perfectionnée. A la base, au lieu d'esclaves tirés de la masse vaincue comme chez les Osmanlis, des enfants libres pris chez eux. Sur ces enfants, le même travail que sur les janissaires: sélection sévère, spécialisation absolue, stricte surveillance de la vie privée, développement de l'esprit d'émulation, récompenses et punitions également excessives. Et, par derrière, Sparte en état de tension et de tremblement perpétuels. Sparte, cette ironie : une armée incomparable mais dont les Spartiates, infime minorité, n'osent profiter parce que l'équilibre social, strictement calculé, laisse si peu de marge aux fantaisies qu'une victoire de trop le dérangerait et le mettrait à bas. Ainsi la victoire fatale de 404 amena la défaite fatale de 371. Et le déclin (III, 71-75).

Civilisations arrêtées. Civilisations ossifiées. On songe aux insectes : rigidité, immobilité, point d'essor possible. Tout se tend en vue d'une seule fin : ne pas baisser.

A quoi donc mesurer la vitalité d'une société ? Toynbee énumère ses critères. D'abord la maîtrise progressive du milieu humain. Puis la maîtrise progressive du milieu physique. Puis la spiritualisation progressive de toutes les activités humaines. Même dans le domaine de la pure technique : n'y saisit-on pas le passage du plus lourd au plus léger, du plus épais au plus subtil - du charbon au mazout, de l'eau motrice à la vapeur? Enfin, p132 dernier critère, le transfert des sommations, et des ripostes, du dehors au dedans. Pour nous, par

\footnotetext{
49 La supériorité des Grecs sur les Barbares était telle que, d'une part, de petits contingents suffisaient à assurer la maîtrise des premiers; de l'autre, que les terres colonisées, par eux mises en valeur, suffisaient à la fois aux besoins des conquérants et des conquis. D'où ces symbioses que furent les cités grecques de la Sicile, de la Grande Grèce, de la Thrace, etc.
} 
exemple, les problèmes extérieurs sont résolus. Qu'on ne dise pas que, du dehors, le bolchevisme nous menace. Il est un fait occidental, et non un fait étranger: la critique par l'Occident de l'ordre social instable et transitoire qu'a instauré le $\mathrm{XIX}^{\mathrm{e}}$ siècle. Et le plan quinquennal, une victoire de la technique occidentale, un effort paradoxal pour fondre, dans la paysannerie russe, les idéaux contradictoires de Lénine et de Ford. Ou plutôt, les méthodes de Ford et l'idéal de Lénine (III, 202). — Pour nous, les problèmes extérieurs sont résolus; notre technique les maîtrise - mais sommes-nous capables de maîtriser notre technique? de vaincre sur le plan intérieur? C'est la grande question et la grande épreuve. Veillons.

Voilà qui amène Toynbee, par un chemin un peu divaguant, à poser la question du développement interne des sociétés, - et notamment des relations entre sociétés et individus. Sa réponse ? La Société ne crée pas. Elle n'est qu'un lieu commun où se rencontrent les activités individuelles. Elle organise les communications entre individus, - mais ce sont ceux-ci, et non les sociétés, qui font l'histoire (III, 231). Les sociétés s'avancent par les génies qui modifient le milieu commun, ripostent aux sommations qu'il reçoit, lui imposent les mêmes transformations qu'ils se sont imposées à euxmêmes. S'ils n'y réussissent pas, c'est qu'ils devancent les temps : alors, qu'ils disparaissent ${ }^{50}$.

Parfois, on constate une éclosion simultanée de génies. Des progrès sont dans l'air. Des sommations toutes pareilles, s'adressant à des individus baignant dans le même milieu, provoquent des réponses identiques. Mais la masse est toujours inactive. Et ce qui distingue radicalement les sociétés primitives des civilisations véritables, c'est l'absence de minorités créatrices. Partout, toujours, le chemin de l'histoire passe sur la crête qui sépare des masses stagnantes les minorités en éveil - les génies, qui ont leurs lois particulières, leur rythme de vie à eux...

50 Tout génie ébranle un équilibre plus ou moins laborieusement établi, avant qu'il ne vienne le remettre en question. L'ayant ébranlé, le rétablira-t-il sur ses bases anciennes, dans la ligne du temps, ou sur des bases nouvelles, dans une ligne imprévue ? Dans tous les cas, le génie se bat contre la société, et le conflit ne peut se terminer que par sa défaite, ou son triomphe (III, 236). 
Action, extase, et de nouveau action. Ce que Toynbee nomme la loi de Retrait et Retour, Withdrawal and Return, - et qu'il illustre ensuite en mettant sous nos yeux, piqués par une épingle en plein corselet, une galerie stupéfiante de génies ; transcrivons : saint Paul, saint Benoit, saint Grégoire le Grand, Ignace de p133 Loyola, le Bouddha, David, Solon, Philopœmen, César, Léon Syrien, Mahomet, Pierre le Grand, Lénine, Garibaldi, Hindenburg, Thucydide, Xénophon, Josèphe, Ollivier (Émile !), Machiavel, Polybe, Clarendon, Ibn Khaldoun, Confucius, Kant, Dante et... Hamlet. L'humour britannique ne perd jamais ses droits ${ }^{51}$.

Retrait et Retour : mouvement universel. Il n'affecte pas seulement les individus, mais les groupes qui, châtiés par la vie, se replient sur eux-mêmes pour se détendre ensuite avec plus de vigueur que jamais (III, 233). Il affecte les civilisations elles-mêmes, et Toynbee prétend le découvrir, à l'œuvre, dans la Russie soviétique; mais il précise bien, pour ne pas être infidèle à ses théories sur l'impuissance des masses, que le withdrawal de la minorité créatrice précède toujours celui de la civilisation dans son ensemble. Et également que, souvent, les créateurs répondent déjà à de nouvelles sommations, alors que la masse digère, simplement, les résultats obtenus précédemment.

D'où ce fait que la marche de la civilisation se fait par bonds. Brusques détentes suivies de repos - qui eux-mêmes préparent de nouveaux bonds (III, 375). Car, dans une société vivante, toute réponse à une sommation fait naître, aussitôt, une sommation nouvelle. Et comme les expériences qui s'ensuivent varient, les civilisations se trouvent différer l'une de l'autre. Chacune possède son style particulier: Toynbee suit ici fidèlement Spengler. Le style de la nôtre, et depuis bien longtemps - depuis bien avant les découvertes contemporaines - le style de la nôtre, c'est le mécanisme. Et le troisième volume de Toynbee se clôt sur cette conclusion optimiste : épanouie, avortée ou arrêtée, toute civilisation prend son sens dans un Univers animé par ce rythme qu'exprime le verset du Coran $(\mathrm{X}, 4)$ :

51 Chacun de ces génies a droit à une petite notice, de 2 à 8 pages; il en sort à l'état de pièce anatomique, mutilé, déformé, mécanisé à souhait. Par les soins d'un homme, Toynbee, qui clame à toutes les pages son culte de la vie... 
«Vous retournerez tous à lui. Telle est la promesse véritable de Dieu. Il fait émaner la création - et puis la fait rentrer. »

\section{La leçon de «A Study of History »}

Telle est cette œuvre, ou du moins ses débuts (Toynbee annonce vingt volumes). Telle l'atmosphère de cette grande entreprise pleine de qualités sensibles, d'éclat un peu théâtral, de vivacité et d'adresse.

Atmosphère de frisson devant l'ample majesté de l'Histoire; sensation produite chez le lecteur confiant par l'évocation magistrale p134 de toutes ces civilisations en nombre clos, qui se déroulent sous ses yeux éblouis comme les tableaux d'un mélodrame; admiration non marchandée pour le prestidigitateur qui manie avec un tel brio les peuples, les sociétés, les civilisations du passé et du présent, de l'Europe et de l'Afrique et de l'Asie et de l'Amérique; sentiment de la grandeur des destinées collectives de l'Humanité, de la petitesse individuelle de l'homme, de sa puissance aussi puisque — guidé par Toynbee - il parvient à entrevoir d'un seul coup d'œil les vingt et une civilisations fatidiques dont est tissée la trame de l'histoire humaine... Et cette omniscience, cette omnicertitude, ces explications si totalement, si parfaitement explicatives qu'on sent, au bout de cinquante pages, naître en soi une frénétique envie de ne plus tout comprendre, mais d'apprendre, enfin qu'on ne sait pas tout, toujours, sur tout - et qu'il reste, encore, à lever quelques rares et bienheureuses énigmes...

Si on résiste à la séduction du magicien; si on se refuse à l'attitude sentimentale du croyant assistant au culte; si on examine les idées froidement, et les conclusions : quoi de neuf, en tout ceci ; quoi de vraiment neuf et qui puisse, historiens, nous inciter à un retour sur nous-mêmes, à une condamnation de nos méthodes, à l'adoption de méthodes neuves?

Nous arrêterons-nous à ces artifices séduisants, à ce goût décadent des rapprochements brusques, des contacts imprévus de faits, d'idées et d'aspects divergents que déjà nous notions chez Spengler ? Voici le grand Mommsen (I, 3). Il a commencé, chacun le sait, par écrire aux 
environs de 1854 une histoire "nationale », celle du peuple romain. Après quoi, il s'est voué à publier des textes et des inscriptions, le Corpus, le Code théodosien, le Digeste... Qu'est-ce à dire, sinon que la courbe de cette vie reproduit sans effort la courbe même du siècle : hantise " nationale » au début, et donc réduction du champ visuel de l'historien à ces morceaux d'humanité qu'enclosent les frontières ; hantise industrielle ensuite, souci de la matière première à recueillir, élaborer, triturer : et donc, l'historien travaillant aux « sources ", à la matière première de l'histoire... — Voilà bien de l'ingéniosité. Une ingéniosité qui devrait nous conduire, logiquement, à faire d'un Mabillon, authentique pourvoyeur de matière première historique, le contemporain ignoré (et qui s'ignorait) d'une grande industrie déjà soucieuse de ses matériaux et de leur trituration...

Descendons plus avant. Toynbee prêchant, après Spengler, la guerre sainte contre les coupures arbitraires, le cloisonnement, p135 l'esprit de monographie ? Parfait. Nous ne serons jamais trop à mener cette croisade. Encore sommes-nous plus ou moins qualifiés pour le faire, et la bonne volonté ne suffit pas toujours en ces matières : il y faut la compétence. Mais Toynbee n'a rien à apprendre, certes, à aucun de ceux qui, depuis des années - en France et à l'étranger participent à l'effort du groupe qu'a su constituer, autour de sa Revue de Synthèse, depuis 1901, Henri Berr, l'animateur de L'Évolution de l'Humanité. Ni non plus aux jeunes travailleurs qui se rassemblent autour des Annales d'Histoire Économique et Sociale — ou aux savants éprouvés qui, répondant à l'appel du «Comité de l'Encyclopédie française », se sont réunis pour penser l'univers contemporain non par spécialités, mais par problèmes vivants, et sans souci des délimitations d'école, ou de métier. A. J. Toynbee joint simplement une voix d'Angleterre à nos voix françaises. Il ne nous appartient pas de dire à quel point, dans le monde britannique, cette voix se détache des autres. Dans notre monde à nous - elle ne trouve d'emploi que dans les chœurs.

Quant au procès des histoires nationales qui ne sont que nationales et des historiens myopes (I, 15) qui se refusent à voir dans leur pays un simple élément d'une totalité — Toynbee a raison de le faire allégrement. Il enseigne à ses lecteurs, avec une ardeur de néophyte, qu'on ne doit pas s'hypnotiser sur la seule Angleterre, mais prendre 
égard à la société occidentale tout entière — de même qu'on ne saurait consacrer ses veilles à la seule Athènes ou à l'unique Lacédémone : c'est la société hellénique qui les réclame. Fort bien. A condition de se rappeler un menu fait : c'est que l'homme qui, avec le plus de vigueur et d'autorité, proclamait, il n'y a point si longtemps, les vertus de la Méthode comparative en histoire - cet homme, précisément, c'est l'auteur d'une histoire nationale, de cette Histoire de Belgique dont Henri Pirenne a su faire le plus riche chapitre d'une histoire européenne encore toute à créer. Ce qui tendrait à nous mettre en garde, s'il le fallait, contre des oppositions faciles et des prédications un peu simplistes: à la mode du publiciste, mais à l'horreur du savant.

Tout ceci écarté, reste ce bilan : 1300 pages de texte que nous venons de résumer, tant bien que mal, en une vingtaine - et dont le contenu « original» se réduit, finalement, à trois ou quatre thèses. Discutables pour l'historien ? Oui, à condition de s'entendre d'abord sur quelques précautions. p136

Toynbee, à la différence de Spengler, ne professe pas de pessimisme radical. Il enseigne, au contraire, ce qu'on pourrait nommer un optimisme cosmologique. Pour lui, la signification de tant de civilisations mises au monde et disparues se révélera dans un autre monde. Croyance respectable, encore qu'assez vague (si j'osais, je dirais : un peu chlorotique) : mais nous n'avons pas à la discuter; elle ne relève ni de l'histoire ni de la critique.

Soucieux de redonner à l'histoire son élan vital, Toynbee cherche, d'autre part, à la sauver de la mécanisation. A lui, dès lors, tout l'arsenal des expressions et des métaphores «vitalistes"; à lui surtout, la loi suprême de la vie (à son avis du moins), la loi de Challenge and Response. Et cette fois nous disons, historiens: formule philosophique. Vérité philosophique, si Toynbee préfère. Mais que nous n'avons pas à discuter. Non plus que cette loi de Withdrawal and Return qui conduit notre auteur à installer sur la même chaîne, pour les faire défiler devant nous, Thucydide, Mahomet et... Émile Ollivier. Ici encore, nous dirions simplement : rien là pour nous ; rien qui ait rapport avec notre travail, nos préoccupations et nos méthodes - rien, si Toynbee ne prétendait avoir découvert ces lois 
par la grâce d'une méthode : la méthode comparative de l'histoire. Et alors, pour nous, chercheurs et amateurs de réalités historiques mais non de vérités philosophiques, la question se pose: instituer entre vingt et une civilisations échelonnées d'un bout à l'autre de la chaîne des temps et distribuées, sur toute la circonférence du globe, une série de comparaisons valables et fécondes - est-ce chose licite, de bonne méthode et de procédure correcte?

Voyons avec Toynbee, car, dans la première partie de son livre, il consacre quarante pages à faire l'apologie, ne disons pas de la mais de sa méthode comparative. Et tour à tour il expose, puis réfute, les objections qu'il redoute le plus. Celle-ci d'abord : les sociétés ne sont pas comparables parce que hétérogènes. Elles n'ont rien de commun, hormis ce fait brut : elles représentent, toutes, des domaines également valables d'investigation historique - ce qui est un peu vague pour permettre d'asseoir de vraies comparaisons. - Erreur, répond Toynbee. Les vingt et une sociétés ont, en tout cas, ceci de commun, qu'elles sont des «civilisations » et non pas des sociétés primitives. Les sociétés primitives sont 650 . Mais ces vingt et une civilisations comptent plus de membres, à elles seules, que toutes les sociétés primitives totalisées n'en ont jamais compté. Et le fait qu'elles sont toutes également « des civilisations » nous fournit une base valable de p137 comparaison. - Soit : mais il faudrait d'abord s'entendre sur ce qu'on nomme civilisation?

Seconde objection, qui s'oppose diamétralement à la première : hétérogénéité des civilisations, nous venons de voir ce qu'il en faut penser; unité de la civilisation, on ne se privera pas de soutenir la thèse : l'humanité est une ; elle ne se laisse pas découper en tranches donc, on ne peut parler de civilisations; il n'y en a qu'une, la Civilisation. - Toynbee ne consacre pas moins de 22 pages (I, 150172) à combattre cette thèse et, du même coup, la conception européocentrique d'une histoire qui, en son cœur, placerait la civilisation occidentale du XXe siècle. Et c'est très bien - mais le lecteur français sourit d'abord de voir Don Quichotte foncer avec tant de conviction sur ce mirage ; après quoi, il s'étonne un peu : quoi donc, la GrandeBretagne resterait si fidèle aux idées du XVIII siècle déclinant qu'il faudrait tant d'efforts, et de pages, pour les combattre? 
Toynbee prévoit une objection plus grave: «Les vingt et une civilisations, dira-t-on, ne sont pas contemporaines ; elles s'espacent sur 6000 ans. Et alors, comparer ?»- Mais, 6000 ans, qu'est-ce, lorsqu'on pense que le monde remonte à deux milliards d'années, la vie sur terre à 300 millions et l'apparition de l'homme (nous laissons naturellement à Toynbee la responsabilité de tous ces chiffres) à 300000 ? Dès lors, 6000 ans, et vus de Sirius, ce n'est rien. Une pellicule de temps sans épaisseur appréciable. Et nous allons y faire des différences? Allons donc: toutes les civilisations sont contemporaines. D'autant que chacune d'elles, prise pour un individu véritable, ne représente jamais que trois âges successifs : celui de la genèse et, s'il y a lieu, de l'accrochage à une civilisation extérieure ; celui de l'épanouissement; celui de l'affiliation à une nouvelle civilisation, ou de l'extinction pure et simple. Passez muscade ! La muscade passe; l'escamoteur est adroit, mais aboutit peut-être à mécaniser une histoire qu'il s'agissait de vitaliser? - Laissons, et laissons également ce qui suit. La nouvelle porte que Toynbee, les deux bras tendus, enfonce avec véhémence (I, 175-177) : toutes les civilisations se valent, affirme-t-il, et la nôtre n'est pas un couronnement. Dont acte!

Reste la dernière objection: "Tout fait historique est un fait unique - et donc, par nature et définition, impossible à comparer à d'autres. » - Toute vie, répond Toynbee, non sans quelque malaise, toute vie est à la fois unique et comparable aux autres p138 vies. L'existence de sciences comme la botanique et la zoologie, les sciences biologiques en général et la Physiologie, démontre à elle seule, expérimentalement, que les phénomènes de la vie peuvent être comparés. Et pareillement, l'existence de l'anthropologie, qui ne se prive point de comparaisons... - Comparaisons ? Mais les sociétés primitives sont des sociétés sans histoire... - Elles ne vous semblent telles, riposte Toynbee, que faute de documents. Vous admettez qu'on compare les institutions primitives. Si vous pouviez reconstituer l'histoire des sociétés qui les ont adoptées, ou créées, vous admettriez tout aussi bien qu'on étudie comparativement ces sociétés dans leur évolution. Dès lors, qui vous empêche d'admettre qu'on étudie comparativement, de la même façon, les sociétés, les civilisations qui 
possèdent tous les documents nécessaires à une pareille étude ? D'autant que, glisse adroitement Toynbee (I, 180) : de toute étude empirique des civilisations ressort l'existence d'un élément de régularité et de répétition qui fournira à notre méthode comparative la meilleure des bases : façon astucieuse, comme on voit, de donner pour établi ce qu'il faudrait établir.

Et puis quoi, ajoute notre auteur : vous ergotez, historiens, sur la possibilité d'appliquer la méthode comparative à des faits vivants, ou qui furent tels? Les hommes d'affaires ne discutent pas tant. Sur quoi fondent-ils leurs entreprises ? Sur quoi les Compagnies d'assurances, par exemple, basent-elles leur activité ? Sur des statistiques. C'est-àdire sur des comparaisons valables entre faits réputés « uniques ». Ces statistiques ne trompent pas : négligez-les, votre entreprise périclitera ; utilisez-les judicieusement, elle prospérera. Donc... Donc, imitons les hommes d'affaires, nous, historiens timorés. Et, comme eux, manions la méthode comparative.

Un moment ! Je ne dis pas : c'est donc à la notion de prix de revient, ou de primes d'assurances à calculer qu'aboutissent finalement tant de belles déclarations sur la vie et l'histoire vivante? Je dis simplement : les hommes d'affaires, assurez-vous, doivent leur bon sens au fait qu'ils n'ont point été formés aux méthodes désuètes de l'histoire ? Parfait. Ce bon sens les incite à trouver «tout naturel » l'emploi de la méthode comparative dans leur domaine? D'accord. Mais que comparent-ils donc ? Et dans quelle limite de temps jouent leurs comparaisons? S'ils sortaient de ces limites, je leur déconseillerais, sans hésiter, de baser leurs calculs pour la prochaine récolte sur les fluctuations des prix du blé aux bords du Nil, Ramsès II régnant... Et je n'hésiterais même pas à les prier d'y regarder à deux fois, avant de déduire de l'observation ${ }_{\mathrm{p} 139}$ des faits européens d'il y a cinquante ans, des lois applicables, telles quelles, aux faits européens d'aujourd'hui ! Mais cessons de suivre Toynbee sur son terrain, et de polémiquer fictivement, à son exemple, avec des interlocuteurs britanniques qui, vus à travers lui, nous semblent à nous vieilles gens de vieux pays arriérés, d'une naïveté un peu trop favorable aux succès de Toynbee. Je ne crois pas que, ni moi, ni aucun de ces compagnons d'armes historiques dont je parlais plus haut - ceux de la Revue de Synthèse, des Annales, de l'Encyclopédie — nous fassions 
spécialement figure d'historiens réfractaires à toute innovation. Je ne crois pas - et la collection de ces publications en porterait le témoignage à $\mathrm{M}$. Toynbee s'il avait plus de curiosité des choses et des idées de France (Émile Ollivier et Gobineau mis à part) — je ne crois pas que j'aie jamais pris position contre la méthode comparative. Je crois bien savoir, au contraire, que $\mathrm{j}$ 'ai rompu pas mal de lances pour elle. Mais avec les prudences requises.

Comparons, oui. Mais en historiens. Non pour la joie perverse de nous plonger dans le néant de 21 coquilles vides : pour la joie saine et forte d'appréhender du concret, de disséquer de plus en plus finement ces cadavres de temps révolus que sont les civilisations. Comparons, non pour fabriquer, finalement, avec des faits chinois mêlés de faits indiens, russes et romains, pêle-mêle, je ne sais quels concepts abstraits d'Église œcuménique, d'État universel ou d'Invasion des Barbares. Comparons pour pouvoir, en connaissance de cause, substituer des pluriels à ces singuliers. Pour pouvoir dire, s'il m'est permis de choisir un exemple familier : non plus la Réforme, mais les Réformes du XVI ${ }^{\mathrm{e}}$ siècle - en montrant comment elles se sont opérées différemment dans les divers milieux, nationaux ou sociaux, en réponse aux «sommations» du monde médiéval décomposé; les Réformes, ce qui ne veut pas dire une collection de dissertations monographiques sur le détail des dogmes formulés par Luther, Zwingli, Melanchton, Bucer ou Calvin - mais l'explication des variantes qu'introduisait la vie, avec ses particularités, dans l'ensemble des «conceptions du monde» que ces hommes formulaient pour leur usage propre, et pour celui de leurs contemporains : variantes dont chacune devait tenir compte de toutes celles des voisins - et qui prenaient leur source dans les conditions d'existence propre aux individus, aux groupes, aux classes et aux nations. Entreprise de longue haleine - certes. Modeste après tout, si nous la comparons à celle de Toynbee. Moins d'un siècle en face de 6000 ans : pellicule pour pellicule, la première est plus mince. p140

Et qu'on n'objecte pas: «Ce passé, que vous travaillez à comprendre et à interpréter, mais vous-même, en définitive, ne le reconstruisez-vous pas réellement?»—Eh si! Toute science est constructive. Mais toute construction n'est pas également solide, loyale et licite. Dire que les documents ne disent pas tout. Dire qu'il 
ne découle pas d'eux, irrésistiblement et automatiquement, les mêmes conclusions. Dire que, pour les interpréter, il faut à l'historien de la divination, une certaine espèce de sensibilité, des antennes : autant de truismes. Mais prétendre, à l'aide d'une centaine de données tirées de quelques mémoires de spécialistes, reconstituer valablement le passé d'une civilisation: c'est une audace. Prétendre le faire de troisième main, d'après des données puisées dans des manuels : c'est une chimère.

J'ajoute : continuer d'opposer, comme on le fait paresseusement, le "spécialiste », auteur de monographies, au véritable historien, bâtisseur de synthèse — c'est vraiment retarder. Je parle ici en praticien de l'histoire. Spécialiste ou synthétiste ? mais les deux à la fois, mais on ne peut être que les deux à la fois. Généraliser dans le concret, sans souci des abstractions faites en série : c'est un dernier sommet à franchir par l'historien, le plus haut et le plus malaisé. Tous ne l'atteignent pas — ne sont pas doués pour l'atteindre. Mais ne le passent jamais que ceux qui, d'abord, lentement, difficilement, péniblement, auront fait toutes leurs marches d'approche à travers la montagne. Rien n'en peut dispenser personne. Prétendre se jucher d'un bond sur la crête; y prendre une pose avantageuse et puis repartir d'un autre bond, avec un petit salut: très bien pour une photographie, en tête d'un magazine illustré. Mais on ne compte pas ainsi parmi les alpinistes. Je veux dire, les historiens.

Et de grâce: que Toynbee et ses émules de tous pays cessent d'ironiser sur les spécialistes, ces myopes, ces arriérés d'où vient tout le mal. Toynbee et ses émules «datent» au moins autant qu'eux. Ils sont «d'hier », eux aussi, sinon d'avant-hier. «La vie » : ils en ont plein la bouche. Comme ceux de 1900. Mais ce n'est pas en comparant ensemble vingt et une civilisations étalées sur 6000 ans qu'on la saisira. Entre les mains de «comparatistes» télescopant Assourbanipal dans saint Louis ou Sésostris dans Lénine, elle ne saurait que s'évanouir. Moins de dévotion verbale pour la Vie, et plus de respect pour les Vies. Dans les limites d'une période déterminée, il est si difficile déjà à l'historien de ne pas projeter ses idées, ses sentiments, ses préoccupations d'homme du $\mathrm{XX}^{\mathrm{e}}$ siècle dans les esprits et les cœurs des hommes du XVI ${ }^{\mathrm{e}}$ siècle, j'imagine, ou du XIII ${ }^{\mathrm{e}}$ ? Placer

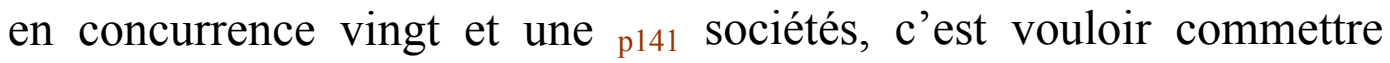


vingt et une fois multipliées par vingt et un le péché capital, le péché irrémissible d'anachronisme. Et, du même coup...

Les « primitifs » ont-ils, n'ont-ils pas une histoire ? A mon sens, la question n'est pas là. Ce qui distingue les tribus de «primitifs » des sociétés de « civilisés », c'est essentiellement ceci : on peut dire, avec quelque légitimité, les Zoulous, les Cafres, les Toucouleurs - parce qu'ils sont relativement très peu différenciés à l'intérieur du groupe ; beaucoup moins, en tout cas, que les «civilisés »; mais dire : les Grecs, les Romains, les Français du moyen âge, les Italiens de la Renaissance - à plus forte raison les hommes du moyen âge ou ceux de la Renaissance ( « tout court» si l'on peut dire !) — si l'on n'y fait pas attention, c'est risquer de commettre un abus de confiance historique. Et brutaliser la vie, sous prétexte de l'exprimer d'un mot. Reprenons un exemple cher à Toynbee. Le "tour de force» de ses Spartiates existe bien réellement: mais c'est le tour de force d'un adroit journaliste. Sautons les siècles, nous aussi, pour une fois. Quelles belles pages n'écrirait-on pas, si on voulait, sur Sparte « comparée » à l'Allemagne des Nazis ? Mais l'Allemagne des Nazis qu'est-ce donc, sinon un titre, une rubrique, une façon commode de s'exprimer? L'Allemagne nazie ? Ce sont les Nazis eux-mêmes qui la donnent comme une réalité. Mais la réalité vivante de l'Allemagne contemporaine, elle est faite, aux yeux de l'historien et pour parler la langue de Toynbee, des réponses différentes que les différents groupes et les différents individus font aux «sommations» du NationalSocialisme. Elle est faite de toute la gamme des compromis qui l'échelonnent, depuis les 95 p. 100 d'adhésion jusqu'aux 100 p. 100 de refus, et de cet assemblage mouvant (et vivant) de traditions vivaces, de survivances en lambeaux et d'expériences vécues que recouvre le manteau du conformisme officiel. Alors, Sparte? Si l'uniformité nazie n'est qu'un mot, que penser de l'uniformité spartiate et de l'image que Toynbee nous en livre? Ne jetons pas sur tant de lacunes le masque d'un décor en carton peint, d'ailleurs prestigieux et tout à fait au goût de Londres 1936.

Histoire comparée à la Toynbee... Ne serait-ce pas la résurrection, $\mathrm{au} \mathrm{XX}^{\mathrm{e}}$ siècle, d'un vieux genre littéraire qui eut sa vogue et ses chefsd'œuvre ? - De Lucien à Fontenelle, il s'appela Dialogues des morts. 
Concluons en deux mots. Ce que A Study of History nous apporte de louable n'a pas grand'chose de neuf pour nous. Et ce qu'il nous apporte de neuf ne vaut pas grand'chose pour nous.

Le livre lu, nous nous tâtons un peu partout : rien de cassé, rien de touché ; nous ne sommes pas plus infatués de nos conquêtes qu'avant, - pas plus découragés de nos insuccès. Dans notre poche nous ne découvrons aucune clef: c'est vrai. Aucun passe-partout capable d'ouvrir, indistinctement, les vingt et une portes des vingt et une civilisations. Mais nous n'avons jamais cherché à l'avoir! Sans orgueil, nous ne sommes pas sans confiance. Que l'Histoire soit encore, dans l'assemblée des sciences humaines, une Cendrillon assise au bas bout de la table - nous savons bien pourquoi. Et nous savons aussi qu'elle participe à cette crise générale et profonde des idées et des conceptions scientifiques qu'a provoquée une poussée soudaine de certaines sciences : la physique en particulier, ébranlant des notions qui, depuis plusieurs décades, semblaient acquises et sur lesquelles l'Humanité se reposait en toute quiétude. Nous savons qu'en fonction de telles transformations, et parce que la Science est une et toutes les sciences solidaires - nous savons que nos idées, fondées sur une philosophie scientifique périmée doivent être revisées, toutes - et nos méthodes en fonction de nos idées. Rien là qui nous effraie, rien qui puisse nous inciter, renonçant à notre labeur prudent et difficile, à nous jeter dans les bras de faiseurs de miracles, de thaumaturges à la fois candides et astucieux, de fabricants de Philosophies de l'Histoire à bon marché. Mais en vingt volumes.

Et quant à l'affirmation implicite qui se dégage du livre de Toynbee, qu'il ne formule point, mais qu'on sent derrière toutes les pages de son livre: "L'histoire se répète » — oui. L'histoire se répète, en effet. Dans toute la mesure qu'exprimait ce vieux bibliothécaire d'un Shah agonisant. Le monarque, à la dernière minute de sa vie, aurait tant et tant voulu apprendre toute l'Histoire... « Mon prince, lui dit le sage vieillard, mon prince, les hommes naissent, aiment et meurent. " p143 


\title{
ALLIANCES ET APPUIS
}

\section{LA LINGUISTIQUE ${ }^{52}$}

\author{
Histoire et Dialectologie
}

AUX TEMPS OU NAISSAIT LA GÉOGRAPHIE LINGUISTIQUE

$\underline{\text { Retour à la table des matières }}$

Il était plus facile dans ces dernières années d'apprécier le vif intérêt que pourrait présenter, pour l'étude de certaines questions particulières, la collaboration de l'histoire et de la dialectologie — que de réaliser cette collaboration même. C'est qu'on ne s'improvise pas dialectologue - et que, d'autre part, les monographies des spécialistes, occupés uniquement de recherches phonétiques ou grammaticales, restaient lettre-morte pour les historiens. A tous ceux qui ont connu et déploré cet état de choses, nous voudrions signaler ici l'apparition et les tendances de deux ouvrages récents : malgré des différences profondes de méthode, d'origine et d'inspiration, ils nous paraissent, de notre point de vue spécial, également riches en promesses.

52 Dans cette revue des Alliances et des Appuis, d'une histoire soucieuse de rénovation devrait prendre place la géographie. Au premier chef. Mais nous lui avons consacré trop d'études, en cinquante ans, pour ne pas désirer grouper ces études à part. D’où une absence, ici, qui pourrait surprendre. 
I.

Voici d'abord, consacrée à l'étude d'une intéressante question de peuplement, une thèse de l'École des Chartes, revue et complétée après la mort de son auteur en vue d'une publication dans la Bibliothèque de l'École des Hautes Études ${ }^{53}$ : livre plein de clarté et dont le dessein général se saisit sans effort.

L'auteur, en septembre 1890, part en tournée dans le Sud-Ouest de la France pour étudier les patois béarnais. Il sait d'avance que dans la région qu'il va parcourir l'article se présente p147 sous deux formes différentes : dans la plaine sub-pyrénéenne, la forme $l u, l a$; dans les vallées habitées de la montagne, la forme et, era. Partout en effet cette règle se confirme, sauf dans le seul val d'Ossau où, dans tous les villages excepté trois, situés précisément à la limite de la plaine et de la montagne, il trouve $l u, l a$, au lieu de et, era. Et voilà le problème posé : comment expliquer à la fois cette double anomalie?

La première idée qui vient à l'esprit, c'est qu'il a dû se produire là une invasion de forme : l'article de la plaine aurait progressivement remonté dans la vallée, en éliminant devant lui l'article de la montagne. Oui, mais dans ce cas, comment expliquer qu'il n'ait point triomphé dans les trois premiers villages qu'il rencontrait? Et puis, pourquoi cette invasion du seul val d'Ossau et non des autres? L'Ossau n'a pas plus de relations avec la plaine que les vals voisins - et d'ailleurs, les exemples abondent dans la région qui montrent que, de relations constantes, continues, étroites entre villages de la plaine et villages de la montagne, n'est nullement résulté pour ces derniers l'abandon de leur article.

Il faut chercher ailleurs. Si ce n'est pas une invasion de forme qui s'est produite, c'est vraisemblablement une invasion de population ? L'arrivée en Ossau d'une population venue de la plaine, et s'y installant avec son patois, rendrait compte heureusement des faits qu'il s'agit d'expliquer. Hypothèse plausible; des déplacements de

53 J. PASSY, L'origine des Ossalois. Ouvrage revu par P. PASSY. Bibliothèque de 1'École des Hautes Études, $152^{\mathrm{e}}$ fascicule ; Paris, 1901, 6 cartes. 
population analogues ont été maintes fois signalés, surtout en pays de montagne. Encore faut-il la justifier, la confirmer par des faits : c'est ce que tente l'auteur en s'appuyant sur les données de la dialectologie et de l'histoire.

Longuement il étudie les dialectes du val d'Ossau et des vals voisins. Il montre les ressemblances frappantes que présentent entre eux tous ceux qui, à l'Est et à l'Ouest du pays ossalois, ont conservé la forme et, era - leur concordance remarquable surtout pour les faits anciens. Il établit qu'à ces dialectes est étroitement apparenté le dialecte des trois villages d'Ossau qui, seuls, n'ont pas pris l'article de la plaine. Enfin il confirme ce fait, que prouvait déjà, à elle seule, la répartition géographique de l'article : les patois du val d'Ossau, ceux qui disent $l u, l a$, sont bien des patois reliés à ceux de la plaine - des patois qui viennent de la plaine.

Ainsi les recherches proprement linguistiques, qui ont permis de poser le problème, viennent en préciser les termes, Elles font plus encore : elles fournissent des éléments de solution. Car de l'étude des dialectes de la plaine, ne ressort pas seulement leur p148 parenté générale avec ceux du val d'Ossau - mais la parenté particulière de quelques-uns d'entre eux, répartis géographiquement en deux groupes distincts, avec ceux des villages ossalois.

Entre ces deux régions, peut-on choisir? Oui, mais non plus à l'aide de la dialectologie. D'elle est né le problème ; avec elle, on a pu le «poser correctement »; par elle enfin, on a entrevu d'abord, puis approché la solution; à l'histoire maintenant d'achever et de confirmer ce que l'étude des faits linguistiques a déjà commencé.

Tâche difficile, semble-t-il d'abord. Des textes et des documents - très rares avant le $\mathrm{XI}^{\mathrm{e}}$ siècle, très abondants depuis — qui concernent le val d'Ossau ou les régions de la plaine circonvoisine, aucun n'a trait à l'occupation supposée. Mais de cette constatation négative ne peut-on pas tirer déjà ceci de positif : si l'occupation s'est produite, elle n'a pas dû être postérieure au XI siècle, - car alors, l'un des nombreux textes que nous avons conservés nous aurait gardé le souvenir d'un fait aussi considérable? 
Voilà donc, vraisemblablement, l'émigration circonscrite, quant au temps, entre le $\mathrm{VI}^{\mathrm{e}}$ siècle, époque probable de la romanisation complète de la région, et le $\mathrm{XI}^{\mathrm{e}}$. Période de grandes invasions, de ravages, de désastres. Précisément, nos textes disent que, vers le milieu du $\mathrm{IX}^{\mathrm{e}}$ siècle, les Normands détruisirent, dans la région du SudOuest, une certaine cité de Beneharnum, qui devait occuper l'emplacement de Lescar. Le dialecte de Lescar est un de ceux dont l'examen dialectologique a montré la parenté la plus étroite avec les patois ossalois: de là à rattacher l'émigration supposée à la destruction de Beneharnum, il n'y a qu'un pas. L'auteur le franchit d'autant plus aisément qu'un fait encore lui paraît confirmer son hypothèse : la possession, de temps immémorial, par tous les villages d'Ossau d'un vaste territoire de landes, le Pont-Long, situé précisément aux environs de Lescar. Constatant l'accord de ses conjonctures historiques et de ses observations linguistiques, il se croit fondé à conclure que les Ossalois sont les descendants d'habitants de Lescar et des environs, chassés au IX ${ }^{\mathrm{e}}$ siècle dans la montagne par l'invasion, et allant occuper tout le val, sauf trois villages restés en possession des habitants primitifs. Ainsi s'expliquerait ingénieusement l'état actuel des faits.

Ingénieusement, mais non certainement. Notre exposé, nous l'espérons, laisse bien voir tout ce qu'il y a de séduisant, mais d'aventureux aussi dans le travail qui nous occupe. A des hypothèses linguistiques l'auteur ajoute des hypothèses historiques : p149 d'une somme d'hypothèses ne saurait résulter une certitude. - Mais ce qu'il y a pour nous d'intéressant dans cet ouvrage, ce n'est point la valeur exacte de ses conclusions ; c'est la nouveauté de sa conception. Que les Ossalois soient les descendants des habitants de Lescar chassés par les Normands - c'est un fait historique de mince importance. Mais, écrit lui-même le frère de l'auteur, qui a publié le livre : "Ce qui est intéressant, c'est le fait d'avoir, pour l'établir, appliqué la dialectologie à l'histoire. Sauf erreur, c'est là un fait nouveau. On avait bien appliqué la linguistique à l'histoire, mais non la dialectologie. »

Un fait nouveau, un fait fécond aussi, nous l'espérons. C'est qu'elles sont nombreuses, les questions que des études analogues à celles-là pourraient permettre d'aborder et parfois de résoudre. 
Questions de peuplement d'abord, qui se posent à chaque instant pour l'historien, dans les régions de montagne notamment - Jura, Vosges, Alpes, Pyrénées, ces pays restés si longtemps comme de grands chantiers de défrichement, de grandes colonies de peuplement ouvertes dans l'Europe aux activités libres des vieilles populations. Importantes par elles-mêmes, ces questions se relient à d'autres; elles peuvent éclairer d'un jour inattendu l'histoire du droit, des institutions politiques ou municipales, du régime du travail, de l'activité économique même de toute une région. Les textes ne sont pas assez abondants, les témoignages documentaires pas assez précis en de telles matières, pour que nous puissions dédaigner l'aide du dialectologue s'efforçant de déterminer, par ses études propres, l'origine géographique de tel groupe de mots dans un certain patois et de tel patois dans une région donnée.

De même, s'il s'agit d'étudier la formation, la genèse de nos provinces. On ne l'a guère fait encore jusqu'à présent. On s'est borné le plus souvent à déterminer le tracé de leurs frontières. Lorsqu'on aura bien vu qu'une province, comme tout être vivant, a une longue, une lente croissance; que, pour en comprendre l'existence et l'histoire, il ne faut point se la représenter comme conditionnée dans son développement par on ne sait quelle armature rigide de frontières naturelles, mais chercher pour ainsi dire au dedans d'elle-même la loi de son développement progressif, le secours sera bien venu, du dialectologue confirmant nos recherches par ses travaux - et nous aidant, par exemple, à démêler, aux confins de deux groupes historiques, la part de chacun dans l'occupation et l'aménagement du sol. p150

\section{II.}

Tout différent par sa méthode, son origine, sa portée - le second des travaux que nous avons en vue. Il se rattache étroitement, par ses auteurs et par sa conception, à la publication en cours d'un ouvrage dont l'apparition a été saluée comme un événement d'importance 
exceptionnelle par tous ceux qu'intéresse la dialectologie romane : l'Atlas linguistique de la France ${ }^{54}$.

C'est une œuvre considérable. Dans 639 stations établies sur tout le sol de la France romane, - c'est-à-dire de la France diminuée des pays flamands, bretons et basques, mais augmentée de la Belgique wallonne, de la Suisse romande et de quelques vals piémontais, - un enquêteur, M. Edmont, a relevé les équivalents patois d'un certain nombre de mots et de phrases soigneusement préparés d'avance. Ces équivalents, notés d'une manière rigoureusement phonétique et transcrits dans l'alphabet spécial des dialectologues, ont été répartis ensuite par les soins du directeur de la publication — un maître éprouvé, Gilliéron - sur une série de cartes reproduisant les contours de la France et les limites des départements. Chaque carte n'est consacrée qu'à un seul mot ou à une seule phrase, et chaque équivalent patois de ce mot ou de cette phrase s'y trouve porté à côté d'un chiffre désignant son lieu d'origine. Travail énorme, on le devine - aussi long et délicat que dispendieux - mais qui se poursuit avec une énergie, une méthode remarquables. Il constituera, une fois terminé, il constitue dès maintenant une œuvre unique dans les fastes de la dialectologie romane.

C'est sur cet Atlas, c'est sur trois de ces cartes que s'appuie le travail de Gilliéron et Mongin ${ }^{55}$ : travail neuf et curieux, première manifestation d'une discipline nouvelle, la géographie linguistique, dont la publication même de l'Atlas a fait sentir à la fois l'intérêt et la légitimité. "Un mot, nous disent les auteurs, a des conditions géographiques précises, qu'il importe avant tout de déterminer. Un fait géographique est souvent la clef de son histoire. Si des couches de mots coexistent actuellement sur le sol, il y a lieu de montrer que l'une est par rapport à l'autre un sous-sol, et ainsi de suite : nous devons d'abord réaliser une géographie ou géologie du langage qui nous permettra de situer les mots chronologiquement, de définir leurs

54 Atlas linguistique de la France, publié par J. GiLliÉron et E. EDMOnT, Paris, Champion, en cours de publication. (Livraisons I à XXIII en vente.)

55 J. GiLliÉron et J. MongIn, «Scier » dans la Gaule romane du Sud et de l'Est (Étude de géographie linguistique), Paris, Champion, 1905, 30 pages in- $4^{\mathrm{o}}$ et 5 cartes. 
rapports, de reconstituer ${ }_{\mathrm{p} 151}$ leur genèse. " L'étude des mots scier, scie, sciure dans les divers patois du Sud et de l'Est de la France n'est qu'une illustration de ces constatations.

Les vocables par lesquels le mot scier est représenté dans ces patois, sont loin de pouvoir se ramener à un seul et même type latin. De ces types, on en peut dégager jusqu'à cinq. Si, sur une carte de la région, on teinte d'une couleur particulière l'aire occupée par chacun d'eux, on obtient une figure très parlante, où de grandes taches de couleur montrent aux yeux le domaine occupé par chaque vocable.

Un fait frappe tout de suite. L'aire d'un des types distingués - le type serrare - ne s'étend pas sur un territoire d'un seul tenant. Elle est comme brisée en cinq fragments, bizarrement répartis sur toute l'étendue de la France du Sud-Est. C'est ainsi que les vocables patois qui veulent dire scier se rattachent à serrare d'abord dans les HautesPyrénées, puis dans la Loire, puis dans le Jura et l'Ain, enfin dans l'extrême Sud-Est de la France (Hautes et Basses-Alpes, AlpesMaritimes, Var), et, par delà la Méditerranée, dans les PyrénéesOrientales. Singulière répartition des dérivés d'un même type, qui nous les fait rencontrer à la fois à Tarbes et à Bourg-en-Bresse, à Puget-Théniers et à Perpignan, mais nulle part à l'intérieur de l'immense territoire que circonscrivent des points si éloignés les uns des autres. - Que signifie-t-elle ?

Première explication: serrare est un mot moderne qui a surgi spontanément dans cinq territoires distincts, très éloignés les uns des autres. Explication absurde. Pour qu'un mot moderne surgisse ainsi, à la fois, en cinq points aussi distants, il faudrait qu'il s'agisse d'un mot dont la création s'impose en quelque sorte fatalement à l'esprit : ce n'est vraiment pas le cas.

Donc serrare n'est pas un mot moderne. C'est un mot ancien. Un mot latin, arrivé dans la Gaule au temps de la romanisation et qui s'y est implanté. Mais alors, pourquoi s'est-il implanté seulement sur les cinq territoires où nous le retrouvons aujourd'hui ? Pourquoi n'a-t-il pas pris également sur les territoires intermédiaires où nous trouvons installés, pour dire scier, d'autres mots que serrare? Faut-il donc admettre qu'au temps de la latinisation de la Gaule trois ou quatre mots différents, signifiant également scier, se sont précipités pêle- 
mêle sur le pays et s'y sont répartis au hasard? Hypothèse absurde également.

Une conclusion s'impose. Les cinq territoires disjoints où nous trouvons aujourd'hui serrare n'en formaient jadis qu'un; "ces îles attestent un continent disparu »; jadis un mot latin qui $\mathrm{p}_{152}$ signifiait scier, le mot serrare, est venu dans la Gaule, s'y est implanté dans toute la région du Sud et de l'Est, $\mathrm{y}$ a occupé une aire homogène et cohérente dont les plages où il subsiste permettent de se figurer approximativement les contours. Alors, pourquoi l'aire homogène qu'occupait serrare a-t-elle été brisée ? Pourquoi ce mot a-t-il été chassé de la plus grande partie de son domaine primitif, par des concurrents venus postérieurement?

C'est, nous répondent Gilliéron et Mongin, qu'il avait un point faible. Il ressemblait trop à un autre mot latin, très usuel, qui lui aussi, était venu s'implanter en Gaule : serare signifiant fermer. De là, un continuel malaise linguistique, causé par la confusion toujours menaçante de serrare: scier, et de serare: fermer. De cette confusion, quelques patois prirent leur parti. Fondant en une seule les deux formes serrare et serare, ils eurent un se(r)rare qui signifia à la fois scier et fermer. D'autres firent un choix, gardèrent se(r)rare, mais en ne lui laissant que l'un de ses deux sens - soit scier, soit fermer, ce qui nécessitait le recours à un nouveau mot. Allant plus loin, quelques-uns se débarrassèrent du couple incommode serrare-serare, traduisirent à l'aide de nouveaux vocables les deux sens de fermer et de scier.

Ainsi, dans les patois du Sud et de l'Est de la France apparurent, se développèrent, s'étendirent lentement aux dépens de serrare des mots dont nous trouvons en place les descendants — des mots patois signifiant scier qui ne se rattachent pas au type serrare, mais aux types resecare et sectare ${ }^{56}$. Sous une double forme, le premier de ces types occupe aujourd'hui une étendue considérable. Quels titres avait-

Les auteurs observent à plusieurs reprises que les expressions qu'ils emploient: resecare, sectare, serrare, ne sont pas des types rétablis, " mais de purs schémas chargés de représenter l'ensemble des mots patois ayant même genèse et réductibles au même type ». 
il pour remplacer l'équivoque serrare dans un nombre considérable de patois?

Son sens? Mais secare, nous disent les dictionnaires, signifie couper, trancher n'importe quoi. Si le mot n'a pas une signification plus précise, on ne voit pas bien comment il a pu être pris pour exprimer l'idée de scier? De plus, on n'a pas pris secare mais resecare, c'est-à-dire un itératif de secare. Évidemment, parce qu'on a eu le sentiment que scier était une opération itérative de secare. Or, si secare veut dire couper, trancher n'importe quoi, resecare voudra dire recouper ou aller et venir en coupant. De là à scier, il y a loin.

Ces remarques amènent à une double conclusion. D'abord, si les patois qui cherchaient un mot pour remplacer serrare défaillant, p153 n'ont pas pris secare mais re-secare - ce n'est pas qu'il leur ait paru que le fond même de l'idée de scier était une idée d'itération ou de vaet-vient ${ }^{57}$, c'est très probablement que secare vivait déjà dans les patois où serrare voulait dire scier, avec un sens bien plus défini et restreint que celui de couper, trancher en général. D'autre part, l'action définie, l'action précise que secare exprimait ainsi devait être telle que son itération par mouvement de va-et-vient pût se présenter naturellement à l'esprit pour rendre l'idée de scier. Quelle était donc cette action définie, précise ? Celle, nous répondent les auteurs, de l'instrument avec lequel on coupait céréales et herbes, de cet instrument d'autrefois dont l'usage va disparaissant, la faucille dentelée. "Secare, c'est se servir de la faucille dentelée ; resecare, c'est répéter une action simple, qui par elle-même est déjà scier - la répéter par mouvement de va-et-vient, re exprimant ici non pas seulement le recommencement de l'action, mais l'opération du bras qui ramène en arrière, pousse, ramène. »

Trame serrée de déductions et d'hypothèses ingénieuses, se soutenant, s'étayant l'une l'autre : elle souligne l'intérêt de cette lutte de mots, de ce drame linguistique que, nouvelle venue dans le domaine des sciences, la géographie linguistique permet, seule, de reconstituer et de suivre.

\footnotetext{
57 Il serait alors curieux que, nulle part, on ne trouve des re-serrare pour exprimer l'idée de scier?
} 
Jusqu'au bout, car les auteurs ne s'arrêtent pas là. Ils nous ont dit le pourquoi de la répartition actuelle des mots dont serrare est le type - le pourquoi de l'élimination de ce type par une foule de patois le pourquoi du remplacement de serrare par resecare. Mais resecare n'est pas le seul substitut de serrare. Il y a toute une série de patois, formant sur la carte une aire compacte, où scier ne se dit ni serrare, ni resecare, mais sectare. Que veut dire ce sectare? d'où vient-il ?

Première hypothèse : c'est un mot ancien, un mot latin, un itératif de secare. Arrivé en Gaule en même temps que serrare (scier du bois, des ais, etc... ) et que secare (scier des céréales avec la faucille à dents), il s'est installé dans les mêmes patois qu'eux comme itératif de secare. Et tout naturellement, lorsqu'on a voulu se débarrasser du gênant serrare, il s'est trouvé sur place, disponible, pour le remplacer.

Hypothèse simple. Oui, mais alors les patois où il a occupé ainsi la place de serrare ont donc eu, à un moment donné, trois mots pour dire scier, deux titulaires et un suppléant en quelque sorte : serrare, secare et sectare? Une langue qui, comme le disent fort ${ }_{\mathrm{p} 154}$ joliment les auteurs, «n'est que du parler en vie et en travail, du parler utile ». Et donc « une langue profondément étrangère à tout ce qui est tradition, survivances et contraintes de la langue littéraire, bref un patois, ne peut pas tolérer de pareilles coexistences $\gg$. - D'autre part, l'aire de sectare coupe en deux l'aire de resecare. Si sectare est un mot ancien, il faut donc admettre que resecare a surgi spontanément à la fois dans deux régions géographiquement distantes, et que les deux resecare, ainsi constitués indépendamment l'un de l'autre, le premier dans l'Est, le second au midi de la France, ont vécu respectivement de la même vie et se sont développés parallèlement, en se correspondant toujours, bien qu'évoluant dans des patois séparés?

Donc sectare n'est pas un mot ancien. Donc, n'étant pas un mot ancien, il n'est pas un itératif de secare. Qu'est-il alors ? Un petit fait va nous aider à trouver la solution. Dans la Drôme, sur quatre points on rencontre sectare avec le sens de faucher. Or, il y a un mot latin, authentiquement latin, un mot ancien qui se rattache à cette idée de faucher: c'est sector, le faucheur. Voilà le générateur de sectare. Comment alors et pourquoi ce sens de faucher est-il passé à celui de scier? Pourquoi dans les pays où nous le trouvons en possession de ce 
dernier sens, n'a-t-on pas eu, comme ailleurs, au moment où serrare = scier fléchissait, recours à secare pour construire un resecare propre à le remplacer?

Nouvelle conjecture : un changement dans les habitudes rurales s'était produit, qui avait détaché de secare l'idée de lame dentelée, de scie; la faucille lisse s'était substituée à la faucille dentelée. Et voilà l'évolution reconstituée. Secare et sector sont arrivée ensemble dans la Gaule romane. Ce sont deux mots anciens. Secare, c'est faucher avec la faucille dentelée. Le sector est celui qui secat. A un moment donné, la faucille lisse intervient et s'empare naturellement du verbe secare qui prend peu à peu le sens de faucher avec la faucille lisse ${ }^{58}$. Mais, comme la faucille dentelée n'est pas expulsée du jour au lendemain, le besoin linguistique, correspondant au besoin rural de distinguer l'ancienne opération, appelle un mot. De sector se tire sectare; l'ancien opérateur sert à désigner l'ancienne opération - et l'image de la faucille à dents, prête à s'enfuir de sector, est ressaisie, revivifiée par le mot nouveau : rien d'étonnant à ce que ce soit lui qui porte le sens de scier. 155

Tel est, résumé en ses traits essentiels — un peu schématisés peutêtre - ce très intéressant (pour un peu on dirait très amusant) travail de Gilliéron et Mongin. Sans doute, sinon du point de vue linguistique (nous sommes incompétents), mais du point de vue géographique, on serait peut-être tenté de faire aux auteurs quelques objections. Tel n'est pas notre but. Ce que nous nous sommes proposé, c'est simplement de faire connaître à des historiens, curieux de méthodes nouvelles et soucieux de tout ce qui peut les aider dans leur tâche propre, un travail neuf et fécond.

L'intérêt qu'il présente pour les études historiques est peut-être moins immédiatement visible que celui du travail de J. Passy. Cependant, il n'est pas difficile de saisir la grande valeur que pourront présenter, lorsqu'elles se seront multipliées, des recherches du genre de celles dont les deux auteurs viennent de nous fournir un premier échantillon. A tous ceux qui voudront s'efforcer de reconstituer dans

58 D'après la carte, faucille de l'Atlas linguistique; dans toute l'aire de sectare, le mot faucille est actuellement représenté par volan, qui signifie faucille lisse. 
une région donnée l'évolution de la vie rurale, avec ses vicissitudes, ses transformations de matériel, ses variations et ses progrès ; à tous ceux qui voudront tenter de déterminer l'itinéraire, la marche progressive, le rayon d'action, l'origine même d'un certain nombre de courants de civilisation dans un pays donné ; à tous ceux enfin qui sentent le besoin, pour satisfaire leur goût de précision vivante et de réalité, de ne plus s'en tenir aux systématisations juridiques, où s'ordonnent de haut et se figent les faits, mais de pénétrer, par delà, jusqu'à l'infinie variété des réalités mouvantes — à ceux-là, dans leur effort difficile, il ne sera pas besoin de longues réflexions pour sentir immédiatement tout ce que de telles recherches peuvent leur procurer d'aide. Quelle riche et curieuse contribution n'apporterait pas à l'histoire d'une région de la France une série de monographies, non plus de ses patois individuels ${ }^{59}$, mais de ses mots les plus vulgaires, les plus usuels : ceux qui servent à désigner les objets familiers, le matériel courant, les actions quotidiennes de l'existence - tous ces termes si riches d'humble vie profonde, accumulée en eux par le temps?

Et puis, ce petit opuscule apporte une méthode. Il est plein d'idées qui attestent un sentiment très net des réalités historiques. De notre point de vue, nous ne pouvons que les approuver lorsque, s'élevant contre « la témérité antiscientifique des ${ }_{\text {p156 }}$ spéculations d'étymologie pure qui encombrent certains dictionnaires », ils montrent « l'absurdité qu'il y a à admettre dans la Gaule romane, à l'époque de sa latinisation, une réceptivité égale ou à peu près égale sur tous les points »; — c'est-à-dire à admettre « qu'une pluie qui tomberait avec la même abondance sur toute la France pénétrerait le sol à une profondeur égale, quelle que soit la nature du sol ${ }^{60} \gg$.

59 S'il est vrai, comme 1'écrivent nos auteurs (p. 27), que « la réflexion et les faits s'accordent pour détruire cette fausse unité linguistique dénommée patois, cette conception d'une commune ou même d'un groupe qui serait resté le dépositaire fidèle d'un patrimoine latin... Aucune recherche de dialectologie ne partira de cette unité artificielle, impure et suspecte ; et à l'étude du patois nous opposerons l'étude du mot ».

60 Un mot latin, remarquent-ils au contraire, «pouvait ne prendre que sur un point qui seul avait la chose ou l'idée et c'est ce point qui l'a fourni aux autres quand ils ont eu la chose ou l'idée ». 
Même sens avisé des réalités et, notons-le, même promesse d'études intéressantes pour nous, dans cette constatation : "C'est folie de croire que le matériel latin, à travers toutes les péripéties que put endurer pendant plus de 1500 ans la vie d'une commune de France, s'y soit conservé à peu près constant. La vie étant toute l'activité économique et morale de l'homme, il n'y a pas un mot qui ne puisse être atteint et il n'y a pas un mot qui ne puisse se ranger parmi les Culturwörter - qui ne soit, qui n'ait été, en acte ou en puissance, un mot voyageur. » — Et celle-ci encore : «Il est clair que l'uniformité lexicale présente d'une aire comme resecare ou sectare est un aboutissant ; qu'elle est non pas unité mais uniformisation. Lente a été la corrodation de serrare, lente l'infiltration des nouveaux venus que nous voyons encore à l'œuvre... La presque totalité des points compris dans ces aires ont reçu le mot d'ordre de formation, la secousse inspiratrice - voire même la forme — d'un lieu voisin qui lui-même subissait peut-être la répercussion d'autres lieux. »

Réjouissons-nous - même en dehors de tout espoir de profit immédiat - de voir, dans un domaine voisin du nôtre, prévaloir ces idées. C'est, sous une forme nouvelle, la nécessité une fois de plus proclamée de s'attaquer au gros problème de l'action des faits sociaux sur le langage. Mais c'est également une affirmation de l'esprit de vie en face de l'esprit formaliste. p157 


\section{Antoine Meillet et l'Histoire}

\section{LA GRÈCE ANCIENNE A TRAVERS SA LANGUE}

$\underline{\text { Retour à la table des matières }}$

Laissons les saints dans leur niche. Adressons-nous au Maître. Nous le pouvons d'autant mieux qu'après avoir donné, en 1912, une troisième édition corrigée et augmentée - et la formule, ici, n'est pas de style ! - de son Introduction à l'étude comparative des langues indo-européennes ${ }^{61}$, Antoine Meillet vient de publier par surcroît un Aperçu d'une histoire de la langue grecque ${ }^{62}$ qui est bien un des livres les plus suggestifs et les plus vivants que je sache. Si d'aucuns s'étonnaient de voir un historien, d'une incompétence linguistique notoire, signaler ici de semblables travaux, ce dernier ouvrage, plus encore et mieux que le premier, nous donnerait une réponse facile. Elle tiendrait en deux mots : lisez-le.

Car c'est un livre d'histoire, au sens large et véritable du mot. Et comment en serait-il autrement? Personne mieux qu'A. Meillet ne s'est employé ces derniers temps à battre en brèche le tenace préjugé de la " filiation directe », du " développement linéaire simple » que les historiens - des institutions, par exemple - connaissent bien, connaissent trop pour leur part. Nul n'a mieux montré que tout ne se passait pas comme si la langue se transmettait purement et simplement de génération en génération, et que tous les changements résultassent

61 Paris, Hachette, 1912, XXVI-502 pages in- $8^{\circ}$. La première édition a paru en 1903 ; de la seconde, Meillet a pu dire qu'aucune page n'en reproduisait exactement une page de la première ; et dans la troisième, il est vrai que « peu de pages sont restées ce qu'elles étaient dans la seconde $»$.

62 Paris, Hachette, 1913, XVI-368 pages in- $8^{\circ}$. 
de cette transmission constamment renouvelée. Nul enfin n'a davantage insisté sur le rôle capital, sur le jeu si constant de l'emprunt - rôle si capital, jeu si constant que Meillet, étudiant les procédés par lesquels se détermine le caractère indo-européen d'un mot, p158 a pu écrire dans la troisième édition de son Introduction ${ }^{63}:$ " Sauf en ce qui concerne certains mots, semi-grammaticaux, comme le verbe être, les pronoms, les démonstratifs, les préverbes - on n'a jamais le droit d'affirmer, a priori, qu'un mot donné a été transmis de génération en génération depuis l'époque indo-européenne jusqu'à la forme attestée dans un parler donné. " Tant apparaît immense, aujourd'hui, la part des emprunts préhistoriques d'un dialecte indo-européen à un autre ou de plusieurs dialectes indo-européens à des langues d'autres familles.

Mais de ces remarques mêmes, que résulte-t-il ? Ceci, que toute explication linguistique comporte la considération de faits multiples - et « que l'on ne peut se rendre compte de l'évolution d'une langue qu'en tenant compte des situations historiques et des conditions sociales où cette langue s'est développée ». Ainsi la linguistique fait appel à l'histoire, et pour ses fins propres lui demande un concours désintéressé. Ne suit-il pas de là, inversement, que de semblables études linguistiques présentent pour l'histoire le plus vif intérêt ?

Inutile de raisonner in abstracto. Ouvrons les livres de Meillet. Et voici d'abord pour les préhistoriens - mieux, pour tous ceux d'entre nous que sollicite le mystère des passés sans textes, sans témoignages écrits - voici de fortes leçons de prudence méthodique.

On sait quels espoirs, un instant, nos pères crurent pouvoir fonder sur la linguistique. A l'aide du vocabulaire, patiemment restitué, de cette langue indo-européenne qu'on disait alors "primitive», n'arriverait-on pas à déterminer la race, la religion, les usages et, dans une large mesure, l'histoire des peuples qui parlaient cette langue ? Ce qui subsiste de ces espérances, la critique de Meillet le détermine rigoureusement : et c'est peu. 
$\mathrm{Au}$ chapitre VIII de l'Introduction, on trouvera classés les principaux éléments du vocabulaire indo-européen. Racines d'abord, presque toutes indiquant des actions banales et vagues : boire, manger, dormir, aller, courir, etc... Mots isolés ensuite, plus riches de sens : les noms de parenté, révélant par l'imprécision des termes concernant la famille de la femme un état social où celle-ci entrait dans la famille du mari, mais où le mari n'avait point de parenté définie avec la famille de sa ${ }_{\text {p159 }}$ femme; noms d'animaux, domestiques ou sauvages, assez abondants et attestant une alimentation plutôt carnivore, des habitudes de chasse et d'élevage ; noms de végétaux, plus rares et de sens moins précis : il est curieux que la forêt n'ait pas un nom qui puisse être sûrement tenu pour indo-européen ; noms d'objets enfin, mais rares, et Meillet nous en donne la raison : ces noms sont éminemment sujets à changer. "Aussitôt que le commerce ou l'imitation des voisins introduit une nouvelle forme ou un nouveau perfectionnement, de nouveaux noms, soit étrangers soit indigènes, s'introduisent et remplacent le plus souvent les anciens ${ }^{64}$. Avec le temps, les noms d'objets analogues et servant aux mêmes usages se trouvent ainsi différer dans des langues assez pareilles par ailleurs. » Rien qui illustre mieux cette remarque que l'absence d'un même mot, dans les diverses langues indo-européennes, pour désigner la hache, l'outil précieux dont l'apparition dans l'industrie humaine marque le passage du paléolithique au néolithique. Or, point de doute qu'au temps de leur vie commune, les hommes qui parlaient l'indo-européen connussent non seulement la hache taillée, mais la hache polie, puisque les noms, communs à plusieurs langues indo-européennes, du cuivre, de l'or et de l'argent attestent une civilisation où les métaux jouaient déjà un certain rôle. - Mais rien non plus qui légitime davantage, notons-le en passant, des études parallèles et mixtes de

\footnotetext{
64 Ainsi le latin nous offre plusieurs exemples d'emprunts globaux, faits à des populations étrangères, d'outils et d'objets avec les noms servant à les désigner. Les termes désignant l'huile sont tous, en latin, empruntés au grec. C'est que l'olea europaea a été colporté dans le bassin Ouest de la Méditerranée par des colons grecs et importé sans doute à Rome par les Grecs de Campanie. Mais d'après Meillet, ces termes même ne seraient pas de vieille souche grecque -

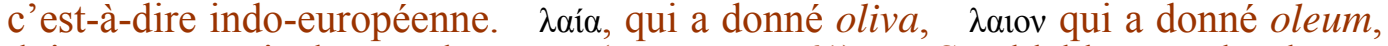
doivent provenir du monde égéen (Aperçu, p. 61). - Semblablement, la plupart des termes techniques de la carrosserie romaine sont d'origine gauloise. - On pourrait multiplier de semblables exemples.
} 
technique et de linguistique dont nous avons déjà parlé : études de choses et de mots, Wörter und Sachen - c'est le titre même d'une Revue au nom plein de promesses.

Pourquoi cette sorte de faillite des anciennes espérances, cette maigreur des résultats que donne la restitution laborieuse du vocabulaire indo-européen?

Les raisons qu'en fournit Meillet sont bien suggestives. «A parcourir un dictionnaire étymologique, écrit-il, on a l'illusion que la langue indo-européenne aurait procédé par mots et par racines d'une valeur abstraite et très générale, alors qu'on doit $\mathrm{p}_{60}$ au contraire se représenter chaque parler indo-européen à l'image d'un parler lithuanien moderne, pauvre en termes généraux et plein de termes précis indiquant les actions particulières et le détail des objets familiers. »

Singulier renversement, mais qui s'explique aisément. C'est que le procédé même par lequel on détermine le caractère indo-européen d'un mot exclut dès l'abord la connaissance de ce qui, dans ce vocabulaire, était concret et précis - de ce qui par conséquent était essentiellement susceptible de varier. Les seuls termes qui aient subsisté dans plusieurs dialectes différents sont, précisément, ceux qui désignaient les actions ou les choses banales et universelles - celles dont il y a le moins à tirer. De plus, pour rapprocher les mots des diverses langues, il faut ne considérer que ce qu'ils ont de commun, éliminer les nuances - arriver en somme à une abstraction, vidée de signification concrète. Enfin les dialectes qu'il faut interroger pour en tirer, par comparaison, les éléments d'un vocabulaire indo-européen ne peuvent nullement donner l'idée de ce que fut réellement la langue des populations demi-civilisées comme celles qui parlèrent l'indoeuropéen commun: tous ces dialectes, en effet, nous ne les connaissons que sous une forme très tardive ; entre la période indoeuropéenne et les plus anciens textes de chacun d'eux, il s'est écoulé des centaines d'années : et que d'emprunts possibles, que d'altérations pendant ces longues périodes ? - Ainsi s'évanouissent les grands rêves, au souffle de l'esprit critique. Mais quelle bonne et saine leçon, 
précisément, de mesure, de prudence et de méthode : recueillons-la en passant, pour nous en inspirer.

Donc, le mystère subsiste. La linguistique ne peut rien ou presque rien pour le dissiper. Elle permet d'énoncer, timidement, une date très approximative, que la connaissance des métaux laisse deviner. Elle n'interdit pas de placer dans les régions septentrionales, soit en Europe, soit à la limite de l'Europe et de l'Asie, aux environs de la Baltique peut-être, 1'habitat des populations qui parlaient l'indoeuropéen commun. Mais pour résoudre l'irritante question : "Dans ces armes, dans ces objets que les fouilles archéologiques nous restituent; dans ces matériels de civilisation que nous classons méthodiquement dans nos musées : quel était leur lot propre, à ces populations ? » - c'est en vain que nous attendrions des linguistes la moindre indication: "Les trouvailles archéologiques sont muettes. " Un outil n'apprend rien sur la langue de son possesseur. "Les faits historiques ne se laissent pas deviner. " p161

Un seul point, somme toute, est hors de doute et ressort avec une pleine évidence : pour créer l'unité de cette langue dont les dialectes indo-européens que nous connaissons sont des démembrements et des transformations - il a fallu, il y a eu une "nation». Grande affirmation et dont tout récemment, dans sa leçon d'ouverture du Cours des Antiquités nationales au Collège de France ${ }^{65}$, Camille Jullian, de son point de vue d'historien, soulignait la valeur et la portée. Une nation - et qui peut-être englobait des races distinctes, soit surperposées, soit juxtaposées, soit mélangées, peu importe ; une nation, non une race, comme on disait jadis d'un mot vague, faux et dangereux, car n'éveille-t-il pas « la pensée d'une conformation physique à laquelle nul n'échappe en naissant, d'habitudes matérielles que le corps nous contraint de subir, d'une inéluctable fatalité qui pèse sur les individus et les sociétés $» ?$

65 L'ancienneté de l'idée de Nation, leçon d'ouverture du Cours d'Histoire de d'Antiquités nationales au Collège de France, 1912-1913 (Revue Politique et Littéraire [Revue Bleue], $\mathrm{n}^{\text {os }}$ des 18 et 25 janvier 1913 ; à part, Paris, 1913, 35 pages in $\left.-8^{\circ}\right)$. 
Jullian nous le montre, ce concept de race, rayé, proscrit par Michelet de notre histoire de France où Augustin Thierry, Guizot, Henri Martin le maintenaient à l'envi. Il nous le montre, pourchassé ensuite par Fustel, sous les Carolingiens et les Mérovingiens, jusqu'au temps des invasions, aux siècles des empereurs. Il nous le montre enfin, traqué maintenant par toute une jeune école d'historiens novateurs dans les âges primitifs — et jusqu'au seuil même de la préhistoire. Vieux procès, vieille querelle. Il y a plusieurs années déjà que, dans l'Anthropologie, à propos de Rome, Jullian posait le problème nettement ${ }^{66}$. Mais par delà, dans le passé ? Là aussi, ce que nous devinons - ce sont de grands États formés par la volonté des hommes, d'autres nations unies par un lien public, « sans rapport avec la parenté animale qui serait le sang ou la race ». Et Jullian les énumérait : nation ligure, en Occident, avant les Gaulois ; nation-mère des langues indo-européennes en Europe avant les Ligures ${ }^{67}$, " voilà les trois dernières étapes que notre monde a parcourues avant d'arriver à l'Empire romain - et il les a parcourues à l'abri ou à l'ombre de pensées ou de noms nationaux ». p162

Or, ce mot de nation, Meillet lui aussi, parlant en linguiste, le prononce. Et il a le droit de la prononcer, «car l'expérience montre que, si une langue commune peut survivre à la rupture d'une unité nationale, il faut une certaine unité - unité politique ou, du moins, unité de civilisation - pour constituer une langue commune ». De la langue commune, en d'autres termes, de la langue indo-européenne, le linguiste conclut à la nation européenne. Et c'est ce qu'indique encore, avec une pleine netteté, un texte de l'Introduction: «Une langue aussi une que celle qui est supposée par les concordances entre les langues attestées suppose qu'il a, durant une période de temps

66 Lettre à S. Reinach, Anthropologie, 1903, p. 252. « Combien les Latins étaient plus heureux que nous et plus sages, écrivait C. Jullian, d'ignorer quand il s'agissait de nation le mot et le concept de race - et de ne parler, en cette chose, que de nom ! Ils disaient Nomen Latinum, Nomen Romanum, et cela leur suffisait. Et cela était la vérité ; car les Romains étaient surtout un nom, et les Celtes n'étaient pas davantage. »

67 [Inutile de dire que, notamment, le concept de Ligure a bien évolué depuis 1913, et que Jullian, aujourd'hui, raviserait sans doute sur ce point ses conceptions. Mais, nous n'avons pas, nous, à réviser le fond de ces articles. Ils portent témoignage de ce qu'était la science au temps où on les écrivait.] 
assez étendue, existé une nation qui présentait une certaine unité. Des nations diverses peuvent conserver une même langue; mais il faut pour créer une unité linguistique une nation qui sente son unité. Rien n'autorise à parler d'une race indo-européenne; mais il y a eu nécessairement (on ne sait en quel lieu ni en quel temps exactement) une nation indo-européenne ${ }^{68}$. $\gg$

Ainsi la linguistique permet aux historiens de découvrir un coin du "passé sans textes » par une induction bornée peut-être, mais forte, solide, fondée sur une expérience inattaquable. Langue et nation " entre ces deux choses, il y a partie liée ». L'histoire de la langue suppose celle de la nation. Mais inversement, qui fait l'histoire de la langue écrit, par partie, celle de la nation. Et c'est ce que montre, précisément, le plus récent des deux ouvrages de Meillet.

Le beau livre d'histoire grecque, en vérité, ce livre de linguiste, écrit par un homme qui, maître dans son domaine, s'y renferme strictement. Mais, de son domaine, n'a-t-il point sur l'Univers les vues les plus larges? Sans sortir de chez lui, il parcourt un monde.

Un monde d'histoire. Nous avons le droit de le remarquer, nous qui, depuis plusieurs années, ici, notons comment peu à peu deviennent plus connaissables pour les historiens, plus proches par leurs méthodes, par leur esprit et par leurs résultats, les travaux des linguistes. Analyser ces 360 pages claires, alertes, p163 accueillantes mais d'une plénitude et d'une précision sans égales; faire une réduction décharnée d'un petit livre où tout se tient, où rien ne vient $\mathrm{du}$ hasard - tentative chimérique. En deux mots, indiquons de quel point se prend la perspective.

68 Introduction, $3^{\mathrm{e}}$ éd., p. 405. Ce passage figure dans un chapitre sur le développement des dialectes indo-européens, qui n'existait pas, il est intéressant de le noter, dans la première édition du livre. - Cf. également Aperçu, p. 18 : « De même que l'indo-européen suppose une nation ayant une certaine unité, de même le grec commun suppose qu'il a existé, à une époque antérieure aux plus anciennes données historiques sur les Grecs, une nation hellénique ayant une unité sensible et s'étant par suite donné une langue une. » 
Jadis, 1'histoire des langues était un monument grandiose, aux lignes simples: l'histoire d'une continuité sans trouble, d'une transmission régulière, d'un développement purement linéaire. Rappelons-nous ce qu'on nous enseignait du latin. Langue issue par filiation directe de l'indo-européen commun, on nous la montrait dans son unité majestueuse, dans la plénitude de son rayonnement sur le monde. Elle évoluait sans doute, elle se transformait peu à peu; mais cette évolution, cette transformation résultait simplement d'une transmission de bouche en bouche, de génération à génération, d'un travail sur place, pour ainsi dire, et purement interne. Un moment venait où l'on nous montrait le vaste monde romain tronçonné, morcelé, découpé par les bandes barbares. Mais chaque tronçon, chaque morceau, chaque découpure de l'Empire retenait son lambeau de latin - c'était par le même procédé, à sa guise, solitairement, qu'il travaillait ce patrimoine linguistique, et en faisait peu à peu une langue romane : une langue fille du latin par filiation directe, paisible et sans secousses. Belle vue, bien logique et qui satisfaisait l'esprit, beau procès de différenciation simple. Trop simple même: car d'abord il y a l'emprunt.

Voici, dans un canton d'altitude, une population qui vit enclose, enchâssée dans quelque alvéole naturelle. Peu de rapports avec les groupes voisins; peu de besoins d'échange ; un idéal invariable : se suffire sans recourir à l'étranger. Dans de telles conditions, le parler du canton pourra évoluer, évoluera sur place, par le jeu d'innovations de détail communes à toute une génération ou spéciales à un groupe particulier de la population: un des sexes, par exemple, ou telle profession, telle classe sociale, telle occupation temporaire même, ou tel mode d'activité transitoire. - Mais que des relations se nouent, entre cette population isolée et ses voisines; qu'un besoin de communication naisse, pour des causes impérieuses et vitales (commerciales, politiques, religieuses ou intellectuelles) ; qu'au lieu d'hommes repliés sur eux-mêmes, il s'agisse d'une population active, à relations étendues et lointaines. Voilà des emprunts qui, de parler à parler, s'établissent : emprunts de mots isolés, s'il s'agit de langages hétérogènes ; emprunts de mots, de prononciations, de flexion, s'il s'agit de langages proches; emprunts qui parfois, se généralisant, s'étendent à la totalité de la langue. p164 
Faits de conquête, dira-t-on - guerrière ou pacifique : quoi de neuf là-dedans? N'y a-t-il pas longtemps qu'on sait, naturellement, que des populations entières ont changé de langue et, par exemple, que du gaulois, le vieux français dérivé du latin ne retient, pour ainsi dire, plus rien ? - Mais c'est qu'il ne s'agit pas seulement de ces « faits de conquête ». L'emprunt n'a pas seulement cet aspect. Il n'est pas synonyme non plus de rafle, de pillage, de razzia linguistique. Il ne s'exerce pas uniquement de langues très différentes à langues très différentes ; il s'exerce continuellement, continûment de parler voisin à parler voisin — et il faut qu'il s'exerce ainsi.

Car, ces innovations que tout à l'heure nous décrivions, et qui affectent les parlers isolés - il n'y a point de raisons pour qu'elles soient les mêmes, pour qu'elles se ressemblent de village à village, de groupe à groupe. Ce mécanisme d'innovations locales aboutit donc, en définitive, à briser sans cesse l'unité linguistique - à rendre les parlers de plus en plus étrangers, de plus en plus incompréhensibles les uns aux autres. Et ce morcellement va à l'encontre de ce que l'on peut appeler, sans finalisme, l'objet du langage: la facilité des relations entre les hommes.

A ce morcellement, du reste, ce n'est pas seulement la géographie qui contribue. Nous parlions tout à l'heure de "canton d'altitude » : l'exemple, utile, était trop spécial. Car ce n'est pas seulement dans tous les cas d'isolement par « barrières naturelles », que s'exercent ces forces actives et puissantes de différenciation - c'est en réalité dans tous les cas où des groupes d'hommes voisins, pour des raisons quelconques, cessent d'entretenir des relations suivies. Faible densité d'une population; troubles politiques ou sociaux tarissant les courants commerciaux, morcelant et spécialisant la vie économique, détruisant dans un pays donné toute vie de relations: autant de causes qui concourent au même résultat. Mais alors, il n'y aurait que poussière linguistique? Il n'y aurait, en France, que patois ? La nécessité apparaît évidente d'un remède. Il n'y a pas, il ne peut pas y avoir seulement à l'œuvre des forces de différenciation. Il y a nécessairement - et du reste, la réalité linguistique l'établit nettement — des forces d'unification. Il n'y a pas que des parlers s'isolant progressivement les uns des autres. Il y a des langues communes qui, aux époques de morcellement excessif et croissant, surgissent, 
recouvrent d'un manteau uniforme les diversités locales, rétablissent entre hommes la communication.

Ainsi se varie, ainsi s'enrichit singulièrement la conception moderne du développement linguistique. Ainsi devient-elle, p165 vraiment, proprement historique. Car le fait dominant dans l'histoire des langues, il apparaît maintenant que c'est, précisément, la création, à certaines époques, de ces langues communes « qui sont le produit de l'unité de civilisation sur des domaines plus ou moins vastes ». Le mécanisme ? Encore, toujours l'emprunt. Fait historique, entre tous fait dont toutes les conditions sont, au sens large, des conditions historiques. Ainsi se vérifie que «toute explication linguistique comporte la considération de faits multiples » et qu'on ne peut se rendre compte de l'évolution d'une langue « qu'on tenant compte des situations historiques et des conditions sociales où cette langue s'est développée ». Déclaration nette. Elle est de Meillet. Tout l'Aperçu en est l'illustration.

Deux ou trois exemples seulement, pour mieux préciser encore le caractère du livre et ce qu'il y a dans sa conception d'ampleur, de force et de nouveauté.

Voici, à l'origine même du travail de Meillet, une langue commune - une pure abstraction, du reste, comme l'indo-européen : le grec commun, la langue de cette nation hellénique qui, possédant une unité sensible, s'était par suite donné une langue une, et dont les tribus devaient les unes après les autres conquérir la Grèce et coloniser la Méditerranée. Pour nous faire connaître, pour étudier cette langue, l'auteur va-t-il s'appuyer sur la grammaire comparée des langues indo-européennes?

Certes, dans le chapitre très plein où il analyse « la structure du grec commun » (chap. II), il marque avec force les traits essentiels par lesquels cette langue, en son ensemble, s'oppose à l'ensemble des autres langues indo-européennes. Mais ceci terminé, il ne se tient pas pour satisfait. Car, si l'on peut se faire quelque idée des procès linguistiques par lesquels l'indo-européen a pris l'aspect qu'il a en grec commun - de l'un à l'autre stade linguistique, comment la 
langue s'est-elle transmise? Comment s'est faite son unité ? Comment, en quelles conditions sont intervenus les changements qui lui ont donné ses caractères propres ? On l'ignore. Encore convient-il de poser la question. Et c'est, pour une bonne part, une question historique.

Car, le grec commun, c'est une langue indo-européenne, certes mais qui dut être, qui fut influencée, nécessairement, dans son évolution par les langues des populations traversées, assimilées ou remplacées par les Hellènes durant leur migration du domaine indoeuropéen au domaine grec. Une langue indo-européenne, p166 oui : mais qui s'enrichit nécessairement de mots que les Hellènes pour ainsi dire "ramassèrent en chemin », ou trouvèrent en Grèce même, ou reçurent des diverses populations du monde égéen. Or, de leur langue, nous ignorons tout aujourd'hui. Encore faut-il indiquer le problème. Encore faut-il noter que la plupart des noms de lieux de la Grèce ne s'expliquent pas, ou mal, par la langue grecque. Encore faut-il ne jamais oublier que le grec présente un nombre immense de mots d'origine inconnue, en grande partie sans doute empruntés à des idiomes non indo-européens - et, pour préciser davantage, à la langue de cette brillante civilisation égéenne dont hier encore nous ignorions tout, mais que les trouvailles de Crète nous révèlent si féconde et si avancée. Noms de plantes, comme l'olivier, la rose, le lis; noms de produits, comme le vin ou l'huile qu'on ne saurait reconnaître comme indo-européens - ce sont sans doute des emprunts faits par des Hellènes aux Égéens; et si l'on constate avec Meillet que les mots comme $\beta \alpha \sigma i \lambda \varepsilon u ́ s$ ou $v \alpha \xi$ n'ont rien qui rappelle l'indo-européen - n'est-on pas conduit à se demander «si la civilisation égéenne n'a pas exercé sur la constitution politique des Hellènes une action considérable ${ }^{69} \gg$ ?

Simples hypothèses, évidemment. Le peu qu'on sait aujourd'hui ne permet pas l'affirmation. Il dicte, simplement, la méfiance, féconde et scientifique. Mais d'abord l'avenir est là, avec tout ce qu'il peut nous

69 Aperçu, p. 64. - A noter tout particulièrement, dans le même chapitre, les remarques extrêmement utiles et intéressantes d'A. Meillet sur l'onomastique et son utilisation possible. Il y a là des notes de méthode singulièrement précieuses pour l'historien (p. 55-99). 
fournir de belles découvertes. Et puis, ce qui nous intéresse en ce moment, ce que nous essayons de montrer en action, c'est un esprit, l'esprit d'un linguiste pour qui la science qu'il représente n'est pas une mécanique plus ou moins bien montée et fonctionnant à vide, indéfiniment - mais qui du langage sait et saisit tous les rapports, tous les liens avec la vie, avec l'histoire des hommes et de leurs sociétés.

«Faire l'histoire des dialectes grecs, c'est faire l'histoire de la colonisation grecque ${ }^{70}$. » Et cette histoire, prolongée jusqu'à la période historique, nous permet précisément de juger en quelque mesure d'une « histoire préhistorique » qui échappe, faute de textes, à nos prises certaines. - «L'histoire des dialectes grecs reflète celle des conquêtes d'un peuple de soldats hardis qui ont dû à leurs armes leurs conquêtes - et qui, fiers d'eux-mêmes et de leurs forces, se sont soumis partout des serfs et des esclaves dont la langue a disparu sans laisser de traces. » p167 — « Deux tendances s'opposent, durant cette période ancienne de la langue grecque : d'une part, la langue tend à se différencier à l'infini, et à prendre autant de formes nettement séparées qu'il y a de cités autonomes; de l'autre, elle tend à s'unifier ${ }^{71}$... »Mais n'est-ce pas là toute l'histoire du peuple grec, tout le rythme alterné de son développement propre? — «C'est la création de l'Empire achéménide qui a été la première cause de la création de la коเví ionienne-attique. L'organisation de l'Empire achéménide a fait sentir aux Grecs leur unité.» - «Le succès définitif de la langue d'Athènes a été décidé le jour où la Macédoine a eu en Grèce l'hégémonie ${ }^{72}$. » — Ces citations n'indiquent-elles pas, mieux que de longues phrases, jusqu'à quel point le petit livre de Meillet est un vrai livre, un beau livre d'histoire ? Et pas seulement d'histoire grecque. Une monographie d'une telle ampleur ne vaut pas que pour un peuple, pour une langue, pour une histoire - même quand, par une bonne fortune unique, cette histoire peut se suivre des plus lointaines origines jusqu'aux temps les plus immédiatement

\footnotetext{
Aperçu, p. 74-75.
}

Aperçu, p. 116.

Ibid., p. 269-272. 
contemporains, de la кoเví préhistorique à la кoเví d'aujourd'hui. C'est le modèle, le type même de l'histoire d'une langue.

A fermer ce beau livre, un regret nous vient. Quand nous nous reportons aux temps de notre apprentissage scolaire; quand nous songeons à la façon sèche, pauvre, mécanique dont on nous enseignait ce qui est si vivant, si riche de substance et qui aurait pris si ardemment nos imaginations déjà toutes passionnées d'histoire comment ne pas envier nos plus jeunes successeurs? Mais quelle ironie ! Le livre paraît aujourd'hui — et il n'y a plus de grec. p168 


\section{Politique Royale ou Civilisation Française ?}

\section{LA CONQUÊTE DU MIDI PAR LA LANGUE FRANÇAISE}

$\underline{\text { Retour à la table des matières }}$

Imaginez qu'en 1923 un curieux d'histoire se soit dit : « La France, la France... Ces historiens, toujours, nous parlent de la France comme d'une réalité constante, parfaitement définie, identique à elle-même à travers les âges. Tout de même, qu'était-elle donc vraiment, cette France, que représentait-elle pour les étrangers et pour les Français mettons, par exemple, au temps d'un Louis XI ? Autour de ce roi dont on nous dit qu'il fut un «centralisateur», qu'il eut le sentiment particulièrement vif de certaines nécessités et de certains périls. Quelle idée se faisait-on d'une unité nationale ? S'en faisait-on une ? Et si oui, quels fondements lui assignait-on communément? Par exemple, la langue: quelle langue parlait-on en France à cette époque ? Sentait-on le besoin d'une uniformité linguistique qui nous paraît aujourd'hui l'une des conditions essentielles d'une vie nationale bien réglée ? Gros problèmes, problèmes capitaux et qui vingt fois sans doute ont dû solliciter la curiosité des érudits : renseignonsnous. »)

Sur quoi, le premier beau bibliographe consulté : «Mille regrets, mais je n'ai rien dans mes fiches. Il s'est bien trouvé jadis un certain Paul Meyer pour s'intéresser à la question. A son appel comme à celui du Comité des Travaux Historiques, une vingtaine de travailleurs locaux ont répondu. On leur doit quelques monographies, les unes courtes, les autres longues, celles-ci sérieuses, celles-là légères. Au total, elles tiennent dans le creux de la main. Et ce ne sont que des monographies locales. Leur horizon cesse aux limites d'un canton. Cherchez-y la France, vous ne l'y trouverez point. » 
Or, voici qu'un homme courageux, en 1923, s'est enfin avisé p169 de nous donner le livre d'ensemble ${ }^{73}$, le tableau complet et général de la vaste opération de conquête et de pénétration linguistique qui, installant la langue du roi de France dans tout le domaine méridional, y établit un bilinguisme durable. Grâces lui soient rendues. Sur un sol morcelé, broussailleux, inégal, il a su tracer un ample réseau d'avenues bien aérées. En bordure, les constructions changeront; des fondations seront refaites, des façades transformées. Le dessin général restera. Et toutes les améliorations de détail, c'est au premier maître de l'œuvre, en définitive, qu'il faudra en rapporter le mérite.

I.

Allons droit à l'essentiel. Le livre d'A. Brun démontre, précisément, ceci : le français s'est introduit dans le Midi entre 1450 et 1600 .

L'introduction s'est faite en quatre temps. Si l'on veut, il y a eu quatre vagues successives, chacune portant la langue du roi un peu plus avant vers les limites du royaume. La première, de 1450 à 1520, emporte les avancées du Nord : Limousin, Périgord, Bordelais, HauteAuvergne, Velay, et le long du Rhône, non pas toutes mais la plupart des villes notables: Tournon et Valence ; Beaucaire avant Tarascon; Arles précédant Orange, Montélimar et Avignon; par delà, Montpellier et Nîmes. La dernière vague, de 1550 à 1600, vient à bout des ultimes résistances : celles des Landes, du pays basque, des hautes vallées pyrénéennes de la Bigorre et du val d'Aure; elle submerge avec le rebord méridional des Cévennes, d'Aniane à Saint-Pons, l'ensemble du pays rouergat et du Comté de Rodez et, plus loin, les vallées isolées de la Haute-Provence. Le gros du travail, c'est en trente ans seulement qu'il s'accomplit. La date réellement intéressante à retenir est 1540. Si l'on veut, 1539, date de Publication d'un document décisif, cette ordonnance royale de Villers-Cotterets à laquelle A. Brun dans tout le cours de son livre attribue - nous y

A. BRUN, Recherches historiques sur l'introduction du français dans les provinces du Midi, Paris, Champion 1923, in- $8^{\circ}$ (Thèse, Paris). - Du même : L'introduction de la langue française en Béarn et en Roussillon, ibid., 94 pages in- $8^{\circ}$ (Thèse complém.). 
reviendrons - l'influence la plus considérable : de façon catégorique elle enjoignait d'employer désormais dans tous les actes judiciaires non plus le latin ou les parlers locaux, mais, exclusivement, le « vulgaire » français.

D'ailleurs, point d'imprévu dans la marche du phénomène. La langue française s'est introduite dans le Midi de proche en ${ }_{\mathrm{p} 170}$ proche et par l'effet d'une pression continue. Cependant elle ne s'est point bornée à attaquer de front. Elle a manœuvré par les ailes. A l'Est, elle a gagné de l'avance dans la vallée du Rhône; à l'Ouest, dans la Saintonge et le Bordelais ; le Toulousain s'est vu réellement cerner, et c'est une fois cerné seulement qu'il s'est rendu. La géographie rend compte des progrès de la langue royale, bien plus que l'histoire ou que la politique. L'exemple typique entre tous est celui d'Avignon et de ce Comtat Venaissin qui, possédé par le pape, n'obéissait point aux injonctions administratives des rois de France. Or, le Comtat, à faire du français sa langue écrite, ne met pas plus d'hésitation ou de lenteur que les pays qui l'entourent et qui dépendent du roi ${ }^{74}$. Avignon, ville cosmopolite d'affaires et de plaisir, s'ouvre même avant les autres villes du Midi à l'idiome de la France royale. Dès le XV ${ }^{\mathrm{e}}$ siècle, celuici y tient sa belle place; son triomphe définitif s'opère, comme dans les autres cités rhodaniennes, au milieu du XVI siècle.

$\mathrm{Du}$ reste on suit fort bien, à travers tout le livre de Brun, l'influence des grands courants de circulation. Voici le Rouergue et le Gévaudan, deux pays difficiles, qu'on serait tenté de grouper dans une même catégorie de provinces «retirées mais vivaces": des géographes l'ont fait ${ }^{75}$. Or, Mende est francisée un bon demi-siècle avant Rodez. Influence évidente de cette vieille voie de communication, voie regordane, dont les travaux de Bédier ont mis le rôle en valeur. J'ajoute: confirmation nouvelle de ce que nous apprend la géographie linguistique ${ }^{76}$.

74 Ouvr. cité, p. 404.

75 Brunhes, Géographie humaine de la France, t. I, p. 355.

76 Résumé de DAUZAT, La géographie linguistique, Paris, Flammarion, p. 156195. Sur les influences géographiques dans le Cantal, bonnes indications de BRUN, ouvr. cité, p. 57-58. 
Ainsi, point de mystère, de miracle de coup de baguette magique introduisant brusquement la langue du Nord dans le domaine méridional. Avant de retracer les étapes de cette introduction, A. Brun a eu soin de suivre la marche conquérante du français, sa substitution graduelle aux parlers locaux dans les contrées immédiatement limitrophes de celles qu'il étudie, c'est-à-dire au Nord de cette limite traditionnelle des deux langues d'oc et d'oïl que tant d'érudits, jadis, ont perdu leur temps à vouloir déterminer sur la carte. De ce travail préliminaire, son livre reçoit une grande clarté. Car, en réalité, il n'y a pas eu deux mouvements distincts, mais un seul qui, commencé aux bords de la Seine, s'est propagé lentement jusqu'aux Pyrénées. p171

Naturellement, point de place dans cette histoire restituée et rendue parfaitement plausible, pour ce qu'on pourrait nommer " le coup de théâtre albigeois ». On sait qu'autrefois nul ne croyait à la propagation graduelle - et tardive — du français dans le Midi au cours du XVI siècle. Le dogme était que, d'un seul coup, au lendemain de la croisade des Albigeois et en suite de cette croisade, la langue des vainqueurs s'était vue porter jusqu'aux frontières des Alpes et des Pyrénées.

A. Brun discute le dogme. Il le ruine. Je retiens malaisément deux mots, qui pourraient passer pour une critique : "sans effort». C'est qu'un historien n'apprend pas sans surprise quelle opinion dominait jusqu'à présent chez les érudits sur le sujet difficile qu'aborde A. Brun. Romanistes et linguistes ne sont pas tenus, sans doute, d'ignorer totalement les travaux des historiens. Or, il y a de belles années que ceux-ci — référons-nous notamment à la thèse bien connue de Paul Dognon qui fait toujours autorité en la matière ${ }^{77}$ ont montré que la conquête française ne s'était accompagnée, en Languedoc, d'aucune tentative, réussie ou non, de « francisation » des institutions ou du droit. Les livres de vulgarisation eux-mêmes professent cette doctrine et la répandent dans le grand public. "Rien ne semble changé au fond, écrit par exemple M. Gachon, dans son excellente petite Histoire du Languedoc ${ }^{78}$. Si les sénéchaux viennent

\footnotetext{
77 Les institutions politiques et administratives du Languedoc, du XIII siècle aux guerres de religion.

78 Paris, Boivin, 1921, p. 102.
} 
toujours de France, la plupart des autres officiers sont du pays et en connaissent la langue et les mœurs. Ce n'est donc point encore [au temps de saint Louis] l'aspect de ce qu'on est convenu d'appeler la centralisation monarchique. " Il est même curieux de voir au XIV siècle grandir et naître dans ce Midi qu'organisent les États du Languedoc, une sorte de conscience régionale qui s'exprime par des formules comme Patria ou Respublica Occitana, Patria Lingue Occitane $^{79}$. Donc, la croisade des Albigeois n'a pas tué dans le Midi les parlers locaux. $\mathrm{Au} \mathrm{XIII}$, au XIV ${ }^{\mathrm{e}}$, au début du XV $\mathrm{XV}^{\mathrm{e}}$ siècle, ceux-ci demeurent les maîtres de leur domaine. Parlés, et exclusivement parlés par les populations méridionales, ils sont écrits toutes les fois qu'on ne leur préfère point le latin. Et lorsque le latin commence à décliner, ce sont eux qui profitent de ce déclin pour s'épanouir « de plus en plus à mesure qu'on approche de $1500 »$. Telle est la vraisemblance, telle la vérité. p172

\section{II.}

Ainsi, le livre d'A. Brun est vraiment plein de bon sens et de saine doctrine. Est-ce à dire que ce soit un livre parfait? Il n'en est point, sans doute. Si nous le notons, ce n'est pas par vain souci de critique ; c'est par intérêt profond pour une question ou plutôt un complexe de questions qu'A. Brun ne prétend point, certainement, avoir traitées toutes également et à fond. Questions linguistiques, questions historiques. Or, sans vouloir insister, il nous semble qu'à traiter les uns et les autres, A. Brun n'était peut-être pas également et suffisamment préparé. Son livre est un recueil de faits. Comme tel, singulièrement précieux et d'un prix inestimable pour les travailleurs futurs. Mais son bon sens, parfois, a quelque chose d'un peu court et d'un peu restrictif. Je veux dire qu'il manifeste une extrême défiance à l'égard des théories, quelles qu'elles soient. Les faits seuls : ils parlent d'eux-mêmes, assez haut.

Forse che si. Mais souvenons-nous toujours de ces historiens qui ne s'embarrassent point de doctrine lorsqu'ils font de l'histoire économique. C'est chez eux que leurs invalides trouvent la fameuse 
« loi de l'offre et de la demande » et vingt autres vieilles éclopées de cet ordre - promues il est vrai à la dignité de «vérités de bon sens ${ }^{80} »$. En fait, j'ai un peu peur que cette défiance instinctive dont nous parlions n'ait ôté au livre de Brun un peu de sa netteté, à la fois, et de sa portée. Il jette son lecteur in medias res, sans préparation, sans avertissement préalable. Joanne et Baedeker, voyageurs experts, y mettent plus de façon: " Costume et bagages. - Monnaie et change. - Aperçu géographique et résumé historique »: après toutes ces généralités seulement vient la description. Joanne pressé, M. Brun a sauté le paragraphe des boussoles et négligé celui des cartes. Quatre cents pages durant, il retrace l'histoire de l'introduction du français dam le Midi, des origines à 1600. Et c'est seulement ensuite que, dans un très court chapitre intitulé : « Modalités et causes de la pénétration du français », il se soucie de définir l'objet de son livre. Souci un peu tardif, en vérité.

- Mais, dira A. Brun, je n'avais pas à préjuger des résultats de mon enquête. - Eh, qui vous demande de l'improbité ? Mettre par ordre les éléments d'un problème avant de s'attaquer à sa solution ; énoncer, avant de se donner à elle tout entier, les p173 conditions générales d'une recherche érudite - ce n'est point se livrer pieds et poings liés à l'hypothèse " préconçue », cette pelée, cette galeuse d'où vient tout le mal. L'histoire que A. Brun entreprend de retracer n'a rien d'unique ni d'exceptionnel. Les peuples, depuis que le monde est monde, passent leur existence à changer de langues. C'est par centaines et centaines que se comptent les révolutions linguistiques. Des classifications sont donc possibles. Elles existent. Toute étude qu'on peut tenter aujourd'hui rentrera, on le sait d'avance, dans un des cadres que le labeur des spécialistes a su assembler. Sans aller plus loin, on les trouve mentionnés dans un livre aussi accessible que le petit chef-d'œuvre de Meillet: Les langues dans l'Europe nouvelle. Mais le préjugé qu'acheter une lanterne et de quoi l'allumer avant de se mettre en route, c'est témoigner d'un fâcheux parti pris - ce préjugé, sans doute, n'est pas près de disparaître.

80 Cf. les réflexions toujours justes qu'inspiraient naguère à M. SIMIAND, dans L'Année Sociologique, les études de P. GuIRAud sur l'économie du monde antique. 
Et voyez les conséquences. Faute de quelques indications préalables, A. Brun nous laisse croire, et fait comme s'il croyait luimême - que le but de son livre, c'est de nous décrire un duel entre deux adversaires : le français d'une part, qui veut pénétrer; le roman de l'autre, qui défend ses positions. Mais, Brun le sait tout le premier, il y a une tierce partie sous les armes : le latin. Il y en a même une quatrième, me souffle un bon connaisseur de la littérature médiévale du Midi : cette langue littéraire, distincte des dialectes, qui sert au XII siècle dans les Cours riches et policées des princes, en Languedoc, en Auvergne, dans le Velay, en Provence, à traduire les thèmes raffinés de l'amour courtois. Langue littéraire qui n'eut pas le temps de devenir une langue de civilisation véritable; langue poétique plus précisément, idiome précieux d'inventeurs plus subtils que puissants : tant que subsiste la civilisation originale dont elle traduisait les aspirations lyriques et le souci d'analyses délicates, le latin, cette langue politique et savante, nuit à son développement, l'empêche de créer sa prose, sa langue du droit, de la politique, de la religion. Et quand le latin petit à petit détend ses prises et commence, un peu partout, à céder de la place aux « vulgaires » qui grandissent — il n'y a plus de civilisation originale dans le Midi, il n'y a plus d'autonomie méridionale ; dès le milieu du XIII ${ }^{\mathrm{e}}$ siècle, c'est un procès jugé. Aussi «la littérature languedocienne n'aura-t-elle pas de prose. Son vocabulaire ne s'élèvera pas à l'expression des idées générales, le latin y suffisant alors. Elle a eu ses fleurs colorées et délicates; elle n'arrivera pas jusqu'aux fruits, n'atteindra pas la maturité ». On ne saurait mieux dire que ne dit M. Gachon. p174

Cependant, dans le Nord, une prose s'est formée, savante, énergique, claire, organe d'une civilisation qui ne cesse de grandir, d'étendre ses prises sur le monde occidental par son art, sa pensée, le prestige de ses rois, le génie de ses architectes de cathédrales, la science de ses docteurs. Rien ne servirait d'alléguer que ce prestige, pendant les longues années de la guerre de Cent Ans, subit de dures atteintes, s'il est vrai qu'au cours de cette crise violente, les provinces du Midi restant délibérément fidèles au roi de France, refusant de céder à l'attraction du roi d'Angleterre, maître cependant de la Guyenne toute proche, « reçoivent fortement l'empreinte de la patrie commune et s'habituent à fixer sur le roi puis sur le royaume de 
France leur attention, bientôt leur attachement ${ }^{81} \gg$ - un attachement d'ailleurs qui s'accorde avec leurs intérêts.

Aussi lorsque, le latin se repliant petit à petit, il y aura dans le Midi un beau rôle à jouer pour une langue vulgaire, celui de langue de civilisation : ce ne sera pas tel ou tel dialecte méridional qui pourra s'en emparer; ni cette кoívm à l'usage des notaires qui avait dû se constituer par régions dans le monde du Midi et dont l'étude serait sans doute propre à satisfaire certaines curiosités d'A. Brun. Ces dialectes, ce langage commun d'intérêt tout pratique, ils peuvent pendant un temps recouvrir, tant bien que mal, le découvert du latin. Ils sont vivants, c'est vrai. A. Brun a raison de le dire; ils semblent forts ; ils règnent sans partage sur tout le domaine languedocien, sur tout le domaine provençal; ils se parlent, seuls; ils s'écrivent, seuls à côté du latin. Encore faut-il noter que déjà, dans les Cours, c'est le français qui se parle et s'écrit. Mais l'apparente fortune des dialectes méridionaux ne durera point. Dès que le problème se posera réellement, leur faiblesse apparaîtra à tous les yeux. Le français paraîtra, et triomphera. Rejetés au rang de patois, les dialectes s'effaceront des documents écrits. Ils ne vivront plus que comme langue familière, pour les besoins triviaux des hommes. Et ainsi, si cette évolution est bien celle qui s'est accomplie, la croisade des Albigeois, aux yeux de l'historien, et «l'invasion des hommes du Nord », ces vieux clichés odieux à Brun, reprennent quelque jeunesse et quelque à-propos. p175

III.

Mais pareillement, on le devine d'avance, sur un point capital nous ne sommes plus d'accord avec A. Brun. C'est quand il s'agit d'expliquer pourquoi le français s'est emparé du Midi avec l'irrésistible élan d'un mouvement de masse, et, précisément, de 1450 à 1600, dates larges; de 1500 à 1550, dates strictes.

81 GACHON, ouvr. cité, p. 118. Et p. 116: «Elle acheva [la région languedocienne] de devenir française par ses services, fut même un moment, avec les provinces du centre, la France contre les Anglais. " Nous puisons à dessein ces indications dans un livre d'histoire écrit pour tous, fait de main d'ouvrier, du reste. 
A. Brun se défend d'examiner longuement cette question. «A quoi bon disserter sur les causes que l'exposé des faits suffit à révéler?» A. Brun ne disserte pas : il constate. Il voit, d'une part, que la royauté entre 1450 et 1550 , par un resserrement obstiné de son autorité, fait prévaloir «un système administratif qui tend à l'unité et à la centralisation ». Il voit d'autre part que, parallèlement, les dialectes du Midi « qui jusqu'alors n'ont donné aucun signe d'affaiblissement », sont proscrits de l'écriture et délogés de toutes leurs positions administratives ou littéraires par le français «dont la souveraineté s'impose comme corollaire à celle du roi ». Ces deux faits synchroniques s'ajustent «comme la doublure au vêtement». Le premier est la cause du second. Le triomphe du français dans le Midi : une œuvre politique, l'œuvre d'une politique, rien d'autre ${ }^{82}$. Le couronnement de cette œuvre ? c'est l'ordonnance de Villers-Cotterets avec son ton impératif, sa rédaction sans équivoque, ses injonctions catégoriques. Sic volo, sic jubeo. Le roi commande. Le Midi obéit...

Je suis toujours un peu éberlué, je l'avoue, par la simplicité schématique de telles explications. Oh! culte inébranlable des " décisions gouvernementales » se perpétuant sans atteintes, même après la terrible crise de 1914-1918, où l'on vit au pouvoir tant de pauvres hommes, menés à la dérive par des forces aveugles qu'ils avaient bien pu déchaîner, mais qu'ils ne savaient conduire ni maîtriser. - Laissons cela, et revenons à Brun. J'entend bien : de-ci, de-là, il esquisse une réserve, glisse un mot qui fait naître l'espoir. Il concède (p. 421) « qu'une révolution pour être féconde en résultats durables, doit venir juste à son heure ». Il accorde que l'ordonnance de Villers-Cotterets «répondait à une prédisposition latente des générations nouvelles ». Déjà, quand elle parut, «une portion importante $\mathrm{du}$ domaine méridional adhérait spontanément au français... Il y avait une sorte de poussée de l'esprit public, qui cherchait à se préciser dans le sens de la modernité [?]... une évolution favorable aux vues de la monarchie ». p176 Mais c'est tout. A. Brun ne va pas plus loin. Aucun effort d'analyse. Il s'en tient à son mot, si

82 Texte très net, à la page 1 du livre de Brun : « Fait d'histoire, n'est-ce pas, et d'histoire politique, tel est le caractère spécifique du phénomène que nous étudions. »" 
vague, d'opportunité. Pourquoi cette «opportunité »? C'est toute la question.

Qu'on m'entende bien. Je n'en veux pas à l'ordonnance de VillersCotterets! Elle a joué son rôle, son grand rôle, dans l'histoire linguistique qu'A. Brun nous retrace ${ }^{83}$. Je ne nie pas l'action, encore moins, de ce que, d'un mot commode, nous appelons les progrès de la centralisation royale. Bien plutôt, je reprocherais volontiers à A. Brun (si je ne redoutais l'accusation de pédantisme professionnel ) les faiblesses et les lacunes des pages qu'il consacre à ce puissant travail des officiers royaux. Trop de formules anachroniques sans doute ${ }^{84}$, trop de méprises sur la portée de certaines décisions; trop d'oublis surtout. A. Brun parle des Parlements, dont le rôle fut capital, en fort bons termes. Il parle moins bien, ou même pas du tout de la manière dont, de plus en plus, les officiers royaux brisent, à la fin $d u X^{e}$, au début du XVI ${ }^{\mathrm{e}}$ siècle, les franchises municipales, peuplent les corps municipaux, arbitrairement, de créatures à eux, font à Toulouse des capitouls, à Montauban ou à Marseille des consuls : gens dociles, soumis à leur direction. Tout ceci était à dire, avec force. Rien n'éclaire mieux sans doute certains aspects de «la question du français ॥; rien ne contribue mieux à expliquer, pour une part, l'emploi de la langue royale, bien avant l'ordonnance de VillersCotterets, dans les registres de délibérations et même de comptabilité de tant de municipalités méridionales.

Après quoi, et tout ceci noté, une vérité demeure, évidente aux yeux du linguiste, plus évidente encore aux yeux de l'historien. Et que nulle part, malheureusement, on ne trouve affirmée par A. Brun. Ce qui peut inciter un peuple à renoncer à sa langue ou tout au moins à écrire cette langue ; ce qui peut l'amener à consentir, en fait, à ce que

83 Une phrase bien amusante, p. 421 ; « Il est désormais acquis que la portée [de cette ordonnance] fut quasi démesurée. »

84 Exemple : «L'avènement des fonctionnaires » (p. 82): un «corps de fonctionnaires » (ibid.), et cent autres à peu près de ce genre. on ne lit pas sans effroi, dans la petite thèse d'A. Brun, cette appréciation (p. 62). " Le moyen âge, avec ses atermoiements optimistes et son opportunisme confiant, n'était plus de mode. » Quand il écrit que la poste, créée sous Louis XI, établit la liaison entre les administrations locales et centrales, $\mathrm{M}$. Brun ne se doute évidemment pas que la « poste » de Louis XI n'avait rien de commun avec ce que nous appelons de ce nom. Ne multiplions pas ces exemples. Il y aurait de l'injustice à le faire. 
son dialecte tombe au rang de patois - ce n'est pas le sentiment qu'il est dominé et qu'il doit dès lors adopter la langue de son dominateur ; il y a des dominés qui méprisent, et qui ont de quoi mépriser leur dominateur; ou, tout au moins, de quoi se considérer, malgré leur infériorité politique, comme égaux à lui par la culture. Ce fut le cas des p177 populations de langue grecque, dans l'antiquité, qui ne s'ouvrirent point au latin (à quelques très rares exceptions près) lorsque Rome eut conquis toute la partie occidentale de la Méditerranée ${ }^{85}$.

Non. Quand la langue des dominés prétend à un prestige sinon supérieur, au moins égal à celui dont jouit la langue des dominants : rien à faire. La contrainte échoue, échouera toujours. Même aujourd'hui où, cependant, la mécanique de l'État moderne, si bien montée, retient et triture l'individu, sans arrêt, de sa naissance à sa mort, le façonne linguistiquement par l'école obligatoire, par le service militaire obligatoire, par les innombrables rapports obligatoires avec une administration qui se mêle de tout et qui ne parle et n'entend que la langue officielle. Cependant la contrainte ne peut réussir qu'au prix d'une abominable violence, d'une inquisition publique et privée recourant à toutes les délations, d'un de ces régimes de terreur que les Allemands ont appliqué, de 1914 à 1918, aux populations francophones d'Alsace et de Lorraine ${ }^{86}$. Encore n'ont-ils

A. MeILlet, Aperçu d'une histoire de la langue grecque, 1913, III ${ }^{\mathrm{e}}$ partie, chap. VI, p. 345.

86 Puisque son nom vient sous notre plume, noterons-nous qu'un voyage d'étude dans cette Alsace où s'accomplit un si intéressant travail linguistique, n'aurait pas été inutile à Brun ? Nous y pensions en lisant la discussion, assez preste sous sa plume (p. 467), de ces témoignages souvent cités d'écrivains français du XVII ${ }^{\mathrm{e}}$ siècle, déclarant (tel Racine à Uzès) que les naturels du Midi n'entendent pas plus le français des Français, que ceux-ci le français des Méridionaux. Quant au témoignage de Racine, A. Brun oppose ce fait qu'en 1664, précisément, le curé d'Uzès substitue dans ses registres paroissiaux le français au roman, nous songeons aussitôt qu'en Alsace, aujourd'hui, exercent beaucoup d'instituteurs qui ne savaient pour ainsi dire rien de notre langue à l'armistice. Certains, les moins bien doués, apprennent chaque jour la leçon de français qu'ils font ensuite à leurs élèves : il arrive même qu'ils l'oublient, tout au moins partiellement, après l'avoir faite. Fort empêchés d'haranguer, sinon Racine, du moins A. Brun, ils n'en tiendraient pas moins, en français approximatif, si on le leur demandait, les registres d'état-civil de leur village. - Et encore, il y a l'exemple de Molière parcourant le Midi avec sa troupe. "Jouait-il donc devant des banquettes vides?» questionne A. Brun. Mais que d'Alsaciens vont aux représentations classiques du 
pu tuer le désir du français, s'ils sont parvenus à en prescrire l'usage. Tant qu'il ne s'agit pas d'une infime minorité qui s'abandonne dans le sentiment de son impuissance, on n'impose pas à un peuple, qui la hait ou la méprise, une langue nouvelle, fût-ce celle d'un vainqueur.

Il faut, pour qu'une mutation de langue soit possible, la complicité du sentiment. Il faut que les dominés sentent, et se trouvent disposés à reconnaître le prestige des dominants. Ou plutôt il faut que renonçant à tout particularisme irréductible, national ou religieux, ils aspirent à ne plus se distinguer des dominants, à se fondre avec eux et en eux de plus en plus intimement, à participer à leur civilisation reconnue supérieure, à leur culture morale, scientifique, littéraire, artistique, religieuse, p178 considérée comme enviable et belle. Tel fut le cas des Gaulois en face des Romains. Tel fut, d'une façon générale, le cas des Populations soumises par Rome, à l'exception des populations de langue grecque. Et l'on ne voit point que Rome ait dû mettre sur pied, pour imposer sa langue, toute une politique spéciale de contrainte: son prestige, celui de sa civilisation, suffisait; l'intérêt des vaincus faisait le reste.

Eh bien, pareillement, tel fut le cas des populations du Midi ; et du moment qu'A. Brun, ne se contentant pas de grouper des faits et des dates, esquissait une explication, tout en s'en défendant - ou plutôt, du moment qu'il proclamait qu'une seule explication sortait des faits, directement : l'explication «politique » - nous sommes fondés à lui reprocher de ne pas l'avoir dit, de ne pas l'avoir montré avec toute la force nécessaire. Les gens du Midi, à la fin du XV ${ }^{\mathrm{e}}$ siècle, au début du $\mathrm{XVI}^{\mathrm{e}}$, comment auraient-ils eu le sentiment de participer par leur langue à une culture supérieure ? Leur langue n'était plus pour eux qu'un outil d'usage pratique et journalier, depuis que leur littérature, toute littérature méridionale de valeur était morte. Leur art? ils n'en avaient plus qui fût à eux. Après l'art gothique, si peu fait cependant pour leur pays, c'est une sculpture parente des sculptures françaises nordiques (on l'a qualifiée longtemps de bourguignonne, sur la foi, trop expansive, de Courajod) qui les envahit ; c'est elle qu'on admire à Albi, à Toulouse, à Rodez. Leur conscience nationale? Les

théâtre de Strasbourg (et y entendent du Molière parfois), non parce qu'ils savent, mais parce qu'ils s'efforcent de savoir le bon français ! 
populations sont satisfaites des privilèges qui constituent la charte spéciale de chaque province et que le roi, à son avènement, confirme solennellement. Elles en désirent le maintien intégral. Au delà, elles ne désirent rien.

Ainsi, point de culture propre au Midi. Par contre, une culture française, de jour en jour plus forte et plus prestigieuse. Une France qui renaît de ses ruines, respire et s'épanouit dans la paix, se rue au travail avec une ardeur fiévreuse et gaie, traverse, de 1480 à 1520, quarante ans de prospérité, de bonheur, de vie facile et joyeuse, et porte en elle à la fois, parmi tant d'espérances illimitées, la Renaissance et la jeune Réforme. Mais comment M. Brun a-t-il pu ne pas nous le dire, ne pas nous l'indiquer, ne fut-ce que d'un mot? Comment, après avoir omis de nous signaler ce puissant travail qui, aux heures les plus graves de la guerre de Cent Ans, s'opère dans les consciences méridionales, en Languedoc notamment ${ }^{87}$; comment a-til pu passer sous silence ce formidable p179 effort de renaissance économique; cette fièvre passionnée de labeur et de gain; cette profonde transformation sociale qui transfigure en quelques années le Midi, comme tout le reste d'une France unifiée dans le succès et dans le bonheur de vivre?

La France se refait. Les villes dévastées, les campagnes désertées se repeuplent. Dans tout le Midi, on défriche les garrigues, les « paluns », les terres abandonnées; on plante en Provence oliviers et figuiers; en Languedoc oliviers aussi, et mûriers et guêde; à Montpellier, à Narbonne, à Carcassonne, à Pezenas, à Alais, à Uzès, regarnies d'hommes en partie par l'immigration d'étrangers désormais exempts, dans le Midi provençal ou languedocien, du droit d'aubaine - les rois donnent les privilèges nécessaires pour que s'installent des ateliers de draperie qui libèrent la contrée des draperies du Nord. Les douanes intérieures s'effacent, entre Languedoc, Provence, Dauphiné et Bourgogne. Les fleuves, la Garonne, le Rhône, nettoyés de leurs péages abusifs, de leurs écluses, de leurs barrages de moulins, redeviennent libres pour tous. Et la royauté mène le jeu; c'est vers

87 [Au temps où ,écrivait cet article, on ne pouvait parler du Bordelais. On le peut, depuis l'apparition, en 1947, de la belle thèse de R. BOUTRUCHE, Seigneurs et paysans du Bordelais pendant la guerre de Cent Ans.] 
elle qu'on se tourne, qu'il faut se tourner de plus en plus, dès qu'on veut «proufiter» et " gaigner» : les deux grands mots de ce temps qui voit naître et prospérer un capitalisme à la fois ingénu et féroce. Parallèlement, tout un travail s'opère, en profondeur, dans les rangs de la société. Le clergé se serre de plus en plus autour du roi et du gouvernement royal. Il y participe, largement. Les évêques peuplent les Cours souveraines, siègent dans les parlements, à Paris comme à Toulouse ou à Aix, président les états de Languedoc, occupent, en Languedoc, en Provence, les fonctions de lieutenant-général du roi. Mais la bourgeoisie surtout grandit, s'enrichit, varie ses prises, s'annonce comme la maîtresse incontestée des temps nouveaux. Elle est partout où il y a à gagner, à s'ingénier, à tirer profit. Son arme à elle ce n'est pas l'épée, c'est la plume :

Vive la plume magnifique,

Le papier et le parchemin!

Qui d'escripre sçait la pratique,

Il peut bien aller par chemin!

Devise authentique de tout un peuple, avide de culture, parce que la culture pour elle, c'est le moyen de la fortune et de l'élévation avide de culture française, naturellement, par ce que le temps n'est plus où l'on pouvait "gagner» assis dans sa maison, au fond de sa petite ville, sans rien savoir du monde et ${ }_{\mathrm{p} 180}$ sans le parcourir - avide de la culture qui permet au marchand de courir la fortune sur les hauts chemins; au financier, de se mettre au service du roi; au robin, d'entrer dans ses «justices » et dans ses parlements. Les causes de cette révolution linguistique qui, d'un Midi ignorant le français en 1450, fait, en 1550, un Midi qui n'écrit plus que le français - en vérité, comment ne pas dire, comment ne pas crier d'un mot tout au moins qu'elles sont là ! Il ne s'agit pas, encore une fois, de nier le rôle de la royauté, du pouvoir central dans ce grand procès de civilisation. Il ne s'agit pas de chicaner sur l'action que les décisions de ce pouvoir et, d'une façon générale, que les faits d'ordre proprement politique et administratif ont pu exercer à la fin $d u X V^{\mathrm{e}}$, au début du XVI siècle, sur la révolution linguistique qu'étudie $\mathrm{M}$. Brun. Il s'agit d'absorber pour ainsi dire, comme on le doit, ce rôle du pouvoir politique, ce rôle de la monarchie française et de ses agents dans le rôle, encore plus 
vaste et plus important, de la civilisation française tout entière de ce temps.

Ce n'est pas un « Je veux » de François $\mathrm{I}^{\text {er }}$, ou de quelque autre roi, qui explique le miracle de cette conversion linguistique du Midi. Le monde méridional n'a pas obéi au cri d'un héraut, lisant, après trois appels de trompette, devant les populations prosternées, l'ordonnance de Villers-Cotterets. C'est la grandeur, la prospérité, la vitalité d'une France dont tout le Midi, qui déjà en faisait partie de fait et de volonté, a voulu faire partie de langue, c'est la vie puissante du grand pays qu'incarnent des rois honorés et craints de toute l'Europe, assez forts pour briguer la Couronne impériale ; c'est une orientation nouvelle de l'activité générale du royaume qui, se détournant de la Méditerranée, se laisse aimanter par l'Océan, par les terres neuves d'Amérique plus près, par la grande place cosmopolite d'Anvers - c'est tout ce remuement des hommes, ce fourmillement des intérêts, ce bouillonnement des idées qui explique, en définitive, le grand fait qu'A. Brun a mis en pleine lumière (et c'est son grand mérite) mais qu'il a voulu expliquer (et ce fut une faiblesse) : l'adhésion non point contrainte et imposée, mais libre et joyeuse, l'adhésion de désir des Méridionaux à une pratique linguistique que d'ailleurs, à la même époque, l'imprimerie fixait et la littérature « illustrait».

Mais pour exprimer tout ceci, que nous nous contentons d'indiquer de façon sommaire et grosse - ce n'était pas un homme qu'il fallait, mais deux, unissant leurs efforts. Un linguiste, un historien. Vox clamantis in deserto ? On nous pardonnera d'être, sans nous lasser, ce trouble-fête. p181 


\section{Problèmes d'Histoire Greffés sur « le Brunot »}

\section{LA NATIONALITÉ ET LA LANGUE EN FRANCE AU XVIII SIÈCLE}

\section{Retour à la table des matières}

De plus en plus, à mesure qu'il avance dans son grand dessein, Ferdinand Brunot manifeste le souci de lier étroitement l'histoire de la langue française à l'histoire générale de la France. Philologues et linguistes ont dit tout ce que leurs disciplines pouvaient gagner, et gagnaient, à semblable méthode. On permettra à un historien qui, depuis longtemps, suit dans cette Revue, de son point de vue spécial, le développement des études linguistiques, de marquer avec force tout ce que l'histoire générale doit à des travaux aussi neufs, aussi hardis et cependant aussi prudents.

Dans le tome V de l'Histoire de la langue française des origines à 1900, Brunot étudiait la marche du français en France et hors de France au XVII ${ }^{\mathrm{e}}$ siècle. Il nous montrait notre langue conquérant, d'un élan, l'Europe, cependant qu'à l'intérieur du royaume elle n'avançait que pied à pied, lentement, obscurément, à travers mille obstacles et mille résistances. Contraste étrange, mais combien instructif ; comme il illustre, d'une façon saisissante, l'histoire de la France «louisquatorzième $»$ !

Aujourd'hui, avec le tome VII, c'est la propagation du français en France au cours du XVIII siècle qui nous est retracée, d'ensemble, dans toutes ses vicissitudes ${ }^{88}$. Sujet tout neuf, et d'un intérêt passionnant. Ceux qui, un jour, nous doteront de cette histoire du 
sentiment national en France que personne encore n'a entrepris sérieusement d'écrire — et qu'on a raison d'ailleurs d'ajourner jusqu'au temps où des travaux préparatoires auront ouvert quelques larges perspectives sur cette ${ }_{\mathrm{p} 182}$ énorme et magnifique question ceux-là devront tenir un compte minutieux des faits recueillis par $\mathrm{F}$. Brunot; mais surtout, ils auront à tirer de son étude, si dense et si sagace, les conclusions qui s'imposent. Je ne sais pas de livre qui nous incite à plus de réflexions, et plus fécondes, sur la texture intime d'une nationalité avant la crise révolutionnaire. Je n'en sais pas qui nous aide mieux à comprendre comment et en quoi nos États modernes diffèrent profondément des États d'autrefois. Je voudrais le montrer en quelques mots. Mais avant, j'aurai plaisir à suivre Ferdinand Brunot dans ses démarches et à retracer rapidement la marche du français à l'intérieur du royaume, depuis la fin du règne de Louis XIV jusqu'au seuil de la Révolution.

I.

Le français, à la fin du règne de Louis XIV, trouvait en face de lui deux adversaires inégalement armés, mais encore redoutables: le latin, le patois. Au cours du XVIII ${ }^{\mathrm{e}}$ siècle s'achève la déroute de l'un d'eux.

Le latin est vaincu. Cela veut dire, d'abord, que nul vers 1760 ne s'avise plus de considérer comme des écrivains véritables les faiseurs de distiques, d'iambes ou de saphiques qui, de moins en moins facilement d'ailleurs, trouvent encore des éditeurs.

\section{Aetas egregios duos poetas Haec fert aurea...}

s'exclamait en 1538 le bon Nicolas Bourbon. Ne cherchez pas qui sont ces deux poètes. Ronsard peut-être ? Ou encore Marot ? ou du Bellay? Non, il s'agit de Germain Brice et de Salmon Macrin que nous autres, rats de bibliothèque, nous grignotons encore à l'occasion; il faut bien faire des fiches; mais leur langue - fabriquée de mots et de "tournures » puisées à même cinq siècles de latinité, dans plus de vingt poètes hétéroclites - représente, pour qui a le sens du latin, ce que serait cette monstruosité : un pot pourri de 
classicismes raciniens et de métaphores romantiques avec, saupoudrant le tout, quelques réminiscences verlainiennes et une poignée d'archaïsmes marotiques.

$\mathrm{Au} \mathrm{XVIII}^{\mathrm{e}}$ siècle, ces tristes jeux prennent fin. Non qu'on cesse brusquement de lire ou d'éditer les poètes latins modernes, tant à l'étranger (en Hollande notamment) qu'en France même. J'ai devant moi, en écrivant ceci, un de ces livres délicats et charmants que

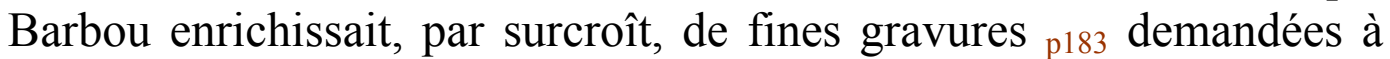
Cochin, à Eisen, à Gravelot et autres petits maîtres : c'est une édition du Praedium Rusticum du Père Vanière, de 1786 ; et voici, dans la même série, pêle-mêle avec un Lucrèce, un Virgile, un Horace et un exquis Martial en deux volumes, le De Hortis de Papin (1780) ; les Juvenilia de Bèze, de Muret et de Jean Second (1779); les tristes Fabulae de Desbillons (1778), d'autres encore. Il y aurait même, sur ces éditions et rééditions, à mener une de ces innombrables petites enquêtes statistiques dont la simple lecture du livre de M. Brunot fait, à chaque page, surgir l'idée ${ }^{89}$. Mais dans l'ensemble, c'est vrai ; il ne naît plus de poètes latins: formule prudente que les fervents du Thesaurus Poeticus et du Gradus ad Parnassum adoptent avec empressement pour déguiser à leurs propres yeux l'horreur du tombeau qui les guettes ${ }^{90}$.

Plus de poésie latine. Plus d'éloquence latine. Plus de science latine en un temps où le goût, l'engouement même, pour la science devient ce que l'on sait. L'Encyclopédie ne s'exprime qu'en français. Mais même dans leurs mémoires techniques, astronomes, physiciens, chimistes, philosophes, historiens, politiques : tous composent en leur langue. Déjà Fontenelle, le Fontenelle des Dialogues des morts et des Entretiens sur la pluralité des mondes, a enseveli dans les plis subtils d'une langue toute de finesse et de clarté la grande génération de la transition, de Malebranche à Leibniz et à Newton. Personne qui, dans la génération suivante, ne parle en français : Buffon ou d'Alembert,

89 Barbou, dans la même série, reproduisait l'Encomium Moriae d'Érasme et l'Utopia de Morus; il y a quelque chose d'intéressant dans cette résurrection à l'extrême fin du XVIII ${ }^{\mathrm{e}}$ siècle, et même sous le couvert de la bibliophilie, de certaines œuvres caractéristiques de la pensée, ou du sentiment du XVI ${ }^{\mathrm{e}}$ siècle.

90 Déjà Bayle, à cette époque notait que les poètes savants poussaient «les derniers soupirs de la poésie latine » (p. 7). 
Laplace ou Daubenton, Monge et Lalande, Lakanal et Réaumur ; c'est un procès gagné ${ }^{11}$. Je m'amusais, en lisant la thèse récente de Henri Daudin (De Linné à Lamarck, 1740-1790), à pointer, dans la Bibliographie, le nombre des mémoires ou des livres d'histoire naturelle composés par des Français entre 1740 et 1790, et écrits respectivement en français ou en latin: trente-trois contre quatre, chiffres éloquents ${ }^{92}$.

Signe révélateur: les collèges eux-mêmes commencent à s'émouvoir. Le concours général est créé en 1748 ; dès 1749 , il ${ }_{\text {p1 } 184}$ comporte en rhétorique un prix de Discours français. Et timidement, voilà les exercices français introduits dans les classes. Ils gagnent du terrain peu à peu, surtout chez les Oratoriens ; en 1759, il se trouve même des religieux pour instituer un enseignement sans latin; on devine que F. Brunot n'omet pas de saluer au passage ces précurseurs, les bons Bénédictins de Sorèze. Cependant, dans l'ensemble, l'esprit des régents reste latin. Dans ce milieu, les résistances sont tenaces, les routines invincibles. Il faudra du temps pour en avoir raison. Mais il ne s'agit plus que d'un petit milieu de professionnels, plus coupés du monde et de la vie, sans prises réelles sur l'esprit du temps.

Quand la Révolution commença, avec une pointe de témérité les partisans d'un large enseignement du français auraient pu sonner "Ville gagnée ». L’école résistait. La société était conquise.

Plus dure à mener, la lutte entre les patois. Certes, nulle part ils ne font plus figure de langue littéraire. Ni de langue écrite. Dans le Midi même, où si longtemps ils avaient régné en maîtres, leur domination est terminée ${ }^{93}$. Plus d'actes publics, de procédures, de papiers

\footnotetext{
91 Sur la période précédente, Cf. BRUNOT, t. V, p. 21 : « Le latin résiste dans les sciences... Quoique la science prît sa place dans l'estime publique, les savants ne prenaient que difficilement la leur dans la société », etc.

Sur l'apparition des journaux de science en français : Journal des Savants (1665) ; Nouvelles de la République des Lettres (1684); Bibliothèque Universelle (1668) ; Journal de Trévoux (1701) ; cf. également le t. V, p. 23 et suiv.

93 Voir BRUN, Recherches historiques sur l'introduction du français dans les provinces du Midi, Paris, 1923.
} 
notariés en «langue d'oc ». La langue littéraire, la langue d'apparat - bien plus, la langue qu'on écrit dès qu'on prend la plume, c'est le français. Mais qui n'est pas encore la langue vraiment maternelle, celle qu'on apprend sur les genoux des vieilles femmes, qu'on entend à la maison, dans la rue, et qu'on emploie tout naturellement pour parler à l'ami qui passe : ce «vulgaire » d'usage courant et spontané, c'est toujours le patois lorsque s'ouvre le XVIII ${ }^{\mathrm{e}}$ siècle ; c'est encore le patois lorsqu'il se clôt sur la Révolution naissante.

Est-ce à dire qu'il n'y a pas eu de progrès? Problème d'une ampleur énorme. La langue étant le fait social par excellence, reflète avec une fidélité unique l'état général de la civilisation aux diverses époques. La liste des influences qui s'exercent sur elle est illimitée. Mais il y en a d'importantes et de secondaires : le mérite de F. Brunot, c'est précisément d'en marquer l'étagement et les répercussions.

Gens du $\mathrm{XX}^{\mathrm{e}}$ siècle et puisqu'il s'agit des progrès du français en France, nous nous tournons vers l'école d'un geste spontané. Qui aurait appris le français aux petits patoisants, sinon «le maître »? Brunot nous retient par la manche : " Une école d'aujourd'hui ${ }_{\mathrm{p} 185}$ est une maison où on enseigne ; une école de jadis était un endroit où on gardait, où on élevait des enfants. ॥ D'ailleurs, que d'obscurités dans l'histoire de ces garderies! S'agit-il de leur nombre ? Une inégalité extrême de région à région. Et là où il y avait le plus d'écoles, que savaient les maîtres ? «Il n'est point de marchandise qu'on puisse dire plus mêlée que celle des maîtres d'école », déclare mélancoliquement un subdélégué de Lunéville. Le maître qui ne sait ni lire ni écrire n'est point un personnage de vaudeville; c'est un des types, réels, du petit monde d'autrefois ${ }^{94}$. Il chante, il est vrai, ce qui compense : le maître d'école, c'est l'homme du lutrin. Quand il a conduit tous les matins les enfants à l'église ; quand il s'est rompu le gosier à chanter en sus de tous les offices, et les messes de fondation et les messes des morts, qu'il apprenne aux écoliers, moyennant cinq sols par mois, à lire, écrire et l'arithmétique, soit. Mais c'est bien souvent un surcroît.

$\mathrm{Du}$ reste, à ces petits sauvages qu'il gardait sous la menace des coups, parlait-il français, ou patois ? Français dans l'Est; et dans le 
Nord ; et dans le Centre aussi, semble-t-il. Français avec des réserves, naturellement. Non seulement les écoliers entre eux parlaient toujours patois, mais l'instituteur était souvent obligé, pour se faire comprendre, de leur donner des explications en patois. Il ne patoisait pas systématiquement; il en aurait d'ailleurs été souvent assez empêché ${ }^{95}$. Il s'efforçait de franciser. Mais son effort se brisait à chaque instant. Quant au Midi ? Deux sons de cloche s'entendent, à laisser l'historien plus perplexe que Panurge en instance de mariage. Répondant à Grégoire : "Les maîtres ne parlent ordinairement que patois, ou parlent très mal français », dit un correspondant. Mais un autre : "L'enseignement se fait en français. » Est-ce le troisième larron qui les départagera? Écoutons: «Dans nos écoles de campagne, l'enseignement ne se fait en patois ni en français »... Nous voilà bien antidotés! Un quatrième survenant aurait pu ouvrir un nouvel avis. Car, si les maîtres avaient été instruits, c'est en latin qu'ils auraient appris à lire aux enfants ${ }^{96}$. Le français n'y aurait point gagné... p186

Chose curieuse : "L'administration éclairée », au temps de Louis XVI, ne favorisait nullement l'instruction des campagnes. «Un paysan qui sait lire et écrire quitte l'agriculture »: propos sans fard d'un intendant de Provence, tard dans le siècle (1782). Et cet autre, en Navarre : «Je ne crois pas qu'il soit nécessaire de faire de grands raisonnements pour prouver l'inutilité des régents dans les villages... Je supprime toutes les écoles de cette nature qui se font dans les communautés, lorsque j'en ai connaissance. » La République n'a pas besoin de savants : il se peut. Monseigneur l'Intendant, lui, à cent reprises, proclame qu'il faut une ignorance pour le peuple ${ }^{97}$.

La plupart des maîtres d'école nomadisaient. Ils devaient donc mal parler le patois, qui varie de village à village. Or, qui parle mal le patois prête à rire, de ce rire aisément cruel du paysan d'autrefois, peu tendre pour les fainéants qui ne tiennent pas la queue de la charrue : le tailleur, le cordonnier, le tisserand et, plus que tous, ce propre à rien de maître d'école, qui n'est bon qu'à faire des paresseux.

96 Songeons qu'il fallait lire avant tout les prières et le rituel en latin, dût-on en rester là. Brunot met en lumière les obstacles de toute nature qui s'opposaient au passage facile de la lecture en latin à la lecture en français. L'enfant qui a appris à lire de-u-s en détachant toutes les lettres est perdu quand il faut qu'il dise : deux.

97 ARDASCHEF (Les intendants de province sous Louis XVI, trad. Jousserandot, Paris, Alcan, 1909) confirme tout à fait ceci. Cf. p. 373 : «Les intendants se 
Comment donc le français a-t-il réussi, entre la fin du XVII ${ }^{\mathrm{e}}$ et celle $\mathrm{du} \mathrm{XVIII}^{\mathrm{e}}$ siècle, à gagner dans le royaume un terrain appréciable ? Le royaume? c'est assez bien cette Asie, ou cette Amérique que les cartographes du temps nous représentent dans leurs somptueux atlas. Les côtes sont connues, à peu près. Les villes aussi, et la banlieue des villes, et quelques grandes zones de circulation et de trafic; mais, entre le réseau plus ou moins dense des zones battues, il y a des blancs. Des manières de désert en réduction qu'habitent, à l'écart de toute circulation d'hommes, de denrées ou d'idées, des populations enlisées dans une routine sordide et que rien n'incite à en sortir. Tous les deux ou trois ans, un voyageur égaré ; chaque année, quelques colporteurs et les collecteurs d'impôts : voilà la liste des visiteurs de ces solitudes. Si âpres, si pénibles d'accès, que les hommes même qui, par fonctions, auraient dû s'y rendre annuellement, ne le font pas. Parlant de son diocèse, Le Camus, évêque de Grenoble, écrit à Pontchartrain (1672) : «Il y a quarante ans qu'on n'a visité. » En Morvan, dans le canton de Montsauche, de 1704 à 1825, pas de confirmation : l'évêque allègue ne pouvoir s'y rendre. On comprend pourquoi, au cœur de son livre, F. Brunot met six chapitres sur les routes, les transports, la circulation générale au XVIII siècle. Pour la langue même, le problème primordial, c'était un problème routier.

Faut-il le dire ? Ce que j'aime, dans le livre de Brunot, ce n'est pas tant le soin qu'il met à proclamer cette grande vérité ${ }_{\mathrm{p} 187}$ que la façon infiniment nuancée et aussi peu dogmatique que possible dont il procède à ses démonstrations. F. Brunot ne se satisfait pas en assénant, d'un air doctoral, des formules massives sur la tête du lecteur. Il n'est pas tenté de croire, ou de faire croire, que la seule existence d'un réseau routier ait suffi à entraîner, automatiquement, la diffusion du français à travers la France. L'œuvre fut de longue haleine. Dans des contrées qui n'ont rien de sauvage, nombre de villages ne reçurent les bienfaits de la viabilité que bien après le milieu du XIX ${ }^{\mathrm{e}}$ siècle. L'effort routier de la Monarchie de Juillet vint

préoccupent beaucoup moins des écoles primaires pour le peuple. » Ils s'intéressaient avant tout aux écoles techniques. Somme toute, c'était l'utilité matérielle qui les guidait. 
utilement renforcer celui de la vieille monarchie; et les régimes ultérieures parfirent la besogne. Mettant en forme des souvenirs qui datent de 1870 à 1880, Ch. Roussey, l'auteur d'un excellent Glossaire du parler de Bournois (un village du plateau franc-comtois, entre Doubs et Ognon), peut encore écrire : «Le jour où un rétameur ou un quincaillier nous rendait visite, c'était un véritable événement; ils étaient entourés, regardés avec de grands yeux; le bourriquot et la voiture à deux roues étant examinés dans leurs détails avec force commentaires. » Il ajoute : "Avec la route, le progrès a pénétré à Bournois. » Oui, mais la route elle-même n'a pénétré à Bournois qu'aux environs de 1880 .

Et puis, Ferdinand Brunot nous montre fort bien, par surcroit, que toute invention produit des effets contradictoires. Encouragés par des communications plus faciles, les paysans se rendirent plus volontiers à la ville, château-fort du français. Il est vrai. Mais l'amélioration des routes entraînait la suppression de ces nuitées d'auberge que la lenteur des communications imposait auparavant aux vendeurs. L'auberge n'était pas d'ailleurs, nécessairement, un conservatoire de noble langue, et il demeure vrai d'une vérité générale, qu'en augmentant les relations entre villes et campagnes, le développement du commerce sur route assurait à la langue centrale des chances nouvelles de se répandre.

Au fond, le difficile, c'est de faire l'addition, le total. Nous voyons très bien de grands ensembles de faits. Très bien aussi les exceptions, les remous. Établir les proportions des divers éléments et calculer la somme ensuite : voilà qui n'est pas aisé. «Hardi qui affirmerait... La réserve s'impose... De loin, d'aujourd'hui, quelle constatation faire sur un passé lointain ?... Combien on s'aventure en tranchant ces matières !... » Je cueille en deux pages, au hasard, ces formules sous la plume de Brunot. Qu'elles sont sympathiques et rassurantes! C'est parce qu'elles abondent, ces intelligentes formules de doute, que l'ouvrage tout entier est si fécond et, j'ajoute, si certain de durer. p188

J'hésite à augmenter d'un "peut-être » la liste des objections que F. Brunot fait lui-même, à chaque instant, aux opinions trop vraisemblables qui se présentent à son esprit. Prenant texte d'un passage d'Arthur Young qui s'étonne du vide des routes françaises à 
la fin du XVIII ${ }^{\mathrm{e}}$ siècle: " On pourrait contester, écrit-il fort judicieusement. L'affirmation est en contradiction avec des données formelles et positives comme celles des péages. " Mais il n'insiste pas. Il préfère se rendre compte des choses. "Les corvées étaient d'hier, note-t-il, le dommage d'aujourd'hui, les bénéfices ne s'annonçaient pas encore; les turgotines n'emportaient vers la ville ni les bêtes, ni les produits du paysan. » Il passe sur cette remarque. Qu'il me permette de m'y arrêter un instant.

Ce n'étaient pas les turgotines seulement, c'étaient les charrettes du paysan lui-même qui n'emportaient encore vers la ville que trop peu de produits, et trop peu souvent. Car les routes, c'était bien. Mais pour qu'elles fussent encombrées de voitures pleines de gerbes ou de sacs de blé dirigés vers le marché voisin, il fallait que la production fût suffisante, en graines ou en bêtes, que le paysan, sa consommation prélevée, eût de quoi vendre un reliquat important. Pour cela, une révolution était nécessaire : cette révolution des méthodes culturales que des précurseurs commencent précisément à amorcer à la fin du $\mathrm{XVIII}^{\mathrm{e}}$ siècle dans les Académies, dans les sociétés d'agriculture et autres. Révolution qu'on ne saurait dater; elle fut longue à s'accomplir, très longue. Je relisais ces jours-ci la Préface d'une des meilleures monographies que nous ayons sur nos patois de l'Est bourguignon et comtois; j'ai déjà eu l'occasion de la citer tout à l'heure : c'est celle de Roussey sur Bournois. Les détails que l'auteur donne sur la culture dans son village, sa technique plus que rudimentaire, son rendement invraisemblablement faible ${ }^{98}$ - cela,

\footnotetext{
98 Paris, Welter, 1894, in- $8^{\circ}$, page $7:$ «En 1877, j’ai encore labouré avec la charrue en bois... En 1874, les gens de Bournois se servaient encore du fléau et pour mon compte, j'ai battu cette année-là, avec mon seul frère Florentin, douze cents gerbes... Ne sachant pas tirer du sol le quart de ce qu'il aurait pu produire..., les gens de Bournois se nourrissaient très mal. » P. 8 : «Loin de vendre du grain, beaucoup de familles en manquaient dès le printemps... Pour les animaux, il en était de même. Aux premiers jours du printemps, les greniers étaient à peu près vides. » P. 10: «En dehors de la culture, les gens ne cherchaient aucune ressource $»$ : notation qui nous introduit dans une sphère morale et psychologique fort curieuse à explorer. P. 19: «Selon l'ancienne coutume, tous les chemins étaient en ligne droite, mal tenus et à peu près impraticables... C'est grâce à ces accidents de terrain qu'en 1815 Bournois a pu échapper assez longtemps aux allées et venues de l'ennemi. "

Même note dans l'intéressante notice de Ch. PERRON sur un village de la même région, Broye-les-Pesmes (Mém. Soc. Émulation Doubs, 1889, p. 373) :
} 
p189 de 1870 à 1880 environ - ces détails nous montrent que construire des routes ne suffisait pas, certes, à créer dans toute la France une circulation prospère. Le bloc de la routine était plus difficile à entamer que celui des cantons sans chemins. Et pour que les chemins une fois construits vissent circuler sur leurs chaussées solides des voitures lourdes et des bêtes bien nourries, il fallait plus que la science des ingénieurs: une révolution agricole et, par delà, une révolution morale ; l'appétit du gain se développant chez le paysan et, dans ce vieux métier routinier, l'éveil d'un esprit nouveau, d'un esprit de commerce et de profit qu'on croit, à tort, éternel - et qui est souvent, à la campagne, récent : quasi contemporain...

Du reste, Brunot ne se borne pas à retracer les progrès du réseau routier. Il recherche comment, sous quelles influences, des centres de parler français ont pu se constituer un peu partout à la fin du XVIII siècle. Parmi eux, les agglomérations ouvrières qui se concentrent autour des mines et des manufactures; puis, les châteaux où, de plus en plus, le goût public aidant, grands seigneurs ou bourgeois enrichis vont s'établir une partie de l'année; dans les petites villes, ces colonies de fonctionnaires nomades, venus des quatre coins de l'horizon et qui ne parlent que français. Il ne note pas (sans doute parce qu'il aura l'occasion d'y revenir plus tard) l'influence, certaine aussi dans les villages, des anciens soldats revenus du service ${ }^{99}$. Par

« On peinait beaucoup et on ne récoltait guère... Quand un laboureur avait mis de côté la graine nécessaire pour les semailles prochaines et pour la consommation de son ménage, le produit du surplus suffisait à peine pour payer les tailles, le valet et une petite redevance au vieil usurier de Pesmes à qui il avait emprunté cent écus depuis l'année où tout son bétail avait péri... »

99 Cf. ce que dit Ch. RousSeY de son père (ouvr. cité, p. 6) : «Ses parents le destinaient à l'enseignement, mais il préféra s'engager. Après avoir fait ses sept ans, il rentra au village avec le grade de sous-officier. Dès lors, il ne cessa d'être en quelque sorte le secrétaire de toute la commune. Il comptait parmi ses cousins plusieurs sous-officiers et un instituteur. - Sorte de petite aristocratie de village, qui n'était point morte hier encore. Combien de fois, rencontrant dans nos villages comtois d'anciens compagnons de régiment, ne les ai-je point entendu m'énumérer fièrement le nombre des enfants du pays revenus sous-officiers, voire officiers, de la « grande guerre »? - Ch. ROUSSEY note fort bien l'accroissement de cette petite caste des " brevetés », des sous-officiers, des instituteurs, des petits fonctionnaires, par suite du développement de l'école primaire. Cf. p. 20 : «Tout le monde veut être savant. C'est une véritable fièvre qui envahit la population... Dans ces dernières années (1894), la commune qui ne compte plus que 395 
contre, il n'a garde de négliger ce que nous savons sur l'activité des compagnons en route pour le Tour de France. Ces faits si variés se corroborent, s'étaient l'un l'autre. Ils justifient le jugement qu'il y a plus d'un siècle formulait un des correspondants de Grégoire : "Les campagnards permanents parlent peu français, et très mal ; ceux qui voyagent le parlent moins mal; ceux qui se sont absentés plusieurs années le parlent assez bien $\gg{ }^{100} \cdot \mathrm{p} 190$

II.

Toutes ces remarques vous excitent l'esprit et vous donnent à penser. Mais on en revient toujours, avec plus de curiosité, à l'irritant problème central : celui des rapports de la langue et de la nationalité. Entre les progrès du français et la prise de conscience par les Français d'un sentiment national, quel lien se nouait, directement?

Ce problème, F. Brunot ne l'aborde pas de face. Il en fait le tour. A la fin de son livre, il passe en revue, d'abord les provinces particularistes ou de langue étrangère qui ceinturaient la France. Qu'y savait-on de français? Voici le Béarn, pays «étranger à la France quoique soumis au même roi » et qui s'obstine à maintenir jusqu'à la Révolution son particularisme linguistique ; le pays basque, tout fermé encore à la culture et à la langue de France; le Roussillon, théâtre sous Louis XIV d'une intéressante tentative de francisation par l'école, mais qui ne dura pas et ne fut pas suivie. En Corse, tout restait à faire. Quand Napoléon, fort jeune, arrive à Autun en 1779, il ignore tout du français ; c'est là qu'il en apprend les premiers mots, avant de gagner Brienne. Et Brunot passe encore en revue la Bretagne, où le peuple, ne sachant pas le français, se presse aux sermons en breton, aux mystères en breton, tandis que dans les villes on parle français, ce qui fait que «le sentiment si fort de l'unité et de l'indépendance

habitants a produit un prêtre, six instituteurs et deux institutrices, sans compter ceux qui ont échoué à leurs examens, et ceux qui se préparent à devenir savants. »

100 C'est pour cela que le conventionnel breton Lequinio, parcourant le Jura sous la Révolution, peut nous signaler « la perfection du langage » des montagnards du haut Jura (Voyages dans le Jura, I, p. 261). «Toutes ces tribus voyageuses de Saint-Laurent et des alentours savent, note-t-il, très bien lire, écrire et calculer; la soif des papiers-nouvelles est une de leurs jouissances. » 
bretonne ne pouvait se confondre en aucune façon avec le goût de la langue indigène et ne lui servait pas de soutien ». C'est ensuite le tour de la Flandre maritime, de l'Alsace, de la Lorraine : ici, on tend à se rapprocher de la France, tout en restant attaché au parler local ; là, on se laisse pénétrer par le français, tout en demeurant très particulariste. Et mille nuances, mille variétés intermédiaires.

Certes, quand son tour de frontières terminé, Ferdinand Brunot parcourt la France proprement dite, il peut noter un peu partout le bilinguisme des populations. On parle patois dans les campagnes. On le parle encore dans les villes, parfois. Mais on n'écrit qu'en français. Et quand il le faut, avec des passants, de hauts personnages - les paysans même se risquent à parler français. Non sans hésitation ni pudeur. Car, de même qu'on se déclassait par le haut aussi bien que par le bas, le petit bourgeois qui épousait une fille de grande maison

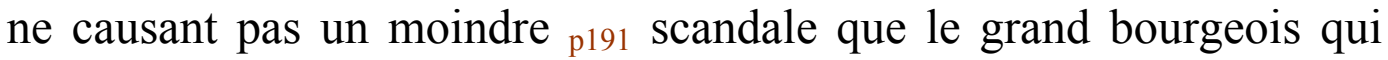
épousait sa servante - de même, dans un village, renoncer à son patois sans absolue nécessité, ç’aurait été se déclasser. Quelles railleries cruelles n'auraient pas accueilli l'audace anti-sociale d'un laboureur «osant parler français »? On l'aurait accusé de «faire le monsieur », et quelle pire accusation ? En tout cas, ceux qui parlaient français, par occasion et par nécessité, le faisaient sans se rallier jamais, consciemment ou non, à ce qu'on pourrait nommer une mystique de la langue nationale. Pas de nation, pas de langue nationale. Et reprenant une phrase de Rabaut Saint-Étienne en 1789, Brunot note qu'on pouvait se demander encore, à la veille de la Révolution et à ne considérer que l'état des patois, "si l'association de toutes les provinces se confondant sous une seule loi, s'administrant par les mêmes principes, n'était point une chimère ? » Une fois de plus, sa prudence avisée et son sens critique servent bien Ferdinand Brunot. Il l'a senti : il n'y a pas là un problème, mais une série de problèmes.

$\mathrm{Au}$ fond, quand on y réfléchit, dire que sous l'Ancien Régime, les deux concepts de langue et de nationalité n'étaient point liés - c'est constater simplement que le mot de Nation ne rendait pas le même son, prononcé en 1750 ou en 1793. En 1750, il n'y avait pas encore, unique, la Nation qui devait figurer en 1791, avec le Roi et la Loi, sur le porche de tant d'églises et de mairies. Cette nation, elle existait sans 
doute, comme un idéal, dans l'esprit de beaucoup d'hommes. Mais d'autres «nations », anciennes, traditionnelles, et qui pendant des siècles avaient encadré les hommes, subsistaient encore à côté d'elle - et n'empêchaient qu'on ne la voie, qu'on ne pense à elle seule, qu'on ne l'organise. Or, chacune de ces nations se posait à sa manière le problème linguistique.

Je connais un peu l'histoire d'une de nos provinces les plus résistantes, si je puis dire — une de celles qui se sont le mieux souvenu, et le plus longtemps, de leur passé autonome : la FrancheComté. Rien de curieux comme l'attitude des Franc-Comtois vis-à-vis $\mathrm{du}$ français. Culturellement parlant, ce sont des Français, du type « bourguignon ». Mais, politiquement, ils vivent leur vie en marge de l'histoire française, largement. Du haut moyen âge à la conquête de 1674, la Comté n'a rien à voir avec le royaume, sauf de 1295 à 1384, pendant une période de moins d'un siècle, d'ailleurs assez remplie et de 1477 à 1493, pendant seize ans a peine. p192

Sujette des pires adversaires du Très Chrétien, au XVI ${ }^{\mathrm{e}}$, au XVII ${ }^{\mathrm{e}}$ siècle, elle n'est pas étrangère à la France : elle lui est ennemie. La sauvagerie, les violences sans nom de Louis XI, les excès de ses troupes pillant et saccageant le pays ont achevé de faire des Bourguignons du Comté les irréductibles adversaires de la monarchie française. A la fin $\mathrm{du} \mathrm{XVI}$ siècle, la brutalité, la rapacité sans foi ni grandeur de Henri IV n'arrangeront pas les choses. Quelle langue parlent-ils donc? Leurs patois sans doute, promus à la dignité de parlers nationaux, et, quand ils ont besoin d'une langue de culture, le latin naturellement, puis plus tard l'espagnol?

L'espagnol ? Non seulement aucun Espagnol n'a jamais vécu en Comté, contrairement à la légende tenace qu'un vers de Hugo contribue à maintenir et à perpétuer; mais je ne sache pas qu'aucun Comtois ait jamais eu l'idée d'aller parfaire ses études dans une Université d'Espagne. Nombre d'entre eux ont fait le voyage de la péninsule, et plusieurs s'y sont établis: ce n'était pas comme étudiants, certes. Inversement, on ne trouve pas dans les registres 
matricules de l'Université comtoise de Dole le nom d'un seul Espagnol, étudiant ou professeur, pendant tout le XVI ${ }^{\mathrm{e}}$ siècle ${ }^{101}$.

Le latin? Certes, lorsqu'il règne encore partout, au XVI $\mathrm{X}^{\mathrm{e}}$ siècle, il tient sa place en Comté comme ailleurs, mais une place qui n'a rien d'excessif. Et qui est plutôt moindre, semble-t-il, que celle qu'il occupe dans nombre de provinces françaises de ce temps. Il est curieux de voir que tous ceux qui impriment, en Comté, au XVI è siècle, paraissent avoir la coquetterie de donner quelques marques de leur science $d u$ français ${ }^{102}$. Visiblement, la langue du grand royaume voisin, la langue de Paris, mais de Dijon aussi et de Lyon, jouit d'un prestige solide dans la Comté. On s'y pique de l'écrire avec autant de correction et d'élégance que par delà la Saône. Un pur humaniste, un érasmisant comme ${ }_{\text {p193 }}$ Gilbert Cousin dont toute l'œuvre est latine, publiera cependant, à Lyon, deux ou trois opuscules en français ${ }^{103}$. A Besançon, c'est en français qu'en 1557 le notaire Ferry Julyot publiera ses Élégies de la belle fille lamentant sa virginité perdue. C'est en français également que le juge Morelot donnera, en 1588, son Discours en vers, aux magistrats de Besançon. C'est en français encore que Chassignet, l'émule provincial de Malherbe, composera, en 1594, les 400 sonnets de son Mespris de la Vie en attendant ses Paraphrases sur les prophètes et sur les psaumes. Exemples pris entre

101 Cf. le judicieux article de Roussey: La Franche-Comté a-t-elle été espagnole ? dans les Mémoires de l'Académie de Besançon, 1905. Je cite ce travail sans illusion. Il y a encore de beaux jours pour la légende et on n'a pas fini de découvrir en Comté de bruns descendants des hidalgos de Castille, ou des « maisons espagnoles », des « grilles à l'espagnole », des « fenêtres espagnoles » par douzaines. Or, la Comté n'a jamais eu en résidence, dans ses villes ou ses villages, ni gouverneurs, ni magistrats, ni prélats, ni érudits, ni capitaines, ni soldats, ni marchands, ni étudiants espagnols. Par contre, l'Espagne a connu des ministres, des diplomates, des gens de guerre, des laboureurs, des marchands franc-comtois. C'est le mot de notre historien de la Guerre de Dix Ans, Girardot de Nozeroy : «La monarchie d'Espagne est une Bourgogne étendue partout. »

102 Avec quelque appréhension au début: Petit livret, interroge Ferry Julyot en 1557 (p. 3),

Petit livret qu'en azard te veulx mettre, En France aller, fontaine d'éloquence,

Doubte-tu point rencontrer quelque maistre

Qui mocquera ta rustique loquence?

103 Cf. (avec prudence) le Répertoire bibliographique des ouvrages franc-comtois imprimés antérieurement à 1790, de l'abbé M. PERROD, Paris, Champion, 1912. 
bien d'autres. La liste est longue des poètes — ou des versificateurs — franc-comtois qui usent du français au siècle de la Renaissance ${ }^{104}$. Ils en usent de plus en plus, d'ailleurs, et avec un succès croissant. Cousin, Morelot, et bien d'autres: ce ne sont que des noms. Littérairement, Chassignet est déjà quelqu'un. Et Du Monin, de Gy. En attendant le polygraphe Mathieu, de Pesmes, son Esther, sa Vashti, son Aman, sa Clytemnestre, sa Guisiade, ses Pastorales — et bientôt Jean Mairet, l'envieux de Pierre Corneille, le Mairet de Sylvie et de Sophonisbe.

Quant aux patois? C'est le bien propre des paysans. C'est la langue dont on use pour entrer en relations avec eux. Chose curieuse, c'est la langue que, de bonne heure, les gens de lettres du Comté se plaisent à mettre dans la bouche des rustiques. Notre historien Gollut, l'auteur des Mémoires historiques de la République séquanoise (1592) - un professeur de latin qui a rédigé toute son œuvre en français, et même en bon français bourguignon, savoureux, rythmé et correct imprime à Dole, en 1589, un petit livre devenu extrêmement rare : les Paroles mémorables de quelques grands personnages, entre lesquelles sont plusieurs mots joyeux et rustiques. Ces mots rustiques sont mis en patois dans la bouche des paysans comtois qui sont censés les avoir dits ${ }^{105}$. Leurs interlocuteurs, nobles ou bourgeois, parlent le français de Gollut.

Nulle fierté nationale, ai-je besoin de le dire? dans cette transcription de patois. La curiosité d'un Noël du Fail plutôt, en p194 moins littéraire. Quand Gollut introduit quelque souci d'orgueil dans ses divagations historico-linguistiques, c'est pour proclamer une sorte de patriotisme non pas français, certes, mais « gaulois », dans lequel il

104 Cf. par exemple, les œuvres françaises de Jean DE LA BAUME PERÈS, élève de G. Cousin (Aulcunes ouvres gallicaines, Lyon, 1556); celles de J. FLORY DE VERCEL; du greffier Claude DE LESMES; du médecin Jean VuILLEMIN (Éclogue du Verbe Divin, Lyon, 1573, etc.).

105 Voir pages 333-334-335; 345-346-347-348; 389; 406-407. Voici un échantillon de ces «notations » patoises : il s'agit de l'émoi des paysans comtois lorsque le bruit se répandit que le duc Casimir menaçait leur pays. Ils se disaient, nous raconte Gollut: "Qu'au souque ce M. Cassenesille vin fare en ce pei ? et mérite ben qu'on lou pegne in pouchot. - Coise tay, respondoit l'autre; et ne nou demande ran ; ce et ne tin qu'à l'y baillie des ne filles, y seu contan de l'y en donna pour ma part un sachoutot. » (P. 397.) 
faut bien qu'il communie avec les Français. Lui, cet adversaire de la France et qui trace en tête de ses Mémoires, dans sa Requête à Philippe II, un programme si net ${ }^{106}$ de l'œuvre polémique qu'accompliront, au cours du XVII ${ }^{\mathrm{e}}$ siècle, contre la monarchie des fleurs de lys, tous les propagandistes comtois anti-français, d'Antoine Brun à François de Lisola - il faut l'entendre, ce Gollut, né en terre impériale, interpeller les Allemands ${ }^{107}$, leur crier sa fierté d'être « Gaulois », de parler une langue qui " provient des Celtes anciens » et, glissant de l'histoire linguistique à la militaire, vanter, comme il le dit ailleurs ${ }^{108}$, les exploits de «ces deux braves et belliqueuses nations », que personne n'a jamais su battre : les Bourguignons et... les Français !

Quel paradoxe! Voici un homme pour qui parler français est visiblement l'un des traits caractéristiques de son nationalisme. Et ce nationalisme est anti-français. Voici par ailleurs un pays où l'application des plus habiles à manier et à utiliser adroitement le français se rapporte en partie à des desseins hostiles à la France ! La situation est plutôt étrange.

Récapitulons. $\mathrm{Au} \mathrm{XVI}{ }^{\mathrm{e}}$ siècle en Comté, la langue officielle de la politique, de la diplomatie et de l'administration, c'est toujours le français. Le gouverneur du pays correspond en français avec les cours des Pays-Bas et d'Espagne, et inversement. Le Parlement de Dole, de même. La justice parle français. Le droit, la coutume de Franche-

106 Gollut, Mémoires historiques, réédition de 1846, p. XX: «Que si quelques subjects de la Gaule semblent devoir recevoir commission, il ne serait inconvénient que les Bourgougnons fussent empliés, non seulement pour ce qu'ils sont la langue de ceux qui sont les plus hardis à escripre contre V. M., mais encore pour ce qu'ils sont... au nombre des loïaux subjects et des mieux affectionnés serviteurs des maisons impériale et roïale d'Austriche et d'Hespagne; je dicts, pour escripre et respondre aux François en l'histoire politique, et aux Huguenots françois en l'histoire de la religion. »

107 Cf. livre I, chap. XXII, p. 56 : «Ne vous souciés pas, Gaulois, si les Allemans crieront icy et diront que bonne partie de noz voix sont de leur cru ; respondés que noz Celtes... les hont vaincu, assubjectiz et seigneurié plus de six cens ans avant qu'ilz ne se feissent cognoistre dehors du rivage du Rhin et du Danube », etc.

108 Livre II, chap. I, 90. - Id., p. 94. 
Comté, pareillement ${ }^{109}$. Les juristes, même ${ }_{\text {p195 }}$ quand ils pourraient faire autrement, rédigent leurs écrits en français avec une particulière application. Bien plus, il y a une Université en Franche-Comté, à Dole : or, c'est à Dole que, pour la première fois, le droit français a été enseigné - avant même qu'il ne le fût en France ${ }^{110}$. Et Dole, c'est avant tout une «Université pour étrangers » : si on y vient pas mal, d'Allemagne, d'Angleterre et des Pays-Bas, ce n'est pas parce qu'on espère trouver aux bords du Doubs un foyer particulièrement puissant et actif de haute culture ; Dole n'est ni Orléans, ni Bourges, ni Padoue. Mais de même qu'aujourd'hui nombre d'étrangers vont apprendre le français dans ces villes de la Suisse romande qui ont l'adresse de leur faire croire qu'elles parlent « la vraie langue » (et sans accent !) — de même les étrangers, souvent ennemis de la France, fréquentaient volontiers au XVI ${ }^{\mathrm{e}}$ siècle un petit centre de culture française sis hors de France, où ils étaient reçus avec bonhomie dans un pays plantureux et où ils apprenaient à parler français ${ }^{111}$. Le complément des leçons professorales, c'étaient ces conversations quotidiennes des alumni de notre mère l'Université avec les jeunes filles de la bourgeoisie locale. On ne les appelait pas encore des marraines. Ce n'étaient que des Valentines. Mais ces aimables personnes mériteraient une mention dans l'histoire de M. Brunot ${ }^{112}$. Elles ont bien travaillé, pendant plus d'un siècle, à la diffusion de la langue française...

109 Non seulement la coutume proprement dite, mais les Ordonnances, que vulgarisent de nombreux recueils imprimés au cours des XVI ${ }^{\mathrm{e}}$ et XVII ${ }^{\mathrm{e}}$ siècles. Le livre de chevet des praticiens comtois, la Pratique de SAINT-MAURIS (1577), est en français. Des ouvrages aussi répandus que le Discours des sorciers de BoGUET sont rédigés également non en latin, mais en français.

${ }^{110}$ Le plus remarquable des professeurs de droit comtois du XVII ${ }^{\mathrm{e}}$ siècle, Cl.-Fr. Talbert, fut, par patentes du roi d'Espagne en date du 4 mars 1653, institué professeur de la leçon quotidienne de coutume à l'Université pour trois ans. Son succès fut tel que la chaire de coutume resta définitivement acquise à l'Université. Or, l'enseignement du droit français en France ne date que de l'édit d'avril 1679.

111 Inversement, les Comtois étant fort soucieux à cette époque de faire apprendre à leurs enfants, non seulement l'italien et à l'occasion l'espagnol, mais l'allemand (cf. les matricules de Heidelberg publiés par Toepke) et le « thiois » des Flandres. Acquisitions utiles à de futurs officiers de la monarchie habsbourgeoise.

112 Sur les Valentines doloises, cf. les curieux Mémoires du tyrolien GEIZKOFLER traduits et édités par Fick, Genève, 1892, in- $8^{\circ}$. M. Brunot a parlé utilement de l'Université de Dole dans son livre V (p. 215 et n. 6). Il se réfère à l'excellente notice d'E. LongIn, La nation flamande à l'Université de Dole, qui vaut pour le $\mathrm{XVII}^{\mathrm{e}}$ siècle. La situation était déjà tout pareille au XVI ${ }^{\mathrm{e}}$ siècle. Cf. L. FEBVRE, 
Voilà pour le $\mathrm{XVI}^{\mathrm{e}}$ siècle, siècle latinisant. $\mathrm{Au} \mathrm{XVII}^{\mathrm{e}}$ siècle, naturellement, la situation ne fait que se développer et se confirmer. Et la Comté francise, avec de plus en plus d'ampleur - contre la France assez généralement. Or, une catastrophe attendue se produit. La dernière survivante des deux Bourgognes est « réunie » par le Roi Très Chrétien à son domaine. Qui ne sent l'étrangeté du problème qui se pose pour la Comté ?

Sa langue était une des caractéristiques de sa nationalité. p196 J'entends, sa langue écrite, le français : le patois est hors de cause, et l'annexion ne le fera pas revivre ${ }^{113}$. Et j'entends aussi sa petite nationalité, autonome et si longtemps anti-française. Or, le français,

Philippe II et la Franche-Comté, chap. XX, et, pour la période antérieure, quelques indications sur les érasmiens flamands de Dole en 1530 dans : Gilbert Cousin et la Réforme en Franche-Comté (Bull. Soc. Hist. Protestantisme français, 1907).

$113 \mathrm{Du}$ moins pas plus qu'ailleurs. On s'amusera au XVIII ${ }^{\mathrm{e}}$ siècle, après la conquête française, à écrire en Comté (comme dans tant d'autres provinces) quelques "poèmes » en patois. Les deux pièces maîtresses (à adjoindre à la liste que donne M. Brunot) sont, de 1735, L'arrivée d'une dame en l'autre monde habillée en paniers, poème satirique en patois de Besançon (Bogillot, s. d. in- $8^{\circ}$, 16 pages) qui suscita des imitations: un curé de Courroux (Suisse) nommé Ferdinand Raspieler, le traduisit «en patois du Cornat, vallée de Délémont»; sous cette forme, il a été édité par A. Rosset dans les Archives suisses des traditions populaires (Schweizer. Arch. f. Volkskunde, Zürich ) de 1903-1906. Et de 1735, La Jaquemardade. Poème épicomique en dialogue au patois de Besançon, Dole, J.-B. Tonnet. C'est un dialogue en vers patois de huit pieds entre le Jaquemart de la Madeleine de Besançon, qui venait d'être rétabli sur l'église reconstruite, et un savetier son voisin. Mais l'auteur, le conseiller au présidial Bizot, note lui-même que c'en est fait du patois :

Lou bé peuple de Besançon

La z'antandan pâla Francet ;

Et Bizot se croit tenu de publier un avertissement au lecteur en tête de son poème, dans lequel il traite... de la façon de prononcer le patois qu'il imprime. Ce document a été réédité récemment, avec tout le poème, dans les Mémoires de la Société d'Émulation du Doubs. A la même date exactement (1753), une Comtoise des confins de la Bresse, Marguerite DE MAISONFORTE ( $\mathrm{M}^{\mathrm{me}}$ Brun), publiait son Essay d'un Dictionnaire comtois-français par un vigneron de la rue du Sachot (Besançon, 1753, in- $8^{\circ}, 39$ pages; $2^{\mathrm{e}}$ éd., $\left.1755 ; 3^{\mathrm{e}}, 1759\right)$ qui atteste plus fortement encore la prise du français sur la province. Car il ne s'agit pas de patois dans le Dictionnaire de $\mathrm{M}^{\mathrm{me}}$ Brun, mais des tournures et des expressions régionales qu'elle condamne au nom du bel usage. Sur les Noëls comtois en patois, cf. la bibliographie de BEHRENS et une fine étude de Max BUCHON en tête de ses Chants populaires de la Franche-Comté, Paris 1878. Sur le Dictionnaire de $\mathrm{M}^{\mathrm{me}}$ Brun, quelques remarques d'Édouard Droz dans les Mémoires de la Société d’Émulation du Doubs, 1919. 
c'est précisément la langue de sa nationalité nouvelle : la langue de son souverain par droit de conquête, la langue des nouveaux maîtres. Pour que les Comtois fussent amenés à voir dans cette langue une des caractéristiques, un des signes, un des éléments fondamentaux de cette nationalité nouvelle à laquelle, de gré ou de force, ils sont incorporés à la fin du XVII ${ }^{\mathrm{e}}$ siècle, que fallait-il ? Évidemment, que la mémoire de la nationalité autonome, de la petite nationalité - disons, pour la commodité et au risque de déplaire aux mânes de $\mathrm{M}$. Brette, de la nationalité provinciale - fût abolie totalement, ou du moins que, dans un grand élan, sous l'action puissante d'un de ces jets de flamme intérieurs qui bouleversent les traditions historiques et les statuts politiques comme le feu de la terre, les couches et les assises géologiques, les Comtois fissent passer délibérément au-dessus de leur sentiment provincial relégué dans le passé, un sentiment national nouveau, venant occuper et remplir tout le champ de leur conscience !

Mais à cela, point d'obstacles réels. Ce sentiment national nouveau, il ne devait avoir à lutter contre aucun sentiment de même rang, de même valeur et de même dignité. L'attachement ${ }_{\mathrm{p} 197}$ pur et simple à d'antiques survivances n'est pas un sentiment de l'ordre d'un véritable sentiment national. Et ces «provinces» fraîchement « réunies » à la Couronne de France, de quelles traditions réellement vivantes pouvaient-elles encore se réclamer? La religion monarchique française, si atteinte déjà dans ses œuvres vives et qui commençait à douter d'elle-même ${ }^{114}$, elle ne représente rien, strictement rien pour des Franc-Comtois si longtemps étrangers - et hostiles - aux rois de France. Quant à leur patriotisme provincial, il n'était plus, il ne pouvait plus être qu'une routine. Parce qu'aucune idée vivante ne venait plus l'animer, lui donner corps et force. Patriotisme provincial : dans ces pays comme la Comté du XVIII ${ }^{\mathrm{e}}$ siècle, de quoi un tel sentiment se serait-il nourri ? Fidélité vis-à-vis du «seigneur naturel »? Mais le vieux sentiment « bourguignon » qui, si longtemps, avait soutenu les populations riveraines de la Saône et du Doubs dans leur opposition à la grande monarchie de l'Ouest, il avait eu beau attester longuement sa force et sa vitalité dans le Duché - Henri

114 Voir les chapitres terminaux du beau livre de Marc BLOCH: Les rois thaumaturges (Publications de la Fac. des Lettres de Strasbourg, 1924). 
Hauser l'a montré excellemment — et dans la Comté, j'ai essayé naguère de l'établir, la fidélité « bourguignonne » était morte et bien morte depuis la fin du XVI siècle. Morte, parce que plus rien ne lui permettait de vivre - ou de survivre. De Charles Quint, héritier du Téméraire et du bon duc Philippe, au pauvre Charles II d'Espagne, quel lien réel ? quelle tradition véritable?

Un instant, à la fin du XVI ${ }^{\mathrm{e}}$, au début du XVII ${ }^{\mathrm{e}}$ siècle, la Comté avait essayé de se donner pour âme un sentiment religieux très fort et très profond. Elle s'était livrée toute au catholicisme rénové, transformé par les ordres modernes, Jésuites et Capucins pour ne parler que d'eux; elle s'était ouverte sans réserves à cette religion tridentine si prenante, si expressive, si véhémente même - et elle avait cherché en elle sa véritable raison de vivre. $\mathrm{Au} \mathrm{XVIII}^{\mathrm{e}}$ siècle? Ces temps d'enthousiasme et de mysticisme étaient loin, de plus en plus loin; et même dans ce pays croyant — mais qui ne croyait plus en 1720 comme en 1620 - le scepticisme et l'esprit critique faisaient leur œuvre ${ }^{115}$. Alors ? p198

Destin tragique de tous ces petits pays qui s'attardent dans une autonomie précaire, plus apparente que réelle. Leurs privilèges ? Bon pour les juristes attachés à la lettre, de s'en exagérer la valeur et de les mesurer à l'aune des vieux parchemins lourdement scellés qu'ils compulsent avec orgueil dans les chartriers poussiéreux ${ }^{116}$. Les peuples s'en désintéressent. Il n'y a pas, dans ces chartes mortes, de quoi alimenter une foi nationale. Partout les sentiments «provinciaux» agonisaient, parce qu'ils n'étaient plus vivifiés par des idées, par des croyances véritablement vivantes. Et là où, sur les

115 Il n’y a pas à tenir compte non plus de l'esprit de guerre, de la résistance prolongée des Comtois du fait de la conquête. Les irréductibles étant sortis du pays, ceux lui restèrent se rallièrent assez vite à leurs nouveaux souverains. Légende, l'histoire des Comtois se faisant enterrer « la face contre terre », pour ne pas voir leurs maîtres abhorrés, légende et littérature. En une génération, tout fut fini. De 1720 à 1789, pas trace de sentiments antifrançais agissants dans la province.

116 J'ai bien peur qu'après ces juristes beaucoup d'historiens ne s'exagèrent la valeur de ces "privilèges", je veux dire leur importance réelle dans les consciences aux environs de 1789 . Il ne faut pas confondre ce qui se passe dans des plans différents : celui du droit public et des intérêts et celui de la conscience et des sentiments. 
ruines déjà anciennes d'un certain nombre de ces sentiments provinciaux démantelés, un sentiment national plus large s'était développé : ce sentiment, lui aussi, se desséchait progressivement et pour ainsi dire se flétrissait. La religion monarchique, solidaire de la religion chrétienne, souffrait de plus en plus des attaques et des progrès $\mathrm{du}$ rationalisme critique. Et des clameurs de triomphe accueillaient, célébraient avec une sorte de joie désespérée et sauvage, aux alentours de 1760, toutes les défaites de Louis XV, toutes les humiliations et les déceptions — de la France ? Sans doute. Mais ce n'était pas « la France » qu'on l'appelait; c'était le « despotisme »...

Ici et là, les voies étaient libres. Le sol était débarrassé, pour une construction nouvelle et désirée. Sur les ruines d'une religion monarchique qui s'effondrait d'elle-même; sur les ruines de sentiments provinciaux qui n'étaient plus que des survivances desséchées ou des conceptions arbitraires de robins, que surgisse enfin la Nation, telle que les hommes de la fin du XVIII siècle la définiront, non par le territoire mais par la totalité des citoyens, siège du pouvoir souverain ${ }^{117}$ — et ce sera l'immense enthousiasme qui, à distance, nous surprend encore, d'un peuple avide de croyance collective et qui retrouvera, qui reconquerra une foi jeune et ardente : une raison de vivre.

A ce moment et à partir de ce moment, oui : il y aura lieu sans doute d'envisager un problème unique des rapports de la langue ${ }_{\mathrm{p} 199}$ et de la nationalité en France. Au XVIII siècle, non pas. C'est dix, c'est vingt problèmes de rapports qui se posent: ceux de l'usage linguistique et des patriotismes provinciaux dans l'ancienne France.

117 Même dans les livres de propagande élémentaire, cette distinction apparaît. Voici par exemple l'Almanach du père Gérard pour l'année 1792, ouvrage qui a remporté le prix proposé par la Société des Amis de la Constitution, séante aux Jacobins à Paris, par J.-M. COLlot-D’Herbois (Besançon, Simard, 1792); à la fin du premier entretien un paysan interroge le père Gérard: "Qu'est-ce que la Nation? C'est tout ce pays-ci, n'est-ce pas ? » A quoi le père Gérard répond aussitôt: "C'est bien davantage.» Et dans le second entretien, il s'explique ainsi : «La Nation est la totalité des citoyens, c'est dans cette totalité que réside le pouvoir souverain. De ce pouvoir-là découlent tous les autres par le moyen des différentes élections, et nul pouvoir ne peut être légitime s'il n'est pas conféré par la Nation. " Passage intéressant d'une notion territoriale à une notion sociojuridique. 
Et on mesure, sur ce terrain comme sur d'autres, l'importance vraiment fondamentale et l'ampleur du travail de simplification et de transformation qui fut celui des hommes de 89, de 91 et de 93 .

Mais n'anticipons pas sur ce qui sera le sujet des prochains volumes de F. Brunot. Nous les attendons avec une curiosité et une impatience que justifient amplement ces tomes V et VII de sa grande œuvre, si vraiment neufs, si hautement intéressants pour l'historien. C'est comme un magnifique commentaire perpétuel des grandes pages de notre histoire nationale que M. Brunot écrit, avec une maîtrise et, en même temps, une prudence, une réserve, une finesse critique singulières. C'est bien plus. Le faisceau de lumière qu'établi solidement sur ses positions à lui, il dirige sur tout l'ensemble d'un passé que nous croyons parfois connaître dans ses grandes lignes, mais qu'en réalité nous ignorons encore profondément, est si révélateur parfois; il éclaire des trous d'ombre si profonds, il revêt des paysages familiers d'un éclat si imprévu, que nous nous arrêtons brusquement surpris, un peu déconcertés : "Allons, voilà qui est à reprendre, voilà qui est à bâtir entièrement, voilà qui est à changer de fond en comble...» Que de bienfaits, et quel progrès dans cette collaboration vivante et intime de deux disciplines si bien faites pour se féconder l'une l'autre! Mais ce n'est peut-être pas l'histoire tout court qui gagne le moins à ce renouvellement, à cet élargissement si ingénieux, et si puissant, de l'histoire linguistique. p200 


\title{
LA PSYCHOLOGIE
}

\author{
Méthodes et Solutions Pratiques \\ HENRI WALLON ET LA PSYCHOLOGIE APPLIQUÉE
}

$\underline{\text { Retour à la table des matières }}$

Que l'homme d'entreprise, dont les initiatives tissent au jour le jour la trame des faits présents, soit, tout aussi bien que l'historien, tributaire et bénéficiaire des progrès de la psychologie : cette vérité ne justifierait pas nos Annales de vouloir suivre, dans leur complexité mouvante, des recherches conduites partout, aujourd'hui, avec un renouveau d'ardeur et d'énergie. Ni même de faire place, dans leurs comptes rendus, à des ouvrages généraux, si pleins d'enseignements soient-ils : je songe tout particulièrement, pour n'en citer qu'un, à la remarquable Introduction à la psychologie collective publiée, il n'y a pas longtemps, par le $\mathrm{D}^{\mathrm{r}}$ Charles Blondel ${ }^{118}$. Par contre, les Principes de psychologie appliquée que le $\mathrm{D}^{\mathrm{r}}$ Henri Wallon vient de faire paraître dans la même collection ${ }^{119}$ tombent trop directement sous le coup de nos curiosités de spécialistes pour que nous ne saisissions pas l'occasion, rarement offerte, de mettre le pied sur un domaine dont l'abandon ou le défrichement fécond ne sauraient nous laisser, ici, indifférents.

118 Un volume, $\mathrm{n}^{\circ}$ 102, de la Collection Armand Colin, Paris, 1929, in-16, 211 pages.

119 Paris, 1930, in-16, 224 pages $\left(n^{\circ} 127\right)$. - [Depuis que cet article a été écrit, la section de psychologie de la Collection Armand Colin s'est enrichie de plusieurs volumes. Citons : H. PiÉron, P. Guillaume, J. Piaget...] 
Psychologie appliquée : en train de passer dans l'usage courant, l'expression cependant n'est pas heureuse. Elle évoque l'idée d'une dépendance, alors qu'il s'agit d'une opposition. Elle donne à croire qu'existe une psychologie théorique dont l'autre ferait passer les principes dans la pratique : telle la mécanique appliquée découlant de la mécanique rationnelle. Or, tout au contraire, la psychologie dite appliquée a, sinon pour but, du moins pour résultat - tout comme la psycho-pathologie et la biologie — de faire subir à la psychologie traditionnelle une conversion entière et radicale. C'est ce que montre avec une ${ }_{\text {p201 }}$ vigueur incisive le $\mathrm{D}^{\mathrm{r}}$ Henri Wallon, non seulement en tête de son livre, mais surtout dans un vigoureux article de la Revue philosophique ${ }^{120}$. N'insistons avec lui que sur un ou deux de ces contrastes, mais décisifs. Pour l'ancienne psychologie, le fait psychique était irréductible au nombre, parce qu'essentiellement personnel, subjectif et, à tout instant, d'une qualité unique et incomparable. Pour la psychologie appliquée, la mensuration systématique des capacités du sujet est méthode de choix, méthode fondamentale. Bien maniée, elle permet d'abord d'établir l'assujettissement de l'individu aux lois du milieu, «de faire apparaître comme mécanique vis-à-vis de conditions ou d'influences extérieures l'activité en apparence la plus spontanée ${ }^{121}$ »; elle révèle, d'autre part, grâce aux comparaisons qu'elle rend possibles chez le même individu entre des séries de mesures différentes, l'intime corrélation des fonctions psychiques, la dépendance mutuelle ou l'incompatibilité des activités variées d'où résulte la vie de l'esprit. Par là, elle n'aboutit point à dissocier l'individu en une diversité de relations particulières sans rapport avec une personnalité totale; ou plutôt, après avoir amené l'observateur à reconnaître, dans chacune des manifestations d'activité qu'il examine, l'effet et le signe d'une aptitude plus ou moins spécialisée, elle le conduit à réintégrer comme facteur fondamental de ses recherches l'individu dans son équilibre total : si l'on veut, à chercher le rapport de chaque relation particulière à la personnalité totale.

120 Janv.-févr. 1930, p. 97-107.

121 Article cité, p. 99. 
Simples vues théoriques, et bonnes à alimenter des discussions de méthode plus ou moins byzantines? En aucune façon. De telles constatations importent au plus haut point à l'avenir même de la jeune discipline que le $\mathrm{D}^{\mathrm{r}}$ Wallon nous présente aujourd'hui : à son crédit scientifique comme à son crédit pratique. Chaque fois, note-t-il, que la psychologie appliquée «a ignoré ou laissé oublier l'existence de l'individu, elle a méconnu ou laissé méconnaître ses propres possibilités scientifiques ou ses enseignements pratiques ». Et il insiste: de l'épreuve accomplie ne retenir qu'un rapport unique et particulier? Tout l'intérêt se bornera alors à déterminer le rang de chacun dans une catégorie qui demeurera tout abstraite; ainsi restera inutilisé un précieux instrument de comparaison et d'analyse. Mais sur cette simple cote prétendre fonder une décision nécessairement applicable à un individu tout entier; sur la simple mesure d'une unique aptitude, sur le chronométrage d'un seul geste, vouloir régler

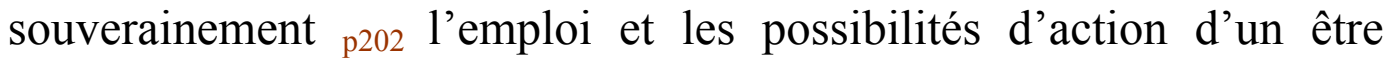
humain, ce complexe : c'est courir le risque de transformer en déchets des forces productives et, partant, de multiplier dans l'économie publique et dans le corps social les agents inutiles ou nuisibles.

Risque grave, s'il est vrai que la psychologie appliquée est de plus en plus mise à contribution pour des fins pratiques ${ }^{122}$; elle devient donc comptable, non seulement des intérêts individuels, mais de l'intérêt commun qui totalise à sa façon les intérêts particuliers. Ainsi (et dans nos Annales, où nous cherchons à montrer quelles relations nécessaires doit entretenir avec les recherches désintéressées l'action pratique, nous ne pouvons que souligner combien de semblables observations renforcent nos thèses favorites) - ainsi on saisit une fois de plus l'importance capitale, même pour la pratique, surtout pour la pratique, de considérations qui, au premier abord, peuvent paraître

122 L'enjeu n'est pas négligeable. Veut-on quelques chiffres, que nous emprunterons au docteur Wallon ? Limitons-nous à ce qui est du ressort de l'orientation professionnelle. L'Association des industriels de France contre les accidents du travail évalue à 3000 par jour le nombre de ces accidents, et leur coût à plus d'un milliard par an. Or, dans la proportion de 43 p. 100, un auteur, Frois, les attribue à la mauvaise adaptation de l'ouvrier. - En Angleterre, on estime que l'instabilité de la main-d'œuvre (suite, pour une part, d'une mauvaise appropriation entre le travailleur et son métier) coûte, en moyenne, 100 millions de livres par an, soit de 12 à 15 milliards. Voilà de quoi justifier l'entretien d'Instituts de recherches psychotechniques. 
d'intérêt purement théorique et méthodologique. On voit surtout, si l'on ne veut pas, sous prétexte de progrès, aboutir à une régression certaine, combien il importerait de confier les observations et les discriminations de psychologie appliquée, non pas à ceux qu'on pourrait nommer des "mécaniciens » : chronométreurs ou mesureurs spécialisés, j'allais dire «taylorisés », dans un même genre d'exercices pratiques : à des hommes, au contraire, de forte culture, de sens psychologique éprouvé et portant en eux, avec l'expérience profonde de la vie, avec de larges sympathies humaines, un sentiment aigu de ce qu'est l'individu : non pas cette abstraction, chère à la psychologie traditionnelle, «ce sujet abstrait qui se croit essentiellement identique à travers toute la série de ses âges et qui assisterait au défilé de sa vie uniquement pour la déclarer sienne et sans commune mesure avec d'autres " : mais, bien au contraire, cette personnalité vivante, cause à la fois et conséquence de toutes les réactions qu'enregistre et mesure la nouvelle discipline.

Ces remarques préliminaires, cette forte conception du rôle, de l'avenir et du véritable intérêt, à la fois scientifique et humain, que présente et présentera de plus en plus la psychologie appliquée, dictait son plan à l'auteur. Ou, plus exactement, l'empêchait p203 de s'égarer, et de nous égarer, et suivant un plan empirique et par là-même défectueux.

Moins averti, prenant les choses de moins haut, il aurait pu distribuer sa matière en chapitres consacrés successivement à l'un des domaines particuliers sur lesquels, dès maintenant, la psychologie appliquée a commencé d'exercer son activité : l'école, l'atelier ou l'usine, la maison de commerce, le prétoire. Ces cadres pourraient séduire par leur apparence concrète et pratique. Mais leur grand inconvénient (ils en ont de moindres), c'est précisément, note le $\mathrm{D}^{\mathrm{r}}$ Wallon, «de diviser ce qui est psychologiquement uni». En étudiant séparément chacune des activités qui sollicitent l'individu, on finit toujours par rencontrer, identique à lui-même chaque fois, cet individu en personne. Il peut bien, comme le note ingénieusement l'auteur, " être taillé à facettes par la diversité de ses contacts avec le milieu ; mais c'est lui qui transparaît derrière ». Renoncer au plan qui semblait s'offrir de lui-même, ce n'est donc pas seulement s'épargner un grand nombre de vaines répétitions ; c'est bien plus encore et bien 
mieux, manifester le souci profond de montrer, «convergeant vers certaines lignes de force relevant de sa structure intime », les relations multiformes que la personne humaine soutient avec l'extérieur : souci à quoi se reconnaît un vrai psychologue, qui ne se borne pas à collectionner une série de données empiriques, ou, si l'on veut, à poser une série d'équations plus ou moins accidentelles ou essentielles - mais, de chaque relation particulière, prétend dégager le rapport à la personnalité totale, cet objet d'études bien à lui, spécifiquement à lui.

Et ainsi s'expliquent les divisions adoptées heureusement par le $\mathrm{D}^{\mathrm{r}}$ Wallon. La psychologie appliquée s'attache à étudier l'activité réalisatrice de l'homme. Or, un acte peut être soit en expectative, soit accompli. En expectative, il a pour conditions, d'abord, les capacités de l'agent; et celles-ci dépendent ou bien des conditions générales de toute action, ou bien de ce qui constitue l'apanage variable des individus ; il a pour conditions, ensuite, les motifs qui sollicitent l'être humain à l'action : car l'acte en expectative exige le consentement du sujet. De là, trois champs d'études distincts. Les conditions communes à toute action ressortissent à la psychologie du travail ; et c'est de cette psychologie que traite en premier lieu le $\mathrm{D}^{\mathrm{r}}$ Wallon au cours de cinq chapitres, respectivement consacrés aux conditions physiologiques, aux effets psychiques, aux courbes du travail, aux facteurs de l'effort et du rendement et, finalement, à certains problèmes concrets qui ont motivé des recherches particulières. p204 Les conditions propres aux agents, ce sont des aptitudes particulières et individuelles. Une méthode se présente, qui se fait forte de les déceler : c'est la méthode des tests. Son étude scrupuleuse et attentive remplit la seconde partie du livre; et l'importance pratique des conclusions $\mathrm{du} \mathrm{D}^{\mathrm{r}}$ Wallon égale au moins leur importance méthodologique. - Mais évidemment, c'est sur le terrain de la profession, c'est dans l'exercice de l'activité professionnelle qu'il importe avant tout de saisir et de dégager les aptitudes des sujets. D'où la troisième partie consacrée, tour à tour, aux problèmes brûlants de la rationalisation, de la sélection, de l'orientation professionnelle et, d'une manière générale, aux méthodes préconisées et suivies pour déterminer l'accord ou l'incompatibilité d'un homme ou d'un métier, voire même pour tenter de faire l'inventaire général d'une personnalité. - Enfin, l'art de susciter une réaction, de provoquer un 
choix, de déterminer l'individu à l'acte, voilà ce que commence d'abord par étudier la quatrième partie. Mais l'acte une fois accompli n'est pas perdu pour la psychologie. Il laisse, chez l'acteur lui-même, des traces perceptibles; par une espèce de choc en retour, il modifie cet acteur que, dans une certaine mesure, il est possible de déceler et d'identifier par ces suites psychiques. Aussi, à un premier chapitre sur la réclame s'adjoint, tout naturellement, un second chapitre sur le fait et le témoignage : pour un historien, ce n'est pas le moins important, le moins abondant en suggestions de tout l'ouvrage.

On voit quelle est la richesse de ce petit volume, et tout ce qu'il renferme d'indications intéressantes et neuves sur une série de problèmes qui tendent de plus en plus à s'installer fortement sur le domaine pratique ${ }^{123}$. Nous ne pouvons montrer, à propos de chacun d'eux, quelle est la plénitude d'information, la vigueur critique, le sens psychologique nuancé et profond d'un auteur p205 qui a derrière lui des années de réflexion, d'observations cliniques, d'études non point livresques mais « humaines » poursuivies dans les milieux les plus divers sur les sujets les mieux différenciés : normaux, arriérés, malades, hommes faits, enfants surtout (ce qui confère une autorité particulière à ses jugements en tout ce qui concerne les problèmes de pédagogie, objets d'application première et préférés de la méthode des

123 En France, dans le domaine pédagogique, la série de tests que Binet et Simon ont publiée d'abord en 1905, puis, révisée, en 1908 et 1911, ont joué un rôle d'initiation réel. Mais, dans l'industrie, la psychotechnique est d'un emploi encore sporadique. Certaines grandes entreprises en ont cependant entrevu l'intérêt : par exemple, la Société des Transports en Commun de la Région Parisienne, à qui la sélection de ses wattmen et chauffeurs aurait permis d'économiser $1300000 \mathrm{fr}$. par an en abaissant de 16 p. 100 le nombre des accidents, et qui gagnerait, d'autre part, 150000 fr. en faisant tomber de 20 à 3,4 p. 100 le nombre des apprentis à éliminer pour défaut d'aptitudes, après un temps d'apprentissage plus ou moins long. Un Institut national d'orientation professionnelle s'est créé récemment pour promouvoir les recherches et former un personnel de techniciens. Tout cela est encore assez rudimentaire. En Allemagne, par contre, il n'y a pas d'industrie qui n'ait ses comités de recherches ou ses psychotechniciens. En Angleterre, l'«Industrial Fatigue Research Board», d'origine gouvernementale, et le « National Institute of Industrial Psychology », d'origine privée, conjuguent leurs efforts pour instituer des enquêtes et des expériences. Mais c'est aux États-Unis et dans la Russie soviétique que, pour des fins tout opposées, les recherches psychotechniques ont pris un développement considérable. - [On sait l'extension prise depuis un quart de siècle par la psychotechnique.] 
tests $\left.{ }^{124}\right)$. Un livre comme celui-là aurait pu aisément prendre l'allure d'une carte d'échantillons, d'une sorte de nomenclature anecdotique et amusante de procédés ou de pratiques plus ou moins curieuses, mais fragmentaires. Un livre de recettes, si l'on veut, qu'on aurait consulté avec un mélange de curiosité et d'appréhension. En place de quoi le $\mathrm{D}^{\mathrm{r}}$ Wallon nous a donné une œuvre. Je puis bien sentir, mais il ne m'appartient pas de dire quelle en est l'importance pour les études psychologiques en général : d'autres s'en chargeront. A tous ceux, par contre, que les recherches de psychologie appliquée intéressent pour des fins d'ordre pratique; à tous ceux qui, sur des questions trop souvent tranchées, avec une suffisance coupable, par des experts riches uniquement en tours de main, aimeraient à posséder des vues d'ensemble saines, équilibrées et prises de haut - recommandons chaudement la lecture d'un travail qui, précisément, s'élève bien audessus d'un empirisme misérable ou d'un prophétisme romantique. Il s'établit résolument sur le plan de la science. Et, sans rien perdre de sa sérénité, il s'y manifeste avec autorité comme l'œuvre très personnelle, par là-même très attachante, d'un observateur dont la lucidité et la clairvoyance se trouvent fécondées par un sentiment qui ne cesse de s'affirmer à travers ces pages et qui, en profondeur, les unit intimement : le sens de l'humain, le sentiment toujours présent de ce qu'est, de ce que représente dans sa réalité vivante et agissante une personnalité, une individualité humaine. Par là, le livre du $\mathrm{D}^{\mathrm{r}}$ Henri Wallon revêt toute sa signification. A côté d'un savant, on y saisit un homme. p206

Retour à la table des matières

124 Cf. sa thèse de doctorat ès lettres, L'enfant turbulent : Études sur les retards et les anomalies du développement moteur et mental, Paris, Alcan, 1925, et, parmi de nombreux travaux et articles, son cours récemment publié dans la Revue des Cours et Conférences, 1930. — Dans les cadres de la psychologie appliquée, le $\mathrm{D}^{\mathrm{r}}$ Wallon n'a pas fait rentrer la psychothérapie : il s'en explique dans sa conclusion. 


\section{Une Vue d'Ensemble}

HISTOIRE ET PSYCHOLOGIE

$\underline{\text { Retour à la table des matières }}$

«Aptitude à découvrir des corrélations »: une des définitions les plus satisfaisantes du génie scientifique. Qu'on songe au grand médecin, au grand clinicien qui, en rapprochant des signes et des symptômes épars, invente et crée véritablement un nouveau type de maladie. "Aptitude à négocier des accords, des échanges entre disciplines voisines » : pour une science en voie d'expansion, une non moins bonne définition du progrès. On traduit souvent d'une autre façon cette vérité d'expérience : «Les grandes découvertes se font aux frontières mêmes des sciences. »

Dès lors, que la psychologie, connaissance scientifique de la fonction mentale, doive nécessairement nouer des rapports étroits avec la connaissance scientifique de la fonction sociale, la sociologie ; qu'elle doive, non moins nécessairement, entretenir des relations suivies avec les disciplines mal définies que nous confondons sous le nom traditionnel d'Histoire - voilà qui n'a pas besoin d'être expliqué longuement. Mais qu'à l'heure actuelle ces rapports ne puissent guère être qu'assez décevants — on s'y sent résigné d'avance. La psychologie se dégage à peine des controverses philosophiques pour s'installer sur le terrain solide de la recherche expérimentale. La Sociologie n'a de nom parmi les hommes que depuis un siècle à peine; elle n'a de réalité que depuis beaucoup moins longtemps encore. Quant aux disciplines qui, dans un siècle, se seront dégagées du magma confus de l'Histoire, elles n'ont même pas d'état civil. Raison de plus pour qu'on ne néglige rien des aspects si mouvants de la vie des sciences humaines. 
Entre psychologues, sociologues et historiens, quel serait à première vue l'enjeu d'un débat de compétence et d'attributions? p207 Évidemment, la connaissance de l'individu. «La psychologie, disait Baldwin, traite de l'individu, et la sociologie, du groupe. » Quant à l'histoire, Baldwin, s'il l'avait définie, aurait j'imagine enfermé en elle, comme en un champ clos, l'individu et le groupe - et professé qu'armée des résultats acquis par la psychologie et la sociologie, elle s'efforçait de définir dans le cadre du passé leurs rapports réciproques. Excellentes notions pour étudiants; elles les munissent de clefs d'emploi facile. Le malheur, quand on essaie ces clefs, c'est qu'elles laissent toujours la seconde porte close ! - Au lieu de disserter dans l'abstrait et de tracer sur le papier des limites bien profilées, mettonsnous en face des réalités. Et appliquons la bonne méthode: compliquons ce qui paraît trop simple.

I.

Quel est l'objet d'étude de l'historien? L'opinion commune répond: d'une part, les mouvements confus de masses d'hommes anonymes voués en quelque sorte aux grosses besognes de l'histoire ; d'autre part, émergeant de cette grisaille, l'action dirigeante d'un certain nombre d'individus qualifiés de « personnages historiques ».

Peu connues sont les masses. Des époques entières ne nous ont laissé sur elles aucun témoignage direct et détaillé. Aristocratique de par ses origines, l'histoire n'a eu d'yeux pendant des siècles, elle n'a encore d'yeux, bien souvent, que pour les Rois, les Princes, les Conducteurs de Peuples et d'Armées - les hommes "qui font l'Histoire », Menschen die Geschichte machen : c'est le titre d'un gros recueil de biographies historiques paru, récemment, en Allemagne ${ }^{125}$. Ceci étant, les rapports de la psychologie et de l'histoire s'établissent, aux regards de l'opinion commune, fort simplement.

Les masses anonymes? Elles seront justiciables d'une psychologie collective à fonder sur l'étude des masses actuellement saisissables, et qui étendra sans effort (on le suppose du moins) ses conclusions aux 
masses d'autrefois, aux masses historiques. Quant aux individus distincts, aux «personnages historiques», ils ressortiront naturellement à la psychologie individuelle. Les documents qui les concernent (et dont beaucoup comportent une interprétation psychologique de leur activité et de leur p208 caractère) seront de bonne prise pour les psychologues. Ils grossiront le trésor de leurs observations. Inversement, les conclusions que ceux-ci peuvent tirer de l'étude des cas humains qu'ils ont sous les yeux, permettront aux historiens de mieux interpréter, de mieux comprendre la conduite et l'action des «dirigeants» des sociétés passées, des artisans authentiques de l'histoire humaine.

Et donc, nous revoici toujours en face du binôme individu-société. Mais continuons à serrer le problème de plus près.

Que sont ces individus prestigieux, les «personnages historiques »? Ce sont, avons-nous répondu naguère, « les auteurs responsables d'une grande œuvre historique ${ }^{126} »$. - Mais qu'est-ce qu'une grande œuvre historique? Un ensemble de faits recueillis, groupés, organisés par les historiens, de façon telle qu'ils constituent un anneau d'une de ces grandes chaînes de faits homogènes et distincts (politiques, économiques, religieux, etc.) dont nous jetons le réseau plus ou moins serré sur le passé historique de l'humanité. Ces chaînes, c'est nous qui les forgeons et les reforgeons sans cesse, dans notre besoin "d'organiser le passé », de mettre de la clarté et de la régularité dans l'ensemble perpétuellement mouvant, dans le papillotement et le scintillement de faits qui, sans loi apparente, se heurtent, se mêlent et se commandent réciproquement autour de chaque homme à chaque moment de sa vie — et donc de la vie des sociétés à quoi il participe.

Grandes chaînes, grands déroulements : pourquoi grands ? Parce qu'il faut distinguer, parmi les œuvres humaines, celles qui n'intéressent guère qu'un petit groupe d'hommes particulier - et les

126 Centre International de Synthèse, $3^{\mathrm{e}}$ Semaine Internationale : L'individualité Paris, Alcan, 1932, p. 129. 
autres qui, par-dessus les frontières des petits groupes, tendent à unir ceux-ci ou, du moins, à les orienter dans une même direction. Telles, les religions dans la mesure où elles ne sont pas des religions fermées de groupes, interdites aux non-participants du groupe. Tels, les grands systèmes d'idées et de doctrines qui se répandent hors des frontières, et rallient des hommes de tous les groupes. - Telles, les œuvres politiques également: organisations et révolutions,

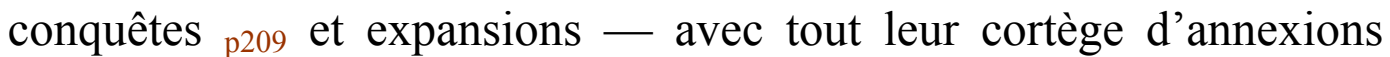
d'une part, de résistances d'autre part.

Des œuvres historiques? Oui, dans la mesure où elles ne restent pas le simple fruit de la violence mais bénéficient de la durée - et du ralliement des hommes qui, ayant d'abord subi, acceptent ensuite, adoptent et propagent. Oui, dans la mesure où elles ne sont pas uniquement faites par quelques hommes à l'usage, au profit de quelques groupes - mais peuvent se ramener à un effort d'ensemble pour organiser la vie des masses humaines. Oui, dans la mesure où ce qui, d'abord, fut œuvre de particularisme et, si l'on veut, d'égoïsme, se mue en œuvre de civilisation. Les faits de civilisation ne sont-ils point - en partie du moins - des faits qui, ne se limitant pas à une société donnée, s'avèrent susceptibles de migration et d'implantation dans des domaines parfois très éloignés, et très différents de leur domaine d'origine?

Ainsi, œuvre historique : celle qui, par delà le «local» et le «national», vise à l'humain. Celle qui s'affirme susceptible de rayonnement et d'expansion pacifique. Mais alors, le personnage historique ? Il répond à une exigence élémentaire de la croyance commune: "Toute montre suppose un horloger, toute œuvre historique postule un auteur. » Ainsi joue la catégorie fondamentale de l'engendrement : père-fils.

Le père de l'œuvre historique, c'est le personnage historique l'homme à qui la croyance commune attribue la paternité de cette œuvre : simplification nécessaire et mnémotechnie commode. Mais si ce que nous venons de dire est vrai ? Si l'auteur — et non pas l'auteur "prétendu » d'une œuvre d'organisation collective à répercussion durable, mais l'auteur "certain » d'une grande œuvre scientifique, 
littéraire, philosophique ou religieuse qui paraît vraiment sortir de son cerveau (Darwin, Shakespeare, Marx, Calvin) — si cet auteur ne saurait cependant donner d'efficience à cette œuvre sans la collaboration, sans la participation active du groupe qui l'adopte ? Si le drame est sinon normal, du moins fréquent — de l'homme qui lance une idée et à qui cette idée revient totalement déformée et transformée par le «milieu»? Si elle est typique, l'aventure de Martin Luther, père authentique du luthéranisme, mais cent fois confessant son trouble, son désarroi, lorsqu'il doit constater combien les masses, dès le début, modifient ses idées en se les appropriant et leur font subir le sort que connaissent tous les grands créateurs p210 d'idées ou de sentiments : cette dénaturation, parfois ce renversement total d'idées dont ils portent, malgré tout, devant l'Histoire l'illusoire paternité ?

Et d'autre part, personnage historique : mais où est l'être humain qu'on peut considérer comme une puissance autonome, indépendante et isolée, une sorte de création originale et spontanée, alors que toute personne humaine subit si fortement des influences - les unes venues du fond des âges, les autres exercées, de la façon la plus immédiate, par le milieu actuel — et d'abord véhiculées par le langage et l'outillage?

Langage : le plus puissant de tous les moyens d'action du groupe sur l'individu. Langage, technique lentement élaborée par l'humanité, et parvenue à son état actuel, à son état perpétuellement changeant et mouvant, après, ne disons pas des siècles, mais des millénaires de travail. Langage chargé, au bout de ce temps, de toute la série des distinctions, des dissociations, des catégories que l'humanité est parvenue à créer peu à peu. Langage, dont l'action rejoint et celle des mythes qui ont tenu lieu de techniques à l'humanité quand lui faisait encore défaut l'outillage capable de lui donner prise sur les choses et celle des techniques elles-mêmes, si fortement apparentées entre elles à une même époque, si fortement participantes d'un même style susceptible d'être daté sans erreur. - Tout cela, d'un mot, permettant de dire que l'individu n'est jamais que ce que permettent qu'il soit et son époque, et son milieu social. 
Mais alors, l'alternative: individus ou masses? si l'on préfère, autre énoncé du même problème : individus ou sociétés ? Le milieu social par avance pénètre l'auteur de l'œuvre historique, l'encadre et dans une large mesure le détermine dans sa création. Et quand celle-ci est faite, ou bien elle meurt, ou bien, pour qu'elle vive, il faut qu'elle subisse la collaboration active, la redoutable collaboration des masses, la pesée du milieu, irrésistible et contraignante.

En d'autres termes, la société est pour l'homme une nécessité, une réalité organique. A lui seul, pour reprendre une expression du $\mathrm{D}^{\mathrm{r}}$ Wallon, «le langage implique la société comme les poumons d'une espèce aérienne impliquent l'existence de l'atmosphère ». Et de cette société, l'individu reçoit ses déterminations; elles sont pour lui un complément nécessaire. "Il tend vers la vie sociale comme vers son état d'équilibre. » p211

\section{II.}

Ainsi, tout nous paraît moins simple qu'au départ. $\mathrm{Si}$, dans tout individu il y a lieu de distinguer d'abord une certaine personne caractérisée, plus ou moins nettement, par un ensemble de traits lui appartenant en propre et dont l'assemblage se fait suivant une formule et avec un dosage très particulier; si l'on doit saisir ensuite dans ce même individu, et un représentant de l'espèce humaine porteur des mêmes caractères distinctifs que les membres d'un certain groupe de cette espèce - et, surtout, un participant d'une société bien déterminée et datée : d'une part le contraste s'atténue singulièrement entre l'individu et la société qu'il n'y a plus lieu d'opposer schématiquement l'un à l'autre; d'autre part, la méthode d'investigation, lorsqu'il s'agit de l'individu, commence à se préciser nettement.

Trois séries d'enquêtes occuperont tour à tour le psychologue. Il devra d'abord s'adonner à la recherche de ce que l'homme doit à son milieu social : psychologie collective. Ensuite, se demander ce que l'homme doit à son organisme spécifique : psychologie spécifique ou psycho-physiologie. Enfin étudier ce que tel être humain doit aux 
particularités individuelles de sa physiologie, aux hasards de sa structure, aux accidents de sa vie sociale : psychologie différentielle.

En bonne logique d'ailleurs, cette dernière ne devra intervenir qu'après approfondissement des deux précédentes. Et tant que cellesci n'auront pas fait de progrès décisifs, tant que, au chaos des cas individuels, les psychologues ne seront point parvenus à substituer des « espèces psychologiques » bien caractérisées, comme, au chaos des symptômes, les médecins substituent des «espèces morbides" largement conçues; tant qu'il n'y aura pas eu création de «types » permettant, en face d'un individu, l'opération toujours délicate de « diagnostic » - qui consiste à relier le cas individuel à quelqu'une des espèces préalablement créées — la psychologie différentielle devra se résigner à beaucoup d'empirisme.

Ceci, vrai de la psychologie actuelle, mais qui l'est bien plus encore de la psychologie rétrospective. Si l'on veut, de la psychologie historique. p212

Car il y a un problème spécial de la psychologie historique. Quand, dans leurs mémoires, dans leurs traités, les psychologues nous parlent des émotions, des décisions, des raisonnements de «l'homme »-en réalité, c'est de nos émotions, de nos décisions, de nos raisonnements qu'ils traitent. De notre lot à nous, hommes blancs d'Europe occidentale, intégrés à des groupes de très vieille culture. Or, comment nous, historiens, pourrions-nous nous aider, pour interpréter les démarches d'hommes d'autrefois, d'une psychologie issue de l'observation des hommes $\mathrm{du} \mathrm{XX}^{\mathrm{e}}$ siècle? Et comment eux, psychologues, pourront-ils retrouver dans les données que l'histoire leur fournit (ou devrait leur fournir) sur la mentalité des hommes d'autrefois, de quoi grossir purement et simplement une expérience acquise au contact de leurs contemporains? Tout au plus, cette expérience peut-elle les munir de types de comparaison leur permettant de mieux appréhender les différences que nos ancêtres, directs ou non, lointains ou proches, présentaient avec nous.

En réalité, ni la psychologie de nos psychologues contemporains n'a de cours possible dans le passé, ni la psychologie de nos ancêtres, d'application globale possible aux hommes d'aujourd'hui. Qu'il s'agisse aussi bien des «héros» de l'histoire, des "personnages 
historiques » connus par un plus ou moins grand nombre de documents biographiques et de " portraits » physiques et mentaux que des masses anonymes dont on ne s'est guère soucié ni d'analyser psychologiquement les éléments, ni de caractériser globalement les réactions. Dans un cas comme dans l'autre, « il ne saurait être question (pour employer les termes dont usait Charles Blondel dans son Introduction à la psychologie collective, p. 197) de s'obstiner à déterminer de plano des manières universelles de sentir, de penser et d'agir peut-être inexistantes, en tout cas actuellement insaisissables ». Et Blondel précisait : "Considérant isolément les groupes humains répandus dans le temps et dans l'espace, son rôle est au contraire de décrire les systèmes mentaux propres à chacun et de les analyser, autant qu'il est possible, en s'attachant à saisir le mécanisme de leur élaboration, le jeu de leur développement et la nature des rapports qui lient entre eux leurs éléments. »

On ne saurait mieux dire, ni plus nettement dénoncer le danger: celui de vouloir passer directement (et sans même soupçonner la difficulté) des sentiments et des idées qui sont nôtres aux sentiments et aux idées que des mots pareils, ou que les mêmes mots générateurs des plus graves confusions par leur hypothétique et fallacieuse identité — servent toujours à signifier, à quelques siècles de distance parfois. Faut-il deux ou trois exemples? p213

N'allons pas les chercher trop loin. Car, Charles Blondel le notait fort bien (p. 202) : «Si nous prenons deux collectivités suffisamment éloignées l'une de l'autre dans le temps ou dans l'espace, la différence des mentalités correspondantes nous sautera aux yeux. » Mais si elles sont plus proches l'une de l'autre, il faudra des efforts et des recherches parfois longues et délicates pour déceler des divergences, souvent d'ailleurs considérables. Ne nous adressons donc ni aux primitifs dont Lucien Lévy-Bruhl s'est efforcé d'analyser les façons de sentir, de penser et d'agir (ses observations conviennent essentiellement à la formation, non d'une Histoire, mais d'une Préhistoire, ou, si l'on préfère, d'une Paléontologie psychologique) ni à ces Chinois dont les livres si riches de Granet nous permettent de comparer aux nôtres les démarches intellectuelles. Posons simplement une question : à quoi tient le plus ou, si l'on veut, à quoi renonce le moins aisément l'homme d'aujourd'hui ? Question qui déjà nécessite 
des réserves, car, l'homme: quel homme? - On s'accordera cependant pour répondre, sans plus de réflexion : "C'est à sa vie. A sa propre vie. »

Sur quoi, ouvrons quelqu'un des ouvrages de Frazer. Et dans ces livres classiques, nous puiserons à pleine main des faits surprenants (du moins pour nous) qui nous montreront, entre des sociétés relativement proches et nos sociétés à nous, des différences, des contrastes vraiment énormes dans l'appréciation de cette valeur que la «Nature » même semblerait promouvoir au premier rang de toutes. Nous y apprendrons que des peuples entiers, pendant des siècles et des siècles, ont non point protégé mais détruit leurs fils en les offrant spontanément au sacrifice. Nous y apprendrons que l'union, pour nous indissoluble, de la divinité et de l'immortalité (sinon de l'éternité) — des millions et des millions d'êtres humains l'ont ignorée et l'ignorent toujours, qui ont cru, qui croient à la mort des dieux - qui ont fait les dieux mortels à leur image.

Histoires anciennes? Sans doute. Mais ouvrons le tome IX de l'Histoire littéraire du sentiment religieux en France d'Henri Bremond. Il est intitulé : La vie chrétienne sous l'ancien régime et contient sur L'art de mourir un étonnant chapitre. On y verra tout à loisir comment, il y a moins de trois siècles, on traitait les mourants avec une espèce de cruauté psychologique — à notre jugement du moins - qui nous transporte, d'un coup, singulièrement loin de nousmêmes et de notre mentalité. p214

Autres exemples. Dans les vies romancées que nous vîmes ces années dernières se multiplier à plaisir — le plaisir étant d'ailleurs pour les éditeurs beaucoup plutôt que pour le lecteur cultivé - qu'estce qui choque l'historien? Les bévues, confusions et maladresses répétées d'auteurs sans compétence ni préparation? Le détroussement organisé, le démarquage cynique d'historiens véritables par les folliculaires pressés de l'historiographie ? - Chose bien plus grave, c'est le perpétuel et irritant anachronisme commis inconsciemment par des hommes qui se projettent tels qu'ils sont dans le passé, avec leurs sentiments, leurs idées, leurs préjugés intellectuels et moraux et qui, ayant travesti Ramsès II, Jules César, Charlemagne, Philippe II (et même Louis XIV) en Dupont ou Durand 1938, retrouvent dans 
leurs héros ce qu'ils viennent d'y mettre, s'en étonnent gentiment et concluent leur «analyse» par un nil novi d'avance attendu : "Ainsi l'homme est toujours identique à lui-même. »

Or, sans aller plus loin, faisons appel à notre expérience d'historien. Impossible d'étudier la vie, les mœurs, les façons d'être et d'agir des hommes du moyen âge (un moyen âge qui se prolonge jusqu'au $\mathrm{XVI}^{\mathrm{e}}$ siècle au moins, et par delà encore) - impossible de lire, dans des textes authentiques, des récits sur les princes, des relations de fêtes, de processions, d'exécutions judiciaires, de sermons populaires, etc., sans être frappé de l'étonnante mobilité d'humeur, de la perméabilité excessive aux impressions du dehors que manifestent les hommes de ce temps. Prompts à s'irriter, prompts à s'enthousiasmer; toujours prêts à tenir l'épée, mais à s'embrasser non moins. On danse, on pleure ; on respire le sang et puis les roses ${ }^{127}$.

«Il faut se rappeler, écrit dans un livre fort suggestif l'historien hollandais Huizinga (Le déclin du moyen âge, Paris, 1932, p. 16) - il faut se rappeler cette réceptivité, cette facilité d'émotions, cette propension aux larmes, ces retours spirituels, si l'on veut concevoir l'âpreté de goût, la violence de couleur qu'avait la vie en ce tempslà. » Sans doute : mais il faut surtout expliquer. Et l'explication n'est pas simple. Elle met en jeu une multitude de données que les historiens, jusqu'à présent, ne se sont point souciés de réunir, de rassembler en corps. A quoi ils n'ont pas songé à donner leur vraie valeur. p215

Des hommes tout en contrastes? Mais leur vie matérielle - nous le notions déjà en 1925 — n'était-elle point elle-même toute faite de contrastes? Songeons à des choses très grosses, dont nous ne mesurons jamais le poids :

Le contraste du jour et de la nuit, qu'est-ce pour nous, hommes du $\mathrm{XX}^{\mathrm{e}}$ siècle ? Rien, ou presque. Un bouton, un geste - la lumière électrique succède à la lumière solaire. Maîtres du jour et de la nuit, nous en jouons en virtuoses. Les hommes du moyen âge ? Ceux du

127 Dans une suite d'articles publiés par la Revue des Cours et Conférences (1925) : Une civilisation : La première Renaissance française. 
$\mathrm{XVI}^{\mathrm{e}}$ siècle ? Ils n'en étaient pas les maîtres, les pauvres gens - eux qui n'avaient même pas de lampes à huile, même pas de bougies à allumer quand le soir tombait. Une vie scandée, rythmée chaque jour par la succession des ténèbres et de la lumière; une vie tranchée en deux parts (inégales suivant les saisons et les lieux) : le jour, la nuit ; le blanc, le noir; le silence absolu et le travail bruyant - croit-on qu'elle ait pu engendrer chez les hommes les mêmes habitudes mentales, les mêmes façons de penser, de sentir, de vouloir, d'agir et de réagir que notre vie stabilisée, dépouillée de heurts, de contrastes et d'oppositions brutalement tranchées?

Jour et nuit - mais hiver et été, c'est-à-dire froid et chaud ? L'hiver existe-t-il encore pour un Européen, un Nord-Américain à leur aise ? Quand ils le veulent, oui bien; quand ils vont le chercher là où il est le plus marqué, afin d'y prendre « leurs plaisirs d'hiver». Mais cet hiver est perpétuellement accompagné, dans de confortables hôtels, d'un été qui ne demande qu'à le relayer. On skie toute la journée sur la neige ; le soir on est chauffé à $20^{\circ}$. Et chauffé partout.

- Qui entre dans une maison "bourgeoise », aujourd'hui, dans une grande ville, au fort de l'hiver, sent tout de suite au visage l'haleine chaude des radiateurs. Aussi se dévêt-il. Qui pénétrait dans sa maison au XVI ${ }^{\mathrm{e}}$ siècle, en janvier, sentait le froid tomber sur ses épaules : le froid immobile, silencieux et noir des logis sans feu. On grelottait d'avance au logis. Comme on venait de grelotter à l'église. Comme on grelottait dans le palais du Roi, en dépit des hautes cheminées consumant des arbres entiers. Et le premier geste de l'homme qui rentrait n'était pas d'ôter son pardessus - c'était de passer une houppelande, plus chaude que sa houppelande de sortie - et de coiffer un bonnet fourré, plus épais que le bonnet de rue.

Hiver, été : contrastes adoucis pour les plus humbles des hommes de notre temps. Contrastes d'une violence sauvage pour les plus fastueux, les plus riches des hommes d'autrefois. Et sans doute mais c'est aux psychologues à nous le dire: égalisation ${ }_{\text {p216 }}$ des conditions de vie matérielle, égalisation des humeurs : les deux choses ne se suivent-elles pas, ne s'entraînent-elles pas logiquement, ne se conditionnent-elles point? 
Quant aux conditions de sécurité ? Sécurité de fortune: un incendie aujourd'hui, un accident, une mort prématurée : l'assurance joue. Autrefois... ? Et notons qu'il ne s'agit pas de cas individuels. Quand le feu prenait à l'une des extrémités d'une ville aux maisons couvertes d'ancelles; quand, chassé par un vent violent, il les consumait toutes, quand il anéantissait en quelques minutes tout un village surpris dans la nuit, sans moyens de défense, incapable de sauver même ses bêtes - c'étaient dix, vingt, cent familles qui brusquement voyaient leurs liens se dénouer: les enfants partis à l'aventure sur les routes, se perdaient de vue, ne sachant plus jamais où retrouver leurs frères. - Mais que dire des sécurités de vie?

Et l'immense domaine de l'alimentation? La psychologie de populations surnourries, comme l'ont été pendant des années, en dehors des périodes de guerre, les Occidentaux disposant en abondance croissante, au $\mathrm{XIX}^{\mathrm{e}}$, au $\mathrm{XX}^{\mathrm{e}}$ siècle, d'aliments riches et variés - peut-elle être celle de populations perpétuellement sousalimentées, édifiant un régime de vie précaire aux marges de l'inanition et finissant par périr en masse - soit par carence alimentaire, soit, destin plus tragique, par la bonne volonté mal éclairée de bienfaiteurs qui deviennent des meurtriers : rappelons-nous ces Eskimos dont parle Lucie Randouin - ces Eskimos victimes de la philanthropie d'Européens compatissants qui, croyant bien faire, introduisirent dans leur ration des aliments plus riches: mais ces aliments vinrent rompre cet équilibre précaire de la ration à quoi les pionniers de la nouvelle science de l'alimentation accordent tant d'importance... Et les Eskimos, qui végétaient dans le besoin, périrent en masse de la profusion.

Faut-il rappeler que le moyen âge a été une époque de perpétuelle sous-alimentation, de disettes et de famines coupées, à de certains jours, par d'anormales bombances ? Ce régime, faut-il supposer qu'il engendrait, qu'il conservait des hommes de même texture physique et mentale que nous - nous et nos régimes de sédentaires gras, faisant succéder le martyre de l'obèse au martyre du famélique ? Songeons à la succession brutale de ces images de peuples, enregistrées sur la rétine de leurs proches voisins; songeons au peuple de grenouilles 
blafardes et affamées que les ${ }_{\text {p217 }}$ Anglais du XVIII ${ }^{\mathrm{e}}$ siècle se représentaient (et sans doute n'avaient-ils pas tort) comme vivant sur les bords de la Seine - alors qu'eux-mêmes se reconnaissaient avec plaisir dans John Bull l'apoplectique, copieusement nourri de viandes rouges et saignantes arrosées de bières alcooliques. Autant de suggestions, de sollicitations pour des études qui ne sont pas faites, et qu'il faudra faire.

Nous en avons assez dit pour montrer que, si nous nous interdisons de projeter le présent, notre présent, dans le passé ; si nous nous refusons à l'anachronisme psychologique, le pire de tous, le plus insidieux et le plus grave; si nous prétendons éclairer toutes les démarches des sociétés, et d'abord leurs démarches mentales, par l'examen de leurs conditions générales d'existence - il est évident que nous ne pourrons considérer comme valable, pour ce passé, les descriptions et les constatations de nos psychologues opérant sur les données que notre époque leur fournit. Il est non moins évident qu'une psychologie historique véritable ne sera possible que par l'accord, négocié en clair, du psychologue et de l'historien. Celui-ci orienté par celui-là. Mais celui-là tributaire étroitement du premier, et obligé de s'en remettre à lui du soin de créer ses conditions de travail. Travail en collaboration. Travail d'équipe, pour parler plus clairement.

Et en effet : inventorier d'abord dans son détail, puis recomposer pour l'époque étudiée, le matériel mental dont disposaient les hommes de cette époque; par un puissant effort d'érudition, mais aussi d'imagination, reconstituer l'univers, tout l'univers physique, intellectuel, moral, au milieu duquel chacune des générations qui l'ont précédé se sont mues; prendre un sentiment net de ce que, d'une part, l'insuffisance des notions de fait sur tel ou tel point, d'autre part, la nature du matériel technique en usage à telle date dans la société qu'il s'agit d'étudier, engendraient nécessairement de lacunes et de déformations dans les représentations que se forgeait du monde, de la vie, de la religion, de la politique, telle collectivité historique; se rendre compte enfin, pour emprunter la remarque d'Henri Wallon, qu'un univers « où la seule force musculaire de l'homme est aux 
prises avec les êtres concrets qui se dressent devant lui »n'est pas, ne peut pas être le même univers que celui où l'homme asservit l'électricité à ses besoins - et, pour produire cette électricité, asservit les forces de la nature même; comprendre d'un mot, que « l'Univers» n'est pas plus un absolu que «l'Esprit», ou que « l'Individu » — ${ }_{\text {p218 }}$ mais qu'il va sans cesse se transformant avec les inventions, avec les civilisations qu'engendrent les sociétés humaines : voilà le but dernier de l'historien - mais qui ne sera pas atteint par des isolés, même s'ils ont souci de prendre la liaison avec les psychologues.

La tâche est énorme pour les historiens, s'ils veulent procurer aux psychologues les matériaux dont ceux-ci ont besoin pour élaborer une psychologie historique valable. Si énorme, qu'elle ne dépasse pas seulement les forces et les moyens d'un seul homme : elle dépasse le domaine d'une seule science, ou de deux. Elle suppose, pour être menée à bien, la négociation de tout un réseau d'alliances.

Techniques? Il faut, s'agissant des sociétés civilisées d'autrefois, le secours efficace d'une archéologie étendant ses prises sur des temps beaucoup plus proches de nous que les temps antiques proprement dits. Il faut, s'agissant des sociétés présentes, le secours non moins efficace d'une ethnologie ne limitant point aux primitifs ses efforts d'inventaires et traitant, de la même façon que Soustelle ses Lacandons, ou Métraux ses Tupi-Guarani, des populations plus proches de nous et beaucoup plus riches en ressources de civilisation.

Langage, cette autre voie cardinale d'accès du social dans l'individu? Il faut la coopération des philologues, dressant ces inventaires de langues qui ne sont pas faits pour les historiens, mais dont ceux-ci peuvent tirer un si grand parti : non pas les inventaires globaux de ces grandes langues de civilisation qui fusionnent les apports de tant de groupes, locaux ou sociaux, différents, et nous les transmettent en vrac - mais ces inventaires de patois qui, interprétés par l'historien des sociétés rurales, nous livrent tant de précieux renseignements qu'ils sont seuls à pouvoir livrer. Non moins, il faut la collaboration de ces « sémantistes » qui, en nous restituant l'histoire de mots particulièrement lourds de sens, écrivent du même coup des 
chapitres précis d'histoire des idées. Il faut la collaboration de ces historiens des langues — tel Meillet écrivant l'histoire de la langue grecque, tel Ferdinand Brunot suivant pas à pas les destinées de la langue française - qui notent l'apparition à de certaines dates de tout un contingent de mots neufs ou de sens nouveaux donnés à de vieux mots. Il faut, pour passer d'un jeu de signes à un autre, la collaboration de ces exégètes de l'iconographie qui, avec des monuments datés, restituent l'histoire de sentimentalités p219 religieuses fort complexes. Il faut... ne continuons pas l'énumération, car aussi bien tout tient en un mot : il faut des esprits alertes, inventifs, ingénieux, qui recherchent les collaborations et, devant tout travail intellectuel, se posent la question du chercheur: "Pour moi, à quoi cela peut-il servir? et comment utiliser ce qui n'est pas fait pour moi ?»

Donc, à la besogne ! Le problème n'est pas de théorie. Il n'est pas de savoir si toute l'histoire, politique, sociale, économique, intellectuelle, des groupes humains doit s'ordonner en fonction d'un «Psychologique d'abord» intempérant, autour d'une histoire des pensées, des sentiments et des volontés saisies dans ses transformations chronologiques. C'était l'idée, naguère, de Karl Lamprecht. Grandes thèses doctrinales. Pour l'instant, ne les discutons point. Mais, simplement, appelons de nos vœux l'urgente recherche du travail positif dont nous venons de fixer les conditions. Ce dont il s'agit - c'est d'intégrer une psychologie historique tout individuelle (à créer) dans le puissant courant d'une histoire en marche, comme toutes choses, vers le destin inconnu de l'Humanité. p220 


\section{Comment Reconstituer la Vie Affective d'Autrefois ?}

\section{LA SENSIBILITÉ ET L'HISTOIRE}

$\underline{\text { Retour à la table des matières }}$

La Sensibilité et l'Histoire : sujet neuf. Je ne sais pas de livre où il soit traité. Je ne vois même pas que les multiples problèmes qu'il engage se trouvent formulés nulle part. Et voilà donc (qu'on pardonne à un pauvre historien ce cri d'artiste) - et voilà donc un beau sujet. Tant de gens s'en vont qui se désolent à chaque pas : plus rien à découvrir, paraît-il, dans des mers trop frayées. Qu'ils se plongent dans les ténèbres de la Psychologie aux prises avec l'Histoire : ils reprendront du goût à l'exploration.

Il n'y a pas très longtemps, je lisais le compte rendu d'une séance académique. Un «historien » présentait à la docte compagnie les conclusions d'un mémoire qu'il venait de composer sur un des cas désespérés de l'histoire anecdotique: quelle portée convient-il de donner aux fameuses «Lettres de la Cassette » de Marie Stuart, et quelle explication sied-il, en vérité, d'adopter pour traiter "scientifiquement» ce fait divers illustre : le mariage de la reine d'Écosse avec l'assassin de son mari ? Notre homme expliquait donc que l'on pouvait, de guerre lasse et faute de mieux, recourir à la psychologie pour élucider ce mystère. Il parlait aussi de "l'imagination intuitive»: on peut l'employer, déclarait-il, comme un mode de divination, quand il s'agit d'un cas individuel; elle est d'ailleurs très décevante, car enfin, le Napoléon de Stendhal n'est pas celui de Taine, qui n'est pas celui de, etc. - Je ne développe pas davantage : mais lui, il développait, et il ajoutait : il y a en tout cas un domaine qui est totalement fermé à la psychologie. Un domaine où elle n'a que faire. C'est celui de l'histoire impersonnelle, de l'histoire 
des institutions et de l'histoire des idées : institutions, idées saisies dans une société donnée pendant une certaine durée; là, « l'imagination intuitive» ne peut jouer aucun rôle. - Si j'avais eu p221 quelque doute sur l'opportunité d'un examen des rapports de la Sensibilité et de l'Histoire, ma lecture l'aurait dissipé sur l'heure. Je voudrais essayer de dire pourquoi.

Mais d'abord, deux mots de définition. Sensibilité est un assez vieux mot, Il est attesté dans la langue au moins depuis le début du $\mathrm{XIV}^{\mathrm{e}}$ siècle; son adjectif, sensible, l'avait précédé quelque peu, comme il arrive. En vivant, comme il arrive également, sensibilité s'est chargé de sens divers. Il y en a d'étroits, il y en a de plus larges et que, dans une certaine mesure, on peut localiser dans le temps. C'est ainsi qu'au XVII ${ }^{\mathrm{e}}$ siècle le mot semble surtout désigner une certaine susceptibilité de l'être humain aux impressions d'ordre moral: on parle alors beaucoup de sensibilité au vrai, au bien, au plaisir, etc. $\mathrm{Au} \mathrm{XVIII}^{\mathrm{e}}$ siècle, le mot désigne une certaine façon particulière d'avoir des sentiments humains - des sentiments de pitié, de tristesse, etc. Et le travail des synonymistes consiste surtout alors à opposer le sensible au tendre : la sensibilité, écrit par exemple l'abbé Girard dans son exquis traité des Synonymes français (je me sers de l'édition revue par Beauzée, Paris, 1780, t. II, p. 38) — « la sensibilité tient plus à la sensation, la tendresse au sentiment. Celle-ci a un rapport plus direct aux transports d'une âme qui s'élance vers les objets; elle est active. Celle-là a une relation plus marquée aux impressions que les objets font sur l'âme; elle est passive... La chaleur du sang nous porte à la tendresse ; la délicatesse des organes entre dans la sensibilité. Les jeunes gens seront donc plus tendres que les vieillards ; les vieillards plus sensibles que les jeunes gens $\gg . .$.

Mais il y a d'autres sens du mot. Des sens mi-scientifiques et miphilosophiques que la culture, telle qu'on la distribue dans les lycées, tend à faire prédominer petit à petit. "Sensibilité, commençait déjà par dire Littré : propriété dévolue à certaines parties du système nerveux, par laquelle l'homme et les animaux perçoivent les impressions, soit faites par les objets du dehors, soit produites à l'intérieur. " Disons, nous, sans nous embarquer dans un effort de 
définition personnelle totalement illusoire et sans nous référer, d'autre part, à la vieille psychologie périmée des facultés de l'âme (elles étaient trois, comme chacun sait : intelligence, sensibilité et volonté) - disons que sensibilité évoque pour nous, et évoquera dans le cours de notre étude présente, la vie affective et ses manifestations. p222

Sur quoi, j'attends l'objection : «Ceci étant, où prenez-vous votre sujet : la sensibilité et l'histoire ? Choisissons un exemple : à la base de la vie affective, et donc de la sensibilité telle que vous la définissez, il y a les émotions. Or, quoi de plus rigoureusement individuel, quoi de plus strictement personnel qu'une émotion? »Examinons l'objection. Mais d'abord que j'en prévienne mes lecteurs : dans tout ce qui va suivre, je me référerai à l'excellent tome VIII de l'Encyclopédie française, La vie mentale, où, pour la première fois, les savants qui sont à l'extrême pointe de la recherche psychologique dans notre pays nous ont donné, avec une rare et heureuse audace, un tableau d'ensemble du développement psychique de l'homme observé d'un bout de sa carrière à l'autre — du jour de sa conception au jour de sa mort. Et je me référerai, plus particulièrement, à l'original article sur les émotions qu'a signé le $\mathrm{D}^{\mathrm{r}}$ Wallon lui-même : peu de lectures peuvent mieux éclairer une lanterne d'historien en quête de clarté.

Donc, objectera-t-on, quoi de plus rigoureusement individuel, quoi de plus personnel qu'une émotion? Bien plus, quoi de plus strictement momentané ? Ne sont-elles pas une parade, ou une riposte instantanée à de certaines sollicitations de l'extérieur? Et ne traduisent-elles pas des modifications de nos organes qui, par définition, sont incommunicables ? La vie affective est, en fait (pour employer une formule de Charles Blondel dans son Introduction à la psychologie collective, p. 92) ce qu'il y a « de plus nécessairement et de plus inexorablement subjectif en nous ». Dès lors, qu'est-ce que l'histoire a à démêler avec tout ce personnalisme, tout cet individualisme, tout ce subjectivisme psychologique ? Lui demande-ton d'analyser dans ses causes organiques tel accès de peur, de colère, de joie ou d'angoisse de Pierre le Grand, de Louis XIV ou de Napoléon ? Et quand cet historien nous aura dit : «Napoléon eut un 
accès de rage » ou bien « un moment de vif plaisir » — sa tâche ne sera-t-elle pas terminée ? Lui demandera-t-on de descendre dans le mystère physiologique des viscères du grand homme ?

Tout ceci, fort spécieux. D'abord, parce qu'il ne faut pas confondre : une émotion, c'est autre chose sans doute qu'une simple réaction automatique de l'organisme aux sollicitations du monde extérieur. En tant que parade et riposte, il n'est pas prouvé que les réactions dont elle s'accompagne, et qui la caractérisent, soient toujours de nature à accélérer, à rendre ${ }_{\mathrm{p} 223}$ plus précis, plus divers et plus vifs les gestes de l'homme en proie à l'émotion. Tout au contraire.

En fait, les émotions, le $\mathrm{D}^{\mathrm{r}}$ Wallon dit fort bien qu'elles constituent une formule nouvelle d'activité, qu'il ne faut pas confondre avec les simples automatismes de réplique. Et d'abord, elles puisent à d'autres sources de la vie organique : mais ceci est peu important pour nous, historiens, qui ne sommes point habilités pour prospecter ces sources. Ce qui est beaucoup plus important, c'est que les émotions, contrairement à ce qu'on pense quand on les confond avec de simples automatismes de réaction au monde extérieur — ont un caractère particulier dont l'homme qui s'occupe de la vie sociale de ses congénères ne peut plus, cette fois, faire abstraction. Les émotions sont contagieuses.

Elles impliquent des rapports d'homme à homme, des relations collectives. Elles naissent sans doute dans un fond organique propre à un individu donné, et souvent à l'occasion d'un événement qui touche cet individu seul, ou du moins qui le touche avec une gravité, une violence toutes particulières. Mais elles s'expriment d'une façon telle; si l'on veut, leur expression est le résultat d'une telle série d'expériences de vie commune, de réactions semblables et simultanées au choc de situations identiques et de contacts de même nature; elle est le fruit, si l'on préfère encore, d'une telle fusion, d'une telle réduction réciproque de sensibilités diverses - que, très vite, elles ont acquis le pouvoir de provoquer chez tous les présents, par une sorte de contagion mimétique, le complexe affectivo-moteur qui correspond à l'événement survenu et ressenti par un seul. 
Et ainsi, petit à petit, les émotions, associant plusieurs participants tour à tour initiateurs et suiveurs - en sont arrivées à constituer un système d'incitations interindividuelles qui s'est diversifié suivant les situations et les circonstances, en diversifiant du même coup les réactions et la sensibilité de chacun. Ceci, d'autant plus que l'accord ainsi établi, que la simultanéité ainsi réglée des réactions émotives se montrant de nature à conférer au groupe une plus grande sécurité, ou une plus grande puissance - l'utilité s'est trouvée bientôt justifier la constitution d'un véritable système d'émotions. Elles sont devenues comme une institution. Elles ont été réglées à la façon d'un rituel. Bien des cérémonies, chez les primitifs, sont des ensembles de simulacres qui ont pour but évident de susciter chez tous, par les mêmes attitudes et les mêmes gestes, le même émoi — et de les souder tous dans une sorte d'individualité supérieure, de les préparer tous à la même action. p224

Arrêtons-nous ici. Tout ceci n'est point sans doute de nature à laisser indifférents les historiens ? Certes, il s'agit là de ces sociétés que nous continuons d'appeler «primitives», tout en continuant également à déclarer le mot absurde. Disons, si l'on veut, qu'il s'agit de sociétés encore balbutiantes. Mais enfin, ne faisons pas la petite bouche. Ces sociétés balbutiantes couvrent plus de temps et d'espace, dans le passé de l'homme, que nos sociétés disertes d'aujourd'hui. Ces sociétés balbutiantes ont laissé en nous beaucoup de leurs balbutiements. Car rien ne se perd, si tout se transforme. Et surtout, ce que nous venons de dire, brièvement, nous permet de saisir autre chose, de plus grave. Ce que nous venons de dire nous permet d'assister, simplement, à la genèse de l'activité intellectuelle.

L'activité intellectuelle suppose la vie sociale. Ses instruments indispensables (au premier rang le langage) impliquent, en effet, l'existence d'un milieu humain dans lequel ils se sont élaborés nécessairement - puisque leur but est d'opérer la mise en relation de tous les participants à un même milieu. Or, où trouver le premier terrain connu des relations interindividuelles de conscience entre les hommes sinon dans ce que nous venons de décrire et qu'on peut nommer la vie émotionnelle? L'organe spécialisé du langage, la parole articulée, n'est-on pas fondé à croire qu'elle a surgi, qu'elle s'est développée à partir du même fond d'activités organiques, 
d'activités toniques que les émotions, lorsqu'on voit, encore aujourd'hui, les troubles des fonctions toniques entraîner aussitôt des troubles d'élocution? - Seulement, très vite, entre les émotions et les représentations un antagonisme a surgi. Une incompatibilité s'est révélée. Car d'une part, on a eu vite fait de constater que, dès qu'elles se produisent, les émotions altèrent le fonctionnement de l'activité intellectuelle. Et d'autre part, on s'est vite aperçu également que le meilleur moyen de réprimer une émotion, c'était de s'en représenter avec précision les motifs ou l'objet - de s'en donner le spectacle ou, simplement, de se livrer à un calcul, à une méditation quelconques. Faire de sa douleur un poème ou un roman - ce fut sans doute pour beaucoup d'artistes un mode d'anesthésie sentimentale.

Et ainsi on a pu assister dans les civilisations en voie d'évolution à ce long drame - au refoulement, plus ou moins lent, de l'activité émotionnelle par l'activité intellectuelle; d'abord seules capables de réaliser entre les individus l'unité d'attitude et de conscience d'où a pu naître le commerce intellectuel et son premier outillage, elles sont dans la suite entrées en conflit avec ces instruments nouveaux de relation dont elles avaient seules p225 rendu possible la création. Et plus les opérations intellectuelles ont pris de développement dans des milieux sociaux où toutes les relations entre hommes se trouvent de mieux en mieux réglées par des institutions ou des techniques - plus la tendance est devenue forte à considérer les émotions comme une perturbation de l'activité - quelque chose de dangereux, d'importun, et de laid : disons, tout au moins, d'impudique. L'honnête homme ne se pique de rien. S'il se piquait de quelque chose, ce serait de garder toujours son sang-froid, et de ne jamais trahir son émotion. Il est vrai que nos sociétés ne comptent pas que des honnêtes hommes.

Dira-t-on qu'un tel schéma - dont je répète que les éléments sont empruntés au bel article de Henri Wallon dans le tome VIII de l'Encyclopédie française - est sans valeur pour l'historien? Tout dépend de ce qu'on nomme histoire. Je crois tout de même qu'il a quelque intérêt. Et qu'il nous permet non seulement de comprendre, un peu mieux, l'attitude des hommes d'autrefois, mais peut-être de définir une méthode de recherche, ce qui est notre but ici. 
Voici un livre qui n'a pas eu en France, est-on tenté de dire, toute la fortune qu'il méritait : c'est l'Automne du moyen âge (Herbst von Mittelalter), de Huizinga, devenu en français, prosaïquement, le Déclin du moyen âge (Payot, 1932). Un beau livre, je tiens à le redire. Encore est-il qu'à son manque de succès relatif il y a peut-être quelques causes profondes?

J'ouvre le chapitre premier, intitulé : L'âpre saveur de la vie. L'auteur nous montre, en cette fin du moyen âge, la puissance souveraine des émotions, leur violence explosive, capable de renverser parfois les plans les plus rationnels et les mieux étudiés. « Nous ne pouvons guère nous faire une idée de l'extravagance et de l'émotivité médiévales », écrit-il (p. 24). Et il dénonce, dans le sentiment de justice si fort en ce temps, la simple transposition, dans la plupart des cas, d'un besoin de vengeance. Il montre ce sentiment atteignant son maximum de tension entre ces deux pôles : la loi du talion, chère au païen, et l'horreur religieuse du péché, don du christianisme: mais le péché, pour ces violents et ces impulsifs, c'était le plus souvent une autre manière de nommer les actions de leurs ennemis. Il nous montre, en face de nous, hommes du $\mathrm{XX}^{\mathrm{e}}$ siècle et déjà (et surtout, peut-être ?) du XIX siècle - en face de nous qui cherchons à doser les peines avec lucidité et précaution, à les administrer avec lenteur ${ }_{\mathrm{p} 226}$ et modération, au compte-gouttes si j'ose dire - il nous les montre, eux, les hommes du moyen âge finissant, ne connaissant qu'une seule alternative, catégorique et brutale : la mort ou la grâce. Et la grâce incompréhensible souvent - brusque, soudaine, totale, imméritée si une grâce pouvait jamais être imméritée... La vie, conclut Huizinga, "était si violente et si contrastée qu'elle répandait l'odeur mêlée du sang et des roses... ».

Et bien, tout cela est justement, tout cela est même assez joliment dit - mais laisse tout de même un certain malaise dans l'esprit. Estce là du bon travail ? Je veux dire : la question, posée comme elle l'est, peut-elle être résolue ? Peut-on vraiment parler, à ce propos, d'une période particulière et distincte de l'histoire affective de l'humanité ? Ces brusques révolutions, ces brusques retournements de la haine à la clémence, de la cruauté la plus furieuse à la pitié la plus 
pathétique - serait-ce donc le signe d'un dérèglement particulier à une certaine époque, le signe de la fin du moyen âge, du déclin du moyen âge, de l'automne médiéval — par opposition, j'imagine, au seuil du moyen âge, au printemps médiéval ou bien, au contraire, au seuil des temps modernes?

J'en doute un peu pour le début du moyen âge. Une lecture de Grégoire de Tours éclaircirait vite le débat... Et j'en doute un peu pour le début des temps modernes. Car enfin ? Il y a quelques années, dans une tournée de conférences que je faisais à Genève, à Lausanne, à Neuchâtel, sur les origines de la Réforme française, je proposais déjà à mes auditeurs ce thème à méditations : quand Jean Calvin insiste avec force, dans sa théologie, sur le caractère de don, totalement gratuit et inconditionnel, que revêt l'octroi de la grâce aux élus; quand il témoigne ainsi de cette répugnance invincible, qu'il proclame souvent et en termes exprès, pour la comptabilité en partie double des bonnes œuvres et des péchés, tenue dans les bureaux de la Divinité par une armée de comptables incorruptibles et suivie d'une ventilation finale, ne s'accorde-t-il pas tout spontanément, lui qui par ailleurs, si souvent, compare son Dieu à un Roi — ne s'accorde-t-il pas au sentiment des Français de son temps qui, voyant passer le Roi dans leurs campagnes, au cours de sa perpétuelle randonnée à travers le royaume, commencée dès le jour du Sacre, pour ne finir qu'au jour du transfert à Saint-Denis - posaient leurs outils et couraient à toutes jambes baiser, qui son étrier, qui le pan de son manteau, qui du moins le flanc de son cheval ? C'est la Justice du Roi qui passe en majesté, c'est le lieutenant de Dieu sur la terre et qui, comme Dieu lui-même, peut tout, ${ }_{\text {p227 }}$ au-dessus de toute loi. Un geste, la tête tombe. Un geste, l'homme est sauvé. Pas de milieu. Pas de gradation. Pas de moyen terme. La grâce, ou la mort...

Mais pourquoi la grâce, plutôt que la mort ? Serait-ce qu'après une étude attentive des faits et des mérites, un doute ?... Jamais. C'est notre justice qui pèse et soupèse, qui hésite, tâtonne et dose. La justice $\mathrm{du} \mathrm{XVI}^{\mathrm{e}}$ siècle? Tout ou Rien. Et quand la justice a dit Tout, ou bien Rien, le Roi intervient. Pour nuancer, lui ? pour doser? Non. Le Roi donne librement non pas sa justice mais sa pitié. Elle peut tomber sur un indigne. La Charité aussi, cette grande vertu du monde chrétien. Peu importe. Le peuple ne se pose pas plus la question que le Roi. Il 
est aussi heureux du don de la grâce, si ce don tombe sur un criminel, que s'il tombe sur un pitoyable. Comme il est aussi satisfait de faire la charité à un coquin qu'à un brave homme. Ce qui compte, ce ne sont pas les circonstances atténuantes et le degré de comptabilité. Ce qui compte, c'est la Pitié en tant que telle. Le don qui est pur don. La grâce qui est pure grâce...

Rappelons-nous tel récit de ce temps, le coupable agenouillé, les yeux bandés, la tête sur le billot... Déjà, l'homme rouge brandit sa redoutable épée nue. Et brusquement des cris, un cavalier à fond de course qui envahit la place en brandissant un parchemin: grâce, grâce ! le mot juste. Car le Roi donne sa grâce ; il ne tient pas compte d'un mérite. Tel le Dieu de Jean Calvin. Tel l'homme à brusque révolution, à soudain revirement - l'homme blanc-noir, qu'Huizinga nous assure être, par excellence, l'homme de la fin du moyen âge et qui court fort le risque d'être l'homme éternel... Car le vrai, c'est que Huizinga sans doute eût tout éclairé d'un mot (et son livre y eût grandement gagné en clarté) s'il eût d'abord posé ce fait, qu'il y a de l'ambivalence dans tout sentiment humain. Disons, en clair, que tout sentiment humain est à la fois lui-même et son contraire. Qu'une sorte de communauté fondamentale unit, toujours, les pôles opposés de nos états affectifs. Que les circonstances, le jeu de nos représentations, certaines attitudes personnelles peuvent bien expliquer, dans tel cas et tel moment, que l'un de ces pôles prédomine assez généralement sur l'autre: la haine sur l'amour; le besoin de pitié sur l'instinct de cruauté, etc. Mais ces états contrastés restent solidaires, et l'un ne peut se manifester sans que l'autre ne s'éveille, plus ou moins, à l'état latent. D'où des p228 oscillations, des changements brusques qui déconcertent la logique, des conversions soudaines, etc. Pas plus que la vie affective des hommes pris à part, la vie des groupes humains au cours d'une certaine époque ne put être rendue par une simple juxtaposition de teintes plates. Elle est une résultante - et de tendances opposées qui s'induisent naturellement, et d'appétits que leur fixation sur des objets peut diversement orienter.

Alors, si on a commencé par poser les choses ainsi, si on a commencé par le général, par l'humain, pour descendre au particulier 
et au circonstanciel — on n'est plus tenté de parer « la vie du moyen âge », pour reprendre l'expression de Huizinga, d'une sorte « d'âpreté » particulière qui lui conférait quelque chose de particulier, d'original et de distinctif. La vie du moyen âge n'a rien à faire làdedans. Ou plutôt le problème est déplacé. Il est mal posé.

Étant donné ce fait universel, ce fait « humain », l'ambivalence des sentiments - y a-t-il lieu de distinguer des époques, dans l'histoire des sociétés humaines, où les renversements de courants s'opéreraient avec plus de fréquence, plus de violence aussi ? Y a-t-il lieu de penser que, dans cette même histoire, à de certaines époques, des tendances d'un certain ordre l'emportent en fréquence et en violence sur les tendances de l'ordre opposé : plus de cruauté que de pitié ; plus de haine que d'amour? - D'une façon plus générale encore, y a-t-il lieu de penser qu'il y a dans l'histoire des périodes de vie intellectuelle prédominante succédant à des périodes de vie affective particulièrement développée ? Et pourquoi, et comment? - Voilà cette fois les vraies questions posées. Celles que Huizinga n'a pas posées, au risque de confusion, faute de ce retour aux origines, de cette remontée vers les problèmes de genèse qui, à quelques-uns de nos lecteurs, pouvait paraître fastidieuse et importune; je crois maintenant qu'ils se l'expliquent et la comprennent.

Le vrai, c'est que, prétendre reconstituer la vie affective d'une époque donnée, c'est une tâche à la fois extrêmement séduisante et affreusement difficile. Mais quoi ? l'historien n'a pas le droit de déserter.

Il n'en a pas le droit - parce que, faute d'entreprendre cette tâche (sinon de la mener à bien), il se rend le complice d'affirmations comme celles que je rappelais en commençant. On peut, nous disent encore trop d'historiens, on peut «utiliser la psychologie » pour interpréter les faits fournis par des documents valables sur le caractère, l'action, la vie d'un homme de premier plan, d'un de ces hommes «qui font l'histoire ». La psychologie, p229 qu'entendre par là ? Cette espèce de sagesse un peu prudhommesque, à base de vieux proverbes, de ressouvenirs littéraires fanés, de prudences acquises ou héritées qui sert à nos contemporains de guide dans leurs relations quotidiennes avec leurs semblables? 
Farcie de quelques citations bien choisies, de quelques sentences à effet, revêtue de beau style académique, c'est elle qui a fait merveille dans les innombrables chefs-d'œuvre de l'histoire romancée qui envahirent, pendant dix ans, les devantures de nos librairies - mais il semble que leur affreux relent ait fini par mettre en fuite les lecteurs. La psychologie: entendons Bouvard ou Pécuchet, forts d'une expérience puisée dans la fréquentation des modistes et des boutiquières de leur quartier, et partant de là pour accommoder de telle façon les sentiments d'Agnès Sorel pour Charles VII, ou de Louis XIV pour la Montespan, que leurs parents et amis s'exclament à la lecture : «Comme c'est ça! » Cette psychologie, c'est le Childéric de l'abbé Velly, qui divertissait notre bon maître Camille Jullian: Childéric, dit Velly dans son Histoire de France (1755), «Childéric fut un prince à grandes aventures. C'était l'homme le mieux fait de son royaume. Il avait de l'esprit, du courage. Né avec un cœur tendre, il s'abandonnait trop à l'amour: ce fut la cause de sa perte...» Dérision.

Mais, par contre, ce domaine d'où on prétend exclure toute imagination intuitive, le domaine de l'histoire des idées, le domaine de l'histoire des institutions: quel beau champ de recherches, et de reconstitution, et d'interprétation pour historien psychologue ! Son champ d'investigation par excellence. Car, bien au contraire, le mécanisme des institutions d'une époque; les idées de cette époque ou d'une autre : voilà ce que l'historien ne peut comprendre et faire comprendre sans ce souci primordial, que j'appelle, moi, psychologique : le souci de relier, de rattacher à tout l'ensemble des conditions d'existence de leur époque le sens donné à leurs idées par les hommes de cette époque. Car ces conditions, elles colorent les idées, comme toutes choses, d'une couleur très nette d'époque et de société. Car ces conditions, elles mettent leur griffe sur ces idées, comme sur les institutions et leur jeu. Et pour l'historien, idées, institutions, ce ne sont jamais des données de l'Éternel; ce sont des manifestations historiques du génie humain à une certaine époque et sous la pression de circonstances qui ne se reproduisent jamais plus.

Seulement, pas d'illusions : la tâche est rude, les instruments rares et de maniement difficile. Quels sont les principaux ? 230 
D'abord, voici les linguistes, ou plus exactement les philosophes - qui nous offrent leurs vocabulaires et leurs dictionnaires. Si insuffisants du reste, si incomplets encore et si peu précis... Or, que peut-on tirer d'une étude de vocabulaire? S'il s'agit de sentiments, peu de choses. Parfois, elle permet d'isoler et d'atteindre certaines conditions d'existence fondamentale des hommes qui créèrent tel vocabulaire. Pour prendre un exemple plus que classique, elle permet de bien marquer l'aspect paysan qu'ont conservé les mots d'une langue comme le latin, où la rivalité est ainsi nommée du débat de voisins prétendant au même canal d'irrigation, rivus; où l'excellence de l'homme, egregius, est comparée à la valeur de la bête qu'on tire, pour la soigner à part, hors du troupeau, e grege; où le faible, imbecillis, évoque l'idée de la plante sans tuteur, bacillus; où la notion de joie, laetitia, reste épaissement liée à celle d'engrais, laetamen. Seulement, dès qu'il s'agit d'un ensemble de sentiments, et de leurs nuances changeantes, on peut bien suivre, encore une fois, des évolutions individuelles et fragmentaires. Aucune étude de vocabulaire ne permet de reconstituer une évolution d'ensemble de tout un système de sentiments dans une société donnée à une époque donnée. Il faut se contenter de recherches monographiques qui jouent, si l'on veut, le rôle d'une coupe géologique à travers une grande quantité de terrains dont on n'a pas le temps de prospecter la masse. Et le schéma qu'on en peut tracer peut bien être générateur de mille suggestions diverses. Il n'a valeur que d'échantillon. Il ne saurait constituer un élément statistique pour l'étude d'un ensemble.

Seconde ressource: l'iconographie artistique. Celle sur qui, en France, le labeur ingénieux et adroit d'Émile Mâle a attiré si fortement l'attention depuis un bon demi-siècle. Et certes, la ressource est d'importance.

On sait comment, à l'aide de l'iconographie, É. Mâle a reconstitué ce qu'on peut nommer des modes successives et souvent contrastées de sentimentalité religieuse. On sait comment il a pu opposer à l'art classique divin, rationnel et tout empreint de sérénité du XIII ${ }^{\mathrm{e}}$ siècle gothique, l'art pathétique, humain, sentimental et parfois sensuel, l'art expressif et tourmenté du XV siècle flamboyant. On sait comment il a pu dater avec précision l'apparition dans l'art plastique de telle ou telle nuance d'expression sentimentale qui, rapprochée d'autres, 
permet de composer les chapitres enchaînés d'une histoire artistique du sentiment religieux en France, du XII ${ }^{\mathrm{e}}$ au début du XVII ${ }^{\mathrm{e}}$ siècle. Et de cette tentative, et des travaux qu'elle a suscités, il faut bien se garder ${ }_{\text {p231 }}$ de diminuer la très haute valeur, je ne dis pas pour l'histoire de l'expression artistique, mais pour l'Histoire tout court. Encore est-il bon de se montrer prudent.

D'abord parce qu'il faut ici tenir compte de l'emprunt. De l'imitation des arts voisins. Il faut même en tenir un compte beaucoup plus grand qu'Émile Mâle ne l'a fait - s'il est vrai, par exemple, que quelque chose a faussé dès l'origine la perspective de son second volume - quelque chose que, depuis, il n'a pu rattraper qu'imparfaitement: je veux dire, son insouciance relative de l'art italien - sa méconnaissance de la puissante action exercée par l'art italien $\mathrm{du} \mathrm{XIV}^{\mathrm{e}}$ siècle sur l'art français dans la genèse de cet art pathétique, réaliste et humain dont Mâle rapporte uniquement la naissance aux influences combinées des Meditationes vitae Christi du pseudo-Bonaventure, et du théâtre des Mystères.

L'emprunt, ce très gros problème. Car il ne suffit pas de dire, évidemment : "Voyez : dans cet art saisi en France, toute une part vient de l'Italie, ou des Flandres ", pour rendre impossible tout raisonnement ultérieur sur l'évolution sentimentale de l'art français, de l'art saisi en France, à l'époque considérée. S'il y a emprunt, c'est qu'il y a besoin. Si les Français s'emparent de thèmes sentimentaux développés par les voisins d'Italie ou des Pays-Bas à une époque donnée - c'est que ces thèmes sentimentaux les touchent profondément. Et en s'en emparant, ils les font leurs. Tout de même qu'en empruntant globalement tout un vocabulaire à une langue voisine, ils en font leurs les éléments divers. Voyez ces livres massifs, curieux, à la fois pesants et subtils, informés et tendancieux, que Louis Reynaud jadis consacra au problème des relations culturelles entre la France et l'Allemagne médiévales. Il prétendait y montrer cette dernière empruntant d'un bloc à la France tout le vocabulaire de la courtoisie : les mots et, avec les mots, un vouloir de créer (et d'abord de créer artificiellement) la série des états d'esprit ou de cœur correspondants. Le mot étranger, comme le thème artistique étranger, 
s'il est adopté, c'est qu'il répond à un besoin. Du moins au besoin de quelques-uns qui l'adoptent...

Car ici, deuxième difficulté. Du sentiment religieux des masses, tel qu'il en reconstitue les nuances sentimentales à l'aide de documents figurés, Mâle parle beaucoup trop comme d'un tout. «Tout» si l'on veut - mais il y a des nuances, et qui, dès qu'on ${ }^{2} 232$ examine les choses d'un peu près, reparaissent. Un exemple. S'il y a un thème pathétique dont on puisse suivre l'élaboration et l'évolution de façon excellente à travers les documents figurés de la fin du moyen âge, c'est bien ce thème de la souffrance de Marie, de la Passion de la Mère se soudant à la Passion du Christ, avec tout son cortège de dévotions du sang et des plaies, tantôt étalées sous les yeux des fidèles pour émouvoir le double instinct de pitié et de cruauté qui sommeille au fond de chacun - tantôt transfigurées, sur le plan mystique, en représentations comme celles de la Fontaine de Vie ou du Pressoir mystique. Le tout pour aboutir, finalement, au groupe de Marie au pied de la croix : tantôt prostrée, à moitié évanouie, pitoyable et tragique ; tantôt debout, dans l'attitude que décrit le Stabat :

\section{Stabat Mater dolorosa \\ Juxta crucem lachrymosa \\ Dum pendebat filius.}

Or, dès le début du XVI ${ }^{\mathrm{e}}$ siècle, dès 1529 , dans le livre d'un docteur catholique, Jean de Hangest, polémiquant contre les adversaires du culte de Marie, on lit déjà une protestation contre les propos de certains qui, réagissant contre ces représentations de la Vierge douloureuse, s'inscrivent en faux contre elles sous le prétexte suivant : non super Filii passione doluit, aut lachrymata est...

Boutade ? Mais ce texte me revenait en mémoire naguère, en lisant, dans l'Histoire littéraire du sentiment religieux en France d'Henri Bremond, un passage consacré aux controverses qu'au XVII siècle cette critique du Stabat soulevait avec passion. Et, plus encore, en lisant, dans le beau livre de Marcel Bataillon sur Érasme et l'Espagne, ce qu'il écrit du succès que connut le thème de la Vierge prostrée et pleurante au pied de la croix dans l'Espagne pathétique de la fin du $\mathrm{Xv}^{\mathrm{e}}$ siècle - et des protestations qu'y provoqua, non moins, cette introduction dans la pitié d'une sorte d'élément de douleur 
vériste. Conflit de deux méthodes et de deux écoles; de deux conceptions du pathétique dans la religion intérieure : c'est l'éternelle opposition que traduit tout d'abord le sonnet de Campanella, se détournant de l'image du Crucifié pour s'abîmer dans la contemplation glorieuse du Ressuscité :

«Quelle raison à le montrer partout, peint ou dépeint, au milieu de tourments qui pèsent si peu devant la joie qui les suivit?

«Ah! vulgaire insensé, vulgaire aux yeux toujours fixés à terre, vulgaire indigne de voir son triomphe céleste : quand porteras-tu tes regards ailleurs que sur le jour de l'atroce combat? ... » p233

A quoi répond éternellement l'oraison de sainte Thérèse, ce magnifique cri de femme passionnée :

« Moi je t'aime plus à cause de ton agonie et de ta mort qu'à cause de ta résurrection. Car je m'imagine que, ressuscité, remontant dans les espaces azurés, ayant ton univers à tes ordres, tu as moins besoin de ta servante... »

La conclusion c'est que, tout de même, il faut savoir doser, peser, évaluer. Ne pas généraliser abusivement et sans précaution. Ne pas se figurer qu'à un moment donné la foi est une. Plus elle est vive, diraisje, plus elle est personnelle, plus elle est diversifiée aussi et intransigeante sur ses modalités. Ne prenons pas telle forme d'adoration spécifiquement franciscaine - celle du Dieu piteux ou de la Mère prostrée ; ne prenons pas telle méthode d'évocation du Dieu de la Passion et d'exaltation sur ses plaies, pour la méthode universellement admise par tous les croyants mystiques d'une époque avide de christianisme intérieur.

Correctifs qui ne diminuent en rien la valeur d'une œuvre comme celle d'Émile Mâle, mais qui nous enseignent, à nous, une prudence que, personnellement, il n'a point toujours eue.

Quelle ressource encore? La littérature. Et non seulement l'enregistrement par elle, l'enregistrement que nous lui devons, des nuances de sensibilité qui séparent les unes des autres les époques, et 
plus précisément les générations - mais l'étude de la façon même dont elle crée et répand ensuite telle forme de sentiment parmi des masses dont il y a lieu d'ailleurs d'évaluer avec précision l'importance. Car le public d'un roman courtois du moyen âge n'est pas précisément le même, ni en quantité ni en nature, que celui d'un roman-feuilleton $\mathrm{du} \mathrm{XIX}^{\mathrm{e}}$ siècle, ou d'un film populaire $\mathrm{du} \mathrm{XX}^{\mathrm{e}}$. Mais comment, puisqu'il s'agit en ce moment de sensibilité et de nuances de sensibilité, - comment ne pas aller droit aux deux admirables volumes parus du Préromantisme français d'André Monglond, apportant à composer les chapitres d'une Histoire du sentiment littéraire en France la même exquise finesse, la même délicatesse de pensée et de goût qu'un Henri Bremond à rédiger les volumes successifs de son Histoire littéraire du sentiment religieux ? Comment ne pas aller droit, en particulier, à ce beau tome II consacré tout entier au «maître des âmes sensibles », à J.-J. Rousseau, à ceux qui l'ont préparé, à ceux qui l'ont aidé, à ceux qui l'ont protégé ?

Tout ceci, d'un prix inestimable. A condition, naturellement, p234 j'y reviens, qu'on observe les mêmes précautions critiques dans le maniement des textes littéraires que dans l'étude et l'utilisation des documents de l'art figuré. A condition qu'on ne s'aveugle pas sur l'extension, non plus que sur la profondeur réelle des rayons de sentiment que l'histoire de la littérature nous montre se succédant les uns les autres avec une sorte de logique implacable - alors qu'en réalité, il faut bien le voir, elles ne font que se recouvrir et se découvrir perpétuellement?

$\mathrm{XVIII}^{\mathrm{e}}$ siècle, époque triomphale de la sensibilité reine ? J'en suis certain. Mais enfin, je reviens à mes Synonymes français de Girard (édition de 1780). "La tendresse est un faible. La sensibilité une faiblesse... La sensibilité nous oblige à veiller autour de nous pour notre intérêt personnel. La tendresse nous engage à agir pour l'intérêt des autres... Le cœur sensible ne sera pas méchant : car il ne pourrait frapper autrui sans se blesser lui-même. Le cour tendre est bon puisque la tendresse est sensibilité agissante. Je veux bien que le cœur sensible ne soit pas l'ennemi de l'humanité. Mais je sens que le cœur tendre en est l'ami. » 
Et voilà, en quelques lignes (mais le parallèle tout entier occupe quatre pages), un beau réquisitoire daté de 1780 , et qui certes peut passer pour une traduction valable du sentiment français (je veux dire, du sentiment des Français les plus cultivés et les plus fins de ce temps) — voilà un beau réquisitoire de 1780 contre cette sensibilité larmoyante et débordante qui sans doute a rempli toute une part du $\mathrm{XVIII}^{\mathrm{e}}$ siècle. Toute une part seulement, on le voit, et non sans susciter quelques réactions sans violence. D'autant plus clairvoyantes d'ailleurs, et moins capables d'illusion.

Récapitulons. Documents moraux : éléments fournis et par les archives judiciaires et ce qu'on peut nommer, d'un mot large, la casuistique. - Documents artistiques: ceux que fournit l'art plastique, mais, également, l'art musical correctement interrogé. Documents littéraires, avec les réserves que je viens d'indiquer. Non, tout de même, nous ne sommes pas démunis? Et si nous maintenons, toujours et avant tout, le contact avec les recherches des psychologues et les résultats par eux procurés; si nous prenons pour règle de ne jamais nous embarquer dans ces recherches de psychologie appliquée à l'histoire, ou l'histoire cherchant à reconstituer l'évolution des données psychologiques, sans d'abord nous initier au dernier état de la question (car, à quoi bon feuilleter ces vieux livres dont nous gardons le titre dans nos mémoires p $235_{5}$ parce qu'on nous en a parlé, il y a vingt, trente, quarante ans, quand nous étions au lycée, et alors que déjà, bien souvent, ils étaient périmés) — si nous prenons appui fortement, au départ, sur les derniers résultats acquis par le labeur critique et positif de nos voisins, les psychologues - alors nous pourrons, je crois, entreprendre une série de travaux qui, tous, nous font défaut : et tant qu'ils nous feront défaut, il n'y aura pas d'histoire possible. Nous n'avons pas d'histoire de l'Amour, qu'on y pense. Nous n'avons pas d'histoire de la Mort. Nous n'avons pas d'histoire de la Pitié, ni non plus de la Cruauté. Nous n'avons pas d'histoire de la Joie. Grâce aux Semaines de Synthèse d'Henri Berr, nous avons eu une rapide esquisse d'une histoire de la Peur. Elle suffirait à montrer de quel puissant intérêt de telles histoires pourraient être... 
Quand je dis : nous n'avons pas d'histoire de l'Amour, ni de la Joie - entendez bien que je ne réclame pas une étude sur l'Amour ou la Joie, à travers tous les temps, tous les âges, et toutes les civilisations. J'indique une direction de recherche. Et je ne l'indique pas à des isolés. A des physiologistes purs. A des moralistes purs. A des psychologues purs, au sens mondain et traditionnel du mot. Non. Je demande l'ouverture d'une vaste enquête collective sur les sentiments fondamentaux des hommes et leur modalités. Que de surprises à prévoir! Je parlais de la Mort. Ouvrez donc le tome IX de l'Histoire littéraire du sentiment religieux en France d'Henri Bremond - son étude sur la Vie chrétienne sous l'ancien régime (1932). Ouvrez-le au chapitre intitulé : L'art de mourir. Pas même trois cent ans; quel abîme entre les mœurs, les sentiments des hommes de ce temps — et les nôtres?

Et maintenant, pour un dernier coup d'œil, évoquons de nouveau cette esquisse par quoi je commençais - cette esquisse du rôle de l'activité émotionnelle dans l'histoire de l'humanité, comparé au rôle de l'activité intellectuelle, que je traçais à l'aide des données élaborées par le tome VIII de l'Encyclopédie Française. Rappelons-nous cette sorte de courbe qui nous montrait, d'ensemble, le système des activités émotionnelles tenu en respect, mais de plus en plus refoulé par la masse proliférante, par le système envahissant des activités intellectuelles : conquérantes, dominatrices, et rejetant de plus en plus les émotions, en marge, pour ainsi dire, de la périphérie, dans un rôle secondaire et méprisable. p236

Fort bien. Et l'on peut, partant de là, si on est un de ces rationalistes intempérants à l'ancienne mode que nous avons tous connus (et que peut-être, nous pouvons encore connaître assez facilement, rien qu'en descendant en nous-même à de certaines heures) - l'on peut, partant de là, entonner un assez bel hymne triomphal au Progrès. A la Raison. A la Logique. Mais voulez-vous que nous relisions ensemble le texte que j'utilisais tout à l'heure ?

«Ainsi, petit à petit, les émotions, associant plusieurs participants tour à tour initiateurs et suiveurs, en sont arrivés à constituer un système d'incitation interindividuel qui s'est diversifié suivant les 
situations et les circonstances, en diversifiant du même coup les réactions et la sensibilité de chacun. Ceci, d'autant plus que l'accord ainsi établi, que la simultanéité ainsi réglée des réactions émotives se montrant de nature à conférer au groupe une plus grande sécurité ou une plus grande puissance, l'utilité s'est trouvée bientôt justifier la constitution d'un véritable système d'émotions. Elles sont devenues comme une institution. Elles ont été réglées à la façon d'un rituel. Bien des cérémonies chez les primitifs sont des ensembles de simulacres qui ont pour but évident de susciter chez tous, par les mêmes attitudes et les mêmes gestes, le même émoi, de les souder tous dans une sorte d'individualité supérieure, de les préparer tous à la même action. »

Ceci, qui s'applique excellemment à ces grandes fêtes des sociétés indigènes et par exemple à ce Pilou des Canaques de NouvelleCalédonie dont on peut lire la description dans le très beau livre de Maurice Leenhardt, Gens de la Grande Terre, un livre qui honore à la fois la science française et l'humanité - ceci, avons-nous besoin d'y changer une seule ligne pour l'appliquer à tant de spectacles tragiques qui se déroulent sous nos yeux, à tant d'efforts patients, obstinés, savants et instinctifs à la fois, pour s'emparer par surprise de ce qu'il y a, en chacun de nous, de vie émotionnelle toujours prête à déborder la vie intellectuelle et pour opérer un brusque renversement de cette évolution dont nous étions si fiers: de l'émotion à la pensée, du langage émotionnel au langage articulé...

Sensibilité dans l'histoire, un sujet pour amateurs distingués... Vite, vite, retournons, n'est-ce pas, à la véritable histoire? Aux circonstances de l'affaire Pritchard. A la question des Lieux saints. Ou au dénombrement des greniers à sel en 1563. Voilà de l'histoire. Qu'il convient d'enseigner à nos enfants, dans les classes, et à nos étudiants dans les universités. Mais l'histoire ${ }_{\text {p237 }}$ de la haine, l'histoire de la peur, l'histoire de la cruauté, l'histoire de l'amour: laissez-nous, de grâce, avec ces fades littératures. - Ces fades littératures, étrangères à l'humanité, mais qui, demain, auront achevé de faire de l'univers un charnier puant.

Oui. Ceux qui, d'abord, se sont demandés, peut-être : «A quoi tend toute cette psychologie mise en résumé ?» — je crois qu'ils 
peuvent conclure, maintenant: elle tend à l'histoire. A la plus ancienne comme à la plus récente des histoires. A celle des sentiments primitifs en place, in situ, comme à celle des sentiments primitifs ressuscités. Comme à notre histoire de perpétuelles résurgences et résurrections sentimentales. Culte du sang, du rouge sang, dans ce qu'il a de plus animal et de plus primitif. Culte des puissances élémentaires traduisant la lassitude des bêtes forcées que nous sommes - des bêtes écrasées, usées, laminées par le bruit forcené, par le dynamisme forcené de milliers de machines qui nous obsèdent. Résurrection compensatrice d'une sorte de culte de la Terre Mère sur le sein de qui il est si bon, le soir, d'allonger filialement ses membres endoloris. Résurrection, non moins universelle, d'une sorte de culte du Soleil nourricier et guérisseur: nudisme et camping, glissements éperdus dans l'air et dans l'eau. Exaltation de sentiments primaires, avec brusque rupture d'orientation et de valence; exaltation de la dureté aux dépens de l'amour, de l'animalité aux dépens de la culture - mais d'une animalité donnée, éprouvée comme supérieure à la culture ; en vérité, je conclus : la sensibilité dans l'histoire vaut-elle une enquête, une large, puissante et collective enquête? Et la psychologie, est-ce un rêve de malade si je pense, si je dis ici qu'elle est à la base même de tout travail d'historien valable? 2238 
Psychologie et Physiologie Nationales

LES FRANÇAIS VUS PAR ANDRÉ SIEGFRIED

OU PAR SIEBURG?

$\underline{\text { Retour à la table des matières }}$

Chez un même éditeur, à peu près en même temps, deux livres ont paru - deux livres sur la France et les Français d'aujourd'hui, leur caractère et la place qu'occupe ou devrait occuper leur pays dans le monde. L'un d'un Allemand: Dieu est-il français? se demande Friedrich Sieburg ${ }^{128}$. L'autre, d'un Français, l'observateur plein de talent des États-Unis d'aujourd'hui et de la Crise britannique, André Siegfried : il a composé, lui, un Tableau des partis en France ${ }^{129}$ qui tient plus encore que le titre ne promet...

A brosser ce tableau, nul n'était mieux préparé. Fils d'un père qui sut marquer sa place et jouer son rôle dans la politique, il a personnellement «toujours vécu dans l'atmosphère parlementaire ». Jeune, tenté d'entrer lui aussi à la Chambre, il a pendant quelques années joué le jeu : ses réflexions sont au départ d'un livre plein de substance, le Tableau politique de la France de l'Ouest sous la Troisième République ${ }^{130}$, qui a fondé chez nous les études de psychologie politique à base géographique. - Mais, depuis 1914, A. Siegfried a couru le monde. Ou plutôt, il a visité, attentif et clairvoyant, l'Australie, le Canada, les États-Unis, l'Angleterre. Ayant

128 Paris, Grasset, 1930 ; 370 pages in-16 (accompagné d'une lettre de Bernard Grasset à Fr. Sieburg).

129 Paris, Grasset, 1930 ; 248 pages in-16.

130 Paris, Armand Colin, 1913 ; XXVIII-536 pages in- $8^{\circ}$, 102 cartes et croquis, 1 carte hors texte. 
vu devant lui vivre ces sociétés «basées sur la coopération », il est revenu dans notre pays "d'individualisme doctrinaire ». Qu'il en ait mieux senti l'originalité, quoi d'étonnant? Et voici, dégagée par ses soins, une image claire et vive de ${ }_{\text {p239 }}$ la démocratie à la française. N'entrons pas dans le détail: il faut lire, si on ne l'a déjà fait, le volume en entier. Mettons seulement l'accent sur les thèmes principaux.

Il y a, dans le livre d'André Siegfried, d'abondantes pages d'analyse, vivantes, instructives à souhait. Et quelques pages, sobres, de considérations pour orienter l'ouvrage. La France, économiquement parlant, n'est pas «contemporaine » des pays qui, aujourd'hui, donnent le ton : voilà le fait initial, le point de départ. La France est à la fois beaucoup plus ancienne - et beaucoup moins avancée qu'eux dans les voies de ce qu'on pourrait nommer la civilisation industrielle. D'où le problème : Changera-t-elle ? Tenterat-elle d'adapter au goût du jour ses modes de production et ses manières de vivre? ou bien restera-t-elle ce qu'elle est, traditionnellement, dans un monde qui adopte l'éthique la plus opposée à la sienne : masse et série remplaçant la qualité ; l'équipe se substituant à l'individu?

Or, reportons-nous au livre de Sieburg. Livre double : d'une part, des descriptions très fines de la France et des Français ; des croquis alertes d'homme qui sait voir ; des réflexions vives, parfois profondes, de moraliste qui ne regarde pas seulement, mais observe. D'autre part, des oppositions d'idées, un peu massives à notre gré, et pas toujours claires : voici, face à face, l'idée allemande de culture, l'idée française de civilisation; voici l'idée française de progrès et, l'affrontant, l'idée allemande qui lui ressemble dans les dictionnaires, mais seulement, nous dit-on, dans les dictionnaires... Qu'il faille analyser de semblables concepts, d'accord, mille fois. Mais la tâche exige plus que des dons naturels d'observation, plus qu'un incontestable talent de présentation: de longues études, historiques et philosophiques, fondées sur de patientes monographies ${ }^{131}$ — tout ce dont témoigne un

131 Celle, par exemple, toute récente, de Joachim MoRAS, Ursprung und Entwicklung des Begriffs der Zivilisation in Frankreich (1756-1830), Hamburg, Seminar für romanische Sprachen und Kultur, 1930 ; in- $8^{\circ}$, XVI-88 pages - et 
savant réputé pour son intelligence des choses françaises, le professeur Curtius, d'Heidelberg, dans un gros livre qui ne nous est point parvenu - puis dans une excellente conférence sur L'idée de civilisation dans la conscience française : on en goûtera la conclusion nuancée : «Il ne s'agit pas de faire comme s'il n'y avait entre l'idée allemande de culture et l'idée française de civilisation aucune différence véritable. Il s'agit de ne plus s'imaginer $\mathrm{p}_{240}$ que ce sont deux puissances hostiles, condamnées à une guerre sans relâche et sans merci. ${ }^{132}$ »

Laissons cela - sur quoi précisément ont porté maints débats : une lettre de l'éditeur Grasset à l'auteur en témoigne, un peu enveloppée au début et comme entortillée dans ses gentillesses; mais elle se ramasse à la fin, se resserre, prend et donne de l'accent... Ouvrons simplement Dieu est-il français ? à la page 100: «Il faut que la France sacrifie sa conception de la civilisation si elle veut vivre. Il faut qu'elle veuille vivre. Elle n'a pas le droit de mourir. » Tout le livre de Fr. Sieburg, tout son esprit en une phrase. Des conseils impérieux et donnés de haut : sa voix ne tombe-t-elle pas du sommet d'une pyramide autrement importante que celle de Khéops: l'économie allemande, entassée sur l'économie britannique et l'économie américaine ; en voilà, j'imagine, les modestes assises ? En même temps, une sollicitude réelle, un peu condescendante, pour la pauvre, puérile, assez risible France... Mais écoutons A. Siegfried, à la dernière page de son livre: "Quel sera demain le choix de l'humanité ? Si elle entend s'équiper, organiser son confort, élever son standard of living, sa réponse est claire, elle dira : Hoover! — Par contre, s'il est de nouveau question de l'individu, de ses droits et de la liberté imprescriptible de son jaillissement, alors, ne nous y trompons pas : l'idéologie française, dont le dynamisme est intact, retrouvera

dont l'auteur a pu utiliser mon propre travail : Civilisation, évolution d'un mot et d'un groupe d'idées, publié avec divers autres mémoires de MAUSS, A. Niceforo, E. TONnelat, L. WeBer dans Civilisation. Le mot et l'idée (Publication du Centre International de Synthèse), Paris, La Renaissance du Livre, $1930 ; 144$ pages in-16.

132 E. R. CURTIUs et A. BergstÄSSER, Frankreich, Berlin, 1930, 2 vol., t. I ; E. R. CURTIUS, Die französische Kultur, eine Einführung. — La conférence de M. Curtius a été traduite et publiée par les soins de la Dotation Carnegie, Paris, 1929, 64 pages in-16. 
toute sa puissance... » Le problème est bien le même qu'agitent l'Allemand et le Français. L'esprit, la conclusion? Ne soulignons rien.

Détournons-nous de ces grandes vues d'avenir. Tenons-nous sur les coteaux modérés de l'analyse sociale. Que nous disent les deux voyageurs qui pèlerinent pour nous à travers la France ? Sensiblement les mêmes choses. Plus d'apprêt, de recherche littéraire, de gentillesse voulues chez Fr. Sieburg. Parfois mais rarement, le piment d'une fausse note : l'auteur de Dieu est-il Français ? n'abuse pas... - Chez A. Siegfried, une parfaite justesse de ton, une constante modération de jugement. Ce que peuvent, ce que doivent dissiper, à l'étranger, d'erreurs d'appréciation et de malentendus ces pages lucides, voilà qui est proprement incalculable. Sur la persistance du « sens paysan »dans p241 la société française; sur l'idéal du Français de condition moyenne : petite maison, petit commerce, petite retraite ; sur l'artisan, cette quintessence de «l'homme du peuple » : le menuisier de village, le mécano de petite ville (j'ajouterais le maréchal-ferrant, cette Providence omnisciente); sur le vigneron aussi et l'horticulteur, ces artisans du sécateur; sur le goût «d'autonomie » du Français et les erreurs qui en procèdent (illusion qu'on peut toujours, en 1931, « être riche seul ») — sur vingt autres sujets, des remarques excellentes, qui toutes séduisent et donnent à penser.

Il est curieux de voir comment Sieburg fait écho à A. Siegfried. Les mêmes observations, bien souvent - mais colorées autrement, par un vif sentiment, toujours présent, de la nature allemande : ses notations, dès lors, sont à base de contraste. « Non pas la forêt, dira-til, mais le jardin. » Et l'on songe à ce qu'il écrit plus haut du Français «qui a toujours redouté un glissement vers la matière brute, là où s'ouvre l'infini ». D'où peut-être sa médiocre musicalité, « la musique reliant l'homme à cet univers primitif auquel le Français s'enorgueillit, précisément, d'avoir échappé...». - Que, par contre, ce soit A. Siegfried qui insiste sur l'importance capitale de ce grand principe de discrimination entre Français : l'acceptation ou le refus de la Révolution; que ce soit lui qui explique, avec une rare lucidité, comment l'Église «a beau déborder de beaucoup les aristocraties de 
naissance et de fortune, compter parmi ses dirigeants plus d'hommes du peuple que d'hommes du monde $»$ : cependant, du consentement unanime des hommes de gauche, elle demeure rejetée à droite, maintenue à droite, - que ce soit un Français seul ${ }^{133}$, et remarquablement clairvoyant, qui pénètre au cœur d'un problème si complexe, qui s'en étonnerait ? Fr. Sieburg, ce qui le frappe fortement en sa qualité d'Allemand, ce qu'il met en lumière avec un rare bonheur d'expression — c'est le fait « qu'être Français, ce n'est pas appartenir à une race ", mais acquérir une foi : la foi en la France, cette communauté fondée non sur le sang, mais sur l'esprit. Tellement qu'aujourd'hui « nombre de Nègres, d'Arabes, d'Indochinois sont des Français authentiques - qui se sentent ${ }_{\mathrm{p} 242}$ caution de l'idée française de civilisation ». Tellement encore qu'en France point d'hostilité contre l'étranger, sauf peut-être s'il apporte son pays avec lui et le remporte tel quel, en fin de séjour... Ainsi se complètent, se renforcent, se contrôlent l'une par l'autre remarques et réflexions.

Une grosse infériorité toutefois, d'ailleurs fort naturelle, du côté de l'observateur du dehors. Sieburg connaît Paris. Il en parle excellemment, à vingt reprises. La province, comment ne l'ignoreraitil pas ? Or, c'est elle qui joue, à bon droit, le premier rôle dans le livre de Siegfried ${ }^{134}$. Et que, sur tout ce qu'il en dit, nous soyons presque toujours d'accord avec lui - voilà proprement qui tient du prodige. Car nous n'avons pas, Français du Nord, de l'Est, du Centre ou du Midi les mêmes expériences, ni les mêmes réalités sous nos yeux...

133 Non que Fr. Sieburg néglige les questions religieuses. Il y a des remarques utiles sur la nécessité périodique où Rome s'est trouvée de «rappeler, de temps à autre, à la France que le rocher de Pierre n'était situé que sur le bord du Tibre ». Peut-être A. Siegfried aurait-il pu insister davantage sur cet aspect de la question. Isolement de la France : il y a les motifs qu'il indique; il y a ce fait aussi que la France n'a visiblement pas les faveurs du Vatican; que son catholicisme volontiers fait cavalier seul en Europe ; mais elle n'est pas davantage dans le grand courant de la sensibilité protestante; et de la Suède luthérienne à cette Amérique que connaît si bien A. Siegfried, on ne se prive guère de le lui montrer. Sur un autre aspect du problème que pose A. Siegfried, voir plus loin, en note, une remarque de Péguy.

134 Sur la perte d'influence politique de Paris, depuis 1889 et le Boulangisme sur la naissance d'une politique parisienne de grand intérêt régional, excellentes remarques d'A. Siegfried (p. 193-194). 
S'il fallait, je ne dis pas discuter, mais échanger des impressions, je me demanderais peut-être, à la lueur de ce que j'entrevois dans l'Est, si la revue fine et nuancée que passe A. Siegfried des cadres ruraux de la « gauche ", ne répond pas plus pleinement déjà à un passé encore vivant qu'à un avenir qui s'annonce ? Parfait, le dénombrement des puissances autour desquelles gravitent toujours « les clientèles ». Mais au prêtre, au noble, au grand bourgeois, je serais tenté d'ajouter certain type d'agriculteur, mieux, d'éleveur, gros trusteur de laitage, fabricant avisé de beurre et de fromage, oracle des Comices agricoles ; bien souvent, juché déjà sur le premier échelon du cursus honorum politique - conseiller général de son canton, et voyant dans ses rêves, pour plus tard, qui sait? un fauteuil quiet au Luxembourg... Type de l'Est peut-être, d'un pays de petite et moyenne propriété, cet homme " pas fier» avec les paysans, vivant au milieu d'eux et non pas à la ville, recommandable à leurs yeux parce qu'il travaille à hausser, ou du moins à maintenir les prix...

Autre remarque : l'instituteur, le facteur, piliers du régime ? Oui, au temps des «fondateurs", comme disait Péguy, analyste clairvoyant des réalités paysannes ${ }^{135}$. En ce temps-là, certes, il ${ }_{\mathrm{p} 243}$ y avait «dans chaque commune française le parti de l'instituteur qui veut affranchir le peuple et, derrière le curé, le noble ou le riche bourgeois, celui de la hiérarchie "; mais je mets à l'imparfait ce qu'A. Siegfried met encore au présent. Car je ne suis pas si sûr qu'aujourd'hui, partout, l'instituteur demeure en parfaite communion avec les cultivateurs. Parce qu'il est communiste ? Quelquefois, et il y a un communisme paysan qui n'a rien de commun avec le communisme «Côte d'Azur » dont parle A. Siegfried. Mais la vraie raison, je crois, c'est que l'instituteur est pris dans un grand engrenage : celui du

135 2. Je songe aux très belles pages qui ouvrent le Cahier intitulé L'Argent (Cahiers de la quinzaine, $\mathrm{XIV}^{\mathrm{e}}$ série, $6^{\mathrm{e}}$ cahier, p. 9-21 et 30-51). Cf. le passage de la page 38: "Nous ne croyons plus un mot de ce que nous enseignaient nos maîtres laïques. Nous sommes intégralement nourris de ce que nous enseignaient les curés... Or, nos maîtres laïques ont gardé tout notre cœur et ils ont notre entière confiance. Et malheureusement, nous ne pouvons pas dire que nos vieux curés aient absolument tout notre cœur ou qu'ils aient jamais eu notre confiance... Ne nous le dissimulons pas, c'est le problème même de la déchristianisation de la France... » Politique à part, le passage est à rapprocher de celui que nous notons plus haut, dans le livre de Siegfried, sur le paradoxe d'une Église qui peut être parfois « à gauche » socialement, mais demeure « à droite» politiquement. 
syndicalisme administratif. Mouvement urbain dans son principe, et nullement rural. Mouvement peu goûté du paysan qui, volontiers, jalouse la situation qu'ont obtenue dans ces dernières années les «maitres d'école », surtout lorsqu'ils ont épousé des institutrices. Pour expliquer le recul, depuis la guerre, du vieux radicalisme anticlérical dans certaines régions, il faudrait, je crois, songer à ce détachement relatif des cultivateurs pour le maître d'école — ou du maître d'école pour les cultivateurs. Les changements se font vite et l'anticléricalisme paysan n'est peut-être plus partout, exactement, ce qu'il était avant 1914.

Nuances, et qui confirment une fois de plus ceci : qu'il n'y a pas « la province », mais « des provinces » en France. On trouve « tant de variété dans la géographie de la France », notait un jour Vidal de la Blache. Et il ajoutait: "L'aptitude à la vie moderne, par toutes les qualités qu'elle met en jeu, est au premier chef une question de psychologie... »p244 


\title{
REGARDS CHEZ LE VOISIN OU FRÈRES QUI S'IGNORENT
}

\author{
LES HISTORIENS DE LA LITTÉRATURE
}

L'HOMME, LA LÉGENDE ET L'đEUVRE

Sur Rabelais : Ignorances Fondamentales

$\underline{\text { Retour à la table des matières }}$

Donc, par les soins de Jean Plattard, professeur à l'Université de Poitiers, nous voici en possession d'une biographie de Rabelais ${ }^{136}$ dont le moins qu'on puisse dire est qu'elle vient à son heure. On sait comment, sous l'impulsion de la Société des Études Rabelaisiennes et de son fondateur, Abel Lefranc, un énorme travail s'est accompli au cours des trente dernières années pour éclairer dans la mesure du possible l'obscure histoire de la vie, de l'œuvre, de la pensée de François Rabelais. Ce labeur a porté des fruits. Nous voyons plus clair dans la vie de l'homme et moins trouble dans son œuvre touffue. Nous, je veux dire ceux qui, au jour le jour, ont le loisir, ou le devoir, de suivre le travail des fouilleurs. Au grand public qui n'en a pas le moyen, il fallait un livre pour résumer, d'ensemble, les résultats

136 La vie de François Rabelais, Paris et Bruxelles, Éditions Van Oest, 1928, VIII266 pages in- $4^{\circ}$, LXIV planches hors texte. 
acquis. Plattard était particulièrement qualifié pour l'écrire. Dès 1910, il publiait sur L'œuvre de Rabelais, au sens littéraire du mot (sources, invention et composition), une thèse qui témoignait d'une solide connaissance des lettres françaises du XVI ${ }^{e}$ siècle. Depuis, il n'a cessé de participer aux recherches rabelaisiennes; nombres d'articles en témoignent et quelques études plus étendues, sur L'adolescence de Rabelais en Poitou notamment, sans compter une édition du texte même de Rabelais ${ }^{137}$. Un éditeur actif, G. Van Oest, s'est rencontré pour habiller presque luxueusement La vie de François Rabelais de Jean Plattard. Il l'a ornée de belles planches en héliogravure, qui complètent le dossier graphique réuni naguère par Arthur Heulhard dans son très vivant ${ }_{\text {p247 }}$ Rabelais. Réjouissons-nous de tenir ainsi ce qui nous manquait : un tableau complet, et non plus une esquisse, de l'existence mouvementée du père de Panurge.

A première vue, un tel tableau n'était pas très difficile à composer. N'avait-on pas sous la main les dix volumes de la Revue des Études Rabelaisiennes, les quinze volumes de la Revue du XVI Siècle, les deux préfaces pleines de vie et de passion composées par Lefranc pour le Gargantua et le Pantagruel de la grande édition Champion des Euvres de Rabelais? Il suffisait d'être prudent, de savoir lire et composer: le livre serait fait. Seulement, d'une vie de Rabelais beaucoup attendent plus, et mieux. Les historiens notamment. Michelet, dans un chapitre de son Histoire de France ${ }^{138}$ — étonnant, parce que, n'ayant à sa disposition que des faits erronés et des légendes controuvées, le grand visionnaire, soutenu par sa puissance de compréhension et guidé par sa sympathie, a su nous fournir cependant de Rabelais un croquis d'une parfaite justesse et d'un bel accent, — Michelet s'écriait : «Plût au ciel qu'on pût faire une vie de Rabelais ${ }^{139}$ ! » C'est que, les livres de ce singulier personnage étant «empreints du temps» à un rare degré, écrire la vie de l'auteur, c'était au gré d'un Michelet retracer, d'ensemble, la courbe du siècle

137 Euvres complètes de Rabelais. Paris, Éditions Roches, 1929, 5 vol. in-8 (Les Textes français, publiés sous la direction de l'Association Guillaume Budé).

138 La Renaissance, chap. XIX.

139 Il ajoute aussitôt : « Cela est impossible. » 
«héroïque »: une courbe que Rabelais, dans son œuvre, épouse étroitement.

Or, de la première partie de sa tâche, Jean Plattard s'est acquitté avec soin, exactitude et mesure. Rien de compliqué dans son plan. L'ordre chronologique: naissance, éducation, moinage. Puis les années de Poitou, au service de Geoffroy d'Estissac. Les errances ensuite et leurs incertitudes: Bordeaux ? Toulouse ? Bourges? Orléans ? Paris ? Mieux connues, les années de Montpellier, de Lyon, d'Italie: Rome et le séjour en Piémont auprès de Guillaume du Bellay. Le Tiers et le Quart Livre enfin, et la disparition dans l'obscurité.

Sur la naissance, l'origine, la jeunesse de Rabelais, rien d'imprévu. Ce sont les thèses d'Abel Lefranc qui nous sont présentées. François est fils d'Antoine, avocat au siège royal de Chinon, légiste aisé et qui, à une lieue de la ville où il exerce son industrie juridique, possède cette métairie, la Devinière, dont parle souvent Rabelais. Il y serait né, aux termes d'une tradition plausible. p248 Quand? J. Plattard, comme Abel Lefranc, comme H. Clouzot dans sa Chronologie rabelaisienne, dit: en 1494. Tout cela n'est pas démontré, mais s'avère probable. Après quoi, un trou noir. Enfance, rien. Études, rien. Relations de famille, rien. Entrée au couvent; vocation, contrainte ou démarche personnelle, rien. Jean Plattard penche pour la seconde hypothèse et voit Rabelais «que ses goûts orientaient vers le travail intellectuel, cherchant un asile dans la paix du cloître franciscain ${ }^{140} »$. Je n'en suis pas si sûr, Les "cloîtres franciscains » n'étaient pas spécialement voués au « travail intellectuel». Surtout, le passage amer et violent sur les vocations contraintes me poursuit. Et aussi, un petit fait, qu'on n'a peut-être pas suffisamment noté. Futur franciscain, Rabelais a reçu au baptême le nom de François. Il aurait eu comme sœur une Françoise. Dévotion particulière au saint d'Assise ? Peut-être même, vœu du père ou de la mère ? Pure hypothèse, je me hâte de le dire. Gardons-nous de vouloir combler avec des conjectures un trou plein de mystère. Et si impressionnant que J. Plattard, tout prudent qu'il soit, cède parfois au désir de le combler avec des "peut-être ». Sans doute, Rabelais

${ }^{140}$ Plattard, ouvr. cité, p. 14. 
jeune a pu visiter Angers. Mais ne croyons pas que « la famille de sa mère, les Frapin, y résidaient ${ }^{141} »$. La mère de Rabelais, s'il est fils d'Antoine, est une Dusoul. C'est sa grand-mère, née Pavin, qui s'est, après le décès de son mari, un Rabelais, remariée, avec un Frapin ${ }^{142}$. Et ces Frapin, à proprement parler, n'étaient rien à Rabelais. - De même, « il a pu » entrer tout d'abord au couvent franciscain de la Baumette, près d'Angers, à qui s'intéressaient les du Bellay ${ }^{143}$. " Il a pu» suivre là «le cours d'études indispensable pour devenir un clerc ». «Il a pu», ou comme écrit l'auteur, « il n'y avait pas de raison pour qu'il n'entrât pas (ensuite) dans l'ordre de ces Cordeliers de qui il avait reçu ses premières leçons à la Baumette ${ }^{144} »$. Pardon! de qui on peut supposer qu'il avait reçu... Mais on peut aussi supposer le contraire. Comme il faut se défier, scrupuleusement, de ces passages si glissants et si naturels de l'hypothèse à la certitude ! p249

En somme, disons-le nettement: de la vie de François Rabelais, depuis sa naissance (à une date incertaine dans un lieu approximativement connu, et de parents à rigoureusement parler hypothétiques) - jusqu'au 4 mars 1521, date de la lettre qu'un religieux de Fontenay-le-Comte en Bas-Poitou écrit, non sans émoi, à Guillaume Budé, père des lettres et parangon des érudits - nous ne savons rien, si savoir c'est connaître par documents authentiques, explicites et rigoureusement critiqués.

Or, la méthode qui consiste à conclure « des cercles dans lesquels Rabelais a vécu, des maîtres dont il s'est avoué » à Rabelais luimême, lorsqu'elle s'applique à des années totalement "noires » si

141 ID., ibid., p. 7.

${ }^{142}$ Cf. le tableau généalogique dressé par Grimaud, Revue des Études Rabelaisiennes, IV, 1906, 228. Noter que dans l'ancien Prologue du Quart Livre, Rabelais ne parle pas d'un sien oncle, seigneur de Saint-Georges, nommé Frapin, mais «d'un vieux oncle » de ce nom, ce qui est tout différent. Notons encore que, s'il faut voir dans le passage du Tiers Livre sur les secondes noces de Varennes (III, VI) que les prescheurs détestent « comme folles et deshonestes » une allusion au remariage d'Andrée Pavin avec un Frapin, il n'y aurait alors pas lieu d'insister trop sur l'intimité de Rabelais avec les Frapin ?

143 PlatTARD, ouvr. cité, p. 8. Leurs armes brillent encore sur les verrières de la chapelle.

${ }^{144}$ ID., ibid., p. 15. 
l'on peut dire, ne saurait pas ne pas être dangereuse parfois et décevante : je pense aux pages dans lesquelles J. Plattard se demande du jeune François s'il fut « un bon escholier bien peigné » à la mode d'Epistémon, ou « un gars timide et gauche » à la façon de Janotus ${ }^{145}$. Mais dès qu'on atteint un terrain plus ferme, elle devient réellement intéressante. On le voit dans les chapitres très pleins que l'auteur, reprenant les indications de son petit livre sur l'adolescence de maître François, consacre à nous camper un « Rabelais poitevin » réellement vivant, plausible et quelque chose de plus encore. Là, la connaissance des milieux vient à point pour permettre de relier les unes aux autres les quelques données certaines que nous fournissent les textes. Elle éclaire vingt passages obscurs de l'œuvre rabelaisienne. Elle encadre ingénieusement les activités multiples du moine qui finit, comme on sait, par passer d'une maison franciscaine à une maison bénédictine, grâce sans doute à la protection de son ordinaire, l'évêque de Maillezais, Geoffroy d'Estissac, dont il devint le secrétaire et qui peut-être le chargea d'instruire son neveu Louis : il eut, semble-t-il, son cabinet d'étude à Ligugé ${ }^{146}$, prieuré bénédictin à deux petites lieues au Sud de Poitiers ; le Ligugé, singulière rencontre, où J.-K. Huysmans, quatre siècles plus tard, sera oblat. Mais Huysmans n'était ni Poitevin, ni Tourangeau...

Seulement, quels que soient les services qu'elle nous rende, cette méthode d'explication par les milieux ne va pas très loin. Ou, plus exactement, n'atteint pas l'essentiel. Au fond, nous parvenons aujourd'hui à reconstituer très suffisamment le décor des diverses

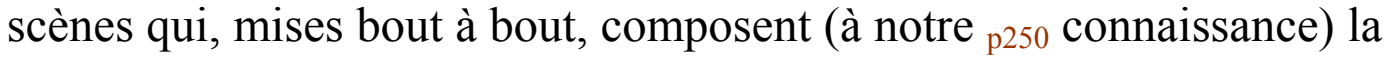
vie externe de Rabelais. Pour un biographe un peu adroit, c'est un jeu, dès lors, suivant son héros de ville en ville, de pays en pays, que d'écrire un gros livre instructif et qui n'ennuie pas: une sorte de tournée circulaire à travers les cercles lettrés de l'Europe humaniste, de 1520 à 1550. Seulement, restent deux choses. Deux petites choses : l'homme et l'œuvre. Deux choses qu'après comme avant nous voyons

145 PlatTARD, ouvr. cité, p. 8.

146 On sait qu'il date une aimable épître adressée à son ami Jean Bouchet le Rhétoriqueur : 
mal. L'homme qu'était vraiment François Rabelais ou, si l'on veut, l'homme qu'il semblait être à ses contemporains, amis, ennemis aussi, s'ils étaient intelligents et clairvoyants. L'homme qu'était ce quasimiraculeux écrivain, jailli brusquement d'un néant, en 1532, pour nous donner le premier de ces quatre romans, de ces quatre images surprenantes d'un siècle que sont Pantagruel, Gargantua, le Tiers et le Quart Livre: laissons de côté le litigieux Cinquième. Parties successives et distinctes d'une grande œuvre. Or, cette œuvre, nous la connaissons bien maintenant, du dehors. Nous la comprenons sinon dans tous, du moins dans presque tous ses détails. Mille obscurités de langue et d'expression, mille allusions plus obscures encore à des faits purement circonstanciels nous ont été expliquées par le labeur collectif, vraiment héroïque, d'une armée de chercheurs : parmi eux, cet infatigable lexicologue, L. Sainéan, qui, à deux gros volumes nous donnant l'inventaire systématique de La langue de Rabelais, a pu donner ce sous-titre mérité : Civilisation de la Renaissance ${ }^{147}$. Plus encore, et mieux, l'ardeur, la patience, le flair subtil d'Abel Lefranc lui ont permis de montrer comment, entre les choses et les lieux du pays chinonais - et des chapitres entiers du roman rabelaisien, s'étaient noués des liens multiples et amusants. Tout cela ingénieux, frappant parfois, piquant toujours. Mais le problème central - le seul qui compte, au fond, celui de la « création »-comment l'envisager ? comment même le poser?

$\mathrm{Au}$ fond, avouons-le, nous ne « voyons pas » Rabelais.

Voilà un gros livre, un beau livre de trois cents grandes pages qui porte au fronton le nom du Chinonais. Nous le fermons, après lecture diligente : nous ne voyons toujours pas Rabelais, ni avec les yeux du corps, ni avec ceux de l'esprit. Pas un portrait de maître François qui nous satisfasse ${ }^{148}$. Ou même qui ne nous satisfasse pas, mais qui soit authentiquement un portrait de ${ }_{\text {p251 }}$ Rabelais. Un pauvre diable de prosodiste latinisant, un chevalier sans gloire du dactyle et du

\footnotetext{
147 Paris, De Boccard, 1922, 2 vol. in- $8^{\circ}$.

148 Sur l'iconographie de Rabelais, cf. H. Clouzot dans J. BoulengER, Rabelais à travers les âges, Paris, Le Divan, 1925.
} 
spondée, Nicolas Bourbon, rencontre tout comme Érasme, Hans Holbein sur sa route. Et de cette triste figure à qui nous n'avons rien à demander, nous voilà munis d'une image saisissante. Rabelais ? Des peintures fantaisistes. L'image sans joie de la Chronologie Collée ${ }^{149}$. Rabelais, ce renfrogné, un peu chafouin? C'est possible. Mais alors, renonçons à tant de clichés périmés.

Les yeux de l'esprit? Quelle gageure ! Une manière de Tabarin avant la lettre, pique-assiette sans vergogne payant son écot en farces bruyantes, d'ailleurs se crevant de mangeaille, s'ivrognant à plein gosier et, le soir venu, écrivant des ordures... Ou bien, un docte, médecin, un savant humaniste nourrissant de beaux textes antiques et de curiosités ardentes sa prodigieuse mémoire, ignorante de toute saturation; plus encore, un grand philosophe célébré comme tel par un Théodore de Bèze, un Louis le Caron : bien mieux, le prince des philosophes :

In primis sane Rabelæsum, principem eundem. Supremum in studiis Diva tuis Sophia ${ }^{150}$.

De ces deux Rabelais, lequel choisir et adopter?

Nos arrière-grands-pères étaient plus heureux que nous. Ils ne choisissaient pas. Ils accueillaient l'une et l'autre image, la respectable et la triviale. Et sans difficulté, ils s'en accommodaient d'autant qu'ils ne les rapprochaient ni ne les comparaient. Lorsqu'ils rencontraient chez les Estissac ou chez les du Bellay, ou à AiguesMortes dans l'entourage du roi François, ce personnage bien en Cour et très docte, maître François Rabelais; lorsqu'ils se trouvaient en présence, là ou dans cent autres endroits honnêtes et prestigieux, d'un helléniste, d'un médecin, d'un poète vanté et glorifié tant en vers qu'en prose, en grec qu'en latin et même qu'en français par les plus

149 Gravée en 1601, d'après un modèle antérieur perdu, insérée par Léonard Gaultier entre les effigies des médecins Dubois (Sylvius) et Rondelet (Rondibilis) dans une grande planche qui réunit 144 portraits d'hommes illustres du XVI siècle français. Elle figure, réduite, sur la couverture des cahiers de la Revue du $X V I^{e}$ Siècle, et en tête de l'Introduction au Gargantua, d'Abel Lefranc.

150 Sur ce texte des Epigrammaton libri duo de Gilbert DUCHER D'AIGUERERSE (Lyon, Gryphe, 1538) cf. Abel LEFRANC, Revue des Études Rabelaisiennes, t. I, p. 202. 
grands lettrés et érudits du temps — de Guillaume Budé à Joachim du Bellay en passant par le jeune Théodore de Bèze ${ }^{151}$, par le bruyant Étienne ${ }_{\text {p252 }}$ Dolet et par vingt autres d'égal renom - ils ôtaient leur bonnet à deux mains, l'appelaient révérencieusement Messire le Docteur ${ }^{152}$ et guettaient sur les lèvres disertes l'apparition de belles sentences antiques. Quand ils lisaient ensuite, à leurs heures, Gargantua ou Pantagruel, ils étaient pris aussitôt, tout entiers. Pris comme des badauds sur le champ de foire par un bonisseur verveux. En ouvrant ces livrets d'ailleurs, qu'avaient-ils conscience de faire ? Une lecture "littéraire », si on peut user de cet anachronisme? Nullement. On les aurait bien stupéfiés en leur confiant qu'entre la geste gigantale et les lettres, les bonnes lettres, humaniores litterae, il existait un rapport quelconque. Le testament de Lucius Cuspidius, Romain de l'invention de Pomponio Leto, oui, évidemment oui. Les démêlés de Panurge avec Dindenaut, allons donc! Des « contes pour rire ».

Les hommes du XVI ${ }^{\mathrm{e}}$ siècle ne mêlaient pas les genres. Conviés à rire, ils riaient. Sans malice, à ventre déboutonné. Et sur le coup, ils concluaient de l'œuvre à l'homme. Ce conteur qui désopillait si heureusement leurs rates mélancoliques, ce conteur intarissable, quel joyeux luron sans doute? Ce chantre de la Dive Bouteille, quel prodigieux biberon? Notons qu'à passer ainsi du livre à l'auteur Rabelais invite lui-même ses lecteurs. Le narrateur ne se met-il pas en scène ? Ne dit-il pas perpétuellement «Je»? Ce n'est pas le

151 Le témoignage de Théodore de Bèze est fourni par le distique des Poemata de 1548 (Paris, Conrad Badius, petit in- $8^{\circ}$, p. 66, De Francisco Rabelaeso, supprimé dans les éditions ultérieures).

Qui sic nugatur, tractantem ut seria vincat,

Seria quum faciet, dic, rogo, quantus erit?

Quant à l'entretien philosophique dans lequel Louis le Caron (Charondas) fait intervenir Rabelais comme protagoniste avec Claude Cottereau et Monsieur l'Escorché (?) qui lui donnent la réplique, il constitue le troisième de ses Dialogues (Paris, 1556, in- $8^{\circ}$ ).

152 Voir le ton dont use l'évêque Guillaume Pellicier, lorsqu'il écrit à « messire le docteur Rabelais » ou qu'il le consulte avec grande révérence (Cf. J. ZELLER, La Diplomatie française d'après la correspondance de Guillaume Pellicier, ambassadeur à Venise, Paris, Hachette, 1881, et notamment p. 91, et n. 1). 
rapporteur impersonnel des hauts faits de Panurge. C'est le compère de la revue, le montreur de phénomènes : "Gens de bien! Dieu vous sauve et guard! Où estes-vous ? Je ne vous peux voir ? Attendez, que je chausses mes lunettes... Ha, ha, bien et beau s'en va Quaresme, je vous voy ${ }^{153}$ ! ... » - Et alors, quand ils font de Rabelais un ivrogne et un bouffon, ce n'est pas une méprise qu'ils commettent. Moins encore, un témoignage qu'ils versent au dossier de l'histoire. Le Rabelais auquel ils songent, c'est bien un ivrogne et un bouffon, puisqu'il incarne en lui toutes les beuveries, les gaudrioles et les facéties du roman rabelaisien. Le «vrai » Rabelais n'existe pas pour eux. Le seul Rabelais qui existe, c'est celui-là qu'ils créent, celui qu'ils se ${ }_{\text {p253 }}$ fabriquent pour eux, à la semblance du livre et de ses héros. Rabelais a engendré Gargantua, Pantagruel et Panurge. Genuit autem Gargantua, Gargantua en retour engendre un Rabelais à son image : le seul, le vrai pour ces lecteurs très peu blasés, ces grands enfants avides et naïfs, dépourvus d'ailleurs d'idées précises sur une question qu'ils ne se posaient pas, qui n'existait vraiment pas pour eux : celle de la création, de la genèse de l'œuvre littéraire. Même quand ils s'appelaient Ronsard, ou du Bellay. Le Ronsard de l'Epitafe de François Rabelais dans Le Bocage de 1554. Le du Bellay du Tombeau latin de Pamphagus, dans les Poemata ce $1558^{154}$.

153 Prologue du Quart Livre.

154 Rabelais meurt dans les derniers mois de 1553 ou dans les premiers de 1554. Aussitôt Ronsard de consacrer une épitaphe :

Au bon Rabelais qui boivait

Toujours, cependant qu'il vivoit

et de décrire en termes truculents le galant, couché entre les tasses : «Et parmi des escuelles grasses — sans nulle honte se touillant — alloit dans le vin barbouillant - comme une grenouille en la fange. - Description fort réaliste à notre gré. Mais n'oublions pas que, parlant de lui-même, Ronsard dans l'Odelette à Corydon des Meslanges de 1555 se montrait en pareille posture, couché « à la renverse »

Entre les pots et les jonchées.

Quant à du Bellay qui, ne donnant en exemple dans la Deffence et Illustration que trois écrivains français, compte parmi ces trois, avec Budé et Baïf « celui qui fait renaître Aristophane et feint si bien le nez de Lucian » — du Bellay qui, dans la seconde édition de L'Olive (1558), met «l'utile-doux Rabelais » au catalogue des grands poètes français, s'il publie en 1558 une épitaphe latine de l'Avale-tout, Pamphagus, accablé sous le poids d'un ventre sans limites et qui joignait à l'art de guérir celui de faire rire les humains, n'oublions pas non plus que si Pamphagus, c'est Rabelais - ce n'est pas cependant de Rabelais, mais de Pamphagus que du Bellay écrit les choses, assez plates du reste, qui composent 
De sorte que le grand, le fameux problème de la légende rabelaisienne, si souvent débattu naguère autour de ces textes si surprenants pour nous que nous allons imaginer, assez puérilement, des histoires de rancune privée pour les éclaircir, comme s'il s'agissait non pas d'images littéraires du Bon Biberon, décrit avec truculence, mais d'une fiche de police sur les mœurs intempérantes du dénommé Rabelais, François, profession de docteur en Médecine - et, j'ajoute, me réservant de la développer s'il le fallait, comme si tel autre grand gaillard de son temps, Marot, pour n'en citer qu'un seul, n'avait pas eu les honneurs lui aussi d'une légende toute semblable et d'analogue formation - ce problème n'est en définitive qu'un problème de psychologie collective. «Recomposer par la pensée, pour chacune des époques qu'il étudie, le matériel mental des hommes de cette époque »: je m'excuse de me citer moi-même, c'est le but que, récemment, p254 $\mathrm{j}$ 'assignais à l'histoire des sciences ${ }^{155}$. «Cesser de nous considérer comme un exemplaire partout valable de l'humaine condition; renoncer en conséquence à repenser et à reprendre à notre compte les états mentaux qui s'offrent à notre examen », tel est le programme que trace Charles Blondel aux pionniers de la psychologie collective ${ }^{156}$. Pénétrés de ces notions simples, évoquons alors devant nous les contemporains de François Rabelais, leurs violences et leurs caprices, leur peu de défense contre les impressions du dehors, l'extraordinaire mobilité de leur humeur, cette étonnante promptitude à s'irriter, à s'injurier, à tirer l'épée, puis à s'embrasser qui nous explique, même dans le monde des lettrés, des érudits, des poètes, tant de querelles pour rien, d'accusations atroces, de hurlements au vol et au plagiat, d'appels à la justice des hommes et de Dieu, - à quoi succèdent d'affreux coups d'encensoir et les plus folles comparaisons avec Homère, Pindare, Virgile et Horace. Produit naturel, je l'ai dit bien souvent, "d'une vie faite de contrastes »brutaux et bien plus marqués que nous ne l'imaginons : du jour et de la nuit, de l'hiver et

cette pièce. Et notons à nouveau que Rabelais helléniste et médecin, Rabelais versificateur dont les vers gisent au fond de la Loire : personnage digne de respect. Mais Rabelais auteur de contes en vulgaire, plus rien ne le protège. Il appartient à tous, corps et biens. On en peut dire librement ce qu'on veut.

155 Un chapitre de l'histoire de l'esprit humain, Revue de Synthèse Hist., t. XLIII, 1927.

156 Introduction à la psychologie collective, Paris, Colin, 1928. 
de l'été, de la chaleur et du froid glacial... Égalisation des conditions de vie, égalisation des humeurs: les deux se suivent, et se conditionnent. Mais pareillement nos nerfs se sont blasés. Nous avons trop mangé de fruits - nous ou nos parents - de ces fruits dont nous gardons, comme dit la Bible, les dents agacées. Eux ? ce n'étaient pas des blasés, Dieu non! Et par exemple, qu'ils étaient sans défense contre l'attaque violente et souveraine des sons. Je songe toujours à ce passage des Contes d'Eutrapel, où Noël du Fail nous décrit l'effet, sur ses contemporains, du chœur descriptif de Clément Jannequin, la Bataille de Marignan ${ }^{157}$. Personne qui échappât aux prises de cette musique à la fois puissante et puérile, avec ses «bruits de la bataille » en harmonie imitative ; personne qui «ne regardât si son épée tenoit à son fourreau, et ne se haussât sur ses orteils pour se rendre plus bragard et de la riche taille!» Croquis bien expressif des effets musculaires de la musique sur des simples se livrant sans se contrôler. Mais nous, nous refoulons. p255

Et derechef nous voici au rouet. Il faut choisir. Un Rabelais décent, lettré et respectable? Ou bien une trogne bavarde et gourmande. Un homme comme tous les hommes, sans type bien tranché ? Ou bien, pour emprunter son vocabulaire à la morphologie, un digestif rond et court : si l'on veut, le Balzac à table décrit par Léon Gozlan, tel que l'exhumait hier Pierre Abraham ${ }^{158}$, «superbe de pantagruélisme végétal, sa cravate ôtée, sa chemise ouverte, son couteau à fruits dans la main, riant, buvant, tranchant dans la pulpe d'une poire de Doyenné... »Et le nom attendu venant sous la plume : «Le franc Tourangeau remontait à la surface, continue Gozlan. Nous croyions voir Rabelais à la Manse de Thélème. Il se fendait de bonheur surtout à l'explosion d'un calembour bien stupide — inspiré par ses vins qui, pourtant, étaient délicieux...»

157 «Quand 1'on chantait la Chanson de guerre, faite par Jannequin devant ce grand François, pour la victoire qu'il avait eue sur les Suisses... » Sur la mort de $\mathrm{M}^{\text {lle }}$ de Limeuil, une des filles de la reine qui, sentant sa fin proche, fit venir son violon Julien, et lui dit « de jouer la Défaite des Suisses de son mieux, tant qu'il pourrait; et quand, il vint à Tout est perdu, elle le récita par deux fois et mourut ». (Cf. Brantôme, éd. Lalanne, t, IX, p. 416.)

158 Pierre ABraham, Balzac, Paris, Rieder [1929], p. 8 -9. 
Heureux Gozlan qui savait comme était fait Rabelais, et qui le voyait à l'abbaye de Thélème, comme un prototype de son Balzac aux épaules dansantes sous un menton réjoui ! De quel prix ne paierionsnous pas, nous, un croquis d'après nature de maître Alcofribas, tel qu'on pouvait le voir, en chair et en os aux environs de 1532, courant les boutiques des libraires lyonnais ? Ce croquis, nous ne l'aurons jamais. Alors, nous aussi, nous faisons comme les auteurs de sa légende. Nous tirons notre Rabelais de ses livres. Seulement, nous manifestons, comme toujours, un souci de logique que nos ancêtres dédaignaient fort. Nous voulons accorder aux témoignages flatteurs de ses amis sur le savant et digne docteur de Montpellier, les témoignages variables d'une œuvre touffue. Nous tranchons donc. Les bouffonneries, les truculences, les gros mots: nous baptisons « jeu littéraire, à la manière d'Ubu Roi », tout ce « charme de la canaille », - et nous passons vite. Mais les doctes propos, les homélies de Gargantua, les prônes moralisants de son fils : voilà notre lot. Et si seulement on savait de quel aspect physique revêtir un homme dont tant de statuaires intrépides ont dressé l'effigie sur nos places publiques, un Forain pourrait refaire, avec Rabelais comme centre, la caricature célèbre des deux Zola, celui du Rêve et celui de Nana: «Moi ? J'ai engendré le saint homme Pantagruel... Et c'est ce... pitrelà qui a fait Panurge ! »

Nous en sommes toujours là. Nos pères optaient pour l'ivrogne et l'insultaient avec truculence: qu'on songe à l'apostrophe comiquement grandiloquente de Lamartine, dans son Cours p256 de littérature $^{159}$. Nous optons, pour nous, le vieil universitaire rangé. Il y

159 Entretien XVIII, $§ 7 .$. « Rabelais, le génie ordurier du cynisme, le scandale de l'oreille, de l'esprit, du cœur, du goût, le champignon vénéneux et fétide né du fumier du cloître du moyen âge..., le pourceau des moines défroqués se délectant dans son bouge immonde et faisant rejaillir avec délices les éclaboussures de sa lie sur le visage, sur les mœurs et sur la langue de son siècle... » Le tendre élégiaque chausse ainsi les pantoufles du Philarète Charles de 1828 (concours de l'Académie française sur la poésie française au XVI ${ }^{\mathrm{e}}$ siècle), décrivant Rabelais « revêtu du froc, l'œil aviné, appuyé sur les faciles compagnes de ses plaisirs et suspendant à sa marotte la couronne des rois, le rabat du prêtre, le cordon du moine et l'écritoire des pédants !» Sur quoi le vertueux Philarète s'étonnait que «le bûcher qui dévora Servet se soit éteint pour cet homme qui, de toutes les 
a du pour et un peu de contre. Notons seulement, pour nous consoler de ne savoir être assis dans la certitude, que même si nous connaissions réellement Rabelais; si nous avions de lui des confessions, ou de ses contemporains des souvenirs, directs et détaillés, - il resterait toujours un autre gros problème, un autre formidable problème à traiter : celui de l'œuvre, et d'abord de son apparition.

Je ne veux pas empiéter sur un terrain qui n'est pas le mien. Mais enfin, de l'homme à l'œuvre, — du «commis voyageur légitimiste » et pansu, grand faiseur de mots salés, grand amateur de calembredaines et de contes « rabelaisiens », grand buveur aussi et gros mangeur que cent témoignages concordants nous décrivent sous le nom de Balzac, aux quatre-vingt dix-sept romans de la Comédie humaine et aux deux mille personnages dont ils abritent le grouillement forcené, quand on conclut (c'est Pierre Abraham qui nous le dit dans un petit livre très riche auquel déjà je me référais tout à l'heure), quand on conclut dans un sourire: "Voilà, ceci c'est l'œuvre, cela c'est l'homme ; ceci a été fait pour cela » — il y a là un passez, muscade, qui éveille les soupçons. Ou encore, "un hiatus qu'aucune bonne volonté ne comblera». Et je continue à transcrire ${ }^{160}:$ «On arrive à trouver des analogies occasionnelles; on arrive à noter des concordances ou plutôt des transports de faits de l'un à l'autre de ces deux domaines clos, oui ; mais guère plus, somme toute, qu'entre n'importe quelle existence humaine et les souvenirs qu'elle grave dans la mémoire. En a-t-on jamais vu, pourra-t-on jamais tirer une filiation de cause à effet ? »

Notons-le tout de suite : la tâche que se donne Pierre Abraham au sujet de Balzac, la recherche d'une cause commune dont la vie et l'œuvre seraient deux séries divergentes d'effets - cette tâche, comment l'accomplir jamais, s'agissant d'un homme dont on ignore à peu près tout, je veux dire tout ce qui, pour une ${ }^{257}$ semblable recherche, serait l'essentiel? Reste tout de même une question.

puissances du ciel et de la terre, ne respecta jamais que la Dive Bouteille ! » (Cf. FLeURY, Rabelais et ses œuvres, 1827, t. II, p. 548.] Nous n'écrivons tout de même plus autant d'insanités...

160 Ouvr. cité. 
Rabelais a écrit Pantagruel. C'est un fait. Mais précisément, quelle raison a mû ce docte médecin du Grand Hôtel-Dieu, cet humaniste révéré, cet helléniste nourri de Plutarque et dévot de Platon, le jour où il a commencé d'écrire, de la même plume et de la même encre qui venaient de transcrire une traduction latine des Aphorismes d'Hippocrate, cet humble livret promis à de si longues destinées : Les horribles et espoventables faictz et prouesses du très renommé Pantagruel, Roy des Dipsodes ? Silence inviolable des textes. Et que pèsent, en face, nos conjonctures? Mieux vaudrait peut-être n'en point former, et se borner à cerner d'un trait vigoureux la vaste plage de nos ignorances.

Cependant, sur l'apparition du Pantagruel, J. Plattard risque une hypothèse. "On peut, écrit-il (page 99) sans faire injure à Rabelais, supposer qu'il y chercha d'abord un profit pécuniaire. » Il n'y a point là d'injure. Mais c'est J. Plattard lui-même qui nous le rappelle, quelques pages plus loin : "La littérature au XVI siècle ne créait pas de revenus. Les éditeurs ou libraires en percevaient presque tout le profit, n'ayant généralement qu'à remettre une gratification à l'auteur au moment de la vente des livres. »Q Quoi qu'il en soit de cette gratification, et de sa réalité dans le cas d'Alcofribas Nasier, il n'est pas tout à fait exact de dire que la littérature, au XVI ${ }^{\mathrm{e}}$ siècle, n'était jamais une source de profit. La littérature savante en latin, voire en grec, procurait quelque argent. Non que les éditeurs se montrassent généreux avec leurs auteurs: telle n'est point la tradition. Mais on avait la ressource de dédier. Une épître latine, en belle prose cicéronienne, «payait », parce que son heureux destinataire, s'il avait été bien choisi (et les auteurs, d'habitude, savaient choisir), n'hésitait pas à reconnaître, en bonne espèces sonnantes et trébuchantes, l'honneur de voir son nom, dûment latinisé, s'étaler en capitales sur la première page d'un ouvrage érudit ${ }^{161}$. Si Rabelais avait voulu « faire

161 Le problème a été repris pour Érasme par M. HAYOUX, dans un intéressant article de la Bibliothèque d'Humanisme et Renaissance. Érasme ne touchait pas de pourcentage de l'auteur, mais il recevait un certain nombre d'exemplaires qu'il envoyait à des destinataires choisis, avec des dédicaces qui, ainsi multipliées, représentaient chacune, à notre sentiment, " une sorte de petite imposture ». En échange, il recevait des cadeaux, souvent considérables. 
de l'argent », n'aurait-il pas plutôt écrit en latin, et des œuvres d'humaniste?

Mais M. Plattard, pour sa part, ne renonce pas aisément à son hypothèse. Il la retrouve lorsqu'il s'agit d'expliquer l'apparition du Tiers Livre au début de 1546 : «Faulte d'argent (écrit-il p258 p. 172) fut sans doute le principal motif qui poussa le docteur en médecine à publier une suite à ses deux premiers livres de joyeuses folâtries. » Je répugne encore à cette explication. Non par désir puéril d'élever audessus des contingences un François Rabelais idéal, vivant de l'air du temps, et méprisant la pécune même quand il n'en a point dans ses «marsupies ». Je redoute l'anachronisme. Et puis, j'ai l'impression, en lisant ces passages-là (parce que j'en ai lu et noté d'autres), que J. Plattard a une certaine tendance à sous-estimer un peu son auteur. Au point qu'on se demande parfois si ce rabelaisant de marque goûte Rabelais vraiment ${ }^{162}$, profondément. Ne soyons pas dupes, c'est entendu. Mais Stendhal nous a dit, assez souvent, à quoi pouvait conduire précisément "la crainte d'être dupe ». Et s'il faut redouter comme le feu les transpositions d'idées et les anachronismes de sentiments, il n'en est pas moins vrai que toute création littéraire a ses raisons et ses lois - qu'elle s'explique, si l'on veut, par d'autres raisons que des raisons purement circonstancielles, extérieures et fortuites. Qu'on sente, presque à chaque page du roman rabelaisien, ce besoin qui est proprement celui du créateur de types littéraires: le besoin de se libérer soi-même, d'extérioriser sa pensée, de la faire vivre en dehors de soi - en vérité, comment le nierait-on ? Mais c'est de tels sentiments, précisément, qu'il faut interroger, si l'on veut poser le problème, le vrai problème de la naissance du Pantagruel, et puis du Gargantua - et puis, plus tard, des deux, ou des trois autres livres...

En tout cas, et pour revenir au domaine particulier de l'histoire, sachons résister à une tentation dangereuse. On a dit de Rabelais bien des sottises, c'est entendu. Des sottises injurieuses; de

162 Cf. p, 182 : «Si doctes que soient les propos du Tiers Livre, ils ne sont généralement ni secs, ni ennuyeux. » L’éloge peut paraître un peu mince? 
dithyrambiques non moins. On en a fait, nous le rappelions plus haut, un philosophe d'une insondable profondeur, un encyclopédiste ou plutôt toute une encyclopédie à lui tout seul, et miraculeuse ; le père des hommes et des siècles futurs, le fondateur de la pensée libre ${ }^{163}$, le précurseur de la Révolution, que sais-je? Sourions de ces enthousiasmes. Mais ne nous croyons p259 pas tenu, pour mieux les répudier, de rapetisser à l'excès la taille de ce créateur de géants.

Aux temps heureux d'avant-guerre, à la fin d'un de ces dîners que la Société des Études Rabelaisiennes dans sa fleur organisait chaque année, Anatole France, rabelaisant de marque, prononça l'éloge du Pantagruélisme ${ }^{164}$ — «vous entendez que c'est certaine gayeté d'esprit conficte en mespris des choses fortuites». "Rabelais, Montaigne, Voltaire, proclamait France, c'est la Bible moderne et le plus nouveau Testament. On y puise la foi la plus nécessaire à l'homme, la plus conforme à sa nature, la plus propre à le rendre heureux : le doute. » On voit le thème, on devine comment l'expert musicien sut l'orchestrer. Ce qu'il admirait surtout dans la philosophie pantagruélique, «c'est qu'elle est proportionnée à la faiblesse humaine, et qu'elle ne nous fait point tendre à la perfection, à la fâcheuse perfection. Elle craint tout excès, même l'excès de vertu, qui est, à vrai dire, un terrible excès... ». Dont maître François ne souffrait guère : « Rabelais n'était point un saint. La nature l'avait fait bien trop aimable pour cela. Il n'avait pas la vocation du martyre... » Tout cela, plein de finesse et de grâce tourangelle. Et c'est bien le Pantagruélisme. Le propre Pantagruélisme d'Anatole France. Mais est-ce Rabelais ? le vrai Rabelais ? ou du moins, tout Rabelais ? Je ne le crois pas, pour ma part. En maître François, je vois moins de scepticisme aristocratique, de prudence philosophique, de mépris intellectuel pour le commun des hommes et leurs idées. Si l'on veut, mon Rabelais ressemble un peu moins à $\mathrm{M}$. Bergeret ou à Jérôme Coignard, un peu plus à Frère Jean et au noble Pantagruel. Ou encore,

163 Voire l'une des lumières de la franc-maçonnerie ou le disciple des sages de l'Orient. Cf. E. LEVÊQue, Les mythes et les légendes de l'Inde et de la Perse dans Aristophane, Aristote, Virgile, Ovide, Tite-Live, Dante, Boccace, Arioste, Rabelais, Perrault, La Fontaine, Paris, 1880. On y apprend que « pour le fond et pour la forme, l'éducation de Gargantua est imitée de l'éducation de Bharata dans le Ramayana ».

164 Cf. Revue des Études Rabelaisiennes, X, 1912, p. 168-170. 
mon Rabelais est moins citoyen du monde des esprits, et plus citoyen de la France de son temps ${ }^{165}$. C'est par là précisément qu'il me semble digne d'intéresser l'histoire.

Ne l'oublions pas. Par ses origines, s'il est bien le fils d'un avocat de Chinon, Rabelais est un bourgeois. De bonne heure en tout cas, on le voit accueilli dans de doctes sociétés où l'élite d'une bourgeoisie studieuse peinait à dégager de ses lectures et de ses réflexions des idées nourries de prudence héréditaire et de réflexions antiques: rappelons-nous ces doctes entretiens de Fontenay, où, dans la compagnie du savant Tiraqueau, Rabelais recueillit sans doute les premiers éléments du futur Tiers-Livre. Plus tard, au cours d'une longue et diverse carrière, il ne fréquenta pas seulement p260 une bourgeoisie d'offices correcte, sédentaire et studieuse ; ni la demibourgeoisie intellectuelle, un peu en marge des érudits, poètes, docteurs, imprimeurs : c'est la bourgeoisie marchande également qu'il a hantée de près, celle des maîtres de métier au labeur de qui, son vocabulaire l'atteste, il s'est intéressé passionnément; celle des grands marchands naviguant sur la Loire, ou des armateurs lançant jusqu'au Canada d'une part, à Sumatra de l'autre, leurs nefs aventureuses : hommes de traditions, hommes de novations ; Rabelais les a connus, visités, étudiés. Et en définitive c'est pour eux qu'il a écrit.

Car enfin, on l'oublie trop aisément. Il n'a pas travaillé pour les lettrés de son temps : il aurait dans ce cas rédigé en latin. Il a écrit pour ceux qui ne latinisaient pas, ou guère; ceux que cherchait à atteindre Claude Nourry dit le Prince, libraire de livres à lire en bon français. Il a écrit pour traduire, dans une prose qui s'est trouvée magnifique, les sentiments profonds qu'il découvrait en eux, et qu'il leur révélait avec un éclat incomparable, gonflés et de sa substance à lui et de tout le miel antique butiné çà et là. Ce grand artiste, ce puissant esprit recevait du Tiraqueau. Il en faisait du Rabelais.

165 Et d'autres temps, ce qui restitue son sens au propos de Gambetta rapporté par Eug. ÉTIENNE (Revue des Études Rabelaisiennes, t. IV, p. 292) : “C'est avec Rabelais que je veux faire une bonne, saine et patriotique politique pour mon pays. » 
Et c'est un fait que, sur trois points d'importance vraiment capitale, les meilleures traductions que nous puissions trouver, historiens, des sentiments profonds des hommes de son pays, de son temps et de sa classe - ce sont les traductions de maître François. Qu'il s'agisse de la passion de connaître que traduit, de façon symbolique, la grande soif rabelaisienne. Ou de certains aspects des réactions qu'une catégorie de bourgeois français éprouve vis-à-vis des choses de la religion. Ou de ces aspirations de justice pacifique, de paix par la justice dans le droit, qui déjà étaient le propre de ces hommes, et qui le sont restés.

Voilà qui nous empêche de médiocriser, comme J. Plattard, peutêtre, ne s'y oppose pas avec trop de vigueur, la pensée et l'action de François Rabelais. Jaurès, un jour qu'il rencontrait devant lui ce grand problème: Pourquoi la France s'est-elle refusée à la Réforme? répondait hardiment (et il connaissait bien, et il aimait Rabelais) : Parce que déjà, quand elle est apparue, «des hommes comme Rabelais avaient entrevu toute la grandeur future de la Science

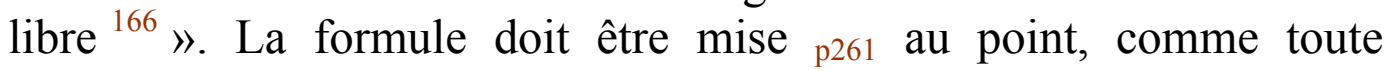
formule, c'est entendu. Historiquement parlant, comme elle rend un son plus juste que la phrase de cet érudit - je ne le nommerai pas qui, après nous avoir enseigné doctement ${ }^{167}$ : «Rabelais n'est pas original, ne se soucie pas de l'être... Les idées de son livre qui semblaient les plus nouvelles et les plus hardies ne sont pas, chez lui, le fruit de la réflexion personnelle; elles lui viennent pour la plupart des humanistes qui avaient écrit avant lui »- conclut : « Il est avant tout un splendide metteur en œuvre des lieux communs. » Eh non! si l'œuvre de Rabelais n'était qu'une cantate, même "splendide ", de distribution de prix, une Marseillaise impersonnelle et ronflante de Concours général, aux thèmes pris de toutes mains dans tous les Larousses humanistes de son temps - il y a des siècles qu'elle serait morte. Morte, elle n'est pas. Et si elle vit toujours — c'est qu'elle est,

166 Cf. Revue des Études Rabelaisiennes, t. III, p. 249, et pour le texte complet du discours, Journal Officiel, 22 avril 1905, p. 1640. A propos de la Séparation des Églises et de l'État.

167 Revue d'Histoire Littéraire de la France, 1904, p. 259. 
non pas « un assemblage inouï de matériaux disparates », comme dit encore notre homme - mais l'œuvre d'un incomparable créateur de types expressifs et vivants qui a cherché son centre de gravité - et qui l'a trouvé - sur notre terre, dans l'homme même. Humaniste par là, dans toute la dignité du terme. Et s'il fallait résumer en une phrase ce que signifie cette œuvre, toujours jeune et fraîche - je l'emprunterais, sans plus, à quelqu'un qui doit être indulgent aux emprunts, je veux dire à Panurge : "Je ne bâtis que pierres vives, proclame-t-il, ce sont hommes. » Rabelais non plus, symboliquement parlant, n'a rien bâti d'autre. Mais l'éloge n'est pas mince. p262 


\title{
Littérature et Vie Sociale
}

\section{DE LANSON A DANIEL MORNET UN RENONCEMENT ?}

\author{
Retour à la table des matières
}

Décidément, j'en ai peur: les historiens et les professeurs de littérature française ne parlent pas le même langage. Histoire de la littérature classique, 1600-1700; ses caractères véritables et ses aspects inconnus : Daniel Mornet, professeur à la Sorbonne, publie un gros livre sous ce titre attirant ${ }^{168}$. L'historien de se précipiter: caractères véritables, aspects inconnus : de quoi faire battre son cœur, en vérité. Le livre ouvert, il tombe par surcroît sur cette déclaration (p. 6) : «J'ai cru que le moment était venu de tenter ce que j'appellerai, une fois de plus, une histoire historique de notre époque classique. » Une histoire historique ! On lui aurait dit : "Une histoire purement littéraire » - il ne se serait pas senti chez lui, ce lourdaud d'historien. Il aurait pu craindre de se trouver gêné dans la société diserte de fins lettrés, passant leur vie au contact d'écrivains, excellents, médiocres ou pires - et qui précisément sont aptes à discerner, par définition, le bon du médiocre (même s'ils s'en défendent, comme d'une tare secrète) ; il aurait pu redouter que, se gaussant de sa rusticité, ces fins connaisseurs ne le renvoient, sans plus, aux écuries de l'histoire. Mais, précisément, on lui promet une «histoire historique»! Allons-y et sans scrupule ! Car enfin, quand il lit (p. 7) cette phrase en son genre assez mémorable - c'est, si j'ai bien compté, la deuxième phrase du chapitre premier : On n'a pas encore prouvé que, même en littérature, personne soit jamais indispensable - il est bien fondé à se dire, l'historien : «Cette fois, me voilà bien chez moi. A mon aise. Entre

${ }^{168}$ Paris, Armand Colin, 1940, 428 pages in- $8^{\circ}$. 
rats de bibliothèques et de fichiers. En manches de chemise, si l'on préfère... » Mais voilà, il lui faut bien vite déchanter. p263

Une « histoire historique », pour lui, cela veut dire ou voudrait dire l'histoire d'une littérature, à une époque donnée, dans ses rapports avec la vie sociale de cette époque. Et je n'ai pas besoin de dire qu'ainsi conçue une telle histoire présenterait, en effet, des « aspects inconnus ». Il faudrait, pour l'écrire, reconstituer le milieu, se demander qui écrivait, et pour qui ; qui lisait, et pour quoi ; il faudrait savoir quelle formation avaient reçu, au collège ou ailleurs, les écrivains - et quelle formation, pareillement leurs lecteurs; car enfin... ${ }^{169}$; il faudrait savoir quel succès obtenaient et ceux-ci et ceux-là, quelle était l'étendue de ce succès et sa profondeur; il faudrait mettre en liaison les changements d'habitude, de goût, d'écriture et de préoccupation des écrivains avec les vicissitudes de la politique, avec les transformations de la mentalité religieuse, avec les évolutions de la vie sociale, avec les changements de la mode artistique et du goût, etc. Il faudrait... Je ne continue pas.

Histoire historique... Mais voilà que rien de tout cela n'apparaît dans le gros livre de D. Mornet. Absolument rien. Ce n'est pas que son auteur ignore que de tels problèmes se posent. Il est l'élève de Gustave Lanson, qui tenta si vigoureusement de rapprocher l'histoire littéraire et l'histoire — de la rajeunir et de la renouveler en l'amenant à s'intéresser à cent problèmes proprement historiques. La tentative était vouée à l'insuccès, d'ailleurs. Car il eût fallu, pour qu'elle réussisse, constituer fortement un corps d'historiens formés aux méthodes et initiés aux curiosités de l'histoire proprement dite - de l'histoire sociale surtout : la plus délicate peut-être à écrire de toutes les histoires - puis cette formation générale acquise, orientés spécialement vers leur tâche particulière d'historiens des littératures. - Mais enfin, Lanson a posé les problèmes ${ }^{170}$. On le lui a

169 Car enfin, je lis, p. 370 : «Dans son ensemble, et malgré de nombreuses exceptions, la littérature classique tend vers l'universel. » Mais cette constatation ne pose-t-elle pas le problème de la culture des collèges, et en particulier des collèges de Jésuites?

170 Et parfois excellemment. Nous qui ne lui avons jamais rien dû, qui ne l'avons jamais eu pour maître n'hésitons pas à redire tout ce qu'avait d'intelligence dans l'esprit un homme qui, malheureusement, ne portait point aux questions 
suffisamment reproché, de divers côtés - on a suffisamment découvert, non sans scandale, qu'il voulait être, qu'il aspirait à être un historien et non pas un critique, pour qu'on lui laisse, pour que nous lui reconnaissions tout spécialement, nous autres historiens, le mérite qu'il eut à vouloir se faire l'un des nôtres - à ne plus p264 mettre devant ses yeux, et devant les nôtres, uniquement, quelques grands textes, quelques exemplaires uniques du génie humain, dus à des hommes qui furent eux-mêmes des exemplaires uniques de la race des grands créateurs - des "irremplaçables », hélas, j'écris le mot au risque de me faire bien mépriser par D. Mornet, émancipé de tant de préjugés. Porter son attention sur toutes les productions littéraires d'une époque, avec le souci de montrer en elles des manifestations, des expressions, des traductions valables de la société à cette époque - c'était bien le programme, c'était bien la chimère de Gustave Lanson.

La chimère - car encore une fois, la tentative supposait, pour qu'elle pût réussir, une révolution préalable de programmes pédagogiques. Et ces révolutions-là, en France, se sont toujours avérées de toutes les plus malaisées à mener à bien. En fait, Lanson conviait des hommes qui n'avaient pas commencé par s'inquiéter de savoir comment on démontait le mécanisme des sociétés; des hommes qui n'avaient point commencé par étudier longuement, minutieusement, mais d'ensemble, pendant des années, les origines, la structure, l'orientation, les moteurs essentiels et les ressorts cachés d'une de ces sociétés ${ }^{171}$ — Lanson conviait ces hommes, formés exclusivement à l'étude de la langue grecque, de la langue latine, de la langue française et à l'intelligence de textes littéraires grecs, latins et français - il les conviait à nous apporter, du jour au lendemain, à l'aide de matériaux et uniquement de matériaux littéraires, une

d'hommes l'attention qui convient. Un manifeste comme celui que reproduit le recueil d'Études d'histoire littéraire publié en 1930 en l'honneur de Lanson et qui s'intitule : Programme d'études sur l'histoire provinciale de la vie littéraire en France, ne peut que séduire et gagner sans réserve un historien.

171 sur certaines conséquences fâcheuses qui peuvent résulter d'un tel manque de préparation, même pour des hommes de parfaite bonne volonté et de réel talent je me permets de renvoyer le lecteur à mon article de la Revue de Synthèse (t. III, mars 1932, p. 39), consacré au livre très nourri et très sympathique de BOUCHARD, De l'humanisme à l'Encyclopédie ; l'esprit public en Bourgogne sous l'ancien régime (1930). 
contribution valable à la connaissance d'un milieu qu'ils n'avaient appris à connaître que de seconde ou de troisième main, dans des manuels simplistes. Ceci, alors qu'une société, c'est la combinaison, à des degrés divers, d'une multitude d'éléments hétérogènes : politiques les uns, économiques les autres, et religieux, artistiques, philosophiques, moraux, que sais-je? Un tout; un ensemble, une articulation prodigieusement compliquée...

Mais, dira-t-on, les historiens sont là pour ?... Non. N'y comptez pas. Certes, dans son travail journalier, l'histoire accumule les éléments triés, vérifiés, certifiés d'un bilan. Mais elle peut rester dix ans, vingt ans et plus sans dresser ce bilan. Pendant ce temps-là ?... En fait, l'historien est un homme qui sait, généralement, sur beaucoup de questions, bien plus de choses p265 qu'il n'en dit, qu'il n'en met en forme, qu'il n'en livre au public. Ces choses-là — sur quoi il s'entend à demi-mot avec trois ou quatre confrères qui possèdent les mêmes curiosités - le profane les ignore. Et l'historien de la littérature qui n'est qu'historien de la littérature, compte ici parmi le profane. Mais nous, historiens, nous allons de par le monde, caressant en nous une sorte de rêverie rétrospective, imprécise encore dans sa forme, mais nourrie de détails nettement écrits, fortement dessinés. Trésor particulier, qui donne à chacun de nous toutes sortes de facilités propres et d'aptitudes spéciales dans son domaine. L'historien de la littérature ne participe point à ce trésor-là.

Et la question est de savoir si, dès lors, il peut valablement accomplir une œuvre d'historien. Apporter, si l'on veut, une contribution de valeur à l'histoire générale et particulière des civilisations.

Or, quand on se trouve en présence d'un livre comme le livre récent de Daniel Mornet, on est bien forcé de se dire que la question paraît résolue. Par la négative. Car Daniel Mornet commence par dépouiller la mariée de tous ses atours. Les instruments dont elle se sert, je veux dire la langue du temps, sa syntaxe, son matériel de mots, son rythme ? Non, non : ceci, c'est de la technique. Enlevez! - La pensée qu'elle traduit, les sentiments qu'elle exprime, les passions qu'elle sert, ou qu'elle combat? Non, non. On verra plus tard! Je cite (p. 4) : «Des ouvrages comme la grande œuvre de l'abbé Henri 
Bremond, le livre de $\mathrm{H}$. Browen nous ont montré l'importance des courants mystiques ${ }^{172}$, ou de la curiosité pour les sciences (au XVIII ${ }^{\mathrm{e}}$ siècle). Mais on peut passer tout cela sous silence, sans déformer l'image que j'ai essayé de donner de la vie littéraire générale... » Alors, s'il en est bien ainsi, tant pis pour l'image de D. Mornet ! Et même la perspective de posséder « quelque jour », de sa propre main, une histoire de la pensée française au siècle de Descartes («J'espère écrire moi-même, quelque jour, une histoire de la pensée française au $\mathrm{XVII}^{\mathrm{e}}$ siècle », p. 3) - cette perspective ne nous console pas de la carence présente. Car, nous en avons peur (et il faut bien que nous en ayons peur), il s'agirait sans doute d'une histoire de la pensée désincarnée, comme toujours. Puisque, de l'aspect social de l'histoire littéraire, il n'est même pas question dans le présent livre — ni dans son corps, ni dans sa préface, ni ${ }_{\text {p266 }}$ pour en parler, ni même pour dire : «La question ne sera pas posée ! »-Alors ?

Alors, voilà bien clos l'épisode lansonien. Alors, nous revoilà plongés dans l'histoire littéraire pure : «On trouvera dans ce livre une histoire de la littérature, de l'art littéraire classique, et non pas une histoire générale de la pensée française à l'époque classique... J'ai cru qu'on pouvait séparer, sans inconvénient grave, ces deux histoires, à l'époque que j'étudie...» — Pauvre mariée, que te reste-t-il ? Pas même la " pensée ». Rien, que la peau sur les os.

Et ce n'est pas beaucoup. Et ce n'est pas, surtout, sauf erreur, matière à « histoire historique $» . .$.

Naturellement, et ceci n'a pas besoin d'être dit : écrivant son gros livre en 1940, D. Mornet a pu bien utiliser l'apport des nombreux travailleurs qui pendant des années, depuis près d'un demi-siècle, ont consacré leurs veilles à ressusciter, les uns après les autres, les vedettes et les comparses de l'art classique. A quoi lui-même a joint, comme de juste, son abondant apport personnel. Aussi, les vingt

${ }^{172}$ La grande œuvre d'Henri Bremond montre bien autre chose, en vérité, que « l'importance des courants mystiques ». Cf., sur son tome IX en particulier, $L a$ vie chrétienne sous l'ancien régime, mes remarques dans la Revue de Synthèse ( $\mathrm{t}$. III, 1932, p. 199 : La dévotion en France au XVII siècle). 
chapitres de son livre sont-ils pleins de précisions circonstanciées, de dates bien contrôlées, de noms d'écrivains et de titres d'ouvrages ${ }^{173}$. Un petit lot de peu connus, qui se révèlent à nous par quelques extraits souvent curieux; une familiarité certaine avec le petit monde de la plume, au grand siècle : j'entends bien. Mais tout ceci ne rend que plus saisissant ce que j'appellerai l'aveu muet, mais implicite, d'un découragement. Sinon d'un échec. Disons, d'un renoncement. En somme, si je comprends bien, l'idée de D. Mornet, c'est qu'il y a Rodin mais aussi Injalbert. Et qu'après tout, l'État a commandé, payé, installé en belle vue beaucoup plus de navets de celui-ci que de statues de celui-là. Et aussi que Rodin est mort, emportant dans sa tombe le secret de son art personnel - mais qu'Injalbert n'est pas mort, et qu'il y aura de beaux jours encore pour son académisme exsangue. Et finalement, qu'on ne voit pas pourquoi Injalbert, et ses émules, et ses continuateurs, n'auraient pas droit de cité dans une histoire de l'art français, tout autant, sinon plus, que Rodin, ou que Bourdelle, et leurs œuvres « dont le temps a fait des chefs-d'œuvre ». C'est une idée. C'est une façon de présenter les choses. Elle ne m'intéresse pas beaucoup, sous ${ }_{\mathrm{p} 267}$ cette forme. Car l'étude des Injalbert ne peut être que statistique. Elle ne saurait être esthétique. Elle pourrait peut-être se dire sociale : mais il y faudrait une grosse préparation.

Et, historien, je demeure perplexe devant ce qui nous est donné comme neuf, comme "véritable», comme « inconnu». Des études comme celles qu'au Collège de France a inaugurées Paul Valéry, titulaire d'une chaire de Poétique - entendons d'une chaire consacrée à l'étude du «faire », du poïein, dans le domaine de l'esprit, des œuvres de l'esprit? Fort bien. Ce sont des études difficiles ${ }^{174}$, qui ne sont point, et pour cause, à la portée de tous - mais elles ont un avenir devant elles. L'Encyclopédie française, pour sa part, a tenté d'en tracer le plus vaste cadre dans ses deux tomes XVI et XVII : Arts et littératures dans le monde contemporain. - Des études d'histoire sociale poursuivies avec l'aide de documents littéraires, et dans le domaine des littératures? Parfait. Ce sont également des études fort

${ }^{173}$ Cette abondance même rend plus regrettable l'absence d'Index dans l'ouvrage.

174 Cf. Paul VAlÉRY, Leçon d'ouverture du Cours de Poétique, Collège de France, 1938. 
difficiles, mais, j'en suis non moins assuré, de grand avenir, quand on les abordera après préparation. Et après tout, nous en avons déjà quelque échantillons? Entre ceci et cela, quoi ? La vieille histoire littéraire - celle qui nous renseigne sur les faits de la vie des écrivains, sur les vicissitudes de leur existence, sur les circonstances extérieures de leurs publications - celle qui recueille traditions et documents. Une érudition chronologique. Elle n'est pas, certes, dépourvue d'utilité pratique. Se suffit-elle à elle-même ? Personne qui le prétende. A telle enseigne qu'on la farcit de problèmes dérisoires. Et de combats contre des moulins à vent. Qui l'eût cru, qu'en 1940 il fallût combattre Taine ${ }^{175}$ et «la doctrine qui fait d'une œuvre de génie l'expression rigoureusement fidèle du milieu, du moment, de la race, d'une faculté dominante !»-1940 : à quoi donc ont servi trois quarts de siècle de dissertations sur cette nouveauté tainienne ${ }^{176}$ ?

Qu'on y prenne garde. Ces sortes de régressions vont loin. Elles ne sont pas signe de santé, de jeunesse, d'énergie. De tout ce dont, plus que jamais, nous avons besoin. Il faut reprendre la marche. Qui n'est pas le piétinement. p268

175 Page 370: «La littérature classique est bien une littérature raisonnable. Seulement, si elle n'avait été que raisonnable, elle aurait été nécessairement médiocre », etc.

${ }^{176} \mathrm{Ou}$ encore qu'une discussion s'imposât sur ce thème: Molière, le grand ennemi et le vainqueur de la préciosité... - Oui, mais : on a pu écrire un livre " fort judicieux » sur Molière auteur précieux... - Alors ? Alors, " Molière est précieux. Sans l'être ». J'ajoute, respectueusement: tout en l'étant (voir p. 148149). 


\section{DU GOUT CLASSIQUE AU FOISONNEMENT ROMANTIQUE}

I.

UN LIVRE DE RAYMOND NAVES : LE GOÛT ET LA VIE

« Et voilà, dira-t-on, un beau livre de professeur! S'attaquer à Voltaire ; pouvoir mettre devant soi, pour l'étudier à fond, un grand livre comme l'Essai sur les mours - et s'attacher uniquement au Temple du Goût ; consacrer 566 pages à l'étude attentive des Lettres sur Edipe et de l'Essai sur la poésie épique, c'est-à-dire à ce qu'il y a vraiment de mort dans le siècle de l'Encyclopédie, quelle gageure !» Lecture faite du livre de R. Naves ${ }^{177}$, on peut répondre : "Gageure, soit ; mais elle est tenue. » Ce n'est pas seulement l'historien de la littérature, c'est l'historien tout court, l'historien de la Société et de la Civilisation qui peut et doit reconnaître que ce travail est loin, bien loin d'être ce qu'on pourrait craindre, faute d'informations, et sur la foi d'un titre trop vite lu: un amas de pages vaines sur des pages

177 Raymond NAVES, Le goût de Voltaire, Paris, Garnier, 1938, 572 pages in- $8^{\circ}$. Inutile de dire que le livre apporte à la connaissance même de Voltaire une contribution singulièrement intéressante. J'ai beaucoup goûté, pour ma part, le crayon original et neuf qu'il nous donne de Voltaire dans un paragraphe intitulé : «Le génie de Voltaire » (p. 173-178). " Que lui manquait-il donc ? interroge-t-il. Avant tout, la méfiance et le mépris des hommes. Il est foncièrement naïf et optimiste... La rouerie de Voltaire est constamment voulue et se perce à jour... Il commence par des projets grandioses et des espoirs fous, il termine par des récriminations et des chicanes, car c'est le propre des hommes naturellement confiants que d'étaler après coup et à contre-temps leur méfiance... mais il suffit de le voir aux prises avec un roué authentique, avec Frédéric, pour mesurer sa simplicité. » Cette image de Voltaire, du sardonique Voltaire, est neuve; elle a bien des chances pour être ressemblante. 
vaines. S'il fallait une preuve, ce compte rendu, dans cette revue d'histoire, pourrait sans doute l'administrer.

C'est que, dit très finement R. Naves, la conception du goût qui est celle de Voltaire est aussi conception de la vie. Ne traduit-elle pas, d'abord, un idéal aristocratique : celui de l'honnête homme qui est surtout un amateur, et pour qui la distinction ${ }_{\mathrm{p} 269}$ et la justesse du ton sont, mieux que des qualités mondaines, des qualités morales? « Rejetant les instincts populaires, les élans religieux et romantiques, l'adhésion totalitaire et l'affirmation brutale, l'homme de goût évite de se donner largement et pesamment; il réserve toujours en lui une zone libre, qui lui permet de dominer et de juger ses entraînements les plus légitimes. Le lyrisme personnel, le laisser-aller de la douleur ou de la joie, le réalisme sont, au fond, plébéiens. L'honnête homme a une dignité à préserver et il la préserve tantôt par l'élégance et la noblesse, tantôt par le persiflage... La profondeur de l'homme inspiré est toujours quelque peu béotienne. » Telle est la valeur voltairienne du goût : certainement issue du XVIII siècle et particulièrement de cette période de la Régence où «la dislocation des synthèses volontaires obligeait les bonnes volontés à chercher, au-dessus de ces ruines, un principe irréductible mais acceptable pour l'esprit le plus indépendant». Et quand $M$. Naves ajoute que Voltaire voit très lucidement la décadence, mais ne peut se résigner à sacrifier l'essentiel des grandeurs passées; quand il écrit: "Voltaire aura toujours pour le classicisme mourant des gestes doux et attendris; ce qui l'intéresse, ce n'est pas l'héritier turbulent, qui n'a que trop de santé, et grandira bien tout seul »; quand il nous montre l'auteur de La Henriade penché sur «cet illustre malade dont il faut, par un cordial savamment dosé, prolonger la vie délicate, riche de souvenirs grandioses et de réussites irremplaçables » — cet historien du goût littéraire n'attire-t-il point du même coup l'attention des historiens tout court sur une certaine attitude, plus ou moins inconsciente, des hommes du XVIII ${ }^{\mathrm{e}}$ siècle vis-à-vis du passé », sur une certaine nostalgie de ce qui fut grand, et qui meurt, bien propre, sans doute, à faire comprendre comment et pourquoi il fallut la force, la force brutale et plébéienne, pour mettre au monde une société nouvelle dont deux générations attendront la venue avec une alternance de craintes inavouées et d'espoirs candides ? Et nous, hommes de 1938, encore attachés au $\mathrm{XIX}^{\mathrm{e}}$ siècle et à sa douceur de vivre par tant de liens 
sentimentaux et charnels, nous qui reculons devant l'appel de l'inconnu - ne sommes-nous pas faits pour comprendre pleinement de tels états d'esprit, les revivre et les ressusciter en les animant de nos soucis à nous?

Ainsi, « le goût», dans sa forme consciente, mérite de fixer l'attention de l'historien. Car il propose une attitude spirituelle devant le problème du monde. Et l'attitude que Voltaire et ses contemporains prirent spontanément devant un tel problème, si $M$. Naves croit pouvoir la formuler ainsi : «Faire ce que l'on ${ }_{\text {p270 }}$ doit faire, c'est-àdire ce que l'on peut faire»; s'il peut écrire que "l'homme fut vraiment le centre de la sensibilité littéraire d'un Voltaire, l'homme avec son histoire, ses progrès, sa civilisation, son idéal moral coupé de tout lien suspect avec les forces confuses de l'inconnu ", ne se trouvet-il point rattacher ainsi, de façon imprévue, cette partie qu'on croyait négligeable et morte d'une œuvre militante, à la conception même de l'Encyclopédie, telle que Diderot l'exprime lorsqu'il interroge: «Pourquoi n'introduirions-nous pas l'homme dans notre œuvre comme il est placé dans l'univers ? Pourquoi n'en ferions-nous pas un centre commun? Est-il dans l'espace infini quelque point d'où nous puissions, avec plus d'avantages, faire partir les lignes immenses que nous nous proposons d'étendre à tous les autres points? »

II.

UNE RÉVOLUTION : LE ROMANTISME

A Travers André Monglond

L'apparition du tome II de l'admirable et précieux dépouillement de livres et de brochures qu'André Monglond intitule La France révolutionnaire et impériale ${ }^{178}$, nous offre l'occasion non seulement

178 La France révolutionnaire et impériale. Annales de Bibliographie méthodique et description des livres illustrés. Grenoble, Éditions B. Arthaud, 1929 et suiv., in$8^{\circ}$; t. I (1789-1790), 1929, XVII pages et 1330 col., 24 planches hors texte ; t. II (1791-1793), 1931, X pages et 1166 col., 24 planches hors texte. - Index des t. I et II, 1931, 92 col. ; t. III (1794-1796), 1933, VII pages et 938 col., 32 planches 
de signaler l'intérêt prodigieusement varié de cet ouvrage fondamental, peut-être trop peu connu encore et pratiqué, mais surtout de jeter un coup d'œil sur l'œuvre d'un historien des idées et des sentiments qui a tout pour intéresser nos Annales et leurs lecteurs.

Dès sa jeunesse, dès ses premières lectures, André Monglond a cru s'apercevoir que le romantisme était « la force qui gouverne deux siècles de notre littérature, et dont les effets ne sont pas encore épuisés ». A rechercher les points de départ, à suivre la marche d'un courant aussi puissant, tous ses travaux ont été consacrés. Travaux d'histoire littéraire au sens étroit du mot? Non, quelle que soit la finesse, la sensibilité de leur auteur ; non, car un renouvellement p271 profond de la vie intérieure donne naissance au romantisme, et c'est ce renouvellement qu'étudie André Monglond; non, car le mouvement romantique " ne cesse de se relier en progressant aux formes diverses de l'activité française », et ce sont ces liens, c'est cette progression qui est l'objet de ses soucis ${ }^{179}$.

- Romantisme : rappelons à nous nos souvenirs de lycée. Un mouvement littéraire plus ou moins factice en France, nous disait-on - presque tout entier importé de l'étranger, d'ailleurs circonscrit en d'étroites limites chronologiques. Candidats au baccalauréat des années 1900, nous étions priés d'en saisir le premier frisson, aux environs de 1800, sur " la cime indéterminée des forêts », ou dans les bagages suspects de cette grosse Madame de Staël, contrebandière un peu hommasse du germanisme : combien de fois, lui prêtant nos plumes de rhétoriciens, n'avons-nous point composé, sous son nom, d'éloquentes lettres de protestation au général Savary, gendarme napoléonien et persécuteur, par ordre, de l'Allemagne?

Or, pour André Monglond, auteur de vingt essais substantiels et de deux grands livres d'histoire morale et sociale, captée dans les

hors texte; t. IV (1797-1799), 1935, VIII pages et 1230 col., 24 planches; t. V (1800-1802), 1938, XVI pages et 1514 col., XXIV planches hors texte.

179 Le Préromantisme français. Grenoble, Éditions B. Arthaud, 1930, 2 vol. in$8^{\circ}$; t. I, Le héros préromantique, XV et 291 pages, 23 planches hors texte ; t. II, Le maître des âmes sensibles, 508 pages, 25 planches hors texte. - Cf. également, Vies préromantiques (Paris, Belles-Lettres, 1925 ; 291 pages in- $8^{\circ}, 4$ planches) et Jeunesses (Paris, Grasset, $1933 ; 308$ pages in $-8^{\circ}, 6$ planches). 
témoignages littéraires - à la façon dont Henri Bremond a saisi, et capté, dans les mêmes témoignages, les subtiles nuances du sentiment religieux en France au $\mathrm{XVI}^{\mathrm{e}}$ et au $\mathrm{XVII}^{\mathrm{e}}$ siècle — pour André Monglond, le Romantisme, c'est une révolution: le mot est de Michelet, qui vécut la chose. Couvrant deux siècles de notre histoire, et non plus cinquante ans, c'est, fondamentalement, une révolte de tendance et d'aspirations éternelles contre cette misère du cœur, cette pauvreté d'imagination, cette absence de poésie qui caractérisaient, durement, un siècle - le XVIII ${ }^{\mathrm{e}}$ - dont Sénac de Meilhan dénonçait en 1767 l' "âme de vieillard», et, comme il disait, le «caractère sexagénaire $»$.

Partant sans parti pris pour un long voyage d'exploration sentimentale, laissant derrière lui toute idée préconçue ; n'emportant comme viatique que le mot de Pascal: "A mesure qu'on a plus d'esprit, on trouve plus d'hommes originaux » - André Monglond s'est plongé sans terreur dans l'amas formidable de livres, de brochures, de plaquettes préromantiques, romantiques - et antiromantiques - que lui livraient nos bibliothèques. Il a tout vu, tout lu; mais, possédant au plus haut point ce «savoir-lire» que le vieux Gœthe prétendait modestement avoir passé p272 quatre-vingts ans de sa vie à acquérir, jamais il ne s'est enlisé ou égaré au milieu de ce fatras. Dès que, dans un texte insipide ou absurde, quelque âme tâtonnante balbutie un seul mot; dès qu'entre cent mille, un soupir, une confidence à moitié retenue anime brusquement trois lignes, au bas d'une page : le chasseur, sautant sur son bien, s'en empare - et, de tels témoignages humains, tisse la trame vivante de cent portraits.

Rien d'émouvant comme cette quête des premières paroles lourdes de sentiment, des premières tendresses réchauffant l'air glacé, des inflexions sensibles et des fléchissements d'hommes et de femmes avouant, comme malgré eux, leur lassitude, leur dégoût de raffinements exquis mais desséchants.

On part des Liaisons dangereuses, fleur suprême d'un esprit tout classique et d'un siècle tout mondain. On marque l'étape de ceux qui, tel Diderot, prennent encore leur tête pour leur cœur - ou comme, 
$\mathrm{M}^{\mathrm{me}}$ du Deffand, s'avouent à eux-mêmes, un soir d'abandon, «qu'il n'y a que les passions qui fassent penser ».

Et l'on s'achemine, à travers les reposoirs de cette " histoire du cœur humain » dont s'inquiétait déjà Marivaux en 1740, jusqu'au « Maître des Ames Sensibles », Rousseau, emplissant de son œuvre et de son influence tout le second volume d'André Monglond: Rousseau, incomparable chef d'orchestre des sentimentalités qu'il oriente et discipline; Rousseau, entraînant dans son sillage une étonnante file de disciples hétéroclites: mages et ratés, apôtres et illuminés, tous ceux qui défilent, pour notre joie, dans le livre de Monglond - de l'abbé Lamourette, précurseur du christianisme social, à l'abbé Cournaud, précurseur provençal du communisme ; de Gracchus Babeuf, tête rebelle de Picard, tempérament sanguin d'orgueilleux et de violent, formé, à la fois, par ses lectures de JeanJacques et par ses expériences d'exploitant rural ; ajoutons : de Manon Phlipon, fille accomplie de Jean-Jacques, à Lucile Desmoulins, Parisienne de primesaut: tout un peuple, et qui, grâce à l'exégèse patiente d'André Monglond, à son auscultation sagace des «morts sans crédit ", nous permet d'enregistrer et de mesurer avec exactitude le retentissement profond des grands événements dans les cœurs solitaires.

Commentaire psychologique perpétuel en marge de l'histoire politique, économique et sociale; broderie d'âmes individuelles éclairant, illustrant le sens profond des mouvements de masse : p273 faut-il le dire ? historien voué, comme tous les historiens, à l'étude de ces mouvements massifs, je préfère de beaucoup les discrets enseignements des expériences humaines d'André Monglond à ces tentatives d'une histoire littéraire faussement statisticienne et prétendument scientifique qu'on nous offre avec tant de prodigalité ; œuvres d'hommes mal habitués à manier la machinerie compliquée de l'histoire politique, économique et sociale, elles se contentent trop aisément d'improvisations sans nuances, dans un domaine où la nuance est tout et la lente expérience.

$\mathrm{Au}$ reste, qu'il nous suffise de transcrire ici les titres de quelques chapitres du premier volume : comment s'est retrouvé et approfondi le paysage, le goût des ruines et des tableaux, la restauration de l'amour 
— et comment l'expérience libertine des mondains, reflétée par la littérature, a changé la pente de la vie sentimentale; les générations préromantiques, ou l'idée de "génération» dans la critique et l'histoire romantique - ou bien encore, au tome II, la passion de l'égalité ou les origines sentimentales de la Révolution; les sources de la révolte ; la promotion et le sacerdoce de l'homme de lettres; sous le titre d'ensemble «La conversion du bourgeois », toute une série de notations précieuses sur la texture de la bourgeoisie et notamment sur l'esprit de la bourgeoisie parisienne ou provinciale à la fin du XVIII siècle: ne continuons pas: tout historien, tout homme soucieux de culture humaine peut juger, en parcourant ces simples notations, de l'ampleur, de la variété des thèmes que traite, tour à tour, André Monglond, biographe de l'âme française romantique.

Faut-il, d'un mot, marquer l'un des résultats capitaux de cet effort novateur? Pendant deux ou trois décades, ce fut en France un mot d'ordre trop suivi que de faire chez nous du Romantisme un apport étranger - et de dénoncer nos grands romantiques comme les fourriers et les bâtards, tout à la fois, d'un germanisme clandestin, mais trop réel. Thèse de partisan peut-être : ne nous aventurons pas sur le terrain de la politique ; André Monglond n'y pénètre jamais, et c'est un de ses mérites. Certainement, en tout cas, illusion d'esprits trop vite satisfaits. Au-dessus d'une terre française qu'on laisse obscure et noire; d'un pays riche de toutes les richesses spontanées d'un incomparable terroir moral, croiser très haut dans le ciel les feux de l'Espagne romantique, de l'Allemagne romantique, de l'Angleterre romantique et composer ainsi une sorte de féerie suspendue qui brille, p274 tremble, amuse le regard et séduit; tenir cependant pour néant, au mépris de toute réalité et de toute vérité, les actions et réactions spontanées de la France, et de quelle France : la France tourmentée, grosse de désirs, foisonnante d'idées, de la fin du XVIII ${ }^{\mathrm{e}}$, du début du $\mathrm{XIX}^{\mathrm{e}}$ siècle : le jeu a pu paraître amusant à jouer, mais ce n'est qu'un jeu. Et je retrouve là, historien $d u X{ }^{e}$ siècle, ce qui s'est passé semblablement pour la Réforme, "importation de l'étranger», déviation germanique de l'âme française : la Réforme, dont il a fallu des années de recherches pour qu'on s'aperçoive qu'elle fut aussi profondément française en France qu'allemande en Allemagne, 
anglaise en Angleterre. Tout comme le Romantisme, cette Réforme sentimentale, cette révolution morale engendra une révolution littéraire : le facteur permanent d'une histoire non seulement littéraire, mais humaine.

Il faut souhaiter, pour l'honneur de ce pays, pour le profit de nos études à tous, pour la satisfaction même d'André Monglond et sa récompense désintéressée - que cet admirable inventaire de près de quinze ans de vie française, de vie tragique et endiablée, puisse se poursuivre jusqu'à l'achèvement. Ah! si nous avions pour les années décisives $\mathrm{du} \mathrm{XVI}^{\mathrm{e}}$ siècle ou pour le $\mathrm{XVII}^{\mathrm{e}}$ siècle, cet inconnu, l'équivalent de ces cinq précieux volumes, où les Français semblent venir, d'eux-mêmes, inscrire à leur date leurs rêves, leurs espérances, leurs sentiments et leurs transformations! Du moins, que, pour les années décisives de la Révolution et de l'Empire, l'œuvre si intelligemment mise sur pied par André Monglond puisse atteindre son terme : vœu égoïste — si la science peut jamais l'être. p275 


\section{LES HISTORIENS DE LA PHILOSOPHIE}

\section{LEUR HISTOIRE ET LA NÔTRE}

Retour à la table des matières

Il y a quelque temps, par les soins de l'éditeur Röhrscheid, de Bonn, un des deux maîtres livres de Nicolas de Cues - le De concordantia catholica de 1433 - réapparaissait tel qu'en 1514 Josse Bade Ascensius en gratifia les Parisiens ${ }^{180}$. Et presque en même temps, le beau mémoire d'Ernest Cassirer, Individuum und Kosmos in der Philosophie der Renaissance ${ }^{181}$, nous apportait, à la suite de son texte, deux éditions critiques importantes : celle du Liber de Mente, du même Nicolas, texte latin publié par Joachim Ritter, traduction allemande de Cassirer lui-même ; et celle, par Klibansky, du Liber de Sapiente de notre Bouelles, "la création la plus remarquable peutêtre, écrivait Cassirer (ouvr. cité, p. 93) ; en tout cas, et à de nombreux égards, la plus caractéristique de la philosophie de la Renaissance ». Grande nouveauté, cette publication: l'Amiénois Bouelles, encore desservi par son affreux latin, n'est pas habitué aux éditions critiques. Le Cusan, lui, est moins délaissé. Déjà, en 1913, son De docta ignorantia avait été l'objet d'une édition critique, procurée par Paolo Rotta; en 1927, le même savant avait traduit en italien ce texte capital; enfin, en 1928, il avait publié sur l'évêque de Brixen une

180 Nicolai DE CUSA, De concordantia catholica, libri III. Faksimiledruck, Bonn, 1928, gr. in- $8^{\circ}$. Cf. Revue Critique, 1929, p. 502.

181 Leipzig, Teubner, 1927 ; VI-458 pages in-4. 
monographie copieuse ${ }^{182}$ dont la partie biographique n'ajoutait rien au livre solide de Van Steenberghe, mais la seconde, plus originale, plus indépendante aussi, visait à « moderniser » davantage sa doctrine — non sans quelque arbitraire peut-être, ni quelque parti pris.

Or, dans son beau livre, Ernest Cassirer ne se bornait pas à publier ou à faire publier des ouvrages importants et rares de ${ }_{\text {p276 }}$ philosophie « renaissante ». Dans une riche et personnelle étude sur la pensée philosophique en Italie, en Allemagne et en France pendant la dernière moitié $d u X V^{e}$ et le début $d u X V I^{e}$ siècle, il réagissait fortement contre l'opinion, accréditée un peu partout par divers auteurs et, en particulier, par Burckhardt : qu'il n'y eut en Europe, à cette époque, aucune philosophie digne de ce nom. Les hommes que le Bâlois nous montrait partant, libres d'idées routinières, à la conquête du monde - il les disait timides d'une excessive timidité dans leurs spéculations philosophiques. Et certes, Cassirer ne le nie pas ; toute cette philosophie demeure fortement engagée dans les liens de la scolastique ; il est difficile de tracer les limites qui la séparent de la pensée religieuse ${ }^{183}$; et les trois grands problèmes qui s'imposent aux méditations des hommes de ce temps, Dieu, la Liberté, l'Immortalité, ne sont pas vraiment, de la façon dont ils demeurent posés, des problèmes «modernes». Toutefois, ne voir dans la philosophie de la Renaissance qu'une continuation, plus ou moins abâtardie, des controverses médiévales, c'est l'erreur de Burckhardt, et ce fut une erreur. Car les hommes de ce temps ne vivaient plus dans l'atmosphère " $\mathrm{du}$ moyen âge » — et le but de Cassirer, c'est précisément de montrer comment leurs conditions d'existence les amenaient à concevoir "un nouvel univers de la pensée », comment, dans cet univers spirituel, toute leur vie se reflétait à la fois et se rendait manifeste. Il n'y a pas, pour un historien, de tentative

182 Il Cardinale Nicolo di Cusa : La vita ed il pensiero (Pubblic. d. Università cattolica del Sacro Cuore, Sc. fil., vol. XII), s. d. [1928], in-8 ${ }^{\circ}$. Cf. Edm. VAN SteenBerghe, Le Cardinal Nicolas de Cues, Paris, 1920, in- $8^{\circ}$.

183 «Die Philosophie des Quattrocento ist, und bleibt, gerade in ihren bedeutendsten und folgereichsten Leistungen, wessentlich Theologie », ouvr. cité, p. 4). 
plus sympathique et plus digne d'intérêt que celle de ce maitre des études philosophiques ${ }^{184}$.

Or, voici que quelqu'un s'émeut en France du peu de hâte que nous manifestons - et qu'en particulier nos éditeurs manifestent - à suivre un mouvement qui s'amorce. Publications de textes sur cette période, si vivace et si agitée - celle qui a préparé la triple éclosion de la pensée humaniste, de la pensée réformée et de la pensée catholique rénovée : néant chez nous. Qui donc se soucie - à part un historien, à vrai dire éminent : j'ai nommé Augustin Renaudet — de Bouelles et de son maître ${ }_{\mathrm{p} 277}$ Lefèvre d'Étaples ${ }^{185}$ ? C'est Ernest Cassirer, c'est la maison Teubner qui nous dotent du Liber de Sapiente. D'aucun des grands livres du Xv siècle finissant, $\mathrm{du} \mathrm{XVI} \mathrm{e}^{\mathrm{e}}$ ses débuts, nous n'avons chez nous d'éditions critiques... A défaut d'éditions, voici qu'Abel Rey nous apporte une première série de traductions ${ }^{186}$. Sa collection vient à son heure; on doit en saluer l'apparition avec joie.

Qui, on? Les historiens de la philosophie? Je n'ai point qualité pour parler en leur nom. Mais puisque l'occasion s'en présente, qu'ils me laissent dire deux mots. De tous les travailleurs qui retiennent, précisé ou non par quelque épithète, le qualificatif générique d'historiens, il n'en est point qui ne le justifient à nos yeux par quelque côté - sauf, assez souvent, ceux qui, s'appliquant à repenser pour leur compte des systèmes parfois vieux de plusieurs siècles, sans le moindre souci d'en marquer le rapport avec les autres

184 Étant bien entendu qu'E. Cassirer se défend d'être autre chose qu'un philosophe, je veux dire de se placer à un point de vue autre que le point de vue philosophique pour examiner les systèmes de ce temps. Mais qui ne souscrirait à sa formule (p. 6) : "Sie ist nicht nur ein Teil, der sich mit anderen Teilen verbindet, sondern sie stellt das Ganze selbst dar und bringt es zum begrifflichsymbolischen Ausdruck. Wie das neue universelle Leben, zu dem die Renaissance sich durchringt, $\mathrm{zu}$ der Forderung eines neuen Universum des Gedankens führt... »?

185 Cf. Augustin Renaudet, Préréforme et humanisme à Paris pendant les premières guerres d'Italie, Paris, Champion, 1916, in- $8^{\circ}$.

186 La collection s'intitule: Textes et traductions pour servir à l'histoire de la pensée moderne, Paris, Alcan (depuis 1929) ; 1929, XX-98 pages in- $8^{\circ}$. 
manifestations de l'époque qui les vit naître - se trouvent ainsi faire, très exactement, le contraire de ce que réclame une méthode d'historiens. Et qui, devant ces engendrements de concepts issus d'intelligences désincarnées - puis vivant de leur vie propre en dehors du temps et de l'espace, nouent d'étranges chaînes, aux anneaux à la fois irréels et fermés...

Et je sais bien qu'il y a trop d'historiens pour ne voir des hommes que la pure apparence, se refuser à rien apprendre de la pensée cartésienne s'ils ont Descartes à mettre en place dans son siècle, et se satisfaire d'anecdotes sur Frère Martin, lorsqu'il s'agit pour eux d'étudier la genèse du luthéranisme. Mais voilà précisément pourquoi, des deux mains, j'applaudis à l'entreprise d'Abel Rey. Dans toute la mesure où elle jettera des ponts entre groupes de travailleurs qui, cantonnés chacun sur leur rive, s'ignorent réciproquement; dans toute la mesure où elle engagera les historiens de la philosophie à être, si peu que ce soit, des historiens - et les historiens, à se soucier enfin de pénétrer au delà du monde des apparences - elle sera féconde et salutaire.

Que nous apporte la nouvelle collection ? Pour suivre l'ordre des temps, du Pétrarque d'abord. Une élégante traduction, préfacée par P. de Nolhac, du célèbre traité : Sur ma propre ignorance, et celle de beaucoup d'autres. Courte introduction de la p278 traductrice, Mme Juliette Bertrand, un peu littéraire peut-être, et dont une ou deux appréciations surprennent légèrement le lecteur.

Faut-il le dire, je n'aime pas beaucoup ces ironies faciles sur « le cher Cicéron » de Pétrarque. - C'est un des mérites du livre de M. Henri Busson sur le Rationalisme, que d'avoir mis en pleine valeur le rôle d'initiateur, le rôle d'émancipateur intellectuel que joua au XVI siècle l'auteur, nullement négligeable, du De Natura Deorum, ce manuel d'" athéisme», et du De Divinatione, ce prône de 
déterminisme ${ }^{187}$. De même, je ne souscris pas sans réserve à l'appréciation de la page XIX, sur « l'ennuyeux syncrétisme de Ficin ». De nombreux travaux ont montré la puissance de rayonnement et d'action de Marsile dont l'esprit enthousiaste et religieux revit sinon chez Érasme, plus proche du criticisme d'un Laurent Valla, du moins chez notre Lefèvre d'Étaples - et dont le symbolisme est un des éléments qui se fondirent et s'amalgamèrent pour faire jaillir du pinceau de Michel-Ange, à la Sixtine, « le plus admirable poème que, depuis Dante, ait conçu l'intelligence italienne ${ }^{188}$.

La médiocrité philosophique de Cicéron, «l'ennuyeux syncrétisme » de Ficin : formules, pour ne pas dire clichés, de la plus mauvaise " histoire de la philosophie » - au regard d'un historien, s'entend. C'est précisément contre la conception d'une histoire aussi antihistorique, ou, si l'on veut a-historique, que doit réagir une entreprise comme celle d'Abel Rey, historien précis et réaliste de la Science Antique - et bientôt, nous l'espérons, de la Science Moderne. Il y a la Philosophie, la Pure Philosophie, la Haute Philosophie - que je salue avec respect. Et qui, de toute sa hauteur, peut dédaigner un Ficin, mépriser un Cicéron - on me permettra d'ajouter : se gausser d'un Pétrarque et de sa Docte Ignorance. Mais il y a l'histoire de la Pensée Moderne qui, elle, sait, au Romain du ${ }^{\text {er }}$

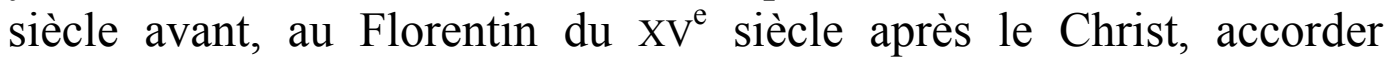
l'hommage et la place qui conviennent.

Voici maintenant une œuvre d'autre caractère, et d'autre portée. C'est, traduit par L. Moulinier, « introduit » par Abel Rey (1930), le traité De la docte ignorance de ce Nicolas de Cues dont la pensée, écrit Abel Rey, "incarne le passage du moyen âge aux temps modernes sur le terrain philosophique et scientifique, comme sur le terrain théologique et religieux $»$ : entendons qu'elle ${ }_{\text {p279 }}$ concilie avec la raison grecque, puisée par Nicolas aux sources platoniciennes et néo-platoniciennes, ce vieil esprit scientifique des maîtres d'Oxford épris de mathématiques et de sciences expérimentales, qu'enrichissent

187 Les sources et le développement du rationalisme dans la littérature française de la Renaissance (1523-1601), Paris, 1922, in- $8^{\circ}$; sur Cicéron, p. 16-23 et passim.

188 A. Renaudet, t. VIII de la Collection Peuples et Civilisations, p. 120. 
à Paris les Buridan, les Oresme, les Albert de Saxe, les Marsile d'Inghen, tous disciples de leur venerabilis Inceptor, Ockham : double héritage de la pensée antique et de la science médiévale, auquel le cardinal de Brixen ajoutait celui d'un mysticisme dyonisien et augustinien, grossi d'apports des Victorins, de saint Bernard, de saint Bonaventure, de Raymond Lull — et de ce maître Eckhart dont il lui reprochera de renouveler l'hérésie ${ }^{189}$.

Dans son livre déjà cité, E. Cassirer fait au Cusan une large place. Des quatre parties dont il se compose, les deux premières sont consacrées, l'une à caractériser d'ensemble la philosophie du cardinal, et surtout à montrer l'originalité de sa position philosophique l'importance de sa théorie de la connaissance, son rôle comme propagateur des idées platoniciennes, ses idées enfin sur la religion universelle, la vision en Dieu, les rapports de Dieu et du Monde, le Christ. La seconde marque l'influence que, sur cette pensée très compréhensive, exerça l'Italie. Préface monographique aux deux vastes ensembles que brosse ensuite le philosophe de Heidelberg. De ce Cusan, si étudié dans ces derniers temps, nous n'avions chez nous ni édition critique ni traduction. On se félicitera de pouvoir lire, dans la traduction exacte de M. Moulinier, l'un des deux écrits principaux du docteur mosellan.

Tout différent du Nicolas Krebs que ses succès mêmes débaptisèrent, l'auteur du Prince, Nicolas Machiavel. C'est par la traduction de ce petit livre, si gros par l'influence qu'il a exercée depuis quatre siècles — que s'est inaugurée (1929) la Collection Textes et Traductions.

Le Prince, 1513. Ou plutôt, date de la publication, 1532. Les Questions péripatéticiennes de Césalpin qui, traduites par Maurice Dorolle (1929), prennent également place dans la Collection, sont de 1574. Et le De Causa de Giordano Bruno ${ }^{190}$, qui suit, traduit et

189 Sur ces aspects de la synthèse cusienne, voir RENAUDET, La fin du moyen âge, t. VII de la Collection Peuples et Civilisations.

190 Cause, Principe et Unité, 1930, 220 pages. - Sur les rapports de la pensée de G. Bruno avec celle de Nic. de Cusa, cf. Cassirer, ouvr. cité, p. 49 et suiv. 
introduit par E. Namer à qui l'on devait déjà un livre sur Les aspects de Dieu dans la philosophie de Giordano Bruno (Alcan, 1926), est de... - Au fait, de quand est-il ? On parcourt toute ${ }_{\mathrm{p} 280}$ l'introduction sans y découvrir cet humble fait, profondément négligeable mais que la radicale infirmité d'un historien l'oblige à préférer d'abord à toute dissertation. Mettons que ce soit 1584 ; mais ce n'est pas M. Namer, ravi par le furor philosophicus, qui nous l'apprend...

Or, cet oubli n'est pas sans intérêt. Un «philosophe » à qui l'on jette en pâture le De Causa se rue sur cette proie avec volupté. Il s'assouvit. Bruno et lui, ils sont entre eux, bien entre eux, entre philosophes. Et M. Dorolle a du mérite, qui n'a pas oublié de dater son Césalpin. Car à lui aussi, c'est un texte « pour philosophes » qui a été dévolu. Or, 1574, 1584, Césalpin, Bruno ; mais Le Prince, 1513 : comme la pensée des deux «clercs » paraît gauche et retardataire, au prix de celle du laïc; je veux dire, comme elle se montre étouffée de bandelettes, ligotée d'aristotélisme, bardée de platonisme et de plotinisme - scolastique, au sens étymologique du mot. M. Namer s'en délecte, et même M. Dorolle qui cependant perd beaucoup moins de vue la terre, la pauvre terre du XVI ${ }^{\mathrm{e}}$ siècle sur laquelle, historiens débiles, nous voudrions tant qu'on nous montre, en pied, ce Césalpin et ce Bruno : mais nous ne les voyons que suspendus à Aristote, ou flirtant avec Plotin ${ }^{191}$.

Sur quoi, j'entends bien qu'on me remontrera mon ignorance. Bruno nous guide vers Leibniz et vers Spinoza... Oui, mais en luimême, et par rapport à son temps, et pour ses contemporains, qu'étaitil ? Ce n'est pas «toute la question» pour l'historien; évitons ces formules absolues qui appauvrissent et dessèchent ce qui a vie ; disons simplement : c'est un aspect essentiel de la question. Et revenons à notre propos, en en demandant pardon à Cassirer : comme Nicolas Machiavel, diplomate roué, réaliste sans scrupules idéologiques, étranger non seulement à tout mysticisme, mais encore au

191 Qu'une autre conception soit possible, sans qu'il s'agisse pour l'auteur de se désintéresser des questions proprement philosophiques qui l'attirent, voilà, faut-il le rappeler, ce qu'a démontré péremptoirement, il y a douze ans, l'un des livres les plus vivants qui soient sur ces problèmes : le Campanella de Léon Blanchet (Paris, Alcan, $1920 ; 596$ pages in- $8^{\circ}$ ). 
christianisme (je veux dire à ce qui, dans la religion, est pour un chrétien nourriture spirituelle) - comme il apparaît, ce Machiavel, plus proche de nous, plus moderne mille fois et plus libéré que ces faiseurs de systèmes qui, pour s'affranchir des antiques servitudes, commencent par s'enfermer dans les prisons séculaires de l'humanité ? Ils cherchent à s'en évader, c'est entendu ; mais ce sont eux qui d'abord s'y sont verrouillés.

Et qu'on ne me dise pas que Machiavel, c'est Machiavel... Je p281 viens de lire avec intérêt le gros livre que M. P.-H. Michel consacre à La pensée de L.-B. Alberti ${ }^{192}$. Au-dessus du titre, on lit: Un idéal humain au $X V^{e}$ siècle. Humain, très humain, cet idéal du Florentin que ses dates de naissance et de mort (1404-1472) font contemporain de Laurent Valla et de Nicolas de Cues. Qu'on lise, dans ce livre un peu long peut-être, parfois un peu lâché, mais qui touche, à la suite d'Alberti, à tant de choses : aux sciences et aux arts, au monde et à l'homme - qu'on lise ce que M. Michel a tiré du traité, cher à Sombart, Della Famiglia, divulgué dans son ensemble en 1443 (et qui se relie à toute une littérature contemporaine sur le sujet) — ou encore, à l'analyse qu'il donne de la pensée religieuse de son auteur, ou de sa pensée morale : même impression, même choc : celui qu'on éprouve, lorsqu'on ouvre cet affreux, hérissé et proprement illisible De Anima, de Pomponazzi, qu'on évoque sa date (1516), et qu'on se rappelle qu'alors était écrit Le Prince, alors taillés et arrachés de leurs blocs de marbre les Captifs et le Mö̈se de Michel-Ange... Qu'on me pardonne, mais, s'agissant de contribuer à cette histoire de la pensée moderne qu'il faudrait, en vérité, qu'Abel Rey trouve le temps de nous donner - je voudrais que quelque philosophe consentît à réfléchir, un jour, sur ces rapprochements-là. Et sur les leçons qu'il en faut dégager.

Deux esprits, c'est entendu : le philosophe et l'historique. Deux esprits irréductibles. Mais il ne s'agit pas, précisément, de les « réduire » l'un à l'autre. Il s'agit de faire en sorte que, demeurant l'un

192 Paris, Les Belles-Lettres, 1930 ; 650 pages in- $8^{\circ}$. 
et l'autre sur leurs positions, ils n'ignorent pas le voisin au point de lui demeurer sinon hostile, en tout cas étranger.

Est-ce chimérique ? Mais voici le livre de Cassirer. C'est bien le livre d'un philosophe, et qui, nous l'avons vu, se défend d'être historien, de façon expresse. Or, lorsque, après avoir consacré a Nicolas de Cues, à sa théorie de la connaissance, à son rôle comme propagateur des idées platoniciennes, à ses idées sur la religion universelle, la vision en Dieu, les rapports de Dieu et du monde, etc., des pages substantielles ; lorsque, après avoir marqué, dans un second chapitre, l'influence qu'exerce l'Italie sur l'auteur du De Ignorantia - il retrace d'ensemble l'histoire des principales questions philosophiques à travers les doctrines de la Renaissance; lorsqu'il esquisse l'évolution du problème de la liberté ${ }_{\text {p282 }}$ et de la nécessité (celui qu'Érasme débattra contradictoirement avec Martin Luther), depuis Laurent Valla jusqu'à Pomponazzi ; lorsqu'il étudie l'Oratio de hominis dignitate de Pic de la Mirandole, le De Sapiente de Charles de Bouelles, ou encore l'attitude d'un Ficin, d'un Pomponazzi, d'un Pic de la Mirandole vis-à-vis de la magie : qui donc, parmi les historiens soucieux de comprendre, du dedans, les sociétés de la Renaissance et leurs buts d'existence - qui ne trouvera pas là des aliments substantiels pour ses constructions propres ? En tout cas, ce ne sera pas l'auteur de ces chapitres d'histoire intellectuelle, qu'Augustin Renaudet a composés pour les tomes VII et VIII de la Collection Peuples et Civilisations : le plus solide, le plus intelligent tableau qu'historien puisse tracer des courants de pensée de l'Europe occidentale, entre l'avènement du Scotisme puis de l'Ockhamisme et la formation de ce Rationalisme français dont la parenté est évidente avec le mouvement italien et, si l'on veut, padouan de la fin $d u X V^{e}$ et du début du XVI siècle : la filiation directe, c'est une autre affaire, je veux dire un problème qu'on aurait tort de croire résolu parce qu'on l'a posé.

Pour la réalisation de semblables ententes, que la Collection Textes et Traductions se développe. Que les collaborateurs d'Abel Rey songent, non pas seulement au jeu des idées pures, ni même à leur filiation logique, mais à leur genèse et à leurs rapports avec le mouvement général du siècle qui les vit naître. Et une grosse lacune de notre outillage intellectuel sera comblée. p283 
$\underline{\text { Retour à la table des matières }}$ 
Doctrines et Société

ÉTIENNE GILSON ET LA PHILOSOPHIE DU XIVe SIÈCLE

$\underline{\text { Retour à la table des matières }}$

Étienne Gilson vient de publier chez Payot - sous forme, cette fois, d'un gros traité de 782 pages in- $8^{\circ}$ — une seconde édition, entièrement revue et augmentée, du très utile petit manuel que, chez le même Payot, en 1922, il avait présenté sous forme de modestes livrets extrêmement précieux déjà, mais que l'œuvre actuelle dépasse largement.

Il s'agissait, alors comme aujourd'hui, de donner de La philosophie au moyen âge, des origines patristiques à la fin du XIV siècle, une vue d'ensemble qui ne constitue ni un guide érudit, comme l'Ueberweg, ni un guide philosophique et systématique à la façon de Maurice de Wulf, ni une étude sur les rapports de la pensée médiévale et de la pensée grecque, à la mode d'Émile Bréhier. Étienne Gilson, lui, s'est attaché avant tout à dérouler sous les yeux du lecteur le film chronologique de la philosophie médiévale depuis son premier contact avec la philosophie grecque, au II siècle de notre ère, " dès qu'il y eut des convertis de culture grecque », jusqu'à cette fin du XIV siècle qui voit se lever l'aurore de temps nouveaux. Par là même, son livre est, pour l'historien des civilisations, un livre d'importance journalière.

Ceci, quant à l'extérieur. S'agissant de l'intérieur, j'aurai tout dit quand j'aurai répété que c'est un livre d'Étienne Gilson. On y goûtera d'un bout à l'autre cette cohérence de pensée, cette sûreté d'expérience, cette vigilance d'attention, ce quelque chose de fort, de solide et de ferme, qui équivaut à une signature. Ce quelque chose d'ingénieux aussi, de personnel et d'actif qui vivifie tout. Les 
critiques, les exposés sont coupés de remarques familières et d'interventions directes : «Attendez ici ! N'allez pas croire que... »Ou bien : «Problème ardu ! Ne le résolvons pas par la facilité... »Et toujours cette grande clarté, qui ne ${ }_{\mathrm{p} 284}$ vient pas de simplifications arbitraires, mais d'une maîtrise plénière des sujets. Le livre d'un grand professeur, et qui enseigne excellemment ; mais il ne se contente pas, certes, d'exposer ce qui est acquis, ni même d'avoir lu et relu tous les textes et d'en avoir extrait avec bonheur les préceptes les plus caractéristiques; il sait, de sa personne, se porter, tantôt seul, tantôt accompagné de ses disciples, à la pointe même de la recherche pour y accomplir les travaux nécessaires, animer de sa curiosité les équipes de jeunes, provoquer les études nouvelles, les publications de textes, les rapprochements féconds. La distance même qui sépare les deux versions du livre - celle de 1922 et celle de 1944 — en dit long, non seulement sur les immenses progrès qu'en vingt ans a fait notre connaissance du moyen âge et de ses penseurs, mais encore sur le labeur personnel d'Étienne Gilson, sur ses conquêtes et celles de ses disciples. La constatation est réconfortante.

Bien sûr, je me suis porté tout de suite vers les chapitres de la fin : ceux qui présentent au lecteur ce riche $\mathrm{XIV}^{\mathrm{e}}$ siècle, si original et si fécond, cette sorte de faux départ vers la modernité. Ou plutôt ce vrai départ: mais des accidents survinrent, et il fallut aux voyageurs rentrer chez eux provisoirement, en attendant que les voies fussent rétablies. L'exposé du scotisme, celui de l'occamisme, sont de tous points originaux et neufs dans leur densité. Et, de même, la mise en place de l'averroïsme, celui de Jean de Jeandun et de Marsile de Padoue. Quelques pages excellentes sur Gerson permettent de donner du XIV ${ }^{\mathrm{e}}$ siècle une vue d'ensemble intéressante ${ }^{193}$. Mais ici, historien, je voudrais dire un mot.

Quand Étienne Gilson écrit (p. 591) que les siècles sont peut-être des points de repères commodes pour situer les événements et les hommes dans l'histoire - mais que l'histoire de la philosophie médiévale ne connaît pas de coupure entre le XIII et le $\mathrm{XIV}^{\mathrm{e}}$ siècle ;

193 Je ne parle pas, parce que ce n'en est point ici le lieu, des deux chapitres fort curieux qu'Étienne GILSON intitule Le retour des lettres, en Italie, et hors d'Italie. J'aurai l'occasion d'y revenir ailleurs, je l'espère. 
qu'il verrait, au contraire, d'un œil favorable l'établissement d'une vaste période s'étendant de 1228 environ, c'est-à-dire du début de l'enseignement, à Cologne, d'Albert le Grand, jusqu'à 1350, date de la mort de Guillaume d'Ockham, - je comprends, certes, ses raisons qui sont d'ordre philosophique ${ }^{194}$. p285 Mais, cependant, historien, je me sens gêné. Parce que le XIV $^{\mathrm{e}}$ siècle diffère tout de même profondément, à mes yeux d'historien, comme aux yeux de l'artiste qui, du premier coup d'œil identifie, en entrant dans une église, une nef du XIV ${ }^{\mathrm{e}}$ siècle - qui la sent, si j'ose dire, comme nef du XIV", avant même d'avoir regardé dans le détail le profil des moulures, le dessin des supports, le décor des chapiteaux - parce que le $\mathrm{XIV}^{\mathrm{e}}$ siècle diffère radicalement du XIII ${ }^{\mathrm{e}}$. Il en diffère par sa curiosité ; par son effort de nouveauté ; par sa volonté de secouer le joug des vieilles traditions, qui lui semblent périmées : celles des corporations de métier, par exemple; et aussi, celles des traditions et des enseignements moraux qui tendent à limiter l'activité économique des sociétés chrétiennes; et encore celles des vieilles formules politiques, puisque en Italie s'épanouissent alors les «tyrannies», celles des Visconti, des Sforza, qui n'ont plus rien à voir avec les rois du XII ${ }^{\mathrm{e}}$, du $\mathrm{XIII}^{\mathrm{e}}$ siècle ; il en diffère puisque, entre France et Empire, se constitue alors un État nouveau, l'État des Valois de Bourgogne ; puisque enfin, disons le grand mot, on peut parler alors valablement d'un capitalisme moderne déjà constitué, avec ses conséquences si souvent déduites.

Et, certes, je ne demande pas qu'on explique Ockham et l'ockhamisme par les succès du premier capitalisme, du capitalisme

194 «L'âge d'or de la théologie et de la philosophie, dites scolastiques, qui fleurirent, en effet, alors dans les écoles coïncidèrent plutôt avec la période qui s'étend d'environ 1228 jusque vers $1350 \ldots$ La fin du XIII ${ }^{\mathrm{e}}$ siècle et le début du $\mathrm{XIV}^{\mathrm{e}}$ ont vu paraître des synthèses doctrinales de grand style, comme celles de Duns Scot et de Guillaume d'Ockham, ou des œuvres comme celles de Maître Eckhart, dont la qualité philosophique s'impose dès qu'on en commence la lecture. » - Oui, certes. Mais ces synthèses doctrinales de grand style, sont-elles du même style que les synthèses immédiatement antérieures ? E Etienne Gilson ajoute: «Ce qui est vrai des hommes de cette génération, c'est qu'ils ont inévitablement pensé en fonction de ceux de la génération précédente... Mais leur propre pensée dépend moins de celle de leurs prédécesseurs qu'il ne pourrait d'abord le sembler. En effet, s'ils partent, comme leurs devanciers, d'Aristote, de Proclus, d'Avicenne et d'Averroes, n'est-il pas fatal qu'ils rencontrent à chaque pas leurs aînés ? Mais, s'ils s'écartent d'eux, n'est-ce pas dans une large mesure parce qu'ils vivent dans un climat historique différent? 
marchand du XIV ${ }^{e}$ siècle. J'oublie encore moins que la première moitié de ce siècle marque l'apogée des métiers, que ces métiers fournissent à la petite bourgeoisie des cadres merveilleusement adaptés à sa nature; que jamais, comme Pirenne le faisait remarquer, elle n'a vraiment été plus heureuse que sous leur égide, et que, s'ils l'ont garantie contre la concurrence, ils l'ont garanti également, pour un temps, contre le capitalisme, cet intrus, cet ennemi. Mais enfin, l'intrus est là, il règne à Florence, ave le popolo grasso, malgré les révoltes du popolo minuto. Il règne dans les villes flamandes, en dépit des révoltes furieuses des tisserands contre « les bonnes gens qui ont à perdre ». Car le $\mathrm{XIV}^{\mathrm{e}}$ siècle est un siècle de révoltes. Duns Scot, Guillaume d'Ockham et les suivants, pour ne point parler de Marsile de Padoue et de Jean de Jeandun, n'ont point vécu dans la même atmosphère de paix sociale que saint Thomas d'Aquin. - Ceci noté, je dis simplement: les hommes qui ont lu et médité Ockham, p286 qui ont tiré les conclusions de ses originales prémisses, - ces hommes sont les mêmes qui ont assisté, par ailleurs, à de grandes transformations, à de grandes innovations politiques, économiques et sociales ; qui en ont subi le contre-coup ; qui (même moines dans leur cellules, même docteurs dans leurs studia) ont bien été contraints, à la longue, de s'apercevoir de leur puissance et de leur prise sur les concitoyens.

Quand Étienne Gilson nous dit (p. 638) que «le XIV siècle est, dans une large mesure, un siècle de critique », nous répondons: « D'accord. Mais, pourquoi ? — - Parce que, nous dit l'historien de la philosophie, on lui offrait (par «on», entendez les maîtres de la scolastique, du XIII ${ }^{\mathrm{e}}$ siècle), pour chaque problème d'importance, deux ou trois solistes sans contradicteurs. De sorte que, placé devant une pluralité de solutions et de solutions non discutées, le docteur du XIV siècle devenait critique par nécessité ${ }^{195}$. Cependant, les hommes de ce temps ne semblent pas spécialement amateurs d'unité? Ils ne

195 Critique conduite par des théologiens, précise É. Gilson (p. 639), et pour des fins théologiques. Mais, précisément, les théologiens, en ce temps, vivaient-ils dans la pleine sérénité ? au temps où Marsile de Padoue définissait l'Église, la communauté de tous ceux qui croient en Jésus-Christ? où les mystiques laïcisaient, pour la première fois, leur pensée, en l'exprimant dans leur langue vulgaire? où la Papauté, établie à Avignon, subissait tous les contre-coups de la politique française ? Je ne continue pas. 
semblent pas spécialement désireux de rivaliser avec ces grands prédécesseurs qui s'efforçaient d'embrasser, d'un point de vue choisi, toutes les connaissances données dans un vaste et unique système intellectuel?

Mais, moi, historien, comment ne serais-je pas sensible au fait que l'apparition, au cours $\mathrm{du} \mathrm{XIV}^{\mathrm{e}}$ siècle, d'un capitalisme marchand, principalement dans les cités trafiquantes de l'Italie, s'accompagne de l'apparition d'une morale nouvelle — d'une morale de profit qui dresse (dans les milieux capitalistes du moins, encore restreints, mais d'autant plus influents qu'ils sont urbains) le profiteur ou l'apprenti profiteur contre ses semblables, considérés par lui comme autant de rivaux, de concurrents, d'ennemis ? Morale qui rompt l'unité dans l'ordre social et dans l'ordre individuel. Morale qui doit engendrer, et qui engendre, une conception profondément pessimiste de l'humanité, dont les instincts mauvais s'écartent si résolument des normes d'une saine moralité. Morale qui réagit sur les conceptions politiques de la société : d'une société qui n'est plus formée, comme la société médiévale, de groupes hiérarchisés, coopérant humainement entre eux, mais d'individus luttant un à un, et tous contre tous, pour leur profit. Et pour maintenir cette société anarchique dans l'ordre, c'est le p287 recours au tyran de Machiavel, c'est l'appel au Prince de Martin Luther.

Je ne continue pas. Et je ne viens pas plaider une vieille thèse de filiation, d'engendrement que j'ai toujours considérée comme sans valeur pour nous. Je ne parle pas de primat, je parle d'interférences. Si l'on veut, de climat. Et je dis simplement : Étienne Gilson a fait effort — il le dit et il fait mieux que de nous le dire - Étienne Gilson a fait effort pour jeter entre l'évolution de la littérature et celle de la philosophie au moyen âge, quelques ponts placés à de bons endroits. Il a eu bien raison. Je crois qu'il lui eût été facile de lancer, entre l'évolution politique et économique générale et l'évolution de la philosophie au moyen âge, quelques autres ponts, qui eussent donné à tous les usagers de son Traité, une largeur de perspective incomparable. Il ne s'agit pas de sous-estimer le rôle des idées dans l'histoire. Encore moins de le subordonner à l'action des intérêts. Il s'agit de montrer qu'une cathédrale gothique, les halles d'Ypres, victimes de l'éternelle Barbarie, et une de ces grandes cathédrales 
d'idées comme celles qu'Étienne Gilson nous décrit dans son livre ce sont les filles d'un même temps. Des sœurs grandies dans un même foyer. Aussi bien, quand le philosophe nous montre (p. 536), dans le système de saint Thomas, toutes les créatures s'ordonnant selon un ordre hiérarchique de perfection, en allant des plus parfaits, les anges, aux moins parfaits, les corps, « et de telle manière que le degré le plus bas de chaque espèce supérieure confine au degré le plus haut de chaque espèce inférieure », - peut-il ne point penser à ces belles constructions de juristes à la Beaumanoir, qui nous décrivent dans les mêmes termes l'ordonnance des sociétés?

Je ne demande certes pas à l'historien des doctrines de s'improviser historien des sociétés politiques et économiques. Je lui demande de tenir ouverte, toujours, une porte de communication, par où le monde des idées puisse reprendre dans nos esprits le contact qu'il avait tout naturellement avec le monde des réalités — quand il vivait. p288 
Esprit Européen et Philosophie

UN COURS DE LÉON BRUNSCHVICG

$\underline{\text { Retour à la table des matières }}$

«Je me propose de traiter de l'esprit européen — sujet d'ordre purement spéculatif, et dont l'étude sera maintenue dans les limites d'une analyse strictement philosophique. » Ainsi débute le cours sur L'esprit européen que professa en Sorbonne, de décembre 1939 à mars 1940, Léon Brunschvicg, et qui paraît aujourd'hui en volume ${ }^{196}$.

Nous n'aurons jamais assez de ces « revues » qu'un bon esprit, une tête fortement pensante et philosophante consent à donner au public de temps à autre. Elles nous aident dans nos démarches particulières, nous autres historiens, dès lors que notre ambition tend à reconstituer la totalité des manifestations par quoi s'affirment dans leur succession les états divers de civilisations. J'ai procuré au public, en 1934, une de ces revues, celle qu'Abel Rey, ami trop tôt enlevé, composa pour le tome premier de l'Encyclopédie Française, sous ce titre: De la pensée primitive à la pensée actuelle. Elle débutait par cette affirmation : "Il est impossible de saisir l'outillage de la pensée sans faire son histoire. La pensée (le sujet) est en action et en réaction continues avec ce qu'elle veut penser (l'objet): une lutte et une conquête. Pour comprendre son activité présente, force est de se soucier, et avant tout, de son activité passée. »

196 A Neuchâtel, Éditions de la Baconnière, mai 1947 ; 187 pages in- $8^{\circ}$. Dans la même série a paru précédemment (1945-1946) le dernier volume que Léon Brunschvicg publia de son vivant: son Descartes et Pascal, lecteurs de Montaigne. 
«Saisir l'outillage de la pensée », écrit A. Rey. En effet, son travail remplit la première partie d'un volume intitulé L'outillage mental, qui présente au lecteur non seulement le raccourci d'une histoire évolutive de la Pensée (je ne pouvais mieux demander ce raccourci qu'à l'auteur des précieux volumes sur La science p289 grecque qu'achève de publier Henri Berr dans l'Évolution de l'Humanité), mais encore une puissante étude de Meillet sur le Langage, et une présentation de la Mathématique contemporaine, faite sous la direction de Paul Montel par nos plus grands mathématiciens. Le souci de Léon Brunschvicg n'est pas celui d'Abel Rey. Il ne le définit nulle part de façon explicite, trouvant sans doute que son titre, L'Esprit européen, rapproché de son nom à lui, suffit à caractériser l'entreprise. Ce qui serait vrai, ou du moins plus vrai, si les deux mots qui composent ce titre étaient clairs par eux-mêmes, et sans équivoque.

Européen ? Au temps même où Léon Brunschvicg professait ses leçons en Sorbonne, j'essayais, à Genève, de préciser le sens et d'esquisser l'histoire de la notion d'Europe; et la chose n'allait de soi ni pour les étudiants de cet Institut des Hautes Études Internationales, qui m'avaient demandé de réfléchir à la question, ni pour moi-même, historien. Quand à Esprit, faut-il lui donner le sens que le Vocabulaire de Lalande inscrit sous la rubrique $\mathrm{D}$, quand il parle de cet esprit qui «s'oppose à la sensibilité» et qui devient «synonyme d'intelligence »? Léon Brunschvicg écarte bien de ses leçons tout souci de sensibilité; mais parler d'intelligence? Oui, au sens d'entendement, de connaissance conceptuelle et rationnelle; mais enfin, l'intelligence n'est point que cela. Peut-être devrait-on parler d'intellectualisme, d'intellectualité, de réduction de tout l'existant (et d'abord de l'esprit européen) à des éléments purement intellectuels ? Ne poursuivons pas. On nous accuserait de chicane, et ce n'est point une accusation que nous affronterions de gaîté de cœur.

Mieux vaut dire que ce petit livre est, à sa manière et dans ses limites, un de ces chefs-d'œuvres de la vieille Université, que nous n'aurons peut-être plus beaucoup d'occasions d'accueillir et de louer, car la génération s'en va, de leurs auteurs possibles - elle s'en va grand train. Génération encore fortement nourrie aux lettres, aux bonnes lettres grecques et latines. Génération bien encadrée, au 
départ, par des maîtres auxquels elle travailla tout naturellement à ressembler et dont elle put prendre la suite sans déchirement ni rupture, ni véritable «crise» pour parler le langage de Léon Brunschvicg : car de Lachelier et de Lagneau à Boutroux et, par delà, à Brunschvicg, quelles causes profondes de rupture ou d'incompréhension! Excellentes gens, cultivés, pleins de finesse et parfois de subtilité, passionnés de spéculations philosophiques, s'enfermant volontiers dans le cercle enchanté de leurs pensées et de leurs spécialités ; remarquables, quand il s'agit soit de critiquer les doctrines, soit d'en marquer l'enchaînement ; p290 moins remarquables sans doute, quand ils prennent la parole en leur nom personnel et se placent sur un terrain si difficile qu'il n'a jamais pu être dominé que par une dizaine de très grands créateurs de systèmes : mais ici, nos philosophes universitaires ne se hâtent-ils point, judicieusement, d'observer que les grands systèmes dont ils enregistrent les vicissitudes n'ont jamais figuré que « des étapes dans la marche d'un progrès qui paraît illimité $»$ - et voilà donc leur échec par avance justifié, prédit et rendu nécessaire... Leur échec de penseurs originaux et «maîtrisants », car, en tant qu'exégètes des doctrines, il faut parler de réussite et non d'échec. De plénière réussite. Le livre de Léon Brunschvicg en serait une preuve nouvelle, s'il en fallait une.

Mais même dans ce domaine, et à propos de cette réussite, que de choses à dire ! Nous, qui ne sommes point des philosophes - mais, en tant qu'historiens, des usagers de la philosophie, sommes-nous, pouvons-nous être pleinement satisfaits par des livres de ce genre ? Je suis bien forcé de répondre : Non.

Que d'œillères, et gênantes... Ces philosophes, ces techniciens de la philosophie sans doute suivent avec puissance les filiations de certaines formes de pensée, de certaines réponses d'un certain ordre à de certaines questions. Mais hors de cette filiation? hors de ces formes et de ces pensées ? S'il y en a d'autres (et il y en a toujours), on ne les voit guère : formule polie pour dire qu'on ne les voit jamais. 
Qu'il y ait eu, au XVII ${ }^{\mathrm{e}}$ siècle, toute une école de naturalistes ${ }^{197}$; qu'elle ait eu une énorme audience dans tous les milieux de tous les pays occidentaux d'alors; que cette importance soit attestée, jusqu'au temps de Pascal, par les controverses violentes auxquelles elle donna lieu ; que d'ailleurs le courant de pensée que représentent ces hommes soit revenu baigner, plus tard, les hommes du XVIII ${ }^{\mathrm{e}}$ siècle : voilà ce dont aucun lecteur ne se douterait en lisant l'esquisse tracée, d'une main sûre mais dédaigneuse, par Léon Brunschvicg.

A juste titre, répondra-t-il. Vous parlez de pensées: ce sont, avouez-le, de bien médiocres pensées, et donc méprisables. Volons de cime en cime, c'est un exercice assez fatigant et assez périlleux pour que nous ne le compliquions pas inutilement de descentes p291 fastidieuses dans les bas-fonds. On s'y crotte les semelles; on ne s'y élargit point 1'esprit... - Propos de grands seigneurs. Mais le temps des grands seigneurs semble révolu. Quel est votre critère pour déterminer ce qui est "médiocre » et ce qui ne l'est pas ? Médiocre, vocabulaire d'hommes de génie, manié par des hommes bien doués qui ont eu le goût, la noblesse si l'on veut, de passer leur existence à coudoyer le génie; mais le génie, à la différence du talent, ne se délègue point par procuration. Et d'ailleurs, médiocre, soit. Admettons que toute une génération, ou deux, ou trois, à la fin $d u X{ }^{e}$ siècle, n'aient été composées que de médiocres, capables tout au plus de goûter des médiocrités; le problème pour nous, historiens, est de savoir pourquoi, d'expliquer comment ces générations ont pu se contenter de telles nourritures. Rayez-les de vos listes; cachez-les pudiquement dans vos «Enfers» idéologiques: vous faussez la perspective des temps. Rien de plus mais rien de moins.

Et encore, je parle d'œillères. Mais il y a celles qui empêchent, volontairement, nos gens de regarder ce qui se passe chez les voisins. Léon Brunschvicg cite (p. 183) un excellent passage d'Émile Boutroux: «La science véritable n'est pas un système de

197 Cf. Lucien FeBVRE, Aux origines de l'esprit moderne: libéralisme, naturalisme, mécanisme, Mélanges d'Histoire Sociale, t. VI, 1944, p. 9-26, repris dans $A u$ cour religieux du $X V I^{e}$ siècle, en préparation. Et Le Problème de l'Incroyance au XVI ${ }^{e}$ siècle. La religion de Rabelais, Paris, Albin Michel, 1942, in- $8^{\circ}$, passim. 
compartiments construit une fois pour toutes, où doivent venir se ranger, de gré ou de force, tous les objets qui se rencontrent dans la nature. La science est l'esprit humain lui-même, s'efforçant de comprendre les choses et, pour y parvenir dans la mesure du possible, se travaillant, s'assouplissant, se divertissant... » La Science, disait Boutroux ; mais leur philosophie, nos philosophes n'ont qu'un souci : l'enfermer dans un de ces compartiments dont parle l'auteur de la Contingence des lois de la Nature. Et certes, je ne leur reproche pas d'être des philosophes, conscients de leur philosophie - et non des historiens prisonniers de leur histoire. Je ne leur reproche rien du tout: de quel droit? J'observe seulement qu'ils n'ont pas l'idée, quand ils font de la philosophie, qu'il puisse exister des hommes d'un autre type que le leur. Avec d'autres préoccupations et d'autres formules. Des hommes qu'on ne leur demande pas de mépriser, - ce serait peine superflue, - mais de jauger, d'évaluer, d'apprécier dans leur rôle historique : ce rôle fût-il muet. Les silences ont leur poids et leur utilité, dans un chant ou dans un discours.

Chacun dans sa niche, l'historien à l'enseigne de Clio, le philosophe à l'enseigne de Socrate ? Chacun gardant jalousement, dans cette niche, de vieux os cent fois rongés et rongillés ? Et tous montrant les dents au chien d'à côté : si peu engageants, qu'ils font peur aux ouvriers convoqués pour réparer l'immeuble ${ }_{\mathrm{p} 292}$ dont ils sont censés assurer la garde, et qu'ils empêchent ainsi, ces mal-vêtus, d'y percer des murs, d'y établir des portes et des communications, d'y dresser des escaliers, et finalement de coiffer la bâtisse tout entière d'un ample toit unique, permettant à la vie de s'épanouir à l'aise, sans contrainte ? A la vie joyeuse : mais nous ne leur devons que la vie hargneuse.

Ce sont pourtant de grosses questions que posent, à chaque instant d'une évolution, les rapports nécessaires qu'entretiennent les sociétés qui se transforment, et les idées qui, elles aussi, changent de caractère et de direction. Je reviens à mes siècles familiers, le XVI ${ }^{\mathrm{e}}$ et le XVII ${ }^{\mathrm{e}}$. Ce passage singulier, ou mieux, cette défaite des philosophes naturalistes de la Renaissance par Descartes et ses tenants; défaite de l'irrationnel, victoire du rationnel ; et parallèlement, ce passage au moins singulier, ce passage de la Réforme - c'est-à-dire d'une religion en voie de rationalisation progressive, consciente ou non - à 
une religion de plus en plus chargée d'éléments sentimentaux et irrationnels : deux mouvements de sens contraire, et contemporains. Pas un mot de cela, dans le livre de Léon Brunschvicg, pas une minute d'attention pour ce "chiasme " étrange. Or, serais-je dupe d'une illusion? Je ne vois pas un historien, digne de ce nom, partant pour esquisser cette difficile histoire, pour poser les problèmes compliqués qu'elle dresse devant lui, sans sentir le besoin de consulter, chemin faisant, Gilson, Abel Rey, etc..., Brunschvicg lui-même.

« Naturellement, diront les philosophes. Vous, vous ne pouvez vous élever autrement... » Et je pense à ces officiers de marine qui accablent d'un incommensurable mépris les officiers mécaniciens sans quoi ils ne pourraient, ne sauraient rien faire. Ou, plus noblement, je me souviens de ce texte admirable de Malebranche (Recherche de la Vérité, I, VI, I ${ }^{\mathrm{re}}$ partie, chap. 2) parlant au nom de ceux «qui ont l'imagination pure et chaste », c'est-à-dire de ces spéculatifs «dont le cerveau n'est point rempli de traces profondes qui attachent aux choses visibles ». Du sommet de cette Jungfrau idéologique ils déversent un radical mépris sur « ceux qui sont dans le grand monde (et qui, plus que nous, historiens, est dans le grand monde, dans le vaste monde ?) et dont l'imagination est toute salie par les idées fausses et obscures que les objets sensibles ont excitées entre eux ». Les premiers "peuvent facilement se rendre attentifs à la vérité »; les seconds, ces malheureux, ne s'y peuvent appliquer que s'ils sont «soutenus de quelque passion assez forte pour contrebalancer le poids du corps qui les entraîne ». Méditons, mes frères en histoire. Et rentrons dans notre humble coquille de créatures « salies »...

p293 Cependant... Léon Brunschvicg parle de Cournot remarquablement, avec une sympathie visible et justifiée. Cournot, mais précisément: quelle régression! Cournot, ce mathématicien philosophe, ce grand théoricien du hasard, cet investigateur des probabilités, Cournot est plein d'histoire. Ce n'est pas lui, certes, qui refuse d'examiner les problèmes qu'à chaque pas cette histoire pose au philosophe. Cournot: mais à le lire, quel profil pour nous, historiens - Et comme s'est rétrécie, desséchée et ridée la large vue d'ensemble qu'il promenait sur les civilisations! A quoi attribuer ce rétrécissement? Faut-il inculper, ici encore, ces institutions 
universitaires, ces agrégations maîtresses de cloisonnements, et qui engendrent, tout naturellement, entre mandarins de couleurs diverses, ces «querelles de bouton» que connaissent nos marins? Je ne sais. Mais le fait est là, qu'il faudrait expliquer.

Tout ceci, en marge, je tiens à le redire en terminant ce bout d'article, d'une remarquable et par moment puissante synthèse de cette histoire que les philosophes excellent à composer - eux qui, résolument, ignorent notre histoire, notre pauvre histoire d'historiens souillés par l'impur contact des réalités - mais capables, cependant, de goûter le talent là où il est, et de faire leur profit de livres vigoureux, fortement pensées, sobrement écrits: testaments d'une génération pour qui on m'excusera d'avoir quelque faiblesse. p294 
LES HISTORIENS DE L'ART

Histoire de l'Art, Histoire de la Civilisation

DE SLUTER A SAMBIN

$\underline{\text { Retour à la table des matières }}$

L'histoire de l'art: une discipline qui trop souvent se nourrit de monographies individuelles — d'artistes les unes, de monuments ou d'œuvres les autres : et ces monographies peuvent être pleines de talent ou désolantes de banalité : toutes, du point de vue de ce que Paul Lacombe nommait 1'Histoire-Science, offrent pareillement les inconvénients cent fois dénoncés du genre, plus quelques autres. Car à quoi tendent-elles nécessairement, sinon à mettre en lumière ce qui, dans un artiste ou dans une œuvre, est original, personnel, unique ce qui l'isole et le distingue : par conséquent, ce qui n'est point objet de connaissance scientifique, s'il est vrai qu'il n'y a point de science possible de l'individuel ? On objectera que, bien faite, la monographie ne doit pas se borner à signaler ce qui distingue et isole, mais aussi ce qui apparente et réunit, ce qui rapproche un artiste de ses contemporains, un monument des édifices ses voisins dans le temps et dans l'espace... Théoriquement, rien de plus vrai : pratiquement? l'effort qu'il conviendrait de faire relier utilement une œuvre à toutes les manifestations de la société dans laquelle elle prend jour - cet effort serait si lourd, si disproportionné qu'il aboutirait, simplement, à noyer l'étude de l'œuvre ou de l'homme dans un flot sans rives de considérations sans ordre... 
A tous ces défauts, la monographie régionale doit échapper nécessairement. Une contrée étant donnée, en dresser, entre deux dates appropriées, la statistique artistique; à l'aide des témoins subsistants et répertoriés, reconstituer ensuite (sans s'interdire d'ailleurs, à l'occasion, le recours aux documents graphiques ou aux documents d'archives) l'évolution particulière des divers arts; ne point se borner à constater soit l'homogénéité, soit la diversité de la production à un moment donné : ${ }_{\text {p } 295}$ en chercher les causes; établir la destination des œuvres, la condition des producteurs, celle des clients ; se demander s'il s'agit d'un art «local» ou d'un art d'exportation; enfin, tenter de déterminer l'influence des idées du temps sur l'activité artistique qu'on reconstitue : c'est la tâche d'analyse. Après quoi vient la synthèse : confrontation des résultats obtenus ; essai pour dégager ce que l'enquête aura pu livrer de certain sur les tendances, l'esprit, le caractère même de la civilisation qu'on étudie. - Mais la personnalité des artistes s'évanouira à ce jeu? Non, elle s'inscrira dans un cadre. Ils cesseront d'apparaître, les uns après les autres, comme les perles d'un collier mobile de noms propres, qu'on ôte, qu'on remet et qui ne tient à rien. Ils s'intégreront dans un ensemble — soit qu'ils se fondent en lui, soit qu'ils tranchent sur lui.

De semblables monographies, nous en possédons encore fort peu chez nous, en France et pour la France. On a vite fait d'en citer deux et qui ne répondent qu'imparfaitement à notre vœu: l'une, celle de Kœchlin et Marquet de Vasselot sur la sculpture à Troyes, fit naguère époque ; l'autre se pare d'un nom d'artiste, mais en réalité nous apporte les résultats d'une enquête «territoriale »: c'est le Michel Colombe de Paul Vitry. Voici qu'Henri David nous en apporte une troisième, apparentée d'ailleurs aux deux premières par de nombreux traits : il l'intitule, d'un titre expressif qui définit parfaitement son dessein et délimite son champ d'action, sinon dans l'espace, du moins dans le temps : De Sluter à Sambin : Essai critique sur la sculpture et le décor monumental en Bourgogne au $X V^{e}$ et au $X V I^{e}$ siècle ${ }^{198}$.

198 Paris, Ernest Leroux, 1933, 2 vol. in- $4^{\circ}$ de XX-398 et XXXII-496 pages, cartes, nombreuses figures dans le texte; à la fin de chaque volume, index des noms de personnes et table précieuse des noms de lieux et des œuvres d'art; copieuse et précise bibliographie. 
Même médiocre, elle serait la bienvenue. Disons de suite qu'elle est de qualité.

Henri David baptise son premier livre, en sous-titre : La fin du moyen âge, Et le second, La Renaissance. Simples désignations chronologiques; elles n'expriment pas son vrai dessein — du moins dans son ampleur et ses raisons.

En fait, le premier livre traite un gros problème : Sluter étant mort après avoir lancé dans la circulation une formule originale et personnelle dont l'influence se fit sentir au cours $d u X V^{\mathrm{e}}$ siècle à travers tout l'Occident - il y a gros intérêt à se ${ }_{\text {p296 }}$ demander ce qu'en Bourgogne et dans les contrées immédiatement voisines (disons, si l'on veut, dans cette "Grande Bourgogne» dont E. Champeaux s'efforce d'accréditer, dans d'autres domaines, la notion parfaitement juste et légitime) devient, après la mort du maitre, l'art implanté par lui dans la capitale du Duché. C'est un art solidement constitué, avec des traditions très fortes, des caractères très accusés : va-t-il s'éteindre ? l'hypothèse n'aurait rien de choquant. L'atelier de Champmol n'est pas fils du terroir. C'est un prince français, puissant et riche, un de ces fils fastueux et raffinés de Jean le Bon à qui l'art doit tant en tant de contrées; c'est Philippe le Hardi frère de Jean de Berri - qui pour l'exécution de commandes personnelles a transplanté à Dijon et « surimposé à la Bourgogne » un groupe d'imagiers d'origine nordique, parfaitement étrangers au pays et d'ailleurs astreints à une tâche qui ne les mettait en rapport, originellement, qu'avec le prince lui-même. Ces hommes morts ainsi que leur client, l'atelier aurait pu disparaitre sans laisser de racines dans le pays... Ou bien, s'ils avaient eu des continuateurs, ceux-ci auraient parfaitement pu reproduire indéfiniment et sans changements les poncifs qui leur auraient été légués.

Par une analyse très fine et très neuve des œuvres étudiées et classées par lui, Henri David démontre, non seulement que la tradition slutérienne s'est puissamment et abondamment maintenue en Bourgogne, mais encore qu'elle a fortement évolué. 
Le processus de cette évolution est extrêmement curieux à étudier. Elle s'opère à la fois, naturellement, sous la poussée de forces internes et sous la pression de forces extérieures. Et d'abord, avec une précision chronologique, un sens historique et artistique remarquable, Henri David nous décrit pour la première fois le grand procès d'enracinement d'un art d'importation qui se mue peu à peu en art local, en art du cru, fleurant bon le terroir bourguignon et les vertus de la province française...

Les imagiers, à l'origine? des étrangers. Voici qu'ils se recrutent de plus en plus sur place en France - et même en Bourgogne. Et qu'ainsi, à leurs œuvres, ils impriment tout naturellement les caractères de spontanéité, de force, de réalisme à la fois dru et tempéré qui nous font dire d'elles, aujourd'hui, dès que nous les rencontrons : « Comme c'est bien bourguignon! - Et parallèlement, les clients ? A l'origine, un seul, le prince et ses commandes. Petit à petit les grands ; les prélats; et puis les bourgeois riches ou simplement aisés — bientôt même les simples gens, ceux des corporations ou les personnes rustiques. Et par p297 la nécessité de contenter ainsi la clientèle locale, l'accentuation progressive des caractères locaux... L'évolution est décrite magistralement. Et jamais, je crois, un tel «passage » n'avait été l'objet d'une étude si fouillée et si compréhensive.

Ainsi, c'est un art vigoureux, un art bien raciné qui voit passer sur lui, au cours $\mathrm{du} \mathrm{XV}^{\mathrm{e}}$ siècle, tant de courants divers venus parfois de loin. Jeu subtil et compliqué, celui des forces extérieures - qu'Henri David ne nous explique pas avec moins de sûreté et d'intelligente compréhension que l'autre. Action de l'art flamand proprement dit, avec qui jamais l'art d'influence et de tradition slutérienne ne s'est pleinement confondu : l'auteur, pour le montrer, écrit quelques pages excellentes. Lui tend à rapetisser l'idéal de l'art plastique « bourguignon », à compliquer son style, à abattre son souffle; l'art champenois, par contre, s'applique à enjoliver les types féminins, à introduire dans les costumes des recherches un peu mièvres de coquetterie et de parure qui signent chacune de ses interventions; cependant, sur les marges de la Franche-Comté, et d'ailleurs exceptionnellement, quelques interventions - particulièrement curieuses pour l'historien — se produisent, de cet art rhénan (et notamment de l'art des tombiers) dont Henri Drouot, autre 
connaisseur émérite de l'art bourguignon, a noté ingénieusement jadis quelques-unes des manifestations exotiques. Enfin, l'art français de la Loire moyenne, l'art de Michel Colombe, n'est point sans faire sentir vers le Sud-Ouest de la Bourgogne son influence normative et tend à passer au cou d'un art rustique, plein de sève et de familiarité, proche de la nature, le carcan d'un «style » un peu guindé parfois et d'une distinction... un peu beaucoup conventionnelle. Or, tiraillée ainsi, sollicitée contradictoirement par tant d'appels variés, l'école bourguignonne résiste et persiste. Plus exactement, tout en évoluant, tout en s'adaptant perpétuellement aux goûts du temps, elle sait rester elle-même : franche d'accent, gardant des maîtres de force qui furent ses premiers maîtres un sens incontestable de la grandeur, un lyrisme puissant du geste et de la draperie; au total, une de nos écoles provinciales les plus expressives, les plus proches du sentiment et du goût populaires.

Premier livre, La fin du moyen âge : mais j'aurais dit, bien plutôt : L'enracinement. Second livre, La Renaissance. Mais j'aurais dit, de nouveau : Bourgogne ou Italie ? C'est qu'à la fin du XV siècle et à partir des toutes premières années $d u \mathrm{XVI}^{\mathrm{e}}$, une autre action se fait puissamment sentir et se développe rapidement : l'action de l'Italie. L'étudier à la fois minutieusement et ${ }_{\mathrm{p} 298}$ pas à pas ses vicissitudes et marquer ses progrès : c'est tout l'objet du second livre ; c'est le grand objet de ce livre vivant et saisissant.

Car c'est une école non point finie, comme un silence à peu près universel sur ses manifestations terminales le donnerait à penser : c'est une école en pleine force, en pleine vitalité que trouvent devant elles les «nouvelletés» importées d'Italie par les rois de France maîtres de la Bourgogne depuis la mort du Téméraire - et par les gros seigneurs qui les servent et les imitent. De sorte qu'il faut, en effet, tout un livre pour retracer les péripéties de ce drame passionnant: la résistance à l'invasion bruyante des formules italiennes - grandiloquentes, agitées, théâtrales et souvent creuses d'un art en pleine force, robuste et qui n'accepte pas de céder la place sans tenter de se maintenir une fois de plus, d'absorber l'assaillant de traduire d'une façon nouvelle les mêmes constantes de sentiment et d'idéal sous le manteau de théâtre des formes ultramontaines. Formes qui d'ailleurs (et de l'avoir bien montré, c'est un des mérites de 
H. David) lui viennent non pas de la tragique Florence, mère d'un hellénisme plastique nerveux et dépouillé ; non pas de la puissante Rome, mère des majestés lourdes et bien rythmées - mais par l'intermédiaire de médailleurs et de vulgarisateurs éclectiques, tantôt de Naples, tantôt des petites villes du Nord à l'accent provincial. En bref, d'une Italie de province, et non pas de 1'Italie des cimes... - Au terme, l'épanouissement chez le huchier graylois, Hugues Sambin, d'une formule décorative savoureuse: pétrie d'italianisme et cependant, malgré les doctrines, fortement, irrécusablement bourguignonne dans sa sève. Cueillons de lui, dans sa Diversité des termes publiée à Lyon en 1572 - cueillons avec H. David cette formule qui dit tant: "Le naturel accommodé d'un artifice est beaucoup plus à priser que la simple beauté, sans autre ayde que d'elle-même. » Et voilà l'annonce des temps nouveaux.

Je n'avais point tort de noter, on le voit maintenant, qu'au cœur de l'œuvre de M. David il y a un sujet. Un vrai et grand sujet. Est-ce dire que ces deux beaux livres d'un historien de l'art, qui entend se maintenir sur son terrain à lui et n'en point sortir — satisfassent complètement et absolument tous les désirs d'un historien de la civilisation, repensant à sa mode et de son point de vue l'histoire que déroule devant lui Henri David? Mais qui pourrait le prétendre?

Évolution, nous dit-il ; oscillations entre le goût spécifiquement flamand, et le goût spécifiquement français des pays de ${ }_{\mathrm{p} 299}$ la Loire ; incarnation d'un art de provenance étrangère dans les hommes et les œuvres d'une province très consciente d'elle-même. J'entends bien. Mais l'historien que je suis se pose une question. 1477, la mort du Téméraire, la Bourgogne (Duché et Comté) saisie par Louis XI et ramenée à la France. Un drame politique, avec ses péripéties habituelles, ses ralliements, ses refus, ses secrets aussi : Henri Hauser jadis, et du temps qu'il était " bourguignon », en a donné l'esquisse. Ce drame, H. David certes ne l'ignore pas. A plusieurs reprises, on voit très bien qu'il tient compte dans ses appréciations des événements politiques et de leurs réactions dans le domaine qui est le sien. Mais il en tient compte ainsi dans le détail. L'historien aurait aimé que la question fût posée d'ensemble, une bonne fois, avec l'insistance et les développements qu'elle mérite... 
Une détente progressive, un adoucissement, la fougue pathétique de Sluter, la somptuosité du grand art funéraire de Champmol se muant finalement en sourire apaisé, sous le règne d'Antoine le Moiturier arrivant d'Avignon ? J'entends ; mais pourquoi ? car il y a toujours non pas un, mais des pourquoi... Et je me dis, historien, qu'aux évolutions psychologiques des hommes de ce temps il y a des livres qui ont été consacrés - de très beaux livres même: je n'en citerai qu'un, le chef-d'œuvre d'Huizinga, son Déclin du moyen âge, cette admirable monographie psychologique toute nourrie de textes bourguignons, que je ne vois pas citée (ceci est véniel) - mais surtout que je ne crois pas utilisée spirituellement (et ceci est plus grave) par H. David ni sous sa forme allemande ni sous son titre français. D'autres encore, naturellement, qu'il eût été bon sans doute d'interroger? ...

Une clientèle élargie enfin : à côté du prince, des grands d'abord ; des bourgeois ensuite ; et par eux, posé, tout le problème de "l'art bourgeois »... C'est moi du moins, historien, qui le dis. Henri David, lui, qui l'écrit deux cent fois dans ses notes et ses analyses; Henri David qui à vingt reprises crayonne des types représentatifs, ce Bénigne Serre par exemple, grand bourgeois de robe arrivé, riche et de goût affiné ${ }^{199}$ - Henri David finalement ne le marque pas une fois comme j'aurais aimé, historien, qu'il le fasse. Le souci de dire toujours, avec la plus attentive précision: "Telle œuvre a été commandée par tel homme, de ${ }_{\mathrm{p} 300}$ telle milieu, de telle origine, de telles attaches » — il le manifeste constamment et de la plus heureuse façon. Ses deux livres abondent en trouvailles à ce sujet. D'autant plus aurions-nous aimé qu'il pût — dans une conclusion par exemple ramasser en faisceau, d'un seul coup, ces données éparses pour poser le problème d'ensemble : faire la synthèse.

Qu'on m'entende bien : pas plus qu'aux historiens de la littérature, je ne demande d'improvisations d' « histoire sociale» aux historiens de l'art: je m'en suis expliqué, souvent. J'aurais aimé, simplement,

199 Et bien d'autres : les Rolin et les Rochefort au XV ${ }^{\mathrm{e}}$ siècle; plus tard, à maintes reprises, les Chabot, les Civry, les Longvy; les Bouton de Beaune et tout leur cortège de chanoines beaunois; les Fontette de Verrey sous Drée, dans le très intéressant chapitre consacré à l'atelier de la Dame de Fontette... 
que les soucis qu'il a eus, constamment et méritoirement - Henri David les accusât nettement dans son livre : soucis non pas d'historien de l'art, au sens étroit du mot, mais d'historien tout court. Soucis qui l'honorent et que sont bien loin d'avoir au même degré — ou même, tout simplement, d'avoir — les meilleurs même de ses confrères directs.

Et pareillement enfin, j'aurais souhaité qu'ici ou là parût un dernier souci. Que le sépulcre de Solesmes et le tombeau de François de Bretagne à Nantes soient contemporains, à quelques années près, de l'ouverture à Venise des ateliers d'Alde Manuce; que le David de Michel-Ange voie le jour en même temps que le Manuel du chevalier chrétien d'Érasme ; que Raphaël meure l'année où Luther lance son Appel à la Noblesse allemande — on peut dire : curiosités. On a tort sans doute. Car ces rapprochements posent un problème, un grave problème. Entre l'évolution de la pensée intellectuelle et celle des formes plastiques - y a-t-il, ou n'y a-t-il pas concordance ? De quelle allure s'avancent, parallèlement, ce qu'on peut nommer, à l'aide de mots très gros, l'Humanisme et la Renaissance ? Certes, poursuivant le dessein qu'il avait formé, Henri David n'avait point à ratiociner sur de semblables questions: je l'entends bien. J'aurais aimé pourtant qu'à quelques endroits bien choisis, un mot de rappel — un nom, une date, et puisés si possible dans l'histoire intellectuelle et religieuse de la Bourgogne même - nous invite à penser au destin différent et à la marche convergente des arts, des littératures et des philosophies. p301 


\title{
Résurrection d'un Peintre
}

\author{
GEORGES DE LA TOUR
}

$\underline{\text { Retour à la table des matières }}$

Historien, fils d'historien, élève à Strasbourg de toute une pléiade de bons historiens, François-G. Pariset s'est de bonne heure tourné vers l'histoire de l'art. On lui doit, sur Mathias Grünewald et les artistes alsaciens de son temps, d'intéressants travaux de recherche et de mise au point. Il s'est attaqué ensuite à un très gros sujet; au peintre lorrain Georges de La Tour, hier inconnu, aujourd'hui célèbre, il a consacré une ample thèse dactylographiée, qui lui a valu le laurier doctoral en Sorbonne. Il en a tiré un livre, qui vient de paraître chez Laurens ${ }^{200}$ - un gros livre, abondamment illustré de planches hors texte, qui transmet au public l'essentiel de la thèse telle qu'elle fut présentée aux membres du jury pour la soutenance.

Le travail est solide, approfondi, conforme aux bonnes méthodes. Il ne néglige rien de ce qui peut faire comprendre l'œuvre de La Tour. L'historien se révèle dans le souci attentif que François-Georges Pariset apporte à reconstituer les « milieux » successifs qu'a traversés son héros. Voici Vic, terre d'évêché, Vic au contact de deux langues, la française et l'allemande - donc des deux cultures et (ce qui importe peut-être ici dans une certaine mesure) au contact de deux religions : les protestants abondaient autour de Vic et à Metz où le pasteur Paul Perri s'acquérait alors un grand renom; mais Vic n'en était pas moins une citadelle du catholicisme — Vic, le premier

200 Georges de La Tour, Paris, H. Laurens, 1948 ; 438 pages in-4 48 planches hors texte, notes, bibliographie chronologique. 
théâtre d'activité de ce Nicolas Coëffeteau qu'on célèbre, dans les histoires de la littérature, comme un des «fondateurs de la prose française » du XVII ${ }^{\mathrm{e}}$ siècle : on sait qu'il finit évêque à Marseille, mais il commença sa carrière ecclésiastique comme suffragant de l'évêque p302 de Metz. Autour de lui, des religieux en nombre. Et d'intéressantes personnalités locales à qui François-G. Pariset, par ses soins attentifs, rend une vie curieuse : cet Alphonse de Rambervilliers, par exemple, lieutenant-général $d u$ bailliage et qui écrit par divertissement sans doute et " relâche d'esprit»- mais aussi pour exalter la foi catholique : ses Dévots élancements du poète chrétien ne sont point un témoignage négligeable sur la piété du temps. Après Vie, voici Lunéville et, après Lunéville, Nancy, le Nancy de Callot, de Deruet, de Le Clerc: Nancy et sa Cour cosmopolite, précieuse et dévote, avec ses ducs alliés aux maisons de France, de Bavière, de Toscane, ouverts aux quatre vents du monde, tiraillés entre les politiques et les cultures adverses. Un bien curieux et complexe milieu. Tout cela, François-G. Pariset s'attache à nous le restituer avec infiniment de soins et de scrupules. Mais son livre ne vaut pas seulement par cette probité de la documentation. Il nous incite à réfléchir sur certains des problèmes que l'œuvre d'art pose à l'historien.

Georges de La Tour, un inconnu d'hier, disais-je à l'instant. De fait, j'ai passé à Nancy toute une jeunesse cependant très préoccupée d'art (mon premier dessein était de me consacrer à des études d'histoire picturale). Or, nourri de Callot, de ce Callot dont l'œuvre m'était devenue familière rien qu'à fréquenter les devantures des marchands d'estampes de Nancy et les vitrines de Grosjean-Maupin, rue Héré - je n'ai, en revanche, pas une fois entendu prononcer par personne à Nancy, entre 1895 et 1900 le nom de Georges de La Tour. $\mathrm{Ni}$ vu, dans les Musées, dans les Expositions d'art lorrain, une seule toile de La Tour. Je me rappelle mon saisissement quand, en 1934, à l'Orangerie des Tuileries, dans une Exposition qui s'intitulait (assez bizarrement du reste) : Les peintres de la réalité en France au XVII siècle (exposition qui, d'ailleurs, dans son domaine, joua le même rôle que, dans le sien, en 1904, l'inoubliable exposition des Primitifs français) - je vis rassemblés une douzaine de tableaux assignés par le 
Catalogue 201 à ce mystérieux, à cet inconnu Georges de La Tour qui, du premier coup, après trois siècles et demi d'attente, s'établissait dans la gloire. Peu importait du reste la gloire : l'intéressant, c'est que ces tableaux bouleversaient l'ordonnance d'une exposition destinée peut-être d'abord, dans la pensée de ${ }_{\mathrm{p} 303}$ ses promoteurs, à asseoir et à élargir encore le renom des Le Nain. - Merveilles de candeur, de pureté, d'originalité, ces toiles brusquement sorties de l'oubli. Car un La Tour est un La Tour et ne peut rien être d'autre. Pas de confusion possible. Du mystère. Des lignes simples. Des volumes bien accusés. Des zones de silence et d'isolement entre des personnages aux gestes lents. Un parfum pénétrant qui se dégage dans la nuit. Et de tout cela, hier, nous ne soupçonnions rien?

Or, précisément, voici la première question que pose la résurrection de Georges de La Tour. Résurrection pourquoi, résurrection comment?

Louis Gonse, l'auteur des Chefs-d'œuvre des Musées de France, prospectant en 1900 les collections de province, tombait en arrêt devant un "étrange et délicieux tableau» du musée de Rennes. "Chaque fois que je suis revenu à Rennes, écrivait-il, cette œuvre m'a charmé davantage ; elle me hante. » Le tableau de Rennes, c'est une Nativité, "le chef-d'œuvre des tableaux nocturnes de La Tour », disait le catalogue de l'exposition des Peintres de la Réalité en 1934 (p. 66) — «le plus poétique et le plus habilement exécuté ». D’abord attribué aux Le Nain dans la période d'inflation qui suivit leur propre résurrection, il a été restitué à partir de 1915, par un Allemand, Hermann Voss, au Lorrain inconnu. Et le même Gonse, pareillement, tombait en arrêt devant un énigmatique tableau du musée d'Épinal, « une femme tenant une lumière dans sa main et visitant un prisonnier dans son cachot». En réalité, le sujet du tableau était «Job querellé par sa femme ». Peu importe. - Un amateur d'art remarque un tableau dans un musée, puis un autre tableau dans un autre musée. Il est frappé par la tenue de ces œuvres, leur originalité, leur qualité. Il le dit. Admettons que, faisant un pas de plus, il ait l'idée de relier ces toiles à un nom d'artiste totalement oublié (sauf de quelques très rares

${ }^{201}$ Préface de Paul JAMOT, introduction de Ch. STERLING. 
érudits locaux) : en l'espèce, le nom de La Tour. Admettons encore que, se passionnant pour cet artiste ainsi exhumé du néant par son goût, il ait provoqué des recherches, organisé une exposition, proclamé partout la beauté d'œuvres enfin dotées d'un état civil en règle (et notez que la supposition n'est pas absurde ; Gonse était en situation, s'il l'avait voulu, d'obtenir, dès 1900 , ces résultats). Georges de La Tour eût connu une résurrection sans mystère. Une résurrection opérée, pour des raisons d'art, par un homme de sentiment artistique juste. C'était simple.

p304 Hélas, cette simplicité-là n'est pas de mise dans nos études ! Voilà La Tour ressuscité, non par Gonse qu'à Épinal, à Rennes, à Nantes, certaines de ses toiles ont séduit sans qu'il ait su leur imposer de nom d'auteur - mais par Voss en 1915 : Voss, un Allemand, un historien de l'art. Et voilà, à sa suite, les historiens de l'art aux champs. Voilà qu'une à une ils rendent à l'inconnu d'hier des toiles de premier plan ${ }^{202}$. Ils lui en rendent même trop, dans la première ferveur de leur zèle. S'en tiennent-ils là ? Non. Pour qu'on puisse parler vraiment d'une résurrection de La Tour, il faut encore :

$1^{\circ}$ Que La Tour force l'entrée des manuels, afin que chacun sache dorénavant qu'il convient de le tenir pour un grand peintre (ne pas savoir que penser d'un peintre, quel tourment !) ;

$2^{\circ}$ Que le commun peuple qui visite les musées et les expositions apprenne qu'il lui est loisible, à son choix, de qualifier le ressuscité de réaliste, d'intellectuel ou d'énigmatique (cette liste d'épithètes n'étant naturellement pas limitative, et le panachage n'étant point interdit aux esprits conciliateurs) ;

$3^{\circ}$ Que le même commun peuple se trouve incité à témoigner de sa culture en laissant tomber négligemment, devant les œuvres de $\mathrm{La}$ Tour, les noms plus anciennement célèbres de Caravage, Vélasquez, Honthorst, Le Nain, etc. ;

\footnotetext{
202 Le catalogue du Musée de Nantes donnait encore, il n'y a pas si longtemps, les deux tableaux signés G. de la Tour qu'il possédait à... Quentin Latour, le pastelliste du XVIII ${ }^{\mathrm{e}}$ siècle.
} 
$4^{\circ}$ Qu'allant plus loin, il sache qu'il lui est loisible de s'écrier: «Mais, ce La Tour... c'était un cubiste avant la lettre ?» ce qui montrera qu'il est bien de son temps et qu'il n'a pas de préjugés...

Le tout à condition, $5^{\circ}$ qu'il n'oublie cependant jamais que l'œuvre de ce Lorrain « témoigne de la plus pure tradition française ».

Serait-ce tout ? Non. François-G. Pariset cite quelque part un beau texte. Il est du Père Couturier. J'imagine qu'il provient d'un article publié en 1937 dans l'Art sacré et intitulé : « Greco, la mystique et les commentateurs." «Il est peu de choses aussi provisoires et passagères, écrit le $\mathrm{P}$. Couturier, que l'efficacité de l'expression religieuse dans les arts. Des gestes, des visages ont bouleversé - puis leur vertu s'épuise... Des siècles passeront avant que les mêmes œuvres ne retrouvent quelque pouvoir sur les âmes. Il faudra pour cela la reconstitution d'un milieu spirituel ${ }_{\mathrm{p} 305}$ ressemblant à celui qui les vit naître - et que les cœurs soient redevenus un peu ce qu'ils étaient alors. »

Un milieu spirituel, dit le P. Couturier — qui est parti de Greco et non point seulement un milieu sentimental. Voici donc, pour bien faire, que, si nous voulons goûter l'art de Georges de La Tour, nous sommes entraînés à de longues, délicates, décevantes études de spiritualité. Négligeant dans son œuvre tout ce qui n'est pas « peinture religieuse » - nous voici condamnés à prospecter «le milieu spirituel » dans lequel se trouva plongé Georges de La Tour. Et donc à nous plonger (avec lui, hypothétiquement) dans les courants divers qui traversent la «Contre-Réforme lorraine», pour user d'un de ces raccourcis d'expression qui ont le mérite d'être commodes.

Car elle s'ouvre sur la France, la Contre-Réforme lorraine; elle s'ouvre sur l'Italie; elle s'ouvre sur les Flandres. Elle s'opère par les Jésuites, solidement installés dans leur université de Pont-à-Mousson et dans leur collège de Nancy; elle s'opère non moins par les Franciscains, par toutes les variétés de la grande famille franciscaine : les Cordeliers et les Minimes, les Capucins et les Tiercelins, les Clarisses et les Sœurs grises de sainte Élisabeth de Hongrie. Définissons la spiritualité des uns et des autres; posons-nous ensuite 
la question: les peintures de La Tour, à quelle nuance de cette spiritualité répondent-elles le mieux ? Ne serait-ce point à ce qu'on convient d'appeler "l'intimisme» de la piété française - à cette mystique des Capucins qu'on définit « un désir passionné de prendre Dieu se subordonnant le besoin de comprendre Dieu?».

Moi, je veux bien. Et je ne suis pas suspect, sans doute, de me désintéresser de ces problèmes ardus d'histoire religieuse et spirituelle... Mais je m'effraie. Quoi, tout cet effort pour situer l'œuvre d'un homme qu'on a réussi si péniblement à tirer du néant, à qui, patiemment, on a restitué sa date et son lieu de naissance (1593, Vic-sur-Seille), sa généalogie, la date des principaux événements de sa vie civile, de son mariage par exemple, etc. (mais on n'a pas réussi, naturellement, à connaître avec précision la qualité et l'intensité de sa piété personnelle : on est contraint de l'induire à partir de ses tableaux religieux, avec tous les risques que comporte une telle opération) ? Je répète que tout cela m'effraie. Comme m'effraie l'immense labeur en ordre dispersé que les règles du jeu imposent aux travailleurs soucieux de classer les «thèmes" qu'a traités l'artiste, et, chaque fois, de montrer en quoi le peintre étudié s'est montré, ou non, original par rapport à tous les autres artistes de son temps, lorsque, p306 comme eux, il exécutait sur commande des Madeleines et des saints François, des saints Sébastiens et des saints Jérômes, des Songes de saint Joseph ou des Reniements de saint Pierre ${ }^{203}$.

Et l'on voit où tend ce discours. Éternel problème de la monographie biographique... Ou bien, sur La Tour, cent pages dépouillées - la méditation d'un homme doué du sens artistique le plus raffiné et qui, bravement, simplement, oubliant volontairement tout ce qu'il peut savoir d'érudit sur le sujet, se met en face de toiles qui l'émeuvent - et tente de faire passer en nous cette émotion. Mais alors, on dira «Essai ». Et, peut-être, "Subjectivisme », un de ces mots terribles dont le Juge suprême écrasera, le jour du Jugement,

203 Je n'aborde pas le problème de la chronologie. Très peu de tableaux de La Tour sont datés (Le reniement de saint Pierre de Nantes l'est de 1650 ; La Tour est mort à Lunéville en janvier 1652). Il faut donc, pour établir une chronologie approximative des toiles que nous avons toutes raisons d'attribuer à La Tour, tenir compte du style et de la facture seuls. Ce qui est toujours délicat. 
sans appel possible, les malheureux groupés dans la petite chambre Histoire de l'art du grand tribunal de Josaphat. Et, en tout cas, la Sorbonne dira non. Bon... disons pour Fromentin. Qui n'aurait pu enseigner l'histoire de l'art : il n'avait pas les titres requis. - Ou bien, 440 pages attestant une capacité remarquable de travail, une ingéniosité louable à découvrir du nouveau, un effort tout à fait précieux pour reconstituer des milieux, en effet, et des nuances de spiritualité, et des développements de thèmes picturaux. Dans ce cas, succès en Sorbonne. Bien sûr. Mais comment ne pas éprouver le sentiment que l'effort est trop grand et dépasse le but, si ce but est d'éclairer l'œuvre d'un homme — ou qu'il ne le remplit pas suffisamment, s'il s'agit de peindre une époque ? Trop de choses perdues. Parce que rattachées à un homme, sans plus. Ah, si elles étaient rattachées à la peinture d'un milieu !...

En d'autres termes — de même que Braudel n'a pas écrit: Philippe II et la Méditerranée, mais La Méditerranée au temps de Philippe II, ce qui a donné à tout son apport sa signification plénière - j'aurais aimé que François-G. Pariset nous donnât, au lieu de Georges La Tour et le Milieu artistique lorrain - le Milieu artistique lorrain au temps de La Tour. (Il est bien entendu que je ne propose pas ce titre comme valable, je ne l'inscris ici qu'à titre d'indication et pour bien préciser une pensée.) Nous y aurions gagné. Car François-G. Pariset a dû finalement nous p307 priver de beaucoup d'indications qu'il a ramassées chemin faisant, pendant ses dures années de recherche. Et c'est dommage ${ }^{204}$.

204 C'est dommage aussi parce que, rien de plus vivant, de plus attirant par certains côtés que cette Lorraine de la fin du XVI ${ }^{\mathrm{e}}$, du début du XVII siècle Lorraine, comme la Comté de ce temps, elle aussi : mais la réalité comtoise est moins riche à cette époque, moins compliquée que la réalité lorraine - Lorraine, un de ces petits pays originaux qui, parce que petits, parce que ramassés, repliés sur eux-mêmes, guettés du dehors par de plus grands, de plus forts qu'eux, exercent nécessairement sur leurs membres une très forte contrainte morale et sociale. La petite Lorraine, à cette époque, si guettée, si menacée, si malheureuse (voir dans le livre de Fr.-G. Pariset le rappel des affreuses misères, de l'abominable famine dont souffre le pays à la fin des guerres de religion et qui expliquent tant de choses : l'épidémie de sorcellerie, par exemple) - la petite Lorraine est un des grands témoins, et des plus valables, de ce que, dans notre manie d'étiqueter, nous appelons la civilisation du baroque. Fr.-G. Pariset suit les leçons de ses maîtres, quand il s'élève, à diverses reprises, contre l'emploi irraisonné de ces grandes abstractions - de ces grandes machines à empêcher de 
Cela dit - je ne voudrais pas qu'on se méprenne sur ma pensée. Le livre que j'ai lu avec attention est un bon livre, solide, plein de choses, raisonnable et pondéré. Il y a beaucoup d'adresse dans la façon dont son auteur unit à une bibliographie qui toujours tient le dessus de la partition, une étude de milieu qui représente la basse. Dans la mesure où une thèse est « un chef-d'œuvre artisanal», cette thèse lui fait honneur. Elle restera le livre de base sur La Tour. Simplement, historien de la civilisation et non de l'art seul, je dis : «Ce n'est par hasard que s'opère la résurrection d'un peintre comme La Tour. Si elle s'opère à une certaine époque, c'est qu'il y a des raisons pour cela... Seulement, ces raisons, où les chercher? Dans l'état d'âme du peintre? Quel danger! Dans l'état d'âme du public qui adopte le peintre après que les érudits l'ont tiré de son néant? Voilà qui est plus facile à déterminer. Moins dangereux et plus conforme à ce que nous savons de ces grandes révolutions de mentalité qui rythment l'histoire de l'humanité — et qui sont bien autrement profondes que de simples changements de goût ou de modes. Puisqu'elles sont totalitaires en ce qu'elles affectent tout de l'homme, et l'homme tout entier. " p308

Retour à la table des matières

comprendre (voir notamment, p. 104, sur le Caravagisme et le Réalisme, termes équivoques et dangereux). 
I.

L'HUMANISME ROMAN ET LE PROBLÈME DES ÉCOLES RÉGIONALES

Le livre que M. Pierre Francastel, professeur à la Faculté des Lettres de Strasbourg, intitule L'humanisme roman ${ }^{205}$, est plein de choses pour nous, historiens. Il dépasse, en ce sens, la portée des habituels travaux d'une histoire de l'art pour maniaques du fichier ou pour snobs et snobinettes du monde. Ce à quoi l'auteur entend travailler, c'est à une histoire de l'art qui soit de l'histoire. Qui s'intègre dans l'histoire. Qui aide les historiens à écrire leur histoire - et qui s'appuie sur l'histoire des historiens pour mieux comprendre l'histoire propre de l'art. Ou des arts.

Que de problèmes ! Et comment ne pas être frappé de ce qu'ils ont de général, ou plutôt d'universel! Voici — qui tout de suite retient l'attention de M. Francastel, et à quoi s'accroche son livre - voici le problème des écoles régionales d'architecture romane en France. Établir un rapport entre le type architectural «normal» des églises dans une région de la France et les formations politiques territoriales qui s'étendent sur cette région: tentation. Ah! si l'on pouvait superposer à la carte des édifices de même structure et de même caractère une carte des formations territoriales (qu'on les appelle provinces ou grands fiefs) de la France du haut moyen âge... Et voilà

205 En sous-titre : Critique des théories sur l'art du XI siècle en France. Public de la Fac. des L. de Strasbourg, fasc. 96, Rodez, Impr. Carrère, 1942 ; 244 pages in $-8^{\circ}, 32$ planches. 
née la théorie des écoles régionales d'architecture française, formulée pour la première fois, avec force et méthode, vers 1840, par Arcisse de Caumont. - Oui. Seulement, voilà : un type d'architecture normal dans chaque région? où le prendre ? et comment définir les caractères qui permettent d'apparenter les édifices d'une "même province »? regarder l'extérieur, la décoration, l'ornementation? p309 ou bien s'attacher d'abord et avant tout aux problèmes et aux modalités du voûtement ? - De fait, autant d'auteurs, autant de solutions, autant d' " écoles ». Au bout de tout cela, un procès-verbal nécessaire de carence.

Bien. Mais j'observe : établir un rapport entre les dialectes parlés dans un territoire donné et les formations politiques qui s'étendent sur cette région: quelle tentation, là aussi ! Ah! si l'on pouvait superposer à des cartes dialectales des cartes provinciales, et découvrir entre les unes et les autres un merveilleux accord, quelle belle réussite! - Oui, mais voilà l'une de nos provinces les plus homogènes, les plus cohérentes dans son vouloir-vivre, la FrancheComté. Cherchez l'unité de dialecte qu'elle recouvre : vous trouverez à l'intérieur, au beau milieu de ses frontières politiques, de saillantes limites de parlers; d'unité, point. Aux prises avec ces difficultés, le créateur de la géographie linguistique Gilliéron écrivait déjà en 1905, dans cette sorte de manifeste qu'était l'opuscule : Scier dans la Gaule romane, qu'il signait avec M. Mongin: "Aucune recherche de dialectologie ne partira de cette unité artificielle, impure et suspecte [le patois]; et à l'étude du patois, nous opposerons l'étude du mot. » Ici aussi, tentation d'écrire: "A l'étude d'impossibles écoles régionales, opposons l'étude du monument. » Chute dans l'atomisme. Un peu brusque, mais en quelque sorte nécessaire.

Est-ce tout? Non pas, certes. Car voici posée la question des provinces. Des «vieilles provinces», comme on dit souvent, pour rehausser leur prestige dans un pays où l'autorité commence à s'acquérir aux environs de la soixantaine (c'est un septuagénaire qui parle). Ne sont-elles pas en France les unités vivantes, les unités constitutionnelles de premier ordre, les groupements politiques, administratifs, sociaux et pour un peu, si on nous poussait, nous dirions ethniques (mais non point, certes, raciques), qui jouent dans notre histoire, d'âge en âge, le rôle fondamental ? Comment admettre 
qu'à de si forts groupements, et si traditionnels, et si enracinés dans le sol français, ne correspondent pas et des formes monumentales et des formes linguistiques à elles ? Provinces. Dialectes provinciaux. Architectures provinciales. Et tout le reste... Oui, voilà posée la question des provinces.

Et M. Francastel, historien de l'art roman, de nous répondre :

Mais y a-t-il des provinces, en France, quand prend son essor l'architecture romane? Je vois bien qu'au début du $\mathrm{XI}^{\mathrm{e}}$ siècle il existe toujours, et bien vivante, une unité carolingienne. Mais des unités provinciales? Les jeux internationaux d'échanges, extrêmement rapides et étendus, témoignent d'une unité dont p310 les monuments sont les preuves vivantes. D'une unité. Quant au reste ? oui, il y a un royaume d'Arles, une Haute-Bourgogne, une France, un Anjou, une Catalogne: survivances, chez les grands de la terre, de la coutume barbare du partage. Rien de plus. La France romane éveille à la vie et modèle les futurs terroirs; elle ne les trouve pas antérieurement délimités et constitués. Il n'y a pas derrière l'art roman de paysage historique séculaire. (P. 227.)

Renversement, des positions traditionnelles, on le voit. Et M. Francastel conclut: "Là où, comme au $\mathrm{XI}^{\mathrm{e}}$ siècle, l'expression artistique joue un grand rôle, il est impossible de négliger cette étude sans dommage pour l'histoire tout court. » De fait, sur quelques points essentiels, le travail de l'historien d'art confirme les conclusions de Marc Bloch dans sa Société féodale. Non par hasard. M. Francastel ne les a point ignorées en rédigeant son étude. Il a eu toujours le souci de confronter ses conclusions avec celles de l'historien. Et voilà pourquoi le livre est à méditer.

Certes, nous ne prétendons pas en donner ici un « compte rendu ». Nous avons simplifié. Et généralisé. Sacrifié bien des nuances et de menus faits, probants et parlants; bien d'érudites discussions; bien de suggestifs rappels du rôle des techniques (p. 112) ou, dans une tout autre direction, du rôle de la liturgie dans la genèse des édifices. Nous voulons simplement montrer comment un tel ouvrage s'insère dans nos préoccupations. Et comment il peut nous donner à réfléchir. 
II. A PROPOS DU ROMAN EN POITOU

Le livre classique que $\mathrm{M}$. René Crozet a consacré à $L$ 'art roman en Poitou ${ }^{206}$ est un bon livre, dans les limites que l'auteur a voulu donner à sa recherche. Bien présenté, bien illustré, il constitue un remarquable répertoire des monuments subsistants de l'art roman dans une de ses plus importantes provinces. Il est documenté à souhait, précis, exact dans toute la mesure du possible. Il reproduit le plan, devenu courant, de ces sortes de monographies monumentales. Tour à tour. M. Crozet examine ce qu'il nomme « les conditions générales »; après quoi il passe ${ }_{p 311}$ en revue les expériences «pré-romanes » et recense les éléments datés de l'art roman en Poitou. Suit l'étude des «éléments de construction ${ }^{207}$ » (plans ; appareil ; voûtes, arcades, arcatures et supports; baies). C'est l'analyse. Les «synthèses" viennent ensuite : présentation intérieure et présentation extérieure de l'église; activité architecturale des ordres religieux. Enfin, trois chapitres traitent du décor sculpté ${ }^{208}$; du décor peint ; du mobilier, des accessoires et de l'art funéraire. Tout ceci reposant sur des enquêtes personnelles sérieuses et sur des recherches bibliographiques non moins sérieuses. Avec, souvent, des remarques utiles et neuves ${ }^{209}$. Le genre étant admis — on ne saurait mieux faire.

Mais l'honnête homme qui lit un tel ouvrage (dans la mesure où il peut se lire ; car, en fait, il est d'abord et avant tout un répertoire à consulter $^{210}$ ) — cet honnête homme ne peut pas s'empêcher d'être déçu. Que lui reste-t-il de nourrissant, de substantiel pour son esprit,

\footnotetext{
206 Paris, Henri Laurens, 1948 ; 292 pages in- $8^{\circ}$, 48 planches hors texte, carte index.

207 Mais le plan est-il un «élément de construction »? Et cette interprétation purement technique n'engage-t-elle pas l'auteur dans une certaine philosophie de l'œuvre d'art, qui ne manque ni d'étroitesse, ni peut-être de quelque naïveté ?

208 Utiles indications, p. 9-10, sur les matériaux. Et les transports de matériaux. Mais M. Crozet se contente de poser des points d'interrogation. Il eût fallu prendre le problème de ces transports corps à corps et apporter des éléments de solution.

209 Les deux amusants animaux de la page 180 ne seraient-ils pas deux Catoblepas en train de se manger les pieds?

${ }^{210}$ En fait, il serait bien plus commode d'avoir de simples listes de données bien classées, qui remplaceraient avec avantage des pages de texte.
} 
une fois le livre clos? "Pardon, me répondra-t-on: mais il faut commencer par le commencement. Des faits d'abord et bien contrôlés. Le reste viendra ensuite. »- Vous croyez?

Je pense, pour ma part, que les faits sont des clous à quoi accrocher l'idée. La formule n'est pas de moi, mais du philosophe Édouard Le Roy. Elle implique l'antériorité, la précellence, si l'on veut, de l'idée sur le fait. Parlons plus simplement : tant vaut l'idée, tant vaut le fait. En ce sens, pour recueillir le fait, le fait qui sera utile, le fait qui sera valable - il faut partir muni d'une idée... «Préconçue! Dites le mot! » - Je le dis, parce que votre indignation est puérile. Il n'y a dans " préconçu» aucun mystère, aucun secret, aucun scandale. L'idée préconçue, c'est l'hypothèse. Et il n'y a aucun savant, dans aucune science, qui se mette au travail sans hypothèse. Qui parte à la cueillette des faits sans hypothèse. Qui ordonne et clarifie les faits recueillis sans hypothèse. Je me rappelle Langevin, un jour, au Collège de France, à propos d'une candidature qu'il présentait à l'Assemblée des Professeurs, nous disant: «Il y a des tonnes de papier noirci qui sont tout juste bonnes à être jetées au feu. Ce sont ces données chiffrées que depuis quinze ans, ou vingt ans, ou p312 vingt-cinq, selon les stations, on recueille sur la température, l'hygrométrie, etc., de plusieurs centaines de stations munies chacune d'un outillage identique. Ces chiffres recueillis avec un soin pieux en dehors de toute hypothèse préconçue — ne servent à rien. Ils représentent un travail fait en pure perte. »

Et je ne dis pas que les faits recueillis par M. René Crozet, avec un soin et un scrupule louables, soient inutiles. Je dis que par eux-mêmes ils ne signifient rien. Et que, ce qui leur conférerait un sens et une valeur, M. Crozet le passe trop aisément sous silence. L'art roman en Poitou, mais d'abord, qu'est-ce que le Poitou ? En quoi le Poitou, au temps où naquit l'art roman, se distingue-t-il des contrées du voisinage ? Quelle est son originalité ? Son organisation sociale ? La nature et la qualité de sa population? Et puis, l'art roman: qu'appelez-vous de ce nom ? Suffit-il de recourir à la chronologie pour savoir ce que c'est que l'art roman ? Et n'y a-t-il pas, dans son existence même, un gros problème qui mérite qu'on s'y arrête? 
L'art n'est pas un jeu. L'art n'est pas une technique. L'art est l'expression d'un besoin de l'être humain. Des êtres humains. Des groupes humains, à une certaine époque, dans un certain pays. Quel besoin ? Notez qu'il s'agit d'un besoin daté, ou à dater. Et non pas d'un de ces besoins éternels, ou intemporels, dont ont coutume de s'accommoder nos philosophes. Parlons clair. L'art roman a été la manifestation, le signe visible et le produit d'une grande révolution de mentalité. Partez de là - et les faits que vous cherchez à recueillir s'ordonnent d'eux-mêmes dans des cadres valables. Ne partez pas de là. Ne partez à proprement parler de rien. Sinon du désir d'écrire un livre. Et les faits que vous avez recueillis restent sans signification. A l'état de poussière. C'est tout. p313 


\title{
LES HISTORIENS DES SCIENCES
}

\author{
Une Science à travers sa Bibliographie \\ EMMANUEL DE MARGERIE ET LA GÉOLOGIE DU JURA
}

$\underline{\text { Retour à la table des matières }}$

Nous n'avons aucune qualité pour présenter et juger un travail de géologie. Et la Revue de Synthèse, si large qu'en soit l'esprit, n'est pas faite pour suivre l'évolution des sciences naturelles. Mais signaler à ses lecteurs le bel ouvrage intitulé: Le Jura. Première partie, Bibliographie sommaire du Jura français et suisse (orographie, tectonique et morphologie) qu'Emmanuel de Margerie vient de faire paraître dans la somptueuse collection des Mémoires pour servir à l'explication de la carte géologique détaillée de la France ${ }^{211}$ — ce n'est point présenter ni juger un travail de géologie.

L'œuvre risque fort d'être un chef-d'œuvre de présentation matérielle, de distribution intérieure et de précision bibliographique à la fois. Si éminents que soient ces mérites, ils ne nous justifieraient pas de signaler ici le travail d'E. de Margerie. C'est sa valeur d'exemple que nous voudrions indiquer. Il y a bibliographies et bibliographies. Les unes, très rares, représentent d'incomparables instruments de progrès scientifique. Ce sont des bibliographies " choisies ». Euvres de maîtres connaissant à fond les divers aspects d'une question, elles indiquent à la fois, par leur silence, les livres

\footnotetext{
211 Paris, Imprimerie Nationale, 1922 ; XII-642 pages in-4ㅇ 183 figures dans le texte, 30 planches hors texte dont 5 dans une pochette séparée, in-folio. Il paraît difficile d'établir actuellement deux cartes plus belles que les deux cartes en couleurs du Jura, structurale et hypsométrique, que réunit la planche I.
} 
inutiles et par leurs descriptions précises ceux qui servent vraiment. Les gratte-fiches professionnels de la Bibliographie, avec un B, n'ont généralement que dédain pour les œuvres de cette sorte. Elles sont choisies, donc incomplètes. Eux ne choisissent point, et pour cause ; mais ils visent à être complets. De là, tant de recueils funéraires, tant de Pères-Lachaise de bibliographie, dans le dédale encombré desquels se perd le novice et s'impatiente le travailleur qualifié. La p314 bibliographie d'E. de Margerie n'est ni du premier ni, naturellement, du second type. Elle est " complète », dans la mesure où ce mot peut avoir un sens en bibliographie. Mais ce n'est pas un recensement de cadavres. C'est un chapitre véritable, singulièrement nourri et suggestif, d'une histoire encore à peu près inconnue: celle des démarches de l'esprit humain s'appliquant à un objet scientifique particulier...

Il a suffi pour cela, en apparence, d'une application stricte de la méthode chronologique au travail bibliographique proprement dit. Mais notons d'abord qu'il n'est pas déjà si aisé, techniquement parlant, de procéder à cette application : elle implique un surcroît de travail tel que les bibliographies sont singulièrement rares pour préférer au mécanique classement par ordre alphabétique, si favorable aux ignorances et aux paresses, le précieux et suggestif classement par ordre de succession. Ajoutons tout de suite que ce ne sont pas des titres seuls que Margerie classe dans une série de listes chronologiques et méthodiques, d'ailleurs déterminées avec le plus heureux soin. Margerie, géologue et savant, a lu les livres, les mémoires, les articles que Margerie bibliographe a recensés (nouveau sujet de réflexion et d'étonnement). Et il les a lus de la manière la plus intelligemment critique, avec l'intention d'en extraire, en aussi peu de mots que possible, je ne dis pas les données essentielles : il ne s'agit pas ici d'analyses, de ces analyses qui sont comme des réductions photographiques des travaux originaux - mais plus précisément ce qui, lors de l'apparition du travail répertorié, en faisait l'originalité et la nouveauté : l'idée neuve, l'idée de génie parfois, devançant de vingt ans, de trente ans le progrès consécutif de la science. Les idées des géologues ne sont point d'ailleurs des idées abstraites; ou, plus exactement, il n'en est point qui ne se puissent traduire aux yeux sous la forme de croquis, de schémas ou de cartes. Ces croquis, ces schémas, ces cartes, toutes les fois qu'il y avait lieu, E. de Margerie ne 
s'est point contenté de les cataloguer, ou même de les signaler avec éloges : il a fait mieux, il les a reproduits, admirablement d'ailleurs, dans la série de 183 figures qui ornent, éclairent, animent son texte presque à toutes les pages. Souvent même, se substituant rétrospectivement à des auteurs disparus, c'est lui qui a donné de leur travail un résumé graphique parlant aux yeux, plus bref que tous les mots et plus frappant aussi... Qu'on ouvre le livre à l'une quelconque de ses grandes divisions: cartes topographiques, géologiques, tectoniques; descriptions géologiques régionales; travaux spéciaux sur le tracé des cours d'eau, l'hydrologie p315 et la spéléologie, la limnologie, la sismologie du Jura : chaque fois, ce n'est pas devant un catalogue qu'on se trouve, mais devant un bilan; ou plus exactement, chaque fois, c'est un chapitre singulièrement attachant de l'histoire d'une science depuis ses toutes premières origines jusqu'à nos jours. On le lit avec d'autant plus de passion qu'il est plus objectif, plus écrit par les travaux mêmes des "découvreurs ", chacun se succédant à sa date, chacun ressuscitant pour ainsi dire à son rang, dans cette revue d'appel rétrospective des conceptions d'ensemble comme des hypothèses de détail.

L'exemple est à retenir. Par les « scientifiques » sans doute, mais pour les historiens aussi, les linguistes, les archéologues, tous les travailleurs intellectuels. Nous n'avons pas de bonnes histoires des diverses sciences. On s'en avise, ces temps-ci, de plusieurs côtés. Des bonnes volontés, souvent éclairées, s'ingénient à remédier tant bien que mal à ce défaut. Les résultats sont rarement heureux. Pourquoi ? Faute de bases suffisantes pour appuyer des constructions durables. Le jour où une histoire des conceptions géologiques trouverait à se fonder sur le roc inébranlable de quatre ou cinq monographies bibliographiques «évolutives » du genre de celle que Margerie vient de nous donner et qui, du premier coup, est un modèle - ce jour-là, elle pourrait être entreprise sans trop de scrupules et avec la quasicertitude de mériter la peine d'être tentée. Mais le jour où, parallèlement, une histoire des conceptions médicales, ou une histoire des conceptions linguistiques, ou une histoire des conceptions archéologiques pourraient, elles aussi, être tentées dans les mêmes conditions, - ce jour-là, d'autres travaux d'un autre ordre deviendraient possibles et dont la portée philosophique et méthodique ne serait sans doute pas moindre. Car c'est à chaque page presque de 
telles monographies que les sujets de comparaison les plus suggestifs de l'une à l'autre surgiraient pour les esprits soucieux d'étudier non pas seulement le progrès des théories scientifiques dans un domaine spécial, mais la démarche générale de l'esprit humain, toujours semblable à lui-même, quels que soient ses points d'applications et ses objets de réflexions variés.

Dans une tentative comme celle que nous signalons - et qui n'est pas une tentative, à vrai dire, mais une réussite - ce qui importe, encore une fois, ce n'est pas tant le labeur même de l'auteur, ses efforts, son sens de la précision et de l'analyse, l'économie prodigieuse de temps et de peines que représente son livre, que cette sorte d'illumination perpétuelle qu'il entretient dans les esprits et qui résulte, précisément, du rapprochement, à p316 l'intérieur du même livre, dans l'espace étroit de quelques centaines de pages, de tant d'hypothèses, de conceptions, d'idées séparées à leur apparition, par d'infinies distances dans le temps souvent, dans l'espace non moins - mais qui, remises pour ainsi dire au contact par les soins d'un savant d'esprit singulièrement curieux, meublé et intuitif à la fois, entrent aussitôt en réaction les unes avec les autres, s'éclairent, se renforcent, s'exaltent les unes par les autres et reconstituent devant nous, avec une puissance souveraine, ce beau drame émouvant de l'histoire d'une science - qui n'est, à vrai dire, que le drame éternel de la pensée humaine.

Isolée, l'œuvre d'Emmanuel de Margerie demeurerait une des œuvres les plus vraiment achevées que l'érudition contemporaine ait su nous procurer. Mais pour qu'elle prenne toute sa signification, il faut précisément qu'elle ne demeure point isolée. Et c'est pourquoi nous avons tenu ici à la signaler — c'est-à-dire, dans toute la force du terme, à la donner en exemple. p317 


\section{Un Chapitre d'Histoire de l'Esprit Humain}

\section{DE LINNÉ A LAMARCK ET A GEORGES CUVIER}

$\underline{\text { Retour à la table des matières }}$

Sous deux titres distincts, qui indiquent la double nature du lien qui les unit ${ }^{212}$, deux ouvrages ont paru l'an dernier: ils méritent éminemment de retenir l'attention d'un public fait de philosophes, d'historiens, d'érudits, de lettrés et dont les curiosités sont à la fois diverses et convergentes. Le premier, suivant le développement des Sciences naturelles de Linné à Jussieu, étudie, de 1740 à 1790 environ, l'histoire des méthodes de la classification et celle de l'idée de série tant en botanique qu'en zoologie. Le second, consacré à la période immédiatement postérieure, celle qui va en gros de 1790 à 1830, est placé par l'auteur, Henri Daudin, sous le signe de Cuvier et de Lamarck. Il y traite de cette glorieuse et féconde élaboration par Cuvier et les naturalistes anatomistes de son groupe, des grandes classes zoologiques - et des transformations consécutives, ou plutôt corrélatives, de l'idée de série animale reprise et finalement transformée par la puissante réflexion philosophique d'un Lamarck.

De ces travaux remarquablement approfondis et qui, par bien des côtés, ont quelque chose d'exemplaire, je ne voudrais pas qu'on s'étonnât de voir un historien rendre compte. Je souhaiterais moins

212 Henri Daudin, Études d'histoire des sciences naturelles. - I. De Linné à Jussieu : Méthodes de la classification et idée de série en botanique et en zoologie (1740-1790). - II. Cuvier et Lamarck: Les classes zoologiques et l'idée de série animale (1790-1830). Paris, Alcan 1926, 3 vol. in- $8^{\circ}$. — Pour la commodité, nous désignerons par A le premier ouvrage et par B-I et B-II, respectivement, les deux volumes du second. 
encore qu'on ne s'en étonnât point. C'est qu'on se ferait alors, sur la véritable nature de ces deux ouvrages, qui à bien prendre les choses n'en font qu'un, des illusions très préjudiciables.

Ils ne sont pas l'œuvre d'un historien, mais d'un philosophe, fortement nourri de ces sciences naturelles dont, depuis vingt ans p318 et plus, il s'efforce de pénétrer et d'analyser les méthodes et les doctrines dans leur réciproque indépendance. Et s'il tient évidemment, comme nous, l'histoire des sciences pour partie intégrante et fondamentale de cette histoire générale des sociétés humaines qui sera, un jour, l'histoire proprement dite, notre auteur ne s'est point donné pour but d'accorder les résultats de ses enquêtes avec les besoins, supposés ou soupçonnés, d'une telle discipline. Plutôt sans doute a-t-il pensé au mot d'Ostwald sur l'histoire des sciences : une méthode de recherche pour l'extension des conquêtes scientifiques. Et encore, à tout ce qu'a d'instructif, pour le théoricien de la connaissance méthodique et scientifique, une enquête comme la sienne, finement conduite sous le contrôle perpétuel d'une pensée lucide - et qui porte sur les relations, dans un milieu scientifique et à une époque donnée, de l'investigation proprement dite et de la construction doctrinale.

Henri Daudin n'a point songé à nous. Ce n'est pas une raison pour que, résolus à prendre notre bien où il se trouve, nous ne nous emparions pas de ce qu'il nous apporte.

I.

Sur la genèse de son ouvrage, $\mathrm{H}$. Daudin s'est expliqué nettement. Il est parti du désir de se mettre au clair touchant les origines, le sens et la portée du changement profond que les ouvrages de Darwin et les travaux inspirés par eux ont opéré vers 1860 dans les Sciences naturelles. Pour réaliser un semblable dessein, il convenait d'aller saisir d'une prise directe la pensée des hommes qui, pendant les quarante premières années du XIX ${ }^{\mathrm{e}}$ siècle, ont imprimé aux recherches zoologiques une orientation vraiment sûre et féconde. Possédaient-ils des idées et des conceptions telles qu'on puisse faire d'eux, historiquement parlant, des précurseurs authentiques et véritables de 
Darwin? Possédaient-ils d'autres idées, d'autres conceptions qui, évincées du domaine scientifique par la révolution darwiniste, mériteraient cependant de reprendre vie sous une forme adaptée à l'état présent de la connaissance scientifique ? On voit comment la recherche d'une réponse assurée à ces deux groupes de questions, doit conduire à une notion précise de ce que fut, en tant que nouveauté doctrinale, le darwinisme.

Recherche d'idées? Sans doute. Seulement, l'homme qui se proposait, il y a plus de vingt ans - à l'heure où nous formions $\mathrm{p} 319$ côte à côte, les uns et les autres, dans l'effervescence de notre jeunesse et de nos ambitieuses volontés, tant de projets magnifiques et démesurés d'étude - l'homme qui se proposait pour sa part de mener à bien cette enquête délicate, n'était pas d'humeur à se promener dans la rude végétation des idées et des faits comme un herboriste satisfait de cueillir quelques corolles brillantes, mais sans se soucier des racines profondes, ni du sol nourricier. Idées, soit. Mais aux devantures officielles des savants, on rencontre fréquemment, mêlées aux autres, de ces idées en papier peint que prennent pour appât les naïfs lorsqu'ils ne se soucient pas de suivre patiemment les travailleurs dans leur effort quotidien, leurs applications monotones et parfois vaines de techniques spéciales. Ce n'était pas de celles-là qu'avait cure H. Daudin. Ou, plus exactement, s'il n'entendait pas les négliger - car elles existent et leur existence a son intérêt — il savait qu'on ne pouvait les juger qu'en connaissant à fond et, pour ainsi dire, qu'en refaisant soi-même après coup, par un effort d'imagination bien réglé, le travail quotidien de recherche, d'observation et de comparaison, à la fois dépendant et indépendant des concepts théoriques: le travail en même temps libérateur et générateur de concepts qui, à toutes les périodes de l'histoire, s'accomplit dans l'esprit des savants en besogne.

De là, le double effort qui se marque dans l'œuvre de Henri Daudin. L'un, de reconstitution des filiations idéologiques, poussé aussi loin que possible: en l'espèce, jusqu'aux sources aristotéliciennes. L'autre, de restitution patiente et sympathique d'un labeur sans gloire apparente ni retentissement triomphal : celui des savants aux prises avec la réalité des faits et confrontant avec leurs observations de tous les jours, pour les adapter, pour les déformer 
également à ce contact, des notions théoriques héritées, plus encore que préconçues.

Deux écheveaux distincts. Peut-être. Mais les fils de l'un ne cessent de se mêler aux fils de l'autre, de se nouer et pour ainsi dire de se tisser avec eux. Et Henri Daudin n'a garde de rompre des connexions délicates pour satisfaire des besoins scolaires d'illusoire clarté. A chaque instant de la durée, il surveille d'un œil exercé les deux jeux. Il comprend, il explique, il éclaire l'un par l'autre. Qu'il s'agisse de Cuvier et de Lamarck, ou, à la génération immédiatement antérieure, des naturalistes et des théoriciens qui ont poussé et travaillé après que Linné eut mis sur pied sa méthode : Leibniz et $\mathrm{Ch}$. Bonnet; Buffon, Daubenton et son groupe; Lamarck enfin dans ses premiers travaux et A.-L. de Jussieu. Car, ayant décidé, pour les raisons que nous ${ }_{\mathrm{p} 320}$ avons dites, de se reporter pour bien juger du développement ultérieur, à la pensée et à l'effort opiniâtre de Georges Cuvier et de tous les naturalistes que gagnèrent immédiatement les méthodes et les vues du grand Montbéliardais - il a senti en même temps et comme à nouveau le besoin d'éclairer le point de départ de ces hommes par une enquête sur leurs prédécesseurs. De là, son premier livre, sa petite thèse: de Linné à Jussieu — avant de concentrer sur Cuvier et Lamarck lui-même, le Lamarck d'après la fondation du Muséum, un effort décisif. Marche logique d'un esprit qui n'entend rien laisser aux facilités de l'improvisation.

Quelles étaient, à la veille de la fondation du Muséum et de la venue à Paris de Georges Cuvier, les idées courantes des naturalistes sur leur science, ses directives et ses divisions? Demandons-le à un de ces ouvrages moyens qui sont si utiles pour nous autres historiens, en ce qu'ils nous mettent au fait, rapidement et sûrement, des conceptions scientifiques communes d'une époque : tels, l'Astronomie de Lalande avec son Abrégé, ou la Physique de Brisson. Recourons en ce moment aux Éléments d'histoire naturelle et de chimie de Fourcroy ${ }^{213}$.

213 Paris, Cuchet, 5 vol. in- $8^{\circ}$; les trois premiers datés de 1793, les deux derniers de l'an II ; c'est la $5^{\mathrm{e}}$ édition; la première date de 1780-1781. — L'Abrégé de 
En tête de son tome V, dans l'édition de l'An II (1794), Fourcroy, abordant le grave problème « de la classification méthodique et de la physique des animaux », débutait par ces mots :

Le nombre d'animaux qui couvrent la surface de notre globe étant très considérable, l'homme ne serait jamais parvenu à les distinguer les uns des autres et à les bien connaître si la nature ne lui avait offert dans la forme variée de ces êtres des différences remarquables, à l'aide desquelles il lui était facile d'établir des distinctions entre eux. Les naturalistes ont, de tout temps, senti l'utilité de ces différences et ils s'en sont servis avec avantage pour partager les animaux en classes plus ou moins nombreuses et pour former ce qu'on a appelé des méthodes. Quoi qu'il soit démontré que ces sortes de classifications n'existent pas dans la nature, et que tous les individus qu'elle crée forment une chaîne non interrompue et sans partage, on ne peut cependant disconvenir qu'elles aident la mémoire, et qu'elles sont très propres à guider dans l'étude de l'histoire naturelle.

p321 Et Fourcroy d'énumérer, en suivant les idées de Daubenton, les huit «ordres » d'animaux entre lesquels se laissait alors partager tout le règne : quadrupèdes vivipares ; cétacés ; oiseaux ; quadrupèdes ovipares ; serpents; poissons ; insectes et vers, auxquels on associe les polypes. "Peut-être, constatait-il, serait-il possible de multiplier davantage ces classes. Mais - et cette remarque en dit long sur la signification réelle de la classification à cette époque — «en augmentant les divisions, on multiplierait les difficultés et c'est ce qu'il faut éviter dans la méthode artificielle, dont la simplicité et la clarté sont le seul mérite ».

Ceci, en 1794. Or, dix ans plus tard, rédigeant en l'an XII (1804), l'introduction au Dictionnaire des Sciences naturelles de Levrault, le même Fourcroy, visant l'idée qu'il traduisait, en 1794, par les mots de " chaîne non interrompue et sans partage » des créatures, écrivait que des naturalistes célèbres - entendons Cuvier et ses disciples « nient la possibilité de former cette chaîne et soutiennent qu'il n'existe point une pareille série dans la nature ; qu'elle n'a fait que des groupes séparés les uns des autres ; ou plutôt, qu'il y a des milliers

Lalande est antérieur (1774); son Astronomie, $2^{\mathrm{e}}$ éd., de 1771, 3 vol. in-4 ${ }^{\circ}$ - Le Traité élémentaire de physique de M. J. Brisson (2 éd.) est de 1797 (3 vol. in$\left.8^{\circ}\right)$. 
de chaînes indépendantes et continues dans chacune de leurs suites, mais discordantes ou interrompues entre elles, ou dont l'association ne peut avoir lieu ».

Tout un monde d'idées et de faits entre ces deux textes si proches par leur date, 1794, 1804 : on peut mesurer, par leur rapprochement, l'ampleur et la rapidité de la révolution qui se fit en quelques années, à la suite de la création du Muséum et de la venue de Cuvier à Paris.

Dans le texte de 1794, ce sont toutes les tendances et les acquisitions des naturalistes français, réfléchissant et classant de 1740 à 1790, qui se trouvent résumées. Dans celui de 1804, c'est un labeur acharné de sept à huit ans qui dicte des conclusions tout opposées aux anciennes; c'est l'effort de constitution des classes fondées sur l'étude des fonctions qui se trouve synthétisé ; c'est cette conclusion enfin des premiers travaux d'anatomie comparée qui se trouve logiquement déduite : que, d'un groupe zoologique à l'autre, chaque appareil de l'organisme subit une dégradation; mais ces appareils divers " ne suivent pas tous le même ordre de dégradation »; tel est à son plus haut degré de perfection dans une espèce, tel autre dans une autre espèce: d'où autant de séries à former que d'organes régulateurs ; et de ces séries différentes, comment ensuite fabriquer cette échelle générale de perfection ou, comme disait le Fourcroy de 1794, " cette chaîne non interrompue et sans partage ", cette ${ }_{\mathrm{p} 322}$ série unique de créatures à laquelle, traditionnellement, le XVIII ${ }^{\mathrm{e}}$ siècle avait cru après le XVII ${ }^{\mathrm{e}}$ ?

En fait, dans ces deux textes si proches et si éloignés, il y a les deux thèses de H. Daudin. Son enquête sur l'idée de série et les méthodes de la classification au $\mathrm{XVIII}^{\mathrm{e}}$ siècle — puis son étude détaillée de l'œuvre de Cuvier, et par comparaison, de l'œuvre de Lamarck, de 1790 à la fin du premier quart du XIX ${ }^{\mathrm{e}}$ siècle.

Je serais tout à fait ridicule si je prétendais, soit analyser dans leur détail, soit à plus forte raison critiquer dans leurs conclusions ces trois volumes si nourris. Je me suis, en les lisant, énormément instruit : c'est une phrase que devront redire tous les lecteurs de H. Daudin, quel que soit leur degré de connaissance ou d'ignorance de ces 
questions compliquées. Tout au plus aurais-je, sur une question d'ailleurs en dehors des préoccupations directes de l'auteur, une ou deux remarques à présenter.

Cherchant à remonter aux origines de ce travail de classification qu'il montre se poursuivant, avec des fortunes et selon des principes divers, au cours de la vivante période qu'il étudie - Henri Daudin tout naturellement, se reporte d'abord à l'œuvre d'Aristote ${ }^{214}$. Qu'il convienne d'y chercher le résultat d'efforts personnels ou simplement l'encyclopédie pédagogique des connaissances d'une certaine époque, on y rencontre, en tout cas, les grandes lignes d'une classification dont Cuvier dira, non sans quelque complaisance, qu'elle n'a laissé « que bien peu de choses à faire aux siècles qui sont venus après lui »; mieux vaudrait dire que ces siècles se sont assez mollement reposés, en effet, sur le commode oreiller de l'aristotélisme. Mais pareillement, en quête des origines d'une conception tout à fait indépendante dans son principe de la systématique, - celle, si agissante, d'un monde vivant constituant une chaîne de formes qui vont se dégradant petit à petit d'un maximum à un minimum de la vitalité, - $\mathrm{H}$. Daudin à nouveau nous entraîne avec lui jusqu'aux lointains de l'aristotélisme.

Or, parvenu là, que nous donne-t-il ? Une étude, sobre mais scrupuleuse, des conceptions d'Aristote relatives à ces points particulièrement importants. Voilà qui va fort bien. J'y vois cependant deux inconvénients: l'un, quant au livre même de Henri Daudin. L'autre, plus général, et qui pose, malgré tout, p323 une question de méthode. A bien considérer les choses, ces deux inconvénients n'en font d'ailleurs qu'un seul.

Ouvrons le premier ouvrage : chap. I, La classification. Quelques remarques générales puis, tout de suite, un paragraphe : Aristote et le classement des animaux. Après quoi, Linné. - Chap. II, L'idée de série. Et tout de suite un paragraphe : Aristote et la série des êtres vivants. Après quoi, Linné. - Est-ce l'effet de ces déviations professionnelles auxquelles nous n'échapperons guère?

214 Il est bien entendu qu'il ne considère pas Aristote comme un commencement en soi! Voyez ses Remarques générales en tête de son premier livre (p. 1 et suiv.). 
Invinciblement, ce début historique si lointain fait jouer chez moi une sorte de mécanisme réflexe. Ab Aristotele principium: bien; mais descendons, par échelons, d'Aristote aux «modernes »? - Pas du tout, objectera Daudin. Aristote n'est pas là pour lui-même. Il n'amorce point de série. Je n'entends pas dépasser Linné dans ma marche explicative vers le passé. Seulement, comme les naturalistes au temps de Linné (et plus tard) s'absorbent dans une tâche, qui est de classification, et subissent la prise d'une idée, celle de la série : je cherche naturellement d'où provient cette idée et par qui cette tâche, d'abord, fut inaugurée.

Il est vrai. Vrai également qu'en ce qui concerne le travail de la classification tant en botanique qu'en zoologie depuis la Renaissance jusqu'au milieu du XVIII siècle, le $\S 3$ du chap. I, pour la botanique, et le $\S 5 \mathrm{du}$ même chapitre, pour la zoologie, contiennent plusieurs indications historiques utiles. Pas si complètes, évidemment, ni si précises toujours que ne l'aurait souhaité Daudin ; mais ce n'est point sa faute si le vaste domaine de l'histoire des sciences est peu et mal cultivé, au point que nous n'avons pas de travaux de valeur sur le courageux mouvement scientifique de la Renaissance. - En tout cas, en ce qui concerne l'idée de série, ces indications intermédiaires disparaissent. Et l'on passe d'Aristote, tel que le comprend et l'explique en 1926 H. Daudin, armé de ressources de l'exégèse moderne, aux conceptions des hommes du XVIII ${ }^{\mathrm{e}}$ siècle qui, sans doute, dans une certaine mesure, en découlent: mais le contact ne s'établit-il pas bien brusquement entre ce début et ce milieu d'une longue chaîne de siècles dont on fait sauter toute une suite d'anneaux pour rapprocher d'un coup le vingtième du premier?

Je me demande, en d'autres termes, si dans un travail de ce genre, c'était bien ce que j'appellerai, pour la commodité du discours, « le véritable Aristote » qui nous importait, plutôt que ${ }_{\mathrm{p} 324}$ l'Aristote des hommes de la Renaissance - un Aristote qui dominait leur pensée et leur activité d'autant mieux qu'ils l'adaptaient plus ou moins consciemment à leurs besoins et à leur état d'esprit?

Je soumets mes scrupules à Henri Daudin, d'autant moins timidement qu'aussi peu, aussi mal que je connaisse l'histoire des 
doctrines philosophiques et scientifiques au temps de la Renaissance — il me semble bien qu'à côté de l'idée aristotélicienne de la série, il faudrait faire une place à d'autres idées, à d'autres rêveries si l'on veut - mais qui n'ont pas laissé d'avoir leur importance, et, peut-être, d'exercer une influence durable sur ces conceptions semimétaphysiques et semi-scientifiques dont $\mathrm{H}$. Daudin, sur son terrain propre, n'est point sans relever certaines manifestations attardées. Dans leur vigoureux, dans leur héroïque effort pour s'élever au-dessus de l'empirisme pulvérulent des faits, pour se forger tant bien que mal (prématurément, c'est entendu : mais enfin, il nous faut bien, tous tant que nous sommes, nous adapter au perpétuel provisoire de nos connaissances et de nos pensées, si nous voulons nous saisir nousmêmes), - dans leur tentative à la fois chimérique, et puissante, et certainement émouvante, pour se forger de l'univers une représentation cohérente qui ne fût pas simplement celle que leur fournissait une théologie inspirée de la Genèse, les penseurs de la Renaissance - d'Henri-Corneille Agrippa et de Paracelse aux Padouans et à leurs disciples, de Pomponazzi à Cremonini, de Cardan à Giordano Bruno, de Vanini et de Telesio à Campanella - ont affirmé hautement leur croyance dans une solidarité des êtres, une corrélation des existences, un enchaînement des mouvements qui avait, à leurs yeux, l'immense mérite de substituer une conception organique de l'univers à des représentations fragmentaires et disparates.

Application aux faits de Nature d'une conception encore hésitante, mais déjà discernable, du mécanisme universel ? Bien plutôt, conséquence d'une intuition profonde de l'unité de la Nature, assimilée à un organisme vivant dont toutes les parties, également animées, concourent à la même fin par leurs actions et réactions réciproques. Au sein de cette intuition, l'un des rares historiens des idées qui aient travaillé valablement sur ces doctrines, l'historien de Campanella, Léon Blanchet, a parfaitement noté ${ }^{215}$ qu'il n'existait encore aucune dissociation entre l'idée de ${ }_{\mathrm{p} 325}$ solidarité organique et psychologique, et la notion d'enchaînement et de déterminisme

215 Léon Blanchet, Campanella, Paris, Alcan, 1920 ; notamment, chap. III : La critique de l'idée aristotélicienne de la nature dans la philosophie de Telesio et dans celle de Campanella, p. 146 et suiv. 
mécanique. De sorte que, la conscience existant partout où il y a mouvement, le mouvement partout où il $\mathrm{y}$ a conscience, et cette correspondance de fait révélant une identité d'essence - l'aiguillage des sciences de la nature sur la voie de l'interprétation magique ou, tout différemment, sur celle de l'explication mécanique, était, aux yeux de tous ces hommes, aussi légitime, aussi indispensable l'un que l'autre.

Toutes ces vastes conceptions, dont les racines plongent si haut également dans le passé, et qui, au XVI ${ }^{\mathrm{e}}$ siècle, ont été plus vivantes sans doute et plus actives que les idées aristotéliciennes - ont-elles exercé une influence, directe ou indirecte, sur le labeur des naturalistes, botanistes et zoologistes des $\mathrm{XVI}^{\mathrm{e}}$ et $\mathrm{XVII}{ }^{\mathrm{e}}$ siècles ? Ce serait à voir. Après tout, il se peut bien que non et que, l'enquête faite, Daudin n'ait rien à changer dans son mode de présentation des faits. Il $\mathrm{y}$ a là tout de même un scrupule que je trouve naturel de lui soumettre: n'est-il pas un des rares hommes, aujourd'hui, qui pourraient travailler efficacement à le lever?

II.

Qu'il ne faille point au reste, dans des études comme celles qu'il a menées à bien, négliger ou sous-estimer les fruits que peut produire, en dehors de tout labeur technique, une pensée fortement repliée sur elle-même et livrée à l'incessante méditation des processus naturels et de leurs enchaînements, c'est précisément ce que nous montrent, dans son second livre, les chapitres saisissants que H. Daudin a consacrés à la pensée de Lamarck, à la reprise par lui de cette notion de la série unique et graduée, vieillie déjà, discréditée, mais à qui, tout à coup, il confère une puissance, une fécondité, une signification toute nouvelle en lui attribuant ce qu'elle n'avait jamais eu jusqu'alors : la réalité matérielle d'un processus physique.

Lamarck et, en face de lui, Cuvier ; Lamarck et Cuvier étudiés l'un avec l'autre, l'un pour l'autre, on pourrait dire parfois l'un dans l'autre, tant leurs pensées et leurs œuvres, à de certains moments s'enchevêtrent en se répondant: lorsqu'on a lu les deux volumes du 
second ouvrage de M. Daudin, on voit agir, penser et produire ces

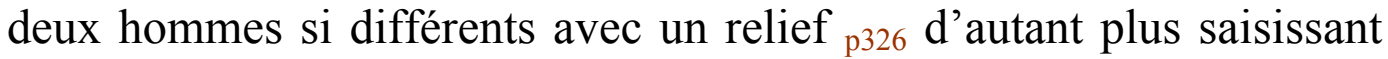
que, pas un instant, l'auteur ne s'arrête à esquisser le portrait, ou la psychologie de l'un de ses deux protagonistes: c'est à force de précision ingénieuse, de scrupuleuse exactitude, d'attention minutieuse à saisir et à marquer les nuances les plus fugitives, les moments les plus instables de leurs pensées et de leurs actions qu'il atteint à une puissance de rendu et d'évocation vraiment remarquable.

Voici Lamarck, botaniste laborieux à la vieille mode, d'abord titulaire d'un modeste emploi de garde des herbiers au Jardin du Roi - puis, dans le nouveau Muséum, acceptant les fonctions de professeur d'histoire naturelle des Insectes et des Vers. Sans doute entrevoit-il, dans l'étude du monde animal, un champ plus favorable à l'application et à la mise en œuvre d'une idée directrice qui s'est dégagée peu à peu de ses travaux antérieurs : celle d'une progression générale de l'organisation, peut-être insensible ou discutable entre les espèces et les genres, mais très nette, très assurée entre les classes ? Idée toute spéculative; mais précisément, en tant que travailleur, Lamarck se trouve à partir de 1795 mis en état d'infériorité manifeste et de relative impuissance par son ignorance des techniques nouvelles de dissection que va mettre en honneur et pratiquer avec maîtrise un nouveau venu, Cuvier. Lamarck ne dissèque pas. Il n'a jamais disséqué. Il s'en tient fidèlement, il s'en tiendra toute sa vie aux modes d'investigation traditionnelles des naturalistes du XVIII ${ }^{\mathrm{e}}$ siècle ; examen, description et comparaison des caractères externes des animaux sur pièces de collection. Et pareillement, le voilà qui (conduit cette fois par une vue théorique, par sa théorie sur les êtres vivants qui se construisent eux-mêmes en agissant, tandis que les corps inanimés tendent continuellement à se détruire) - le voilà qui se met en bataille contre la «nouvelle chimie», celle de Lavoisier et de ses disciples, tout en roulant dans sa pensée de continuelles méditations sur le problème universel de la genèse, de la constitution des choses : de là, un jour, jaillira tout armée sa doctrine d'une formation progressive des êtres vivants.

A ce Lamarck, si hardiment spéculateur, mais si timidement traditionaliste - audacieux dans le domaine de la pensée, entravé 
dans celui de la recherche — comme s'oppose avec vigueur un Georges Cuvier!

Par ses origines d'abord. C'est un Montbéliardais. Et s'il avait écrit un livre d'histoire, H. Daudin se serait arrêté à signaler avec plus de force ce qu'impliquait cette qualité. Il aurait noté tout ce qu'il y avait d'original, de vigoureux et d'âpre dans le particularisme de ce petit pays qui n'était pas français, mais ${ }_{p 327}$ poursuivait en paix, sous des princes d'origine étrangère et de souche allemande, une existence tranquille et somme toute heureuse. "Jurassien tenace, lucide et habile, dit de Cuvier H. Daudin, qui gouverne sa conduite, ses relations, ses amitiés en vue de l'achèvement des tâches entreprises, qui jamais ne s'abandonne ni à un sentiment ni à une idée... ${ }^{216}$ " Jurassien, non! Cuvier n'a aucun droit à revendiquer l'héritage des dons et des défauts, si différents des siens, qu'implique assez généralement ce qualificatif. Et les Montbéliardais protesteraient, si les Jurassiens prétendaient annexer leur Cuvier: il est trop profondément, trop intimement l'un des leurs.

Par ses débuts d'abord. Par ses études achevées en Allemagne, à la Caroline de Stuttgart. Les théologiens de ce petit pays, doublement isolé de la France par ses frontières et par son luthéranisme, se rendaient à Tübingen. Les apprentis savants, il fallait bien qu'ils se rendissent à Stuttgart, depuis qu'au nom du roi de France, le 6 janvier 1699, les fusiliers et les cavaliers de M. de Pelisanne avaient occupé, pour en remettre les locaux au culte catholique qui ne comptait pas un adhérent en ville - le collegium de Montbéliard, embryon d'une Académie tant désirée. L'orientation même des études de Cuvier est toute normale pour un Montbéliardais. Dans cette contrée où, pendant trois siècles, on ne publie pour ainsi dire pas un seul ouvrage de littérature, - juristes, théologiens et savants se multiplient. Il y a, en particulier, une sorte de tradition, assez prestigieuse, d'étude des sciences naturelles: elle s'affirme de Jean Bauhin, l'auteur de

216 B-I, p. 52. Ne jamais s'abandonner à un sentiment ni à une idée : ce ne serait pas le fait des Jurassiens, ces rêveurs réalistes, ces exaltés très maîtres d'eux, ces perpétuels anarchistes de gouvernement... 
1'Historia plantarum, de son frère Gaspard ${ }^{217}$, de son gendre Cherler, de Nicolas Taurellus leur contemporain, jusqu'à Léopold-Emmanuel Berdot, P.-Frédéric Bernard, l'anatomiste J.-Georges Duvernoy, bien d'autres.

Et pareillement, si Cuvier vient en France, ce n'est pas par un hasard individuel. En Normandie, chez les d'Héricy, il succède à un autre Montbéliardais, G.-Frédéric Parrot, physicien, qui devient professeur et recteur à Dorpat. Le préceptorat, avec parfois de longs exils, en Russie notamment, était une industrie nationale des Montbéliardais et des Montbéliardaises. Quant aux sentiments de Cuvier pour la Révolution, à quoi $\mathrm{H}$. Daudin ${ }_{\mathrm{p} 328}$ fait allusion dans une note en se référant à une lettre de Cuvier à Pfaff de 1792 : " Souvienstoi que, pour les honnêtes gens, la liberté existe entre toutes les formes de gouvernement » - ici encore, Cuvier est bien Montbéliardais ; quelques mois d'avance, il refait à sa façon, très exactement, la réponse du maître bourgeois de Montbéliard, Jacques-Frédéric Ferrand, au conventionnel Bernard de Saintes, opérant glorieusement « la conquête » d'une petite ville incapable de toute résistance : « Je vous apporte la liberté ! — Vous vous trompez, répond le compatriote, le contemporain de G. Cuvier : nous la connaissons de longue date, et aussi complète qu'il est possible... ${ }^{218}{ }$ ”

Aspects secondaires, et relativement négligeables, de l'homme. L'essentiel, c'est que Georges Cuvier, dès le temps que, tout jeune homme, dans la campagne montbéliardaise ou wurtembergeoise, il faisait son éducation de naturaliste en récoltant et en dessinant, d'une main remarquablement sûre, le plus de plantes et d'animaux possible, s'initiait en même temps à une technique alors totalement étrangère aux naturalistes, celle de la dissection. Si étrangère que, parce qu'il la possédait, on en déduisait normalement qu'il était, qu'il ne pouvait

217 L'expression dont se sert Daudin (A, p. 23, n ${ }^{\circ}$ 2) pour désigner Gaspard est inexacte. Né à Bâle le 17 janvier 1560, frère cadet de Jean (lui-même né à Bâle en février 1541) il n'a pas eu à «devenir Bâlois». C'est le père de Jean et de Gaspard, Jean I. Bauhin, né à Amiens en 1511, qui, après une vie agitée, dut se retirer pour religion à Bâle.

218 A. Lods, Bernard de Saintes, Mém. Soc, Émul, Montbéliard, p. 133. 
être que médecin : dans cette persuasion, beaucoup plus tard, Mme Fourcroy, une nuit, l'appellera au chevet de son mari malade. Par ailleurs, dès le temps de ses études également, Cuvier, avec une rare clairvoyance, perçoit l'immense portée de la révolution que les découvertes de Lavoisier, les analyses exactes de ses émules et continuateurs, sont en train d'opérer en créant la chimie moderne. Et déjà, l'histoire naturelle de l'avenir lui paraît devoir être un ensemble d'applications spéciales de la physique et de la chimie.

Ainsi, tandis qu'un Lamarck demeure fidèle aux vieilles pratiques, Cuvier, systématiquement, se livre à la dissection sous l'eau des petits animaux et utilise pour rendre plus apparents les systèmes de vaisseaux, la délicate technique des injections colorées. De même, tandis qu'un Lamarck fait sombrer son crédit dans une lutte déconcertante contre la chimie moderne et décourage un Candolle, venu l'interroger sur la botanique et à qui il répond «par de la chimie ou de la météorologie qu'il sait à peine » - Cuvier, s'appliquant à déterminer l'étendue et la signification p329 des variations que comportent dans les divers groupes zoologiques les mêmes appareils fonctionnels, mène cette recherche par les voies d'une expérimentation précise, avec poids, mesures, calculs et comparaisons des substances employées et des substances obtenues... Par le prestige que lui acquièrent, d'emblée, des dons exceptionnels mis au service de la plus tenace volonté d'arriver, le novateur impose rapidement, dans tous les milieux, l'idée qu'on ne doit plus, qu'on ne peut plus classer les animaux d'après leurs caractères extérieurs, sur le vu de leurs dépouilles: l'examen anatomique de l'organisation interne permet seule de décider de la composition et des limites des grands groupes zoologiques. Trouver dans la fonction exercée la raison d'être du dispositif organique - et dans le dispositif organique complètement étudié au moyen d'exactes dissections, les conditions déterminantes de la manière dont s'exerce la fonction : tel est à ses yeux, le double objet de l'histoire naturelle, approfondie, éclairée par des méthodes neuves.

Effets puissants d'une technique sur les progrès et les développements de la science. D'autant plus remarquables que cette technique est rudimentaire encore par certains côtés : ce n'est qu'à partir de 1827 que s'introduira à Paris l'usage du microscope composé 
achromatique d'Amici. Notons tout de suite qu'après avoir si bien marqué le rôle, l'influence des méthodes pratiques de recherche sur les conceptions scientifiques, Daudin se refuse à en tirer des conclusions brutalement exagérées. S'il s'y laissait conduire par un Cuvier, il s'en sentirait empêché par un Lamarck.

Je ne sais pas de formule plus heureuse, sur ce point, que celle qui se dissimule à la fin d'une note du second livre ${ }^{219}$. Rappelant l'Éloge académique, fort déplaisant par tant de côtés, que Cuvier consacra à la mémoire de Lamarck: "L'auteur, note H. Daudin, a parfaitement raison sur un point essentiel : Lamarck n'aurait jamais pensé comme il a pensé s'il avait su disséquer. » Mais tout aussitôt il ajoute : "On n'en conclut pas ici que sa pensée soit sans valeur, mais bien plutôt qu'un penseur vigoureux et sincère peut, dans des sciences encore incertaines de leurs voies, gagner par l'effort intellectuel de belles revanches de son infériorité technique. » On ne saurait plus justement, plus finement traduire les aspects divers de ce gros problème des rapports de l'idée et du fait.

Nous n'avons pas la place - et d'ailleurs, il serait inutile, le lecteur n'ayant qu'à se reporter aux livres de Henri Daudin - ${ }_{\text {p330 }}$ de suivre en détail la genèse des idées dernières de Lamarck telle qu'elle se trouve reconstituée dans ces ouvrages si sûrs et si fins. En maintenant l'existence d'une série unique et totale des animaux, en se refusant à laisser la notion de cette série se résoudre en une analyse comparative des appareils organiques, Lamarck défendait, en somme, l'indépendance et la dignité scientifique de son mode de travail : celui de l'histoire naturelle traditionnelle. Il suivait de près sans doute, de très près, les travaux de Cuvier ; il n'y participait pas. Et tout examen direct et approfondi des organismes, toute analyse réelle des mécanismes physiologiques lui étant interdite faute d'une technique appropriée - il ne lui restait, pour obtenir une détermination positive des êtres auxquels il s'intéressait, qu'une méthode : les situer dans une représentation globale du monde vivant...

219 B-II, p. 116, n. 2. 
Un mot encore. Cuvier, Lamarck : ce serait une grosse erreur de croire que, simplifiant arbitrairement les données du problème, $H$. Daudin ne s'attache qu'à mettre en lumière les idées personnelles et les apports de ces deux puissants esprits. Son souci constant, c'est tout au contraire, avec un sens très sûr des conditions et des nécessités $\mathrm{du}$ travail scientifique, de montrer comment les progrès qu'il enregistre ont été l'œuvre commune de grands et de moyens esprits, le résultat d'une collaboration féconde entre ce qu'on peut nommer le génie - et, d'autre part, l'application patiente et le bon sens estimable du gros des travailleurs ${ }^{220}$; compromis si l'on veut; il est vrai, dans une certaine mesure, que "cette prédominance finale de l'opinion commune des hommes compétents est en somme une caution de vérité, pourvu qu'elle se forme avec une liberté suffisante ».

D'un point de vue plus restreint, il fallait signaler cet aspect de la pensée propre de Henri Daudin. C'est par un tel souci de ne point isoler arbitrairement deux hommes et deux œuvres, qu'il renouvelle complètement le sujet qu'il traite.

p331 Cuvier et Lamarck: un problème posé de la même façon à deux grands esprits, qui en donnent deux solutions dictées par une opposition de méthode facile à concevoir: série unique; séries partielles. - Lamarck et Darwin : ce même problème encore, posé de la même façon. Et d'abord une solution incomplète : c'est Lamarck ; puis une solution définitive : c'est Darwin. - A cette façon puérile d'envisager les choses, le livre entier de H. Daudin donne un formel démenti. Il le donne, parce qu'il nous apporte trois " histoires" distinctes et convergentes. Celle, dans le passé, dans l'œuvre des naturalistes qui les ont précédés chronologiquement, des idées qui seront reprises par Cuvier et par Lamarck. Celle, dans le présent de

${ }^{220}$ Peu de vues plus fortes en elles-mêmes que celle qu'il exprime, une dernière fois, dans les pages finales de son livre. Certes, "réviser à fond des opinions reçues ; constituer des notions sur ce type nouveau ; mettre en œuvre des procédés inconnus d'investigation ou d'analyse » - ce sont tâches à la mesure des seuls grands esprits. Mais il importe beaucoup «que le commun des chercheurs ait assez d'activité d'esprit et d'indépendance de jugement pour débarrasser, le plus vite possible, les doctrines des savants les plus originaux de ce qu'elles contiennent normalement de trop systématique ou de trop exclusif». Et ainsi, c'est bien « un mouvement de pensée collectif» qui prévaut, en dernière analyse, sur les impulsions individuelles les plus puissantes. 
l'époque qu'il étudie, des recherches techniques et réelles auxquelles se livrent botanistes et surtout, à partir de 1790, zoologistes. Enfin, la notion précise et sûre de l'ambiance - des conditions générales de la pensée scientifique et de la recherche pendant tout le cours de la période envisagée.

Quand Henri Daudin a mené à bien sa triple enquête, personne qui songe encore à régler, en deux mots tranchants, le problème des rapports du darwinisme avec le « lamarckisme » ou le « cuviérisme ». Nouveauté, originalité profonde des thèses fondamentales de L'Origine des espèces - mais, pour rendre compte de leur succès et de leur diffusion, importance et intérêt de tout le travail antérieur, de toute l'œuvre des grands naturalistes du début du XIX ${ }^{\mathrm{e}}$ siècle, reprise et élaborée par leurs collaborateurs et leurs continuateurs. Lamarck et (contrairement à un préjugé courant) Cuvier tout autant sinon davantage que lui : ces deux hommes, et tous les travailleurs patients et réfléchis qui les entourent ont débarrassé le terrain d'avance, par leurs travaux, d'idées et de conceptions gênantes qui l'encombraient, ils ont, par un effort collectif puissant, réuni le lot varié des « conditions nécessaires » à Darwin. Originalité, mais continuité : à mettre en pleine lumière ces deux aspects du labeur scientifique, $\mathrm{M}$. Daudin apporte la même finesse et la même largeur de vues qu'à faire dans l'œuvre scientifique collective la part du génie et celle du zèle ou, dans l'œuvre personnelle des grands naturalistes, celle de l'idée par rapport aux faits.

Ne concluons point, rapidement, qu'après tout, cette sorte de haute et profonde intelligence doit être le partage nécessaire d'un historien des sciences. Qu'il n'en soit pas ainsi; que des savants tout à fait éminents aient été dépourvus de ce don, qui n'a rien à voir avec un certain esprit banal de "mesure » et «d'équité » intellectuelle : il ne manque pas, pour en administrer la preuve, 3332 de travaux de tout premier ordre, mais dont les perspectives historiques ont été faussées, ou du moins déformées, par l'attention trop exclusive prêtée à de certains hommes ou à de certaines œuvres étudiées en elles-mêmes, isolées de leur temps, et considérées d'un point de vue trop abstrait. Faut-il rappeler ici, par exemple, l'œuvre, si belle, si puissante, mais dans l'ensemble un peu déconcertante parfois, et un peu hasardeuse, 
d'un Pierre Duhem? Il n'y a qu'à renvoyer, à ce qu'en a dit, à plusieurs reprises, Abel Rey ${ }^{221}$.

Nous l'indiquions en commençant, par souci de ne point égarer le lecteur: les trois volumes de $\mathrm{H}$. Daudin n'ont point été écrits en songeant à nous, historiens. Faut-il qu'en terminant nous le répétions, mais dans une tout autre intention?

Lorsque, bien avant ses thèses, on a lu les deux articles si vivants qu'il enfouit naguère - en 1909 - dans les défuntes Pages Libres, et où il esquissait des débuts de Darwin un tableau si vraiment saisissant ; lorsque, dans ses thèses même, on a goûté, en historien, les pages qu'il consacre à retracer d'ensemble l'activité scientifique des milieux parisiens et provinciaux pendant la Révolution ; lorsqu'on a lu ses appréciations si pleines de sens et de vie sur le rôle joué, dans l'histoire des sciences naturelles au début du XIX ${ }^{\mathrm{e}}$ siècle, par le Muséum, cette grande maison novatrice où affluent, pour être mis en œuvre, les résultats et les produits d'un immense travail d'exploration, d'élargissement et d'approfondissement de notre univers, poursuivi de la fin $\mathrm{du} \mathrm{XVIII}^{\mathrm{e}}$ siècle au milieu du $\mathrm{XIX}^{\mathrm{e}}$ avec une passion si remarquable; lorsque, plus encore peut-être, on rencontre dans des pages qu'il veut rapides, des notations d'histoire sociale si suggestives - sur ces jeunes gens par exemple que «la dislocation des anciens cadres sociaux, les inquiétudes et les espérances suscitées par la crise des institutions, des idées et des mœurs, l'intention très généralement répandue de demander à la science positive l'indication des voies nouvelles » associent dans une volonté désintéressée d'apprendre et de chercher - on ne peut s'empêcher de formuler un vœu.

Le livre qu'il a voulu écrire, H. Daudin l'a écrit, excellemment, avec une sorte de rigueur dans le dessein et de fermeté dans l'exécution qui sont également remarquables. M'en voudra-t-il si je lui avoue qu'historien, j'empêchais mal parfois ma pensée ${ }_{\mathrm{p} 333}$ et mon imagination de broder, en marge de son texte, de perpétuels commentaires historiques, ou, si l'on veut, de concevoir, et non sans

221 Voir notamment Revue de Synthèse, t. XXXI, 1921, p. 122-125. 
enthousiasme, l'esquisse d'un autre livre, tout aussi fécond et que nous accepterions avec tant d'avide reconnaissance ?

Recomposer par la pensée, pour chacune des époques qu'il étudie, le matériel mental des hommes de cette époque ; reconstituer, par un puissant effort d'érudition à la fois et d'imagination, l'univers, tout l'univers : physique, intellectuel et moral de chacune des générations qui l'ont précédé ; concevoir un sentiment très fort et très assuré de ce que l'insuffisance des notions de fait et la pauvreté corrélative des théories devaient produire de lacunes et de déformations dans les représentations de toute nature que se forgeait du monde, de la vie, de la religion, de la politique aussi, telle collectivité historique; se prémunir ainsi contre ces redoutables anachronismes - les moins reconnus comme tels, et les plus énormes cependant - qui ne gratifient points de mousquets les combattants de Fornoue ou de photographie de Marie-Louise Napoléon à Sainte-Hélène, mais font, sans plus d'embarras, de Rabelais un libre-penseur... ou de Lamarck un darwiniste avant la lettre : voilà à mon sens, et plus j'y réfléchis, l'idéal suprême, le but dernier de l'historien.

Idéal aussi lointain, aussi inaccessible qu'on voudra. Du moins, si nous sommes assurés qu'il n'usurpe point son nom; si nous avons conscience qu'il est bien nôtre, qu'il vaut vraiment que nous donnions notre vie à préparer son événement : avouons-le nettement, afin que, peu à peu, s'oriente dans la bonne direction l'effort dispersé, l'effort aveugle des travailleurs...

Or cet idéal, comment jamais l'atteindre si nul ne se soucie de coordonner, d'organiser un tel effort si, dans un monde qui compte après tout si peu de chercheurs intellectuels, ceux-là qui se vouent à des tâches désintéressées ne se soucient pas de donner à leur effort toute son ampleur, à leurs connaissances toute leur portée utile ? " Mais c'est votre tâche à vous, historiens ; allons, vite en besogne... » Quelle dérision! L'histoire, celle que nous venons de définir, ne s'édifiera point par le labeur encyclopédique d'une escouade d'omniscients, donc d'omninescients, s'épuisant à vouloir capturer des chimères au pâturage, bombinantes in vacuo. L'histoire se fera par l'effort convergent d'hommes de provenance, de culture et d'aptitudes diverses ; car ce n'est pas la même formation qu'il faut pour décrire le 
contenu d'une conscience chrétienne au $\mathrm{XVI}^{\mathrm{e}}$ siècle, le processus d'invention de la machine à vapeur ou la conception qu'avaient de la science les contemporains de Jean-Jacques Rousseau. Et $t_{\text {p334 }}$ j'entends bien qu'on se tire d'embarras, aujourd'hui, avec une désinvolte élégance, en ne donnant aux historiens aucune espèce de formation particulière (sans doute, par bonté et afin que rien n'influence leur jugement); mais enfin, si astucieux soit-il, ce n'est là qu'un expédient et qui finira bien par paraître assez ridicule. Qu'on puisse concevoir, d'ailleurs, qu'un nombre restreint de travailleurs, doués de qualités très spéciales et nourris d'une forte culture, soient chargés de coordonner et de synthétiser les résultats obtenus par des spécialistes vraiment dignes de ce nom : il va de soi. Mais les temps ne sont pas venus. Pour le moment, à ceux qui connaissent à fond la technique bancaire et les problèmes du change, la charge d'écrire l'histoire des Fugger; à ceux qui ont étudié les sciences naturelles et leur évolution pendant les quarante premières années $\mathrm{du}_{\mathrm{XIX}}^{\mathrm{e}}$ siècle, le soin de nous dire non seulement ce que dit Daudin, mais par surcroît, ce que nous souhaiterions savoir, nous. Personne ne peut le faire qu'eux; il serait proprement absurde qu'ayant leur préparation, leur acquit, mais abandonnant leurs outils alors que la moitié seulement de la tâche est accomplie, ils envisagent sans scandale la pensée qu'un autre homme, dans vingt ou trente ans, après avoir tant bien que mal repassé par leurs voies, se trouve obligé d'écrire une histoire - qu'ils ont tout pour nous donner, et dès demain.

Je ne pouvais, en lisant, m'empêcher de rapprocher perpétuellement les dates. Eh quoi! voici devant nos yeux la bibliographie détaillée des productions de Lamarck, et celle des mémoires de G. Cuvier. 1791, 1792, 1794, 1795, 1797 : voilà pour l'un ; 1792, 1795, 1796, 1797 : voilà pour l'autre. C'est dans ces années tragiques, que, penchés sur les animaux qu'ils dissèquent ou sur les collections qu'ils examinent, ils impriment à la zoologie une orientation nouvelle et, pour la première fois, "moderne»? Mais quand commence la Révolution, la conception que les hommes, que les Français les plus éclairés se font de la nature et du monde animal dans son ensemble : quoi, c'est encore celle que traduit Fourcroy, au début de ses Éléments de chimie? Ces hommes, sur les idées de qui 
circulent tant de lieux communs légendaires - les plus instruits d'entre eux, les plus « scientifiques » d'esprit et d'aptitude, lorsqu'ils parlent avec attendrissement de la nature, voilà pourtant les pauvres idées, et si archaïques, et si dénuées de critique qu'ils mettent sous ce vocable prestigieux? Mais qui nous dira avec précision les conséquences, ${ }_{\mathrm{p} 335}$ les répercussions de toute nature d'un tel fait? Qui amorcera pour nous l'histoire sociale des idées scientifiques? Qui, sinon ceux-là mêmes qui ont étudié ces idées dans leurs origines, dans leurs expressions diverses et dans leurs conséquences pendant vingt années ; ceux-là qui en ont mesuré les filiations, les répercussions possibles et les limitations?

Mais ils ne sont pas des historiens ? Eh, qui l'est, historien, en ce sens? Qui, sinon celui qui sait? Et comme je souhaiterais, pour ma part, qu'à son livre si riche, si finement daté et nuancé, si important à la fois pour le méthodologiste et pour le savant, Henri Daudin ajoutât ce qu'il peut seul nous donner et ce qu'il nous donnerait si bien : un beau chapitre de l'histoire sociale des sciences de la nature. p336 


\title{
Figures et souvenirs
}

\author{
HOMMAGE A HENRI BERR \\ De la « Revue de Synthèse » aux « Annales »
}

$\underline{\text { Retour à la table des matières }}$

MON CHER AMI, vous avez eu, avant-hier je crois, vos quatre-vingts ans. Nous n'avons pas voulu laisser passer cet anniversaire sans que, ici, sur votre champ de bataille, quelques-uns de vos amis les plus proches ne se réunissent et ne saisissent l'occasion de vous dire ce que, depuis si longtemps, ils pensent - et qu'il faut bien pourtant qu'ils vous disent une fois...

Mon cher ami, nous sommes peu nombreux dans cette salle. Nous l'avons voulu ainsi. L'heure n'est pas aux grandes réunions, aux larges et bruyantes manifestations publiques. Nous sommes peu nombreux - mais ce n'est qu'une apparence. Car nous représentons ici, tout à la fois, et vos amis et vos obligés. Vos amis, c'est-à-dire, heureux homme qui n'avez point d'ennemis, tous ceux qui vous ont approché au cours de votre longue carrière, au cours de cette grande ambassade de la Science qu'avec la collaboration discrète, attentive et souriante de la chère Mme Berr, vous avez menée à bien sans défaillance. - Vos amis : c'est-à-dire tous ceux qui, à des degrés divers, ont profité de votre labeur et de vos initiatives... 
Je me rappelle bien souvent, je me rappelle avec une particulière insistance aujourd'hui les premières, les lointaines circonstances de ma rencontre avec vous. C'était tout près d'ici, 12, rue Sainte-Anne, au siège de la Revue de Synthèse Historique. On entrait et, dans un petit cabinet assez maussade, on trouvait derrière un bureau un homme jeune, svelte, d'une mise sobre mais élégante, avec une grande barbe si foncée qu'elle a bien de la peine, aujourd'hui, à se mettre en gris. Beaucoup de visites ${ }_{p 339}$ toujours, dans le petit cabinet. Des jeunes et des anciens. A gauche, je le vois encore, parfois endormi et silencieux, puis brusquement éveillé, vif, pétulant, l'habitué des habitués, Paul Lacombe, original esprit qui tint sa partie avec autorité dans les premiers concerts de la Synthèse. En face de lui, souvent, Félix Mathieu, "le Mathieu de Pascal », un de ces puits de science insondables mais qui ne rendent jamais leur eau. Et, beaucoup plus proche de moi dans le temps, comment ne pas évoquer le souvenir du pauvre Abel Rey, si brutalement enlevé à la vie et à ses beaux travaux? - On se frayait un passage au milieu des chaises. Et si petit jeune homme, si mince débutant que l'on fût, on connaissait votre accueil. Une parfaite bonne grâce, certes; une parfaite cordialité ; bien plus, un élan : cet élan de l'esprit vers l'esprit, ce fraternel respect de l'homme qui cherche pour l'homme qui vient chercher... Comme on vous en savait gré, mon cher ami, de cet accueil! Comme on sortait de chez vous soulagé, riche de plus de confiance dans la vie - mieux décidé à la rendre utile et belle, à la féconder par son labeur...

Cet élan, c'est lui qui a animé toutes vos entreprises. C'est lui qui leur a donné leur accent, conféré leur vertu. Il y a bien des collections de livres chez les éditeurs de Paris. Il n'y a qu'une Évolution de l'Humanité : la glorieuse Évolution, qui a fait naître déjà, au milieu de soixante volumes profitables et bienfaisants, une douzaine de livres hors pair ; la glorieuse Évolution qui, à elle seule, a compensé tant de faiblesses, d'abandons, de dénigrements d'un pays acharné à se démolir lui-même; la glorieuse Évolution qu'on rencontre partout dans les bibliothèques $\mathrm{du}$ monde - et qui $\mathrm{y}$ porte fièrement les couleurs de France. 
Et de même, il y a bien des revues en France. De savantes revues. Mais il n'y a, au seuil du $\mathrm{Xx}^{\mathrm{e}}$ siècle, qu'une Revue de Synthèse Historique. Quand on fera l'histoire de l'Histoire, mon cher ami, soyez tranquille : elle y trouvera sa belle, sa grande page. Mais ce que je veux dire de plus, c'est qu'elle a été autre chose qu'un appel à l'intelligence, qu'une perpétuelle insurrection contre tout ce qui brise l'unité de l'esprit humain — contre toutes les cloisons que l'on prétend maintenir entre ses activités diverses. Elle a été, de par votre grâce, une réunion d'hommes active, vivante, agissante, conquérante. Elle a été un centre dans toute la force du terme : centre, mot que vous aimez d'instinct. Elle a été un foyer, comme toutes les œuvres que vous avez $\mathrm{su}_{\mathrm{p} 340}$ créer (ce qui est beaucoup) et maintenir (ce qui est bien mieux encore). Et tous tant que nous sommes - tous, qui avons passé par là, qui vous avons vu à l'œuvre, qui vous avons apporté l'appui de nos jeunes forces - tous, dans ce que nous avons créé, dans ce que nous avons tenté, nous aussi, pour la science et pour ses progrès - nous avons rendu hommage en empruntant au grand foyer que vous avez allumé de quoi réchauffer nos entreprises : qu'elles s'appellent (je le dis en mon nom) les Annales d'Histoire Économique et Sociale, ces Annales que j'ai créées avec un de ceux qui, vous le savez, regretteront le plus de n'avoir point été avec nous ce soir - ou qu'elles s'appellent encore l'Encyclopédie française.

Mon cher ami, je parle. Et plus je vais, plus je m'absous de l'innocente supercherie par quoi nous vous avons attiré ici ce soir... Je devais, vous a-t-on dit, je devais parler au centre du mot Civilisation. Beau mot. Belle chose donnée à l'Europe, belle chose donnée au monde par la France. Plus belle de n'être plus pour nous, depuis trois ans, qu'une espérance, un de ces mirages flottants qui vous déçoivent au-dessus des déserts balayés par la tempête. Civilisation : mais vous voyez bien que je ne vous ai point trompé, puisque je parle de vous, et de tout ce que vous avez fait pour elle...

Civilisation, mot abstrait ? Mais qui veut savoir ce que, derrière ce mot, il peut tenir de réalité humaine, de réalité concrète - qu'il vienne assister à vos Semaines de Synthèse. Je reverrai toujours, pour ma part, la saisissante séance de discussion qui clôtura l'une des plus 
riches parmi ces Semaines: celle qui fut consacrée, en 1933, aux notions de science et de loi scientifique. Il y avait là (je ne parle que des absents) Gonseth, de Zurich, mathématicien ; Mineur, astronome, et Bauer, physicien ; Cuénot, biologiste ; Halbwachs, sociologue, et Brunschvicg, philosophe. Il y avait ces deux chers disparus: Abel Rey, plus brillant, mieux en forme que jamais - et François Simiand au regard si prenant, au regard teinté de mélancolie profonde comme ceux qui doivent mourir trop tôt. Il y avait, présidant cette assemblée de grands esprits, tous maîtres dans leur domaine, Langevin, notre grand et cher Langevin, le plus grand de nos philosophes scientifiques à cheval sur les deux siècles. Et j'étais là aussi, historien - modeste de la modestie d'une discipline qui n'a point encore trouvé sa forme véritable, modeste de la modestie de nos réalisations confrontées avec l'ambition de notre ${ }_{\mathrm{p} 341}$ idéal. J'étais là, et j'écoutais ces hommes qui cherchaient, en toute ardente bonne foi, à délimiter, à cantonner, à mesurer avec précision les ravages que la grande poussée de la physique moderne venait de faire subir à nos préjugés. Et voilà que, de ce concert de voix habituellement isolées et qui ne s'écoutaient guère, sortait une harmonie ; voilà qu'elles disaient les mêmes mots avec des accents différents ; voilà qu'elles rendaient sensibles à tous, concrètement sensible, l'unité fondamentale de l'humaine inquiétude... Grande leçon, cher ami, qui grâce à vous cessait d'être pour nous - qui a cessé, à tout jamais, d'être une leçon abstraite. Elle a, si je puis dire, pris figure d'hommes. Et ceux qui ont assisté à cette féconde séance verront toujours, comme moi, ces beaux yeux de savants attentifs, clairs et par instants rêveurs, suivre leur propre pensée ou la pensée des autres et refléter en eux les promesses de leur raison critique et, parfois, les élans mystiques de leur fidélité à la Science. Et de leur optimisme.

Optimisme, le mot que je serais impardonnable de ne point prononcer ici devant vous, en terminant ces quelques mots. Optimisme, votre force et votre beau secret. Optimisme : et laissezmoi relire, en terminant, ces quelques lignes de vous. Elles ont été écrites il y a longtemps. Elles viennent de paraître à une heure singulièrement trouble. Elles disent, avec force, la plus haute des raisons par quoi nous vous aimons : 
Je ne puis croire que la guerre doive être éternelle. Je ne puis croire qu'elle soit, seule, génératrice d'énergie et d'héroïsme. Je ne veux pas croire que l'unité humaine soit une chimère, l'Humanité un mot. Sans doute, un aspect du passé humain, ce sont les luttes, les invasions, les écroulements ou les morcellements d'Empire - mais, malgré tout, le trait dominant de l'histoire, c'est la solidarité des groupes humains, qui se resserrent sans cesse d'une façon presque mécanique; c'est l'avènement d'une complète et commune civilisation matérielle, en attendant la définitive civilisation morale, l'antithétique « Sainte-Alliance ». (Hymne à la Vie, p. 192.)

Voilà qui me permet, mon cher ami, résumant d'un seul mot notre sentiment à tous - voilà qui me permet de vous dire : merci. p342 


\section{ALBERT MATHIEZ}

\section{UN TEMPÉRAMENT, UNE ÉDUCATION}

\section{Retour à la table des matières}

Albert Mathiez n'a rien donné à nos Annales. Ce ne fut ni, de notre part, négligence ni, de la sienne, prévention. Soucieux de rassembler les énergies éparses qui se déploient, en France, et parfois dispersent un peu trop les efforts dans le vaste champ de l'histoire économique - comment n'aurions-nous pas songé à cette grande force qu'était Mathiez? A une demande de collaboration, il m'avait répondu avec empressement, m'offrant (mais pour plus tard) un article d'ensemble sur le prolétariat en France au temps de la Révolution. Et puis, nos Annales connurent quelque engorgement; il fallut ajourner, remettre au lendemain. Le lendemain: ce triste jour de février 1932 où, brusquement, le lutteur terrassé s'affaissa dans sa chaire.

Mais si la signature de cet historien passionné d'histoire n'a jamais paru dans les Annales - son esprit, j'imagine, devait s'y sentir à l'aise. D'abord il avait d'une Revue la même conception fondamentale que nous. Une Revue - ce peut être simplement une boîte aux lettres. Des auteurs que rien ne rapproche y glissent des manuscrits sans unité. Un secrétaire correct les adresse à l'imprimerie ; à quatre ou cinq, ils font un numéro automatique et le directeur signe son « Bon à tirer ».... - Parlons de ce que j'appellerai la Revue-levier. Celle qui soulève pour les jeter à bas les vieilles cloisons désuètes, les amas babyloniens de préjugés, de routines, d'erreurs de conception et de compréhension. Celle-là, ce qu'elle peut coûter de peines et d'efforts, mais aussi quelle en est l'utilité et le prix - Albert Mathiez l'a su qui a voulu, comme nous, ajouter à la liste des Revues françaises d'accent personnel, des Revues où diriger n'est 
pas synonyme d'endosser, une unité excellente et qui, depuis des années, synthétise ce qu'il y a de plus vivant dans l'effort soutenu des historiens révolutionnaires...

p343 Et puis, Mathiez avait de son rôle une autre idée - qui le rapprochait de nous pareillement. On a dit, redit ses emportements, ses véhémentes révoltes contre les choses et les hommes. Manifestation, en partie, d'un de ces tempéraments provinciaux que je connais trop bien pour en médire : qui donc, l'autre jour encore, écrivait que nous autres Franc-Comtois, nous ne savions guère parler sans éclats de colère? Mathiez était de Saint-Germain-lez-Lure, dans cette Comté du Nord qui, s'adossant aux Vosges, en dévale avec cent ruisseaux clairs vers l'Ognon et la Saône : rude contrée, si souvent foulée aux pieds des hommes et des chevaux; la plante humaine ne s'y redresse que plus drue.

Il y a cela. Il y a aussi l'affirmation véhémente chez Mathiez d'une indépendance jalouse, d'une volonté obstinée à ne point placer sous les coudes de pêcheurs fainéants des coussins moelleux - d'un désir raisonné et qui n'était pas chimérique de relever, en fouettant les jeunes énergies, en fustigeant les vieilles paresses d'esprit, le niveau de ces études historiques qui lui tenaient si fort à cœur : il est mort d'elles et pour elles. Sévérités, violences : explosions d'une force en excès et qui fusait en larges jets redoutables, mais devoir aussi, accepté comme tel. Il faut prendre sur soi pour le remplir sans défaillance. Il faut fermer les yeux non seulement à son intérêt personnel, mais à tant de considérations humaines pareillement, à la notion des services rendus par autrui, des mérites acquis, de l'âge, des vertus privées: et c'est dur alors, parfois; mais quoi ? nous ne l'ignorons pas, ici, et Mathiez le savait pleinement dans ses Annales, dans ses livres, dans ses cours : il y a des causes à placer plus haut, beaucoup plus haut que la solidarité banale de corporation, ou la considération nuancée de vertus aimables; et c'est pour les servir, ces causes, que Mathiez s'est montré violent, brutal, emporté : mais injuste vraiment, vindicatif, dur pour le plaisir et, comme on disait au XVIII ${ }^{\mathrm{e}}$ siècle, « méchant »- non pas.

Son âpreté, c'était une prédication morale. Un apostolat. 
Dans le numéro spécial des Annales Historiques, on retrouvera Mathiez, l'homme, l'enseignant, suivi tout au long de sa carrière, à Nancy, à Besançon, à Dijon, à Paris par une douzaine d'amis ou de disciples qui l'ont bien connu et compris. L'historien de la Révolution, la mesure en est prise dans une très belle étude, sereine, forte, large de vues - que notre collaborateur et ami Georges Lefebvre, appelé à recueillir, à la tête de la Société des Études p344 Robespierristes et à la direction des Annales Historiques, la succession de Mathiez, consacre à l'artisan de la dernière en date de ces révolutions qui, tous les tiers de siècle environ, transforment pour de nouvelles générations l'aspect traditionnel des événements qui se déroulèrent, en France, de 1780 à 1800, dates larges. Étranger aux petites passions de groupes et de coteries ; représentant du reste une tendance particulière et des préoccupations différentes de celles que ses confrères, Mathiez compris, ont manifesté jusqu'à présent l'auteur de ce grand livre, Les paysans du Nord et la Révolution, démêle avec netteté les directions de pensée primordiales qui furent, au cours d'une vie trop brève, celles de Mathiez. Inutile de résumer ces pages très pleines. Mais comme, à mon sens, elles illustrent bien un vice très grave de nos études, en France - de notre préparation trop archaïque au métier d'historien!

Si un homme de la vigueur intellectuelle, de la puissance de travail et de réflexion, du tempérament d'Albert Mathiez avait été lancé dans sa vie d'historien muni, non pas seulement de cette bonne culture humaniste que tout normalien des années 90 possédait comme naturellement, mais d'un bagage précis de connaissances positives qui lui aurait épargné les tâtonnements, les hésitations, les indécisions : quel gain au total, et quel profit certain pour nos études !

Georges Lefebvre montre très bien que, si Mathiez a fini par aborder, dans la seconde partie de sa vie, les études économiques et sociales, ce fut sous l'influence d'événements extérieurs. Tranchons le mot, la guerre, en faisant reparaître avec ampleur les difficultés qui, jadis, s'étaient dressées en face du Comité de Salut public, acheva d'imposer à son attention le point de vue économique que Jaurès cependant — dans cette Histoire socialiste que nos vingt ans dévorèrent avec passion et que Mathiez réédita lui-même — avait révélé déjà à un large public: mais composé d'ouvriers instruits, 
d'autodidactes et de militants socialistes ou syndicalistes, beaucoup plus que d'hommes d'études, d'historiens en titre et de professeurs.

N'est-il pas frappant qu'un Mathiez, homme de convictions démocratiques précocement ardentes, citoyen très actif d'un pays en proie, de 1895 à 1914, à tant d'agitations, de crises, de tragédies n'ait composé qu'à partir de 1915 la série d'études qui, groupées, ont formé son livre de 1927, son premier livre d'histoire économique ou, plutôt, sa première tentative d'interprétation économique et sociale de certains aspects politiques du mouvement : je parle de La vie chère et le mouvement social ${ }_{\mathrm{p} 345}$ sous la Terreur ? - N'est-il pas révélateur que cet historien, d'ailleurs si bien doué pour suivre et démêler les intrigues policières et les machinations secrètes des partis (là peut-être était sa faculté maîtresse, son don particulier) — sa première infidélité à l'histoire purement politique, ait été commise sous l'influence de l'école sociologique de Durkheim et s'agissant de faits religieux ${ }^{222}$ ?

Surtout, cet homme dont, en définitive, les besoins d'explications économiques et d'analyse sociale étaient vite satisfaits ${ }^{223}$; cet homme qui eut très peu le sens des réalités paysannes et même, d'un mot plus large, des réalités terriennes - en vérité peu d'œuvres d'historiens contemporains en France sont aussi totalement soustraites que la sienne à l'influence de cette école vidalienne de géographie dont il lui fallait bien cependant, à Besançon, à Dijon, résumer les ouvrages pour son enseignement - cet homme, dont la vigoureuse synthèse, $L a$ Révolution française en trois volumes de la Collection Armand Colin m'apporta dans ses premières pages une déception - si brèves étaient les notations de Mathiez sur la question des droits féodaux par

222 Il s'agit de sa thèse sur La théophilanthropie et le culte décadaire publiée en 1904 et composée au moment où, dans nos milieux de normaliens et de jeunes universitaires, les prises de L'Année Sociologique commençaient à s'assurer. Il faut ajouter, du reste, que le « sociologisme » ne fut qu'un bref épisode dans la vie de Mathiez. Ses travaux ultérieurs n'en portent plus la marque — loin, et peut-être trop loin de là.

223 N'est-il pas curieux de voir que, lorsqu'il oppose, par exemple, les Girondins, incarnation de la haute bourgeoisie, aux Montagnards, porte-parole de la démocratie, lui, ce méfiant, cet ennemi résolu des généralisations abusives, cet apologiste du travail minutieux et patient de recherche historique - il enlumine une image simplifiée, plutôt qu'il ne peint «au vrai » un tableau changeant et nuancé ? 
exemple (quelques lignes de la page 16) ou sur le mouvement de la Grande Peur presque passé sous silence (p. 64-65) ou, plus tard, sur l'immense série d'opérations qui s'appelle la vente des Biens nationaux - n'est-il pas frappant qu'à des étudiants totalement démunis, eux aussi, de formation "réelle », ce maître d'une incontestable activité, d'une irrésistible séduction, ait pu paraître, dans les derniers temps, l'homme qui venait, derrière les effigies traditionnelles des grands lutteurs, des « héros », des hommes de parti dressés pathétiquement les uns contre les autres, brosser enfin la grande toile de fond où se masseraient à la fois, dans les blés et les vignes, les laboureurs et les manouvriers - et dans les hautes bâtisses sans volets de la Croix-Rousse, les ouvriers lyonnais à la vie dolente et repliée, mais coupée de brusques révoltes?

Certes, leur instinct ne les trompait pas. Mathiez, de plus en plus, a voulu dans l'histoire toute politique d'une Révolution de grands premiers rôles introduire, avec la puissante masse ${ }_{\text {p346 }}$ chorale des exécutants sans relief propre, le dynamisme irrésistible des faits économiques et sociaux. Quel dommage qu'une éducation autrement comprise ne lui ait pas mis en main, quand il avait vingt ans, les outils que sa cinquantaine devait forger tant bien que mal - et dont il ne fut jamais vraiment le maître !

Mais ne concluons pas sur un regret, tout impersonnel soit-il. La perte qu'ont faites les études historiques en Mathiez est considérable. C'est un grand animateur, c'est un bon écrivain, c'est un professeur exceptionnellement doué, - c'est un homme d'action enfin et d'autorité qui a disparu prématurément. De sa taille, de sa trempe, non, en vérité, il n'y en a pas beaucoup... Serrons, avec tristesse, des rangs bien clairsemés. Et préparons-nous à soutenir, de toutes nos forces, ceux qui, reprenant en sous-œuvre, patiemment, laborieusement, l'esquisse si largement enlevée jadis par Jaurès, nous donneront cette histoire révolutionnaire qui nous manque toujours : histoire de masses et non de vedettes; histoire vue d'en bas et non d'en haut ; histoire logée, surtout, dans le cadre indispensable, dans le cadre primordial des réalités économiques. Et d'abord, d'analyses monétaires, d'études minutieuses de prix, de salaires, de changes, reprises, coordonnées d'ensemble non pas en France seulement, mais à l'étranger: si nettes, précises et sûres qu'on les puisse traduire en 
courbes et en graphiques avec cet art et cette science du traitement statistique que personne ne s'est soucié d'enseigner aux historiens de la génération de Mathiez et qui ne détruira pas, qui, au contraire, dégagera la notion de ce qu'expriment de vie ces grands mots décharnés d'histoire politique, d'histoire religieuse, d'histoire morale — qu'il est vain de vouloir opposer à ceux d'histoire économique ou d'histoire sociale.

Actions, réactions : il n'y a dans le passé, il n'y a dans le présent ni cloisons étanches ni despotisme écrasant de la Matière ou de l'Esprit. Il y a la vie, cette harmonie. Ce vouloir. p347 


\section{ALBERT THOMAS HISTORIEN}

Lorsqu'il y a trois ans, nous dûmes, Marc Bloch et moi, constituer à côté de nos équipes d'historiens un groupe d'hommes mêlés au maniement des choses contemporaines et susceptibles de les décrire avec compétence - je me tournai aussitôt vers Albert Thomas : ne pourrait-il me mettre en rapport avec quelques-uns des collaborateurs choisis dont je savais qu'à Genève il s'était entouré ? La réponse vint aussitôt. «Viens à Genève, m'écrivait-il toutes affaires cessantes [et la formule n'est pas de style, s'agissant de ce mois de septembre 1928, où tour à tour l'occupaient, sans parler du reste, un vif débat à la Commission financière de la S. D. N., la tenue à Varsovie d'une séance du Conseil d'Administration du B. I. T. et les préparatifs d'un voyage en Extrême-Orient] — viens à Genève : tout en étant un peu jaloux de ne pouvoir revenir au travail scientifique, tu peux être sûr que je t'aiderai de toutes mes forces. " Parole qui fut tenue. C'était l'historien qui parlait en Thomas.

Historien, Albert Thomas l'était profondément et comme d'instinct. Lorsqu'il vint prendre sa place, en novembre 1899, dans une promotion de normaliens où je ne sache pas qu'il ait jamais compté d'ennemis ou d'envieux - il n'hésita pas sur la voie à suivre. C'est avec une sorte de ferveur naïve et enthousiaste qu'on le vit s'asseoir devant nos maîtres, se plier à la forte discipline d'un Gustave Bloch, s'initier sous un Gallois aux séductions d'une géographie rénovée, chercher sous les cendres d'un enseignement austère ce qui couvait encore de flamme dans l'âme d'un Monod: tout cela, sans préjudice de ces leçons d'histoire, de critique et de libre recherche que 
de leur côté, chacun ${ }_{\mathrm{p} 348}$ dans son domaine, nous donnaient un Bédier ou un Charles Andler. A ce jeune homme ardent et sensible, doué d'une puissance de travail formidable encore décuplée par une conscience exigeante de bon élève habitué au succès - qui n'aurait rien su de ses origines aurait prédit, à coup sûr, un magnifique avenir d'historien : plus enthousiaste qu'analyste peut-être ; plus Faustien, si l'on veut, qu'Apollinien; il me faisait toujours rêver d'une œuvre où se serait donnée libre cours, avec les meilleurs de ses dons, cette espèce d'ivresse panthéiste qui semblait parfois bouillonner en lui : une histoire de la Grande Guerre des Paysans, j'imagine, placée sous le triple signe de Michelet, de Marx et de Jean Jaurès.

Qui n'aurait rien su de ses origines... Car, lorsqu'on savait? Je veux dire, lorsqu'à Champigny, dans la petite maison où vivaient ses parents, on avait rencontré le père d'Albert Thomas... Bien plus qu'un père, si fier fût-il des succès de son fils : une tradition vivante. Celle du peuple de Paris. De la vieille France artisanale, frondeuse et cocardière, révolutionnaire et sentimentale, laborieuse, avisée et narquoise. Il en était profondément, ce petit patron boulanger pendant cinquante ans mêlé intimement à la vie de ceux pour qui, sans ménager sa peine, il avait travaillé. Et que d'images au fond des yeux, que de paroles vivant au fond des oreilles : 48, lever de rideau, puis le Second Empire, la Guerre, la Commune, Thiers et la répression, le réveil ouvrier, les premiers syndicats, des souvenirs fouriéristes se mêlant aux leçons proudhoniennes, tout un raccourci d'histoire, à la fois française et ouvrière, jugée avec ce bon sens impitoyable, cette raison crûment lucide, cette simplicité familière mais nuancée dont il est plus aisé sans doute de marquer les limites que de rompre le charme. Alors, quand on avait suivi Albert Thomas, quelques dimanches, dans sa banlieue, respiré cette atmosphère familiale et puis, avec lui, flâné dans les prés, au long de la Marne nonchalante, ou grimpé au pas paisible d'un petit cheval qu'il attelait et conduisait luimême, jusqu'à la Queue-en-Brie, là où commence le grand plateau agricole, le pays monotone des fermes industrielles - on se disait, en rentrant, que nul n'échappe à son destin et qu'Albert Thomas ne serait pas historien, puisque le problème pour lui n'était pas «d'aller au peuple », mais, né du peuple, de ce peuple parisien si prenant et si dru, de ne point se couper lui-même de ses racines. p349 
Et Pourtant il lutta. Il tenta quelque temps de mener de front une vie de chercheur et d'historien avec une vie de journaliste et de propagandiste fort actif. La vie politique proprement dite ne l'attirait pas irrésistiblement. Cet homme qui, après l'assassinat de Jaurès, fit un moment figure de chef de parti, se défiait-il un peu de ses forces? hésitait-il à reconnaître en lui un véritable tempérament de leader ? Il n'était pas non plus un orateur-né. Et l'attitude même qu'il avait prise vis-à-vis des questions sociales, son effort pour étudier dans un esprit de réforme objectif des questions municipales d'administration et d'assistance (par exemple, dans ces Cahiers du Socialiste dont j'ai encore sous les yeux la série complète et qu'il composait avec Bianconi, Robert Hertz, Granet, Edg. Milhaud, M. Halbwachs et bien d'autres : que ces temps sont lointains!) - cette attitude pouvait l'isoler un peu au milieu d'hommes que sollicitait avant tout « l'œuvre immense de la création et du recrutement d'un grand parti », Le fait est qu'il ne se rendit pas tout de suite.

Il avait entrepris, dès sa seconde année d'École Normale, de sérieuses recherches sur les idées populaires de réforme sociale, telles que, sous la pression des circonstances, sous l'action des traditions, elles s'étaient élaborées en France de juin 1832 à avril 1834. Elles l'avaient amené en particulier à bien mettre en lumière le rôle et la valeur de ce Buonarotti à qui l'on doit «la première expression populaire, toute politique et insuffisante, de la lutte de classes ». Embryon, dans la pensée de Thomas, ces premières études poursuivies en vue du Diplôme, de recherches plus vastes qui ne devaient jamais voir le jour. Mais n'oublions pas qu'il composa, à l'usage de la jeunesse, une excellente petite Histoire anecdotique du travail qui aurait mérité, qui mériterait un rayonnement plus vaste. «Professionnellement irréprochable», comme il le souhaitait, proscrivant non seulement les faits dénaturés et les documents faussés, mais « l'introduction dans le récit de jugements susceptibles d'égarer les enfants et de leur inculquer des préjugés ", elle représentait un vigoureux effort pour préparer par l'histoire les esprits à l'examen sérieux des problèmes sociaux — de ces problèmes que la vie «ne tardait jamais à poser devant eux ». Enfin, pour l'Histoire socialiste qui parut sous la direction de Jaurès, Thomas écrivit sur le Second Empire un livre qu'il savait rapide, mais qui, pour la première fois, donnait de la vie économique et sociale d'une époque très mouvante 
une sorte de "mise en place» exacte et commode. Ce fut son testament d'historien. Lorsqu'on s'est voué à soutenir l'action, la propagande, la vie intérieure d'un parti, se dérober ${ }_{\text {p350 }}$ aux charges directes de la vie publique: gageure. Thomas fut élu député. L'engrenage le happa. On sait la suite : la guerre, le Ministère de l'Armement et, après l'armistice, la mise sur pied de ce B. I. T. dont vraiment, quel que fût le prix des collaborations qui l'entourèrent, il sut faire son œuvre à lui — bien à lui, et qui portait sa marque.

Vie dévorante et qui ne lui laissait pas le temps de se reprendre. Il me montrait mélancoliquement, il y a quatre ans, dans une pièce attenante à son cabinet directorial, ses vieux chers livres d'autrefois, ses livres d'histoire et les livres de ses compagnons de jeunesse restés « clercs »... La mélancolie n'était pas feinte. Il était trop naturellement, trop profondément historien pour qu'il ne souffrit pas de ne pouvoir chercher dans des travaux désintéressés " un réconfort pour sa besogne administrative quotidienne ». Et dès qu'il pouvait s'échapper, il le faisait avec joie. C'était une note pour les Mélanges Andler; c'était en Alsace, à Fouday, une commémoration de ce Daniel Legrand en qui le directeur du B. I. T. venait avec joie saluer un précurseur ; c'était, à Berlin, la recherche des procès-verbaux de la Conférence de 1890, ou encore le rêve, maintes fois caressé, d'une sorte d'Université du Travail qui se développerait à l'ombre du B. I. T. L'historien, en Thomas, n'est jamais mort. Il n'a jamais voulu séparer, par une cloison étanche, les deux parties de sa vie: sa jeunesse d'études et de recherches savantes, sa pleine maturité d'action et de création. Et comme il aurait haussé les épaules devant l'attitude puérilement avantageuse de ceux qui vont disant: qu'importe le passé à notre action présente ? Cet homme qui a vécu à même son temps, largement et librement ; cet homme qui a su fonder, créer et développer; cet homme qui ne répugnait pas aux anticipations les plus hardies portait en lui, toujours et en tout, ce souci des traditions, cette hantise de l'histoire qu'il ne devait pas seulement à ses professeurs, mais au premier, au plus fort de ses maîtres : à celui qui lui avait appris, depuis toujours, la solidarité des générations. 
Ainsi Thomas se trouvait-il tout prêt à comprendre l'ambition et le dessein de nos Annales. Ainsi voulut-il s'en occuper de son mieux. J'en eus, dès le début, une preuve touchante. La première fois que je pris connaissance du fichier d'abonnement de notre jeune revue, je fus surpris de voir qu'elle comptait déjà en Extrême-Orient quelques abonnés. C'était Thomas, voyageant en Chine et au Japon, qui, entre deux audiences officielles, avait ${ }_{\text {p351 }}$ trouvé le temps et le moyen de recommander à bon escient le périodique d'histoire vivante dont il avait salué le programme et l'apparition avec une joie sincère. Mais dernièrement encore, nous eûmes une dernière preuve de ses sentiments.

Arthur Fontaine venait de mourir. J'eus l'idée qu'il serait intéressant de faire revivre dans notre revue cette figure à la fois particulière et typique d'homme d'études et d'action. Sachant combien il avait été lié à Thomas, je soumis mon idée à celui-ci. La réponse vint sans tarder. «En dépit de la crise qui devrait commander une activité internationale accrue, on prétend réduire nos besognes quotidiennes... J'enrage, et je dépense mes jours et mes nuits à défendre l'institution que nous avons pu créer. En dépit de cette situation et peut-être à cause d'elle, voici ce que je veux te dire : Je ne connais pas d'autre personne que moi-même qui soit, à l'heure actuelle, plus préoccupé de Fontaine, de sa vie, de ce qu'il nous a légué, de son type d'homme.... Et alors, au risque d'assurer une tâche impossible; au risque de te faire attendre un peu, mais avec une entière bonne volonté, je te dis : Je vais essayer de faire les sept ou huit pages dont tu parles... » La lettre est du 21 septembre 1931. Ces sept ou huit pages, je n'ai pas voulu les réclamer à Thomas. Je savais trop que, s'il ne nous les envoyait pas, c'est qu'il lui était vraiment impossible de les écrire. Pourquoi faut-il qu'aujourd'hui ce ne soit pas comme auteur qu'il paraisse dans nos Annales ? Sous cette rubrique qui semblait faite pour lui : Historiens, hommes d'action... p352 


\title{
Un Tempérament d'Historien
}

\author{
CAMILLE JULLIAN
}

$\underline{\text { Retour à la table des matières }}$

L'idée est excellente qu'a eue Camille Jullian : réunir en volumes, sous un titre commun ( $\mathrm{Au}$ seuil de notre histoire), les leçons d'ouverture des cours féconds qu'il a professés au Collège de France depuis $1905^{224}$. On avait pu lire, au fur et à mesure de leur apparition, ces pages frémissantes de vie dans la Revue Bleue; et je puis bien rappeler qu'ici même certains articles portent témoignage de l'impression profonde qu'on en reçut. On les retrouvera, telles qu'on les a aimées, dans les volumes que nous signalons; on jugera seulement que, de leur rapprochement, elles reçoivent un surcroît de signification et d'efficacité. Et puis, si l'on y reconnait avec tous ses dons l'historien qui a mené jusqu'au terme sa monumentale Histoire de la Gaule, aujourd'hui complète en huit volumes, on y saisit plus directement, plus familièrement le professeur, aussi bien doué pour capter ses auditeurs par la parole que pour convaincre de minutieux lecteurs penchés sur les écrits.

Un grand professeur: il n'est pas donné à tous de cumuler avec celui de grand historien un titre d'une si éminente valeur sociale; et les exemples ne manquent pas de savants admirables, d'érudits novateurs qui, à de libres auditeurs, n'ont jamais rien pu communiquer de la flamme qui cependant les embrasait. Camille Jullian ignore cette disgrâce. Il possède l'art, bien français, de composer clairement, d'ordonner son discours avec lucidité. Il a le trait, la formule 
frappante et qui fait balle. Il a l'imagination, je veux dire le don précieux et rare de se replacer dans les conditions de vie et d'esprit des sociétés disparues, puis de les évoquer avec un saisissant relief. Il a... Mais qui dressera la ${ }_{\mathrm{p} 353}$ liste pareillement, de ce qu'il n'a pas ? Et d'abord le dogmatisme pesant. La certitude arrogante et morose. Le fétichisme des étiquettes et la superstition des genres. Et rien d'original à ce propos, rien de personnel comme la synthèse qu'avec tant de maîtrise et sans jamais repousser l'apport du présent, sans jamais rester sourd à l'appel du nouveau, il a su faire de quatre ou cinq disciplines qu'il ne nomme pour ainsi dire jamais; mais il fait mieux que les nommer, il les recrée à son usage.

Voici, à ses toutes premières origines, l'histoire économique ; et ce sont les victoires parfois surprenantes de techniques imprévues, celle des hommes de Locmariaquer, apportant en place, soulevant jusqu'à les dresser en pied, jusqu'à les faire tenir debout en équilibre, et pour combien de siècles, des masses de pierre plus pesantes que cet obélisque de Louqsor dont l'érection sur la place de la Concorde, en 1836, par des architectes munis de toutes les ressources de leurs techniques modernes, fit crier au miracle. Ce sont les premiers forgerons, les premiers métallurgistes rencontrant, dans leur quête du silex, "le métal, compagnon de la pierre », le métal aux tons fauves, verts ou bleutés: fer et cuivre, or scintillant à travers les sables, jadéite ou callaïs ; et par là, l'homme pénètre « dans ce mystérieux jardin des couleurs lapidaires, plus séduisant peut-être, avec leurs tons passés et leurs nuances éteintes, que les parterres de fleurs trop éblouissantes » ; mais le voilà aussi qui, " dans le lustre doré du métal, peut voir se refléter la lumière du soleil et sa propre image ».

Voici la géographie humaine et, sitôt que les néolithiques avec leurs cultures commencent à mettre sur le sol « un aspect nouveau de richesse et de bonheur », la science des établissements humains, des mariages successifs de l'homme avec la terre ${ }^{225}$. Une science

225 Camille Jullian a été de plus en plus attiré par ces problèmes; on sait comment il a appliqué ses idées notamment à l'étude de la banlieue parisienne : voyez le programme de ses recherches de 1910-1911 (Analyse, du point de vue archéologique et historique, de la carte de l'État-major, feuilles de Paris et de Melun) - puis de 1921-1923 (Formation et développement de la banlieue 
qu'éclairent, à la fois, les trouvailles archéologiques, les textes, un ingénieux usage de la toponymie et surtout, ce que rien ne remplace, la vue directe des lieux; un sentiment personnel, fin et rare, de ce que «l'œil trouve de joies neuves dans la vue changeante des choses du sol »; le don enfin d'animer d'une vie singulière ${ }^{226}$ les choses inanimées : la montagne, le fleuve, p354 l'île; la source surtout et la route, les deux grandes maîtresses de l'habitat humain. L'évocation, à plusieurs endroits, de «l'étrange vie de ce Mont Valérien, qui a protégé Paris, qui l'a opprimé, qui lui a imposé la plus pénible de ses dévotions $»:$ je ne sais rien en vérité de plus frappant ni de plus original.

Et voici, enfin, ce qu'on pourrait nommer la sociologie, si précisément l'historien qu'est Camille Jullian ne répugnait pas de tout son instinct à «nommer», pour s'en réclamer, des disciplines massives. Mais enfin, écoutons-le nous dire comment et pourquoi la préhistoire nous fournira peut-être "plus de réponses que l'histoire elle-même sur les vrais destins de l'humanité » ${ }^{227}$. L'histoire " proprement dite », celle de la Grèce, de Rome, de la France, "se laisse vraiment trop séduire par les accidents et tenter par les grands hommes. Tous ces bruits des individus, des combats et des révolutions, la préhistoire ne les entend pas. Elle ne voit que les œuvres d'une longue époque, les progrès de l'intelligence collective, les résultats acquis par l'humanité qui se fonde. Débarrassée des surhommes qui encombrent l'histoire, la science connaît, enfin, l'espèce humaine ${ }^{228} \gg$.

Dans tout cela, rien de livresque. Camille Jullian n'est pas le prisonnier de ses fiches. Il parle quelque part de ce Quicherat «qui

parisienne). Pour les règles de méthode, cf . dans la Revue des Études Anciennes, 1926, p. 139, l'article sur l'Analyse des terroirs ruraux, ce classique.

${ }^{226}$ Cf . dans la Revue des Études Anciennes, 1925, p. 209 et suiv., Cherchez la source et (ibid., 1926, p. 335) La source en préhistoire. Dans les leçons sur la banlieue parisienne, la source créatrice d'agglomérations humaines est au premier plan.

227 Décembre 1907 : Plaidoyer pour la préhistoire, I, 52.

228 Voyez aussi la leçon de 1913 sur les anciens dieux de l'Occident, ouvr. cité, I, p. 198: «L'historien soucieux de ses devoirs doit interroger l'ethnographie comme une sage conseillère » Et ce qui suit sur Durkheim. Nous ne parlons pas ici des leçons de 1914 à 1916 sur le folklore de la France. 
travaillait ses ruines avec la même logique et la même adresse que Fustel de Coulanges ses auteurs $\gg$. Il travaille, lui, sur les ruines et sur les auteurs, sur les cartes géographiques ou géologiques, sur les noms de lieux et les cadastres, sur bien d'autres choses encore, avec la même curiosité passionnée et le même bonheur. Il a lu Millin et ne dédaigne pas l'archéologue en Mérimée, moins encore en Rabelais pèlerinant à la Pierre-Levée de Poitiers, contemplant la tombe de Geoffroy à la Grand-Dent sous les voûtes de Maillezais, essayant la solidité des Arènes de Nîmes et du Pont du Gard. Et c'est encore, conclut-il, Pantagruel qui avait l'intelligence la plus vaste : " car il sut voir tout à la fois un dolmen, un aqueduc romain, des tombes de chevalier. Il embrasse les trois âges de nos antiquités nationales » ${ }^{229}$.

Ainsi va Camille Jullian à travers les textes et les musées, les livres et la nature. De tout, il sait extraire le grain de vérité qui viendra nourrir telle thèse, renforcer telle conjecture, donner ${ }_{\mathrm{p} 355}$ corps à l'une de ces vingt, de ces cent, de ces mille hypothèses qu'il porte en lui perpétuellement, comme des pressentiments à la fois et comme des certitudes de demain. "Je me demande de plus en plus si..." Ou encore : «J'incline de plus en plus à croire que...» Ces formules reviennent, sous sa plume, à chaque page. Impressionnisme, diront ces rats prudents de bibliothèque qui ne se glissent jamais qu'entre deux coques de noix, parfois creuses : un texte à droite, un texte à gauche. Un texte ? Encore faut-il en avoir un, et pour les temps qu'étudie un Jullian, c'est, on l'avouera, une manière de luxe. Un texte ? Il s'agit bien seulement de textes, ici. Il s'agit de rapports entre des choses très diverses, et qu'il faut des aptitudes toutes spéciales, une sorte de flair intellectuel particulier pour saisir et dégager. Et puis, laissons les jours s'écouler - et à la formule dubitative du début, d'autres petit à petit vont succéder. " Je persiste à croire, et chaque recherche m'en apporte des preuves nouvelles, que... » Ou finalement : «Je répète une fois de plus, et avec une absolue certitude, que... » Seulement, lisons plus loin, et nous trouverons aussi : «J'ai supposé que... J'en suis moins persuadé aujourd'hui. » $\mathrm{Ou}$ bien, tout net: «On est convenu maintenant, et avec raison, d'abandonner cette théorie »; note au bas d'une page datant de quelques années. Ainsi se déroule le cours 
naturel de l'esprit : de l'impression soudaine, de la brusque étincelle à la conviction affirmée ; mais la recherche demeure ouverte.

Aussi Camille Jullian n'est-il pas de ceux qu'un livre épuise fût-ce l'Histoire de la Gaule. Certes, il n'est pas inquiet. Le travail, ce travail dont il parle si souvent et si bien ${ }^{230}$, est trop sa joie pour qu'il connaisse l'inquiétude. Disons qu'il est en quête perpétuelle du mieux. Et toujours cette agitation, ce frémissement, cette vibration de l'esprit : celle-là même qui fait, de ces Chroniques gallo-romaines de la Revue de Études Anciennes, la chose étonnante et vivifiante qu'elles sont, même pour des non-spécialistes, pour tous ceux à dire vrai qui aiment sentir, en face d'eux, un esprit toujours aigu, ingénieux, mobile et en action. Voilà vraiment qui donne aux leçons d'ouverture, si heureusement réunies et groupées, le prix de choses vivantes, sensibles et animées. p356

$\underline{\text { Retour à la table des matières }}$

${ }^{230}$ Cf. notamment la leçon de 1920 : La vie du métier et la loi morale du travail ; II, p. 176 : «Le travail est pour l'ensemble de l'humanité ce qu'est l'âme pour chacun de nous, ce qu'est l'amour pour la famille : le souffle divin qui anime et fait vivre. » 


\section{HENRI PIRENNE}

\section{A TRAVERS DEUX DE SES FUVRES}

\section{$\underline{\text { Retour à la table des matières }}$}

I.

Il y a quelques mois, un livre a paru - petit par le format et le nombre de pages, mais gros d'idées neuves, d'hypothèses et de rapprochements féconds. Un de ces livres comme seuls sont capables d'en produire les hommes qui, ayant excellé toute leur vie dans une profession, ont par surcroît le don d'animer ce qu'ils touchent. Il est signé Henri Pirenne.

Les villes du moyen âge, essai d'histoire économique et sociale ${ }^{231}$. Avec moins de réserve, je dirais volontiers : essai d'histoire générale. Car, se tenant sur un terrain dont tous les coins et recoins lui sont connus, toutes les avenues et les perspectives familières, Pirenne n'a point récrit sous une forme différente cet autre petit livre excellent: Les anciennes démocraties des Pays-Bas ${ }^{232}$, qui a révélé naguère son nom au grand public de langue française. Il n'a point non plus, reprenant les thèmes d'articles classiques de la Revue Historique, institué à nouveau une enquête érudite sur l'origine des Constitutions urbaines au moyen âge ou sur le rôle des marchés et des marchands dans cette genèse ${ }^{233}$. La synthèse magistrale qu'il a tentée et réussie est d'une autre portée, d'une autre envergure aussi. C'est une vue d'ensemble sur quelques aspects fondamentaux de la civilisation

231 Bruxelles, Lamertin, 1927, 206 pages in-12.

232 Paris, Flammarion, 1910 (Bibliothèque de philosophie scientifique).

233 Revue Historique, t. LIII, 1893 ; t. LVII, 1895 ; LXVII, 1898. 
médiévale qu'avec une incomparable puissance, faite de bon sens, de raison lucide, d'imagination aussi et d'intelligence historique singulièrement affinée, un maître historien extrait pour nous du trésor de sa documentation et de son expérience.

Chaque état de civilisation, chaque type de ville. H. Pirenne, pour nous décrire les cités et les bourgs du très haut moyen âge, ${ }_{p 357}$ puis les villes médiévales proprement dites, ne court point d'une haleine s'enfermer dans leurs murailles. Il commence, au contraire, par brosser à grands traits, mais avec une singulière puissance, la série de ce qu'on pourrait nommer les «paysages économiques » successifs par quoi ces agglomérations, d'ailleurs si différentes, ont été tour à tour encadrées, expliquées et dans une large mesure engendrées. Par avance, il nous fait comprendre pourquoi et comment les villes de chaque époque présentent tels caractères, et non point tels autres. Les éléments qu'il dégage de la masse des faits rapprochés et combinés dans ces larges synthèses, il nous les montre ensuite, il nous les fait retrouver, groupés et efficaces, dans l'unité intérieure des organismes urbains. Rien de plus saisissant qu'une telle méthode; rien de plus satisfaisant pour l'esprit; au sens précis du mot, rien de plus intelligent. Et c'est ainsi que, destinés à nous montrer la vigueur persistante jusqu'à la fin du VIII ${ }^{\mathrm{e}}$ siècle, puis la décadence profonde du commerce nourricier de la Méditerranée, de cet «entrecours» de l'Orient et de l'Occident que vint brutalement interrompre l'Islam, deux larges tableaux nous expliquent au préalable les caractères des cités et des bourgs que décrit savamment le chapitre III; c'est ainsi que, précédant l'étude de la formation des villes et des institutions urbaines, les deux chapitres IV et V nous fournissent par avance, en nous exposant les causes et les étapes de la renaissance du commerce et de la formation d'une classe spécialisée de marchands, la clef d'une série de faits proprement urbains que Pirenne n'abstrait jamais, facticement, du milieu dans lequel ils plongent.

On n'attend pas de nous l'analyse d'un tel livre. Il faut le lire. Il est du petit nombre des ouvrages historiques que devrait contenir la bibliothèque de tout homme cultivé de notre temps, à côté de 
l'Histoire de Belgique, du même historien ${ }^{234}$; de ses Démocraties anciennes des Pays-Bas, et de cet autre chef-d'œuvre, le mémoire sur les Étapes de l'histoire sociale du capitalisme ${ }^{235}$, fruits magnifiques d'une maturité pleine de sève et de vigueur généreuse. Par ailleurs, ce n'est pas à nous qu'il appartient d'examiner, en spécialiste de ces histoires lointaines, les thèses fondamentales sur lesquelles s'appuie l'effort de l'historien. Thèses déjà présentées, il y a quelques années - en 1922 et 1923 — dans deux mémoires publiés par la Revue Belge de Philologie p358 et d'Histoire et intitulés, l'un, Mahomet et Charlemagne, l'autre, Un contraste économique: Mérovingiens et Carolingiens $^{236}$. On les connaît dans leur teneur essentielle. Les invasions, dit Pirenne, n'ont pas brisé l'unité économique du monde ancien. Car ce monde, pour le concevoir tel qu'il était, il convient de rejeter d'abord notre notion d'Europe, qui fausse toutes nos idées. Une Europe ? non. Un Empire romain et une civilisation méditerranéenne, l'Empire bordant la Méditerranée sur toute son étendue, et ses frontières formant, autour de la mer intérieure, un vaste cercle de protection destiné à en assurer l'entière sécurité. Une mer liant des hommes unis par les multiples liens d'une même civilisation, et à qui on ne devrait jamais appliquer ces étiquettes d'Européens, d'Asiatiques, d'Africains adaptées (peut-être ?) à nos besoins actuels, mais qui, projetant dans un passé tout différent un présent fort éloigné de lui ressembler, n'engendrent qu'erreurs et confusions graves ${ }^{237}$.

Or, c'est cette Méditerranée qui, au temps des invasions, a attiré les Barbares. Vers elle, ils se sont rués. Sur ces rives ils ont voulu

234 Bruxelles, Lamertin, in $-8^{\circ} ; 6$ vol. actuellement publiés, de 1900 (t. I, $1^{\text {re }}$ éd.) à 1926 (t. VI), tous en seconde ou troisième édition remaniée, sauf le dernier.

235 Publié dans le Bulletin de l'Académie royale de Belgique, Classe des Lettres, 1914. - Cf. L. FEBVRE, Les nouveaux riches et l'histoire (Revue des Cours et Conférences ; $23^{\mathrm{e}}$ année, $2^{\mathrm{e}}$ série, numéro du 15 juin 1922).

236 Revue Belge de Philologie et d'Histoire, t. I, 1922 ; t. II, 1923.

237 Cf. ce qu'écrit de son côté, dans la Revue Historique (t. CLVI), Ferdinand Lot rendant compte de l'ouvrage de Louis HALPHEN, Les Barbares: "Nos conceptions de l'Europe et de l'Asie ne sont pas les mêmes que dans l'antiquité et au moyen âge... Le lien entre les hommes dans l'antiquité, c'est la Méditerranée, sans distinction d'Europe, d'Asie ou d'Afrique. Si l'on part de ce fait, on voit que l'Afrique du Nord, l'Égypte, la Syrie, l'Asie mineure sont des pays beaucoup plus européens pour un ancien ou un homme du pré-moyen âge que la Germanie ou la Scythie » (p. 157). 
s'établir tous, ils se sont battus pour s'établir: Vandales en Afrique mineure, Wisigoths en Aquitaine et en Espagne, Ostrogoths en Italie, Burgondes dans les terres rhodaniennes. Tous sauf quelques-uns, les tard-venus : les Francs surtout. Installés d'ailleurs, une fois conquise leur place au soleil sur les rives de la mer nourricière, ils ne réclament plus rien. Il n'entravent rien. Certes, l'Empire est en morceaux. Certes, cette dislocation ne s'est pas opérée sans dommages. La vieille civilisation méditerranéenne a subi de rudes secousses. L'activité des esprits, comme celle du trafic, s'est singulièrement ralentie. Mais quant au système des échanges, rien de modifié. Entre riverains de la Méditerranée, les relations continuent: moins actives, certes, moins fécondes, restreintes en valeur et en importance : mais la mer exerce toujours, autour d'elle, son attraction séculaire. Il n'y a pas de rupture, pas de fracture entre Orient et Occident...

Brusquement une révolution. L'Islam. L'invasion islamique. "Avec la force d'un cataclysme cosmique », elle se jette en travers du cours de l'histoire. Une cinquantaine d'années, pas plus: et elle touche, d'une part, à la mer de Chine, de l'autre à p359 l'océan Atlantique. Ce gigantesque effort ne saurait se soutenir et ne se soutient pas. Mais quand, au commencement du vIII ${ }^{\mathrm{e}}$ siècle, la force d'expansion de l'Islam paraît brisée, c'en est fait, définitivement, du monde antique. Il est détruit, cette fois, irrémédiablement parce que, sous la brutale poussée des nouveaux conquérants, la mer « familiale » qui en unissait les riverains a changé de maîtres. Elle est en grande partie un lac musulman; en petite partie, un lac chrétien. On s'y poursuit, on s'y heurte, on s'y bat. La Méditerranée sépare, pour la première fois depuis bien longtemps, cet Orient et cet Occident, ces rives d'Asie, d'Afrique et d'Europe qu'elle unissait jadis et rendait pareilles...

Alors, l'État franc prend toute sa valeur. Lui, le tard-venu qui s'était constitué, faute de mieux, loin des rives ensoleillées de la mer unitaire, au contact de l'océan lointain et des grandes artères fluviales de l'Europe médiane. Il devient le centre géographique, et le noyau d'une formation nouvelle qui, petit à petit, se constitue : l'Europe, carolingienne puis médiévale. Qu'il s'agisse de religion, de politique, d'institutions, de langue, de littérature, d'écriture même - partout le contraste se montre saisissant entre les temps mérovingiens en qui 
survivaient, tant bien que mal, les temps antiques - et les temps carolingiens qui annoncent des formations politiques et des destins nouveaux. Mais qui précisément, parce que la solitude se fait de plus en plus dans les ports chrétiens de la Méditerranée - cependant que les Musulmans établissent à Palerme un arsenal et une base pour leurs corsaires - connaissent bientôt une crise économique et financière aiguë qui explique, notamment, la prompte disparition de l'Empire fondé par Charlemagne: obligés de confier à l'aristocratie les pouvoirs qu'ils ne pouvait remettre, faute de ressources, à des fonctionnaires rétribués, les empereurs se détruisent de leurs propres mains...

Cette thèse, si puissante dans sa simplicité, si ingénieuse aussi, les spécialistes la discuteront. Flux et reflux: dans vingt ans, elle n'existera plus, en tant que thèse ; tous les éléments, pesés, contrôlés, vérifiés avec scrupule par des équipes d'érudits, en seront incorporés dans une vaste synthèse, d'aspect probablement assez différent... C'est, en histoire, le sort ordinaire des conceptions neuves et originales : nous le savons d'avance, et nous trouvons, historiens, dans cet anonymat auquel est vouée notre œuvre personnelle - dès lors qu'elle est féconde - une sorte de grandeur qui nous attache davantage encore à notre tâche. A vérifier les idées qu'expose ainsi, dans sa belle maturité, p360 le maître historien, il y a de la besogne assez pour occuper les spécialistes pendant de longues années. Qu'on nous laisse du moins noter deux choses: l'une, l'extrême richesse d'information dont témoigne le petit livre qui nous retient ${ }^{238}$; l'autre, qu'un historien des temps modernes se trouve tout préparé à comprendre «l'hypothèse » de H. Pirenne. Dès ses premiers pas, il rencontre, lui aussi, une révolution de même nature que celle que nous décrit l'auteur des Villes du moyen âge. Car ce qui commande au seuil $\mathrm{du} \mathrm{XVI}^{\mathrm{e}}$ siècle toute une série de transformations graves, c'est précisément une seconde invasion islamique - la substitution, sur les rives de la Méditerranée orientale, des Turcs aux Arabes - et surtout, en 1516, leur installation en Égypte. Fait capital. C'est lui, et non pas les découvertes d'un Colomb ni même, à elles seules, les navigations

238 A signaler notamment de remarquables indications sur le développement de Venise et sur l'histoire et l'évolution de l'Ancienne Russie. 
des Portugais, qui explique les difficultés de Venise. Et également, si l'on y regarde de près, qui rend largement compte de cet effacement brusque de l'Italie, qui précède le déclin de la Renaissance. La crise politique, puis intellectuelle et morale, que traverse alors la péninsule, on l'explique commodément, depuis Guichardin, par la descente des Barbares en Italie. N'y a-t-il pas autre chose ? En 1300, Venise était vraiment au centre, et le centre, du monde chrétien civilisé. En 1520 ? elle n'en est plus qu'un des bastions. L'Italie tenait le milieu d'une Méditerranée où trafiquaient activement Pisans, Génois, Vénitiens et bien d'autres. Elle devient un boulevard, une avancée d'Europe face à l'Islam. Elle fait rempart de son corps, à moitié sacrifié, au bassin oriental de la Méditerranée. Et cette transformation si brusque n'aurait pas eu d'influence sur les destins de la culture italienne?

Pour changer de valeur, selon qu'ils bordent une ruelle étroite au long d'un rempart ou bien une avenue vitale de la cité, il n'y a pas, en vérité, que les immeubles de nos villes modernes. Sachons gré au petit livre de H. Pirenne de nous l'avoir rappelé si opportunément.

\section{II.}

Or, peu de temps auparavant, à Bruxelles, un autre livre avait paru. Transportant le lecteur bien loin des Villes du moyen âge, il retraçait la conquête de la Belgique par les armées de la Révolution française, sa réunion à la France, la vie du pays sous les régimes consulaire et impérial, la naissance en 1815 du p361 royaume des Pays-Bas et sa disparition, en 1830, lors de la révolution d'août et septembre ${ }^{239}$. Avec une remarquable aisance, l'auteur se mouvait à travers tant de faits mal connus encore, difficiles à saisir dans leur liaison. L'auteur : le médiéviste dont nous venons de signaler une des plus belles, des plus entières réussites... Et certes, ce n'était pas la première fois qu'il nous permettait d'admirer cette souplesse d'intelligence, cette aptitude à saisir, par-dessous les apparences, ces ressorts cachés qui font mouvoir les sociétés aux époques les plus différentes. Il n'est pour

239 Histoire de Belgique, t. VI : La conquête française ; le Consulat et l'Empire; le Royaume des Pays-Bas ; la Révolution belge. Bruxelles, Lamertin, VIII-478 pages in $-8^{\circ}$. 
s'en convaincre que d'ouvrir les tomes III, IV et V de l'Histoire de Belgique. Mais il y a quelque chose de particulièrement saisissant dans l'apparition de deux ouvrages qui montrent, presque à la même heure, un maître historien tenant dans ses mains, avec une égale force, deux extrémités de la chaîne des temps.

Ici encore, n'analysons pas ce qu'il convient de lire, et ce qu'on lit avec une curiosité soutenue, de la première à la dernière page. Mais qu'on nous permette de marquer comment ce très beau livre, plein d'enseignements pour qui se propose d'étudier l'histoire, par bien des côtés tragiques, de la Belgique pendant quarante années de contraintes, de bouleversements et de révolutions, présente en même temps pour nous, Français, un intérêt plus immédiat encore et plus direct qu'aucun des précédents volumes. Non seulement parce qu'en fait, de 1782 à 1815, les deux histoires de Belgique et de France se rapprochant au point d'être confondues, nul ne peut étudier les événements belges sans étudier, du même coup, une partie des événements français contemporains: ceci va de soi. Mais parce qu'ayant à faire l'histoire de ce rapprochement forcé, un grand historien belge a été conduit à formuler d'ensemble sur notre Révolution et, de façon générale, sur notre histoire française de 1789 à 1815 puis à 1830 , des appréciations et des idées qui, venant d'un homme tel que lui et placé sur un terrain à lui, se trouvent présenter pour nous, Français, l'intérêt singulier d'une sorte d'expérience, ou mieux de contre-expérience conduite du dehors, avec une maîtrise consommée, et combine des éléments connus, mais dans un autre ordre, en d'autres proportions, et pour d'autres fins que nous. Si l'on veut, c'est parce qu'il est et entend demeurer l'historien de son pays et non d'un autre ; c'est parce qu'il apprécie les événements qu'il nous retrace à la lumière de tout un passé et de tout un avenir dont l'allure propre, la courbe, le p $362_{2}$ rythme expriment une véritable et profonde originalité nationale, que Pirenne a perçu, dans la trame de faits qui nous sont devenus trop familiers pour que nous en ayons une vision fraîche, quelques traits vraiment remarquables. Sur eux, avec la puissante concentration de son savoir, il projette tout au long de son livre une lumière qui nous étonne, et finalement nous séduit. 
De ces traits, je ne retiendrai que deux. Et d'abord, il est saisissant de voir combien Henri Pirenne se montre sensible et nous rend attentifs à ce qu'on pourrait nommer, familièrement, « le côté Joseph II de la Révolution ». Je veux dire, à ce qui fait d'elle dans ses origines et ses débuts non pas tant un fait national et spécifiquement français qu'un fait cosmopolite, ou mieux, européen : cette parenté qui frappe tant le maître belge et qui relie aux desseins et aux réalisations des «souverains éclairés" de la seconde moitié du XVIII ${ }^{\mathrm{e}}$ siècle, l'œuvre même des Constituants, à qui (avec nos habitudes de dresser en pendants violemment coloriés les images contrastées de l'Ancien Régime et de la Révolution) nous ne cherchons d'antécédents et ne trouvons d'analogies qu'en France même et dans notre histoire propre.

Mais non moins saisissante, l'analyse que donne H. Pirenne des événements qui, en très peu de temps, firent d'une République légiférant pour le genre humain une République franchement impérialiste - et d'une France jetant les bases de l'État moderne une France fondatrice de l'État national. Une telle transformation, un historien belge a ses raisons pour vouloir en suivre d'un œil clairvoyant toutes les étapes et les vicissitudes: d'elle a dépendu, pendant des années, le sort de son pays. Pareillement, à marquer le lien qui unit l'un à l'autre ces deux groupes de faits, il met un soin que nous négligeons trop. Au moment où il nous dit combien, lui qui dans son cinquième volume a dû étudier de près le Joséphisme, il est saisi par tout ce qu'il trouve de "despotisme éclairé » dans l'œuvre de la Constituante - il note aussi, avec son habituelle finesse, que la Révolution, "si elle emprunte au despotisme son programme, elle s'élève en même temps contre le despotisme ". De là, la faiblesse du pouvoir royal, l'amoindrissement d'un chef d'État à qui sont refusés, par haine de la tyrannie et des tyrans, les moyens de faire exécuter les lois. De là, à partir de 1792, comme la France est en guerre avec l'Autriche, la Prusse et bientôt toute l'Europe, un réveil du patriotisme

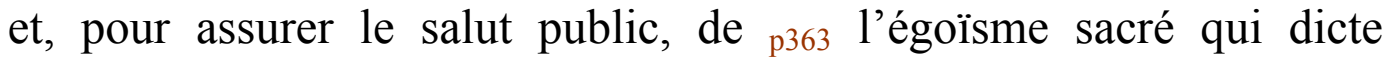
toujours ses lois aux patries menacées lorsqu'elles ne veulent point périr. Et sans doute tout cela a été vu déjà, et dit : mais point de la même façon, ni avec ce son de voix. Et l'idée, si souvent reprise sous des formes et à des occasions diverses, que notre Révolution, après avoir accompli en France l'œuvre qu'un Louis XVI sans doute aurait conduite à bien, «s'il avait possédé le pouvoir d'un Frédéric II ou 
d'un Joseph II », a eu finalement pour résultat en Belgique de réaliser ces réformes: l'égalité civile, l'abolition des droits féodaux, la réforme des codes, celle des tribunaux ecclésiastiques, la suppression des corvées de métier - dont Joseph II avait eu l'idée, qu'il avait édictées sans pouvoir les faire accepter ${ }^{240}$ et qu'il était réservé aux révolutionnaires d'imposer, au Consulat et à l'Empire de faire entrer dans les mœurs des Belges - l'idée qu'ainsi « avec Napoléon Joseph II a triomphé en Belgique ", que sa politique religieuse, après la rupture avec le pape, n'a été en somme pour les Belges qu'un « renouveau de Joséphisme », exactement comme ses lycées leur sont apparus sous les espèces «d'une restauration des collèges thérésiens $»$ : fort de toute son expérience antérieure, H. Pirenne nous la présente avec une vigueur, une nouveauté, une puissance singulières.

Nous serions entraînés beaucoup trop loin s'il fallait noter, même sommairement, tout ce que le sixième volume de l'Histoire de Belgique présente encore d'instructif et de nouveau pour le lecteur français. L'étude des sentiments avec lesquels les Belges - pour qui la République, telle que le Directoire la leur avait fait connaître, n'avaient été qu'une forme de la servitude - accueillirent les régimes consulaire et impérial, et s'accoutumèrent dès lors - eux qui n'avaient point chanté la Marseillaise, fêté la Fédération, donné des volontaires aux armées ou joui orgueilleusement d'affranchir le monde - à « voir dans les droits de l'homme les principes de leur vie collective », cette étude est faite de main d'ouvrier. H. Pirenne, d'un mot heureux, nous dit que le Consulat et l'Empire "ont amené la Belgique au point où ${ }_{p 364}$ ils ramenaient la France $\gg{ }^{241}$. Il dit encore : «A la fin du Directoire, la Belgique ancienne était par terre. A la fin

\footnotetext{
240 Il est bien entendu que nous simplifions et par conséquent appauvrissons beaucoup dans cet exposé rapide les idées de Pirenne. Voir par exemple au t. V de son Histoire de Belgique ce qu'il avait déjà écrit précédemment de la résistance commune des Flamands et des Wallons au Joséphisme (p. 382) et de ce lien nouveau qu'en dépit des différences de langue et des nuances de folklore, cette résistance même avait engendrée, tout comme, au XVI ${ }^{\mathrm{e}}$ siècle, la résistance à Philippe II. Cf. également, au même tome, les indications de la page 423.

241 Pour ces citations, voir les pages 123-124.
} 
de l'Empire, il s'en était élevé une autre sur ses ruines. » Mais il conclut, avec ses compatriotes dont il analyse l'état d'esprit avec une singulière pénétration, en homme pour qui ces problèmes délicats, aux données perpétuellement changeantes, sont toujours au premier plan de la conscience : "Le despotisme éclairé l'a emporté ; mais il reste pourtant le despotisme. » Et il peut bien, lui si soucieux des réalités de l'histoire économique et qui souligne ici d'un trait sûr et le transfert de propriété consécutif à la vente des biens nationaux ${ }^{242}$, et la prospérité croissante de l'industrie belge dans les premières années du $\mathrm{XIX}^{\mathrm{e}}$ siècle: draps de Verviers, cotonnades de Gand; et les progrès du machinisme, l'emploi progressif de la houille comme combustible il peut bien noter, avec sa clairvoyance habituelle, comment la Révolution, renonçant au contrôle qu'au nom de l'utilité générale «les souverains éclairés» exerçaient sur l'activité économique de leurs sujets, a conféré au capitalisme une puissance qu'il n'avait jamais possédée ${ }^{243}$ : cette prospérité économique, cette activité et cette sécurité relative des affaires ne lui font pas prendre le change sur les véritables sentiments des Belges, soumis à la dure loi impériale. Pour décrire leur désarroi moral, il sait trouver des formules comme celle-ci : « Si l'on ne se sent pas Français, on ne se sent pas Belge non plus. » ${ }^{244}$ Et l'analyse est remarquable, qu'il donne de la rapide évolution de leurs sentiments dans les derniers mois qui précèdent la chute de l'Empire.

La chute de l'Empire, le détachement des provinces belges de la France réduite à ses frontières d'Ancien Régime : sans doute; et voici créé ce royaume des Pays-Bas qui groupe sous Guillaume $\mathrm{I}^{\mathrm{er}}$ la Belgique et la Hollande. Mais la ruine de l'influence française ? Ici encore, l'étude de Pirenne est du plus vif intérêt pour nous. "C'est alors, nous dit-il, que se fait sentir avec plus de force que jamais l'emprise de la France sur la Belgique. " ${ }^{245}$ Non seulement parce qu'ici et là, pour les sujets de Guillaume $\mathrm{I}^{\mathrm{er}}$ et pour ceux de Charles X, ce sont les mêmes problèmes vitaux qui se posent; mais encore parce

\footnotetext{
242 Qui profita aux gros acheteurs et non aux petits, pour les causes qu'analyse très finement H. Pirenne (p. 161).

243 Cf. les belles pages 157-159 du livre que nous analysons.

244 Ouvr. cité, p. 141.

245 Ouvr. cité, p. 283.
} 
qu'il y a, pour le roi des Pays-Bas, nécessité politique de s'appuyer contre un catholicisme hostile sur des libéraux fermement attachés à l'État laïc, et dont ${ }_{\text {p365 }}$ les principes, la formation intellectuelle, la langue, tout vient de France: les aides aussi, les auxiliaires que Guillaume $\mathrm{I}^{\mathrm{er}}$ choisit de préférence parmi d'anciens préfets, d'anciens maîtres des requêtes de l'Empire écroulé. « Le royaume des Pays-Bas a beau constituer la barrière de l'Europe contre la France; sa politique a beau s'opposer à la politique française : ce n'en est pas moins la tradition française qui inspire et dirige sa monarchie administrative ${ }^{246}$. » Guillaume considère que les agents de l'empereur constituent son meilleur appui contre les réactionnaires et les cléricaux, car c'est l'État moderne qu'ils ont édifié sur les ruines de l'Ancien Régime et, en servant le roi, c'est cet État qu'ils servent. Cependant, d'un tout autre côté, ce sont des influences françaises également qui jouèrent (celle du Globe en particulier et de ses rédacteurs, sensible en Belgique dès l'apparition du journal) pour déterminer l'évolution si importante qu'accomplit le libéralisme belge entre 1825 et 1826 quand, de parti uniquement anticlérical et prêt à soutenir tout gouvernement hostile au catholicisme, il se transforme peu à peu en parti qui, réclamant la liberté dans tous les domaines et s'insurgeant dès lors contre le despotisme autant au moins, sinon plus, que contre le fanatisme confessionnel - finit par conclure alliance avec les catholiques et préparer, pour sa part, les événements décisifs de $1830 \ldots$

\section{III.}

Transformations incessantes d'idées et de sentiments. A les suivre, à les saisir, à les traduire pour nous de la façon la plus exacte et la plus sensible, Henri Pirenne déploie la même souplesse, la même heureuse plasticité qu'à noter, dans ses Villes du moyen âge, les perpétuelles variations de ce qu'on pourrait nommer «la notion culturelle d'Europe », si importantes par leurs conséquences et leurs répercussions de toute nature. Et l'on s'abandonne à lui avec une parfaite sérénité pour bien des raisons sans doute, qu'explique 
suffisamment et résume le seul mot de talent - mais parce qu'on se sent aussi entre les mains d'un guide qui ne connaît pas seulement des choses dont il parle l'apparence momentanée et d'aspect circonstanciel : qui les pense en réalité, et nous les fait comprendre dans leur genèse la plus lointaine et la plus profonde. A chaque instant, ce sont des rappels du passé, des comparaisons, des retours. L'histoire ne ${ }_{\mathrm{p} 366}$ les impose-t-elle pas d'elle-même, lorsqu'elle nous montre en 1815 , puis de nouveau en 1830 , des politiques songeant à un "royaume de Bourgogne»? Mais l'arrêté de Guillaume I ${ }^{\text {er }}$ enlevant aux Belges, le 14 août 1825, le droit d'être nommés à des fonctions publiques s'ils ont étudié hors du royaume, n'est-ce pas l'ordonnance fameuse de Philippe II interdisant aux mêmes Belges de fréquenter les universités et les écoles étrangères ? Guillaume $\mathrm{I}^{\mathrm{er}}$, à Liège, taxant d'infamie la conduite de l'opposition et appelant ainsi sur lui les coups qu'on s'ingéniait à ne frapper que sur ses ministres — n'est-ce pas «Philippe II couvrant Granvelle »? L'évolution du libéralisme belge, entre 1825 et 1828, sous des influences françaises, n'a-t-elle point son pendant dans l'évolution, sous des influences de même origine, du protestantisme belge ? Et plus tard, en 1830, vis-àvis de Guillaume $I^{\text {er }}$, les avancés ne prennent-ils pas l'attitude qui, au $\mathrm{XVI}^{\mathrm{e}}$ siècle, avait été celle de Guillaume d'Orange vis-à-vis de Philippe II ? Exemples pris entre mille. C'est de façon continue, mais sans esprit de système, et parce qu'il porte en lui toute vivante l'histoire entière de son pays qu'un Pirenne à chaque instant éclaire pour nous le passé par un passé antérieur, et révèle à tous la force du lien qui unit, à travers les vicissitudes d'une histoire singulièrement ballottée, les générations successives qui firent le peuple belge.

C'est à peu près au temps où ses anciens élèves et ses amis lui offraient, à l'occasion de sa quarantième année d'enseignement à l'Université de Gand, deux beaux volumes de Mélanges ${ }^{247}$ que le maître historien affirmait, de la double façon que nous venons de dire, quelques-unes des éminentes qualités qui font de lui, à l'heure actuelle, le plus complet et sans doute le plus riche en dons divers

${ }^{247}$ Bruxelles, Vroomant, 1926, 2 vol. in- $8^{\circ}$. 
mais équilibrés, des historiens médiévistes et modernistes de langue française. Une fois de plus, ce grand travailleur distribuait ainsi le meilleur de sa pensée à ces «élèves du dehors » qui, pour ne s'être jamais assis en face de lui sur les bancs d'une salle de cours universitaire, n'en ont pas moins alimenté leur pensée à la sienne et contracté envers lui une dette de reconnaissance profonde. A vingt ans et quand on hésite, quand les circonstances n'ont pas placé sur votre route celui qu'on attendait et qu'on aurait voulu — c'est une telle joie de découvrir un jour, dans un livre ouvert un peu au hasard, p367 le modèle de l'exemple de ce qu'on désirerait faire... Mais cette maîtrise même de l'historien belge ; cette remarquable plasticité de son talent ; cette aptitude à comprendre et à faire comprendre au lecteur, avec une égale pénétration, les états de civilisation les plus diverses et les moins comparables : voilà qui, tout de même, pose pour nous un problème?

Certes, il y a le don. Il y a les qualités personnelles. Il y a tout ce qui plaît et séduit dans le robuste génie de ce magnifique exemplaire des hommes de son pays et de son peuple. Il y a, rassemblées et portées à leur point de perfection dans ce Belge vigoureux, haut en couleur, à la verve drue, à la parole directe, à l'imagination qu'on sent ardente et toujours au travail, plein de curiosités du reste et d'appétit de vivre en comprenant, - il y a les vertus accumulées de vingt générations, acharnées à de patients labeurs et pareillement ardentes à posséder la vie pour la plier à leur volonté frémissante... Il y a l'éducation aussi, la culture, ce contact établi et maintenu par un esprit d'une rare sagacité entre deux civilisations qu'il ne juge point rivales mais complémentaires, dont il sait à la fois le fort et le faible, et qui lui fournissent l'une et l'autre, selon la proportion dictée par son sens critique et par une appréciation très juste de ses besoins et de ses aptitudes, la matière butinée d'un miel qui n'est qu'à lui. Je sais. Et que, si le don n'est pas là, ni la culture, qu'importe : habillez-les en rouge, en vert ou en bleu...

Tout de même, - comment ne pas s'interroger? Plan horizontal, ou bien plan vertical ? Je veux dire, ne serait-ce pas en partie parce que, historien d'un pays d'étendue relativement restreinte, Henri Pirenne a pu, sans être écrasé sous le poids d'archives démesurées et de monographies innombrables, suivre les destinées historiques de la Belgique depuis les temps romains jusqu'à la guerre mondiale, 
personnellement, et en aidant des documents eux-mêmes; ne serait-ce parce qu'il a pu ainsi prendre conscience, avec une force toute particulière, de cet engendrement continu des faits les uns par les autres et de ces interférences qui rendent si illusoires les " coupures » des pédagogues, - ne serait-ce pas pour ces raisons d'ordre méthodique et technique à la fois, qu'il a pu si bien comprendre dans leur texture interne tous les états de civilisation dont il a déroulé l'histoire devant nos yeux ? Et si n'osant, par crainte de se perdre, sortir de ces limites chronologiques que la tradition assigne à ce qu'on est convenu par exemple de nommer moyen âge, il s'était confiné, en bénédictin scrupuleux, dans l'étude approfondie de cinq ou six siècles d'histoire européenne sans se donner l'expérience ${ }_{\mathrm{p} 368}$ personnelle de ce qui les a précédés, ou suivis, - aurait-il fait preuve, dans l'intelligence des seules institutions, des seules sociétés proprement médiévales, de cette même largeur de compréhension, de cette même vigueur d'intuition qui nous contraignent à saluer un maître en lui ?

Débat académique et vain. Ce qu'enseigne l'exemple vivant de H. Pirenne, c'est ce qu'enseignait déjà sa parole applaudie, le 9 avril 1923, à la séance d'ouverture du $\mathrm{V}^{\mathrm{e}}$ Congrès international des Sciences historiques. Horizontalité ou verticalité ? Les deux. L'élargissement dans l'espace, l'extension dans le temps. Voilà ce qu'exige l'emploi de cette méthode comparative dont Henri Pirenne pouvait, avec tant de clairvoyance et d'esprit critique, définir l'esprit et prôner l'usage. D'ailleurs, pour nous Français, n'est-il pas un moyen commode et pratique de nous donner un peu de cette expérience du déroulement dans le temps, et de l'enchaînement des époques que l'histoire de Belgique permet à un Pirenne d'acquérir pleinement? N'avons-nous point nos histoires de province, qui peuvent nous procurer les mêmes avantages ? Mais il y faut l'esprit celui qui, d'un bout à l'autre de son œuvre féconde, anime et inspire le maître historien à qui, tous, nous devons tant. p369 
UN PSYCHOLOGUE

CHARLES BLONDEL

$\underline{\text { Retour à la table des matières }}$

Je le vois tel qu'en 1899, dans les couloirs de l'École, il m'apparut pour la première fois, cube prestigieux, spirituel et moqueur. Et je le revois, ce matin gris de 1939 où j'allais lui serrer la main, la veille même du jour où on devait l'opérer: si calme dans sa gravité souriante que nous ne saurons jamais s'il cherchait à s'aveugler luimême, ou à rassurer, par une sérénité merveilleusement feinte, des affections qu'il sentait soucieuses. Entre ces images, rien que l'écart normal de deux photographies prises à trente ans de distance; ici, le jeune homme aux yeux vifs, au teint mat, aux lèvres rieuses; là, l'homme déjà marqué et dont le sourire sans illusion, mais sans amertume, trahit l'expérience. Ce qui par contre fut notable en Blondel, à tous les âges, ce fut le contraste des activités de surface et de jeu, chatoyantes, libres, et des façons d'être irréductibles, des assises de fondation sur quoi tout, en tout temps, reposait. Quelles fondations?

Blondel a tenu à ce que nous le sachions de lui, une dernière fois, à l'heure où sa dépouille mortelle achevait de se consumer. Des lignes qu'on nous lut, des lignes que Blondel, regardant bien en face son destin, avait tracées de cette écriture élégante et nette qui apportait toujours un premier plaisir à ceux qui recevaient quelque lettre de lui, aucun de ceux qui se trouvaient réunis, ce soir-là, dans le décor sans âme du Four Crématoire, n'oubliera jamais l'accent. Magnifique témoignage rendu, en toute liberté d'esprit, en tout détachement de croyance positive, à cette formation huguenote, à cette tradition morale si purement française, dont il avait reçu de sa mère 
l'incomparable don : tout un trésor, faut-il dire de vertus ? il aurait honni ce mot de pharisien; disons d'énergies et de manières d'être, héritées des anciens: haine du mensonge sous toutes ses formes; horreur de céder sans examen au préjugé ; résolution, jamais traduite p370 en mots, de tout souffrir plutôt que de manquer, dans une circonstance grave d'ordre public ou privé, au commandement intérieur d'une conscience intraitable.

Sur ce fond, qu'on jette les broderies d'une fantaisie étincelante, d'une curiosité insatiable des hommes et des idées : on aura Blondel, hardi et retenu, prêt à toutes les audaces, mais fils respectueux des vieilles traditions qui valaient le respect. Des élans, mais pas un grain de fanatisme ; des convictions, mais pas la moindre intolérance ; des principes, mais ennemis de tout préjugés et si profondément enracinés en lui, qu'ils avaient perdu toute velléité de se faire dogmatiques. Préfaçant, avec cette piété dont tous ses amis connurent quelque bienfait, un recueil de Reliquiae philosophiques, retrouvées dans les papiers de son grand ami Lecène - ce prince de la chirurgie, complet comme un homme de la Renaissance, et qu'une typhoïde contractée en pansant un malade emporta stupidement à 52 ans : «Il aimait la vie, écrivait Blondel, et l'aimait de la belle manière. Il ne lui portait pas une affection paresseuse et quiète, mais bien un amour généreux et allant. Il lui savait gré de toutes les beautés qu' elle offre à nos sens, de tout le champ qu'elle ouvre à notre action, de tous les problèmes qu'elle pose à notre esprit. » Lui aussi, Blondel, goûta ces joies. A la table de la vie comme à la table de ses amis, son appétit faisait plaisir à voir. Et la joie de se prodiguer soi-même n'est pas de celles qu'il ignora jamais. A ses plaisanteries de la vingtième année, à ses jeux dans la tradition canularesque, d'aucuns parfois trouvèrent quelque excès et comme un arrière-goût de férocité. La cruauté n'était là, chez le meilleur des hommes, qu'une exigence morale poussée à la limite - une révolte, qui s'affirmait durement, contre des bassesses ou des platitudes.

Amis... Le mot plusieurs fois déjà est venu sous ma plume. Quelle place n'a point tenue, dans la vie de Blondel, l'amitié ? Ce fut sa grande passion, son beau souci. 
Parfois dans l'intransigeance un peu raide de nos vingt ans, nous nous étonnions de certaines de ses liaisons ou de ses sympathies. Elles allaient à des hors-série, à des irréguliers, à des hommes parfois si éloignés de lui par l'ensemble de leurs sentiments que nous comprenions mal qu'il les pût adopter. Mais, précisément, c'était cet éloignement qui les rapprochait de lui. Et n'allons pas nous figurer qu'il les observât à distance, comme des objets d'étude bons à lui procurer quelques plaisirs d'intelligence. La curiosité, chez Blondel, masquait souvent un don de charité humaine. Il était celui qui vient s'asseoir, toute une 3371 soirée, au chevet d'un ami malade ou convalescent, un livre à la main qui lui permette de protester : "Mais non, tu vois bien, je ne perds pas mon temps... » Toute une part, une large part de sa vie fut marquée par le dévouement, par d'étonnants sacrifices de temps, de liberté, d'argent ou de bien-être acceptés, ou mieux, offerts avec une gentillesse, une spontanéité qui donnaient chaud au cœur. Gardons-nous d'en trop dire. J'écris sous la pesée de son regard ami. Je sais qu'il n'aurait point pardonné à quiconque, ayant surpris quelque secret de sa prodigieuse générosité de sentiment, l'eût révélé au public. Blondel n'était pas de ceux pour qui l'amitié c'est, en deux ou trois circonstances graves, le don d'une sympathie qu'en pareille occasion les plus indifférents témoignent aux éprouvés. L'amitié, pour lui ? le don total et quotidien.

Parler de son œuvre, d'autres l'ont fait ailleurs, où c'était le lieu. Mais comment ne pas dire un mot de son talent?

Un charmant causeur : ainsi se présentait à vous, tout d'abord, Blondel. Spirituel et vivant, sachant écouter aussi bien que parler, merveilleusement à son aise partout, à Paris comme à Buenos Aires, dans un état-major comme dans un hôpital, dans un salon comme dans une salle de cours, il séduisait les plus libres esprits. Et sa scrupuleuse observance des formes de politesse dont il a parlé si joliment dans l'Introduction à la psychologie collective n'était point pastiche d'Ancien Régime - mais, chez le moins conformiste des hommes, souci de sa dignité et de celle des autres.

Quant à l'écrivain ?... L'espèce de plaisir, physique et logique, que procure une page de lui, prise au hasard, combien de Français sachant 
très bien écrire sont capables de le donner aussi bien que Blondel ? J'ai vu vingt fois la perfection de son style déconcerter d'authentiques écrivains - des maîtres, heurtés par lui dans leur conviction que l'universitaire écrit pauvre. Jamais un mot de trop. Et quelle finesse d'ironie !

«Le nombre des psychologues, celui de leurs publications sont considérables également. L'un et l'autre ne cessent, par bonheur, de s'accroître. Le Psychological Register nous apprend qu'en 19291.627 psychologues, au moins, étaient distribués sur la surface du globe, 682 habitants aux États-Unis ou au Canada, 90 en France (y compris l'Algérie). Disproportion qui, interprétée comme il convient, tourne à notre avantage : car, sauf erreur, ces chiffres donnent, pour $100.000 \mathrm{~km}^{2}$, approximativement 4 psychologues pour l'Amérique du Nord et 7 pour la France... »p372

Voilà qui est signé. C'est du Blondel. De ce Blondel qui, parlant de Durkheim, écrivait un jour : "La gravité quasi religieuse de son esprit garde partout quelque chose d'implacable. Dans ses écrits, il y a des enthousiasmes, des colères, des âpretés. Je ne me souviens pas d'y avoir rencontré un sourire. » Blondel savait sourire. Mais son sourire n'enchantait point toujours tous ses lecteurs...

Faut-il rappeler tels livres de combat et, par exemple, son livre de 1924 sur la Psychanalyse? Blondel, emporté par sa verve, ne s'est-il pas laissé entraîner un peu loin ? Je ne sais : mais que la lecture de ce petit livre alerte et courageux soit un délice, je n'ai que faire d'autorités pour m'en douter. Tel parallèle entre Freud et Gall: «Tous deux d'abord nous sont venus de Vienne en Autriche: manifestation de la tendance impérieuse à la répétition dont il appartient aux psychanalystes de mesurer la portée »: ou encore, telle conclusion cruelle de pince-sans-rire: "Il semble que nous nous acheminions ainsi, doucement, vers une définition de la paranoïa qui définirait en même temps la psychanalyse - et que le paranoïaque ne soit, en somme, qu'un psychanalyste qui a mal tourné » : résistons au plaisir de multiplier de tels textes. Blondel était de ces jouteurs que beaucoup aiment mieux entourer de silence qu'attaquer en face, les armes à la main. Il en a su quelque chose, bien des fois, dans sa vie. 
C'est qu'il ressentait, toujours et partout, ce singulier besoin: comprendre. Curieux de remonter aux origines, il s'était donné, sans bruit, une étonnante connaissance des vieux auteurs, des ancêtres héroïques de la médecine et de la psychiatrie. Ni Gall, ni Broussais, ses bêtes noires, ni Laënnec, Magendie, Esquirol, Falret ou Leuret n'avaient de secrets pour lui. Il ne les lisait point par obligation mortifiante, mais allégrement, curieusement, avec le souci de saisir, par-dessous les formes mortes, les intentions profondes de leur pensée. Par là, ce philosophe était plus cher encore à l'historien que je m'efforçais d'être.

Le vrai, c'est qu'il faisait peu de cas de la compilation prétendue érudite. A cent dissertations inaugurales de "psychologues au kilomètre carré », il préférait les fortes nourritures du lettré. "Telle est mon incurable frivolité, a-t-il écrit, que je relis plus volontiers les pages consacrées par Proust au téléphone et à ses vierges vigilantes que les travaux, très estimables, qui ont fixé le mode de sélection des téléphonistes. " Il faudrait être un sot, et né, comme on disait au XVI siècle, "dans une peau de buffle qui ne vous escorche", pour s'indigner, en relisant ces lignes, du $\mathrm{p}_{373}$ peu d'esprit scientifique dont elles témoignent... Contresens ? malentendu ? rien de tout cela. Un de ces sourires qui ne fleurirent jamais les lèvres du père de la Sociologie. Et une méditation, à quoi Blondel nous convie tous, sur la démarcation du savoir sans esprit, et du savoir pour l'esprit.

Quand on vient de perdre un ami cher, comment refouler la question humaine : fut-il heureux?

Heureux, oui, Blondel le fut, je crois, dans toute la mesure où il put, sans contrainte, se livrer à ses goûts, faire librement sa tâche sans en être détourné par de pressantes, d'ingrates nécessités. Heureux, oui, parce que ses livres trouvèrent un public, et que ceux qui les aimèrent ne les aimèrent point à demi. Heureux, dans toute la mesure ou il put, à Strasbourg, grâce à une tendresse complice, créer l'intérieur accueillant dont il avait besoin pour recevoir et grouper ses amis, et satisfaire ainsi l'un des plus impérieux besoins de sa nature ouverte, sociable et généreuse. 
Voilà qui put adoucir pour lui les rigueurs d'un exil dont il souffrit beaucoup. Car Blondel était Parisien de Paris. Il adorait la grande ville. Or, un jeu de circonstances ennemies fit qu'il attendit longtemps, trop longtemps, le moment de rejoindre à Paris ses collègues et compagnons du Strasbourg d'après-guerre. Encore dut-il souffrir l'affreuse brimade que les sergents-majors de l'Université se plaisent à infliger à tous les provinciaux, quels qu'ils soient, qu'ils daignent agréger finalement à un peuple d'inconnus. Blondel dut prendre son tour de bête, derrière on ne sait qui de ceux que les papiers administratifs ont, pour une fois, raison d'appeler, sans plus de cérémonie : «ce fonctionnaire ». Il faillit mourir «maître de conférences ». Il était maître tout court.

Du moins, n'a-t-il pas subi ce qui eût été pour lui une dure épreuve. Il avait fait la dernière guerre. En France d'abord, puis à l'armée d'Orient, il avait dignement servi; n'usons point d'autres qualificatifs, ils lui eussent souverainement déplu. Voué, cette fois, aux besognes ingrates de l'arrière, il se serait rongé à voir lucidement ce qu'il faut faire et qu'on ne fait pas, ce qu'il ne faut pas faire, et qu'on fait. Il eût été, une fois de plus, l'homme qui écrivait : "Pour connaître, nous n'avons que notre sens critique et notre intelligence et le plus impérieux de nos devoirs est de ne jamais omettre de nous en servir contre les ${ }_{p 374}$ autres, et contre nous-mêmes. " Certes. Mais à ne point pécher ainsi par omission, il faut, assez souvent, beaucoup de grandeur d'âme...

Grandeur d'âme. Le mot tombe, lentement, sur nos pudeurs de sentiment. Dire comment Blondel sut mourir, on me pardonnera de ne le point tenter. Il n'aurait pas voulu. Qu'il ait été, dans cette épreuve suprême, plus purement lui que jamais, - toute douceur, toute sérénité, toute exquise attention pour la peine des autres, tout détachement de lui et de ses souffrances, - nous qui l'avons connu et aimé longuement, nous n'avons point à en marquer de l'étonnement. Les broderies écartées, les feux de surface éteints, le fond de l'homme, seul, se révèle. L'image de sa mort rejoint, pour l'éclairer, l'image de sa vie. p375 


\section{DEUX AMIS GÉOGRAPHES}

\section{JULES SION, ALBERT DEMANGEON}

$\underline{\text { Retour à la table des matières }}$

Jules Sion n'est plus: Sion (1878-1940), ami de quarante ans, vieux et fidèle compagnon d'inquiétudes critiques et de combats pour l'intelligence ; l'un des deux ou trois esprits les plus fins et les plus intuitifs qu'il m'avait été donné de connaître. - Albert Demangeon n'est plus : Demangeon (1872-1940), ami presque aussi ancien, mais avec, de ma part, une nuance de respect que ses six ans d'ancienneté n'étaient pas seuls, certes, à motiver - Demangeon qui, ayant tenu nos Annales sur les fonts, y signait encore dans le numéro de juillet 1940 des comptes rendus : leur auteur nous avait déjà quittés quand ils parurent.

Rappeler en deux mots ce que Sion et Demangeon furent et firent, l'un et l'autre, ce n'est pas remplir un pieux devoir d'amitié. C'est une, fois de plus, définir quelques-unes des attitudes d'esprit qui font de nos Annales ce qu'elles veulent être — ce qu'elles se sont toujours efforcées d'être.

I.

De Jules Sion, la carrière fut toute unie, parce qu'il eut toujours le souci pudique de ne point la mouvementer. Ce Français du Nord ayant trouvé dans un pays de lumière, à Montpellier, une chaire de géographie qui lui plut - il ne fit jamais la plus petite démarche pour l'échanger contre une chaire parisienne : mais nul, on s'en doute bien, ne fit de démarches à sa place; ne demandons à personne des vertus 
surhumaines. Dès ses années d'École Normale (1899-1922), il était pour nous, ses camarades, "le Géographe » par excellence; il n'eut jamais d'autre nom familier; mais c'était un géographe d'espèce $\operatorname{assez}_{\mathrm{p} 376}$ rare. Extrêmement fin et cultivé, soucieux comme pas un de liaisons spirituelles avec ses compagnons de lutte, fuyant d'instinct l'enclos où paissent docilement, sous la houlette du berger, les têtes de bétail incapables d'initiative - il n'aurait pas fallu le prendre cependant pour un "demi-géographe », incertain de ses méthodes et un peu inquiet sur sa discipline.

Je le notais déjà, il y a trente-deux ans (1909), dans un compte rendu de la Revue de Synthèse Historique qui saluait l'avènement de sa jeune maîtrise : si prenant que fût pour l'historien ce beau livre, Les paysans de la Normandie orientale, qui lui servait de thèse, et bien qu'il démontrât de manière éclatante la solidarité nécessaire des disciplines historiques et géographiques — c'était pleinement un livre de géographe... Non seulement parce qu'en deux séries de chapitres initiaux J. Sion y passait en revue, avec un sens géographique très fin, les conditions du milieu naturel - mais, bien plus encore, parce que, avec une maîtrise évidente, tous les problèmes de technique et de production industrielle ou agricole, de démographie ou de statistique, de régime de propriété ou d'exploitation qu'il rencontrait devant lui, « ce n'était pas en historien de l'industrie ou de l'agriculture, de la population ou de la propriété, c'était en géographe qu'il en formulait les termes et tentait de les résoudre. »

1909. Mais dénonçant lui-même, en 1932, les erreurs d'une récidiviste de la candeur, Miss Ellen Churchill Semple, auteur d'une Geography of the Mediterranean Region (à vingt ans de distance, elle reprenait, en les réaggravant, les erreurs d'un autre livre: Influences of Geographic Environment, qui avait échauffé ma propre bile dans La Terre et l'évolution humaine) - Jules Sion, plaidant coupable par gentillesse naturelle, écrivait :

Le géographe ne doit pas aborder d'aussi amples et redoutables sujets d'histoire. Simplement, du fait qu'il a une autre formation, et d'autres curiosités que l'historien - il peut espérer, quelquefois, indiquer des points de vue nouveaux, renouveler une question en insistant sur des facteurs naturels jusqu'ici négligés et poser des problèmes, même s'il n'est pas armé pour les résoudre. Ses erreurs peuvent être fécondes en vérités. Mais c'est à 
condition... qu'il sache le métier d'historien... Il lui faut penser en historien autant qu'en géographe.

Et, reprenant une thèse que j'ai souvent défendue pour ma part: «Comment lui demander, dès lors, non seulement de s'assimiler mais d'entreprendre lui-même des études sur le modelé glaciaire ou polycyclique, sur la météorologie, et ce qu'on appelle p377 la phytosociologie ? N'y a-t-il pas là, géographie physique et géographie liée à l'histoire, deux disciplines différant autant par leur esprit que par leur technique ?» On le voit : du jeune homme qui vient de faire son «chef-d'œuvre » de maîtrise, au maître en pleine possession de son expérience, aucune divergence de vues ni de sentiments. La belle unité d'une pensée qui se tient.

Suivre d'année en année la production scientifique de Jules Sion - ce n'est pas notre dessein. Outre sa thèse déjà citée - (avec le recul du temps, elle nous apparaît de plus en plus comme une des deux ou trois monographies géographiques vraiment originales qu'ait produite notre école française de géographie) — rappelons qu'il nous laisse une étude de géographie physique sur le Var supérieur, faite un peu en rechignant; elle lui aurait servi de pensum si elle ne lui avait procuré des contacts ravis avec un des pays les plus colorés et les plus sauvages de notre France : un chapitre sur la dévastation forestière y semble traduire la soudaine allégresse d'un homme qui revient, enfin, à ses vraies études. Après quoi, ce fut un détournement. Lorsque Vidal de La Blache, ayant conçu le plan de sa Géographie Universelle, dut trouver un homme fort qui pût supporter sans plier le très lourd fardeau des deux volumes consacrés, suivant le projet, aux puissants pays de l'Asie des moussons: Inde, Indochine, Chine, Japon - ce grand connaisseur d'hommes (un de ces connaisseurs qui souvent révèlent à eux-mêmes ceux qu'ils savent juger) n'hésita pas. Des pays aussi riches de passé historique, aussi gonflés de sève humaine, de pareils berceaux de civilisations rivales de la nôtre en grandeur et en rayonnement - il fallait pour les comprendre et les faire comprendre dans l'esprit même du maître, un cerveau de vaste envergure et si intuitif que, sans prendre le temps d'une exploration personnelle des lieux qui n'eût été, le temps pressant, que dérisoire - il pût en donner une vision assez nette pour que les experts dussent s'incliner. - Un 
homme fort, Vidal, choisit le frêle et nerveux Jules Sion qui acheva de démontrer que l'intuition du maître avait été parfaite.

J'avais salué avec joie cette évasion forcée hors du cercle enchanteur des monographies régionales. Je fus moins satisfait, je l'avoue, de voir Sion céder ensuite aux sollicitations d'écrire, dans la même Géographie Universelle, les études consacrées à ${ }_{\mathrm{p} 378}$ l'Italie et à la Grèce ${ }^{248}$. Non que le résultat n'ait été, comme toujours, excellent. Mais j'aurais préféré qu'un tel homme pût étudier le monde méditerranéen librement, et surtout en parler à sa guise, sans se voir plier au joug commun. J'aurais aimé aussi qu'il pût s'affirmer dans une œuvre plus personnelle, et peut-être, qui sait ? nous doter du livre original : moitié Traité de géographie humaine, moitié Discours de la méthode géographique qu'il était seul capable d'écrire utilement, et qui aurait été, sans doute possible, un chef-d'œuvre.

Il ne tint pas à moi que ce chef-d'œuvre ne fût écrit. Quand aux environs de 1910, Henri Berr, méditant le projet de l'Évolution de l'Humanité, me demanda le nom d'un titulaire possible pour un des livres initiaux à quoi il tenait le plus (il devait s'appeler primitivement La Terre et l'histoire, et ne devint qu'ensuite La Terre et l'évolution humaine), je n'hésitai pas un instant: Jules Sion s'imposait au choix. Il refusa, précisément parce que, déjà, il venait d'accepter la commande des deux volumes extrême-orientaux de la Géographie Universelle. Et, par un retournement imprévu, ce fut lui qui insista auprès de moi pour que j'assume, à son défaut, une aussi lourde tâche. Il alla même, pour me mieux convaincre, jusqu'à appeler Vidal de la Blache à la rescousse...

Autres temps... Pas plus le maître que son disciple n'étaient hommes à penser que j'étais étiqueté «historien» et non pas "géographe »; pas plus l'un que l'autre n'étaient de ceux qui organisent le protectorat de la savate contre la cordonnerie.

248 Paris, Armand Colin, 1934, 2 vol. grand in- $8^{\circ}$ (t. VII de la G. U.). On doit à J. Sion, dans le t. VII, $1^{\text {re }}$ partie, deux remarquables chapitres d'introduction : IV, «Le travail et la vie populaire dans le Midi méditerranéen »; V, « La place de la Méditerranée dans l'histoire de l'humanité ». Dans le t. VII, $2^{\mathrm{e}}$ partie, il a donné toute l'étude sur l'Italie (p. 235 à 394) — et toute l'étude sur la Grèce (p. 512 à $575)$. 
Comme livre, en dehors de ses thèses et de ses contributions à la Géographie Universelle, Sion n'aura laissé, finalement, qu'un excellent petit volume de la Collection Armand Colin consacré à la France méditerranéenne (1934). Mais l'erreur serait grande de ne porter à l'actif de Jules Sion que ce seul volume d'études méditerranéennes. Vingt articles, disséminés dans des revues très diverses : outre nos Annales, les Annales de Géographie ; la Revue de Synthèse; Scientia; les Annales Sociologiques; la Revue de Géographie Alpine; le Bulletin de la Société languedocienne de ${ }_{\mathrm{p} 379}$ Géographie, etc.... attestent ses libres curiosités en sens divers, et la vigueur d'une pensée qui n'avait pas à se chercher, mais qui cherchait celle d'autrui pour la susciter et lui faire donner tout ce qu'elle pouvait rendre. Le livre fécond de Marc Bloch - ce beau livre que Sion, en terminant son compte rendu à la Revue de Synthèse, souhaitait voir " vieillir vite en certaines parties, parce qu'il aura suscité toute une floraison d'études en montrant ce que ce sujet ardu a de passionnant et de largement humain ${ }^{249} \gg$ - ce livre avait fait naître dans son esprit méditatif toute une série de réflexions et de projets. Il en fut de même du curieux travail de Lefebvre des Nouettes sur l'Attelage; de même encore du suggestif mémoire de Roger Dion sur la Formation du paysage rural français. - Dans les controverses auxquelles ces travaux féconds donnèrent lieu, Sion marqua sa place avec fermeté comme toujours, puissance et originalité. Par là, il se rapprochait plus étroitement encore de nous et des Annales ${ }^{250}$.

D'une autre façon encore, il s'était intimement uni à moi dans ces dernières années. Il avait accepté avec joie, avec élan, de diriger l'un des tomes de l'Encyclopédie française, celui qui doit traiter de l'Alimentation, de la Vêture, de l'Habitation. Les circonstances ennemies semblent s'être liguées contre ce volume, plus qu'à demi composé, et qu'il a fallu quatre ou cinq fois déjà reprendre et

249 Une histoire agraire de la France (Revue de Synthèse, III, 1932).

250 A nos Annales, Sion a donné un article sur Les tarifs ferroviaires et les courants de circulation (t. III, p. 481) ; un autre, sur Les étrangers en Italie (t. IV, p. 529) et une étude sur Les problèmes de transport dans l'Antiquité (t. VII, p. 628). 
remanier; non que les trois parties plus spécialement procurées par Sion aient eu besoin de subir la moindre retouche ; mais on avait dû, sous la pression de nécessités diverses, le grossir de développements consacrés d'abord aux Sports, puis à l'utilisation des Loisirs développements devenus caducs avant même leur publication. Et les lecteurs n'ont pu rendre à Jules Sion l'hommage que méritaient sa finesse, sa justesse de conception, sa mesure et son sens de la vie.

L'homme était exquis : de ceux dont on se dit, avec désespoir, quand ils vous ont quitté : «Il est parti... Et j'aurais eu tant et tant de choses encore à échanger avec lui... »Il a quitté ceux qu'il aimait, silencieusement, discrètement, à sa manière. Un soir de ce cruel été de 1940, il s'est couché, fatigué. Il ne s'est pas réveillé le lendemain matin. Lourd de trop de soucis et de chagrins, son cœur si tendre s'était brisé. p380

II.

Lui aussi, Albert Demangeon est parti sans bruit, dans le grand fracas de l'année 1940. Des semaines après sa mort, de vieux amis à lui, dispersés par la tourmente, ignoraient encore une perte qui, en d'autres temps, aurait pu, peut-être, être retardée de quelques années...

Quand je pense à Demangeon, je me reporte volontiers à cette soutenance de thèse qui, en 1905, nous réunit — nous, les jeunes d'alors - autour d'un aîné qui semblait, ce jour-là, porter le drapeau commun.

A cette époque, il y avait déjà une école française de géographie. Depuis des années, avec une vigueur croissante, Vidal de La Blache s'était révélé, à l'École Normale, comme un initiateur, puis comme un maître, puis comme un chef. Il y avait eu des thèses de géographie. Mais le "chef-d'œuvre » n'existait pas, qu'on pût pour des années proposer à l'étude et à l'émulation des jeunes «compagnons». Le chef-d'œuvre, ce fut un livre parfait dans sa robustesse, dans son 
équilibre, dans sa compréhension ${ }^{251}$. Un livre qui, d'emblée, s'imposa comme un modèle. Si bien que peut-être, dans sa perfection, il est responsable de l'attachement un peu exclusif que les géographes français ont marqué, après lui, pour la monographie régionale. $\mathrm{Du}$ beau travail français, cette thèse, fignolée avec amour jusque dans ses petits détails. Du beau travail français, ce livre largement et logiquement composé, de la première à la dernière page. Et bien écrit. Le style en était à l'image même de l'ouvrier: sobre, clair, précis, d'une fermeté vigoureuse. Les formules abondaient qui, à force de justesse et de sincérité, faisaient balle. Elles abondèrent aussi à la soutenance, belle fête du travail mais aussi de l'amitié. C'est que, de cet homme fort, solide, robuste, dont la structure physique évoquait les Vosges originelles - un charme se dégageait. Les bons yeux clairs et francs vous attiraient: ils regardaient si droit... Ils promettaient tout de que l'homme tenait. Quand il vous avait adopté, il ne vous lâchait plus. On pouvait avoir des «piques » avec Albert Demangeon : il ne vous en voulait jamais d'avoir été grognon, parfois, avec vous... C'est une mansuétude plus rare qu'on ne croit. Et quand p381 il était dur, d'une dureté saine, salubre et nécessaire Demangeon n'était jamais méchant, jamais perfide, jamais machiavélique.

Passer son œuvre en revue - ce n'est pas le lieu. On sait de quoi elle est composée. Outre la thèse sur la Picardie, il y a les grandes fresques de la Géographie Universelle: les Iles Britanniques et les Pays-Bas (1927) - en attendant la France économique. Il y a cette synthèse : l'Empire britannique (1923). Et cette thèse : Le déclin de l'Europe (1920). Il y a l'immense dossier de l'Habitat rural, la dernière province qu'il se soit annexée: articles, mémoires, questionnaires, expositions même ${ }^{252}$. Et celui de l'Émigration, plus

${ }^{251}$ La plaine picarde, Picardie-Artois-Cambraisis-Beauvaisis. Étude de géographie sur les plaines de craie du Nord de la France, Paris, Armand Colin, 1905, in- $8^{\circ}, 496$ pages. - En librairie, titre différent : La Picardie et les régions voisines, ibid., 1905 (retirage en 1925).

252 Cf. notamment: Un questionnaire sur l'habitat rural (Ann. de Géographie, t. XXXV, 1926, p. 289). - Économie agricole et peuplement rural (ibid., t. XLIII, 1934). - Types de peuplement rural en France (ibid., t. XLVIII, 1939). - En plus, les communications sur l'habitat rural faites au Congrès international de 
récent, presque aussi fourni ${ }^{253}$. Il y a la masse de ses articles, un peu partout; il y a ses comptes rendus, si scrupuleux, si fouillés et si sobres. Et je ne parle pas de son œuvre orale — des cours et des leçons de ce professeur modèle, vivant, incomparable. Une œuvre écrasante. Le fruit d'un labeur qui, souvent, nous effrayait pour lui.

Sans nous perdre dans l'ampleur de cette œuvre, ne parlons ici que d'Albert Demangeon, ami et collaborateur des Annales. Ami de la première heure, ce serait trop peu dire. Il fut bien autre chose. Au vrai, c'est lui qui nous a tenu sur les fonts baptismaux. C'est lui qui mit au service des Annales, quand elles n'étaient encore qu'un projet, toute l'influence qu'il s'était acquise à la librairie Armand Colin, auprès de Max Leclerc, éditeur d'initiative. Et la Revue créée, Albert Demangeon ne l'abandonna point. Il fut pour elle le meilleur des collaborateurs, alors que tant d'autres tâches le sollicitaient - et qu'il aurait pu, tout naturellement, se réserver pour les Annales de Géographie.

C'est que, de lui à nous, pas de mésentente. Venant de lire L'Empire britannique : "Quel beau livre d'historien!" disait un de mes collègues, tout chaud d'enthousiasme. Traduction inexacte d'un sentiment valable. Le livre, au vrai, était le produit, p382 l'excellent et remarquable produit d'une méthode et d'une culture fondées à la fois sur deux disciplines étroitement associées : la géographie, l'histoire. Connaissance approfondie et de première main du milieu naturel; intelligence générale des conditions de développement des sociétés humaines: sur ces deux bases était assise, fortement, l'œuvre géographique de Demangeon. Il avait du milieu naturel cette connaissance scientifique personnelle et directe qui émeut, parce quelle comporte, avec des incertitudes et des ignorances toujours avouées, des espérances et une ardeur sans limites. Des sociétés humaines, il avait la curiosité profonde et sympathique. Il ne projetait

Géographie de Paris, 1931 (t III des Comptes rendus du Congrès, Travaux des Sections IV, V, VI ; Paris, Armand Colin, 1934).

253 Cf. publiés en collaboration avec G. MAUCO, ses Documents pour servir à l'étude des étrangers dans l'agriculture française (Paris, 1939 ; 654 pages in-8 ${ }^{\circ}$ ). 
point sur elles l'ombre massive des fatalités. Il tenait du reste que les plus hauts problèmes de la géographie, ce sont précisément les pays les plus riches en manifestations diverses, les pays les plus avancés dans tous les domaines, qui les présentent — et non pas les groupements simples, ni les hommes proches encore de l'animalité. Mais, par là même, l'histoire s'introduisait dans la place: et Demangeon ne faisait rien pour la repousser. Au contraire. Sa petite thèse, en 1905, il l'avait intitulée hardiment: Les sources de la géographie de la France aux Archives Nationales. Et dédiée à son vieil ami Pierre Caron qui prenait à la restauration des bonnes disciplines historiques une part vaillante. Mais c'est toute son œuvre qui atteste les bienfaits d'une culture double — de géographe et d'historien. C'est que, Demangeon le savait bien : connaître les faits de surface pour le géologue, c'est d'abord connaître les faits de profondeur. Mais connaître l'aspect actuel des sociétés humaines pour leurs exégètes - et le géographe n'est que l'un d'entre eux — c'est d'abord connaître les phases antérieures de leur évolution ${ }^{254}$.

De tout cela, Demangeon eut toujours un sentiment très net. Et c'est ce sentiment qui anime toute son œuvre par le dedans. Il excellait dans ces résumés historiques qu'en tête de ses ouvrages, ou de ses chapitres, il composait avec une merveilleuse aisance, et qui, en quelques pages, fournissaient au lecteur la substance, filtrée, condensée, clarifiée d'une vingtaine de livres lus attentivement et dépouillés avec scrupule. Qu'on ouvre, ${ }_{\mathrm{p} 383}$ sous sa forme première, le gros livre sur Le Rhin ${ }^{255}$ que publia à l'occasion de son premier cinquantenaire (1881-1931) la Société Générale Alsacienne de

${ }^{254}$ Ce petit volume n'importe pas seulement par la masse de renseignements précis, et pratiques, qu'il contient. Dans son texte, il traduit l'état d'indécision dans lequel se trouvait alors la pensée géographique française : oscillant d'une conception de la géographie "science naturelle» à une conception de la géographie « science historique » : nous dirions aujourd'hui « science humaine ».

255 Le Rhin, Société Générale Alsacienne de Banque, sans nom d'éditeur, ni lieu, ni date (Strasbourg, 1931, in- $\mathrm{f}^{\circ}$, hors commerce). Deux parties : I, Le problème historique du Rhin, par Lucien FEBVRE; II, Le problème économique du Rhin, par Albert DEMANGEON. - Le texte de ce volume, remanié, a été réimprimé en 1935, à la Librairie Armand Colin, sous le titre : Le Rhin: Problèmes d'histoire et d'économie (in- $\left.8^{\circ}\right)$. 
Banque, et où nous nous trouvâmes associés Demangeon et moi. Rien qui permette de mieux saisir les dons divers du géographe que les dix premières pages de son travail : d'abord (p. 161-165), une description saisissante, sorte de vue d'avion de la vallée du Rhin — ou plutôt, comme il le dit, suite d'impressions, justes, nettes, et cependant colorées : ce ne sont pas les images, ici, qui traduisent le mieux les paysages, qui enfoncent le mieux dans l'esprit du lecteur la vision de ces terres heureuses ; c'est bien le texte de Demangeon, ses notations sobres qui s'achèvent en une sorte d'hymne au labeur pacifique des hommes et à leurs meilleures œuvres :

Rives construites, fixées par des ouvrages en pierres ou en fascines dont on voit la tête affleurer au-dessus des eaux; énormes repères blancs dont les chiffres indiquent aux bateliers le kilométrage de ]a voie d'eau; groupes de chalands pansus et bas sur l'eau, traînés en files par des remorqueurs... faisant songer aux avenues d'une grande ville aquatique où la circulation serait parfaitement ordonnée ; quelques lourds trains de bois, derniers témoins d'un ancien mode de transport, introduisant leurs formes massives et lentes au milieu de la batellerie trépidante...; étonnante variété de types de bateaux, depuis les puissants vapeurs à hélice remorquant les convois de charbon et de minerai jusqu'aux humbles voiliers hollandais transportant toute une pacotille... Parfois, une silhouette inattendue se dresse sur ces eaux tranquilles : c'est un navire de mer qui remonte le fleuve, apportant avec lui, en ces paysages continentaux, les lointaines perspectives des pays d'outremer. Et comme pour achever l'illusion, des vols de mouettes, poussés par les vents marins, viennent jusqu'ici chercher leur vie dans les eaux du grand fleuve.

Ainsi le géographe. On tourne la page : le ton change.

Dans l'histoire du Rhin, on doit reconnaitre plusieurs grandes périodes qui se distinguent, à la fois, par la nature du trafic qui a suivi le fleuve, et par l'étude des relations qu'il a permises. La vallée du Rhin est d'abord une voie transcontinentale... La vallée du Rhin devient ensuite une voie essentiellement régionale... Mais ${ }_{\mathrm{p} 384}$ depuis le milieu du $\mathrm{XIX}^{\mathrm{e}}$ siècle, une nouvelle phase a commencé pour la navigation rhénane; on peut dire qu'elle est devenue une voie internationale.

Toute l'histoire du fleuve classée, cataloguée, clarifiée. Et Demangeon de reprendre ses trois divisions, et l'histoire d'ajouter son apport à la géographie, de l'expliquer et de la vivifier. - Tout 
naturellement. Sans effort. Ces belles réussites naissaient, comme d'elles-mêmes, sous la plume de Demangeon. C'est que l'effort avait précédé l'œuvre. Et qu'elles étaient le prix d'une longue et forte culture d'humanités et d'histoire. Que rien ne remplace.

C'est là d'ailleurs — je veux dire dans son œuvre positive — qu'il faut chercher le secret de son influence. Théoricien, Demangeon l'était peu. Ou plutôt, quand il traitait de méthode, il semblait toujours se borner à tirer de sa pratique des règles un peu extérieures d'action. Comme il était robuste de tempérament, optimiste à la façon des bons forgerons - l'inquiétude méthodologique n'était pas son fait. On croit toujours l'entendre dire, en prenant sa plume pour trancher un débat : "C'est bien simple ! »Et, de fait, sous sa plume, tout devenait très simple. La clarté de son esprit semblait lui masquer les difficultés - et en tout cas chassait les ombres et les obscurités. Essayant de montrer comment la géographie rejoint l'histoire du peuplement, Jules Sion confessait ${ }^{256}$ : "Malheureusement, à cette histoire la géographie n'apporte guère encore de résultats utiles. Plutôt la liste de ses curiosités, l'indication des sciences connexes qui aideraient à les satisfaire, et les vagues lueurs qu'elle croit entrevoir... » Inquiétudes, goût du conditionnel, sens du relatif...

Ce n'était pas le climat d'Albert Demangeon. Il comprenait mal de telles réserves, de telles limitations volontaires. Il était de ceux à qui le sentiment interne de leur force vitale masque les faiblesses des grandes entreprises à quoi ils s'associent de tout leur cœur.

De ceux aussi à qui il faut, pour agir, des certitudes.

Ils sont partis tous deux, Albert Demangeon, Jules Sion, à une heure deux fois trouble. On est tenté de dire, quand on les a bien aimés : tant mieux pour eux ! Mais ni l'un ni l'autre n'eussent goûté cette forme de piété amicale. Si différents de structure physique et de tempérament, l'homme mince et frêle, 3385 qui vivait de ses nerfs l'homme robuste et vaillant qui paraissait taillé pour vivre encore des

256 Points de vue géographiques, dans Revue de Synthèse, t. XVII, n ${ }^{\circ}$, 1939, Compte rendu des Journées de Synthèse consacrées au peuplement de l'Europe, p. 37. 
années - tous deux étaient de ceux qui ne lâchaient pas l'outil, et qui, ayant travaillé toute leur vie (comme nous tous) avec une passion et une énergie farouche, n'avaient devant le danger, devant le péril mortel, devant le désastre imminent, qu'une commune réaction : celle de Frère Jean, retroussant ses manches pour sauver, si possible, la nef en perdition. Leur disparition est d'autant plus cruelle. Et pour ne parler ici que de nos études - il faut regretter qu'elle se produise à l'heure où des mesures qu'on peut croire imprudentes risquent d'ébranler l'œuvre même à quoi, tous les deux, ils ont attaché leur nom et consacré leur vie.

Histoire, géographie : nous venons d'apprendre que le divorce des deux disciplines s'imposait. Sur le plan pédagogique, s'entend. Mais on sait assez qu'il commande, en France, trop souvent, le plan scientifique. N'entamons pas le procès de mesures sommaires qui n'ont pas encore commencé d'être appliquées, et dont on ne saurait dès lors mesurer les conséquences prévisibles. On voit mal cependant ce que pourra devenir la géographie humaine aux mains d'hommes privés de culture historique? Hier, Sion gourmandait ces géographes qui « hasardent dans le passé rural des coups de sonde bien timides, gênés par la peur de " dévier vers l'histoire ». Que sera-ce demain, si les aménagements nécessaires ne sont pas entrepris, dans un large esprit de collaboration et de curiosité scientifique ? Mais précisément, pour une tâche pareille, comme nous aurions eu besoin de vous, Jules Sion, Albert Demangeon, très chers amis, esprits robustes et pénétrants, grands artisans d'une des belles réussites intellectuelles de nos générations : la géographie humaine?

Nous saurons lutter ici, s'il le faut, pour sauver de votre œuvre tout ce qui peut être transmis à ceux qui, demain, librement, à leur allure, viendront marcher sur les traces de Vidal, ce grand esprit; de Sion, ce pénétrant esprit ; de Demangeon, cet esprit complet. p386 


\title{
Les Morts de l'Histoire Vivante
}

\author{
GASTON ROUPNEL
}

$\underline{\text { Retour à la table des matières }}$

Gaston Roupnel s'est éteint à soixante-quinze ans, au printemps de 46, dans son cher pays bourguignon de Gevrey. Originale figure dans la galerie des historiens français contemporains. Romancier d'une part et historien de l'autre, disaient ceux qui le connaissaient ou le comprenaient mal. En fait, le portraitiste de Nono, vigneron de la Côte (1910) et du Facteur Garain (1913) était bien le même homme que 1'historien de La ville et la campagne (1922), cette originale thèse de Sorbonne qui révéla brusquement un historien, un vrai, à ceux qui en Roupnel ne voyaient qu'un amateur un peu fantaisiste. Cette étude sur «les populations du pays dijonnais », comme dit le sous-titre, est en réalité un des très rares livres nourrissants d'histoire sociale à qui notre XVII ${ }^{\mathrm{e}}$ siècle paysan et bourgeois (ce déshérité) a jusqu'à présent donné lieu chez nous. Roupnel me sut gré (il me l'écrivit) d'avoir, dans le compte rendu que j'en fis paraître dans la Revue Critique, réuni dans un même éloge ses romans bourguignons à sa thèse d'histoire. Quand parut son Histoire de la campagne française, je fus très séduit. Oh! bien sûr, les vétilleux avaient de quoi exercer leur industrie sur ces pages souvent aventureuses, sur ces néolithiques un peu trop mis à profit, sur quelques effusions, trop abondantes, peutêtre, en points d'exclamation. Mais quoi ? Il court à travers ce livre de telles senteurs, un tel parfum de bois et de prairies de terres fraîchement remuées et de vignes en fleurs ; il s'y lève, à chaque page, de si belles images de grâce franciscaine; il s'y exprime un tel amour des gestes du laboureur, "si purs et si doux qu'ils semblent mettre le monde entier en paix », qu'il m'était impossible de m'associer à des 
critiques un peu grincheuses et qui montraient des auteurs insensibles au charme profond et à la forte leçon de ce que je continue ${ }_{p 387}$ à nommer un très beau livre. Un de ceux qui donnent faim et soif de savoir.

Sur les livres philosophiques de Roupnel (les deux Siloë), je ferais plus de réserves. Mais quoi ? Il suffit que sa pensée le ramène à la terre et à la vigne pour qu'aussitôt on oublie tout, tant l'expression est juste et le sentiment profond.

Le courrier m'apporte - tirage à part des Annales de Bourgogne, tome XVIII, 1946 - une excellente notice sur Roupnel, signée de notre collaborateur P. de Saint-Jacob. Le portrait est finement nuancé. Et l'hommage s'adresse à l'historien de Nono comme à l'évocateur de La ville et la campagne. Un livre épuisé, je crois bien. Ne vaudrait-il point la peine qu'à Dijon on en procurât une réédition ? Nous avons si peu d'ouvrages d'histoire sociale de cette qualité ! Et celui-là fait aimer cette forme riche et difficile d'histoire.

\section{UNE LETTRE DE GASTON ROUPNEL}

Quand parut le dernier livre de Gaston Roupnel, Histoire et Destin, j'eus d'abord l'idée d'en faire le compte rendu. Mais Fernand Braudel, qui venait de lire le livre en captivité, me demanda de lui laisser le plaisir de le faire. On a lu ce compte rendu, naguère, au vi ${ }^{e}$ fascicule des Mélanges (1944). Gaston Roupnel, ayant pris connaissance de ce texte, écrivit alors à Fernand Braudel la lettre qu'on va lire. Elle explique la genèse, le caractère, l'esprit du livre. Et surtout, elle éclaire du dedans la physionomie intellectuelle et morale de Gaston Roupnel. Il nous a paru qu'en la publiant nous rendions un dernier hommage à son auteur. Discret comme lui, et intime.

«MONSIEUR, vous avez fait à mon livre Histoire et Destin l'honneur d'un beau et grand article dans le numéro VI des Mélanges d'Histoire Sociale. Je me permets de venir vous en remercier. Et je voudrais que vous discerniez dans ce remerciement autre chose que l'expression d'une banale gratitude. Car j'ai été très touché de la sympathie compréhensive avec laquelle vous avez bien voulu parler 
de mon œuvre. Même dans vos réserves (toujours légitimes), même dans vos critiques (si souvent justifiées), il y a un ton de bienveillance, on y sent un accent de bonté, auquel je n'ai pas été insensible, croyez-le bien... Le vieil homme que je suis est heureux de vous en dire son émotion et sa gratitude. Même un ami n'aurait pu exercer avec plus d'indulgence aimable son droit de libre appréciation.

p388

» Non seulement vous avez apprécié avec clairvoyance et indulgence, mais vous avez deviné que ce livre d'histoire avait « son » histoire. « Histoire et Destin 1944 », dites-vous. Je dirais plus exactement « Histoire et Destin 1940-1942». J'ai commencé de l'écrire dans les tout premiers jours de juillet 1940. Je venais de voir passer dans mon village de Gevrey-Chambertin, sur la grande route nationale, les flots de l'exode, du douloureux exode, les pauvres gens, les voitures, les charrettes, les gens à pied, une lamentable humanité, toute la misère des routes, et cela pêle-mêle avec des troupes, des soldats sans armes, les restes de l'armée française. Cette immense panique : c'était cela, la France !... Et devant notre maison campaient les soldats de la Wehrmacht, les blindés, les chefs, les guerriers, les vainqueurs !... Quelles atroces journées !... Sur mes vieux jours, aux infortunes irrémédiables de la vie privée allait s'ajouter le sentiment de l'infortune publique, nationale... A deux pas de chez nous, l'Allemand était en train de construire sa frontière nouvelle : la ligne de démarcation, cette ligne qui devait pour toujours couper la France en deux !... On en était là. C'était l'aboutissement d'une vieille histoire !... Cette histoire, je l'avais enseignée pendant plus de quarante ans, enseignée avec confiance et avec foi ! ...

» De colère et de dépit j'ai commencé d'écrire cette première partie dont le ton pamphlétaire et l'allure critique ont si souvent déplu et déçu. J'en voulais à cette « histoire » qui aurait dû nous être l'expérience de la vie passée, et qui ne paraissait plus rien, qui n'était ni avertissement, ni souvenir utile, ni espoir, ni consolation !...

» C'est dans les premiers jours de juillet 1940 que j'avais commencé d'écrire. Ce travail me faisait oublier. Puis la lassitude est venue, le découragement s'est emparé de moi. Et la première partie une fois écrite, j'en suis là de l'automne 40 à l'été 41. L'entrée en guerre de la Russie m'a soudain rendu l'espérance. Le miracle inattendu était venu. Et c'est un tout autre homme qui écrit la seconde et la troisième et dernière partie du livre. Vous étonneriez-vous qu'il ait senti se pencher sur lui et les autres une « Providence » protectrice des destins humains ?

» Excusez-moi de cette longue lettre ! Commencée il y a quinze jours, dès que j'ai eu pris connaissance de votre article, j'ai dû l'interrompre à cause d'une grave bronchite. Je l'ai reprise à la page précédente au trait tracé au milieu. J'aurais bien des choses à y ajouter. Mais ce serait abuser de votre patience. Et pourtant je tiens à vous dire que vous avez su être le devin qui voit autre chose encore. Quand vous dites que je voudrais « ne pas me séparer de vous » (p. 76, au milieu de la page), vous dites vrai. Et en dépit de ce que j'ai pu écrire ou paru penser, je me sens tout près de ceux qui ont cru à l'effort humain. Si les Cieux ont leur mystère, la 
désertique sécheresse terrestre a sa stoïque grandeur. Et je continue de penser que des « inconciliables » enveloppent notre sagesse. p389

»Quelques derniers mots avant de conclure cette trop longue lettre! Vous avez raison de me reprocher le mot sur Michelet. Je l'ai tellement aimé ! J'y ai tant cru !... Mais mon terrible ami Mathiez m'ayant montré une lettre écrite par Michelet vers 1827 ou 1828 (?), lettre d'une platitude d'arriviste sans vergogne, mon idole s'est écroulée. Peu après je l'ai trouvé bien " près de ses sous » dans ses comptes avec les éditeurs. Bref, j'ai renié le dieu que j'avais adoré. Et aujourd'hui, j'en reviens à ce que dit si bien Lucien Febvre sur Michelet! De nouveau il me semble le génie qui remplit l'histoire. Il l'a arrachée à ses sommeils savants ; et demain peut-être la revivifiera-t-il encore ! ...

» Il y a aussi quelques autres expressions ou épithètes que je regrette. Elles atteignent injustement tant de braves gens! Mais, dans le combat, que de coups sont maladroits !... »p390

GASTON ROUPNEL 
Souvenirs d'une Grande Histoire

MARC BLOCH ET STRASBOURG

$\underline{\text { Retour à la table des matières }}$

La première fois que nous nous rencontrâmes à Strasbourg, ce fut, je crois, en octobre 1920, à l'une de ces réunions inaugurales de Faculté qui devaient laisser à leurs participants de tels souvenirs d'élan généreux et d'ardeur désintéressée. Nous étions là quarante, arrivés de la veille pour la plupart, venant à peine de quitter l'uniforme - ayant déjà la pudeur, si française, de nos croix de guerre et de nos citations. Français passionnés, certes - et nous venions de le montrer pendant quatre ans les armes à la main : mais ce que nous entendions être désormais, c'était les fidèles serviteurs de cette Alsace déchirée dont nous savions bien que la bonne santé morale allait dépendre, pour une large part, de nous et de nos efforts. Et pendant que, sous l'étincelante présidence d'un Étienne Gilson tout jeune, nous nous entendions sur l'intronisation d'un doyen, élu d'avance dans nos cœurs comme il l'était par toute l'Université de France nous échangions nos noms, quand nous ne connaissions pas encore nos visages. Et nous allions au devant les uns des autres, avec une sorte de spontanéité joyeuse que nous ne devions plus jamais connaître par la suite. Nous cimentions, avec des éléments d'ailleurs cohérents et choisis, un beau bloc d'amitié et de dévouement.

Marc Bloch, né à Lyon le 6 juillet 1886, était un de nos benjamins. Il me semblait très jeune. On est toujours très jeune, à 32 ans, aux yeux d'un homme de 40. Je l'avais cependant entrevu plus jeune, beaucoup plus jeune encore, un jour de 1902, chez son père, rue 
d'Alésia: son père, Gustave Bloch, maître puissant, redouté et accueillant tout à la fois, qui avait, à l'École Normale ${ }_{\mathrm{p} 391}$ de la rue d'Ulm (où il enseignait avec éclat l'histoire ancienne) formé la jeunesse de combien d'entre nous... J'avais gardé de cette entrevue fugace le souvenir d'un adolescent svelte aux yeux brillants d'intelligence, aux joues timides, un peu perdu alors dans le rayonnement de son aîné, futur médecin de grande classe. Je retrouvais devant moi un homme jeune, sur qui la guerre avait mis sa marque au cours de quatre années de vie dure, quatre années remplies d'actions d'éclat qu'attestaient quatre citations, un certificat de blessure et la Légion d'Honneur à titre militaire : le bagage obligé du gentilhomme français en ces années 14 à 19. Marc Bloch, par ailleurs, venait de se marier, et déjà s'employait à faire de son union avec une jeune femme, aussi peu désireuse de paraître qu'avide de se dévouer, la belle œuvre humaine et rayonnante qu'il sut maintenir jusqu'à la dernière heure. S'asseyant ainsi dans la vie, Marc Bloch, en tant qu'historien, se cherchait encore. Son père, ses maîtres de l'École Normale (il retrouvait à Strasbourg le principal d'entre eux, celui qui lui avait ouvert les portes du moyen âge, notre cher Christian Pfister), ses séjours à l'étranger, - notamment, cette année qu'il avait passée à fréquenter, à Leipzig et à Berlin, chez Bücher et chez Harnack, toute cette longue et minutieuse préparation l'avait rendu merveilleusement apte à accomplir une œuvre, une grande œuvre d'historien. Mais quelle? Il hésitait encore sur la direction. En attendant, il achevait sa thèse, Rois et serfs, un chapitre d'histoire capétienne : thèse courte qui devait paraître en 1920. Il alla la soutenir en Sorbonne. Il revint, naturellement, avec son " très honorable ». Et, débarrassé de ce qui, malgré tout, est une obligation plus encore qu'une option, il put s'intéresser librement sur son destin scientifique.

D'instinct, dans cette thèse, Marc Bloch s'était posé un gros, un très gros problème d'histoire psychologique et sociale. Il n'était pas de ceux qui font de l'histoire comme leurs grand-mères ont fait de la tapisserie: pour passer le temps et justifier des titres. Déjà il réfléchissait à son "métier d'historien ». Il s'inquiétait des dates, et, en historien juriste, des institutions. En juriste, en sociologue aussi : le mouvement durkheimien l'avait fortement retenu. Son intérêt était vif pour tout ce qui était, en histoire, croyance collective. Et c'était bien de croyance collective qu'il s'agissait, quand Marc Bloch étudiait le 
problème de la liberté au moyen âge. Fondamentale, la distinction des libres ${ }_{\text {p392 }}$ et des non-libres dans les vieux textes. A quoi répondaitelle? Que signifiait vraiment pour "les hommes du moyen âge », façon ridicule et commune de parler, ce mot si lourd de résonances profondes : LIBERTÉ? — Grosse question, difficile à résoudre; mais c'était déjà bien que de l'avoir, si jeune, posée devant soi avec lucidité.

D'autres recherches d'ailleurs sollicitaient Bloch à pareille époque. Recherches du même ordre, en réalité. L'idée lui en était venue en s'entretenant d'histoire avec son frère le médecin — esprit extrêmement ouvert et curieux. Il s'agissait du problème des Rois thaumaturges : problème qui, cette fois encore, avait de quoi satisfaire les multiples curiosités d'un historien des croyances collectives. Le livre est de rare qualité : un des joyaux de la Bibliothèque strasbourgeoise de la Faculté des Lettres qu'il inaugura presque. J'ai souvent dit à Bloch que c'était un des morceaux de son œuvre que je goûtais le plus - et il me savait gré de ma sympathie « pour ce gros enfant », comme il disait gaiement. Quand on pense à ce qu'un pareil sujet, manié par les lourdes mains d'un candide pourfendeur de miracles, aurait pu donner de vulgaire ou de caricatural, on apprécie mieux, dans cette œuvre de jeunesse touffue et nourrissante, la qualité d'esprit d'un historien véritable — un de ceux qui ne font pas comparaître devant eux les siècles pour les tancer et les morigéner du haut de leur grandeur d'hommes de progrès : ils ont assez de mal à les comprendre.

A l'Université, nos séminaires voisinaient. Nous étions porte à porte. Et les portes étaient ouvertes : il ne s'agissait pas que les médiévistes se crussent tenus d'ignorer les temps modernes, ou inversement, que les modernistes se tinssent à l'écart du moyen âge. Donc, nos étudiants passaient d'une salle à l'autre - et leurs maîtres avec eux. Souvent nous revenions ensemble au logis, et le trottoir médian de l'Allée de la Robertsau a vu bien des allers et des retours, bien des conduites et des reconduites prolongées en dépit du poids des serviettes toutes gonflées de livres. A force de causeries, de longs échanges de vue et de méditations, il se trouva que Bloch, petit à petit, 
s'orienta du côté des horizons nouveaux que j'avais tenté de découvrir en 1911, dans un gros livre d'histoire plus sociale encore qu'économique, et plus économique que religieuse ou politique.

L'histoire qui sent bon la terre, la campagne, le labour et la moisson - cette histoire ne répugnait pas du tout à ce citadin, ${ }^{2} 393$ né cependant à Lyon la brumeuse, élevé dans Paris la pierreuse, et sans attaches provinciales, semblait-il, ni petit pays d'origine. Comme beaucoup d'entre nous, ses contemporains ou ses aînés, il avait subi, fortement, l'influence de cette géographie qu'un maître puissant et ingénieux, d'une rare culture et d'une plus rare largeur d'esprit Vidal de La Blache - venait de promouvoir au rang de discipline nourricière. La géographie, c'étaient bien des choses sans doute, mais pour beaucoup de jeunes Français enfermés dans des salles moroses et laides : le bas en marron, le haut en ocre sale, et, au-dessus des crânes penchés, la blafarde et étouffante lumière du gaz (jusqu'en 1900 et même par delà il régna, en maître de migraine, dans les lycées et dans les écoles), - la géographie, c'était l'air pur, la promenade à la campagne, le retour avec une brassée de genêts ou de digitales, les yeux décrassés, les cerveaux lavés et le goût du réel mordant sur l'abstrait.

Or, notre ami Henri Berr avait lancé aux environs de 1900, dans cette Revue de Synthèse Historique qui fut notre cheval de Troie, et par quoi s'insinuèrent dans la place tant de nouveautés ennemies et troublantes - Henri Berr avait lancé une collection, de Monographies provinciales : «Travail fait, travail à faire », disait la couverture de ces petits livrets prometteurs. Je m'étais chargé d'une Franche-Comté dans la collection. Bloch avait suivi, donné une Ile-de-France : travail de qualité, comme tous ceux qu'il a signés de son nom. Et précisément, on y sent déjà l'éveil d'une vocation d'historien paysan. Rien d'étonnant dès lors à ce que, jeune homme en quête d'un domaine propre, Bloch se soit tourné finalement du côté des études terriennes et campagnardes. Je répugne à dire: «de l'histoire agraire ». Car il y avait déjà des « agrariens » dans notre corporation. Mais c'étaient des amateurs de catégories juridiques. Des hommes qui se satisfaisaient de classer, à la façon des feudistes du XVIII ${ }^{e}$ siècle, les sociétés anciennes, les sociétés médiévales (et le moyen âge, dans le domaine paysan, s'est prolongé, ne l'oublions pas, jusqu'à la nuit du 4 
août, au moins); mais quant à découvrir, par derrière tout ce jeu d'abstraction, les réalités vivantes, quant à poser des problèmes positifs, concrets, humains, d'états d'âme, de genres de vie, de fatigue et de malaise physique ou moral, de financement aussi et de monnaie - quant à sortir, une bonne fois de l'abstraction : non. Rien. C'était le temps (mais est-il révolu partout, en dépit de nos efforts? ) - c'était le temps où les paysans ne labouraient jamais que des cartulaires avec un notaire pour unique auxiliaire. p394

De la répugnance que lui inspirait une telle histoire, de son désir, de son besoin "d'aller à la terre », d'ouvrir les fenêtres de l'histoire rurale sur la campagne vivante et nourricière, de dire la peine des hommes et leurs sentiments et leurs pensées secrètes, plutôt que de confectionner patiemment tout un jeu d'étiquettes pseudo-juridiques à coller sur leur diversité, Marc Bloch s'ouvrit à moi de bonne heure. Je l'encourageai de mon mieux à s'évader dans cette voie. Et désireux de lui laisser toute liberté de démarche, je décidai de ne pas continuer personnellement à travailler dans cette direction. A quoi bon se doubler, quand on est si peu d'hommes, si peu d'ouvriers vraiment qualifiés - et que le chantier est si grand, et si vide ?

Donc, Bloch se mit à la besogne. Avec cette méthode, ce scrupule, cette patience qui soutenait tous ses efforts. Il avait toujours pratiqué les textes. Mais c'étaient des textes français surtout, des cartulaires français qui avaient d'abord retenu son attention. Or, par le propre mouvement de sa pensée, mais sous l'influence également de Henri Pirenne - en 1921, Marc Bloch avait entendu avec moi cet homme étonnant, d'une si rare puissance dans sa simplicité, prononcer à Bruxelles son retentissant discours sur l'Histoire comparée - et les propos du maître historien avaient rejoint dans son esprit les réflexions et les règles que, de son côté, le maître-linguiste Antoine Meillet avait formulées bien des fois sur ce sujet - par le propre mouvement de sa pensée, mais fécondée par tant de propos excitants et nourriciers, Bloch en était venu à la conclusion qu'une histoire rurale de la France ne se suffisait pas à elle-même ; que la solution de bien des problèmes que les historiens se repassaient les uns aux autres, depuis des décades, sans en faire jamais avancer la solution, se trouvait de toute évidence hors de France ; que le tout était d'aller l'y chercher et donc de se préparer à cette quête difficile. Bloch s'y 
prépara. Il apprit des langues, le plus de langues qu'il put en sus de l'allemand et de l'anglais. Des langues modernes, des langues anciennes également: un peu de russe, de flamand, de scandinave, assez de vieil allemand pour pouvoir se plonger, sans perdre pied, dans une littérature d'exceptionnel intérêt; assez de vieux saxon pour ne pas rester fermé à l'intelligence des sociétés nordiques d'outreManche. En même temps, il s'initiait aux réalités de la vie agricole. A la rotation des cultures. Aux techniques du défrichement, du labour, de la moisson. Et il découvrait cet immense domaine du cadastre et des plans parcellaires, dont il allait devenir, en France, l'explorateur. p395

Le tapis bigarré des champs et des cultures : des taches de couleurs vives et contrastées pour la joie d'un Van Gogh. Mais aussi, des problèmes pour l'historien. De très gros problèmes, et passionnants. Bloch eut le grand mérite de s'en apercevoir et, s'en étant aperçu, d'entrer résolument dans le monde nouveau qu'il découvrait ainsi. D'y entrer en explorateur du réel — en commentateur de la vie. Pourquoi, dans cette contrée, ces champs uniformément allongés? Pourquoi, dans telle autre, ces parcelles carrées et massives ? Pourquoi la régularité ici, l'irrégularité plus loin? Pourquoi des champs clos, bordés de haies touffues, ou de rideaux d'arbres enfonçant leurs racines dans des levées de terre ? Pourquoi, là, des champs sans clôture, des champs nus, sans haies, sans buissons même, sans arbres : quand, d'aventure, un chêne touffu et rameux se dresse dans ces « champagnes », il devient tout de suite fameux et notoire; le poirier, le tilleul ou le noyer de Saint-Martin ou de Saint-Adrien s'inscrivent pareillement sur la carte d'État-Major et servent de repère à toute une contrée ? Nous enregistrons sans surprise ces aspects variés. Nous ne les regardons plus, à force de les voir. Il fallait, ici comme ailleurs, recréer l'étonnement. L'étonnement fécond sans quoi point de curiosité, partant point de science. Bloch s'y appliqua. Et que de découvertes, chemin faisant! Car les problèmes qui se posaient devant lui, la géographie pouvait se porter candidate à les résoudre. Champs clos, champs découverts : ne fallait-il pas tenir compte, pour expliquer leur prédominance ici ou là, de la nature du sol et du soussol, de la qualité du climat, du régime des eaux, de vingt autres facteurs "géographiques»? Champs clos, champs découverts : l'Allemagne ne tendait-elle pas au commentateur du grand livre des 
cultures, pour son instruction, la clef, la grosse clef des races : son passe-partout que le vieux Meitzen maniait sans discrétion ? Champs clos, champs découverts : la technique agricole n'avait-elle point son mot à dire sur le problème ? Comment se labourent-ils, ces champs d'aspect divers? A l'aide de quels outils, de quels instruments, de quelles machines ? Et l'usage même de ces outils, de ces instruments, de ces machines, n'explique-t-il point quelque chose?

Le difficile n'était pas de s'initier à tous ces modes divers d'exploitation: géographique, ethnique, agricole, technique. Le difficile était de ne point bâtir de brillant système - mais de ne pas non plus se noyer sous prétexte de largeur d'esprit, dans un éclectisme abstrait et sans vigueur. Le difficile était d'être historien. De se mettre en face des réalités d'abord, des idées préconçues. p396 De les regarder bien droit. De recourir aux textes. Et de les interroger - les textes écrits après les textes labourés - en ne perdant jamais de vue cette définition que Bloch aimait : « l'histoire, science du changement ». Je dirais plutôt, dans mon horreur de l'abstraction: "' l'histoire, science des changements ». - Et donc la clôture, ou l'ouverture des champs, l'openfield ou l'enclosure, ne sont peut-être pas de droit divin, d'institution providentielle immémoriale ? Cinq siècles, dix siècles, vingt siècles; peut-être en trouvera-t-on les débuts, les humbles et patients débuts : une Bretagne de champs ouverts, sans haies ni fossés - étalant ses champs comme une Beauce ou une Champagne?

Le résultat de tout cela, ce fut une série de conférences que Marc Bloch s'en alla professer à Oslo, à " l'Institut pour l'étude comparée des civilisations ». Un Institut fait pour lui, à sa mesure si j'ose dire. Ces conférences sur l'histoire agraire de la France eurent un grand succès. Et sitôt de retour, Bloch, heureux non pas d'avoir trouvé sa voie, mais de voir le succès récompenser ses efforts, les reprit, les précisa, les fortifia. Ainsi naquit ce livre, au titre un peu long mais expressif: Les caractères originaux de l'histoire rurale française, 
qui, en 1931, parut à la fois à Paris et à Oslo ${ }^{257}$. Livre dédié par Bloch à la mémoire d'Émile Besch, un de ses camarades de promotion mort prématurément après une longue maladie. Choses de la vieille École : ainsi avons-nous tous, publiquement ou dans le secret de nos cœurs, dédié légitimement des fragments de notre œuvre à ces compagnons de notre jeunesse qui furent les confidents de nos rêves et de nos labeurs; les accoucheurs de notre jeune pensée, mais nous fûmes, bien souvent, les accoucheurs de leur pensée à eux...

Le livre devint vite classique. Mais non pas du tout à la façon d'un manuel. Mon très cher Jules Sion, rendant compte des fortes impressions que sa lecture avait fait naître en lui, souhaitait qu'il devînt, au bout de trente ans, totalement inutile et périmé. Il faut être historien pour comprendre tout ce qu'un tel vœu implique d'admiration pour un livre d'histoire. Un de ces livres qui ne prétendent point, à la façon d'un manuel, donner de la réalité une image figée, intemporelle et morte; un de ces livres qui ne ressemblent pas à un bloc de gélatine pris par refroidissement, et destiné à tomber, tout d'un coup, en déliquescence, p397 sans avoir nourri personne. Un de ces livres qui font penser, chercher, trouver. Et dont chaque conclusion, révisée et remaniée, se trouve modifiée par le progrès même que le livre a suscité. Chaque conclusion révisée : mais d'abord et avant tout par l'auteur lui-même.

Car c'eût été mal connaître Bloch que de l'imaginer satisfait de son œuvre et passant son temps, dès lors, à en défendre les conclusions avec aigreur. Bloch n'était pas un faiseur de système. C'était un chercheur. Les Caractères originaux ne furent pas pour lui un point d'arrivée. Un point de départ, bien plutôt.

Précisément, en 1928, il s'était ouvert à moi d'un projet. Au lendemain de la guerre, à peine démobilisé, j'avais conçu l'idée d'une grande revue d'histoire économique internationale. Je la voyais, cette

\footnotetext{
257 Épuisé depuis longtemps, il a reparu en 1952 par nos soins à la Librairie Armand Colin. Un volume précieux de compléments, dû à R. DAUVERGNE, l'accompagnera.
} 
revue, dirigée par Pirenne dont l'autorité s'affirmait incomparable. J'étais tout prêt à en assurer à ses côtés le secrétariat général. J'avais poussé mes projets très loin et Pirenne s'y était vivement intéressé. Au Congrès international d'Histoire de Bruxelles, je les avais exposés devant un certain nombre de savants qualifiés, dont sir William Ashley. Une commission avait été nommée. Là-dessus, Pirenne avait cru bien faire d'intéresser les organismes genevois à l'affaire. En conséquence de quoi, la revue projetée s'était enlisée dans les terrains mouvants des bords du Léman. Un peu découragé, j'avais laissé là mes plans et mes rêves. Bloch, un beau matin, me proposa de les reprendre avec moi : mais cette fois, instruit par l'expérience, sous la forme d'une revue nationale à collaboration largement internationale. Je l'encourageai à poursuivre son idée, en l'assurant que, la revue une fois sur pied, je l'aiderais à la faire vivre, mais dans la coulisse, et comme simple collaborateur. Le destin voulut autre chose. Bloch s'achoppant à des difficultés d'éditeur, me demanda de l'aider, de prendre les choses en mains directement. Ainsi réussîmes-nous à mettre sur pied, en joignant nos efforts, les Annales d'Histoire Économique et Sociale, grâce à la largeur de vues d'un éditeur, Max Leclerc, auprès de qui nous fûmes introduits (il me plaît de le rappeler ici) par Albert Demangeon. J'avais pris parti. Il n'y eut plus moyen de reculer. Je fus avec Bloch, passionnément dès lors, le serviteur et le pourvoyeur des Annales - dont nous établîmes le siège à Strasbourg : elles furent pour un temps, et à notre commune satisfaction, les Annales de Strasbourg. - Or, ce sont les Annales, nos Annales, qui devinrent pour Bloch, au lendemain de p398 la publication de ses Caractères originaux, l'instrument rêvé d'une révision continuelle, d'une remise en question inlassable, d'un approfondissement constant et méthodique des problèmes soulevés par son grand livre.

Les Annales entre autres enquêtes, en instituaient une sur le cadastre, sur les plans parcellaires, sur la technique agricole et ses répercussions diverses sur l'histoire des hommes, qui passionne les hommes les plus divers : des géographes, comme Jules Sion dont je citais le nom tout à l'heure, comme Albert Demangeon qui nous suivait avec son affection bourrue, comme Arbos ou Musset, comme Allix et Dion; je ne parle pas de Henri Baulig qui à Strasbourg, auprès de nous, était un appui de tous les jours, à portée de nos mains, et toujours aussi ferme, aussi solide, aussi bon conseiller. 
Ce furent de belles années, ces années trente, à Strasbourg. De belles années de labeur ardent, désintéressé et fécond. Mais aussi, que d'admirables conditions réunies pour le meilleur travail! Et d'abord, que d'amitiés, qui n'étaient pas seulement réchauffantes par leur cordialité, mais excitantes par leur qualité ! C'était le temps ou notre cher Charles Blondel écrivait son Introduction à la psychologie collective, ce chef-d'œuvre : un des grands livres de notre temps, ce petit livre dont l'esprit était nôtre, si la substance et la forme (exquise comme toujours) n'étaient qu'à Blondel et que de Blondel. A côté de lui (parlons surtout des morts : la liste en est longue déjà), toute la gamme de nos linguistes, depuis ce délicieux Ernest Lévy, inépuisable en données sur la vieille Alsace, ses coutumes, ses mœurs, son folklore - ses meubles aussi, et ses bibelots d'antiquaires — jusqu'au bataillon carré de nos germanistes, de nos anglicistes, de nos slavisants. Une difficulté philologique dans quelque texte médiéval: Ernest Hœpffner était là pour la lever. Une difficulté archéologique, et P. Perdrizet déployait pour vous le trésor inépuisable de ses curiosités. S'agissait-il de liturgie, de théologie, d'histoire des dogmes: les Facultés de théologie strasbourgeoises offraient leurs compétences. Une question de droit canon? Gabriel Le Bras intervenait, avec sa science vivante et allègre. Car ni Bloch, ni nous autres, nous ne nous cantonnions dans notre Faculté - quelle qu'en fût la richesse, quelle que fût en particulier la vie et l'activité du groupe des historiens, d'André Piganiol et d'É. Perrin à Georges Lefebvre que nous eûmes la grande joie, Bloch et moi, de voir s'agréger à la Faculté après la p399 mort de Pariset. - Et il y avait les hôtes de passage. Pendant plusieurs années, le plus éminent, sans conteste, et le plus efficient fut ce grand Sylvain Lévi qui, ses cours du Collège de France terminés, venait passer bénévolement quelques mois à Strasbourg. Il y professait l'indianisme, sans doute : il faisait bien plus encore, et bien mieux, il y professait la France, dans ce qu'elle eut toujours de généreux, de noble et d'humain. Cependant Pirenne ne passait pas à Strasbourg sans nous faire signe, à Bloch et à moi. Et il vint même faire à nos étudiants une série de leçons qui leur permirent d'admirer, en connaissance de cause, la puissance incontestable de son esprit. Vedettes sur scène. La toile de fond - c'était la Bibliothèque, l'admirable Bibliothèque Nationale et Universitaire de Strasbourg, ses 
trésors étalés sous nos yeux, à portée de nos mains : un instrument de travail incomparable, unique en France. Si quelques-uns d'entre nous doivent laisser une œuvre derrière eux, c'est à la Bibliothèque de Strasbourg qu'ils le doivent en partie. A ses prodigieuses ressources, qu'ils n'ont fait qu'exploiter.

Les Strasbourgeois recevaient. Les Strasbourgeois étaient reçus. C'est en Norvège, on l'a vu, que Bloch a professé ses Caractères originaux avant de les rédiger et de les publier. En même temps, à Bruxelles, à Gand, à Madrid, à Londres, à Cambridge, il représentait la France dignement et activement: à Londres surtout, où devant l'auditoire qualifié de la "London School of Economics», il prononça de brillantes leçons sur un de ses sujets favoris : Seigneurie française et manoir anglais. Son renom grandissait. On sentait, partout, ce qu'il y avait de force en lui, de vigueur originale et d'intelligence vivifiante. Quand parurent coup sur coup, dans la collection L'Évolution de l'Humanité, ses deux gros livres sur la Société féodale, la partie était gagnée définitivement. On savait partout qu'un grand historien nous était né. Un grand historien européen : c'est le vrai mot. Car de toute évidence, l'histoire des sociétés médiévales dont est issue la nôtre ne saurait s'étudier que dans le cadre européen. C'est précisément au moyen âge que naît l'Europe, au sens humain du mot, par le rapprochement d'éléments nordiques, que Rome avait laissés hors de son attraction, et d'éléments méditerranéens dissous, désagrégés par la chute de l'Europe. Bloch le savait mieux que personne. Et il n'était pas homme - lui qui avait si remarquablement plaidé, dès 1928, Pour une p400 histoire comparée des sociétés européennes; lui qui devait laisser à l'état d'ébauche une Histoire de la France dans le cadre de la civilisation européenne, il n'était pas homme à se contenter, pour retracer l'évolution de la Société féodale, de textes français et de données françaises. Il savait qu'en pareilles matières les frontières ne signifient rien; que, si la seigneurie de l'Ile-de-France se retrouve dans ses grands traits sur le Rhin - elle ne se retrouve point par contre dans le Languedoc ; que si l'on peut rapprocher, comme type de groupement, Amiens de Gand ou de Cologne, on ne saurait par contre l'apparenter à Marseille, à Florence ou à Gênes; il savait que le système agraire d'un village 
champenois, c'est somme toute le système agraire d'un village saxon ; ce n'est pas celui d'un village breton ou languedocien. Et ceci va loin. Que la France, l'Allemagne et l'Angleterre se soient fait, à partir du $\mathrm{XII}^{\mathrm{e}}$ siècle, trois conceptions radicalement différentes de la hiérarchie sociale, voilà sans doute qui explique bien des choses de leur destinée. Présente autant que passée. Nous avons vu comment Marc Bloch s'était patiemment, tenacement doté d'un équipement scientifique incomparable. L'outillage, entre les mains du maître ouvrier, s'avéra parfait. Deux grands livres étaient nés, qui ont marqué nos esprits.

Marc Bloch n'était plus strasbourgeois quand parurent les deux volumes de la Société féodale. La mise à la retraite de Henri Hauser, titulaire de la chaire d'histoire économique de la Sorbonne, lui avait permis de venir rejoindre à Paris tant d'amis fidèles et de compagnons qui, peu à peu, y avaient essaimé. Il n'avait pas quitté les bords de l'Ill joyeusement, avec le geste de l'homme qui secoue la poussière de ses pieds sur le gîte provisoire dont il dut se contenter longtemps. Aucun de nous, je crois bien, Strasbourgeois de la promotion de 1920, n'a jamais éprouvé pareil sentiment. Il avait répondu à l'appel d'un devoir et peut-être aussi songé à ses enfants, à ses six enfants, qu'il jugeait bon de transplanter dans ce grand Paris qui incarne la France dans ce qu'elle a de plus rayonnant.

La tâche qui l'attendait à la Sorbonne était lourde : il le savait d'avance. Heureusement, dans sa chaire d'histoire économique, Marc Bloch restait un peu en marge, puisque l'histoire économique n'a pas cessé, en France, d'être un "en-marge ». Un peu moins accablé de besognes professionnelles que tels de ses collègues, l'auteur des Caractères originaux put toujours travailler, ${ }^{4} 401$ grâce à la robustesse de son tempérament. Je ne dis pas que ce fut sans fatigues. Mais son énergie en triomphait toujours. Et à sa présence dans la vieille maison de Sorbonne, il gagnait de rester en contact étroit avec une jeunesse, habituée à demander à la Faculté des Lettres et, jalousement, à la seule Faculté, sa pâture intellectuelle.

Sitôt arrivé, Bloch s'était préoccupé d'installer, dans un local exigu, un Séminaire d'histoire économique pourvu d'une bibliothèque d'usuels : c'est-à-dire de faire profiter la Sorbonne de ce qui avait été, 
à Strasbourg, le grand et précieux instrument de travail de nos étudiants. Il surveillait de près, en outre, la marche générale des études supérieures en France. Et ce n'était pas pour s'en louer sans réserves. Le grave problème de cette agrégation qui oriente, en la déformant, toute l'activité de nos Universités le préoccupait comme il me préoccupait moi-même. Un gros article, pensé par nous deux et rédigé par lui, formule sur ce point ce que nous appelions, en riant, « la doctrine des Annales ».

Cependant, au dehors, les nuées s'amoncelaient. Bloch n'avait jamais fait de politique. Je me demande toujours comment un véritable historien pourrait en faire. Il n'en était pas moins profondément citoyen. A partir de 1936, nous commençâmes à nous inquiéter sérieusement des événements publics. Munich fut, pour lui comme pour moi, la grande catastrophe qui annonçait le destin. La France sacrifiait ses atouts. La France anéantissait délibérément sa position matérielle et morale en Europe centrale. La France abandonnait, avec une répugnante indifférence, une nation que les meilleurs de ses fils avaient tenue, en la personne de Denis, sur les fonts baptismaux; une nation dont nos meilleurs chefs militaires avaient instruit la jeune armée ; une nation confiante qui s'ouvrait, malgré tant de difficultés, aux promesses d'un avenir heureux; une nation dont la position géographique était telle, qu'elle contenait et dominait à l'Est l'Allemagne, l'éternelle Allemagne d'agression, de rapt et de conquête. Pas plus que moi, Bloch n'admettait ce renoncement. Il ne pouvait, historien et géographe, se leurrer sur la signification d'un abandon qui présageait une défaite. Nous prîmes parti : mais que faire, contre tant de forces coalisées - que faire, sinon sauver platoniquement l'honneur?

La guerre venue, Bloch n'hésita pas davantage. Né le 6 juillet 1886, il avait 53 ans le 6 juillet 1939. Il était père de six enfants, $p 402$ tous mineurs. Il avait été promu capitaine pendant la guerre de 14-19, il y avait plus de vingt ans. N'ayant depuis lors sollicité aucun grade nouveau, il restait, plus de vingt ans après les avoir gagnés sur le champ de bataille, muni de ses trois modestes galons d'officier d'infanterie. "Le plus vieux capitaine de l'armée française », me 
disait-il en riant. Je lui répondais que, si la limite d'âge ne m'eût point atteint définitivement quelque temps auparavant, je lui aurais disputé ce titre, et pour les mêmes raisons. Il aurait pu se faire maintenir dans sa chaire à la Sorbonne très régulièrement, et dégager d'obligations militaires. En dépit de quoi, ce savant, connu de toute la Gelehrte Europa, ce maître incontesté, qui avait tant à dire, tant à écrire encore, qui représentait un tel trésor de richesses intellectuelles et spirituelles, revêtit une fois de plus son uniforme. Il fut de nouveau, simplement, le capitaine Bloch.

On ne sut guère l'utiliser. La France n'a jamais besoin, sinon de chimistes, du moins d'historiens. Il eût été logique que ce maître éminent, célèbre à l'étranger plus encore que chez nous, et en Angleterre mieux encore qu'ailleurs - il eût été naturel qu'un Marc Bloch fût employé à quelque haut service de liaison avec l'armée anglaise. Bloch personnellement le désirait. Il savait, il sentait quels services il pourrait rendre ainsi à son pays. On l'employa à gratter du papier à Strasbourg même, dans un obscur service, qui se replia, au début de septembre 39, sur Molsheim puis sur Saverne. J'ai sous les yeux, en écrivant ceci, les lettres qu'il m'adressait, toutes pleines du désir de servir son pays avec le plus d'efficacité possible. Il m'écrivait le 8 octobre :

Mes tâches ne sont guère importantes et il y en a certainement beaucoup d'autres où je serais plus utile... Je ne parle pas même de tout ce qu'il y a à faire du point de vue économique, et à quoi, j'en suis certain d'avance, tous mes collègues, dans les chaires parallèles d'Oxford, de Cambridge, de Londres sont en ce moment attelés : il n'y a à peu près rien à tenter, chez nous, contre les crasses préjugés des gens d'affaires... Et du reste, je ne tiens pas du tout à Paris : il me déplairait de paraître mettre mes ambitions dans un total repli. Mais quand je pense à tout ce qu'un homme habitué à manier les témoignages pourrait donner dans un $2^{\mathrm{e}}$ Bureau, à tout ce qu'un homme d'esprit à peu près clair pourrait donner, même dans un $1^{\mathrm{er}}$ Bureau; à tout enfin ce que quelqu'un, possédant quelque familiarité avec les choses d'Angleterre, pourrait donner dans de nécessaires et probablement difficiles liaisons - la moutarde me monte au nez de faire ce que je fais... Je puis parfaitement supporter un état-major actif, et je m'en porterai que mieux si je remue un peu. p403

Et m'appelant à l'aide, si je pouvais, puisqu' « il fallait demander à être utile », il me rappelait sa situation militaire, son grade («à T. D. 
depuis $1920 »$ précisait-il, sans ironie apparente) et ses services de guerre « qui étaient normaux » : quatre citations, une blessure, Légion d'Honneur à titre militaire.

Le 15 octobre 39, changement de décor: un gros bourg du Nord. La plaine betteravière et herbagère. Un ciel immense avec de beaux nuages. Et quelque part un Q. G. d'armée. Destiné d'abord au $2^{\mathrm{e}}$ Bureau, Bloch s'était trouvé chargé à l'improviste, au $4^{\mathrm{e}}$ Bureau, d'un service de confiance : le service du ravitaillement en essence. Service assez lourd et qui devait, le moment venu, comporter de dures responsabilités. Comme les trois modestes galons de Bloch lui auraient tout juste permis, dans un $2^{\mathrm{e}}$ Bureau, " de manifester çà et là le plus déplorable caractère » sans qu'il lui fût possible «de rien changer à une méthode particulièrement agaçante, quand on sait quelle serait la bonne », il devint « le grand patron des réserves, des fûts et des camions-citernes » de son armée. Sans déplaisir, sinon sans enthousiasme, et avec le sentiment que, du moins, il était utile à quelque chose. Ce qui ne l'empêchait pas de traduire, à l'occasion, " l'impression de vide, de ridicule, presque de désappointement (cum grano salis) d'un homme qui, parti, mon Dieu, pour Strasbourg un peu dans le sentiment de tant de nos montées en ligne, ne fait depuis plus de sept mois que gratter du papier, aussi à l'abri que dans un bureau de Clermont-Ferrand ou de Bayonne ».

Le réveil fut brutal et terrible. Le 4 juillet 1940, ayant évité de justesse la captivité après avoir été rejeté de Dunkerque en Angleterre et d'Angleterre en Bretagne, Marc Bloch arrivait à Guéret, dans sa voiture préservée miraculeusement, et y retrouvait Madame Bloch et ses enfants qui s'étaient installés dans cette petite ville paisible pendant la "drôle de guerre", à proximité de leur maison de campagne de Fougères. Les événements se précipitaient. Les malheureux qui avaient signé l'armistice devenaient rapidement les exécutants de la politique de persécution raciste de leurs maîtres allemands. Bloch fut l'un des quelques professeurs d'Université qu'on consentit, provisoirement, et par un faux-semblant hypocrite, à laisser en place. Mais pas à Paris. Il fut donc envoyé d'abord à ClermontFerrand (où il s'inscrivit dans les cadres de son ancienne Université, 
l'Université de Strasbourg, repliée en Auvergne), puis l'année p404 d'après, à Montpellier, dont le climat lui semblait devoir convenir à sa femme, très fatiguée, et qu'une pleurésie grave venait d'éprouver. Mais la famille ne se reforma pas à Montpellier au complet. Les fils aînés de Bloch ne tardèrent pas à franchir la frontière des Pyrénées, et, après plusieurs mois de prison en Espagne, à rejoindre les armées de la Libération. Lui-même ne devait pas s'attarder à Montpellier. Quand les Allemands, qui entre temps avaient fait main basse, à Paris, sur sa riche bibliothèque de travail, et l'avaient déménagée jusqu'au dernier livre, de la même façon que, peu avant, ils avaient volé la bibliothèque de Henri Hauser pour la transporter outre-Rhin, - quand les Allemands, franchissant la ligne de démarcation, eurent envahi toute la France, Marc Bloch, sur les conseils des autorités locales, quitta aussitôt Montpellier. Ce qui permit aux gens de Vichy de le révoquer quelque temps après pour «abandon de poste devant l'ennemi ». Formule ignoblement savoureuse quand on pense qu'elle était peutêtre dictée, en tout cas contresignée, par... ce même « ennemi ».

A ce moment-là, Bloch pouvait se cacher simplement, laisser passer les mois et attendre, avec sa femme et les plus jeunes de ses enfants, la catastrophe finale et prévue. Comme toujours, il choisit le parti de l'action. Il se jeta dans la Résistance. Son centre d'opération fut la ville même où il était né, Lyon. Et il cessa d'être Marc Bloch pour devenir à la fois le Maurice Blanchard de sa fausse carte d'identité, et le Narbonne qui, délégué du mouvement Franc-Tireur au directoire régional des Mouvements Unis de Résistance à Lyon, acceptait malgré son âge, malgré une santé qui était loin d'être toujours brillante, malgré ses habitudes de régularité, tous les risques, les alertes, les menaces de la vie clandestine.

Je le vis plusieurs fois, pendant les mois d'angoisse, toutes les fois qu'il se rendait de Lyon à Paris, pour assister à quelque réunion centrale de son organisation. Brusquement, un soir, je recevais un coup de téléphone : "Oui, c'est moi !... Je viendrai dîner chez vous demain, voulez-vous ? » Il descendait très loin du Quartier, du côté du Père Lachaise, par prudence. Il se méfiait beaucoup des abords de la Sorbonne et de l'École Normale, et j'étais le seul des hôtes de ces 
lieux qu'il prévînt et visitât. Parfois, il me demandait de convoquer un ou deux amis, Paul Étard, Georges Lefebvre. Je le retrouvais toujours le même, lucide, optimiste, agissant. Très préoccupé des lendemains de la Libération ${ }_{\mathrm{p} 405}$ et, en particulier, de la réforme nécessaire - non, de la révolution nécessaire de l'enseignement. A l'un de ses derniers voyages il me remit un remarquable Projet d'une réforme générale de l'enseignement qui commençait par ces mots :

Notre défaite a été essentiellement une défaite de l'intelligence et du caractère. Le constater, c'est dire en même temps que, parmi les tâches qui se proposeront à nous, dès la Libération, la reconstruction de notre système d'éducation sera une des plus urgentes. Une France rénovée veut une jeunesse élevée selon des méthodes nouvelles; sans quoi les erreurs d'hier se répéteraient inéluctablement après-demain.

Il en tira des "Notes pour une révolution de l'enseignement» qu'accueillit le troisième fascicule des Cahiers Politiques, publication clandestine dont on avait offert à Bloch (qui ne l'accepta point) la direction. J'y trouve cette formule :

Notre effondrement a été avant tout chez nos dirigeants - et, pourquoi ne pas avoir le courage de l'avouer, dans toute une partie de notre peuple - une défaite à la fois de l'intelligence et du caractère. C'est dire que, parmi ses causes profondes, les insuffisances de la formation que notre société donne à ses jeunes ont figuré au premier rang.

Ces projets de Bloch, je les ai remis à Paul Langevin qui préside aux destinées de la Commission de Réforme de l'Enseignement. J'espère qu'il passera beaucoup des idées qu'ils contient dans la « révolution » que nous attendons tous ${ }^{258}$.

Bloch n'avait pas d'illusions sur les risques qu'il pouvait courir. Je l'entends encore un soir qu'il me quittait après de longues conversations et que bêtement (mais qui n'a été bête de cette façon en pareil cas !) je lui disais : " Soyez prudent ! nous aurons tant besoin de vous après " — je l'entends me répondre: "Oui. Je sais ce qui m'attend, si... La mort ? pas seulement... Une mort horrible, oui. Mais quoi ? »... Et il s'était perdu dans le noir de l'escalier.

258 [Nous l'attendons toujours (1952).] 
Un jour, à Lyon, un sinistre jour de printemps 44, ce fut la catastrophe. La Gestapo, après de longs mois d'efforts, parvenait à mettre la main sur une partie du directoire lyonnais des Mouvements Unis. p406 Bloch fut arrêté, jeté dans une cellule du sinistre fort Montluc, battu, torturé par des brutes. On le vit dans les locaux de la Gestapo, le visage en sang. On sut qu'il avait été soumis à l'affreux supplice du bain d'eau glacé. On le sut parce que Bloch, atteint d'une broncho-pneumonie à la suite de ces traitements abominables, dut être admis à l'infirmerie où, d'ailleurs, il fut bien traité et guéri. Après quoi il revint dans sa cellule. Il s'attendait, il savait qu'il pouvait et devait s'attendre au pire: mais son moral restait excellent. A ses compagnons de captivité, il parlait de la France, de son histoire, de son avenir. Eux ne connaissaient pas son vrai nom, qui d'ailleurs n'eût rien dit à ces hommes simples. Mais ils avaient fini par supposer que leur camarade d'épreuves et d'espérances était un professeur de Sorbonne. Cependant, les Alliés débarquaient en Normandie. Les Allemands, à Lyon, se préoccupaient d'une évacuation possible. Ils vidaient les prisons, à leur manière, c'est-à-dire qu'on voyait, un soir, dans la campagne, à vingt, à trente kilomètres de la grande ville, une auto s'arrêter, des malheureux en descendre : ils étaient fusillés tantôt par les Allemands eux-mêmes, tantôt par leurs valets de la milice. Après quoi, on brûlait soigneusement leurs papiers et leurs marques possibles d'identité. On prévenait le maire, pour qu'il pût faire enterrer les corps. Et on repartait vers d'autres tueries.

Le 16 juin 1944, vingt-sept Français, vingt-sept patriotes, extraits des cellules de Montluc, étaient amenés dans un champ, au lieu dit «les Roussilles» sur le chemin de Trévoux à Saint-Didier-deFormans, à quelque $25 \mathrm{~km}$. au Nord de Lyon. Il y avait là un homme âgé, aux cheveux déjà gris, au regard vif et pénétrant. Et près de lui, écrit Georges Altman dans un article émouvant des Cahiers Politiques, près de lui, un gosse de seize ans, qui tremblait: "Ça va me faire mal... » Marc Bloch lui prit affectueusement le bras, lui dit : «Mais non, petit, cela ne fait pas mal», et tomba en criant, le premier : «Vive la France! »

Ainsi fut anéanti par les balles allemandes l'un des plus grands esprits de cette Europe qui n'était pas pour lui une étiquette, mais une 
réalité vivante. Ainsi mourut un très grand Français. A nous de faire, aujourd'hui et demain, qu'il ne soit pas mort pour rien. p407

$\underline{\text { Retour à la table des matières }}$ 


\section{GEORGES ESPINAS}

Une Conscience d'Érudit

$\underline{\text { Retour à la table des matières }}$

Dans la Revue du Nord, notre collaborateur M. l'abbé Lestocquoy publie une notice nécrologique sur le très regretté Georges Espinas. Il parle à la fois de l'homme et de l'œuvre, en termes justes et, naturellement, sympathiques : ayant connu ce grand travailleur et cet homme excellent que fut Georges Espinas - qui ne saurait avoir pour lui les sentiments de haute estime et de publique connaissance qui s'imposent? Attentif et bon, soucieux d'obliger en toutes choses et si modeste... Je me rappelle qu'un jour, incidemment, je lui avais dit qu'un de ses mémoires manquait dans ma bibliothèque et que je n'avais pu encore me le procurer. Je reçus le lendemain une de ces longues lettres écrites à l'encre violette qui m'étaient familières, et que Georges Espinas avait remplie d'excuses minutieuses, à sa manière : il n'aurait jamais pensé, me disait-il, qu'un de ses livres (il s'agissait d'un de ses portraits de grands bourgeois médiévaux) pût m'intéresser; et, s'il l'avait pensé, il me l'aurait bien certainement envoyé ; en attendant, il n'en avait plus d'exemplaires à offrir... Le touchant, c'est qu'il ne s'agissait pas là de formules de politesse : Georges Espinas s'étonnait très sincèrement qu'un historien qui n'était pas un spécialiste du moyen âge pût s'intéresser à ses travaux... Un mois s'écoula. Et je reçus, un matin, un exemplaire du livre désiré, déniché je ne sais où par Georges Espinas lui-même — et accompagné d'une nouvelle lettre où il s'excusait et se ré-excusait... de son extrême gentillesse et de cette touchante attention.

M. Lestocquoy parle du peu de goût d'Espinas pour la synthèse : "C'était un scrupuleux analyste qui craignait les vues nouvelles. » Je 
ne crois pas la formule tout à fait juste. Scrupuleux analyste, certes. Mais craignait-il les vues nouvelles ? Certainement ${ }_{\mathrm{p} 408}$ pas. Il portait en lui un haut idéal, un exigeant idéal de perfection formelle et d'exactitude minutieuse: d'accord. Il savait, d'autre part, que la perfection est difficile à atteindre : il le savait pour lui comme pour les autres. Mais sa collaboration même aux Annales, l'aide fidèle qu'il apporta à ces non-conformistes résolus et fleurant l'hérésie que nous fûmes dès l'origine - et que, je l'espère bien, nous n'avons point cessé d'être; la manière dont il s'associa si souvent, sans arrièrepensée et de toute sa conviction, à nos campagnes d'idées ; la vigueur avec laquelle, vingt fois, il écrivit des pages de réflexion critique que nous aurions aimé, Bloch et moi, avoir pensées, rédigées et signées : non, tout cela n'est pas d'un homme qui craignait les idées neuves. Si, à la manière $\mathrm{du} \mathrm{XVIII}^{\mathrm{e}}$ siècle, on publiait quelque jour un florilège d'extraits de notre revue sous le bon vieux titre classique d'Esprit des Annales, je sais bien l'article qu'il faudrait mettre en tête. Pour ouvrir le volume. C'est celui qu'Espinas nous apporta en 1934 et qui parut dans notre tome VI (p. 365) sous le titre significatif : De l'horreur du général : une déviation de la méthode érudite. C'est une remarquable affirmation de nos idées communes.

Et j'ajoute : c'est un acte de courage. Car, n'oublions pas que Georges Espinas était chartiste. Et que c'était à un chartiste qu'il reprochait son affectation de s'en tenir « au fait» - ceci dans une revue que des imbéciles ne cessaient d'accuser, prêtant à ses directeurs et à ses collaborateurs leurs pauvres petites préoccupations, d'être «l'ennemie de l'École des Chartes ». J'ai dit que l'Académie des Inscriptions avait commis, vis-à-vis d'Espinas, une grande injustice en ne l'admettant point parmi ses membres. Nul doute que le courage même d'Espinas et son goût des idées — ne disons pas neuves si l'on veut, mais du moins saines et justes — n'aient joué dans cet échec un rôle important.

Quand Espinas, à propos du travail si large et si entraînant de Henri Laurent, exprimait le regret que l'auteur n'eût point terminé son livre par une puissante conclusion qui lui donnât toute sa valeur; quand, avec tant de lucidité, cet homme qui avait été étranger, de par sa formation, à tout le mouvement géographique des années 1900, proclamait la nécessité de fonder en géographie et en topographie 
toute étude valable d'histoire urbaine; bien plus, quand il entreprenait, dès 1902, la série de ses recherches alors si neuves sur Douai - il n'était pas un timide. Il était (et il me plaît d'emprunter ce mot à M. Lestocquoy) un « précurseur ». - Le vrai, c'est qu'il n'avait point d'art. Et que, d'ailleurs, il ne se souciait point d'en avoir personnellement. p409 Mais il savait parfaitement regretter que les autres n'en eussent point. Avec sa mansuétude coutumière, qui était infinie.

Point de numéro des Annales qui paraisse sans que nous nous disions, les uns et les autres : "Comme un de ces articles, si pleins, d'Espinas, nous manque!» Et sans que, personnellement, je ne me rappelle avec émotion l'appui qu'il me donna, de 1940 à 1944, alors que j'étais à peu près seul à faire face aux difficultés du moment. Pas une fois nous n'échangeâmes un mot sur les événements qui se déroulaient. Mais pas une fois il ne me refusa son concours le plus large et le plus courageux. C'était, dans sa pudeur extrême, un homme brave. Et un galant homme. p410 
Les Annales sont en deuil. L'abbé Berthet ou, pour lui restituer son vrai titre, Dom Bernard Berthet, chanoine régulier de l'ImmaculéeConception, a terminé le 24 mars 1950 au presbytère de Gevingey (Jura) une courte et douloureuse vie. Il n'avait que quarante et un ans. Je dis, en pesant bien mes mots: c'est un désastre. Une vraie catastrophe pour les études historiques. Régionales, sans doute : il nous eût doté du grand livre, que nous n'avons pas, sur le Haut-Jura. Mais, par delà l'histoire régionale, il y a l'histoire tout court. Elle aussi peut prendre le deuil. L'abbé Bernard Berthet n'était pas qu'un de ses fidèles. Il avait l'étoffe d'un de ses maîtres.

Ainsi, nous ne trouverons plus sa signature au bas d'un de ces articles toujours originaux et neufs dont chacun représentait la prise de possession d'un problème par un esprit vigoureux que rien n'avait déformé, incliné vers le préjugé. Sa signature - qui dût surprendre, la première fois qu'ils la rencontrèrent, les vieux abonnés des Annales... L'abbé Berthet, qui donc ? Quelque chartiste entré dans les ordres ? Quelque licencié ou diplômé de Lyon, de Dijon, de Besançon ? Point. Quand il dut répondre à je ne sais quel questionnaire du Centre de la Recherche qui lui demandait ses titres universitaires, il fut bien gêné. Et il m'écrivit ingénument: "J'aurais peut-être dû mettre que je n'avais que mon certificat d'études? » En réalité, ajoutait-il, comme pour se rassurer lui-même, "j'avais fait des études équivalentes à celles qui donnent le baccalauréat». Cher abbé Berthet! Ce n'était pas du respect humain ; mais il était un peu intimidé de se voir intégré dans ce beau monde de la Recherche qu'il dotait de plus de mérites, 
peut-être, qu'il ne convenait. Et vis-à-vis de ces licenciés, diplômés, agrégés, sinon docteurs, il méditait sur $\mathrm{p}_{411}$ son certificat d'études... C'était pourtant là sa force, ce certificat. L'abbé Berthet était « franc de pied ». Et nul, sous le prétexte de greffe savante, n'avait introduit dans sa droite nature des germes de banalité prétendue raffinée. Sans doute, c'est parce qu'il sentait combien toutes ces histoires de parchemins (qui ne sont d'ailleurs que du simili) m'importaient peu, qu'il fut si vite en confiance avec moi.

Pour premier maître il avait eu son père. Un de ces artisans si adroits, si ingénieux, si intelligents dont notre Haut-Jura est prodigue. Il y a les lapidaires. Et les horlogers. Et les tablettiers. Et tant d'autres. Lui, il travaillait dans la lunetterie : autre spécialité de nos montagnes. La lunetterie, chef-lieu Morez, mais sous-préfecture Les Rousses... Comme ce père avait, dans sa jeunesse, pensé à se faire prêtre, et donc commencé des études relativement poussées (on dit dans ce cas-là, à Besançon, en usant d'un fort raccourci : «Il a appris curé ») - il put se faire le premier maître de son fils. Mais il n'était pas riche. Il confia donc ses enfants à l'Église ; les frais d'études des deux frères, Marc et Bernard, furent soldés par le diocèse.

Ne suivons pas le futur Dom Berthet de la maîtrise de Saint-Claude au petit Séminaire de Vaux, puis au grand Séminaire de Montciel. Deux années de surveillance d'internat qui interrompirent le cours de ses études lui laissèrent des loisirs — et c'est alors que s'éveilla sa vocation d'historien: innée chez un montagnon, il nous a dit pourquoi, excellemment ${ }^{259}$. Il lut, plume en main, nos vieux auteurs : le romantique président Clerc, les gros in-quartos reliés en veau doré des deux Dunod, de Chevalier, de l'abbé Guillaume. Son imagination brodait des arabesques en marge de toute cette érudition rébarbative. Mais, son apprentissage clérical terminé, il décida d'entrer dans une communauté.

Dans cette démarche encore on peut, peut-être et s'agissant du circonstanciel, retrouver le Jurassien. En 1865, à Saint-Claude, Dom Adrien Gréa, vicaire général de l'évêque, avait fondé la Communauté des chanoines réguliers de l'Immaculée-Conception. Il voulait

259 Cf. Annales, 1946, p. 181-182 (Deux villages du Jura). 
restaurer la vie canonique avec ses observances primitives : chant de l'office divin nuit et jour; abstinence perpétuelle; jeûnes stricts et fréquents. Dom Gréa était un Comtois, de Rotalier. Son lieutenant, Dom Benoît, était de Saint-Claude ${ }^{260}$ et ${ }_{\mathrm{p} 412}$ des Rousses. Et si Dom Benoît ne s'était fait historien que pour servir son apologétique, il n'en avait pas moins doté son pays d'une copieuse Histoire de la terre de Saint-Claude en deux volumes, rédigée entre 1887 et 1891 : inutile de dire que Dom Berthet l'avait lue et relue. Par ailleurs, la Congrégation avait connu au Canada une fortune imprévue. Répondant à l'appel d'un évêque canadien, Dom Benoît avait conduit et installé dans le Manitoba, en pleine forêt, une petite colonie de défricheurs français et suisses. Ils y avaient bâti un monastère et une église ; une paroisse était née : 370 âmes, en 1892, 1025 en 1908. Qu'un Jurassien des Rousses, un « Rousseland », pût rester insensible à l'aspect héroïque de cette sorte d'épopée chrétienne qui devait lui rappeler, tout naturellement, les Pères du Jura, - saint Romain sous son sapin et saint Lupicin, Vita patrum Jurensium, - c'était presque impossible. Quoi qu'il en soit, en septembre 1932, Bernard Berthet gagnait la maison-mère de la Congrégation à Rome.

Et le 8 décembre suivant, son frère, l'abbé Marc, devait le ramener aux Rousses - malade pour toute sa vie.

Alors commença la grande souffrance de Bernard Berthet, celle de se sentir inutile, dans la mesure où sa santé lui refusait les moyens physiques de réaliser ses désirs. Il aspirait à une vie de communauté et se voyait voué à l'isolement. Il voulait servir, et nul ne pouvait ou ne voulait plus lui donner place. Il resta quatre ans aux Rousses, se crut en 1936 assez rétabli pour rejoindre la maison de son ordre, dans la Drôme: le climat, la nourriture, les obligations mêmes de la vie commune le contraignirent, au bout de deux ans, à revenir s'établir en Comté : auprès de son frère cette fois, devenu curé de Château-

260 Voir sur Dom P. Benoît (1850-1915) la notice signée B. M. BERTHET publiée par les Mémoires de la Société d'Émulation du Jura, 1947. Le drame qui secoua la Congrégation et qui aboutit à déposséder Dom Gréa de son autorité et à ruiner systématiquement l'œuvre accomplie par Dom Benoît au Canada — ce drame avait beaucoup frappé Dom Berthet. 
Chalon. Ordonné prêtre en 1939, à la veille de la guerre, - il célébra sa première messe, au milieu du désarroi général, le jour même de la mobilisation. " Il n'eut que très peu de joies humaines », m'écrit à ce propos l'abbé Marc, d'un mot qui fend le cœur. C'est «presque à l'improviste » qu'il put "célébrer une messe solennelle à ChâteauChalon, le 8 décembre 1939 : ce jour-là, il avait $39^{\circ}$ de fièvre $\gg .$. Mais le cadre était beau, dans lequel se déroula l'office : une vieille église $\mathrm{du} \mathrm{XI}^{\mathrm{e}}$ siècle, pure et sobre de lignes, que les deux frères, peu à peu, réussirent à purger de toutes ses laideurs, de tous les enduits et de toutes les statues de plâtre dont l'avaient surchargée les ans. Chefd'œuvre de goût, cette restauration : pourvu qu'elle subsiste ! $\mathrm{p} 413$

Un moment, une grande joie vint à l'abbé Berthet. Il crut avoir trouvé un but pour sa vie quand son frère lui procura quelques heures de professorat dans une Institution de Jeunes Filles de Lons. Il enthousiasma littéralement ses élèves par son ardeur et son don de vie. Hélas ! en 1947, un décret ministériel astreignait tous les maîtres à une visite médicale. Le médecin qui l'examina ne put en conscience autoriser l'abbé Berthet à continuer son enseignement. Ce lui fut, à nouveau, une peine énorme. "Un coup mortel », écrit son frère. Ainsi, il fallait encore repartir sur une autre route! Héroïquement, Dom Berthet tenta de surmonter sa peine. L'histoire était là, qui chaque fois pansait ses douleurs. Il se plongea dans les archives. Mais sans but bien précis. Il flottait, forgeait des projets d'une ampleur déconcertante. C'est alors que je pus intervenir dans sa vie.

J'avais reçu de lui, en 1945, tout à fait à l'improviste, une lettre datée du 8 février. Je l'ai sous les yeux en écrivant ceci. Je l'ai gardée, comme toutes celles qui suivirent. Il me demandait, ayant lu quelquesuns de mes livres (mais il ne connaissait pas encore les Annales), des conseils sur un travail qu'il aurait voulu consacrer aux débuts de la Réforme.

Je ne sais pourquoi cette lettre simple et sobre d'un inconnu me toucha. Je lui répondis longuement. Je le vis aux vacances. Le contact s'établit vite, et bien. Je ne savais pas grand chose de sa vie : il était admirablement discret - mais, à un moment donné, je perçus chez lui un désarroi certain. C'était le temps où il se voyait fermer l'enseignement. J'en parlai à Braudel. Notre décision fut prise : il 
fallait enrôler l'abbé Berthet dans la petite armée des « chercheurs ». Le $1^{\text {er }}$ novembre suivant, nous pouvions lui annoncer que c'était chose faite. Et peu après, il arrêtait le titre de son livre en chantier : Histoire sociale de la terre de Saint-Claude au XVI siècle.

Alors, il se mit à la besogne. Avec une admirable conscience. Il s'était engagé à consacrer à la Recherche tant d'heures par jour. Mais, à la différence de beaucoup, il prenait ses engagements au sérieux. Et quand il avait été trop fatigué, ce grand malade "restituait» le lendemain, en travaillant double, le temps dont il avait "privé » la Recherche. Souvent il m'annonçait, avec une joie qui réchauffait le cœur, telle magnifique trouvaille d'archives. Terriers, rentiers, registres de bourgeoisie, papiers de familles, enquêtes, il dévorait tout avec un appétit de savoir étrange. Et les questions de pleuvoir : que signifie tel mot? quelle valeur attribuer à telle institution ? On partait d'un détail, et brusquement, on se trouvait sur la montagne, au-dessus des brumes... p414

Peu à peu sa confiance en lui croissait. Il savait cependant ce qui lui manquait, et que, faute de culture livresque, il risquait de découvrir des choses connues. «Et puis après, lui disais-je, laissez donc les sots gonflés de manuels s'en scandaliser!»Mais il savait aussi qu'il lui fallait se défier un peu de sa formation première : "Elle me laisse, m'écrivait-il un jour de 1949, une base qui est brisante, cassante, dure. J'ai tendance à condamner, sans avoir toujours entrevu les différentes échelles de valeurs que les hommes peuvent utiliser. » Et il ajoutait : « Le contact avec vos livres, votre présence surtout, l'amitié dont vous voulez bien nous honorer, m'ont permis de penser que l'homme est presque toujours grand, mais que ce sont nos mesures qui ne sont pas à sa taille »... Pour conclure : "La terre de Saint-Claude, au XVI siècle, abonde en hommes, en vrais hommes... Saurai-je les faire sortir des vieux papiers? \ Belle inquiétude d'historien. Bien rares ceux qui l'éprouvent.

Tout allait ainsi, et je n'avais plus de souci particulier à son endroit quand je partis au Brésil. Une grave imprudence qu'il aggrava en ne l'avouant point pour ne pas inquiéter les siens, vint tout compromettre. A la Noël de 1949, il dut s'avouer très fatigué. Assez rapidement, il lui fallut renoncer au travail, à la lecture même, à tout 
effort cérébral ou musculaire. Le 25 février 1950 il s'alita. Mais il voulut que son frère fixât au mur de sa chambre la carte à 1:20000 du Haut-Jura pour la méditer, s'en emplir encore les yeux, étudier les cheminements, les centres du peuplement, les marches et les contremarches de la fourmilière humaine... Il s'éteignit le 24 mars au soir. Ses obsèques, à Gevingey puis aux Rousses où il dort son dernier sommeil, eurent quelque chose de triomphal...

Personne ne s'étonnera que j'aie voulu retracer en détail cette vie perpétuellement provisoire - cette pauvre vie, sommes-nous tentés de dire, d'un point de vue tout temporel - mais ce n'était pas le sien. Et puis, la force, la vigueur, l'originalité de sa pensée n'ont-elles rien à voir avec ce repliement d'un malade sur lui-même, son isolement? Sa pensée, sa pensée d'historien, je ne saurais dire ici, en ce moment, ce qu'elle fut. On verra, un jour prochain, qu'elle justifie tout ce que j'ai dit de lui et des espérances que sa mort a brisées. J'ai simplement voulu dessiner cette très noble figure de religieux, à qui n'a manqué qu'un peu de santé et, peut-être, si on ose dire, un peu moins de tendresse pour les autres, un peu plus d'égoïsme personnel pour accomplir une œuvre de forte originalité et de sens humain profond. Je le remercie de tout ce qu'il nous a donné aux Annales de frais, de ${ }_{\mathrm{p} 415}$ vivant et de neuf ${ }^{261}$. Je le remercie de tout ce qu'il m'a donné personnellement de réconfort et d'encouragement par son amitié, et par son ardeur vivifiante à la recherche. Il pensait m'être redevable. Je ne lui ai pas assez dit, moi, ce que je lui devais...

Et maintenant, je ne verrai plus, aux vacances, s'encadrer dans l'allée sa haute et mince, si mince silhouette. On le retrouvait toujours le même en apparence - simple, calme, doux et si vraiment modeste... Mais, dans sa demeure secrète, une lampe brillait perpétuellement; une intelligence sans cesse en éveil rayonnait — et,

\footnotetext{
261 Je rappelle la liste de ce que Dom Berthet a donné aux Annales : t. I, 1946, p. 43 : Un réactif social, le parrainage; p, 178 : Esquisse de sociologie française, deux villages du Jura; t. II, 1947, p. 87 : Il y a dîme et dîme ; t. III, 1948, p. 41 : Frontières vivantes; des lieux-dits aux provinces ; p. 229 : Appellations locales et nomenclatures géographiques; t. IV, 1949, p. 78: Autour des noms de personnes: nom réel ou nom d'état civil ; p. 213 : Méditation sur la route et l'homme; p. 431: Au sujet de la taille; t. V, 1950, p. 68: Abbayes et exploitations. - D'autres notes et articles suivront.
} 
parfois, un demi-sourire un peu narquois animait d'une pointe de malice indulgente sa figure émaciée de mystique et d'ascète. Homme exquis — d'autant qu'il ne savait point l'être. Homme discret, qui laissait deviner ses sentiments plus qu'il ne les montrait. Homme fin, mais d'une finesse naturelle qui ne devait rien à l'horticulture des pédagogues ni au contact du monde. Il était de ceux qui possèdent le grand art inconscient de se mouvoir avec simplicité dans la vie. Dans une vaste salle de presbytère campagnard blanchie à la chaux, poser sur des rayons de bois net des livres choisis - des livres dont chacun représentait pour lui et pour son frère une conquête ${ }^{262}$, des livres en bel ordre : ici l'histoire, là la philosophie — sans une égratignure, tous a leur juste place. Et dans le jardin montant, sous le soleil, faire doucement, lentement, les gestes patients du travail, tailler, lier la vigne, greffer les roses, avec l'amour ingénu, et qui ne cherche pas à s'exprimer en belles phrases, des plantes du Bon Dieu fécondées par les hommes... - Je n'arrive point à me faire à cette séparation. $\mathrm{p} 416$

Retour à la table des matières

262 «Nous étions pauvres, m’écrit l'abbé Marc en se reportant à son enfance. Pendant les vacances, nous faisions quelques travaux de reliure ou nous donnions quelques répétitions à des enfants pour pouvoir disposer d'un peu d'argent pour l'achat de livres, sans gêner le budget familial. » Je dois dire mon émerveillement de ce que représentait cette bibliothèque des deux frères telle que je la vis pour la première fois en 1946 au presbytère de Château-Chalon. Si bien composée et combinée pour un travail utile. Avec, à peine, deux ou trois ouvrages moins bons, achetés sur la foi de compte rendus de complaisance. C'est là qu'on mesure sa responsabilité de critique, son devoir de dire non à tout ce qui n'est pas de qualité. Sans quoi, on trompe des hommes qu'on ne doit jamais tromper. 


\title{
Espoirs à l'arrivée
}

\author{
VERS UNE AUTRE HISTOIRE
}

$\underline{\text { Retour à la table des matières }}$

Incomplet d'un quart, sinon d'un tiers, un livre, un petit livre vient de paraître. Il porte un beau titre - ou plutôt il en porte deux : Apologie pour l'histoire ou Métier d'historien ${ }^{263}$. C'est le second qui mérite l'épithète ; mais l'auteur, les ayant inscrits tous les deux sur la couverture de ses manuscrits, ne s'est plus trouvé là pour choisir définitivement son préféré : l'auteur, Marc Bloch, fusillé sans jugement par les Allemands le 16 juin 1944, au lendemain du débarquement de Provence, quand ils "vidaient» les prisons en exécutant des tueries en masse de patriotes - Marc Bloch, l'un des plus fermes esprits de ce temps ${ }^{264}$ et parvenu, par un étonnant effort d'apprentissage (langues anciennes et modernes, techniques particulières, lectures prodigieusement étendues, études pénétrantes de

\footnotetext{
263 Cahiers des Annales, fasc. III, Armand Colin, $1949 ; 110$ pages in- $8^{\circ}$.

264 Comme en témoigne, en dehors de ses œuvres proprement historiques, ce petit livre posthume si dense, si profond dans sa simplicité qu'il a intitulé L'étrange défaite, témoignage écrit en 1940 (éd. Atlas, 1946, in-16). C'est une méditation nourrie de souvenirs personnels sur les causes de cette défaite : avant tout, dit Bloch, « une défaite de l'intelligence française ». Trop peu de Français ont lu ce livre amer, d'autant plus douloureux qu'il est plus mesuré. Mais quoi! Marc Bloch n'appartenait à aucun parti politique. Et aucun lycée de France n'a recueilli son nom... Nos amis d'Angleterre ne se sont point mépris, eux, sur la portée du témoignage. Ils l'ont fait traduire, et éditer, par une de leurs plus fameuses presses universitaires...
} 
textes de toutes provenances, voyages et enquêtes à l'étranger) à ce point où les grandes œuvres semblent naître d'elles-mêmes sous la plume du maître qui les porte en lui ; - Marc Bloch, de toutes les pertes en hommes subies par la France entre 1940 et 1945 la plus cruelle peut-être et la plus inexpiable.

J'ai dit ailleurs comment, de retour en France après l'armistice par le périlleux circuit Dunkerque, Londres, Rennes, loin de ses notes abritées à Paris en lieu sûr, plus loin encore de ses livres soigneusement mis en caisse et expédiés en Allemagne par ${ }_{\mathrm{p}} 419$ l'occupant - cet homme qui détestait l'oisiveté prit la plume et commença à jeter sur le papier des réflexions sur l'histoire. Et d'abord sur sa légitimité, tant au regard des historiens eux-mêmes qu'au regard de notre civilisation, directement intéressée dans le débat.

Car elle est, en son fond et dès ses origines, une civilisation d'historiens. A la différence de tant d'autres, dont quelques-unes d'importance, l'indienne par exemple ${ }^{265}$. Et la religion qui exprime tant de ses aspects fondamentaux, le christianisme, est bien vraiment, elle aussi, une religion d'historiens. "Je crois en Jésus-Christ, qui naquit de la Vierge Marie, fut crucifié sous Ponce-Pilate, ressuscita d'entre les morts le troisième jour $»$ : voilà une religion datée. Et ces références ne constituent point pour le fidèle un accessoire. On n'est pas chrétien si on n'accepte pas ces affirmations, que la religion pose au seuil de la croyance comme autant de vérités situées dans le temps. De même, on n'est pas chrétien si on ne se situe pas soi-même, et avec soi les sociétés, les civilisations et les empires, entre la chute, ce point de départ, et le jugement, ce point d'arrivée de tout ce qui vit ici bas. Ce qui est à la fois s'encadrer soi-même et encadrer l'univers dans la durée - donc dans l'histoire.

Or que, dans les dernières décades, beaucoup de porteurs de la civilisation occidentale se soient dépris brusquement de leur vieux goût pour l'histoire ; qu'ils aient marqué avec force leur désillusion

265 Sur l'historicité des diverses civilisations, nous savons bien peu de choses. Trop heureux quand, pour la Chine, nous pouvons recourir à Granet. Il faudrait provoquer des études semblables, alerter les indianistes, les égyptologues, les assyriologues etc. De telles études ne se feront que sur sollicitation directe des intéressés. 
d'hommes qui avaient trop cru dans ce qu'il leur plaisait d'appeler ses «leçons»; que la cadence même, si furieusement accélérée, des révolutions techniques engendrant tous les quinze ou vingt ans dans nos sociétés de véritables mutations psychologiques, correspondant chaque fois à de nouveaux changements: chemins de fer, puis automobiles, puis avions, et la peau de chagrin se rétrécissant par secousses; vapeur, puis force électrique, puis énergie atomique en voie de domestication - et tout le reste, qu'il faudrait des pages pour énumérer, tout ce qui affecte le genre de vie, le comportement individuel ou collectif, les réactions sensorielles des hommes ${ }^{266} ;-$ que cette cadence même, que cette accélération prodigieuse des bouleversements ${ }_{\mathrm{p} 420}$ creuse chaque fois davantage le fossé qui sépare les générations et rompe les traditions: voilà qui n'est point à démontrer longuement. Conséquence, entre autres : un grand dédain pour l'histoire. Le dédain d'hommes qui s'enivrent de leurs réussites, sans avoir le temps de fonder sur elles un établissement durable : car d'autres réussites, demain, viendront tout remettre en question. Dédain d'hommes qui se proclament orgueilleusement fils de leurs œuvres - et non point de leurs ancêtres démodés. Qu'importe Volta à nos constructeurs de centrales électriques ? Autant parler d'Icare à un constructeur d'avions. Vieilles lunes. Et le préjugé gagne de plus en plus : comment peut-on perdre du temps à faire de l'histoire - alors que tant de tâches fécondes, et qui « rendent », requièrent aujourd'hui toutes les énergies, toutes les intelligences?

Faut-il réagir contre ces tendances? Sans doute, dans la mesure où elles risquent d'ébranler les fondements mêmes d'une civilisation d'historiens. Bloch est parti de ce grand souci. En trois mots, le premier titre de son livre nous le révèle excellemment. Mais il y a le second. J'ai dit qu'il était beau. Il est plein de promesses également.

\footnotetext{
266 Pas encore d'étude concertées. A peine si les «filmologistes», de récente naissance, commencent à s'inquiéter. Henri Wallon a tracé dans le cadre de leurs études un programme aussi intéressant pour l'historien que pour le filmologue ; reste à le mettre en œuvre - et à poursuivre simultanément des études sur les organismes humains. Sans négliger le problème de la vitesse.
} 
Il est rare qu'un historien de l'envergure de Marc Bloch tire luimême, de son vivant - alors qu'il est en pleine force de production et que les œuvres qu'il porte en lui l'obsèdent - il est rare qu'il formule les leçons de son expérience pour les communiquer à ses contemporains. Michelet ne l'a point fait, qui était l'histoire même. Ni Fustel. Ni de nos jours Jullian. Pirenne non plus. Ils ont enseigné, et donc transmis à d'autres un peu de leurs réflexions. Mais il y a loin de conseils distribués à des apprentis, sur le tas, d'une façon discursive et fragmentaire - il y a loin de ces indications de travail à cette sorte de confidence humaine d'un maître d'œuvre expliquant à des lecteurs qui ne sont pas nécessairement « de sa partie » ce que représente pour lui son labeur, quelles fins il lui propose et dans quel esprit il le pratique : le tout, non en pédant qui dogmatise, mais en homme qui cherche à se comprendre tout entier. Dans le livre de Marc Bloch, ce qu'on goûtera avant tout, plus encore qu'un plaidoyer pour l'histoire - ce sont ces précieuses confidences. Ces réflexions de maître ouvrier sur un métier délicat. Libres, mais ordonnées — sans rien de scolaire toutefois, ni d'hérité.

C'est là, je crois, ce qui, dans ce livre, peut intéresser surtout, intéresser avant tout le philosophe, curieux de saisir les aspects ${ }_{p 421}$ vivants des disciplines contemporaines. C'est là, en tout cas, ce qui nous intéresse, nous, historiens, au regard de la critique philosophique. Faut-il dire qu'en général celle-ci ne nous rend peutêtre pas tous les services ${ }^{267}$ que nous pourrions souhaiter? C'est sans doute que les philosophes restent un peu victimes des historiens - je veux dire des préjugés que trop d'entre eux continuent à colporter : préjugés hérités d'un lointain passé, acceptés dans discussion par des praticiens peu enclins à manier des idées et prêts à approuver les remarques de Péguy sans en apercevoir l'arrière goût vinaigré.

267 Ceci dit avec toutes les précautions requises. C'est un fait qu'historien et philosophe représentent en général deux types d'hommes assez nettement différenciés. C'est un fait aussi qu'aux origines de ce que nous concevons comme l'histoire, il y eut d'efficaces et fécondes réflexions et suggestions de philosophes. Comment ne pas se reporter à Leibnitz? Et puis naturellement à Herder, en attendant Hegel ? Et même, en ce qui concerne la France, à ce Victor Cousin qui lança Michelet sur la piste de Vico, Quinet sur celle de Herder : Michelet qui, chargé d'enseigner à l'École Normale la philosophie et l'histoire, protesta avec vivacité quand, les deux enseignements ayant été séparés, on lui confia celui de l'histoire? - Et faut-il rappeler le Cournot des Considérations? 
« D’une façon générale (je cite de mémoire et je m'en excuse) il n'est pas bon que l'historien réfléchisse trop sur l'histoire. Du temps qu'il s'y occupe, il arrête son travail. Et le philosophe (dont c'est le métier) se croise les bras. Ce qui fait deux hommes qui ne travaillent point $\gg .$. Péguy dit cela beaucoup mieux. En fait, les petits livres qui s'intitulent Introduction ou Initiation aux Études historiques reflètent trop souvent encore, en 1940, l'état de la Science aux environs de 1880. Et l'image qu'ils présentent de l'Histoire n'est pas faite pour lui concilier les bonnes grâces des gens intelligents et qui réfléchissent.

Il n'y a d'ailleurs pas qu'eux. Tout le monde s'y est mis. Il y a eu ces méthodologistes impénitents qui découvrirent, aux environs de 1880-1890, que 1'histoire, après tout, n'était qu'une méthode. La méthode historique. Laquelle n'était rien d'autre que la méthode critique. Et donc pas le moins du monde un monopole des historiens. D'où suivait que l'histoire, s'évanouissant, perdait tout contenu et toute réalité. Ce qui, entre parenthèses, dispensait les historiens de se poser la redoutable question : «Qu'est-ce que l'histoire ?»

Les sociologues de leur côté, dans l'enthousiasme de leurs premières conquêtes, s'attaquaient avec allégresse à une discipline si mal défendue. Les tenants de l'école durckheimienne ne dissipaient pas l'histoire dans la fumée. Ils se l'annexaient en maîtres. Tout ce qui, dans le domaine des sciences historiques, leur semblait susceptible d'analyse rationnelle leur appartenait. Le résidu, c'était 1'histoire: une mise en pages chronologique, tout ${ }_{p 422}$ au plus, d'événements de surface, le plus souvent fils du hasard. Disons : un récit ${ }^{268}$.

268 En 1934, dans les Annales Sociologiques, Bouglé concédait que la sociologie, " quelques progrès qu'elle puisse accomplir», n'arriverait peut-être jamais, malgré tout, à rendre inutile le récit historique, à supplanter l'histoire ! C'était bien de la bonté. Il ajoutait, avec condescendance : " L'historien aura toujours à noter des collocations et des conjonctures, des rencontres de séries que le sociologue sera impuissant à expliquer par une loi générale. » Merci pour les collocations ; mais tout cela est de notre faute, historiens. Dans le même fascicule des Annales, en effet, M. Mauss expliquait pourquoi les durckheimiens, en traitant de la morphologie sociale, y avaient introduit " une confusion qu'ils avaient évitée ailleurs ». C'est qu'ils trouvaient en face d'eux des « unités » (entendez, la géographie humaine et la démographie) trop fortement constituées déjà pour qu'ils tentent de les rompre. "Nous n'avons pas eu le courage de briser les articulations d'une science provisoirement mieux faite que celle des parties de la 
On comprend alors l'attitude des mondains, et leurs ricanements : les mondains pour qui parlait Paul Valéry dressant, non sans bon sens du reste, le procès d'une certaine histoire en qui, malheureusement, nous sommes quelques-uns à refuser de reconnaître l'objet de nos soucis - Valéry faisant la leçon à ces stupides qui ne s'étaient point avisés, avant lui, que, par exemple, l'apparition dans les foyers de l'éclairage électrique fut un plus grand événement historique que tel congrès diplomatique aux solutions éphémères. Ce qui nous amusait fort, et montrait, avec trop d'éclat, que notre censeur avait de bien mauvaises lectures en histoire : tranchons le mot, qu'il n'avait jamais lu une seule ligne des articles, des discours, des livres, de Henri Pirenne, de Marc Bloch, d'E.-F. Gautier, du Jullian des Chroniques gallo-romaines ou des leçons d'ouverture au Collège, du Jules Sion des Études méditerranéennes : nos classiques, nos bréviaires - et je ne parle naturellement que des morts. Parmi lesquels, en tête, cette incarnation de l'Histoire en qui nous ne cessons de rencontrer d'étonnants pressentiments et des idées de recherche d'une force singulière : nous, les amis de Michelet - depuis mon vieux maître Gabriel Monod jusqu'à son élève Henri Hauser, depuis Marc Bloch jusqu'à Renaudet, depuis.... mais nous sommes trop. Qui ne savons pas ce que c'est que l'histoire, évidemment. De temps en temps, des gens qui le savent (à leur avis) nous infligent une mercuriale que nous subissons avec déférence; ils nous enseignent que Michelet fut tout, sauf un historien. Dont acte. N'en parlons plus - jusqu'au jour où, ce qui de son journal intime a échappé aux ciseaux d'Athénaïs Mialaret se trouvant communiqué au public, Michelet redeviendra digne d'intérêt. Gabriel Monod n'a-t-il point écrit que personne n'avait parlé de sa vie intime avec autant de franchise $\mathrm{p}_{\mathrm{p} 23}$ que son maître ? Voilà de quoi lui concilier, le moment venu, des sympathies spéciales. Et la sollicitude des éditeurs.

Laissons cela. J'ai formulé, il y a quelque temps, de brèves remarques sur une «façon de concevoir l'histoire qui n'est pas la nôtre ». De notre façon à nous, Marc Bloch nous donne un exposé, malheureusement interrompu : mais quel nettoyage !

sociologie que nous entreprenions d'édifier. » — Si l'histoire avait été, elle aussi, une « science provisoirement mieux faite », peut-être que... 
Non que le livre soit le moins du monde polémique. Sa sérénité, au contraire, est frappante. Tous les écrits que Marc Bloch nous aura laissés et qui datent de cette période de 1940 à 1943 traversée par lui avec tant de dignité, d'héroïque résolution et de noblesse, portent le même caractère. De son admirable Testament spirituel et de ses derniers propos, j'ai écrit qu'ils appelaient d'eux-mêmes le mot de Sainteté. C'est bien lui qui monte aux lèvres quand on se remémore ce qu'on a pu savoir de la passion et de la mort de ce grand Français. La tranquillité avec laquelle, risquant sa vie chaque jour, il en envisageait le terme comme à peu près fatal, ennoblissait, épurait toutes ses démarches intellectuelles. Son style même paraissait changé. Plus sobre. Moins malicieux. Plus émouvant par ce qu'il avait de contenu, de souverainement détaché des petitesses et des mesquineries du commerce quotidien. - Mais, pour reprendre mon mot, le nettoyage n'en est que plus total. Et plus décisif.

Une méthode de l'histoire, ce livre ? Pas le moins du monde. Des considérations pseudo-philosophiques ${ }^{269}$ sur l'histoire? Pas davantage. Le redressement de notions erronées ou désuètes? Si l'on veut. Ce livre est bien, avant tout, une revue critique des mauvaises façons de penser et de pratiquer l'histoire : mais sous la forme d'une libre causerie d'honnête homme à honnête homme. Le cuistre, le pédant n'ont rien à faire ici. Un exemple :

Marc Bloch, au seuil de son livre, va-t-il dresser de l'Histoire « une longue et raide définition »? Les précédents ne manquent certes pas. Quel historien, une fois dans sa vie au moins, n'a-t-il cédé à la contagion? Marc Bloch s'y refuse. Il ne définit pas l'histoire. Parce que toute définition est prison. Et que les sciences, comme les hommes, ont avant tout besoin de liberté. p424 Définir l'histoire? Mais

269 «Chaque science prise isolément ne figure jamais qu'un fragment de l'universel mouvement vers la connaissance. Pour bien entendre et apprécier ses procédés d'investigation - il serait indispensable de savoir les relier, d'un trait parfaitement sûr, à l'ensemble des tendances qui se manifestent, au même moment, dans les autres ordres de disciplines. Or, cette étude des méthodes pour elles-mêmes constitue à sa façon une spécialité dont les techniciens se nomment philosophes. C'est un titre auquel il m'est interdit de prétendre. » Ouvr. cité, Introduction, p. 17. 
quelle ? Je veux dire, à quelle date, et dans quel cadre de civilisation ? $\mathrm{Ne}$ varie-t-elle point, l'histoire, perpétuellement, dans son inquiète recherche de techniques nouvelles, de points de vue inédits, de problèmes à mieux poser? Définir, définir : mais les plus exactes définitions, les plus soigneusement méditées, les plus méticuleusement rédigées, ne risquent-elles point de laisser, à chaque instant, le meilleur de l'histoire en dehors d'elles ? Cette grande manie des définitions, bonne au temps où chaque bourgeois vivait, adossé au Grand Livre de la Dette publique, puissamment encastré dans le système de Laplace, le gousset fortement garni de napoléons invariables - qu'en dire en ces temps de bouleversements, d'incertitudes, de destructions ? N'évoquent-elles point le mot qu'on sait, amusant et profond, sur ces élèves d'une grande école scientifique, qui «savent tout, mais rien de plus »? Définir, définir, mais n'est-ce point brimer? «Attention, mon ami, vous aller sortir de l'histoire... Relisez ma définition, elle est si nette !... Si vous êtes historiens, vous ne mettrez pas le pied ici : c'est le domaine du sociologue. Ni là : vous seriez chez le psychologue. A droite? Vous n'y pensez pas, c'est chez le géographe... Et à gauche, chez l'ethnologue $\gg .$. . Cauchemar. Sottise. Mutilation. A bas les cloisons et les étiquettes ! C'est à la frontière, sur la frontière, un pied en deçà, un pied au delà, que l'historien doit travailler librement. Utilement...

D'un bout à l'autre du livre il en va ainsi. Marc Bloch n'attaque pas. Il va son chemin, tout droit, d'un pied sûr. Il dit les choses comme elles sont à ses yeux - et il explique sobrement pourquoi, en effet, elles sont telles à ses yeux. " Histoire, science du passé. » Mais le passé serait-il donc, en tant que tel, un objet de science ? Pourquoi pas, alors, une science du présent, sinon du futur? Non: «Il y a longtemps que nos grands aînés, un Michelet, un Fustel, nous ont appris à le reconnaître : l'objet de l'histoire est par nature l'homme. » Un temps, et Bloch, se reprenant, cite ce propos d'un ami : "Pas l'homme, jamais l'homme, les sociétés humaines, les groupes organisés » ${ }^{270}$ - propos qu'il ne faut pas considérer du reste comme tendant à exclure de l'histoire l'étude de l'individu : on ne saurait trop prendre de précautions avec les formules, ces engins mal réglés et qui 
n'éclatent pas toujours dans le sens prévu. Mais il y a les paysages, et les machines, et les institutions, les croyances, les écrits : derrière tout cela qui intéresse l'histoire, qui est la matière de l'histoire, ${ }_{\mathrm{p} 425}$ ce sont les hommes que l'historien veut saisir. "Le bon historien ressemble à l'ogre de la légende : là où il flaire la chair humaine, il sait que là est son gibier. »

Nous voici sur un terrain solide : il ne reste plus qu'à ajouter un trait, mais essentiel. L'histoire ne pense pas seulement « humain». Son climat naturel est celui de la durée. Science des hommes, oui mais des hommes dans le temps. Le temps, ce continu - mais aussi ce perpétuel changement. "De l'antithèse de ces deux attributs viennent les grands problèmes de la recherche historique. »

Je ne vais pas suivre ainsi la pensée de Marc Bloch du début à ce qui est aujourd'hui, hélas, la fin de son livre. J'en ai dit assez pour en montrer l'esprit et la manière. Quant au reste ? Qu'il s'agisse des limites de l'actuel, de la façon de comprendre le présent par le passé et aussi, et surtout, le passé par le présent ; qu'il traite de l'observation, de ses caractères généraux, de la notion de témoignage et de ce qu'elle implique ; de la critique ; du mensonge et de l'erreur, donc de la vérité en histoire; des problèmes spéciaux de l'analyse et d'abord du but qu'elle poursuit : juger ou comprendre - sur tous ces problèmes, et sur tant d'autres qui s'y rattachent, on trouvera dans ce livre mutilé les avis d'un maître exprimés avec une simplicité, une modestie, une humanité rares.

«Vous approuverez, je m'en flatte souvent. Vous me gourmanderez quelquefois. Et tout cela fera entre nous un lien de plus. " Ainsi se terminent les précieuses lignes que Marc Bloch a tracées à mon intention, "en manière de dédicace », sur la première page de son manuscrit. En fait, j'approuve sans réserves, hélas ! Et si Bloch était là, devant moi, comme si souvent, l'œil curieux et amusé — je ne le "gourmanderais » point. Je le remercierais, simplement, d'avoir si bien traduit des pensées qui nous furent longuement communes et dont il écrivait qu'en toute conscience il ne saurait décider souvent «si elles sont de lui, de moi ou de tous les deux »... Mais je voudrais à ce que Bloch a dit ajouter quelque chose. 
L'histoire évolue rapidement, comme toute science aujourd'hui. Avec bien des hésitations et des faux pas, quelques hommes tentent de s'orienter, de plus en plus, vers le travail collectif. Un jour viendra où l'on parlera de « laboratoires d'histoire » comme de réalités - et sans provoquer de sourires ironiques. Le travail de l'économiste ne se conçoit plus sans outillage de plus ${ }_{p 426}$ en plus perfectionné. Et donc sans constitution d'équipes bien entraînées, bien encadrées. Et donc sans enquêtes bien concertées. A cet exemple, qui les touche de près, il est des historiens qui commencent à s'éveiller à une conception nouvelle de leur travail. Une génération ou deux : le vieux monsieur dans son fauteuil, derrière ses fichiers strictement réservés à son usage personnel et aussi jalousement gardés contre les convoitises rivales qu'un portefeuille dans un coffre-fort - le vieux monsieur d'Anatole France et de tant d'autres aura terminé sa vie falote. Il aura fait place au chef d'équipe, alerte et mobile, qui, nourri d'une forte culture, ayant été dressé à chercher dans l'histoire des éléments de solution pour les grands problèmes que la vie, chaque jour, pose aux sociétés et aux civilisations, saura tracer les cadres d'une enquête, poser correctement les questions, indiquer précisément les sources d'information et, ceci fait, évaluer la dépense, régler la rotation des appareils, fixer le nombre des équipiers et lancer son monde à la quête de l'inconnu. Deux mois, ou trois ou quatre : la cueillette est terminée. La mise en œuvre commence. Lecture des microfilms, mise en fiches, préparation des cartes, des statistiques, des graphiques, confrontation des documents proprement historiques avec les documents linguistiques, psychologiques, ethniques, archéologiques, botaniques.... etc., qui peuvent faciliter la connaissance. Six mois, un an: l'enquête est prête à être livrée au public. L'enquête qu'un travailleur isolé aurait mis dix ans à ne point faire aussi riche, ni aussi vaste, ni aussi probante. Même si, surtout si il en avait conçu l'idée dans son ampleur.

«La fin de tout! Plus d'art. Plus de personnalité. Une mécanisation du savoir, encore et toujours. Une de plus!» — Vous croyez? Je pense quant à moi qu'il faudra plus de savoir demain, plus d'intelligence, d'imagination et de largeur d'esprit — d'un mot, plus d'envergure, pour bien poser une question traditionnellement mal posée - ou, surtout, pour poser enfin, pour la première fois, une question que personne encore n'a posée, et qui importe puissamment à 
notre intelligence, tant du présent par le passé que du passé par le présent. - Et qui donc empêchera le poseur de questions, le maître d'œuvre, d'avoir son talent d'écriture ? Et de l'employer à mettre à la portée de tous les résultats de l'enquête?

Ceci, Marc Bloch ne l'a point dit dans son livre. Je dis : ceci qui, à mon sens, est capital pour l'avenir de l'histoire. Non qu'il ne fût prêt à y souscrire. Quand, en 1936, prenant possession de la chaire d'histoire de la civilisation moderne au Collège ${ }_{\mathrm{p} 427}$ de France, j'exposais dans une leçon d'ouverture - Examen de conscience d'une histoire et d'un historien - ce qui n'était alors qu'une vue d'avenir, il ne me fit, certes, aucune objection. Mais les circonstances, cette sorte de repliement sur lui-même qu'il connut au lendemain du choc de 40, le dépaysement, le besoin de se ressaisir plutôt que de s'étendre - tout cela sans doute explique un silence qui n'enlève rien de leur force et de leur efficacité à ses méditations, mais tout de même les date. Or, depuis 1945, nous vivons des années dont chacune vaut dix. Tel se croit précurseur - que le gros de sa troupe a gagné à la main, déjà, de plusieurs kilomètres...

Techniques tout cela, et rien de plus ? - Techniques, en effet. Mais si vous en parlez avec dédain, je ne saurais vous suivre. Et puisque nous sommes placés sur ce terrain, qu'il me soit permis d'ajouter quelque chose. De moins important, mais qui a son prix. L'histoire se fait avec des documents écrits, sans doute. Quand il y en a. Mais elle peut se faire, elle doit se faire, sans documents écrits s'il n'en existe point. Avec tout ce que l'ingéniosité de l'historien peut lui permettre d'utiliser pour fabriquer son miel, à défaut des fleurs usuelles. Donc, avec des mots. Des signes. Des paysages et des tuiles. Des formes de champ et de mauvaises herbes. Des éclipses de lune et des colliers d'attelage. Des expertises de pierres par des géologues et des analyses d'épées en métal par des chimistes. D'un mot, avec tout ce qui, étant à l'homme, dépend de l'homme, sert à l'homme, exprime l'homme, signifie la présence, l'activité, les goûts et les façons d'être de l'homme. Toute une part, et la plus passionnante sans doute de notre travail d'historien, ne consiste-t-elle pas dans un effort constant pour faire parler les choses muettes, leur faire dire ce qu'elles ne 
disent pas d'elles-mêmes sur les hommes, sur les sociétés qui les ont produites - et constituer finalement entre elles ce vaste réseau de solidarités et d'entr'aide qui supplée à l'absence du document écrit ?

Pas de statistique, ni démographique, ni autre: allons-nous répondre par la résignation à cette carence ? Etre historien, c'est au contraire ne jamais se résigner. C'est tout tenter, tout essayer pour combler les vides de l'information. C'est s'ingénier, le grand mot. Se tromper ou, plutôt, vingt fois se jeter avec enthousiasme dans un chemin plein de promesses - et puis s'apercevoir qu'il ne mène pas où l'on voudrait aller. Tant pis, on recommence. On $\mathrm{p}_{428}$ reprend avec patience l'écheveau aux bouts de fil cassés, emmêlés, dispersés. Relations à longue distance des très vieilles civilisations ? Des textes ? $\mathrm{N}$ 'espérons pas tant. Mais des formes de bateau, aujourd'hui encore associées à tel ou tel instrument, à telle ou telle pratique culturelle, à tel nombre, à tel vocable, à tel rite ? Datées parfois, fortuitement, et qu'on saisit ici, et ici et encore ici : voilà qui permet - avec cette sorte d'ivresse que donne le cheminement sur cette étroite arête, entre vraisemblance et fantaisie, pure invention et constatation - voilà qui permet de préparer les matériaux d'une carte : disons de l'océan Indien, cette grande matrice de civilisations, avant que la Méditerranée, peut-être, ne connût sa première mise en ordre et son premier essor...

Et plus près de nous? Une société médiévale. Point de cadastre, point de plans parcellaires. Alors, nous croiser les bras ? Dire : «On ne sait pas »? Non. Voilà d'autres documents, des rentiers, des terriers, des «aveux ». Essuyons leur poussière, lisons, réfléchissons, inventons: et nous finirons par nous procurer, non seulement une sorte de bilan parcellaire d'un territoire donné - mais bien d'autres données encore. Une statistique familiale à date fixe. Une répartition des cultures, etc.

Gardons-nous de sous-estimer la puissance persistante de ce vieux tabou: « $\mathrm{Tu}$ ne feras d'histoire qu'avec les textes. » J'imagine un historien de la peinture édictant: "Peinture ? C'est quand on étend des couleurs à l'huile sur des toiles avec des pinceaux. » Et donc, qu'on le laisse tranquille, cet homme, avec les fresques de l'Arena à Padoue, le portrait de Jean le Bon au Louvre et tous les primitifs et 
tous les exotiques qui n'ont point étendu de couleurs à l'huile sur des châssis tendus de toile. Qu'on le laisse tranquille avec les chefsd'œuvre retrouvés dans les cavernes par l'abbé Breuil. «De la peinture ? Non. De l'archéologie! N'allons pas franchir d'un pas désinvolte la limite sacrée : histoire ici, et préhistoire là... »

Certes, il n'est pas besoin de démontrer que le métier de connaisseur des stations lacustres exige des connaissances et, sans doute, des aptitudes dont n'aurait pas l'emploi l'historien du chemin de fer au XIX ${ }^{\mathrm{e}}$ siècle. Et réciproquement. Reste que la notion de préhistoire est une des plus cocasses qu'on puisse imaginer. L'homme qui étudie l'ère de diffusion de telle poterie néolithique fait de l'histoire, exactement comme l'homme qui dresse une carte de répartition des postes téléphoniques en 1948 dans l'Extrême-Orient. L'un et l'autre, dans le même esprit, pour les mêmes fins, s'attachent à étudier des manifestations du génie p429 inventif de l'humanité, différentes en âge, en rendement, si l'on veut: assurément pas en ingéniosité. Tout cela, Marc Bloch le savait aussi bien que moi. Épargné par le destin, ayant pu depuis 1945 associer son effort à l'effort de ceux qui, avec moi, autour de moi, dans cette maison des Annales que nous fondâmes tous les deux d'un même cœur en 1929, ont repris le travail pour le pousser plus loin : je me demande s'il n'aurait pas senti le besoin d'ajouter à tout ce qu'il a dit, et si exactement dit, quelques précisions complémentaires. Mais s'agit-il bien de complément?

Au vrai, le grand problème, le capital problème qui se pose à nous aujourd'hui (et je répète que je parle ici en praticien de l'histoire, nullement en philosophe, que je ne suis point; je répète que tout l'intérêt de ces pages est, à mes yeux, d'informer correctement nos amis philosophes sur la façon dont nous sommes quelques-uns, en 1949, en France, à concevoir le travail de l'historien et, de façon générale, le rôle et l'avenir de l'histoire) - le grand problème est d'organisation. 
Faut-il dire de l'histoire ? Le mot est équivoque et ce serait encore une raison pour se passer de ses services ${ }^{271}$ - si on pouvait créer un meilleur terme : mais quel ? Il a, en tous cas, deux sens. Il signifie une science - et le contenu de cette science. On me dira qu'il en va ainsi généralement. Avec moins de conséquences peut-être, et moins d'insistance. Or, c'est de la science, en tant que mécanisme intellectuel, qu'il est généralement traité dans nos livres ou livrets de méthodes. Du contenu, et de la nécessité de l'inventorier, puis de l'organiser — rien, ou pas grand'chose.

Nos traités de méthodologie se bornent le plus souvent à distinguer les opérations de l'esprit humain s'appliquant à traiter la matière historique. Si peu logiciens, leurs auteurs s'obstinent à récrire perpétuellement une sorte de logique superficielle et scolaire de l'histoire. C'est ainsi qu'ils s'accordent, presque tous, à nous dire : l'historien établit d'abord les faits : acte I. Après quoi il les met en œuvre : acte II. Suivent deux développements : "Établir les faits, c'est...; mettre les faits en œuvre, c'est... ». - Je n'en dis point de mal. Sinon que tout cela ne m'apprend rien. p430 Et qu'à de telles analyses il manque bien des choses: d'abord, la notion de ce que cherche, ou doit, ou devrait chercher l'historien. "Que l'art est un grand dessein - et qu'il n'y en a point dans un pot»: ainsi, Brunetière, aux jours de ma quinzième année, prétendait exécuter Bernard Palissy et ses Rusticques figulines. Je ne veux exécuter personne. Il m'ennuie, simplement, que l'histoire n'ait point de dessein - qu'elle en reste aux trouvailles hasardeuses de Magendie (ce qui nous reporte avant Claude Bernard) : "Je me promène là dedans comme un chiffonnier, et je trouve à chaque pas quelque chose d'intéressant à mettre dans ma hotte. » A quoi répliquait Dastre : "Quand on ne sait pas ce qu'on cherche, on ne sait pas ce qu'on trouve. » — L'histoire en est toujours au temps de Magendie...

\footnotetext{
271 Je suis un peu plus pessimiste que ne l'est Marc Bloch (ouvr. cité, p. 1) sur les inconvénients qu'offre l'usage de ce vieux mot éculé et sans signification précise. Mais par quel mot le remplacer qui exprime à la fois l'idée de l'homme, celle du changement et celle de la durée ? "Archéologie 》 est pris — et ramène à cette définition inopérante de l'histoire: la science du passé ; il n'évoque ni l'idée d'humanité, ni l'idée de durée. "Anthropochronologie, ethnochronologie ", inventions barbares et qui auraient besoin d'explications pour être comprises.
} 
Autre chose. Ces livres, ces guides de débutants parlent de faits à longueur de page. Établir des faits; mettre les faits établis en œuvre : mais qu'entendent-ils par faits? Comment conçoivent-ils le fait historique ? On s'aperçoit bien vite que, pour la plupart d'entre eux, il demeure un donné ${ }^{272}$. Brut. Qu'il soit construit en réalité par euxmêmes sans qu'ils veuillent s'en rendre compte, ils refusent de le penser. Ils gardent, en 1949, une sorte de respect superstitieux pour le fait, une sorte de fétichisme du fait qui est bien la chose la plus singulière qui soit, et la plus anachronique. Le savant «qui met son œil à l'oculaire, du microscope » et à qui tout aussitôt des faits sautent aux yeux, bien nets, bien lavés si j'ose dire, probants à souhait cette métaphore chère à nos maîtres d'autrefois avait beau me réjouir il y a déjà cinquante ans (car enfin, j'avais « mis l'œil à l'oculaire » et constaté que les faits que révélait le microscope, dans le laboratoire d'histologie où j'allais visiter des amis, ne s'appréhendaient pas si aisément, même quand on savait ce qu'on cherchait - ce qui n'était pas mon cas, mais celui de mes hôtes, que j'entendais discuter des heures durant sur telle ou telle interprétation possible : mes hôtes, qui d'ailleurs avaient passé bien du temps à faire leurs " préparations » et à les colorer, ce qui excluait la notion du « donné tout fait... ») - ce «savant» de la fameuse métaphore, s'il fait encore recette quelque part, c'est, je le crains bien, chez nous autres historiens. Oh! sans doute, tous protestent: "Nous n'en sommes plus à croire que...» Mais c'est bien sous l'empire, et sous l'empire seul, de ce sentiment compliqué que l'Église nomme le respect humain. Car entendez-les dire : p431 «C'est un fait!» Et regardez-les brandir leurs faits entre deux doigts, comme le bijoutier marron qui fait admirer au client une pierre fausse : vous serez édifiés.

Inutile d'insister ici sur cet aspect des choses. Ce que l'historien s'effarouche encore d'entendre dire - le philosophe, depuis longtemps, le tient pour acquis. Mais je reviens à mon propos. On peut modifier le schéma des manuels, codifiant la façon de procéder de l'historien. On peut le rectifier, le compliquer, le transposer. Ajouter aux opérations décrites des opérations nouvelles. On peut.

${ }^{272}$ Un intéressant article de Henri LÉVY-BRUHL sur Le fait en histoire, publié par la Revue de Synthèse, n'a pas, semble-t-il, attiré suffisamment l'attention des historiens sur ce problème si gros de conséquences. 
Mais ce n'est pas tout. Ce n'est pas ce qui importe le plus pour l'instant. Se promener à l'aveugle, non point dans le dédale du corps humain, mais dans l'amas formidable de notions et de faits qui composent l'histoire au deuxième sens du mot — voilà le genre d'exercice à quoi l'historien doit renoncer. Il y a urgence.

Dire comment, en détail : on me dispensera de le faire ici, dans les limites d'un article qui est d'information avant tout. Il y faudrait un livre - et, j'imagine, un livre collectif. Mais enfin, déjà, des signes précurseurs annoncent l'aurore de nouveaux jours.

Hier, une thèse plus que remarquable soutenue en Sorbonne, une thèse sur La Méditerranée et le monde méditerranéen à l'époque de Philippe II ${ }^{273}$ deux personnages d'inégale grandeur, et ce n'est pas le second qui a le pas sur le premier, grande nouveauté déjà) — hier, la thèse de Fernand Braudel nous apportait un plan tout nouveau et, en un sens, révolutionnaire. Décidé à replacer les grands desseins de la politique espagnole, au sens le plus large du mot «politique », dans leur cadre historique et géographique naturel, il étudie d'abord les forces permanentes qui agissent sur les volontés humaines, qui pèsent sur elles sans qu'elles s'en rendent compte, qui les infléchissent dans telle ou telle direction: et c'est toute une analyse, jamais encore tentée, de ce que représente comme force guidant, canalisant, contrariant aussi et freinant ou, au contraire, exaltant, accélérant le jeu des forces humaines - ce que, d'un mot négligemment prononcé, nous appelons la Méditerranée. - Après quoi, dans une seconde partie, il fait l'appel des forces particulières, mais animées d'une certaine constance - des forces impersonnelles et collectives, mais, cette fois-ci, datées et pour ainsi dire repérées comme étant strictement celles qui agissent au XVI ${ }^{\mathrm{e}}$ siècle, dans la seconde $\mathrm{p}_{432}$ moitié du XVI ${ }^{\mathrm{e}}$ siècle, c'est-à-dire dans l'espace de temps que remplit la vie régnante de Philippe II d'Espagne. - Troisième partie : les événements. Le flot tumultueux, bouillonnant et confus des faits. Aimantés souvent par les forces permanentes qu'étudie le premier livre - influencés et dirigés par les forces stables que le second livre

${ }^{273}$ Paris, Armand Colin, 1949, in- $8^{\circ}, 1160$ pages. 
dénombre - mais le hasard joue sur elles, le hasard brode sur le canevas des enchaînements ses variations les plus brillantes et les plus imprévues.

Schéma audacieux, mais simple: sans bruit, sans fracas, sans déclarations grandiloquentes ni professions de foi avantageuses, ce livre est un manifeste. Un signe. Et je n'hésite pas à le dire, une date. On n'accusera point son auteur de philosopher - ce qui, dans une bouche d'historien, signifie, ne nous y trompons pas, le crime capital : son livre, son très gros livre que seule la crise de l'imprimerie et les prix prohibitifs de la typographie a empêché d'être au moins le double, en volume et en substance, de ce qu'il est actuellement - son livre est une merveille d'érudition. Il représente quinze ans de labeur ininterrompu, de recherches poursuivies dans tous les dépôts d'archives, dans toutes les bibliothèques historiques qui comptent dans le monde méditerranéen et le monde ibérique. D'autant plus probant et plus exemplaire. Et je ne dis pas, et Fernand Braudel pas plus que moi ne dirait: le problème est résolu. Le problème d'organiser en fonction de leur importance présumable le chaos des événements. De mettre un peu d'ordre dans la masse confuse et indistincte des notions et des faits, des permanences, des cohérences et des contingences qui, sans plus d'exigences critique ni de discrimination, se réclament de l'histoire. Le problème n'est pas résolu. Mais le voilà posé à jamais sur le terrain des réalités.

Le livre de Fernand Braudel est le livre d'un homme seul. Une thèse, donc un chef-d'œuvre artisanal exigé par la corporation universitaire de tous ceux qui veulent passer maitres. Encore que l'auteur de ce chef-d'œuvre soit un tenant résolu du travail collectif, il lui a bien fallu se plier aux règlements qui, de longtemps encore, ne reconnaîtront point de vertu probante à l'organisation, à la conception, à l'exécution d'un tel travail. Mais qu'on y réfléchisse : combien la mise en pratique des enquêtes collectives par les historiens serait-elle de nature à faciliter cette organisation de l'histoire dont nous sommes si préoccupés ? C'est le rôle fécond de l'hypothèse rendu visible à tous par l'indiscutables ${ }_{\mathrm{p} 433}$ résultats. C'est, grâce au gain de temps, d'argent, d'effort même que représente ce travail collectif, c'est bien 
plus, le rôle de l'histoire même rendu visible, brusquement, et sensible, à ceux qui s'obstinent à ne voir en elle qu'un jeu de curiosité gratuite, un divertissement mnémotechnique - tranchons le mot, un amusement sans portée.

Aujourd'hui, même dans un pays doté d'une bonne école d'historiens - c'est à peine s'il parait, bon an mal an, quatre ou cinq travaux originaux d'histoire relativement neufs dans leur dessein et dont les auteurs se soient proposés autre chose que de témoigner qu'ils connaissent et respectent les règles de leur profession. Ou encore, que de solliciter la curiosité d'un public friand de lectures « historiques » qui ne lui coûtent point d'effort. Or, ces quatre ou cinq travaux traitent de sujets fort éloignés dans le temps et dans l'espace. Consacrés, j'imagine, l'un à un culte antique, l'autre à un problème de technique médiévale ; celui-ci à l'étude d'une révolution monétaire au temps de la Renaissance et celui-là à l'analyse de la structure sociale d'un grand pays européen du XIX ${ }^{\mathrm{e}}$ siècle — ils piquent la curiosité. Ils font dire de leurs auteurs : "Comme ils sont ingénieux » — et de leurs conclusions : «Comme elles sont nouvelles ». Ils amusent ainsi la curiosité de quelques lecteurs intelligents, qui ont la chance, assez rare, d'être bien conseillés par un ami historien d'esprit novateur : «Lisez ceci, cher ami, et encore ceci... — - C'est tout, Et c'est déjà beaucoup sans doute; mais enfin, ces publications en ordre dispersé, peu nombreuses, peu connues, quasi confidentielles, sont bien insuffisantes pour faire sentir à tous, fortement, la présence de l'histoire - comme tous sentent, j'imagine, la présence de la mathématique, ou de la chimie, ou de la biologie dans leur vie quotidienne.

Imaginez au contraire que paraissent en un an, ou en deux, les chapitres successifs d'une dizaine ou d'une douzaine d'enquêtes bien menées et sur des sujets qui touchent directement l'homme cultivé sur des sujets qui, de toute évidence, lui semblent importer grandement à sa vie, à la conduite de ses affaires, aux décisions d'ordre politique ou culturel qu'il doit prendre: enquêtes convergentes, pensées d'ensemble, lancées simultanément, de façon que tel important phénomène de circulation monétaire, j'imagine, ou de transport, ou de peuplement, ou de psychologie collective soit étudié, dans un même esprit, ou bien dans des civilisations éloignées 
dans le temps, ou bien dans des civilisations séparées dans l'espace par de grandes distances: toutes les conceptions que le public peut avoir de l'histoire seront ${ }_{p 434}$ changées. Et nous n'entendrons plus, avec un amusement un peu agacé, des voix candides et cordiales nous dire : "Vous qui êtes historien, vous devez savoir cela: quelle est donc la date de la mort du pape Anaclet? ou du sultan Mahmoud? »

Qu'on ne s'y trompe pas: c'est le gros problème, en dépit des apparences. Ce ne sont pas ces exhortations venues du dehors; ce ne sont pas des leçons de philosophies, des avertissements d'historiens précurseurs qui détermineront dans le monde même des historiens un changement d'esprit et d'attitude — donc, qui amèneront cette transformation profonde de l'histoire que, dans un pays comme le nôtre, les traditions universitaires rendent si difficile. Il faut des coups répétés. Un harcèlement de l'homme contemporain par l'histoire : une histoire efficace et qui devienne présente à la conscience de tous. On s'exclamera d'abord. On se moquera. Et puis on réfléchira. Et la partie, alors, pourra se jouer. Et se gagner.

On voit pourquoi j'attachais tant d'importance, tout à l'heure, à la conception du travail collectif en histoire. Le commun des hommes ne comprendra le rôle, l'importance, la portée de l'histoire que s'il reçoit, et dans la mesure où il recevra, la leçon non des docteurs, mais des résultats.

Quel rôle, quelle portée, quelle importance? Dernier point sur lequel, au delà du livre de Marc Bloch, je voudrais attirer, pour finir, l'attention. Car de ces questions nous ne traitons pour ainsi dire jamais. J'entends bien que Marc Bloch est parti de là : "Papa, explique-moi donc à quoi sert l'histoire ? »-Et il l'a expliqué. Mais peut-être en restant un peu trop dans les limites de la technique historique. En refusant de pénétrer dans ce no man's land inexploré où l'historien juge qu'il n'a rien à faire - et le philosophe, ou le sociologue, que c'est à l'historien seul de s'y risquer...

Qu'on évoque devant ses yeux la suite proprement innombrable des générations qui ont précédé la nôtre - depuis qu'un être susceptible de répondre à la définition de l'homo sapiens est venu 
figurer l'une des nervures de cet immense éventail de formes vivantes que la nature dans sa fécondité déploie et élargit progressivement : cet éventail dont l'image se substitue en nous de plus en plus, aujourd'hui, à la vieille image d'un continu linéaire chère à nos pères - d'une évolution qui, des animaux à l'homme, était censée tendre un fil unique et sans rupture. Derrière ${ }_{\mathrm{p} 435}$ chacun de nous, quelle suite prodigieuse d'accouplements, de viols, de mélanges brutaux ou d'unions normales : un vertige. Et la mémoire de l'espèce en garde les traces pendant combien de temps ? Mais que d'expériences aussi ! Que de participations à des sociétés prodigieusement différentes les unes des autres !... Que de marques laissées, sur nos ancêtres immédiats et sur nous-mêmes, par des systèmes d'idées et de croyances, par des « institutions », au sens sociologique du mot, dont les brusques réapparitions, les surprenants affleurements nous stupéfient parfois - et nous stupéfieraient bien plus encore, et bien plus fréquemment, si nous nous appliquions à mieux nous observer de ce point de vue! Mais un instinct nous en détourne. Un instinct nous avertit de ne pas nous laisser hypnotiser, envoûter, absorber par ce passé. Un instinct nous dit qu'oublier est une nécessité pour les groupes, pour les sociétés qui veulent vivre. Pouvoir vivre. Ne pas se laisser écraser par cet amas formidable, par cette accumulation inhumaine de faits hérités. Par cette pression irrésistible des morts écrasant les vivants - laminant sous leur poids la mince couche du présent, jusqu'à lui enlever toute force de résistance...

Qu'ont fait, historiquement parlant, les sociétés humaines pour parer au danger? Les unes, les moins développées, les moins exigeantes mentalement, ont tout laissé tomber dans le gouffre d'oubli. Laissons-les à leur misère. Mais les autres ? Elles ont adopté deux solutions. Sur lesquelles bien entendu, nous ne savons rien de précis. Qui donc s'avise d'étudier ces misères?

Les sociétés traditionnelles ont, une fois pour toutes, arrangé leur passé officiellement et pragmatiquement. Elles ont projeté, derrière l'image qu'elles se donnaient à elles-mêmes de leur vie présente, de ses fins collectives, des vertus nécessaires pour réaliser celles-ci une sorte de préfiguration de cette réalité : simplifiée, mais agrandie en quelque sorte et parée de la majesté, de l'autorité incomparable d'une tradition à qui la religion confère ce caractère auguste et sacré. 
Faut-il dire qu'aucune enquête systématique n'a été poursuivie jusqu'à présent, d'ensemble, sur ce problème énorme de la tradition ? Faut-il dire que ce serait, précisément — disons, que ce sera, un jour, un beau thème d'enquête collective organisée et concertée - quand l'histoire sera devenue capable d'embrasser d'aussi gros problèmes. Alors, bien des erreurs se dissiperont. Et d'abord celle qui prétend immuable ce qui ne fait que changer: car enfin, pourquoi ces gros livres intitulés Histoire de la coutume de telle ou telle province ? Ce qui reste immuable n'a pas d'histoire ? - De temps ${ }_{p 436}$ en temps, un chercheur avisé soulève un coin du voile. Il y a les pages de Granet, si remarquables, sur l'aménagement par les Chinois d'une tradition historique qui répond tout à fait à l'esquisse que je donnais tout à l'heure. Il y a les pages, également remarquables, de Dumézil démontant le mécanisme de l'histoire officielle de Rome. Tout cela ne fait pas l'étude sur la tradition dont nous aurions besoin.

Il y a la tradition. Il y a l'histoire. Qui répond finalement au même besoin - que ce besoin soit conscient ou non. L'histoire, qui est un moyen d'organiser le passé pour l'empêcher de trop peser sur les épaules des hommes. L'histoire qui sans doute - je le disais plus haut - ne se résigne pas à ignorer, et donc s'ingénie à accroître, toujours plus, l'amas des faits « historiques » dont disposent nos civilisations pour écrire l'histoire: mais il n'y a pas là de contradiction. Car l'histoire ne présente pas aux hommes une collection de faits isolés. Elle organise ces faits. Elle les explique, et donc pour les expliquer elle en fait des séries, à qui elle ne prête point une égale attention. Car, qu'elle le veuille ou non - c'est en fonction de ses besoins présents qu'elle récolte systématiquement, puis qu'elle classe et groupe les faits passés. C'est en fonction de la vie qu'elle interroge la mort.

Voudrait-on penser à ceci ? Depuis des années et des années dormaient dans des caisses, dans des armoires, dans des tours de châteaux organisées en dépôts d'archives — des documents et des documents qui permettaient d'écrire l'histoire économique de l'humanité. Lettre morte. Personne ne s'avisait de secouer la poussière de ces vieux parchemins ou de ces vieux papiers. C'est quand nos sociétés ont commencé à donner aux soucis d'ordre économique la place qu'elles donnaient auparavant à d'autres soucis — que les historiens ont commencé à secouer la poussière de liasses dont 
personne, jusqu'alors, n'avait imaginé qu'elles pussent présenter un intérêt quelconque. C'est une nouvelle orientation de nos sociétés qui a engendré une série de travaux qui auraient pu naître, sans obstacles, un siècle, un siècle et demi plus tôt. - La contrepartie ? C'est l'histoire généalogique qui la fournit. Si en faveur au temps où la structure sociale exigeait en quelque sorte, dans nos pays d'Occident, qu'elle le soit - elle a cessé d'exister, pratiquement, depuis que la qualité de fils de ses pères (quand elle ne comporte pas un héritage de biens économiques qui n'a rien à voir avec les bienfaits d'une «naissance» au sens Ancien Régime du mot) a cessé d'avoir l'importance qu'elle revêtait autrefois pour ceux qui était «nés ». Je crois cet exemple particulièrement probant. $\mathrm{p} 437$

Organiser le passé en fonction du présent : c'est ce qu'on pourrait nommer la fonction sociale de l'histoire. Cet aspect de nos activités, personne non plus ne l'a étudié. On a fait la théorie de l'histoire. On n'a pas fait sa sociologie. Elle ne saurait s'improviser sans doute. Mais cette revue de ce que semble être vraiment l'histoire à un groupe d'historiens français, travaillant au milieu du $\mathrm{XX}^{\mathrm{e}}$ siècle - cette revue serait, je crois, gravement incomplète si on ne profilait pas, derrière la belle ordonnance de nos esquisses méthodologiques, cet aspect, un peu inquiétant peut-être, des activités historiennes observées sans préjugé ni complaisance. Avec toutes les conséquences qui s'ensuivent. Notamment, en ce qui concerne, une fois de plus, ce problème de l'objectivité, que nous n'avons garde de vouloir poser en théoricien, ou en philosophe : mais c'est notre pratique, sans doute, qui le pose de façon nouvelle. Et peut-être imprévue.

On voudra bien excuser ce qu'a nécessairement de sommaire cette brève excursion à travers ce qu'on pourrait nommer les «zones pionnières » de l'histoire. Pousser plus loin, impossible. Faute de place ou faute de temps, non. Mais parce qu'à une discipline en train de s'organiser ou de se réorganiser il ne convient pas d'imposer du dehors des directions prophétiques. Laissons-la faire ses expériences. Ses écoles. N'essayons pas de lui tracer d'avance des programmes didactiques qui l'embarrasseraient peut-être, la gêneraient dans sa marche et promptement seraient démentis par les faits. Songeons au 
vieil employé de la gare Saint-Lazare: il savait, à deux ou trois dizaines près, combien de billets il devait chaque dimanche préparer pour Chatou. Mais nous ne savons pas, nous, si nous serons du nombre, du grand nombre constant de ceux qui se présenteront, dimanche prochain, au guichet. De la tendance générale de l'histoire vers d'autres buts, vers d'autres réalisations, nous pouvons parler. Du détail de ses réussites, ou de ses insuccès, la vie décidera. p438

Rio-de-Janeiro, 20 juillet 1949. 


\section{BIBLIOGRAPHIE CHOISIE ET MÉTHODIQUE}

Retour à la table des matières

\section{1. — L'Histoire : méthode, organisation.}

Article History, dans The Encyclopaedia of Social Sciences, de Seligman et Johnson (en collaboration avec Henri Berr), 1931. — L'histoire provinciale. Discours de rentrée, Université de Dijon, 1912. — L'histoire dans le monde en ruines (leçon d'ouverture, Université de Strasbourg, 1919), R. S. H., XXX, 1920.

— Le problème des divisions en histoire, R. S. H., XLII, 1926. — Le problème des générations en histoire, R. S. H., XL VII, 1929. — L'individualité en histoire. Le personnage historique. Paris, Renaissance du Livre, 1932 (extr. du volume L'individualité en histoire). - Examen de conscience d'une histoire et d'un historien (leçon d'inauguration, Collège de France), Revue de Synthèse, 1934. De Spengler à Toynbee : quelques philosophies opportunistes de l'histoire, Revue de Métaphysique et de Morale, 1936. — Les recherches collectives et l'avenir de l'histoire, Revue de Synthèse, 1936. - Entre l'histoire à thèse et l'histoiremanuel, Ibid., V, 1933. - De l'histoire-tableau : essai de critique constructive, $A$. H. E. S., V, 1933. - Propos d'initiation : vivre 1'histoire, Mélanges d'Histoire Sociale, 1943. - Sur une forme d'histoire qui n'est pas la nôtre, Annales (E. S. C.), 1947. - Vers une autre histoire, Revue de Métaphysique et de Morale, 1949. - Comment Jules Michelet inventa la Renaissance (Studi in onore di Gino Luzzatto, t. III) . - Villes du Nord, villes du Midi, ou du rôle des grandes machines en histoire, Annales (E. S. C.), 1952. - De la Revue de Synthèse aux Annales, Ibid., 1952.

\section{2. - Civilisation : de la Méditerranée à l'Europe.}

Les principaux aspects d'une civilisation: quatre leçons sur la première Renaissance française, Revue des Cours et Conférences, 1925.

Civilisation, évolution d'un mot et d'un groupe d'idées, Paris, Renaissance du Livre, 1930, 56 p. ( $1^{\text {re }}$ Sem. internat. de synthèse). - Genesis de una civilizacion : la civilizacion mediterranea, El Institudo de la Universidad de Paris en Buenos Ayres, ano 1937, in-4․ - Un essai d'histoire européenne, A. H. S., 1939. - 
Europe : brûler ou marquer l'étape ? Synthèses, Bruxelles, 1947. — Esprit européen et philosophie, Annales (E. S. C.), 1948. - Un livre qui grandit: La Méditerranée de Ferdnand Braudel, Revue Historique, 1950. - De civilisations à civilisations. Parallélisme et homologies, Annales (E. S. C.), 1951. - Géographie et civilisation [P. Gourou], Ibid., 1949. - Maladies et civilisations : la peste noire de 1348, Ibid., 1949. — Une histoire de la civilisation, Ibid., 1950. — Les archives et l'histoire de la civilisation, L'Éducation Nationale, $n^{\circ}$ spécial sur les archives, 1951.

\section{3. - Histoire intellectuelle.}

Les classiques de la liberté : Michelet, Lausanne, Traits, 1946, in-12, 162 p.Guillaume Budé et les origines de l'humanisme français, R. S. H., XV, 1907, Un chapitre d'histoire de l'esprit humain: les sciences naturelles de Linné à Lamarck et à Georges Cuvier, Ibid., XLIII, 1927. — L'Érasmisme en Espagne, Ibid., XLIV, 1927. — Une histoire obscure : la publication du Cymbalum Mundi, R. du XVI $I^{e}$ s., 1930. — L'homme, la légende et l'œuvre : un débat de méthode (à propos de Rabelais), R. de Synthèse, I, 1931. - La Renaissance, Encyclop. Française, t. X VI, 1935, fasc. 16, 10, 13. — L'enquête continue, Ibid., t. XVII, Conclusion. - En Utopie, quelques publications récentes, A. H. E. S., VIII, 1936. - Histoire des sciences et philosophie, Ibid., 1938. — Une révolution, le romantisme, A. H. S., I, 1939. - Le Journal, introduction historique, Encyclop. Française, t. XVIII, 1939. - A. Renaudet et les études érasmiennes, A. H. S., I, 1939. — Littérature et vie sociale : un renoncement? Ibid., III, 1941. — Le Machiavel d'A. Renaudet, Mél. d'H. S., 1943. - Romantisme et société, A. (E. S. C.), III, 1948. - Renan retrouvé, Ibid., IV, 1949. - Savants et métaphysiciens du XVII ${ }^{\mathrm{e}}$ siècle, Ibid., 1950. — Un homme libre, René Descartes, L'Éducation Nationale, 1950. — Esprit de l'Encyclopédie, Ibid., 1952. — Rabelais ou la création de l'œuvre rabelaisienne, Les écrivains célèbres, Mazenod, t. II. - De 1560 à 1660 : la chaîne des hommes. En tête de : Le Pré-classicisme français, Cahiers du Sud, 1952.

\section{4. - Histoire et linguistique.}

Histoire et dialectologie, R. S. H., XII, 1906. - Histoire et linguistique, Ibid., XXIII, 1911. — Le développement des langues et l'histoire, Ibid., XXVII, 1913. — Politique royale ou civilisation française ? Remarques sur un problème d'histoire linguistique, Ibid., XXXVIII, 1924. - Langue et nationalité en France au XVIII siècle, Ibid., XLII, 1926. — Le français sous la Révolution, d'après M. Brunot, Ibid., XLV, 1928. — Une méthode de recherche : trafic fluvial et toponymie, A. $H$. E. S., I, 1929. — Les mots et les choses en histoire économique, Ibid., II, 1930. Capitalisme et capitaliste, A. H. S., I, 1939. — Un grand livre d'histoire : « Le Brunot », Mél. d'H. S., V, 1944. 


\section{5. - Histoire de l'art.}

Pour comprendre l'art chrétien du XVII ${ }^{\mathrm{e}}$ siècle, R. S., V, 1933. - Histoire de l'art, histoire de la civilisation, Ibid., IX, 1935. - Un commerce d'art, les tapisseries d'Anvers, A. H. E. S., VIII, 1936. — L'humanisme roman, Annales (E. S. C.), III, 1948. - A propos de Georges de la Tour, Ibid., 1950. - Penser l'histoire de l'art, Ibid., 1950. — Histoire de l'art, histoire des techniques, A. H. E. S., VIII, 1936.

\section{6. - Histoire religieuse.}

Notes et documents sur la Réforme et l'Inquisition en Franche-Comté, Paris, 1911, in-8, $336 \mathrm{p}$.

Un destin, Martin Luther, $1^{r e}$ éd., Paris, 1928 ; $2^{e}$ éd., revue, Paris, 1945 ; éd. belge, Bruxelles, 1945. - Traduction anglaise, Martin Luther, a Destiny, New York, 1929. — Traduction italienne, Lutero, Florence, 1949.

Origène et des Périers ou l'énigme du Cymbalum Mundi, Droz, 1942, 144 p.

Le problème de l'incroyance au XVI siècle : la religion de Rabelais, Paris (Coll. Évolution de l'Humanité), 1942, in-8º 548 p., $2^{e}$ éd. revue ( $7^{e}$ mille), 1947.

Autour de l'Heptameron : amour sacré, amour profane. Paris, 300 p., 1944.

Un secrétaire d'Érasme: Gilbert Cousin et la Réforme en Franche-Comté, Bull. Soc. Hist. Protest., 1907. — La Préréforme catholique en France d'après A. Renaudet, R. S. H., XVII, 1908. - L'humanisme chrétien, la Renaissance et l'Église ; à propos d'un ouvrage récent, B. S. H., XX, 1910. — L'application du Concile de Trente et l'excommunication pour dettes en Franche-Comté, Revue Historique, t. CIII et CIV. — La genèse de l'iconographie et l'évangélisation chrétienne, Revue des Cours et Conférences, 1914. - Le progrès récent des études sur Luther : essai de mise au point, Revue d'Histoire Moderne, I, 1926, pp. 24-48. - Un chapitre d'histoire de l'esprit humain : les sciences naturelles de Linné à Lamarck et à Georges Cuvier, R. S. H., XLIII, 1927. — Une question mal posée : les origines de la Réforme française et le problème général des causes de la Réforme, Rev. Historique, t. CLXI, 1929. - Martin Luther: note bibliographique, Bull. Faculté des Lettres, Strasbourg, I, 1923 (tirage à part, 6 pages). - Le progrès récent des études sur Luther : essai de mise au point, Rev. d'Histoire Moderne, I, 1926, pp, 24-48. - Crises et figures religieuses : du modernisme à Érasme.... Ibid., Il, 1932. — La dévotion en France au XVII ${ }^{\mathrm{e}}$ siècle, Ibid., III, 1932. — Capitalisme et Réforme, Foi et Vie, 1934. — Une conquête de l'histoire, l'Espagne d'Érasme, A. H. S., I, 1939. - Cosmologie, occultisme, poésie, Ibid., 1939. - Aux origines de l'esprit moderne : libéralisme, naturalisme, mécanisme, Ibid., 1944. - Dolet propagateur de l'Évangile, Bibliothèque d'Humanisme, 1945. — L'origine des Placards de 1534, Ibid., 1945. 
- Une sociologie de la pratique religieuse, Annales (E. S. C.), I, 1946. Histoire de la Réforme: I, L'entrée en scène du luthéranisme; II, L'entrée en scène de l'humanisme, Quillet, Hist. des Religions, 1947, in-4º. - Le cas Briçonnet, idée d'une recherche, Annuaire des Hautes Études, Sc. religieuses, 1946-1947. — Leibnitz, Spinoza et le problème de l'incroyance au XVII ${ }^{\mathrm{e}}$ siècle, Annales (E. S. C.), 1947. - Sorcellerie, sottise ou révolution mentale, Ibid., 1948. — De l'à-peu-près à la précision en passant par oui-dire, Ibid., 1950.

\section{7. - Traditions. Folklore. Ethnographie.}

Une légende de Saint-Simon, Rev. des Cours et Conf., 1926. - Comment et pourquoi se forment les thèmes hagiographiques, $R$. de S., III, 1932. - Une gigantesque fausse nouvelle : la Grande Peur de juillet 89, Ibid., V, 1933. Introduction à dix causeries sur les Arts et Traditions populaires de la France, Cahiers de la Radio, IX, 1938. - Répartition géographique des fonds de cuisine en France, Travaux du $1^{\text {er }}$ Congrès int. de Folklore, Tours, 1938. - Histoire sociale et folklore, A. H. E. S., 1938. - Quelques aspects d'une ethnographie en plein travail, Ibid., 1938. - Folklore et folkloristes, A. H. S., I, 1939. Étrangers et innovations, Ibid., I, 1939. — L'histoire devant le folklore, Cahiers d'archéo-civilisation, fasc. I, 1948.

La voix du sang: fin d'une mystique? Annales (E. S. C.), 1949. — Loki ou l'État social créateur du mythe, Ibid., IV, 1949.

\section{8. - Histoire et géographie historique et humaine.}

La Terre et l'Évolution humaine. Introduction géographique à l'histoire (Coll.

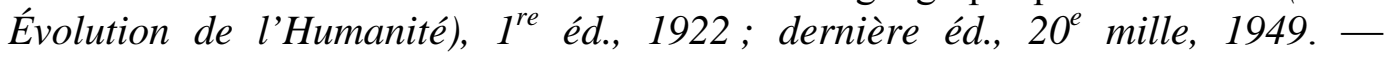
Traduction anglaise: A Geographical Introduction to History, Londres et New York, 1925. - Traduction espagnole: La Tierra y la Evolucion Humana, Barcelone, 1925.

Régions naturelles et noms de pays, R. S. H., XVIII, 1909. - Une étude géographique sur le paysan normand, Ibid., XIX, 1909. - Le problème de la géographie humaine, Ibid., XXXI, 1923. - Sur l'organisation des études de géographie historique: histoire, géographie, cartographie, Bull. du Centre de Synthèse, $n^{\circ}$ 2, 1926. - Instructions spéciales pour la documentation cartographique du Répertoire de synthèse historique, Ibid., $n^{\circ}$ 5, 1928 (R. S. H., $t$. $X L I I$ et $X L V$ ). - L'école géographique française et son effort de synthèse, Ibid., XLV, 1928. — Frontière : étude de vocabulaire historique, Ibid., XLV, 1928. - La maison urbaine : une monographie, une méthode, A. H. E. S., I, 1929. - Imago Mundi : sur quelques volumes de la nouvelle Géographie universelle, $R$. S. H., XLVIII, 1929. - Géographie historique et géopolitique : ouvrages récents, Rev. Critique, 1929, septembre. - Un problème économique posé par la géographie, 
A. H. E. S., III, 1931. - Histoire et géologie, une entr'aide, Rev. de Synthèse, I, 1931. - Problème ou chef-d'œuvre ? Quelques réflexions de méthode sur une thèse récente de géographie, $A$. H. E. S., IV, 1932. - Innovations géographiques ? Rev. de Synthèse, V, 1933. - Une thèse de géographie : Le Val de Loire, Ibid., VII, 1934. - Chez les géographes : positions de problèmes ou répertoires de faits, A. H. E. S., VIII, 1936. — Maison-type et pureté géographique, A. H. S., II, 1940. - La Géographie universelle et La France, d'Albert Demangeon, Annales (E. S. C. ), 1949. — Géographie et civilisation, Ibid., 1949. — Sisyphe et les géographes, Ibid., 1950.

\section{9. - Cartographie historique.}

Un outil attendu : l'Atlas de France, A. H. E. S., VI, 1934. - Un atlas, une carence, Ibid., 1934. — Noir-blanc, un atlas scolaire allemand, Ibid., 1934. L'Atlas de France et les tableaux de l'économie française, Ibid., 1935. Cartographie régionale : 1'Atlas de la Basse-Saxe, Ibid., 1935. - Nouvelles planches de l'Atlas de France, Ibid., VIII, 1936. — L'Atlas de France, Mélanges d'Histoire Soc., I, 1942.

\section{0. - Histoire économique et sociale.}

La France à la veille de la Réforme, d'après P. Imbart de la Tour, R. S. H., XII, 1906. - Les premières publications de la Commission d'Histoire économique de la Révolution, Ibid., XIII, 1906. — Les procès-verbaux des Comités d'agriculture et de commerce à la Constituante, Ibid., XIV, 1907. - Quelques ouvrages récents sur la vente des biens nationaux, Ibid., XIX, 1909. - Une question d'influences: Proudhon et le syndicalisme contemporain, Ibid., XIX, 1909. - Types économiques et sociaux du $\mathrm{XVI}^{\mathrm{e}}$ siècle, le marchand, Rev. des Cours et Conférences, XXIII, I, 1921. - Les nouveaux riches et l'histoire, Ibid,, XXIII, II, 1922. - Le socialisme d'État: L'industrie et les classes industrielles en France pendant les deux premiers siècles de l'ère moderne, par P. Boissonnade, Revue Critique, LXII, décembre 1928. - Ports d'aujourd'hui, ports d'autrefois, A. H. E. S., I, 1929. - La vie rurale dans le Sud de la région parisienne, par Yvonne Bézard, Revue Critique, novembre 1929. - Ports et flottes, A. H. E. S., I, 1929, pp. 602 - 606. - Histoire sociale du temps présent : les journalistes, Ibid., II, 1930, pp. 129-132. - Le Sahara de demain, Ibid., pp. 420-422. - Tunis et le commerce européen, Ibid., pp. 593-596. - Les archives privées et l'histoire : livres de comptes et papiers commerciaux conservés en Belgique, Ibid., III, 1931. — Le problème historique des prix : l'afflux des métaux d'Amérique et les prix à Séville, Ibid., II, 1930. - L'histoire économique et la vie: leçon d'une exposition, Ibid., IV, 1932. - Chiffres faux, courbes vraies, Ibid., 1932. Comptabilité et Chambre des comptes, Ibid., VI, 1934. — Un impôt : études économiques, sociales et cartographiques, Ibid., 1934. - Les mouvements 
paysans en Allemagne, 1525, Ibid., 1934. - Fondations économiques, superstructures philosophiques, Ibid., 1934. - En Toscane au XIII ${ }^{\mathrm{e}}$ siècle : de la ville à la terre, ou de la terre à la ville ? - Genesis de una structura social : los origenes del capitalismo y la formacion del mundo moderno. El Instituto de la Universidad de Paris en Buenos Ayres, ano 1937, 1938. - Un livre d'historien sur les corporations, A. H. S., III, 1941. - Un village du Languedoc sous Louis XV, Ibid., 1941. - Ce que peuvent nous apprendre les monographies familiales, Mélanges d'H. S., I, 1942. — L'homme ou le rendement? Ann. (E. S. C.), I, 1946. — Fils de riches ou nouveaux riches ? Ibid., 1946. — Proudhon, Proudhons, Ibid., 1949. - Industrialisation et technocratie : Introduction au recueil publié sous la direction de G. Gurvitch, Bibl. École Hautes études, VI section, 1949. - Le nombre ou les personnes, plaidoyer pour un peu de psychologie, L'Économie Contemporaine, décembre 1949. - Préface à Auxerre en 1950, par Ch. Bettelheim et S. Frère (Cahiers de la Fondation Nationale des Sciences Politiques), Paris, 1950.

\section{1. - Techniques et machinisme.}

La marine vénitienne de la Renaissance : technique et techniciens, A. H. E. S., 1935. - Une enquête, la forge de village, Ibid., VII, 1935. - Technique, science et marxisme, Ibid. -Réflexions sur l'histoire des techniques, Ibid. - Avant le livre imprimé : la technique du ms. universitaire au moyen âge, Ibid., VIII, 1936. Les techniques, la science et l'évolution humaine : conclusions d'une enquête, Europe, 1938. - L'invention du feu, une méthode, A. H. S., I, 1939. — Les surprises d'Hérodote, Ibid., Il, 1940. — Comment classifier les techniques ? Mélanges d'Histoire Sociale, V, 1944. - Sauter ou marquer l'étape : réflexions sur la modernisation des cultures marocaines, Annales (E. S. C.), I, 1946. L'homme ou le rendement, Ibid.

\section{2. - Histoire et psychologie.}

A propos d'une étude de psychologie historique, R. S. H., XX VII, 1913. - La psychologie appliquée : problèmes de méthode et solutions pratiques, A. H. E. S., III, 1931. - L'histoire de la philosophie et l'histoire des historiens, R. S., III, 1932. - Sur le témoignage, Ibid., 1932. - La psychologie et l'histoire, Encyclopédie Française, t. VIII, 1938. — La sensibilité dans l'histoire, A. H. S., 1941. - Histoire des sentiments, la Terreur, A. (E. S. C.), 1951. — O homem do seculo XVI, Revista de Historia, São Paulo, 1950. - La mort dans l'histoire, Annales (E. S. C.), 1952. - Un moment avec Huizinga (Homo ludens), Ibid., 1952. - Au temps des guerres de religion : en lisant d'Aubigné, Ibid., 1952. 


\section{3. - Histoire de l'Est.}

Philippe II et la Franche-Comté, étude d'histoire politique, religieuse et sociale, Paris, Champion, 1911, LVI-808 p. in- $8^{\circ}$.

Histoire de Franche-Comté, Paris, Boivin (Coll. Vieilles Provinces), $1^{\text {re }}$ éd., 1912, 260 p. ; $7^{\circledR}$ éd. 1923. 308 p.

Le problème historique du Rhin, $1^{\text {re }}$ partie de l'ouvrage Le Rhin, publié par la Société générale alsacienne de Banque, Strasbourg, 1931, 156 p. in-f․ - Repris dans Le Rhin, problèmes d'histoire et d'économie, Paris, 1935, in-8 .

Les régions de la France : la Franche-Comté, Paris, Cerf, 1902, in-8, 76 p. Les contemporaines de Granvelle, Mém. Soc. Émulation Doubs, 1910. - Une vieille famille comtoise, les Granvelle, Paris, Ed. Presse française, 1913. - Les ducs Valois de Bourgogne et les idées politiques de leur temps, Rev. Bourguignonne d'Enseignement Sup., 1913, t. XXIII. - Un bilan : la France et Strasbourg au XVI ${ }^{\mathrm{e}}$ siècle, La Vie en Alsace, 1925, $n^{\circ} 12$, et 1926, $n^{\circ} 2$. - Un chapitre d'histoire politique et diplomatique : la réunion de Metz à la France, Rev. Hist. Moderne, III, 1928. - Dans le Jura: réflexions sur quelques travaux d'histoire locale, A. H. E. S., VII, 1935. - Le Fort de Joux, méditation d'un historien comtois, Franche-Comté et Monts Jura, 1935. - La Ligue en Bourgogne, A. H. S., 1939. - France de l'Est et du Sud-Est : trois études historiques, Revue Historique, t. 188-189, 1940. — Nos généraux de la Révolution, Préface au Catalogue du XXI ${ }^{\mathrm{e}}$ Salon des Annonciades, Pontarlier, 1945. - Louis XI, pèlerin à Saint-Claude, Préface à un livre de G. Gros, Besançon, 1946. - Neuchâtel et la France à travers les âges, Préface à un livre de Ch. Guyot et A. Parreaux, Paris, 1947. — L'Alsace et Bâle, lettre-préface à Ph. Dollinger, en tête de L'Alsace et la Suisse à travers les siècles, Strasbourg, 1952.

\section{4. - Problèmes actuels.}

L'enseignement supérieur en France, Encyclopédie Française, t. XV, 1939. Enseignement 46, L'Éducation Nationale, février 1946. — Lettres, sciences, arts et la paix, collaboration au recueil collectif: Liens entre nations, 1947. L'enseignement supérieur en France, plaidoyer pour une révolution, L'Éducation Nationale, février 1947. — Europe : brûler ou marquer l'étape ? Synthèses, Bruxelles, 1947. — Une réforme de l'enseignement historique: pourquoi ? L'Éducation Nationale, 1947. — Une tragédie, trois comptes rendus, Annales (E. S. C.), 1948. — Positions françaises à Mexico, L'Éducation Nationale, 1948. — Alerte au Français ! L’Éducation Nationale, 1948. 


\section{5. - Histoire contemporaine.}

Prise de température : deux livres allemands sur le moyen âge, Annales H. E. S., VII, 1935. - Le régime fasciste : mise en place historique, Encyclopédie Française, $t$. $X$, fasc. 10. - L'économique derrière le politique, Ibid., fasc. 10. Races et peuples, Revue de Synthèse, IX, 1935. — Le droit et la question paysanne en Allemagne, Ann. H. E. S., IX, 1937. - Titre et contenu : l'Autriche et l'Autrichien, Ibid., IX, 1937. — L'Autriche jusqu'à l'Anschluss, Rev. Trim. de l'Encyclopédie Française, 4, 39. - Sur la doctrine national-socialiste, un conflit de tendances, Ann. d'Hist. Sociale, I, 1939. - Une tragédie, trois comptes rendus, Ann. (E. S. C.), 1948. — Un grand livre sur l'Allemagne, Ibid., 1950. — En lisant les revues allemandes, Ibid., 1950.

\section{6. - Études sud-américaines.}

Un champ privilégié d'études : l'Amérique du Sud, A. H. E. S., I, 1929. Pour comprendre l'Amérique du Sud, Ibid., VI, 1934. - Montevideo, centre de culture française, Tribune des Nations, 1940, et Cahiers français de Montevideo, av. 1940. - L'Amérique du Sud devant l'histoire, Annales (E. S. C.), 1948. Brésil, terre d'histoire, Préface pour Maîtres et Esclaves, de Gilberto Freyre, Paris, Gallimard, 1952.

\section{7. - Figures et médaillons.}

Un tempérament d'historien : Camille Jullian, Rev. de Synthèse, I, 1931. Hommage à Henri Berr, Paris, 1932. - Albert Mathiez : un tempérament, une éducation, Ann. H. E. S., IV, 1932. - Albert Thomas historien, Ibid. - Paul Dognon, Annuaire de l'E. N. S., 1932. - Henri Pirenne : historien européen, Rev. d'Hist. Mod., 1933. - Un deuil de l'histoire vivante: H. Pirenne, Nouvelles Littéraires, octobre 1936. - Henri Pirenne, 1862-1935, Ann. H. E. S., VII, 1935. - François Simiand ou Des conditions faites à la recherche en 1936, Ann. H. E. S., VIII, 1936. - Ch. Blondel, Annuaire de l'E. N. S., 1940. — Deux amis des Annales: Jules Sion, Albert Demangeon, A. H. S., III, 1941. - Marc Bloch historien, Les Cahiers Politiques, mars 1915. - De l'histoire au martyre : Marc Bloch, 1886-1944, A. H. S., VII, 1945. - Marc Bloch, témoignages sur la période 1939-40, Ibid., 1945. — Les morts de l'histoire vivante : Gaston Roupnel, Ann. (E. S. C.), 1947. — Nos deuils : Georges Espinas, Ibid., 1948. — Une vie : Dom Bernard Berthet, 1909-1950, Ibid., 1950. — Un historien de 1'humanisme, Aug. Renaudet, Mélanges Renaudet, 1952. - Camille Bloch, notice lue à l'Institut, 1952. 


\section{8. - Préfaces et Postfaces pour :}

L'Encyclopédie Française, t. X, L'État moderne, 1935. — Ibid., t. XVII, Arts et littératures, 1935. - Hommes d'État, recueil de Duff et Gally, 1936. Histoire du mouvement ouvrier, de Ed. Dolléans, 1936. — L'Encyclopédie Française, $t$. VI, L'être humain, 1936. — Ibid., t. VII, L'espèce humaine, 1937. — Ibid., t. VIII, La vie mentale, 1938. — Ibid., t. XV, Éducation et instruction, 1939. - Ibid., t. XVIII, La civilisation écrite, 1939.

La France bourgeoise, de Ch. Morazé, 1946. - Nouvelles et spéculations à Venise au début du XVI ${ }^{\mathrm{e}}$ siècle, de P. Sardella, 1948. - Trois essais sur histoire et culture, de Ch. Morazé, 1948. - Industrialisation et technocratie, recueil publié par G. Gurvitch, 1949. - Humanisme du travail et humanités, de G. Friedmann, 1950. - Une ville française moyenne : Auxerre en 1950, étude de structure sociale et urbaine, de Ch. Bettelheim et Suz. Frère (Cahiers de la Fondation Nationale des Sciences Politiques), 1950. — La correspondance de Mgr Zaepfel, évêque de Liège, 1801-1808, 1951. — Initiation à la critique historique, de Léon Halkin, 1951.

\section{9. - Entreprises collectives.}

Direction générale de L'Encyclopédie Française : conception d'ensemble et plan des volumes; choix des collaborateurs ; rédaction. - 11 tomes parus, de 1935 à 1940.

Fondation avec Marc Bloch $(\dagger$ 1944) et direction des Annales d'Histoire Économique et Sociale; depuis Annales, puis Mélanges d'Histoire Sociale, puis Annales (Économies, Sociétés, Civilisations). Paris, 1929 et suiv.

Fondation et présidence de la Société pour l'Histoire des Civilisations et des Cahiers de celle Société.

Fondation du Bulletin de la Société des Historiens Locaux et présidence de cette Société.

Mise sur pied des Cahiers d'Histoire de la Guerre, organe trimestriel $d u$ Comité d'Histoire de la Guerre, Paris, Impr. Nationale, in- $8^{\circ}$, et de la Revue d'Histoire de la Seconde Guerre Mondiale, Paris, Presses Universitaires, 1950.

Direction générale de la Collection Destins du Monde, Paris, A. Colin, 1954 et suiv.

Mise sur pied et direction des Cahiers d'Histoire du Monde Paris, Librairie des Méridiens 1953. 


\section{INDEX ALPHABÉTIQUE}

Retour à la table des matières

Abélard, 25.

Abraham (Pierre), 256-257.

Agrégations, génératrices cloisonnement, 294.

Alberti (L.-B.) 282.

Albigeois : croisade et langue française, 172-176.

Alimentation (histoire de l') 95, 217.

Alsace : diffusion du français, 178.

Altman (Georges) 407.

Ambivalence des sentiments, 228.

Anachronismes psychologiques, 213, 230.

«Annales »: pourquoi changent-elles de titre ? 34 - comment nées, 398.

Aptitudes, v. Tests.

Aristote: classification des êtres vivants, 323.

Art : et Science, 51 ; - et Sentiment religieux, 305. Expression d'un besoin, 313. Art roman, 309-311; — en Poitou, 311.

Artisanat scientifique : son déclin, 14.

Ashley (William) 398.

"Atlas linguistique de la France», 151.

Bagdad (califat) vu par Toynbee, 127.
Baldwin, 208.

Ballanche et la mort des civilisations, 36.

Balzac à table, 256; l'œuvre et l'homme, 257.

Barbou : ses classiques latins, 183-184.

Barrès (Maurice) 44.

Bataillon (Marcel) 233.

Bauhin (les) 238 et n. 2.

Baulig (Henri) 399.

Beaumanoir, 288.

Belgique et Révolution française, 364.

Benda (Julien) 81-87.

Bencharnum, 149.

Bergson, 49.

Bernard (Claude) 17, 26, 42.

Berr (Henri) VII, 10, 56 n. 1, 115, 136, 290, 339, 394.

Berthelot (René) 30 .

Berthelot (Marcelin) 116.

Berthet (dom Bernard) 411-416. Subit l'influence de dom Gréa et de dom Benoît, 412. Comment entré aux «Annales », 414. Laisse inachevée son «Histoire sociale de la Terre de Saint-Claude au $\mathrm{XVI}^{\mathrm{e}}$ siècles, 414. Ses articles, 416 n. 1.

Bertrand (Juliette) 279. 
Bibliographie et histoire de la Science, 314, 316.

B.I.T., 348.

Bloch (Gustave) 392.

Bloch (Marc) 15, 19, 57, 117, 198 n. 1,

311. Sa jeunesse, 391-392. Sa

thèse, 392. Ses «Rois thaumaturges », 393. Son « Ile-deFrance », 394. Incline vers l'histoire paysanne, 394-395.

Rapports avec Pirenne, 395. Ses « Caractères originaux », 397. Genèse des «Annales », 398. Sa "Société féodale», 400. Ses projets, 401. Munich, 402. Reprend du service en 1939, 402-403. Mal utilisé par l'Armée, 403-404. De Dunkerque à Clermont-Ferrand via Londres, 404. Dans la Résistance, 405. L'arrestation, 406. La torture, 407. L'assassinat, 407. Son « Apologie pour l'histoire », 419. «L'étrange défaite », 419. Son testament spirituel, 424. Ne définit pas 1'histoire, 425. Son histoire,

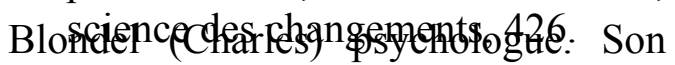
«Introduction à la psychologie collective $», 201,213-214,223$, 255, 399. La vie et l'homme, 370-

Bosšuét, 85 n. 1.

Bouelles, 276.

Bouglé, 423 n. 1.

Bourgeois (Émile) «Manuel de politique étrangère $»$, VII, 18, 63 .

Bourgeois (historiens): attaque et défense, 109-111, 112.

Bourgeoisie française au XVI ${ }^{\mathrm{e}}$ s., 180.

Boussey (A.) 193 n. 1.

Boutruche (R.) 179 n. 1.

Braudel (Fernand) IX, 307; sa thèse sur la Méditerranée, 432-434.
Bremond (abbé) 214, 233, 234, 236, 266, 272.

Brun (A.): son «Introduction du français dans le Midi », 170 sqq. 185 n. 1.

Brunetière et Bernard Palissy, 431.

Bruno (Giordano) 280-281.

Brunot (Ferdinand) : son « Histoire de la langue françaises », 180-200, 219.

Brunschvicg (Léon) 289. Sa génération de philosophes, 290.

Budé (Guillaume) 250.

Buonarotti, 350.

Burckhardt, 277.

Busson (Henri), 279.

Callot (Jacques) 303.

Calvin (Jean) : sa pensée politique, 7579 ; la grâce inconditionnelle, 227228.

Campagne et ville, 93-94.

Campanella, 233, 325.

Candolle, 329.

Capitalisme et scolastique, 236 ; - et métiers, 286 ; — et morale, 287.

Caron (Pierre) 383.

Cassirer (Ernest) 276.

Caumont (Arcisse de) 309.

Cesalpin, 280.

Challenge and Response, loi de Toynbee, 128-130.

Chappey, 68.

Chateaubriand, 98.

Charlemagne (Empire de) 359-361.

Chine : vue par Toynbee, 129.

Choix (l'histoire est) 7, 116-117.

Cicéron : son rôle au XVI ${ }^{\mathrm{e}}$ s. 278-279. 
Civilisations : une c. peut mourir, la c. ne meurt pas, 36. Formation de c. à l'échelle du monde, 37. C. recensées par Toynbee, 128. Leur genèse, 129-130. Leur vitalité, 132. C. française vue par Curtius, et par Sieburg, 239. Le mot, 341.

Classification en histoire naturelle, 321.

Climat des idées, 26, 30.

Collège de France, chaire d'histoire et morale, 3 .

Colonne (Édouard) 46.

Comparative: méthode, en histoire, 115 n. 1, 369. Chez Toynbee, 137$140,142$.

Comte (Auguste) : sa classification des sciences, 29, 102.

Continu en histoire, 436.

Contrastes naturels: leur action psychologique sur 1'homme, 216, Copetric, 26.

Courajod, vi, 24.

Courbet (Gustave) VII, 50, 101.

Cournot (Aug.) ; mathématicien saturé d'histoire, 294.

Coutume médiévale, 15.

Crise de l'histoire, aspect d'une crise générale, 26-27.

Critique : ne doit jamais tromper, 416 n. 2.

Crozet (René) 311.

Cues (Nicolas de) 276, 279.

Curtius, 240.

Cuvier (Georges) 320-323 ; - et Lamarck, 327-333.

Darmesteter (A.) : vie des mots, 122 et n. 1.

Darwin, 319.
Dastre (E.) 58.

Daubenton et la classification, 322.

Daudin (H.) 184, 318-336.

David (Henri) 296 sqq.

Demangeon (Albert) 381-386. Sa thèse sur la Picardie, une date, 381. Patronne les «Annales », 382. Son talent de géographe, 384. Peu théoricien, 385. Esprit complet,

Derülé, artiste lorrain, 303.

Desmoulins (Camille) 107-108.

Dieu seul, 103.

Disettes, 217.

Dissection sous l'eau, pratiquée par Cuvier, 329. Ignorée de Lamarck, 329.

Divisions en histoire, 127 ; — d'après Toynbee, 136.

Dognon (Paul) 172.

Dôle : Université, 196.

Durkheim : influence sur Mathiez, 346. - Vu par Ch. Blondel, 373.

Écoles régionales d'architecture, 309. Difficulté du problème, 310 sqq.

École rurale ancienne, 185-186.

Économique et Social : pourquoi liés, 19.

Edmont (E.) 151.

Égéens : civilisation égéenne, 167.

Eisenmann (Charles) 70.

Émotions, 223-224 ; - contagieuses, 224. Deviennent des institutions, 224. Leurs rapports avec l'activité intellectuelle, 225.

Emprunts linguistiques, 166; artistiques, 232-233.

« Encyclopédie Française »: encyclopédie de problèmes, non de 
références, 59 n. 1, 104-105, 223, 236, 268, 289.

Enquêtes collectives: avenir de l'histoire, 427, 433-435.

Érasme : ses moyens de vie, 258 n. 1.

Eskimos, 217.

Espagnole: langue, jamais parlée en Comté, 193.

Espinas (Georges) 122 n. 2, 408-410. Son article «De l'horreur du général », 409.

Esprit : sens du mot, 290.

Europe: genèse de l' - 360. Variations de la notion, 366.

Européen (l'esprit) 289-294.

Expression religieuse dans les arts: éphémère, 305.

Fait historique: 1'historien le crée, 7, 8, 9, 86. Idolâtrie du fait, 22. Clou à quoi accrocher l'idée, 312-313. N'est pas donné, 431.

Faucille à dents ou lisse : vocabulaire, 154-155.

Ficin (Marsile) 279.

Filmologie : ses débuts, 420.

Fontaine (Arthur) 352.

Fontenelle, 184.

Fourcroy: sa classification, 321-322, 335.

Français : psychologie des -, 80-88. Attitudes politiques, 243.

Francastel (Pierre) 309-311.

France (Anatole) 18, 42, 44, 260.

France : ses formes successives, 9, 97. Sa restauration au XVI s., 180.

Franche-Comté, VI. Son attitude vis-àvis du français, 192-199. Ses habitats définis par Proudhon et
Michelet, VII, 344. En quoi diffère de la Lorraine, 308 n. 1.

Frazer (James) 119, 214

Friedmann (Georges) IX.

Fromentin, 307.

Frontières naturelles: la part du dialectologique, 150.

Fustel de Coulanges, 86, 95.

Gachon : le doyen, 172-174

Gallé (Émile) 46.

Géographie humaine et histoire, v. Histoire. G. humaine dans l'« Encyclopédie Française », 105106. G. linguistique : sa naissance, 151.

Gerson (Jean) 385.

Gide (André) 114.

Gilliéron (E.) 151, 310.

Gilson (Etienne), 284. A Strasbourg, 391.

Girard (abbé) 88, 235.

Gollut, 194 n. 3, 195 n. 1.

Gonse (Louis): découvre La Tour, 304.

Gréco, 305-306.

Gradmann, 13.

Granet et la Chine, 214, 420.

Grégoire (abbé) 190.

Guérin (Daniel) 109.

Hache, 160.

Halphen (Louis) 114.

Hauser (Henri) 21, 61, 300, 401.

Hazard (Paul) 16.

Histoire: mot éculé, mais le remplacer? $430 \mathrm{n}$. 1. Besoin des Sociétés occidentales, 420 . Son état en France vers 1890, 4. Ses 
annexions, 24. Se faisait « avec des textes », ignorait les réalités économiques, 4. Culte du fait, 6 . S'interdisait de choisir, 7. Se réclamait de la Science, 8 ; mais acceptait de n'être qu'une méthode, 10. Rebutait les jeunes, 18. En perte de vitesse, 24. Désertée pour des disciplines nouvelles, 25. Crise d'après-guerre, 11. - Science ou étude conduite scientifiquement? 20. Besoin des Sociétés humaines, 113. Pas cultivée partout identiquement, 420. Est une, 20. Sa fin : expliquer le monde au monde, 40. Comprendre et faire comprendre, 42. Juger, non, 113 ; ni édicter des lois, 15. S'intégrer dans la psychologie des anciennes sociétés, 334. Sa fonction sociale, 438. H. et tradition, 436-437. Science de l'homme, 13, 15, 20, 31, 117. N'échappe pas au milieu, 15. Organise le passé, 15, 438. Requiert des architectes, 33, 59. Pose des problèmes, 22-23. Part d'hypothèses, 8, 117, 312. Collabore avec les autres sciences humaines, 14, 334. Tend au travail collectif, 433-435. Ne se fait pas qu'avec des textes, 429. - $H$. comparée, v. Comparative (méthode). - H. et philosophie: historiens peu enclins à philosopher, 4. Il y paraît trop parfois, 24. Philosopher, crime capital, 433. Historiens et historiens de la philosophie: incompatibilités, conditions d'entraide, 282-283, 422 n. 1. - H. et psychologie: individus et masses, 208-209, 211. Le personnage historique, 209-211. Problèmes spéciaux de la psychologie historique, 213.
L'anachronisme psychologique, 213-217. — La sensibilité, 221-238 v. Émotions, Ambivalence, Huizinga. Résurrection de sentiments primitifs, 238 (soleil, sang, terre mère, nudité). Mort, 214. V. aussi Psychologie appliquée. - $H$. et sociologie : préjugés durkheimiens, contre 1'-, 423 n. 1. H. réduite à la méthode, 10. Problème de l'individu et de la société, 82, 90, 94-95, 113, 210211 ; vu par Toynbee, 133. V. aussi Personnages historiques, Masses, Durkheim. - H. et géographie humaine, 377, 386. - H. et linguistique: langue suppose nation, 162-163. Langue et nationalité, 199-200. Mécanisme de l'emprunt linguistique, 164-165. Suppose la reconnaissance d'une supériorité, 178 Utilisation historique de la toponomastique, 166-167 ; de l'onomastique, 167 n. 1. Espoirs évanouis des historiens dans la linguistique 159, 161. V. aussi Langage, Langues, Linguistique et préhistoire. - H. et arts 50-52. Leçons de l'iconographie, 231. L'emprunt artistique, 232. Alliance à organiser : arts, littérature, structures sociales, 301. V. aussi Monographies biographiques, Écoles d'architecture, Musique, Expression religieuse dans les arts. - H. et littératures: malentendus et déceptions, 263-265. La tentative de Lanson, son échec, 264-265. Un renoncement? 267. H. et sciences, 336. Conditions d'une collaboration, 333-335. Événements politiques et activité scientifique, 335. V. aussi Science, Sciences. - H. diplomatique, 61, 
63, 65, 67. - H. des idées, 76, 77, 78, 320. - H. généalogique, 437. - H. romancée, 230 - $H$. historisante, 114. - H. tableau, 72. - V. aussi Homme, Personnage historique, Justice et grâce, Continu en h., Divisions de l'h., Siècles, Fait historique, Enquêtes, Recherches collectives; Métaphores en h., Spécialisation, Valéry.

Homme : sujet et mesure de l'histoire, 13, 102, 117. Pas l'h. isolé, l'h. en groupe, 15. Pas l'h. éternel, l'h. perpétuellement changeant, 39. Au fond de qui, survivant, les éléments d'une archéologie de la pensée humaine, 39-40. Vu par Voltaire, 270 ; par Diderot, 271.

Huile, 160.

Huizinga, 215, 226-227, 228, 229, 300.

Humanisme roman, 209 sqq.

Hypothèse en histoire, v. Histoire.

Iconographie, 231.

Idées (histoire des) v. Histoire.

Individu en histoire, v. Histoire. Cf. également Personnage historique. Le problème vu par Toynbee, 133.

Inquiétude : moteur du chercheur, 20.

Instruction populaire: mal vue des intendants, 187.

Intendants et instruction populaire, 187.

Islam et Méditerranée, 359-360

Jannequin (Clément) : la « Bataille de Marignan », 255 n. 3.

Jaurès (Jean): historien de la Révolution, VI, 109, 261, 350. Jeanne d'Arc, 89.
Joseph II : le côté - de la Révolution, 363. Triomphe en Belgique avec Napoléon, 364.

Journaux scientifiques, 184 n. 4.

Jullian (Camille) 89, 117 n. 1, 162$163,230,353-356$.

Jura : vu par Lequinio, 190. Sa bibliographie géologique, 314 .

Justice et grâce au XVI ${ }^{\mathrm{e}}$ s., 227.

Klibansky, 276.

Laclos (Choderlos de) 273.

Lacombe (Paul) 295, 340.

Lagarde (G. de) 74-79.

Lamarck, 318 sqq. - et Cuvier, 327333.

Lamartine : sur Rabelais, 257 n. 1.

Lamprecht (Karl) 220.

Langevin (Paul) 312, 341.

Langlois (Ch.) v, 88.

Langage: moyen d'action du groupe sur l'individu, 211, 219.

Langue et nation, 162-163.

Langue française: conquiert le Midi au $\mathrm{XVI}^{\mathrm{e}}$ s., 169. S'impose en Avignon, 171. Triomphe du latin, 175. Se répand en Europe, 182. Refoule les patois, 183 sqq. Progrès comme langue scientifique, 184. Servie par l'école? 185-186; par la circulation, 188-189.

Langue indo-européenne, 159. grecque, 158-168, 178. - latine: recule dans le Midi, 175 ; et dans toute la France au XVIII ${ }^{\mathrm{e}}$ s., 183.

Lanson (Gustave) 264.

Lajeunesse (Ernest) 45.

Lapicque (Louis) 58. 
La Tour (Georges de) 302 sqq. À peu près inconnu jusqu'en 1934, s'établit d'un coup dans la gloire, 303. Pourquoi ? 304.

Lecène, prince de la chirurgie, 311 .

Le Clerc, 303.

Leenhardt (Maurice) 237.

Lefebvre (Georges) 110, 344-345. À Strasbourg, 399.

Lefèvre d'Étaples, 78, 110, 279.

Lefranc (Abel) 247-248.

Legrand (Daniel): précurseur du B.I.T., 351.

Le Moiturier (Antoine) 300.

Lemonnier (Henri) 72.

Le Nain (les) 304.

Lequinio, 190 n. 2.

Leriche (René): son humanisme chirurgical, 39.

Le Roy (Édouard) 312.

Lescar, 149.

Lestocquoy (abbé) 408.

Leuilliot (Paul) VIII.

Lévi (Sylvain) 59, 400.

Lévy (Ernest-Henri) 399.

Lévy-Bruhl (Henri) et le fait en histoire, $431 \mathrm{n} .1$.

Lévy-Bruhl (Lucien) 214.

Ligures, 162 n. 3.

Linné, 318 sqq.

Locmariaquer, 354.

Lorraine des $\mathrm{XVI}^{\mathrm{e}}-\mathrm{XVII}^{\mathrm{e}}$ s. : son originalité, 308 n. 1. ContreRéforme en L., ses courants étrangers, 306. Artistes lorrains, v. Callot, La Tour, Deruet. Lorraine et Franche-Comté, 308 n. 1.

Lot (Ferdinand) 359 n. 2.

Louis XI, 177 et $\mathrm{n}$.
Lunéville, 303.

Luther: sa pensée politique, 75-79. Trahi par le luthéranisme, 113, 210.

Machiavel, 280, 281, 282, 288.

Machine (la) ou l'homme ? 100.

Magendie, 42, 431.

Mâle (Émile) 231-232.

Manuels : leur procès, 23-24, 72, 87, $98,100$.

Margerie (Emm. de) 315.

Marie (la Vierge): le thème de ses souffrances, 233.

Marx (Karl) 109.

Masses: leur étude psychologique, 208. - ou individus? 211.

Matérialisme historique, 56, 68, 109.

Mathieu (Félix) 340.

Mathiez, 107-108, 110, 342-347.

Mauss (Marcel) 423 n. 1.

Maxwell, 28.

Méditerranée: vue par $H$. Pirenne, 359 ; par F. Braudel, 432.

Méditerranéenne (France) 379.

Meillet (Antoine) 158-168, 174, 219, 395.

Métaphores en histoire: leur survie (l'érudit qui taille sa pierre, l'édifice aux assises superposées) 25-26. - de maçon au temps de l'électricité, 26.

Meyer (Paul) 169.

Michel (P.-H.) 282.

Michelet (Jules) : «Le Peuples», IX. Définition des Comtois, VII. Préceptes de méthode et notes de cours, 9, 16, 21, 25. Sa « Jeanne d'Arc », 89, 109. Son « Rabelais », 248. Sur le Romantisme, 272. Compris par Roupnel, 391 ; mais 
non par les incultes, 423. Tenait à enseigner la philosophie, 422 n. 1.

Microbiologie et histoire, 28-29.

Midi : sa conquête par le français, 170181, 186.

Milioukov (Paul) 70, 73.

Mobilité d'humeur au moyen âge, 215, 226, 255.

Molière dans le Midi, 178 n. 2. Précieux sans l'être, 268.

Mommsen : vu par Toynbee, 135.

Monde : son avènement dans l'histoire, 39, 69. Le - d'hier fini, 40.

Mongin, 151.

Monglond (André) 234, 271.

Monographie biographique en histoire de l'art, 296, 307.

Monod (Gabriel) 423.

Monod (Gustave) 38.

Montbéliardais : son originalité, 327329.

Monteil (Alexis) 96.

Morazé (Charles) IX.

Mornet (Daniel) 263 sqq.

Mort: la mort chrétienne au XVII ${ }^{\mathrm{e}}$ s., 214.

Moulinier (L.) 279.

Muséum : sa création, 322. Son rôle historique, 333.

Musique: sa prise sur les hommes du $\mathrm{XVI}^{\mathrm{e}}$ s., 255.

Nancy, fin $\mathrm{XVI}^{\mathrm{e}}$, début $\mathrm{XVII}^{\mathrm{e}}$ s. : ses peintres, 303. - V. Lorraine. vers 1896: vie littéraire et artistique, 44-47.

Napoléon fait triompher Joseph II en Belgique, 364.

Nation : le problème historique de la —, 82-85, 91. Définie par Collot
d'Herbois, 199 n. 2. Nation et langue, 162-163.

Naturalisme de la Renaissance ; défait par Descartes et ses tenants, 293.

Nature (sentiment de la nature) 93.

Naves (Raymond) 269-271.

Newton, 28-29.

Nietszche (Fred.) 118.

Noble (le) : abstraction personnifiée? 92.

Nudisme et nature, 238.

Occitana Patria, etc., 172.

Olive (Olivier) 160, 167.

Ollivier (Émile) 139-140.

Osmanlis : vus par Toynbee, 130, 131.

Ossalois (Val d'Ossau) 147-151.

Ostwald, 319.

Paix armée, 65.

Pantagruélisme: loué par A. France, 260.

Pariset (Fr.-G.) 302 sqq.

Parisienne (banlieue) 354 n. 1.

Partis en France, 239.

Pascal, 272.

Passé: n'oblige pas, 15. Reconstruit par le groupe, 15.

Passy, 7, 147-151

Patois, 156 n. 1, 177, 185 sqq. - en Fr.-Comté, 192, 195.

Patoiseries littéraires en Fr.-Comté, 197 n. 1.

Paysan : ses conditions de vie, 93 n. 1, 95.

Péguy (Charles) 4, 244 n. 1.

Peinture française: l'École de Paris, 47.

« Père Duchesne » (le) III. 
Perrin (Jean) 51.

Perron (Ch.) 189 n. 1.

Persécutions : ripostes aux —, dans Toynbee, 130.

Personnage historique, 90, 94-95. V. aussi Individu en histoire.

Pétrarque, 278-279.

Peuplement (questions de) : 147, 150, 180.

Pfister (Chr.) 392.

Phanariotes : vus par Toynbee, 130.

Philosophes et historiens, v. Histoire.

Physique moderne: influence sur l'histoire, 12, 26-38

Pirenne (Henri) VIII, 21, 71 n. 1, 115 n. 2, 136, 356-369.

Plattard, 247.

Poitou : art roman en,- 311.

Politique de la Réforme, 75.

Pollen et peuplement, 13.

Préhistoire et histoire, 429; - et linguistique, 159-161, 167.

Primitives (Sociétés) 225. - ou balbutiantes ? 225.

Problèmes en histoire, 22, 23.

Profession (psychologie de la) 205.

Progrès : sa faillite, 31.

Proudhon (P.-J.) VII.

Provinces et architecture romane, 310.

Pressions : réponse aux - (stimulus of pressures) dans Toynbee, 130.

Psychanalyse, 110.

Psychologie appliquée, 201. En quoi différente de l'ancienne psychologie, 202. Son rôle pratique, 203. Sauvegarde l'unité de la personne humaine. - et histoire, 207, v. Histoire. historique, 213.
Rabelais : nos ignorances, 248-249. Sa physionomie, 252. Savant ou ivrogne, 252. Sa légende, problème de psychologie collective, 254. L'œuvre et l'homme, 257-259. Libre penseur ou libre chrétien? 260-261.

Race : chez Toynbee, 128. Concept rayé de notre histoire, 162.

Raemond (Fl. de) 8.

Raison: vicissitudes historiques de la notion, 31.

Rambaud (Alfred) 70.

Randouin (Lucie) 217.

Ranke (Léopold) 41, 51.

Rauh (Frédéric) 11.

Recherches collectives: la raison d'être. V. Enquêtes, Travail collectif.

Réforme : son esprit politique, 75-79. La ou les Réformes, 140.

Relativité : drame qui secoue aussi l'histoire, 27.

Renaissance : philosophie des savants de la - 325 .

Renaudet (A.) 278

Réquisitoires en histoire, 108, 109 sqq.

Revenu des écrivains au XVI ${ }^{\mathrm{e}}$ s., 258.

Révolution française; révolution bourgeoise, 109, 112; ou prolétarienne, 109 . $-\mathrm{R}$. et sciences naturelles, 335.

Révolution des méthodes agricoles, 189.

Rey (Abel) 278, 289, 340.

Rhin: histoire du -, 9-10. Le R. étudié par Demangeon et Lucien Febvre, 384.

Riposte aux persécutions: dans Toynbee (stimulus of penalizations) 130. 
Rodin (Aug.) 45. Son « Balzac» bafoué, 46. Son « Claude Lorrain », 45. - et Injalbert, 267.

Romantisme : vu par Monglond, 271.

Roubaud (A.) 65.

Roupnel (Gaston) : historien, 387-390. Lettre de Braudel sur « Histoire et destin », 388-390.

Rousseau, 77, 273.

Roussey (Ch.) 188, 189 n. 1, 190 n. 1.

Russie (Histoire de) 70-79.

Sainéan (Lazare) 251.

Sambin (Hugues) 296.

Sang : culte contemporain du -, 238.

Science : son climat en 1941, 30. Ne se fait pas dans une tour d'ivoire, 56. Crée ou construit son objet, 30, 57. Ce qu'elle enseigne à l'histoire, 57.

Sciences: sommes de résultats, 207. Découvertes à leurs frontières, 30. Classification de Comte, ses vices, 29, 45. Créent leur objet, 30. Au sens napoléonien du mot, 30 .

Sculpture bourguignonne, 297. Euvre de non-Bourguignons, 297. Influences extérieures, 298. S'enracine et persiste, 298. Le problème Bourgogne ou Italie ?

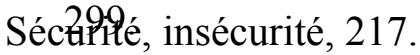

Seignobos (Charles) VII, 70-74, 87-98.

Semple (miss) 377.

Sensibilité et histoire, 221-238. Le mot sensibilité, 222.

Série (idée de) 324-325.

Shaw (Bernard) 11.

Sieburg (Fr.) 239.

Siècles: coupures séculaires, 285. Caractère propre du $\mathrm{XIV}^{\mathrm{e}}$ s., 286287.
Siegfried (André) 239.

Simiand (François) 5, 173 n. 1.

Simplification, simplisme, 79..

Sincérité, 88.

Sion (Jules) 376-380.

Sluter (Claus) 296.

Sociétés : civilisations chez Toynbee, 127.

Soleil nourricier et guérisseur, 238.

Sorel (Georges) 111.

Sparte : vue par Toynbee, 132, 142.

Spécialité : esprit de —, 59, 104-106.

Spengler (Oswald): «Déclin de

l'Occident », 122 sqq. — Rapport avec le nazisme, 124-126.

Stabat, 233.

Stendhal, VI, 49, 85, 259.

Strasbourg : son climat universitaire en 1920, 391.

Synthèse : "Revue de — ", 339, 340341. Semaines de - 341.

Taine, 268.

Techniques, 219.

Terre-mère : culte ressuscité, 238.

Tests : méthode des —, 205.

Théorie, expérience de la Science, 117.

Thérèse d'Avila (sainte) 233.

Thomas (Albert) : historien, 348-352. Son père, 349 .

Toynbee (Arnold J.) 119-143.

Tradition: son poids écrasant, 435438. L'histoire allège ce poids, 437.

Travail : psychologie du - 204.

Travail collectif en histoire, 433-435

Trotzki, trotzkiste, 109, 112.

Turgotines, 189. 
Univers : sa représentation changeante, 219.

Université du Travail : projet, 351.

U.R.S.S. : ses débuts, 74.

Valérien (Mont) 355.

Valéry (Paul): propos sur 1'histoire, 24, 36, 102, 423. Ses études de poétique, 268.

Velly (abbé) 230.

Vercingétorix, 89-90.

Vidal de la Blache, 80, 117. Aux origines de «La Terre et 1'évolution ", 379. - et la génération de Marc Bloch, 394.

Vierge (Daniel) VI.

«Vieux Cordelier », 107-108.
Ville et campagne, 93-94.

Villes du moyen âge: Pirenne, 357 sqq.

Villers-Cotterets (ordonnance de) 170, 176-177, 181.

Vitesse : son accélération, 35.

Vocabulaire : histoire du - 231.

Voltaire et sa conception du goût, 269.

Wallon (Henri) VII, 50, 201-206, 420 n. 2 .

Yonville : le comice agricole d'-, 72.

Young (Arthur) 189.

Zwingli : sa pensée politique, 75-79. 